TIIE

WILIAMS \& WIIKINS CO. BALTIMORE 



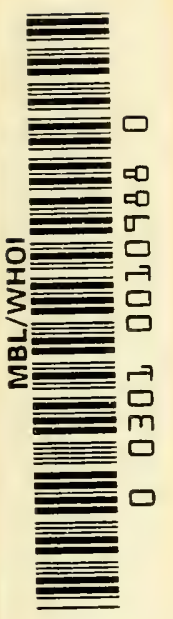



OXIDATION-REDUCTION POTENTIALS IN BACTERIOLOGY AND BIOCHEMISTRY 
This book is protected under the Berne Convention. It may not be re-produced by any means in whole or in part without permission. Application with regard to re-production should be addressed to the Publishers. 


\title{
OXIDATION-REDUCTION POTENTIALS IN BACTERIOLOGY AND BIOCHEMISTRY
}

\author{
BY \\ L. F. $\mathrm{HEWI} \mathrm{T}$ T \\ PH.D., B.SC., F.R.I.C. \\ Director, \\ Serum Research Institute, Medical Research Council \\ Carshalton, Surrey
}

SIXTH EDITION

E D I N B R G H

E. \& S. LIVINGSTONE LTD

$16 \& 17$ TeVIOT Phace

1950 


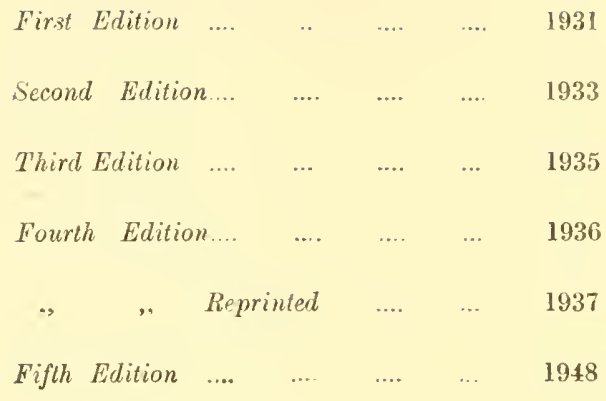

The above Editions were published by the London County Council

1950 


\section{PREFACE TO SIXTH EDITION}

$\mathrm{A}$ LTHOUGH following soon after the fifth edition extensive revisions have been incorporated in the present text. Three new chapters have been added to meet general requests, on pH determinations, metabolic cycles and on chemotherapeutic agents and antibiotics. Some other chapters on biological aspects of the subject have been largely re-written.

The early chapters remain an introduction to the study of oxidation-reduction potentials, but in the later chapters empliasis has gradually shifted in succeeding editions to the implications and effects of oxidation-reduction conditions in metabolic processes and living cells. This broadening of scope has been encouraged by widely scattered correspondents on both sides of the Atlantic, and has necessitated the epitomising of large subjects in small compass. In view of the cordial reception afforded to previous editions, however, it appears unnecessary to apologise for the policy of summarising relevant advances in varied fields.

Apart from considerable internal reconstruction this edition differs from former ones in its publisher. The author is indebted to Sir Allen Daley and the London County Council for facilitating the transfer and to Mr. Charles Macmillan of Messrs. E. \& S. Livingstone for his help in the production in this new form. The opportunity has been taken of improving the binding and it is hoped that the more robust covers of this edition will meet with approval.

The author's task of revision has again been lightened by the co-operation of his wife and colleagues and by the encouragement of many otler friendly research workers. 
Chapter I. General Considerations

$\begin{array}{llllllll}\text { Oxidation-Reduction Processes } & \ldots & \ldots & \ldots & \ldots & \ldots & \ldots & 1\end{array}$

$\begin{array}{llllllllll}\text { Electrode Potentials } & \ldots & \ldots & \ldots & \ldots & \ldots & \ldots & \ldots & 4\end{array}$

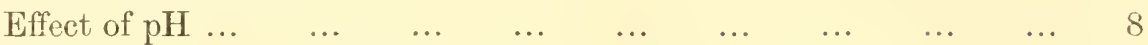

$\begin{array}{llllllllllll}\mathrm{rH} & \ldots & \ldots & \ldots & \ldots & \ldots & \ldots & \ldots & \ldots & \ldots & \ldots & 9\end{array}$

$\begin{array}{llllllllll}\text { Chemical Affinity } & \ldots & \ldots & \ldots & \ldots & \ldots & \ldots & \ldots & \ldots & 12\end{array}$

$\begin{array}{llllllllll}\text { Free Energy Changes } & \ldots & \ldots & \ldots & \ldots & \ldots & \ldots & \ldots & 13\end{array}$

$\begin{array}{llllllll}\text { Standard Oxidation Potentials } & \ldots & \ldots & \ldots & \ldots & \ldots & \ldots & 16\end{array}$

$\begin{array}{llllllllllll}\text { Summary } & \ldots & \ldots & \ldots & \ldots & \ldots & \ldots & \ldots & \ldots & \ldots & 17\end{array}$

Chapter II. Practical Methods

$\begin{array}{llllllllllll}\text { Indicators } & \ldots & \ldots & \ldots & \ldots & \ldots & \ldots & \ldots & \ldots & \ldots & 19\end{array}$

$\begin{array}{lllllllllll}\text { Indicator Data } & \ldots & \ldots & \ldots & \ldots & \ldots & \ldots & \ldots & \ldots & 21\end{array}$

$\begin{array}{llllllll}\text { Limitations of Indicator Methods ... } & \ldots & \ldots & \ldots & \ldots & \ldots & 27\end{array}$

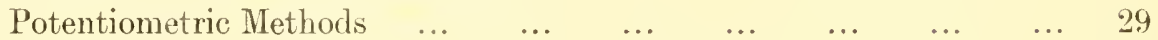

$\begin{array}{llllllllllll}\text { Summary } & \ldots & \ldots & \ldots & \ldots & \ldots & \ldots & \ldots & \ldots & \ldots & 36\end{array}$

Chapter III. Measurement of $\mathrm{pH}$

$\begin{array}{llllllllll}\text { Hydrogen Electrode } & \ldots & \ldots & \ldots & \ldots & \ldots & \ldots & \ldots & 37\end{array}$

$\begin{array}{llllllllll}\text { Quirhydrone Electrode } & \ldots & \ldots & \ldots & \ldots & \ldots & \ldots & \ldots & 38\end{array}$

$\begin{array}{lllllllllll}\text { Glass Electrode } & \ldots & \ldots & \ldots & \ldots & \ldots & \ldots & \ldots & \ldots & 38\end{array}$

$\begin{array}{lllllllllll}\mathrm{pH} \text { Meters } & \ldots & \ldots & \ldots & \ldots & \ldots & \ldots & \ldots & \ldots & \ldots & 40\end{array}$

$\begin{array}{llllllllll}\text { Colorimetric Methods } & \ldots & \ldots & \ldots & \ldots & \ldots & \ldots & \ldots & 42\end{array}$

$\begin{array}{lllllllllll}\text { Summary } & \ldots & \ldots & \ldots & \ldots & \ldots & \ldots & \ldots & \ldots & \ldots & 44\end{array}$

Chapter IV. Systems of Biological Interest

$\begin{array}{llllllllll}\text { Sulphydryl Systems } & \ldots & \ldots & \ldots & \ldots & \ldots & \ldots & \ldots & 45\end{array}$

$\begin{array}{llllllllllll}\text { Hæmoglobir } & \ldots & \ldots & \ldots & \ldots & \ldots & \ldots & \ldots & \ldots & \ldots & \ldots & 48\end{array}$

$\begin{array}{llllllllllll}\text { Cytochrome } & \ldots & \ldots & \ldots & \ldots & \ldots & \ldots & \ldots & \ldots & \ldots & 50\end{array}$

$\begin{array}{lllllllll}\text { Peroxidase and Catalas } & \ldots & \ldots & \ldots & \ldots & \ldots & \ldots & \ldots & 5 ;\end{array}$

$\begin{array}{llllllllll}\text { Copper Prnteins } & \ldots & \ldots & \ldots & \ldots & \ldots & \ldots & \ldots & \ldots & 54\end{array}$

$\begin{array}{llllllllll}\text { Cobalt Complexes } & \ldots & \ldots & \ldots & \ldots & \ldots & \ldots & \ldots & \ldots & 54\end{array}$

$\begin{array}{llllllllll}\text { Flavoprotems } & \ldots & \ldots & \ldots & \ldots & \ldots & \ldots & \ldots & \ldots & 55\end{array}$

$\begin{array}{lllllllllll}\text { Coenzymes } & \ldots & \ldots & \ldots & \ldots & \ldots & \ldots & \ldots & \ldots & \ldots & 57\end{array}$

$\begin{array}{lllllllll}\text { Vitamin-B Complex } & \ldots & \ldots & \ldots & \ldots & \ldots & \ldots & \ldots & 58\end{array}$

$\begin{array}{llllllllll}\text { Ascorbic Acid } & \ldots & \ldots & \ldots & \ldots & \ldots & \ldots & \ldots & \ldots & 59\end{array}$

$\begin{array}{llllllllllll}\text { Folic Acir } & \ldots & \ldots & \ldots & \ldots & \ldots & \ldots & \ldots & \ldots & \ldots & 61\end{array}$

$\begin{array}{lllllllllll}\text { Vitamin } \mathrm{E} & \ldots & \ldots & \ldots & \ldots & \ldots & \ldots & \ldots & \ldots & \ldots & 62\end{array}$

$\begin{array}{llllllllllll}\text { Pigments } & \ldots & \ldots & \ldots & \ldots & \ldots & \ldots & \ldots & \ldots & \ldots & 63\end{array}$

$\begin{array}{lllllll}\text { Naphthaquinones, Mould Products } & \ldots & \ldots & \ldots & \ldots & \ldots & 66\end{array}$

$\begin{array}{llllllllllll}\text { Vitamin } \mathrm{K} & \ldots & \ldots & \ldots & \ldots & \ldots & \ldots & \ldots & \ldots & \ldots & 68\end{array}$ 
Adrenaline

Pituitary Hormones

$\begin{array}{lllllllll}\text { Starch-Iodine Potentials } & \ldots & \ldots & \ldots & \ldots & \ldots & \ldots & \ldots & 73\end{array}$

$\begin{array}{llllllllll}\text { Cells, Tissues, etc. } & \ldots & \ldots & \ldots & \ldots & \ldots & \ldots & \ldots & \ldots & 74\end{array}$

$\begin{array}{lllllllllll}\text { Yeast } \ldots & \ldots & \ldots & \ldots & \ldots & \ldots & \ldots & \ldots & \ldots & \ldots & 79\end{array}$

$\begin{array}{llllllllll}\text { Warburg Manometer } & \ldots & \ldots & \ldots & \ldots & \ldots & \ldots & \ldots & 80\end{array}$

$\begin{array}{llllllllllll}\text { Summary } & \ldots & \ldots & \ldots & \ldots & \ldots & \ldots & \ldots & \ldots & \ldots & 82\end{array}$

Chapter V. Metabolic Cycles and Chatn Reactions

$\begin{array}{lllllllll}\text { Energy-rich Phosphate Bonds } & \ldots & \ldots & \ldots & \ldots & \ldots & \ldots & 83\end{array}$

$\begin{array}{llllllllll}\text { Muscle Glycolysis } & \ldots & \ldots & \ldots & \ldots & \ldots & \ldots & \ldots & \ldots & 84\end{array}$

$\begin{array}{llllllll}\text { Glycogen and Starch Synthesis } & \ldots & \ldots & \ldots & \ldots & \ldots & \ldots & 86\end{array}$

$\begin{array}{lllllllll}\text { Muscular Contraction } & \ldots & \ldots & \ldots & \ldots & \ldots & \ldots & \ldots & 87\end{array}$

$\begin{array}{llllllll}\text { Yeast Alcoholic Fermentation } & \ldots & \ldots & \ldots & \ldots & \ldots & \ldots & 87\end{array}$

$\begin{array}{llllllllll}\text { Bacterial Fermentations } & \ldots & \ldots & \ldots & \ldots & \ldots & \ldots & \ldots & 88\end{array}$

$\begin{array}{lllllll}\text { Aerobic Glycolysis and Citric Acid Cycle } & \ldots & \ldots & \ldots & \ldots & \ldots & 88\end{array}$

$\begin{array}{lllllllllll}\text { Pasteur Effect } & \ldots & \ldots & \ldots & \ldots & \ldots & \ldots & \ldots & \ldots & 90\end{array}$

$\begin{array}{lllllllllll}\text { Photosynthesis } & \ldots & \ldots & \ldots & \ldots & \ldots & \ldots & \ldots & \ldots & 91\end{array}$

$\begin{array}{lllllllllll}\text { Plant Respiration } & \ldots & \ldots & \ldots & \ldots & \ldots & \ldots & \ldots & \ldots & 92\end{array}$

$\begin{array}{lllllllll}\text { Oxidation Chain Potentials } & \ldots & \ldots & \ldots & \ldots & \ldots & \ldots & 93\end{array}$

$\begin{array}{lllllllllll}\text { Summary } & \ldots & \ldots & \ldots & \ldots & \ldots & \ldots & \ldots & \ldots & \ldots & \ldots\end{array}$

Chapter VI. Bacteriological Applications

$\begin{array}{lllllllllll}\text { General Aspects } & \ldots & \ldots & \ldots & \ldots & \ldots & \ldots & \ldots & \ldots & 95\end{array}$

$\begin{array}{lllllllllll}\text { Lag Phase } & \ldots & \ldots & \ldots & \ldots & \ldots & \ldots & \ldots & \ldots & \ldots & 95\end{array}$

$\begin{array}{lllllllll}\text { Logarithmic Growth... } & \ldots & \ldots & \ldots & \ldots & \ldots & \ldots & \ldots & 96\end{array}$

$\begin{array}{lllllllll}\text { Bacterial Reduction } & \ldots & \ldots & \ldots & \ldots & \ldots & \ldots & \ldots & 98\end{array}$

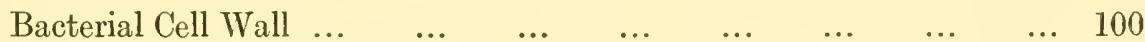

$\begin{array}{llllllll}\text { Potentials in Bacterial Cultures } & \ldots & \ldots & \ldots & \ldots & \ldots & \ldots & 103\end{array}$

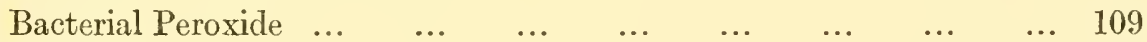

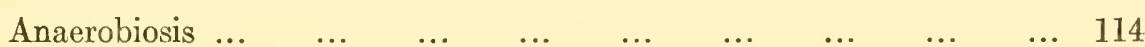

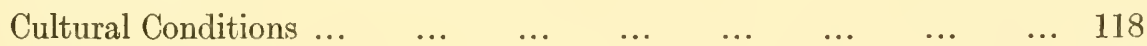

$\begin{array}{llllllllll}\text { Effect of Lysis } & \ldots & \ldots & \ldots & \ldots & \ldots & \ldots & \ldots & \ldots & 121\end{array}$

$\begin{array}{llllllll}\text { Potentials of Different Bacteria } & \ldots & \ldots & \ldots & \ldots & \ldots & \ldots & 123\end{array}$

$\begin{array}{lllllllll}\text { Milk Testing and Grading } & \ldots & \ldots & \ldots & \ldots & \ldots & \ldots & \ldots & 127\end{array}$

$\begin{array}{lllllllllll}\text { Virulence } & \ldots & \ldots & \ldots & \ldots & \ldots & \ldots & \ldots & \ldots & \ldots & 129\end{array}$

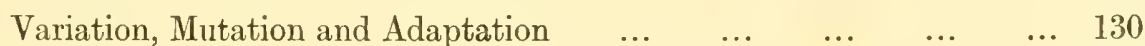

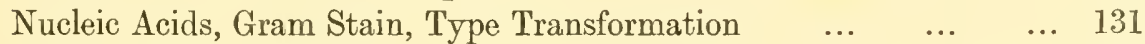

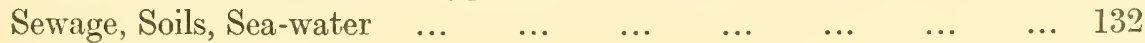

$\begin{array}{lllllllll}\text { Microbiological Assay } & \ldots & \ldots & \ldots & \ldots & \ldots & \ldots & \ldots & 133\end{array}$

$\begin{array}{lllllllllll}\text { Toxins... } & \ldots & \ldots & \ldots & \ldots & \ldots & \ldots & \ldots & \ldots & \ldots & 134\end{array}$

$\begin{array}{lllllllllll}\text { Summary } & \ldots & \ldots & \ldots & \ldots & \ldots & \ldots & \ldots & \ldots & \ldots & 136\end{array}$ 
Chapter VII. Chemotherapy and Antibiotics

$\begin{array}{llllllllll}\text { Antibodies and Immunity } & \ldots & \ldots & \ldots & \ldots & \ldots & \ldots & \ldots & 137\end{array}$

$\begin{array}{llllllllll}\text { Organic Arsenicals } & \ldots & \ldots & \ldots & \ldots & \ldots & \ldots & \ldots & \ldots & 138\end{array}$

$\begin{array}{lllllllllll}\text { Bactericidal Dyes } & \ldots & \ldots & \ldots & \ldots & \ldots & \ldots & \ldots & \ldots & 140\end{array}$

$\begin{array}{lllllllllll}\text { Quinones } & \ldots & \ldots & \ldots & \ldots & \ldots & \ldots & \ldots & \ldots & \ldots & 141\end{array}$

$\begin{array}{lllllllll}\text { Paludrine, Antrycide } & \ldots & \ldots & \ldots & \ldots & \ldots & \ldots & \ldots & 142\end{array}$

$\begin{array}{lllllllllll}\text { Sulphonamides } & \ldots & \ldots & \ldots & \ldots & \ldots & \ldots & \ldots & \ldots & 143\end{array}$

$\begin{array}{lllllllll}\text { Structural Analogues } & \ldots & \ldots & \ldots & \ldots & \ldots & \ldots & \ldots & 144\end{array}$

$\begin{array}{lllllllllll}\text { Diamidines } & \ldots & \ldots & \ldots & \ldots & \ldots & \ldots & \ldots & \ldots & \ldots & 147\end{array}$

$\begin{array}{lllllllllll}\text { Viruses } & \ldots & \ldots & \ldots & \ldots & \ldots & \ldots & \ldots & \ldots & \ldots & 147\end{array}$

$\begin{array}{lllllllllll}\text { Antibiotics } & \ldots & \ldots & \ldots & \ldots & \ldots & \ldots & \ldots & \ldots & \ldots & 147\end{array}$

$\begin{array}{lllllllllll}\text { Penicillin } & \ldots & \ldots & \ldots & \ldots & \ldots & \ldots & \ldots & \ldots & \ldots & 148\end{array}$

$\begin{array}{llllllllll}\text { Streptomycin } & \ldots & \ldots & \ldots & \ldots & \ldots & \ldots & \ldots & \ldots & 149\end{array}$

$\begin{array}{lllllllll}\text { Bacterial Resistance } & \ldots & \ldots & \ldots & \ldots & \ldots & \ldots & \ldots & 151\end{array}$

$\begin{array}{lllllllllll}\text { Chloromycetin } & \ldots & \ldots & \ldots & \ldots & \ldots & \ldots & \ldots & \ldots & 152\end{array}$

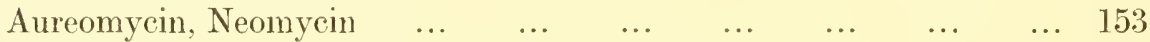

$\begin{array}{llllllllllll}\text { Summary } & \ldots & \ldots & \ldots & \ldots & \ldots & \ldots & \ldots & \ldots & \ldots & 153\end{array}$

Chapter Vili. The Polarograph

$\begin{array}{lllllllllll}\text { General Principles } & \ldots & \ldots & \ldots & \ldots & \ldots & \ldots & \ldots & \ldots & 154\end{array}$

$\begin{array}{lllllllll}\text { Apparent Reduction Potentials } & \ldots & \ldots & \ldots & \ldots & \ldots & \ldots & 155\end{array}$

$\begin{array}{llllllllll}\text { Experimental Methods } & \ldots & \ldots & \ldots & \ldots & \ldots & \ldots & \ldots & 157\end{array}$

$\begin{array}{lllllllllll}\text { Oxygen Waves } & \ldots & \ldots & \ldots & \ldots & \ldots & \ldots & \ldots & \ldots & 159\end{array}$

$\begin{array}{llllllllllll}\text { Cysteine } & \ldots & \ldots & \ldots & \ldots & \ldots & \ldots & \ldots & \ldots & \ldots & 159\end{array}$

$\begin{array}{llllllll}\text { Sulphydryl Protein Waves } & \ldots & \ldots & \ldots & \ldots & \ldots & \ldots & 160\end{array}$

$\begin{array}{llllllllllll}\text { Enzymes } & \ldots & \ldots & \ldots & \ldots & \ldots & \ldots & \ldots & \ldots & \ldots & 160\end{array}$

$\begin{array}{lllllllllll}\text { Semiquinones... } & \ldots & \ldots & \ldots & \ldots & \ldots & \ldots & \ldots & \ldots & 161\end{array}$

$\begin{array}{llllllllllll}\text { Antibiotics } & \ldots & \ldots & \ldots & \ldots & \ldots & \ldots & \ldots & \ldots & \ldots & 162\end{array}$

$\begin{array}{lllllllllll}\text { Mould Products } & \ldots & \ldots & \ldots & \ldots & \ldots & \ldots & \ldots & \ldots & 162\end{array}$

$\begin{array}{llllllllllll}\text { Vitamins } & \ldots & \ldots & \ldots & \ldots & \ldots & \ldots & \ldots & \ldots & \ldots & 163\end{array}$

$\begin{array}{lllllllllll}\text { Sex Hormones } & \ldots & \ldots & \ldots & \ldots & \ldots & \ldots & \ldots & \ldots & 163\end{array}$

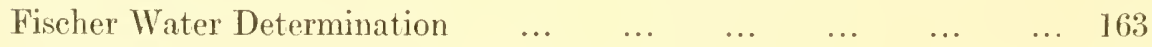

$\begin{array}{llllllllllll}\text { Toxicology } & \ldots & \ldots & \ldots & \ldots & \ldots & \ldots & \ldots & \ldots & \ldots & 164\end{array}$

$\begin{array}{llllllllllll}\text { Summary } & \ldots & \ldots & \ldots & \ldots & \ldots & \ldots & \ldots & \ldots & \ldots & 164\end{array}$

$\begin{array}{llllllllll}\text { Chapter IX. General Conclusion } & \ldots & \ldots & \ldots & \ldots & \ldots & \ldots & 165\end{array}$

$\begin{array}{llllllllllll}\text { Bibliography } & \ldots & \ldots & \ldots & \ldots & \ldots & \ldots & \ldots & \ldots & \ldots & 172\end{array}$

$\begin{array}{llllllllllll}\text { Author INDEX } & \ldots & \ldots & \ldots & \ldots & \ldots & \ldots & \ldots & \ldots & \ldots & 203\end{array}$

$\begin{array}{lllllllllll}\text { SUBJECT INDEX } & \ldots & \ldots & \ldots & \ldots & \ldots & \ldots & \ldots & \ldots & \ldots & 209\end{array}$ 


\section{CHAPTER I}

\section{GENERAL CONSIDERATION OF OXIDATION-REDUCTION PROCESSES}

Oxidation-reduction systems play so intimate and so essential a part in living organisms that life itself might be defined as a continuous oxidation-reduction reaction. It is not surprising, therefore, that theoretical speculations and experimental studies on oxidation and reduction processes in animals and plants have been actively pursued since the isolation of oxygen over 150 years ago. The dependence of animal life on the maintenance of an adequate oxygen supply has, rather naturally, dominated the outlook and led to the assumption that oxygen itself is an essential reactant in all biological processes, a view which was vigorously criticised by Pasteur.

The attention devoted to oxygen gas lias tended to obscure the mechanism of biological processes, many of which are not dependent upon the direct participation of oxygen. Biological systems cannot be expected to yield to study unless there is available a means of measuring their oxidising or reducing properties and of describing in quantitative terms the stage of oxidation or of reduction reached in an oxidation reduction reaction. Other methods of study than that of gas analysis and, above all, a different aspect are necessary in order to proceed to even the faintest understanding of the fundamental features of biological processes.

Organisms are constantly faced with the problem of obtaining the energy necessary for their growth and existence and the problem is solved in different ways by different organisms. Plants, for example, are able to utilise the energy obtained from sunlight to effect reductive syntheses such as the classical one of glucose from carbon dioxide and water,

$$
6 \mathrm{CO}_{2}+6 \mathrm{H}_{2} \mathrm{O}=\mathrm{C}_{6} \mathrm{H}_{12} \mathrm{O}_{6}+6 \mathrm{O}_{2}
$$

Many other organisms reverse this process, oxidising glucose to carbon dioxide and water, thereby deriving energy essential to thenselves. Animals and many bacteria belong to this latter class. The crude result, as represented by the equation above is, however, of little value in studying the essential mechanism of biological processes. The complete degradation of glucose to carbon dioxide and water takes placc by a chain of reactions, many of which are unknown or imperfectly understood. We are particularly interested in those steps in the series of reactions which are reversible and enable the living cell to store energy which may be utilised as required. Such a reaction is readily reversed when the energy liberated in the forward reaction is supplied to the system.

Michaelis (1933) presents analogies between the chain of reactions in the degradation of glucose and an electrical supply circuit. In the circuit most of the current is used for heating lamp filaments, etc., but an accumulator may be charged in the circuit. This provides a reversible mechanism for storing energy. The accumulator may be used, for example, to drive an electric motor or to obtain other forms of energy and may be recharged by the main circuit when required. In an analogous manner, a thermodynamically reversible reaction may be used by living cells to store energy which is utilised when required-those reactions in the degradation of glueose which are irreversible camnot be used for this purpose. 
Our problem, then, is to find a method of quantitative study of reversible oxidation-reduction systems ; and, fortunately, in electrode potential* measurements we have an exact and useful method. As an example, let us suppose that we have a solution of iron salts partly oxidised and partly reduced, say a mixture of ferrous and ferric chlorides. If an unattackable electrode be immersed in the solution an electrical potential difference will be set up between the electrode and the solution. This potential difference will depend on the relative proportion of ferric and ferrous chlorides. In solutions containing the same proportion of the two salts the potential difference will always be the same; but if there is more oxidised (ferric) salt the potential difference will be greater, and if more reduced (ferrous) salt is present the potential difference will be less. It is easy to see that after a few preliminary measurements with mixtures of ferric and ferrous chlorides of known composition we have a method of determining the composition of any unknown mixture of iron chlorides. This method can, of course, be applied to other reversible oxidationreduction systems in the same way, but in order to remove the empirical nature of the observations and to place the method on a sound theoretical basis we must define our terms more closely and apply some physico-chemical algebra.

The terms oxidation and reduction themselves are not free from ambiguity.

The term oxidation immediately suggests the addition of oxygen to the oxidisable substance, for example the oxidation of formaldehyde to formic acid, or ferrous to ferric oxide :-

$$
\begin{aligned}
& \mathrm{HCHO}+\mathrm{O} \rightarrow \mathrm{H} . \mathrm{COOH} \\
& 2 \mathrm{FeO}+\mathrm{O} \rightarrow \mathrm{Fe}_{2} \mathrm{O}_{3}
\end{aligned}
$$

But such reactions as the conversion of hydroquinone to quinone are obviously oxidations although the oxidant contains no more oxygen than the reductant.

$$
\mathrm{C}_{6} \mathrm{H}_{4}(\mathrm{OH})_{2} \rightarrow \mathrm{C}_{6} \mathrm{H}_{4} \mathrm{O}_{2}+\mathrm{H}_{2}
$$

It is evident therefore that the definition of oxidation must be extended to cover the removal of hydrogen. This extension, however, does not cover all cases; for example, the conversion of ferrous to ferric chloride must be regarded as oxidation just as much as the conversion of ferrous to ferric oxide, although oxygen and hydrogen are not concerned in the reaction.

$$
\mathrm{FeCl}_{2}+\mathrm{Cl} \rightarrow \mathrm{FeCl}_{3}
$$

To gain a general view of oxidation-reduction processes it is necessary to consider the electronic concept of atomic constitution. Atoms are composed of a nucleus positively charged with electricity and a number of electrons each bearing a unit negative charge. The positive charge on the nucleus is numerically equal, although opposite in sign to the sum of the unit charges on the electrons, so that the atom taken as a whole is electrically neutral. There is one electron in the hydrogen atom so that there is a single positive charge on the liydrogen nucleus to neutralise it. The carbon nucleus possesses six positive charges and the carbon atom contains six electrons. Chenical reactions involve interchanges and re-arrangements of certain

* The terms oxidation-reduetion potential, reduction potential, redox potential and electrode potential, which are used by different authors, may be taken generally as being synonymous. As far at possible, the expression electrode potential, or $\mathrm{E}_{\mathrm{b}}$, is used througlout this text. 
electrons in the atoms. The electrons tend to group themselves in stable arrangements of pairs or octets. The hydrogen atom which contains only one electron tends to share its electron with another hydrogen atom containing a "lone" electronthus a stable pair of electrons is shared between two hydrogen atoms and a relatively stable hydrogen molecule is formed. Another possibility is for the hydrogen atom to share its lone electron with a chlorine atom which has, in its outer orbit, an unstable arrangement of seven electrons, thus making with the hydrogen atom a stable arrangement of eight electrons. Hydrogen or chlorine atoms cannot, of course, exist by themselves but hydrochloric acid with its stable octet of electrons is relatively stable. In aqueous solution, however, hydrochloric acid does not exist in molecular formit is ionised; the hydrogen part of the molecule separates from the chlorine portion, the hydrogen losing its electron temporarily and the chlorine taking it up. The hydrogen ion, as it is now called, has no electrons, while the chlorine ion has eight, so that both are relatively stable-neither has an unstable electronic arrangement. But now the hydrogen ion has a positive charge, namely, the unit positive charge on the nucleus which was previously balanced ont by the single negative charge on the electron. The chlorine ion has a single negative charge, namely, the charge on the extra electron it has acquired from the hydrogen atom. The ionisation of hydrochloric acid may be represented as follows, ${ }^{\oplus}$ signifying the possession of a single positive charge and $\ominus$ a unit negative charge :-

$$
\mathrm{HCl} \rightarrow \mathrm{H}^{\oplus}+\mathrm{Cl}^{\ominus}
$$

In the same way ferrous chloride is ionised in solution giving a ferrous ion, with a double positive charge, and two chlorine ions:-

$$
\mathrm{FeCl}_{2} \rightarrow \mathrm{Fe}^{\oplus \oplus}+2 \mathrm{Cl}^{\ominus}
$$

and ferric chloride gives a ferric ion, with a treble positive charge, and three chlorine ions :-

$$
\mathrm{FeCl}_{3} \rightarrow \mathrm{Fe}^{\oplus \oplus \oplus}+3 \mathrm{Cl} \odot
$$

The oxidation of ferrous chloride to ferric chloride :-

$$
\mathrm{FeCl}_{2}+\mathrm{Cl} \rightarrow \mathrm{FeCl}_{3}
$$

is really a reaction between ions when it takes place in aqueous solution, so that it should be written :-

$$
\mathrm{Fe}^{\oplus \oplus}+2 \mathrm{Cl} \ominus+\mathrm{Cl} \rightarrow \mathrm{Fe}^{\oplus \oplus \oplus}+3 \mathrm{Cl} \ominus
$$

If the essential reactants only are considered this equation hecomes :-

$$
\mathrm{Fe}^{\oplus \oplus}+\mathrm{Cl} \rightleftharpoons \mathrm{Fe}^{\oplus \oplus \oplus}+\mathrm{Cl}^{\ominus}
$$

That is to say the reaction consists essentially of an exchange of an electron between iron and chlorine. The ferrous ion loses an electron, which is taken up by chlorine. If we consider the iron system alone the reaction may be written :--

$$
\mathrm{Fe}^{\oplus \oplus} \underset{\text { reduction }}{\stackrel{\text { Oxidation }}{\rightleftharpoons}} \mathrm{Fe}^{\oplus \oplus \oplus}+\mathrm{e} \quad \text { (e represents an electron) }
$$

On oxidation the ferrous ion, with its two positive charges, loses an electron and becomes a ferric ion with three positive charges. Conversely on reduction the ferric ion takes up an electron and becomes a ferrous ion. This gives us our general definitions. Oxidation is a process involving the loss of electrons, and reduction one 
involving the taking up of electrons. An academic definition of this sort is isolated in a mental vacuum until it is accepted and absorbed as an integral part of the ordinary point-of-view. By itself such a definition, although possibly of strict accuracy, may appear paradoxical until it is harmonised with every-day laboratory experience. It is therefore a useful exercise to apply the electronic concept of oxidation-reduction reactions to processes not usually regarded electronically. For example, since conversion of metallic silver to silver ion involves loss of an electron it is an oxidation :-

$$
\mathrm{Ag} \stackrel{\text { oxidation }}{\longrightarrow} \mathrm{Ag}^{\oplus}
$$

In the light of ordinary experience this does not appear an obvious example of oxidation. The silver ion in a silver nitrate solution is not obviously in a higher state of oxidation than metallic silver; but if the reverse reaction is considered-for example, the conversion of an alkaline silver nitrate solution to a metallic mirror of silver by warming with a sugar solution - the process is quite obviously a reduction :-

$$
\mathrm{Ag} \stackrel{\text { reduction }}{\longrightarrow} \mathrm{Ag}
$$

Further consideration of similar processes serves only to confirm the logical basis of the electronic concept of oxidation-reduction processes. One further point should perhaps be cmphasised here. It is already clear that oxidation is the reverse of reduction (and rerluction is the reverse of oxidation), but another fact is that every oxidation is accompanied by a reduction and vice versa. In the case mentioned above of the ferrous-ferric chloride oxidation-reduction system. the ferrous ion gives $11 \mathrm{p}$ an electron and is thereby oxidised to the ferric ion:-

$$
\stackrel{\text { oxidation }}{\longrightarrow} \mathrm{Fe}^{\oplus \oplus \ominus}+\mathrm{e}
$$

but at the same time a chlorine atom takes up that electron and is thereby reduced to a chlorine ion :-

$$
\mathrm{Cl}+\mathrm{c} \stackrel{\text { reduction }}{\longrightarrow} \mathrm{Cl} \ominus
$$

Oxidation cannot proceed unless there is a corresponding reductant to take up the electrons liberated, and, conversely, a substance cannot be reduced unless there is a corresponding oxidation to liberate the necessary electrons.

As we have seen, oxidising agents are substances capable of taking up electrons and reducing agents are those able to part with electrons. The readiness with which substances take up, or part with, electrons determines the intensity level of their oxidising or reducing functions. In order to measure the functions quantitatively it is necessary to find a method of measuring electronic escaping tendency, or " fugacity" as Clark $(1923,1)$ has described it. Since oxidation and reduction reactions are, by definition, electronic migrations involving exchanges of electric charges, it becomes clear that the quantitative study of oxidation-reduction processes will be effected by measurements of electric potential differences.

\section{ELECTRODE POTENTIAL RELATIONSHIPS}

It is found, in fact, that if an " mattacliable elcetrode" (such as platinum metal) he immersed in a reversible oxidation-reduction system. a potential difference is set 
up at the electrode and this potential can be measured by the usual potentiometric methods. It will be shown in the next few pages that a relation can be derived from simple physico-chemical reasoning which shows that the potential at the electrode depends on the proportions present of the oxidised and reduced forms of the substance studied. The more highly oxidised a substance is the higher will be the electrode potential, and the more reduced, the more negative will the potential be.

Since some readers may find the algebra in the next eight pages unduly wearisome, it is suggested that, in the first instance, the chapter summary may be sufficient introduction to the later chapters dealing with practical applications and biological problems.

It must be emphasised that we are dealing with truly reversible systems wherein the reaction can proceed in one way or the other according to the conditions. Sucl a reversible system is that of ferrous-ferric ions which we have already considered.

$$
\mathrm{Fe}^{\oplus \oplus} \rightleftharpoons \mathrm{Fe}^{\oplus \oplus \oplus}+\mathrm{e}
$$

This has the form of an ordinary reaction equation and accordingly the ordinary mass action equilibrium equation can be applied, namely :-

$$
\frac{\left[\mathrm{Fe}^{\oplus \oplus \oplus}\right]\left[\mathrm{e}_{8}\right]}{\left[\mathrm{Fe}^{\oplus \oplus}\right]}=\mathrm{k}
$$

where the square brackets indicate the concentration of the reactants when at equilibrium, and " $k$ " is a constant. The exceptional feature of this equation is the significance of the term $\left[\mathrm{e}_{8}\right]$ which, as it stands, is the concentration of free electrons in the system. Without maling any assumptions as to the validity of the existence of such concentration it may be stated that $\left[\mathrm{e}_{\mathrm{B}}\right]$ represents the escaping tendency or "fugacity" of electrons in the system, or some similar electronic function. Its exact definition is unnecessary since it will be eliminated from the equations at an early stage.

From these equations it follows that oxidation-reduction conditions of the system can be controlled by the movement of electrons; for if $\left[\mathrm{e}_{\mathrm{b}}\right]$ is increased the reaction will move in the direction of reduction and if $\left[\mathrm{e}_{\mathrm{B}}\right]$ is decreased, oxidation of $\mathrm{Fe}^{\oplus \oplus}$ to $\mathrm{Fe}^{\oplus \oplus \oplus}$ will occur to balance the equation. Further the oxidation-reduction condition of the system can be observed quantitatively by measurement of the potential at an " unattackable electrode" when electrons tend neither to enter nor leave the system. An "unattackable electrode" is one which when immersed in the system will not participate therein but act merely as an inert conductor of electrons to or from the system when the circuit is suitably arranged.

Let now such an unattackable electrode be immersed in the ferrous-ferric ion system. The electrode can be looked upon as a reservoir of electrons of fixed concentration $\left[\mathrm{e}_{\mathrm{m}}\right]$. The significance of the term electronic concentration is discussed above. Since the concentration or escaping tendency of the electrons in the electrode $\left(\left[\mathrm{e}_{\mathrm{m}}\right]\right)$ is different from that in the system $\left(\left[\mathrm{e}_{\mathrm{s}}\right]\right)$ a potential difference will be set up at the electrode, and this potential difference (E) can be calculated in accordance with thermodynamics. The electrical work done in the passage of a faraday of electricity (F) against this potential difference $(\mathrm{E})$ will be equal to the work done 
in transporting an electron from the solution (at eoncentration $\left[\mathrm{e}_{8}\right]$ ) to the electrode at concentration $\left[\mathrm{e}_{\mathrm{m}}\right]$. That is :-

Electrieal work $=\mathrm{EF}$

"Osmotic" work $=\mathrm{RT} \int_{\mathrm{e}_{\mathrm{s}}}^{\mathrm{e}_{\mathrm{m}}} \frac{1}{[\mathrm{e}]} \mathrm{d}[\mathrm{e}]=\mathrm{RT} \ln \left[\mathrm{e}_{\mathrm{m}}\right]+\mathrm{RT} \ln \frac{1}{\left[\mathrm{e}_{\mathrm{s}}\right]}$

(3) Therefore $\mathrm{EF}=\mathrm{RT} \ln \left[\mathrm{e}_{\mathrm{m}}\right]+\mathrm{RT} \ln \frac{1}{\left[\mathrm{e}_{\mathrm{s}}\right]}$

where, $\mathrm{R}=$ gas constant; $\mathrm{T}=$ absolute temperature ; $\mathrm{ln}=$ natural logarithms.

Since the concentration of eleetrons in the electrode $\left(\left[\mathrm{e}_{\mathrm{m}}\right]\right)$ is a constant, equation (3) may be rewritten as :-

$$
\mathrm{E}=\mathrm{k}_{1}+\frac{\mathrm{RT}}{\mathrm{F}} \ln \frac{1}{\left[\mathrm{e}_{\mathrm{s}}\right]}
$$

where $k_{1}$ is a constant.

From equation (2)

$$
\left[\mathrm{e}_{\mathrm{e}}\right]=\mathrm{k} \frac{\left[\mathrm{Fe}^{\oplus \oplus}\right]}{\left[\mathrm{Fe}^{\oplus \oplus \oplus}\right]}
$$

and substituting this value in equation (4), we obtain :-

$$
\mathrm{E}=\mathrm{k}_{2}+\frac{\mathrm{RT}}{\mathrm{F}} \ln \frac{\left[\mathrm{Fe}^{\oplus \oplus \oplus}\right]}{\left[\mathrm{Fe}^{\oplus \oplus}\right]}
$$

where $\mathrm{k}_{2}$ is a constant.

It is not possible to measure a single potential difference at an electrode as this constitutes only a half-cell; but if the circuit is completed by including a standard half-cell the electromotive foree of the completed cell may readily be measured. The second half-cell to which electrode potentials are referred is the normal hydrogen electrode, which is taken as the standard of reference. Electrode potentials referred to this standard are measured in volts and designated $\mathrm{E}_{\mathrm{h}}$.

$\mathrm{E}_{\mathrm{h}}=\mathrm{E}$ - potential of normal hydrogen electrode $\left(\mathrm{k}_{3}\right)$, and substituting the value for E from equation (6).

$$
\mathrm{E}_{\mathrm{b}}=\mathrm{k}_{2}+\frac{\mathrm{RT}}{\mathrm{F}} \ln \frac{\left[\mathrm{Fe}^{\oplus \oplus \oplus}\right]}{\left[\mathrm{Fe}^{\oplus \oplus}\right]}-\mathrm{k}_{3}
$$

Let $k_{2}-k_{3}=E_{0}=$ constant for system.

$$
\mathrm{E}_{\mathrm{h}}=\mathrm{E}_{0}+\frac{R \mathrm{~T}}{\mathrm{~F}} \ln \frac{\left[\mathrm{Fe}^{\oplus \oplus \oplus}\right]}{\left[\mathrm{Fe}^{\oplus \oplus}\right]}
$$

In order to make this equation more general in applieation, the ferrous-ferric ion system may be replaced by the general reversible oxidation-reduetion system :-

Reduced form $\rightleftharpoons$ oxidised form $+\mathrm{n}$ electrons.

$$
\text { Red. } \rightleftharpoons \text { Ox. + ne. }
$$

and applying equation (8) we obtain the imporlant general electrode equation (Peters, 1898). 


$$
\mathrm{E}_{\mathrm{h}}=\mathrm{E}_{0}+\frac{\mathrm{RT}}{\mathrm{nF}} \ln \frac{[\mathrm{Ox} .]}{[\text { Red. }]}
$$

For the sake of simplicity, let us consider a system at $30^{\circ} \mathrm{C}$. and at constant $\mathrm{pH}$, and let two electrons be concerned in the oxidation process, the equation then becomes :-

$$
\mathrm{E}_{\mathrm{b}}=\mathrm{E}_{\mathbf{0}}+0.03 \log \frac{[\mathrm{Ox} .]}{[\text { Red. }]}
$$

in which log represents ordinary Briggsian logarithms*; [Ox.] and [Red.] are the concentrations of the oxidised and reduced forms respectively of the substance studied.

It is evident from this equation that the electrode potential, $\mathrm{E}_{\mathrm{b}}$, is dependent on $\mathrm{E}_{0}$, a constant for the system, and the proportion of oxidised and reduced forms of the substance studied. The greater the proportion of oxidised form the higher will be the potential, and the more reduced the substance the lower, i.e., more negative, will the potential be. The significance of the constant, $\mathrm{E}_{0}$, is of interest. It will be seen that when $[\mathrm{Ox}]=.[$ Red.], i.e., when the system is 50 per cent. oxidised, $\mathrm{E}_{\mathrm{h}}=\mathrm{E}_{0}$. That is to say $\mathrm{E}_{0}$ is the electrode potential of the 50 per cent. oxidised system. When the value of $\mathrm{E}_{\mathbf{0}}$ of a system is known it is possible to calculate the electrode potential at any degree of oxidation or reduction of the system; and, vice versa, the degree of oxidation can be calculated from the value of the electrode potential. Furthermore $\mathrm{E}_{0}$ is a measure of the oxidation or reduction intensity level of the system and enables oxidising and reducing agents to be graded in their oxidising or reducing effects. Thus a system of $\mathrm{E}_{0}+0 \cdot 1$ volt will oxidise a system of $E_{0}$ say $-0 \cdot 1$ volt, but, on the other hand, will itself be oxidised by a system of $\mathrm{E}_{0}+0 \cdot 3$ volt. Measurement of oxidation-reduction potentials therefore enables us to study the oxidation-reduction conditions of a system and to grade different systems in order of their oxidising or reducing tendencies.

It must be emphasised, however, that $\mathrm{E}_{\mathrm{h}}$ is a measure of intensity level and not of capacity. In this $\mathrm{E}_{\mathrm{h}}$ resembles temperature and $\mathrm{pH}$, and just as temperature and $\mathrm{pH}$ give no information as to heat capacity and buffering power respectively, so $\mathrm{E}_{\mathrm{n}}$ is independent of " poising effect," the capacity term in oxidation-reduction systems. This follows from the derivation of $\mathrm{E}_{\mathrm{h}}$ which is dependent on the ratio of oxidised and reduced forms of the substance studied and not on their absolute quantities. Thus a 90 per cent. oxidised system will have the same electrode potential no matter whether the total concentration is 0.01 per cent. or 10 per cent., but the poising effect will be 1,000 times greater in the latter case. It is particularly important to bear these facts in mind when dealing with biological systems, many of which have well-defined electrode potentials but are not well poised.

* Units employed (Clark, 1928).

$\mathrm{E}_{\mathrm{h}}$ and $\mathrm{E}_{\mathrm{o}}$ are measured in volts.

$R=8 \cdot 315$ joules.

$\mathrm{T}=$ Absolute temperature.

$F=96,500$ coulombs.

$\ln x=2 \cdot 303 \log x$.

At $30^{\circ} \mathrm{C} .: 2 \cdot 303 \mathrm{P} T=0.0601$ 


\section{EFFECT OF $\mathrm{pH}$}

Up to this point we have considered systems of constant $\mathrm{pH}$, but when the hydrogen ion concentration is allowed to vary a further complication arises, and it is necessary to take into account ionisation phenomena. In those reversible oxidation-reduction systems, which are characterised by electron transference, either the reduced or oxidised form, or both, are ionised. The hydrogen ion concentration affects oxidation-reduction systems by altering ionic equilibria.

Let us consider the simple case in which the oxidised form is un-ionised but the reduced form is an anion with one negative charge. The oxidation-reduction reaction may be represented as :-

$$
\mathrm{R}^{\ominus} \rightleftharpoons \mathrm{Ox} .+\mathrm{e}
$$

The general eleetrode equation (10) may be applied to this equilibrium :-

$$
\mathrm{E}_{\mathrm{h}}=\mathrm{E}_{\mathrm{o}}+\frac{\mathrm{RT}}{\mathrm{F}} \ln \frac{[\mathrm{Ox} \cdot]}{\left[\mathrm{R}^{\ominus}\right]}
$$

The reduced form is ionised in accordance with the formula:-

$$
\mathrm{HR} \rightleftharpoons \mathrm{H}^{\oplus}+\mathrm{R}^{\ominus}
$$

to which the usual mass action equation may be applied :-

$$
\frac{\left[\mathrm{H}^{\oplus}\right]\left[\mathrm{R}^{\ominus}\right]}{[\mathrm{HR}]}=\mathrm{k}_{\mathrm{d}}
$$

The total concentration of reduced form ([Red.]) will be equal to the sum of the concentrations of the ionised $\left(\left[\mathrm{R}^{\ominus}\right]\right)$ and un-ionised ([HR]) portions, i.e.-

$$
[\text { Red. }]=\left[\mathrm{R}^{\ominus}\right]+[\mathrm{HR}]
$$

Combining equations (15) and (16) we obtain :-

$$
\left[\mathrm{R}^{\ominus}\right]=[\text { Red. }] \frac{k_{\mathrm{d}}}{\left[\mathrm{H}^{\oplus}\right]+k_{\mathrm{d}}}
$$

and substituting this value in the electrode equation (13) we find :-

$$
\mathrm{E}_{\mathrm{b}}=\mathrm{E}_{\mathrm{o}}+\frac{\mathrm{RT}}{\mathrm{F}} \ln \frac{[\text { Ox. }]}{[\text { Red. }]}-\frac{R \mathrm{~T}}{\mathrm{~F}} \ln \frac{\mathrm{k}_{\mathrm{d}}}{\left[\mathrm{H}^{\oplus}\right]+\mathrm{k}_{\mathrm{d}}}
$$

which is the general electrode equation holding at all values of $\mathrm{pH}$. It will be seen that the electrode potential depends on the hydrogen ion concentration and the dissociation constant of the reduced form. If both the reduced form and oxidised form are ionised, and form polyvalent ions, the expression becomes very complicated.* It is impossible therefore to formulate a general rule as to the effect of $\mathrm{pH}$ on electrode potential, the effect of alteration of hydrogen ion concentration being different in different ranges of $\mathrm{pH}$ ( $c f$. Clark and Cohen, 1923, 1). With systems that have not been exhaustively studied it is necessary therefore to quote results in terms of $\mathrm{E}_{\mathrm{h}}$ and $\mathrm{pH}$.

The fact that the effect of $\mathrm{pH}$ on $\mathrm{E}_{\mathrm{h}}$ is complex does not imply that the effect is necessarily great. To take a hypothetical example, consider a biological system in which the $\mathrm{F}_{\mathrm{h}}$ : $\mathrm{pH}$ curve has "0.03 slope" (a very usual value) in the range

* Ionie concentrations are referred to throughout although, more accurately, ionic activities should be considered in aceordanee with modern views. This has been fone in order to assist lueidity by the avoidance of more complicated symbols and expressions which confuse the issue without any proportionate advantage aceruing save that of emphasising the complex relationship between $E_{h}$ and $p l l$. 
studied. If at $\mathrm{pH} 7 \cdot 1$ the $\mathrm{E}_{\mathrm{h}}$ is -0.314 volt, then at $\mathrm{pH} 7 \cdot 2$ the potential will be $-0.317 \mathrm{v}$. This difference of 3 millivolts is within the limits of experimental error when working with biological material.

It should be noted that, if the hydrogen ion concentration is kept constant, the last term in equation (18) becomes a constant, so that we get back to the general electrode equation (10).

$$
\mathrm{E}_{\mathrm{h}}=\mathrm{E}_{\mathrm{o}}{ }^{1}+\frac{\mathrm{RT}}{\mathrm{nF}} \ln \frac{[\mathrm{Ox} .]}{[\text { Red. }]}
$$

The value of $\mathrm{E}_{\mathbf{0}} \mathbf{1}$ (the electrode potential at 50 per cent. oxidation) varies with $\mathrm{pH}$.

\section{DERIVATION OF $\mathbf{r H}$.}

The effect of $\mathrm{pH}$ on the electrode potential $\left(\mathrm{E}_{\mathrm{b}}\right)$ depends upon a number of factors as mentioned above. In order to avoid confusion, Clark and Cohen (1923) introduced the term $\mathrm{rH}$ which includes $\mathrm{E}_{\mathrm{h}}$ and $\mathrm{pH}$. The term $\mathrm{rH}$ is convenient in theoretical discussions, but it has been used unjustifiably to describe the condition of biological systems such as the interior of cells. Since these are systems of unknown constitution and incompletely studied properties, the relation between $\mathrm{E}_{\mathrm{h}}$ and $\mathrm{pH}$ cannot be defined and hence no term containing both factors can be obtained in our present state of knowledge, whilst the use of $\mathrm{rH}$ makes a tacit assumption that there is a known simple relationship between the $\mathrm{E}_{\mathrm{b}}$ and $\mathrm{pH}$ of the system. For this and other reasons, Clark rightly insists that the use of the term $r \mathrm{H}$, originally introduced by himself, should be discontinued. The results of a considerable number of investigators on oxidation-reduction conditions in biology have, however, been quoted in terms of $\mathrm{rH}$. In order to make the interpretations of such results comprehensible to readers the following description of $\mathrm{rH}$ is included in this monograph, but the author does not wish to encourage the further use of the very misleading term $\mathrm{rH}$.

Just as $\mathrm{pH}$ is the logarithm of the reciprocal of the hydrogen ion concentration of a system, i.e. :-

$$
\mathrm{pH}=\log \frac{1}{\left[\mathrm{H}^{\oplus}\right]}
$$

so $\mathrm{rH}$ is the logarithm of the reciprocal of the partial pressure of hydrogen gas $(\mathrm{P})$ in equilibrium with the system, that is :-

$$
\mathrm{rH}=\log \frac{1}{\mathrm{P}}
$$

The value of $\mathrm{rH}$ is derived from consideration of the simple reversible oxidationreduction system :-

$$
\mathrm{R}^{\ominus}+\mathrm{H}^{\oplus} \rightleftharpoons \mathrm{Ox} \cdot+\mathrm{H}
$$

to which the ordinary mass action equation may be applied, i.e. :-

$$
\frac{\left[\mathrm{R}^{\ominus}\right]\left[\mathrm{H}^{\oplus}\right]}{[\mathrm{Ox} .][\mathrm{H}]}=\mathrm{k}
$$

The general electrode equation (18) for the system is :-

$$
\mathrm{E}_{\mathrm{h}}=\mathrm{E}_{\mathrm{o}}+\frac{\mathrm{RT}}{\mathrm{F}} \ln \frac{[\mathrm{Ox} .]}{\left[\mathrm{R}^{\oplus}\right]}
$$


in which may be substituted the value of $[\mathrm{Ox}] /.\left[\mathrm{R}^{\ominus}\right]$ derived from the mass action equation (23).

$$
\mathrm{E}_{\mathrm{h}}=\mathrm{E}_{\mathrm{o}}^{\prime \prime}+\frac{\mathrm{RT}^{\top} \mathrm{T}}{\mathrm{F}} \ln \frac{\left[\mathrm{H}^{\oplus}\right]}{[\overline{\mathrm{H}}]}
$$

That is to say, the electrode potential may be regarded as being established by the equilibrium between hydrogen ions and hydrogen atoms. The hydrogen concentration $([\mathrm{H}])$ is a function of the partial pressure of hydrogen gas $(\mathrm{P})$, and, in fact,

$$
[\mathrm{H}]=\mathrm{K}_{1} \sqrt{\mathrm{P}}
$$

so that the potential equation (25) becomes :-

$$
\mathrm{E}_{\mathrm{b}}=\mathrm{E}_{\mathrm{o}}^{\prime \prime \prime}+\frac{\mathrm{RT}}{\mathrm{F}} \ln \frac{\left[\mathrm{H}^{\oplus}\right]}{\sqrt{\mathrm{P}}}
$$

To obtain the value of the constant, $\mathrm{E}_{\mathrm{o}}^{\mathrm{III}}$, we may consider the normal hydrngen electrode, which is a special type of oxidation-reduction cell, in which $\mathrm{E}_{\mathrm{b}}=0$; $\left[\mathrm{H}^{\oplus}\right]=1$; and $\mathrm{P}=1$, and substituting these values in the equation (27) we find $\mathrm{E}_{0}^{\prime \prime \prime}=0$, so that equation (27) becomes :-

$$
\mathrm{E}_{\mathrm{h}}=\frac{\mathrm{RT}}{\mathrm{F}} \ln \frac{\left[\mathrm{H}^{\oplus}\right]}{\sqrt{\mathrm{P}}}
$$

or, transferring from Naperian to common Briggsian logarithms :-

$$
\mathrm{E}_{\mathrm{h}}=2 \cdot 3026 \frac{\mathrm{RT}}{\mathrm{F}} \log \frac{\left[\mathrm{H}^{\oplus}\right]}{\sqrt{\mathrm{P}}}
$$

Since $\mathrm{pH}=\log \frac{1}{\left[\mathrm{H}^{\oplus}\right]}$ and $\mathrm{rH}=\log \frac{1}{\mathrm{P}}$

$$
\mathrm{E}_{\mathrm{h}}=2 \cdot 3026 \frac{\mathrm{RT}}{2 \mathrm{~F}}(\mathrm{rH}-2 \mathrm{pH})
$$

For simplicity, let the temperature be $30^{\circ} \mathrm{C}$., then :-

$$
\mathrm{E}_{\mathrm{b}}=0.03(\mathrm{rH}-2 \mathrm{pH})
$$

This equation gives the simple relation between $\mathrm{E}_{\mathrm{h}}, \mathrm{rH}$ and $\mathrm{pH}$ in the reversible system considered; from it $\mathrm{rH}$ may be derived when $\mathrm{E}_{\mathrm{h}}$ and $\mathrm{pH}$ are known, and $\mathrm{E}_{\mathrm{b}}$ may be obtained when $\mathrm{rH}$ and $\mathrm{pH}$ are given. Results quoted in terms of $\mathrm{rH}$ may thus be readily converted to terms of $\mathrm{E}_{\mathrm{h}}$.

It follows from the equation also that the electrode potential, in a reversible oxidation-reduction system at constant $\mathrm{pH}$, is a function of the partial pressure of hydrogen in equilibrium with the system. This gives us a fresh aspect on the mechanism of establishment of electrode potentials; hydrogen may be regarded as being built up at the electrode until a partial pressure is reached which is in equilibrium with the system, and the system is neither reduced nor oxidised.

The hydrogen electrocte used for $\mathrm{pH}$ measurements is a special form of oxidationreduction electrode in which the hydrogen pressure is kept constant $(\mathrm{P}=1$ atmosphere) by bubbling hydrogen at one atmosphere pressure through the system, the value of $\mathrm{r} H$ is therefore zero and the only variations in potential are due to alterations in hydrogen ion concentration, i.e., equation (31) brcomes (at $30^{\circ} \mathrm{C}$.) :-

$$
\mathrm{E}_{\mathrm{h}}=-0.06 \mathrm{pH}
$$


The hydrogen electrode is therefore in equilibrium with a partial pressure of 1 atmosphere of hydrogen; $\mathrm{rH}=0$, and at $\mathrm{pH} 0$ the electrode potential is 0 . A reversible oxidation-reduction system in equilibrium with a partial pressure of $10^{-15}$ atmospheres of hydrogen has :-

$$
\mathrm{rH}=\log \frac{1}{10^{-15}}=15
$$

and at $\mathrm{pH} 7$ the electrode potential will be [equation (31)] at $30^{\circ} \mathrm{C}$.

$$
\mathrm{E}_{\mathrm{h}}=0.03(15-2 \mathrm{pH})=+0.03 \text { volt. }
$$

That is assuming that one electron only is concerned in the reversible oxidationreduction process and that only one dissociation constant is concerned and that

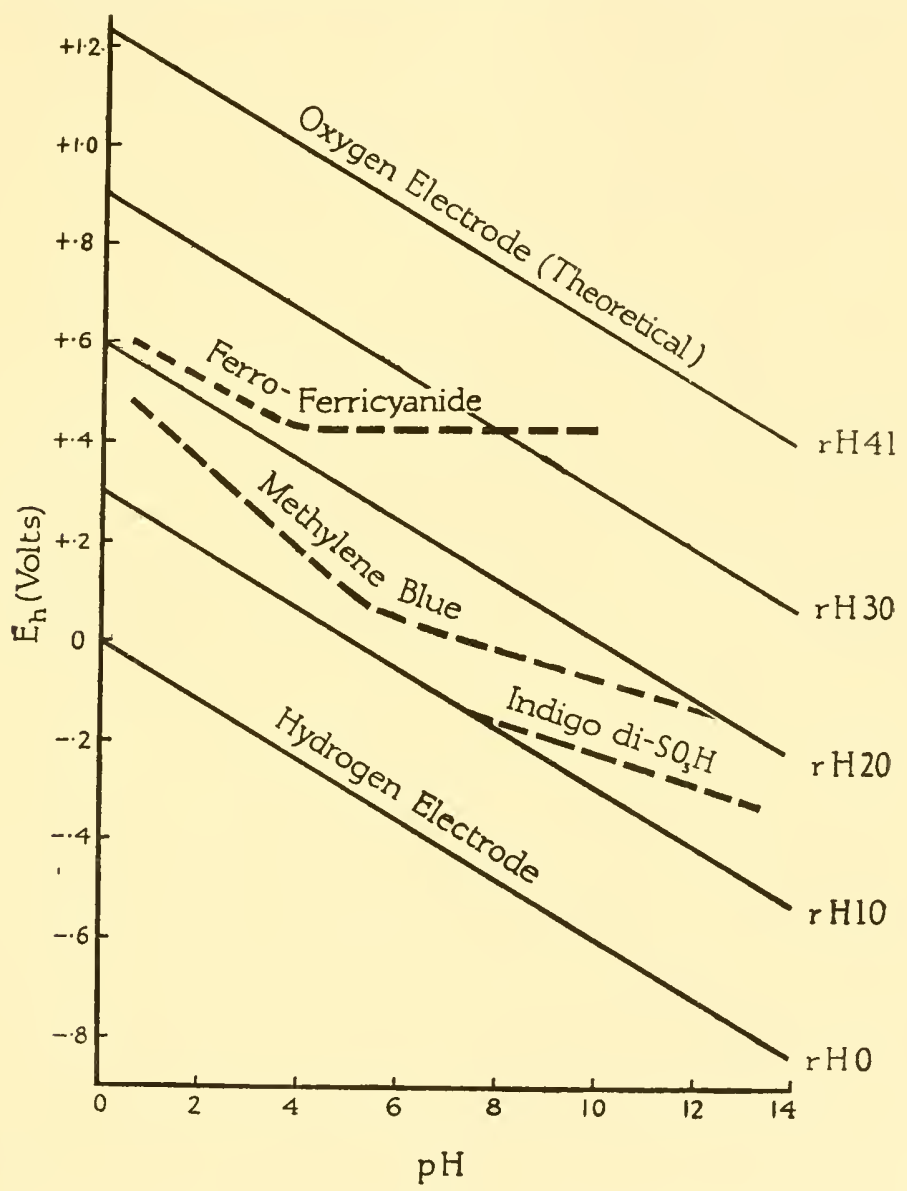

F1G. 1

Electrode potential $\left(\mathrm{E}_{\mathbf{h}}\right): \mathrm{pH}$ curves

Theoretical curves-continuous lines, Actual systems ( $\mathrm{E}_{\mathrm{o}}: \mathrm{pH}$ curves)-broken lines

this constant is effective at $\mathrm{pH}$ 7. With other systems with more complex relationships this simple expression has no significance. It is essential, therefore, especially 
with systems of unknown properties, to avoid the use of the term $\mathrm{rH}$ on account of its spurious effect of apparent simplicity.

With reversible oxidation-reduction systems of the simple type :-

$$
\text { Red. } \stackrel{\ominus \text { oxidation }}{\rightleftharpoons}=0 \mathrm{x} .+\mathrm{e}
$$

the $\mathrm{E}_{\mathrm{h}}$ varies by 0.06 volt per unit $\mathrm{pH}$, that is the $\mathrm{E}_{\mathrm{h}}-\mathrm{pH}$ curve is said to have $0 \cdot 06$ slope $\left(\right.$ at $30^{\circ} \mathrm{C}$.). In such a system as

$$
\text { Red. } \ominus \ominus \rightleftharpoons \mathrm{Ox} .+2 \mathrm{e}
$$

the variation per unit, $\mathrm{pH}$ can be $0.03,0.06$ or 0.09 volt. These facts apply only to ideal systems when hydration may be neglected. The variation of $\mathrm{E}_{\mathrm{h}}$ with $\mathrm{pH}$ occurs only in those ranges of $\mathrm{pH}$ in which the dissociation constants are effective, and the systematic study of all the possible cases is outside the scope of this introductory treatment. A very complete study is reported by Clark and Cohen (1923).

It is shown above that in the simplest case at $30^{\circ} \mathrm{C}$. (equation 31 ) :-

$$
\mathrm{E}_{\mathrm{h}}=0.03(\mathrm{rH}-2 \mathrm{pH})
$$

where $\mathrm{rH}$ is $\log \frac{1}{\mathrm{P}}$ ( $\mathrm{P}$ being the partial pressure of hydrogen in equilibrium with the system). With the hydrogen electrode $\mathrm{P}=1$ atm. so that $\mathrm{rH}=0$ at any $\mathrm{pH}$. The $\mathrm{E}_{\mathrm{h}}$ : pH curve is the lowest one in fig. 1, and shows the electrode potential of an oxidation-reduction system in equilibrium with 1 atnosphere partial pressure of hydrogen. When the partial pressure of hydrogen is $10^{-10}$ atmosphere, this $\mathrm{rH}$ is 10 , and the $\mathrm{E}_{\mathrm{k}}: \mathrm{pH}$ curve runs parallel with that of the hydrogen electrode, and similarly when $\mathrm{P}=10^{-20}$ atmospheres, $\mathrm{rH}=20$. Also included in the figure are the experimentally obtained curves of the methylene blue system at 50 per cent. reduction (i.e., the $\mathrm{E}_{o}^{\mathrm{I}}: \mathrm{pH}$ curve) and of the indigo-carmine system at 50 per cent. reduction.

Theoretically, curves can be drawn showing the $\mathrm{E}_{\mathrm{h}}: \mathrm{pH}$ relationships at various levels of oxygen partial pressure, or $\mathrm{rO}$; but as the true oxygen electrode is not capable of experimental realisation (Richards, 1928), and the oxygen tensions encountered in biological systems, as judged from the potentials, are frequently of the order of $10^{-40}$ atmospheres or less, little advantage accrues from such considerations. Goard and Rideal (1924) and Hoar (1933) are of interest in this connection.

\section{CONSIDERATIONS OF CHEMICAL AFFINITY}

Considerations of chemical affinity lead to the same general electrode equation as that derived previously (Michaelis, 1933). This treatment is of interest as it presents a slightly different aspect of oxidation-reduction processes although leadiug to the same general conclusion.

To return to the ferrous-ferric ion equilibrium :-

$$
\mathrm{Fe}^{\oplus \oplus} \underset{\text { reduction }}{\stackrel{\text { Oxidation }}{\rightleftharpoons} \underset{\mathrm{Fe}}{\rightleftharpoons} \oplus \oplus \oplus \mathrm{e}}
$$


If the system be at equilibrium there will be no tendency for any change. In this case let the ratio (37) at equilibrium be $\frac{\left[\mathrm{Fe}^{\oplus \oplus \oplus]}\right.}{\left[\mathrm{Fe}^{\oplus \oplus}\right]}=\mathrm{k}$ (system I, fig. 2). Now let some other system be considered, not at equilibrium, in which the ratio $\left[\mathrm{Fe}^{\oplus \oplus \oplus}\right]$ is greater than $\mathrm{k}$ (system II). In this case there will be a tendency for

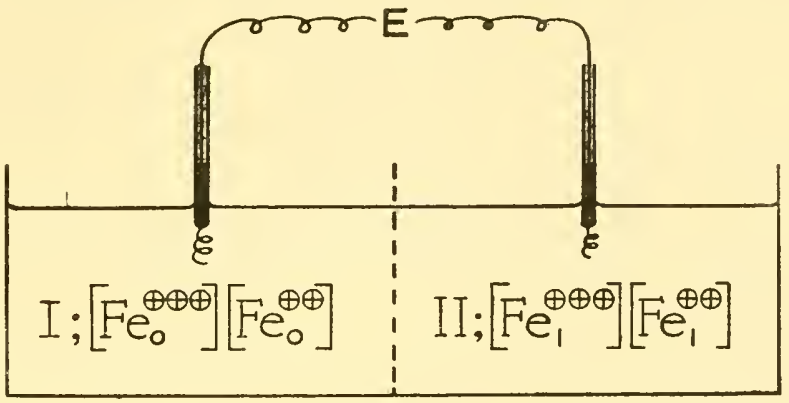

Fig. 2

Ferrous-ferric ion system

$\mathrm{Fe}^{\oplus \oplus \oplus}$ to change to $\mathrm{Fe}^{\oplus \oplus}$. Since this process would result in electromic equilibrium being disturbed the reaction will not proceed but the tendency will exist. Let now platinum electrodes be placed in the two systems and these electrodes be joined and the two systems be brought into contact, e.g., by a semi-permeable membrane, to complete the circuit. The unattackable electrodes will not participate in the systems, but will act as inert conductors of electrons. The tendency of $\mathrm{Fe} \oplus \oplus \oplus$ to be reduced to $\mathrm{Fe}^{\oplus \oplus}$ will now become an actuality in system II, and this reduction in system II will be accompanied by oxidation in system I, so that electrons will pass through the electrodes from systems I to II ; this electronic migration will produce an electromotive force, say $\mathrm{E}$, between the electrodes.

The left-hand half-cell (I) is at equilibrium, so that $\frac{\left[\mathrm{Fe}_{0}^{\oplus \oplus \oplus]}\right.}{\left[\mathrm{Fe}_{0}^{\oplus \oplus]}\right]}=\mathrm{k}$; the right-hand half-cell is not at equilibrium and $\frac{\left[\mathrm{Fe}_{1}^{\oplus \oplus \oplus]}\right.}{\left[\mathrm{Fe}_{1}{ }^{\oplus \oplus}\right]}$ is greater than $\mathrm{k}$. The volumes in the two half-cells are considered to be so large that there will be no appreciable change in concentrations during the experiment. When the electrodes are joined, current will flow. Now let it be supposed that the current flows long enough for one mol of $\mathrm{Fe}^{\oplus \oplus \oplus}$ in the right-hand half-cell to be reduced to $\mathrm{Fe}^{\oplus \oplus}$. At the same time one mol of $\mathrm{Fe}^{\oplus \oplus}$ will be oxidised to $\mathrm{Fe}^{\oplus \oplus \oplus}$ in the left-hand half-cell. Thus one mol of $\mathrm{Fe}^{\oplus \oplus \oplus}$ will disappear from II and appear in I. The work done will be equivalent to the isothermal and reversible transportation of one mol of $\mathrm{Fe}^{\oplus \oplus \oplus}$ from concentration $\left[\mathrm{Fe}_{1} \oplus \oplus \oplus\right]$ to concentration $\left[\mathrm{Fe}_{0}{ }^{\oplus \oplus \oplus}\right]$ through the semi-permeable membrane. The "osmotic" work done in this transportation is :-

$$
\mathrm{RT} \iint_{\left[\mathrm{Fe}_{0} \mathrm{Fe}_{1} \oplus \oplus\right]} \frac{1}{\left[\mathrm{Fe}^{\oplus \oplus \oplus}\right]} d\left[\mathrm{Fe}^{\oplus \oplus \oplus}\right]=\mathrm{RT} \ln \frac{\left[\mathrm{Fe}_{1}^{\oplus \oplus \oplus}\right]}{\left[\mathrm{Fe}_{0} \oplus \oplus \oplus\right]}
$$


At the same time one mol of $\mathrm{Fe}^{\oplus \oplus}$ will disappear from $\mathrm{I}$ and appear in II, and the work done is :-

$$
\mathrm{R}^{\prime} \ln \frac{\left\lceil\mathrm{Fe}_{0}{ }^{\oplus \oplus]}\right.}{\left[\mathrm{Fe}_{1} \oplus \oplus\right]}
$$

The total "osmotic" work done will be the sum of these two, and this total will be equivalent to the electrical work done in the passage of one faraday of electrons (F) across the cell with electromotive force $\mathrm{E}$. Therefore :-

$$
\mathrm{EF}=\mathrm{R} T \ln \frac{\left[\mathrm{Fe}_{1}^{\oplus \oplus \oplus]}\right.}{\left[\mathrm{Fe}_{0}{ }^{\oplus \oplus \oplus}\right]}+\mathrm{RT} \ln \frac{\left[\mathrm{Fe}_{0}{ }^{\oplus \oplus}\right]}{\left[\mathrm{Fe}_{\mathbf{1}} \oplus \oplus\right]}
$$

This may be rearranged as :-

(37) now $\frac{\left[\mathrm{Fe}_{0}^{\oplus \oplus \oplus]}\right.}{\left[\mathrm{Fe}_{0}^{\oplus \oplus]}\right]}=\mathrm{k}$

$$
\mathrm{E}=\frac{\mathrm{RT}}{\mathrm{F}} \ln \frac{\left[\mathrm{Fe}_{\mathbf{0}}^{\oplus \oplus]}\right.}{\left[\mathrm{Fe}_{0} \oplus \oplus \oplus\right]}+\frac{\mathrm{RT}}{\mathrm{F}} \ln \frac{\left[\mathrm{Fe}_{\mathbf{1}}^{\oplus \oplus \oplus]}\right.}{\left[\mathrm{Fe}_{\mathbf{1}}^{\oplus \oplus]}\right.}
$$

so that equation (41) becomes :-

$$
\mathrm{E}=\mathrm{k}_{1}+\frac{\mathrm{RT}}{\mathrm{F}} \ln \frac{\left[\mathrm{Fe}_{1}^{\oplus \oplus \oplus]}\right.}{\left[\mathrm{Fe}_{1} \oplus \oplus\right]}
$$

If the general reaction be considered in place of the iron system :-

$$
\begin{aligned}
\text { Reduced form } & \underset{\text { Red. }}{\rightleftharpoons} \rightleftharpoons \mathrm{Ox} \text {. }+ \text { ne }
\end{aligned}
$$

and the potential is referred to the normal hydrogen electrode, used as a standard of reference, we obtain :-

$$
\mathrm{E}_{\mathrm{h}}=\mathrm{E}_{0}+\frac{\mathrm{RT}}{\mathrm{nF}} \ln \frac{[\mathrm{Ox} .]}{[\mathrm{Red} .]}
$$

which is the general electrode equation (10) derived previously from totally different, considerations. That the same result is obtained when working with different assumptions implies a fundamental unity in the underlying principles involved.

Michaelis (1932) and Elema (1933) have developed mathematically the relevant equations applying to oxidation-reduction reactions which occur in two consecutive stages. The relations are complicated owing to the number of factors involved and the different equilibrium constants of the various reactants. The complex relationships are of some biological interest since certain biological pigments have been found to undergo reversible "two-step" oxidation-reduction within certain ranges of $\mathrm{pH}$ values.

\section{FREE ENERGY CHANGES AND STANDARD OXIDATION POTENTIALS}

The total amount of energy supplied to a thermodynamic system is not all recoverable in the form of work. The change in free or available energy $(\Delta \mathrm{F})$ differs from the change in total energy $(\Delta \mathrm{H})$ by a factor involving the absolute temperature $(\mathrm{T})$ and the change in entropy of the system $(\Delta \mathrm{S})$ :-

$$
\Delta \mathrm{F}=\Delta \mathrm{H}-\mathrm{T} . \Delta \mathrm{S}
$$

The familiar terms exothermic and endothermic applied to chemical reactions refer to reactions which give out or take up heat. Exergonic and endergonic were 
terms introduced by Coryell (1940) to describe reactions involving loss or gain of free energy. When $\Delta \mathrm{F}$ is zero the system is in equilibrium and no reaction occurs; when $\Delta \mathrm{F}$ is positive the reaction cannot occur unless external energy is supplied; but if $\Delta \mathrm{F}$ is negative a spontaneous reaction is possible on thermodynamic grounds. Actually, of course, the liberation of free energy is not the only criterion of whether a reaction can occur under any given conditions since the molecules concerned must be in a reactive state or made so by the presence of a catalyst or enzyme.

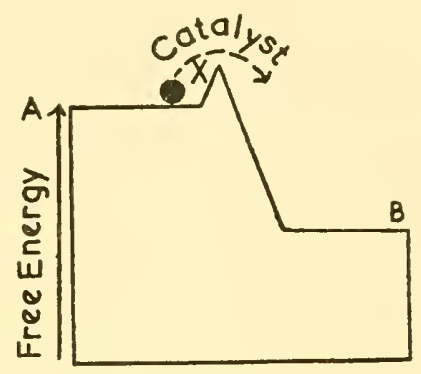

Fid. 3

The function of a catalyst or enzyme

In the diagram although the reaction $A \rightarrow B$ would result in the liberation of free energy the reaction does not occur spontaneously because of the hump, but if a suitable catalyst is present it will supply a little free energy $(\mathrm{X}-\mathrm{A})$ to a small quantity of $\mathrm{A}$ so that it will reach the peak. Having reached the peak there will be spontaneous conversion to $\mathrm{B}$. In sliding down, the free energy liberated will be $\mathrm{X}-\mathrm{A}$ and $\mathrm{A}-\mathrm{B}$. The free energy $\mathrm{X}-\mathrm{A}$ will be given back to the catalyst which will transport more of A over the hump and so on. The net result will be that the catalyst will have given up X-A of free energy and received back X-A so that it will be in the same state finally as at the beginning. During the reaction $A \rightarrow B$ the free energy liberated in the main reaction will be $\mathrm{A}-\mathrm{B}$ regardless of the humps negotiated with the help of catalyst or enzyme.

To repeat therefore, the important feature of a chemical reaction is not the total heat change but the change in free energy. It is possible to calculate the free energy change $(\Delta \mathrm{F})$ from the equilibrium constant $(\mathrm{K})$ of the reaction :-

$\Delta \mathrm{F}=-\mathrm{RT} \ln \mathrm{K}$

( $\mathrm{R}$ being the gas constant, and $\mathrm{T}$ the absolute temperature).

When the reactants form part of a galvanic cell the change in free energy is equal to the electrical work done; so that:-

$(47)$

$$
-\Delta \mathrm{F}=\mathrm{n} \mathrm{FE}
$$

where $\mathrm{n}=$ number of electrons involved in the reaction;

$\mathrm{F}=$ the Faraday;

$\mathrm{E}=$ the electrode potential.

Incidentally, the temperature coefficient of the electrode potential gives a measure of the change in entropy of the reaction.

$$
\Delta \mathrm{S}=\mathrm{nF} \frac{\mathrm{dE}}{\mathrm{dT}}
$$


As given above (expression 45) the change in entropy equals the difference between the total energy of the reaction and the change in free energy.

The importance of the expressions (46) and (47) is that we are now able to calculate the change in free energy of a reaction from the equilibrium constant and also to calculate the standard electrode potential of the system from the change in free energy. It is important in this connection to note the units in which the various quantities must be measured in order to get the calculations to agree. The free energy

TABLE 1

\section{STANDARD OXIDATION-REDUCTION POTENTIALS}

Referred to normal hydrogen electrode at $25^{\circ} \mathrm{C}$ (oxidising systems more positive)

\begin{tabular}{|c|c|c|c|c|c|}
\hline System & & & & & $\begin{array}{l}\text { Potential } \\
\text { (volts) }\end{array}$ \\
\hline $\mathrm{Co} \oplus \oplus \oplus, \mathrm{Co} \oplus \oplus$ & $\ldots$ & $\cdots$ & $\cdots$ & $\ldots$ & $+1 \cdot 8$ \\
\hline $\mathrm{Pb} \oplus \oplus \oplus \oplus, \mathrm{Pb} \oplus$ & & $\cdots$ & $\cdots$ & $\cdots$ & $1 \cdot 7$ \\
\hline $\mathrm{Ce} \oplus \oplus \oplus \oplus, \mathrm{Ce} \oplus \oplus$ & & $\cdots$ & $\cdots$ & $\cdots$ & $1 \cdot 6$ \\
\hline $\mathrm{MnO}_{4} \ominus, \mathrm{Mn}_{n} \oplus \oplus$ & ... & $\cdots$ & $\cdots$ & $\ldots$ & $1 \cdot 52$ \\
\hline $\mathrm{HClO}, \mathrm{Cl}$ & ... & $\ldots$ & $\cdots$ & $\ldots$ & $1 \cdot 50$ \\
\hline $\mathrm{Cl}_{2}, \mathrm{Cl} \ominus \ldots$ & $\ldots$ & $\ldots$ & $\ldots$ & $\ldots$ & $1 \cdot 36$ \\
\hline $\mathrm{Tl} \oplus \oplus \oplus, \mathrm{Tl} \oplus$ & $\ldots$ & $\ldots$ & $\ldots$ & $\ldots$ & $1 \cdot 22$ \\
\hline $\mathrm{Br}_{2}, \mathrm{Br} \ominus$ & $\ldots$ & $\ldots$ & $\ldots$ & $\ldots$ & 1.07 \\
\hline $\mathrm{Hg}^{\oplus} \oplus, \mathrm{Hg}_{2} \oplus \oplus$ & $\ldots$ & $\ldots$ & $\ldots$ & $\ldots$ & 0.91 \\
\hline $\mathrm{Ag} \oplus, \mathrm{Ag} \ldots$ & $\ldots$ & $\ldots$ & $\ldots$ & $\ldots$ & $0 \cdot 8$ \\
\hline $\mathrm{Hg} \oplus \in, \mathrm{Hg}$ & ... & ... & $\ldots$ & ... & $0 \cdot 8$ \\
\hline $\mathrm{Fe} \oplus \oplus \oplus, \mathrm{Fe} \oplus \oplus$ & ... & ... & $\ldots$ & ... & 0.77 \\
\hline $\mathrm{AsO}_{4} \cdot \mathrm{AsO}_{3}$ & $\ldots$ & ... & $\ldots$ & $\ldots$ & $0 \cdot 49$ \\
\hline $\mathrm{O}_{2}, \mathrm{OH} \ominus$ & ‥ & $\ldots$ & $\ldots$ & $\ldots$ & $0 \cdot 4$ \\
\hline 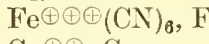 & 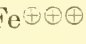 & $\oplus(\mathrm{CN})_{6}$ & $\ldots$ & $\ldots$ & $0 \cdot 36$ \\
\hline $\mathrm{Cu} \oplus \oplus, \mathrm{Cu}$ & $\ldots$ & ... & ... & $\ldots$ & $0 \cdot 34$ \\
\hline $\mathrm{Hg}_{2} \mathrm{Cl}_{2}, \mathrm{Hg}$ & ... & ... & ... & $\ldots$ & 0.27 \\
\hline $\mathrm{AgCl}, \mathrm{Ag}$ & ... & $\ldots$ & ... & $\ldots$ & $0 \cdot 22$ \\
\hline $\mathrm{Cu} \oplus \oplus, \mathrm{Cu}^{\oplus}$ & ... & ... & ... & $\ldots$ & $0 \cdot 17$ \\
\hline $\operatorname{Sn} \oplus \oplus \oplus \oplus, \mathbf{S} n \oplus \Theta$ & & ... & ... & $\ldots$ & $0 \cdot 15$ \\
\hline $\mathbf{T} \mathbf{i} \oplus \oplus \oplus \oplus, \mathbf{T} \mathbf{i} \oplus \oplus$ & & ... & ... & $\ldots$ & $+0 \cdot 06$ \\
\hline $\mathrm{H} \oplus, \mathrm{H}_{2} \ldots$ & ... & ... & $\ldots$ & $\ldots$ & 0 \\
\hline $\mathrm{Pb} \oplus \oplus, \mathrm{Pb}$ & ... & ... & ... & $\ldots$ & $-0 \cdot 13$ \\
\hline $\mathrm{Sn} \oplus \oplus, \mathrm{Sn}$ & $\ldots$ & $\ldots$ & $\cdots$ & $\ldots$ & $-0 \cdot 14$ \\
\hline $\mathrm{Ni} \oplus \oplus, \mathrm{Ni}$ & $\cdots$ & $\cdots$ & $\cdots$ & $\ldots$ & $-0 \cdot 24$ \\
\hline $\mathrm{Co} \oplus \oplus, \mathrm{Co}$ & ... & $\cdots$ & $\ldots$ & $\ldots$ & $-0 \cdot 28$ \\
\hline $\mathrm{Cd} \oplus \oplus, \mathrm{Cd}$ & $\ldots$ & $\cdots$ & $\ldots$ & $\ldots$ & $-0 \cdot 40$ \\
\hline $\mathrm{Cr} \oplus \oplus \odot, \mathrm{Cr} \oplus$ & $\ldots$ & ... & $\ldots$ & $\ldots$ & -0.41 \\
\hline $\mathrm{Fe} \oplus \oplus, \mathrm{Fe}$ & $\ldots$ & $\ldots$ & $\ldots$ & $\ldots$ & -0.44 \\
\hline $\mathrm{Zn} \oplus \oplus, \mathrm{Zn}$ & $\ldots$ & $\ldots$ & $\ldots$ & $\ldots$ & -0.76 \\
\hline $\mathrm{Na} \oplus, \mathrm{Na} \ldots$ & $\ldots$ & $\ldots$ & $\ldots$ & $\ldots$ & -2.71 \\
\hline
\end{tabular}

is generally calculated in calories and the electrode potential in rolts; the gas constant $\mathrm{R}$ is then 1.987 calories per degree per mole and $\mathrm{F}$ is 23,070 calories per volt. It should be noted that in the general electrode equation (10) $\mathrm{R}$ was given as $8 \cdot 3$ joules and $\mathrm{F}$ as 96,500 coulombs, but the value of the expression RT is not thereby affected.

$$
\mathrm{F}
$$

As already mentioned the potential at a single electrode cannot be measured, but this has to be combined with another half cell to eomplete the electrical cell. Also 
there must be a standard of reference, some zero value to which all other potentials are referred; this is the normal hydrogen electrode to which the potential 0 volts is ascribed. The next difficulty is to decide what potentials are to be regarded as positive and which negative. Here, unfortunately, there is confusion and conflict. In this work, and in nearly all biochemical investigations, oxidising systems are regarded as being more positive in potential than any more reducing system. Since oxidising systems are those which take up electrons more readily, i.e., attract negative electricity they are regarded as being more positive. thus :-

$$
\mathrm{Fe}^{\oplus \oplus \oplus}+\epsilon \rightarrow \mathrm{Fe}^{\oplus \oplus}
$$

so that ferric iron is regarded as more positive than ferrous iron. Unfortunately, writers on themodynamics frequently have adopted the opposite convention (Lewis and Randall, 1923) and regard the potential as the tendency of electricity to pass from the right to the left of the cell, i.e., from the electrolyte to the electrode.

In Table 1 are given values of the standard oxidation-reduction potentials of a number of inorganic systems. Potentials are referred to the normal hydrogen electrode as zero and oxidising systems are positive in potential compared with more reducing systems. The data are derived mainly from Lewis and Randall (1923), Latimer (1938), De Vries (1947) and Glasstone (1947).

\section{Summary of Chapter I}

Oxidation and reduction processes are defined in terms of electron migrations; oxidising properties are due to a tendency to take up electrons, and reducing properties to a tendency to part with electrons. When one substance is oxidised (parts with electrons) another is always simultaneously reduced (takes up the electrons liberated). This electronic concept has suggested a method of studying quantitatively those reversible oxidation-reduction processes which are of vital importance to the living cell. The method is the measurement of electrode potentials which enable the degree of oxidation or reduction of a system to be gauged, and which render possible the grading of oxidising and reducing systems according to their intensity levels.

In a reversible oxidation-reduction system the electrode potential depends upon the relative amounts present of the oxidised and reduced forms of the substance studied. If a solution contains a mixture of the oxidised and reduced forms $\mathrm{X}_{0}$ and $\mathrm{X}_{\mathrm{r}}$, the reactants in the reversible oxidation-reduction system :-

$$
\mathrm{X}_{\mathrm{r}} \rightleftharpoons \mathrm{X}_{0}+\mathrm{n} \text { electrons }
$$

then the electrode potential $\left(\mathrm{E}_{\mathrm{h}}\right)$ at $30^{\circ} \mathrm{C}$. will be given by the equation :-

$$
\mathrm{E}_{\mathrm{h}}=\mathrm{E}_{0}+\frac{0 \cdot 06}{\mathrm{n}} \log \frac{\left[\mathrm{X}_{0}\right]}{\left[\mathrm{X}_{\mathrm{r}}\right]}
$$

where $\mathrm{E}_{0}=$ constant for the system ; $\left[\mathrm{X}_{0}\right]$ and $\left[\mathrm{X}_{\mathrm{r}}\right]$ are the concentrations of the oxidised and reduced forms respectively.

It follows from this equation that the more oxidising a system is the higher (more positive) will be the electrode potential and more reducing systems will have lower (or more negative) potentials. Conversely the potential is dependent solely 
on two factors, $(a)$ the proportions present of the oxidised and reduced forms of the substance studied and $(b)$ a constant for the system studied, i.e., $\mathrm{E}_{0}$. The value of $\mathrm{E}_{0}$ is given by the potential of the system when half oxidised and half reduced; that is, when the concentration of the oxidant is equal to that of the reductant.

Hydrogen-ion concentration has definite effects on electrode potentials, so that, strictly speaking, potentials can only be compared directly with others at the same $\mathrm{pH}$. The effect of $\mathrm{pH}$ on the electrode potential is not constant but varies both with different systems and at different ranges of $\mathrm{pH}$ in the same system. Considerable use has been made of the term $\mathrm{rH}$, taking into account both electrode potential and $\mathrm{pH}$, and assuming a simple, fixed relationship between them. This, however, is fallacious, especially in the case of in completely studied biological systems, so that it is inadvisable to use the term $\mathrm{rH}$ which assumes a simple and constant relationship. Particularly in the case of incompletely studied biological systems the use of $\mathrm{rH}$ is inadmissible. The relationship between the free energy changes and the electrode potentials of chemical reactions is discussed and the standard electrode potentials of some inorganic systems are tabulated. 


\section{CHAPTER II}

\section{PRACTICAL METHODS OF $\mathrm{E}_{\mathrm{h}}$ MEASUREMENT}

Naturally the most reliable method of measuring $\mathrm{E}_{\mathrm{b}}$ is the direct electrometric determination of the potential and this will be dealt with in the latter part of this chapter. The universal application of $\mathrm{pH}$ measurements is undoubtedly due in large measure to the simplicity of indicator methods and the first part of this chapter will deal with the present position in the use of dyes as oxidation-reduction potential indicators.

\section{USE OF INDICATORS}

Let $\mathrm{X}_{\mathrm{r}}$ be the reduced form and $\mathrm{X}_{0}$ the oxidised form of the reversible oxidationreduction system,

$$
\mathrm{X}_{\mathrm{r}} \underset{\text { reduction }}{\stackrel{\text { oxidation }}{\rightleftharpoons}} \rightleftharpoons \mathrm{X}_{0}+2 \text { electrons }
$$

The $\mathrm{pH}$ is kept constant throughout so that the general electrode potential equation is

$$
\mathrm{E}_{\mathrm{h}}=\mathrm{E}_{0}+\frac{\mathrm{RT}}{2 \mathrm{~F}} \ln \frac{\left[\mathrm{X}_{0}\right]}{\left[\mathrm{X}_{\mathrm{r}}\right]}
$$

If the temperature throughout is kept constant at $30^{\circ} \mathrm{C}$. the expression is simplified

$$
\mathrm{E}_{\mathrm{h}}=\mathrm{E}_{0}+0.03 \log \frac{\left[\mathrm{X}_{0}\right]}{\left[\mathrm{X}_{\mathrm{r}}\right]}
$$

If the potential of the 50 per cent. oxidised system (i.e., $\left[\mathrm{X}_{\mathrm{o}}\right]=\left[\mathrm{X}_{\mathrm{r}}\right]$ ) be +0.1 volt, then $\mathrm{E}_{0}=+0.1$ volt, and

$$
\mathrm{E}_{\mathrm{b}}=+0.1+0.03 \log \frac{\mathrm{X}_{o}}{\mathrm{X}_{\mathrm{r}}}
$$

From this we can calculate directly the potential at different stages of oxidation of $\mathrm{X}$. Thus, when 98 per cent. oxidised ( 2 per cent. reduced) the potential will be (in volts)

$$
\mathrm{E}_{\mathrm{h}}=0.1+0.03 \log \frac{98}{2}=+0.15 \text { volt. }
$$

In this way the following table can be constructed :-

$$
\begin{aligned}
& \text { Percentage Oxidation } \mathbf{E}_{\mathrm{b}} \text {. }
\end{aligned}
$$

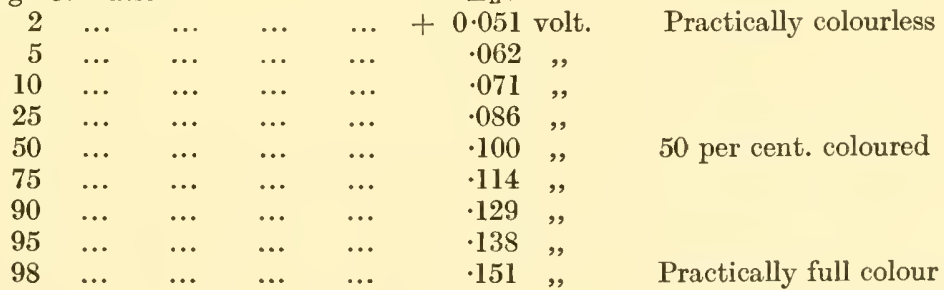

The oxidation-reduction condition of the system can be read off from a determination of the potential. Thus, if the $\mathrm{E}_{\mathrm{h}}$ were +0.13 volt, the system would be 91 
per cent. in the oxidised form and 9 per cent. in the reauced form. Conversely-and this is of importance at the present stage-given a certain degree of oxidation the potential corresponding to this can be calculatea. If $\mathrm{X}_{0}$ be a coloured dye which is colourless when reduced, the amount of colour in the dye solution indicates the percentage of oxidation and hence the potential. Therefore, if the dye is added to an oxidation-reduction system, and the colour of the dye indicates 50 per cent. reduction, the system has $\mathrm{E}_{\mathrm{h}}+0.1$ volt. Hence, with a series of dyes changing colour at different ranges of $\mathrm{E}_{\mathrm{h}}$, a scheme of $\mathrm{E}_{\mathrm{h}}$ determination is possible, directly comparable to $\mathrm{pH}$ determination by the use of indicators.

The dyes used have each a range of about 0.1 volt covering the change of the coloured to the colourless form. Clark and his collaborators (1923-1926) have studied a considerable number of dyes which behave as oxidation-reduction indicators in this way. The majority of these dyes are indophenols or derivatives of indigo and the colour of the oxidised form may be traced to the quinonoid structure of the benzene ring. To take the simple case of hydroquinone : quinone

$$
\begin{aligned}
& \text { ionisation oxidation } \\
& \mathrm{C}_{6} \mathrm{H}_{4}(\mathrm{OH})_{2} \rightleftharpoons \mathrm{C}_{6} \mathrm{H}_{4} \mathrm{O}_{2} \ominus \ominus \rightleftharpoons==\mathrm{C}_{6} \mathrm{H}_{4} \mathrm{O}_{2} \\
& \text { Hydroquinone } \rightleftharpoons \text { anion } \rightleftharpoons \text { quinone. }
\end{aligned}
$$

In the diagram below each single valency bond is represented by a pair of electrons and the mechanism of the oxidation is represented as involving the intermediate formation of the secondary anion (single lines in the formulæ represent electrons and not valency bonds) :-

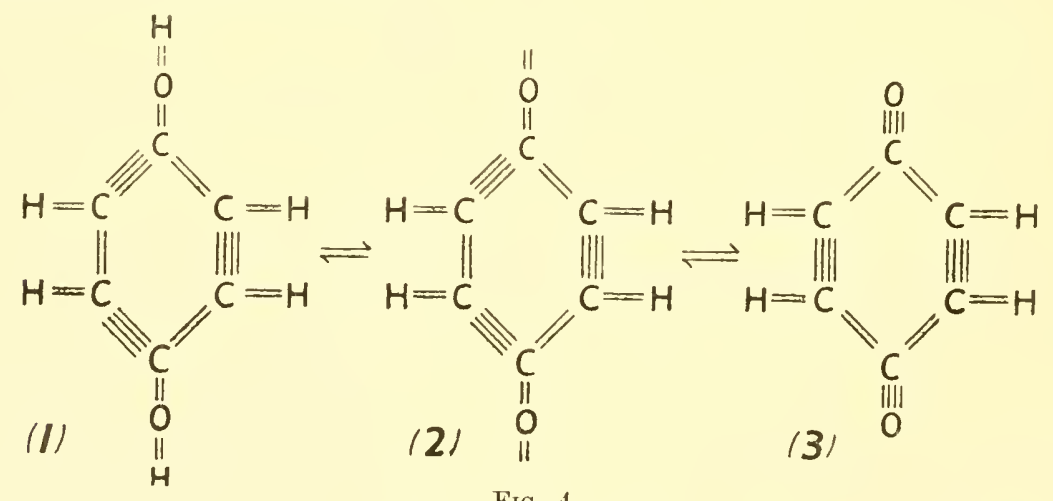

Fia. 4

Hydroquinone SYSTEM

(1) Hydroquinone, 34 eleetrons, colourless

(2) Anion, 34 electrons, colourless

(3) Quinone, 32 electrons, eoloured

A similar mechanism may be postulated for the oxidation-reduction indicators; in such cases as that of methylene blue nitrogen plays a similar part to that of oxygen in the above scheme. The theories of the origin of colour and the formulation of the electronic changes involved in the oxidation and reduction of these dyes are, however, outside the scope of this treatise, and their application to the determination of $\mathrm{E}_{\mathrm{h}}$ is of greater importance. 


\begin{tabular}{|c|c|c|}
\hline & 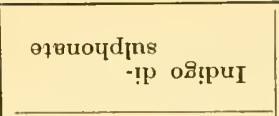 & 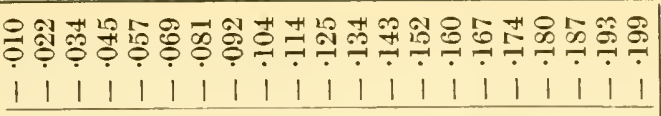 \\
\hline & 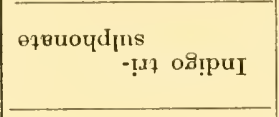 & 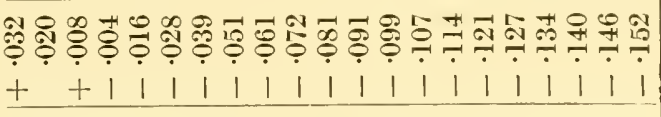 \\
\hline & 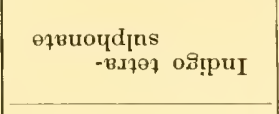 & 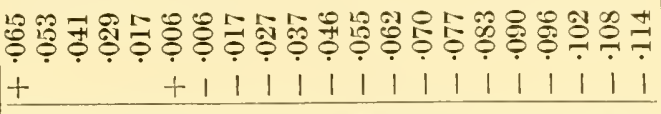 \\
\hline & 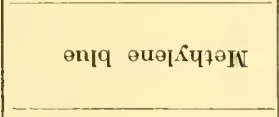 & 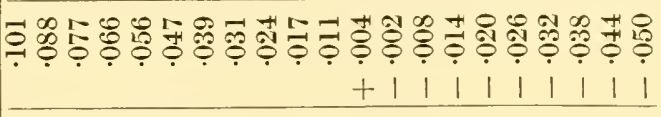 \\
\hline & өน!นо!ЧL & 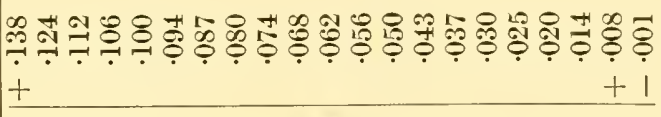 \\
\hline & 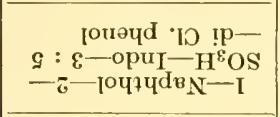 & 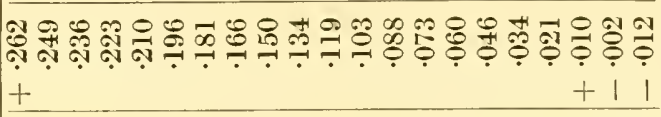 \\
\hline $\begin{array}{l}\text { ñ } \\
\text { 。ै }\end{array}$ & 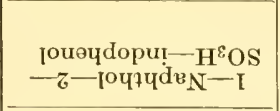 & 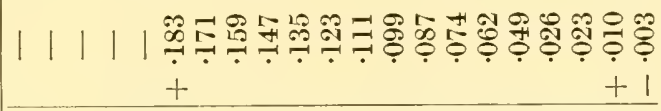 \\
\hline 点 & 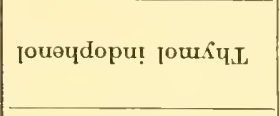 & 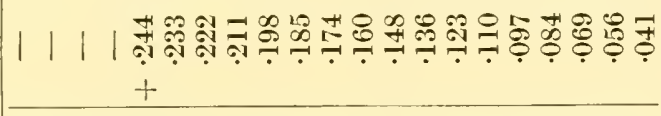 \\
\hline 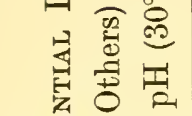 & 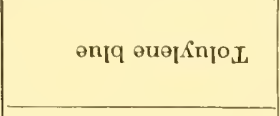 & 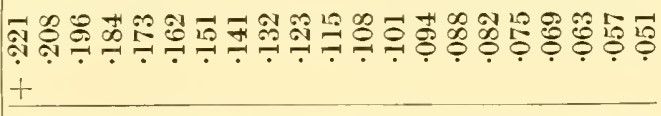 \\
\hline 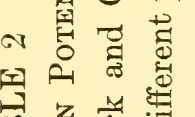 & 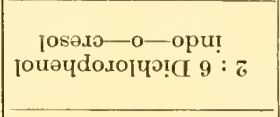 & 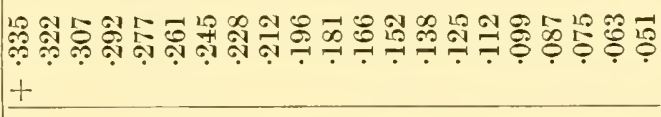 \\
\hline 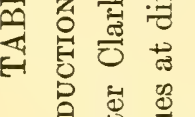 & $\begin{array}{l}\text { foueydopu! } \\
\qquad \text { ןosex } \mathrm{P}-0\end{array}$ & 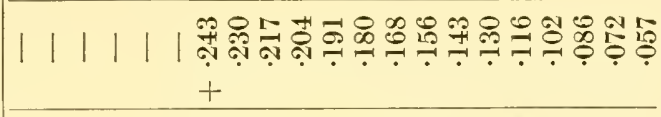 \\
\hline 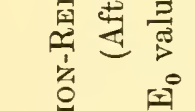 & 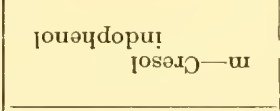 & 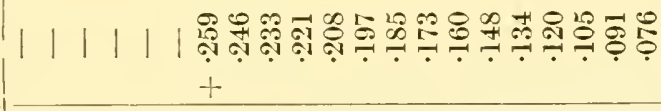 \\
\hline 宸 & 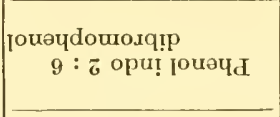 & 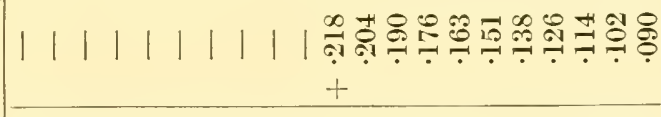 \\
\hline & 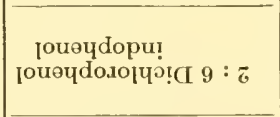 & 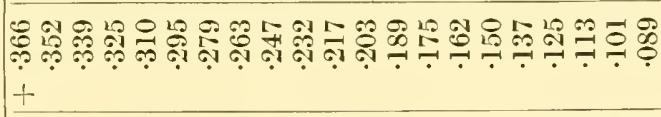 \\
\hline & $\begin{array}{l}\text { jouəydoput } \\
\text { poueydouio.tg-o }\end{array}$ & 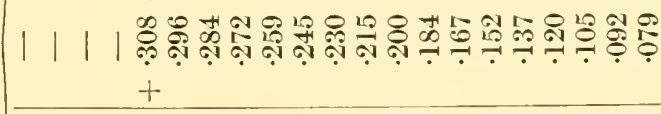 \\
\hline & рочәч dopu! [очәчd & 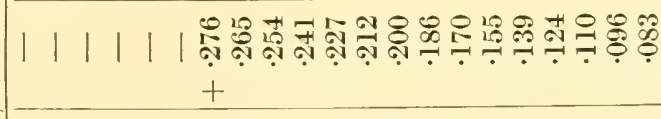 \\
\hline & 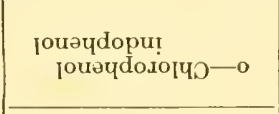 & 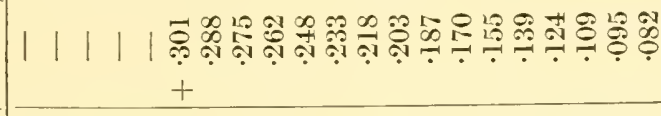 \\
\hline & 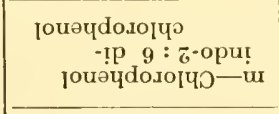 & 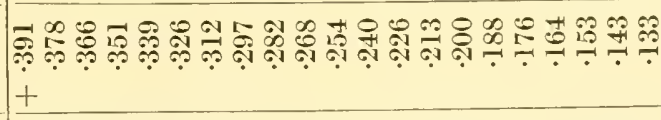 \\
\hline & 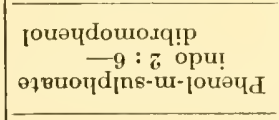 & 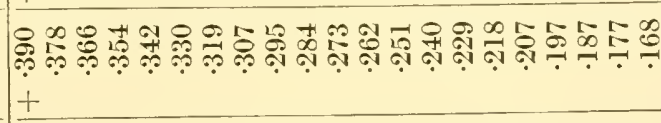 \\
\hline & $\cdot \mathrm{H}^{\mathrm{d}}$ & Q \\
\hline
\end{tabular}


TABLE 3

Variation of Potential with Percentage Oxidation, at Constant pH $\left(30^{\circ}\right.$ C. $)$ of Dyes $\mathrm{E}_{\mathrm{h}}=\mathrm{E}_{\mathrm{o}}^{1}+\mathrm{k}$

\begin{tabular}{|c|c|c|}
\hline $\begin{array}{c}\text { Per cent. } \\
\text { oxidation }\end{array}$ & $\begin{array}{c}\mathrm{k} \\
\text { volts }\end{array}$ & Tint \\
\hline 99 & +0.060 & Almost full colour \\
98 & +0.051 & \\
95 & +0.038 & \\
90 & +0.029 & \\
85 & +0.023 & \\
80 & +0.018 & \\
75 & +0.014 & \\
70 & +0.011 & \\
65 & +0.008 & \\
60 & +0.005 & \\
55 & +0.003 & Half colour \\
50 & 0 & \\
45 & -0.003 & \\
40 & -0.005 & \\
35 & -0.008 & \\
30 & -0.011 & \\
25 & -0.014 & \\
20 & -0.018 & \\
15 & -0.023 & \\
10 & -0.029 & \\
5 & -0.038 & \\
2 & -0.051 & Almost colourless \\
1 & -0.060 & \\
& & \\
\hline
\end{tabular}

In table 2 are given the $\mathrm{E}_{0}^{1}$ values of a number of indicators at different $\mathrm{pH}$. At any given $\mathrm{pH}$ therefore the $\mathrm{E}_{\mathrm{o}}^{1}$ of the indicator can be immediately found. From the usual equation the change of potential at various degrees of oxidation or reduction can be calculated; these values are summarised in table 3 . The application of these data is simple. Let us suppose that to a system at $\mathrm{pH} 7 \cdot 8$ there be added a solution of indigo tetra-sulphonate, and colorimetric comparison of the depth of colour indicates that the dye is 75 per cent. reduced (i.e., the dye has only one-quarter of its full colour). From table 2 the $\mathrm{E}_{0}^{1}$ value is -0.077 volt at $\mathrm{pH} 7.8$, and since the dye is 75 per cent. reduced the potential is 0.014 volt lower (more negative) than the $\mathrm{E}_{0}^{1}$ value (from table 3 ), therefore the $\mathrm{E}_{\mathrm{h}}$ of the system is $-0.077-0.014=-0.091$ volt. From the tables it can be ascertained that indigo tri-sulphonate should be 15 per cent. reduced at this level of potential (i.e., the dye should have 85 per cent. of its full colour when added to the system). The result obtained with the tetra-sulphonate can, therefore, be checked by observation of the behaviour of the tri-sulphonate. 


\begin{tabular}{|c|c|c|c|c|c|c|c|c|c|c|c|c|c|c|c|c|}
\hline \multirow{3}{*}{ Sij } & $(87 ן 0 x){ }^{4}$ & $\begin{array}{l}\stackrel{8}{9} \\
+\end{array}$ & $\begin{array}{l}\stackrel{\leftrightarrow}{9} \\
+\end{array}$ & $\begin{array}{l}\stackrel{\text { ণे }}{+} \\
+\end{array}$ & $\begin{array}{l}\stackrel{10}{7} \\
+\end{array}$ & $\stackrel{\circ}{+}$ & $\begin{array}{l}\stackrel{10}{9} \\
+\end{array}$ & 0 & $\stackrel{10}{9}$ & $\stackrel{\circ}{i}$ & $\stackrel{19}{i}$ & \&ุ & $\stackrel{10}{9}$ & ? & i & 아 \\
\hline & өn & 1 & 1 & 1 & 1 & $\stackrel{\circ}{\circ}$ & i⿱ & ஓे & 1 & 1 & I & 1 & 1 & 1 & 1 & I \\
\hline & จu!̣uo!̣,L & 1 & I & I & 1 & iी & 角 & $\stackrel{0}{-1}$ & 1 & 1 & I & 1 & 1 & 1 & 1 & 1 \\
\hline 它 & 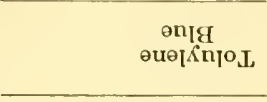 & 1 & 롱 & 1 & $\frac{0}{3}$ & ڤैं & 1 & I & 1 & 1 & 1 & 1 & 1 & 1 & 1 & I \\
\hline | & 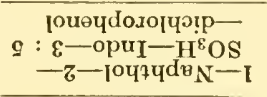 & 1 & 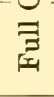 & 1 & $\frac{20}{\sigma}$ & $\stackrel{\circ}{\circ}$ & 1 & I & I & 1 & 1 & 1 & 1 & 1 & 1 & 1 \\
\hline 분 & 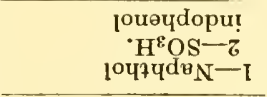 & I & 1 & I & $\infty_{\infty}^{0}$ & is & 1 & 1 & 1 & 1 & 1 & | & I & 1 & 1 & I \\
\hline 点 & $\begin{array}{l}\text { jouøчdopu! } \\
\text { jouкบบ }\end{array}$ & 1 & 1 & $\infty_{\infty}^{\circ}$ & $\stackrel{0}{\stackrel{0}{\sharp}}$ & 1 & 1 & 1 & 1 & 1 & 1 & 1 & 1 & 1 & I & I \\
\hline 崖 & 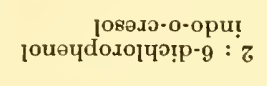 & I & 1 & $\frac{a^{2}}{\infty}$ & के & 1 & I & 1 & 1 & 1 & 1 & 1 & 1 & 1 & 1 & 1 \\
\hline 罂 & $\begin{array}{l}\text { jouөydopu! } \\
\text { [оsəx丂--o }\end{array}$ & I & $\dot{\circ}^{0}$ & $\stackrel{8}{0}^{0}$ & $\stackrel{0}{0}$ & 1 & 1 & 1 & 1 & I & 1 & I & 1 & 1 & 1 & | \\
\hline $\begin{array}{c}2 \\
\text { on } \\
\\
0\end{array}$ & 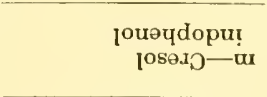 & 1 & $\stackrel{\circ}{\circ}^{\circ}$ & $i_{10}^{0}$ & $\partial_{-1}^{0}$ & I & 1 & 1 & 1 & $\frac{g}{3}$ & 1 & 1 & 1 & 1 & 1 & | \\
\hline 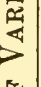 & 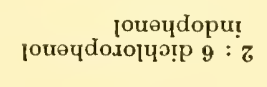 & 1 & हे & $\frac{0}{\mathrm{a}}$ & I & I & 1 & 1 & I & $\frac{0}{0}$ & 1 & I & 1 & I & 1 & | \\
\hline$\frac{0}{0}$ & $\begin{array}{c}\text { [ouөudourosq!p } \\
-9: z \text { opu! ןouөчd }\end{array}$ & & ํำ & $\hat{\circ}^{\circ}$ & 1 & 1 & I & I & I & 1 & 1 & I & 1 & 1 & 1 & | \\
\hline$\bigcup^{1}$ & $\begin{array}{l}\text { jouөydopu! } \\
\text { [оuөчd }\end{array}$ & & $i_{i}^{\circ}$ & 冬 & 1 & 1 & I & 1 & I & 1 & 1 & 1 & 1 & 1 & 1 & I \\
\hline$\frac{z}{z}$ & $\begin{array}{c}\text { louøydopu! } \\
\text { ןouəudowoxg-o }\end{array}$ & & ฌั & $\dot{\circ}^{\circ}$ & 1 & 1 & I & 1 & I & I & I & I & 1 & 1 & I & I \\
\hline 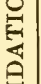 & 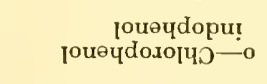 & 1 & 只 & $\dot{\infty}_{\infty}^{\circ}$ & 1 & 1 & I & 1 & I & 1 & 1 & I & 1 & I & 1 & 1 \\
\hline 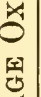 & 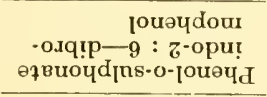 & $\stackrel{\circ}{8}$ & $i^{\circ}$ & $2^{\circ}$ & 1 & I & 1 & 1 & I & 1 & I & 1 & 1 & 1 & 1 & 1 \\
\hline 究 & 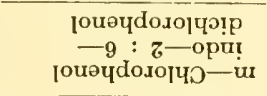 & 兽 & :̊ำ & $\stackrel{\circ}{\circ}$ & 1 & 1 & I & 1 & 1 & I & I & 1 & 1 & 1 & 1 & | \\
\hline 空 & 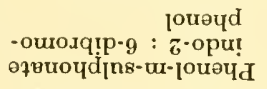 & $\infty_{\infty}^{\circ}$ & id & 1 & 1 & 1 & 1 & 1 & I & 1 & 1 & | & 1 & I & I & 1 \\
\hline & 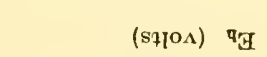 & ஜ্ণ & งึ & คุ & $\stackrel{20}{7}$ & $\stackrel{ }{ }$ & ํํ & 0 & 오 & $\because$ & $\stackrel{10}{7}$ & คุ & ลุง & ฺ̊ & Pी & 东 \\
\hline & & + & + & + & + & + & + & & 1 & 1 & 1 & 1 & 1 & 1 & 1 & 1 \\
\hline
\end{tabular}




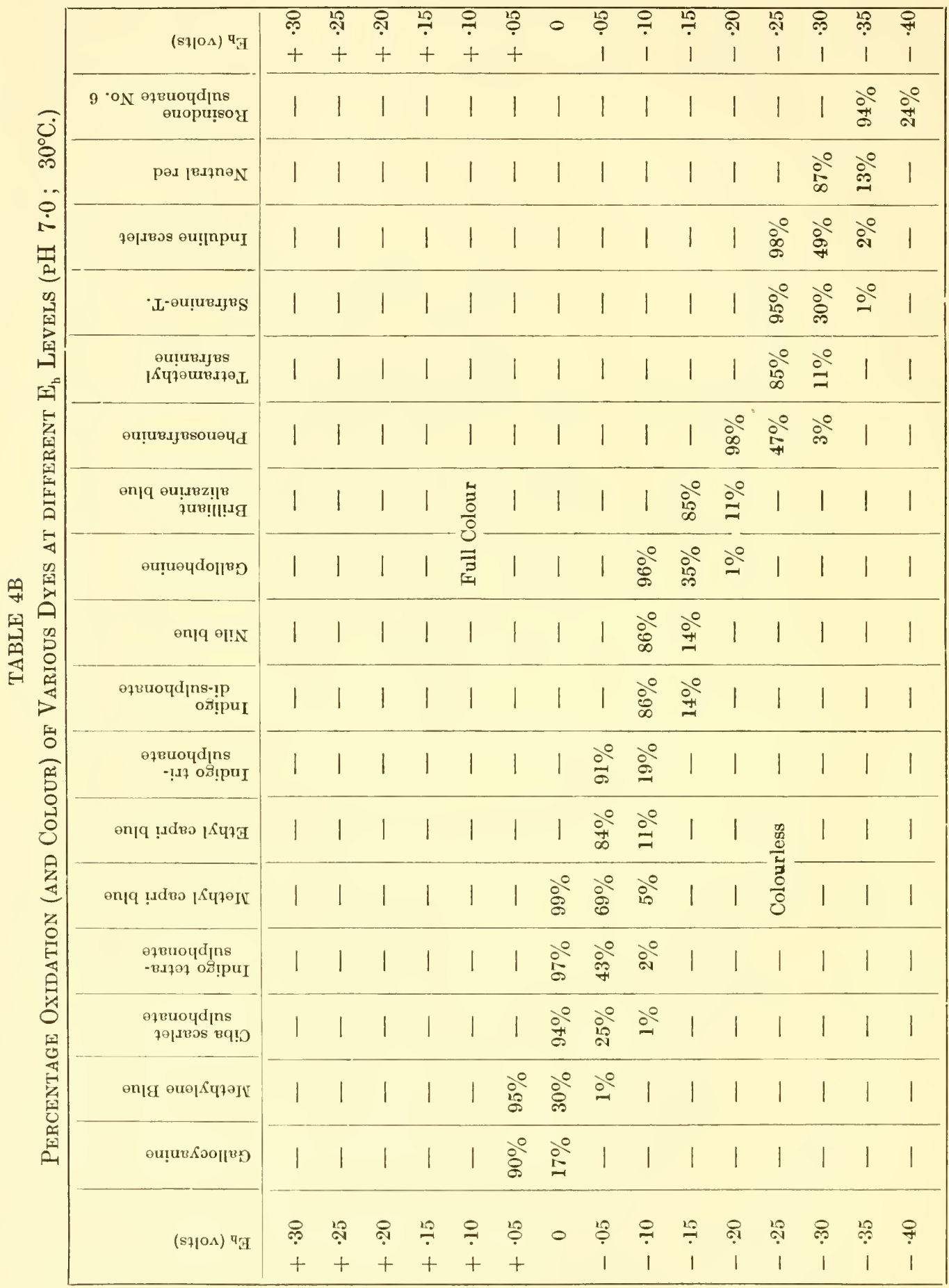


The electrode potential equation referring to the oxidation-reduction indicators is

so that at any $\mathrm{pH}$ and at $30^{\circ} \mathrm{C}$. this becomes

$$
\mathrm{E}_{\mathrm{h}}=\mathrm{E}_{0}+\frac{\mathrm{RT}}{2 \mathrm{~F}} \ln \frac{[\mathrm{Ox} .]}{[\text { Red. }]}
$$

$$
\mathrm{E}_{\mathrm{h}}=\mathrm{E}_{0}+0.03 \log \frac{[\mathrm{Ox} .]}{[\text { Red. }]}
$$

It is obvious therefore that the useful range of a dye will depend on its $\mathrm{E}_{0}^{1}$, the potential at 50 per cent. reduction at the given $\mathrm{pH}$. The useful range extends about 0.05 volt above and below this potential. Thus, if the $\mathrm{E}_{0}$ of a dye at a given $\mathrm{pH}$ is +0.1 volt, the dye will be about 98 per cent. oxidised at +0.15 volt and 98 per cent. reduced at +0.05 volt.

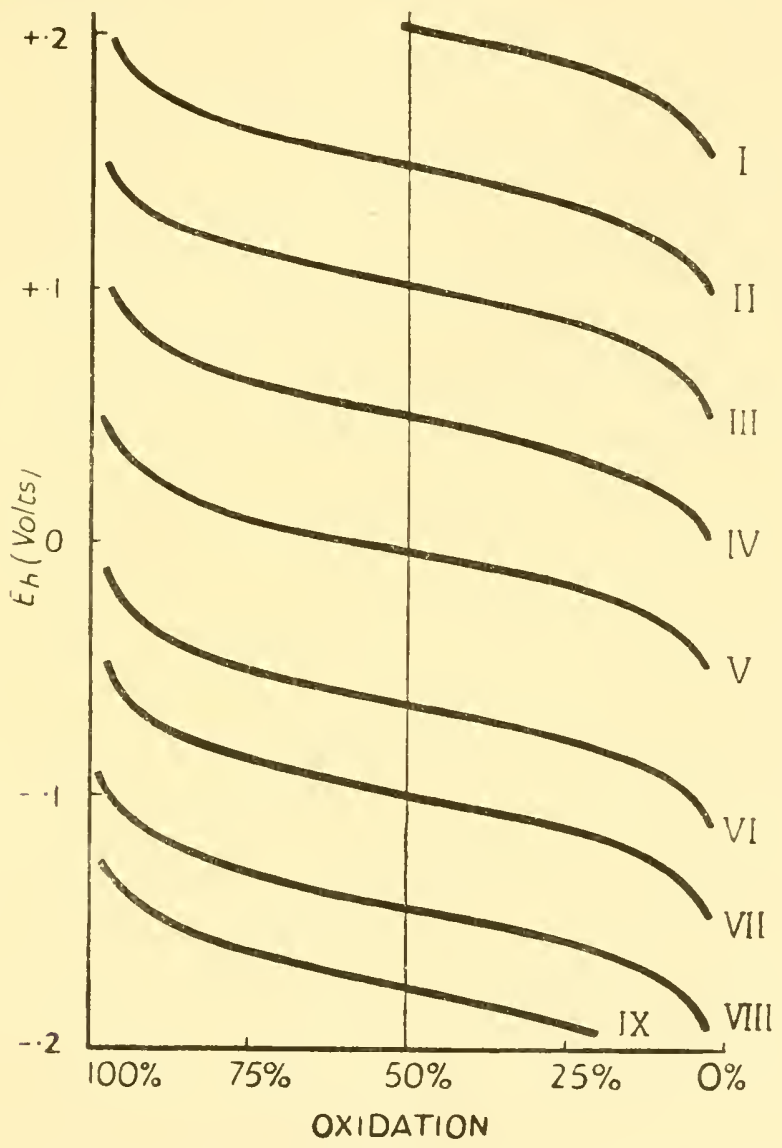

FIG. 5

Reration between $\mathrm{E}_{\mathrm{h}}$ and Percentage Oxidation of Various Dyes Aт $\mathrm{PH} 7 \cdot 4$

I. o-Chlorophenol indophenol

II. Thymol indophenol

III. 1-Naphthol-2-sulphonate indophenol

IV. Thionine
V. Methylene blue

VI. Indigotetrasulphonate

VII. Indigotrisulphonate

VIII. Indigodisulphonate

IX. Indigomonosulphonate 
The choice of suitable indicators for any given range of potentials may be made after consulting tables $3 \mathrm{~A}$ and $3 \mathrm{~B}$, which are drawn up for $\mathrm{pH} 7 \cdot 0$, but can equally well be used for other $\mathrm{pH}$ values, by using the data given in table 1. The range of $\mathrm{E}_{\mathrm{b}}$ covered by each dye is about $0.1 \mathrm{v}$.; that is, from 98 per cent. oxidation (and colour (down to about 2 per cent., the greatest sensitivity being in the centre of the range. Thus in the centre of the range a 10 per cent. difference in oxidation is effected by a change of $0.006 \mathrm{v}$., whereas to pass from 89 per cent. to 99 per cent. oxidation an increase of over $0.031 \mathrm{v}$. is necessary. Having chosen a dye covering the required range, however, dyes that are either totally reduced or totally oxidised are useful checks.

The relation between the percentage oxidation and the electrode potential of various oxidation-reduction potential indicator dyes is represented graphically in fig. 5 .

It may be noted that the curves relating the percentage oxidation and reduction of a system to the oxidation-reduction potential is of the same S-type as the polarographic curves mentioned in Chapter VIII.

In the polarographic curves the electrode potential applied to the dropping electrode is related to the current flowing in the circuit. In both sets of curves, the half-way point of inflection corresponds to the electrode potential of the half-oxidised, half-reduced system, but in the oxidation-reduction potential curves, we are dealing with the proportion of the oxidised and reduced forms, whereas, in polarographic measurements the total concentration of the system determines the scale of the curve.

TABLE 5

Oxidation-Reduction Indicator Dyes

$\mathrm{E}_{0}^{1}$ values (potentials of half reduced dyes) at $\mathrm{pH} 7 \cdot 0$

\begin{tabular}{|c|c|c|c|c|c|c|}
\hline Dye & $E_{o}^{\prime}($ volts $)$ & Dye & & \multicolumn{3}{|c|}{$E_{0}^{!}($volts $)$} \\
\hline Phenol-m-sulphonate-indo-2:6- & & Toluylene blue $\quad \ldots$ & & & & $\cdot 115$ \\
\hline dibromophenol $\quad \ldots \quad \ldots, \quad \ldots$ & $+0 \cdot 273$ & Thionine (Lauth's violet) & ... & ... & & .063 \\
\hline $\mathrm{m}$-Chlorophenol-indo-2: 6-dichloro- & & Prune $\quad \ldots \quad \ldots$ & ... & ... & & $\cdot 056$ \\
\hline phenol $12, \ldots, \quad \ldots, \quad \ldots$ & $\cdot 254$ & Cresyl blue & & & & 047 \\
\hline m-Bromophenol indophenol $\quad$... & $\cdot 248$ & Gallocyanine $\ldots$ & ... & .. & & 021 \\
\hline Phenol-o-sulphonate-indo-2 : 6-di- & & Methylene blue & ... & ... & + & 011 \\
\hline bromophenol $\quad \ldots \quad \ldots \quad \ldots$ & .242 & Ciba scarlet sulphonate & $\ldots$ & & - & .036 \\
\hline o-Chlorophenol indophenol ... & .233 & Indigo tetrasuiphonate & ... & ... & - & $\cdot 046$ \\
\hline o-Bromophenol indophenol ... & $\cdot 230$ & Methyl capri blue $\quad \ldots$ & $\ldots$ & ... & - & $\cdot 060$ \\
\hline Phenol indophenol $\quad \ldots \quad \ldots$ & $\cdot 227$ & Indigo trisulphonate ... & ... & ... & - & $\cdot 081$ \\
\hline Bindschedler's green ... & $\cdot 224$ & Indigo disulphonate ... & $\ldots$ & ... & - & $\cdot 125$ \\
\hline 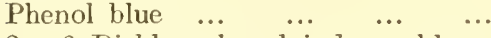 & $\cdot 224$ & Gallophenine $\ldots . \quad \ldots$ & ... & ... & - & $\cdot 142$ \\
\hline 2 : 6-Dichlorophenol indo-o-chloro- & & Brilliant alizarine blue & $\cdots$ & & - & $\cdot 173$ \\
\hline$\cdots, \cdots, \quad \cdots$ & 219 & 2-Methyl-3 hydroxy-1 : 4 & nap & & & \\
\hline 2 : 6-Dibromophenol indophenol & $\cdot 218$ & (phithic & $\ldots$ & & - & $\cdot 180$ \\
\hline 2 : 6-Dichlorophenol indophenol & 217 & Phenosafranine & ... & .. & - & $\cdot 252$ \\
\hline m-Cresol indophenol ... & $\cdot 208$ & Dimethyl phenosafranine & ... & $\ldots$ & - & $\cdot 260$ \\
\hline o-Cresol indophenol ... & $\cdot 191$ & Tetramethyl phenosafranine & & & - & \\
\hline 2: 6-Dichlorophenol indo-o-cresol ... & $\cdot 181$ & Safranine-T & $\cdots$ & $\ldots$ & - & $\cdot 289$ \\
\hline 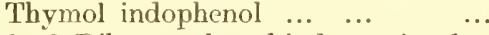 & $\cdot 174$ & Induline scarlet & ... & ... & - & \\
\hline iophenol indo-guaiacol... & $\cdot 159$ & Neutral red ... & $\ldots$ & ... & - & \\
\hline ne indophenol .. & $\cdot 125$ & Rosinclone sulphonate No. 6 & & & - & \\
\hline 1-Naphthol-2-sulphonate indophenol & $\cdot 12$ & Viologens $\quad \ldots$ & ... & ... & & $\cdot 400$ \\
\hline & & Hydrogen clectrode ( 1 ; & & & & \\
\hline phenol $\quad \ldots$ & $\cdot 119$ & pressure) & $\cdots$ & $\cdots$ & & \\
\hline
\end{tabular}




\section{LIMITATIONS IN THE USE OF OXIDATION-REDUCTION POTENTIAL INDICATORS}

With the help of data of the type presented in the foregoing tables, the choice of dyes of suitable $E_{\mathrm{h}}$ range is possible. It is now necessary to apply other criteria. The dyes chosen should have a distinctive colour readily observable in the presence of biological fluids, and should not behave, like some of the simpler indophenols, as $\mathrm{pH}$ indicators (Fildes, 1929). Such dyes, although of an intense blue colour in alkaline solution, may in the biological range of $\mathrm{pH}$ near the neutral point have a dull reddish brown tint, which is barely distinguishable from that of tissue fluids or culture media. Such dyes are, of course, almost useless to bacteriologists and biologists generally.

When, however, dyes have been selected of suitable $\mathrm{E}_{\mathrm{h}}$ range and which have a distinct colour at the $\mathrm{pH}$ of the experimental system, it is necessary to consider further possible limitations and fallacies in interpreting the result obtained.

\section{Capacity and Poising Effects}

Many biological systems, although having a clear-cut and definite level of potential, may be of small effective oxidation-reduction capacity, and not be well poised. (This is equivalent to a solution being not well-buffered in $\mathrm{pH}$ determinations.) In these cases, when the oxidised form of thie dye is added to the system, the dye is capable of oxidising the system entirely without itself being reduced appreciably so that the level of potential of the system approximates to that of the oxidised form of the dye. This, really, follows from consideration of the electrode potential equation. Let us consider the electrode equations of the biological system (B) and of the dye (D), and let them both be of the same form, at $30^{\circ} \mathrm{C}$, and at the same $\mathrm{pH}$.

$$
\begin{array}{ll}
\text { The system } & \mathrm{E}_{\mathrm{h}}=\mathrm{E}_{\mathrm{o}}^{1}+0.03 \log \frac{\left[\mathrm{B}_{\mathrm{ox}}\right]}{\left[\mathrm{B}_{\mathrm{red}}\right]} \\
\text { and the dye } & \mathrm{E}_{\mathrm{h}}=\mathrm{E}_{\mathrm{o}}^{\prime \prime}+0.03 \log \frac{\left[\mathrm{D}_{\mathrm{ox}}\right]}{\left[\mathrm{D}_{\mathrm{red}}\right]}
\end{array}
$$

The level of potential of each is dependent solely on the ratio of the concentrations of the oxidised and reduced form. That is to say, that at any given degree of oxidation, solutions of the dye will have the same $\mathrm{E}_{\mathrm{h}}$, no matter whether the dye solution is of 0.001 per cent., 1 per cent. or 10 per cent. concentration, and the same applies to the system. But if now the two solutions are mixed, their actual total concentrations become of importance. Should the dye contain $100 \mathrm{gm}$. equivalent per litre and the biological system only $1 \mathrm{gm}$. equivalent per litre (of the oxidationreduction system responsible for the potential) the dye can oxidise the whole of the biological system and still remain 99 per cent. oxidised, thus proving useless as an indicator of the condition of the system.

The relative capacities, or poising effects, of the experimental system and of the oxidation-reduction potential indicator must therefore be taken into account in the interpretation of results.

\section{Time Factor}

A considerable time may elapse before the biological system comes into equilibrium with the indicator. This is due in part to the method of establishment 
of electrode potentials in biological systems, which behave, not as systems of fixed capacity or poising effect, but rather like a fountain-pen from which a small quantity of ink may be withdrawn for long periods at a, slow rate. So that although the effective capacity of the biological system at any time may be very low, an almost inexhaustible process of reduction may proceed. If therefore a series of dyes be added to a biological system, they may all at first remain in a highly oxidised condition, but one after another may be reduced as the system effects its gradual reducing processes. Very long periods may be necessary therefore to determine the oxidation-reduction condition of a biological system, and as such a system, particularly in bacteriology, is itself a constantly changing one, it may be impossible to determine the electrode potential at different periods by the use of dyes.

\section{Catalytic Effect of Dye}

To be useful as an oxidation-reduction potential indicator it is evident that a dye must behave as an inert indicator of the potential and must not participate directly or indirectly in the system studied by exerting any catalytic effect. If the dye has such a catalytic effect the equilibrium of the system may be permanently disturbed, and no useful results can be expected with such a dye.

Barron and Hoffman (1930) observed the catalytic effect of different dyes on the oxidation processes taking place in living cells.

As a result of their work on adrenaline, Ball and Chen (1933) find it necessary to give the following warning: "It is emphasised that results obtained by means of oxidation-reduction indicators on unstable systems or on biological material where such systems are present must be interpreted with great care." Certain oxidationreduction potential indicator dyes have been found to promote reactions which will not proceed in their absence. Schott and Borsook (1933) describe such an effect in the case of toluene treated $B$. coli and call the results "coupled reactions." Green, Stickland and Tarr (1934), however, prefer the term "carrier linked reactions," which they apply to the reactions between dehydrogenase systems isolated from the cell structure. These do not proceed in the absence of appropriate artificial hydrogen carriers, such as certain oxidation-reduction potential indicator dyes. These dyes function by being continually reduced by the negative enzyme system and oxidised by the more positive system. It is very significant that the effect appears to possess considerable specificity. Of the naturally occurring substances examined only pyocyanine functioned in this way, and dyes even of similar oxidation-reduction potential differed greatly in their activity. It is evident that the greatest caution must be exercised before dyes or even natural pigments are treated as inert indicators of the potential (see also Meio, Kissin and Barron, 1934 ; Greville and Stern, 1935 ; Lennerstrand and Runnström, 1935; Young, 1937).

\section{Toxic Effect of Dye}

The dye may damage or even kill the cells in biological studies, and the damaged or dead cells may have entircly different oxidation-reduction properties, so that no trustworthy results can be obtained. It must be remembered that either the oxidised or reduced form alone, or both, may have toxic effects. Chambers, Cohen and Pollack (1931) have shown that indicator dyes which penetrated echinoderm ova were toxic and killed the cells. Dyes, particularly basic dyes, have been found 
to have a toxic effect on oxidation enzymes (Quastel and Wheatley, 1931). Perdrau and Todd (1933) describe the photodynamic oxygen-sensitising effect of methylene blue on viruses and bacteriophage.

It must not be forgotten that dyes differ not only in the range of potential in which they change colour, but also in chemical constitution. Dyes containing a sulphonic acid group have been found to behave differently in respect to living cells from dyes without that group. The well-known "protein" and "salt errors" in colorimetric $\mathrm{pH}$ determinations may well have their counterpart in indicator methods of $\mathrm{E}_{\mathrm{h}}$ measurement.

Thus, although dye experiments may yield valuable results, particularly in comparative experiments, data obtained by this means must be accepted with caution. Perhaps negative results, i.e., when the dye is not reduced, should be examined more critically. The ideal to be aimed at in selecting a dye for the determination of oxidation-reduction potential should therefore be one :-

(1) Becoming reduced at a suitable rangé of $\mathrm{E}_{\mathrm{b}}$.

(2) Of distinctive colour, preferably blue, to avoid confusion with the natural colour of the system studied.

(3) Not changing colour with $\mathrm{pH}$ changes.

(4) Of intense colour so that very low concentrations may be used, thus not over-poising the system studied.

(5) With no direct participation in the system studied, i.e., it should not catalyse biological oxidations or have toxic effects on cells or tissues, and should not combine with components of the system.

Unfortunately no approach to ideal oxidation-reduction potential indicators has been made. Despite the careful and continued work of Clark and his collaborators, no simple reliable indicator method has been worked out which will bear comparison with the colorimetric methods of $\mathrm{pH}$ determination. Electrometric methods must remain, at present at all events, of much greater importance in the study of oxidation-reduction processes than in the case of hydrogen ion studies.

\section{DIRECT POTENTIOMETRIC MEASUREMENT OF $\mathrm{E}_{\mathrm{h}}$}

The precautions in technique and interpretation of electrode potential measurements, when using dyes as indicators, make the direct potentiometric method of measurement very necessary for dependable results. It appears doubtful if colorimetric methods can ever attain the dependability and accuracy attained in colorimetric methods of $\mathrm{pH}$ determination.

It is remarkable how comparatively simple the direct potentiometric method of $\mathrm{E}_{\mathrm{h}}$ measurement can be made with suitable equipment. To measure the potential of the half-cell-unattackable electrode/oxidation-reduction system (X)-the cell must be completed by another half-cell (St.). According to definition, the $\mathrm{E}_{\mathrm{b}}$ is the potential referred to the normal hydrogen electrode, but as this half-cell is not a practical possibility any convenient standard half-cell, of known potential referred to the normal hydrogen electrode, may be used. The theoretical circuit used 
is represented diagrammatically in fig. 6. By means of the potentiometer $(\mathrm{P})$ the E.M.F. $\left(\mathrm{E}_{1}\right)$ tapped off is varied until the galvanometer $(\mathrm{G})$ shows no deflection. At this point the E.M.F. $\left(\mathrm{E}_{1}\right)$ must just balance the E.M.F. of the complete cell $\mathrm{E}_{\mathrm{h}}-\mathrm{E}_{\mathrm{st}}$

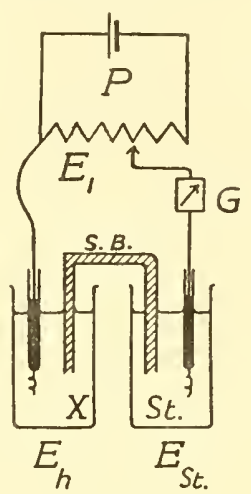

Fig. 6

Potentiometric E $_{\mathbf{h}}$ Measurement. Tueoretical, Cirouit

(the negative sign is included since the two half-cells are in opposition). So that at potentiometric balance

$$
\mathrm{E}_{1}=\mathrm{E}_{\mathrm{h}}-\mathrm{E}_{\mathrm{st}} \quad \text { or } \quad \mathrm{E}_{\mathrm{h}}=\mathrm{E}_{1}+\mathrm{E}_{\mathrm{st}}
$$

(The salt bridge [S.B.] ensures electrical contact without introducing errors due to liquid : liquid interface potentials, etc.)

\section{EXPERIMENTAL DETAILS}

The author's methods (Hewitt, 1930, 1) are described in detail, particularly their application to the study of bacterial cultures. The methods described have been found to function reliably, and their description may assist other workers to establish the best conditions for application to their own problems. In working with cultures of pathogenic bacteria it was necessary to work with sterilised glass apparatus, assembled with aseptic precautions, and to sterilise the apparatus after use. The apparatus described was designed with these special objects in view but its simplicity makes it suitable for other biological investigations.

\section{The Electrode}

The electrode must be, for all practical purposes, unattackable, and must not participate in the oxidation-reduction system in any way, except as an inert carrier of electrons. Although this is possibly an ideal definition, working approximations to it may be obtained in most cases. Electrodes used by different workers are as follows :-

(1) Platinum.-Plain bright platinum foil or wire has been used by nearly all workers in this field. The author has found bright platinum electrodes the most reliable of those used, and for most purposes uses a platinum wire spiral (s.w.g.26) sealed into glass tubing. The glass tubing is, of course, filled with mercury, and an amalgamated copper wire is dipped into the mercury to connect to the rest of the apparatus. Care must be taken that there are no cracks or defects in the glass tubing. Irregular results may be obtained with a 
cracked or faulty seal probably due to direct electrical contact of mercury with the solution studied. Cannan, Cohen and Clark (1926) in one case used platinised platinum electrodes in biological work, but there is no apparent advantage in this for electrode potential studies, except in unstable systems (Ball and Chen, 1933).

(2) Gold.-Gold-plated electrodes have been used, but other workers claim that solid gold is of greater value (Dixon and Quastel, 1923). The author used gold foil and gold wire electrodes, but in neither case did he obtain the reliable, reproducible values observed with platinum. Gold has been recommended for use with the quinhydrone half-cell but platinum seems very satisfactory. The chemical inertness of platinum should make it preferable for an unattackable electrode. Lepper and Martin (1931) found that gold did not give the low potential observed with iridium in the presence of hydrogen gas. Longsworth and MacInnes $(1935,1936)$ are exceptional in preferring gold to platinum electrodes for the investigation of bacterial cultures.

(3) Iridium.--Lepper and Martin (1930) used electrodes of iridium, which is a very inert metal similar in many respects to platinum.

(4) Tungsten.--Tungsten electrodes were found unsuitable by Flexner and Barron (1930).

(5) Graphite.-Impure graphite electrodes were found to be quite useless, and pure graphite electrodes had to be replaced after each experiment (Flexner and Barron, 1930), but Tuttle and Huddleson (1934) used special Acheson graphite electrodes successfully.

(6) Mercury.--Dropping mercury electrodes, in which the surface can be constantly renewed (Clark, Cohen and Gibbs, 1925), have been used, but mercury appears to participate readily in many biological systems (Michaelis and Flexner, 1928). Mercury electrodes give different results from platinum in many cases and probably do not behave as "unattackable" electrodes. If a platinum electrode in a culture be cracked and the mercury come into direct contact with the culture medium the potential is entirely different from that of the platinum electrode (Hewitt, 1930, i.). The dropping mercury electrode is used largely in the polarograph (Chapter V).

(7) Hakamori (1931), investigating hydrogen peroxide solutions, preferred palladium electrodes to gold or platinum.

(8) Various.-Clark and Cohen $(1923,2)$ mention the use of rhotanium alloy, burnt-on platinum, and amalgamated burnt-on platinum electrodes in dye systems, and found general agreement with other electrodes.

It is concluded therefore that no more suitable electrode than bright platinum has been described, and these are readily prepared and cleaned, and yield steady, reproducible readings. After use, the author immerses the electrodes in hot nitric acid. Platinum wire electrodes sealed into glass tubing of about $3 \mathrm{~mm}$. internal bore may be held in test-tubes with cotton-wool plugs for hot-air sterilisation, and transferred from the test-tube to the apparatus when required. It is convenient to select test-tubes for this purpose of the same bore as the orifice in the apparatus into which the electrode is eventually to be placed. When an air-tight apparatus is to be used, the electrode, etc., must be placed in a varnished rubber bung. 


\section{Salt Bridges}

A salt bridge is used in order to connect the experimental half-cell with the standard half-cell. A convenient bridge consists of an inverted glass U-tube of internal bore about $3 \mathrm{~mm}$. One limb of the bridge is turned up at the tip, in order to minimise downward diffusion of $\mathrm{KCl}$ from the agar to the culture, and this limb is plugged into a test-tube with cotton wool. The tip of the other limb is provided with a temporary cotton-wool plug during hot-air sterilisation. Stcrile 2 per cent. agar saturated with potassium chloride is melted in a steamer, and the agar is then drawn into the bridge by suction until it is nearly full. Bubbles in the turned-up tip are expelled by momentary immersion in boiling water, and the tip of the other limb is filled with saturated potassium chloride. In use the agar-filled limb with the turned-up tip is immersed in the oxidation-reduction system studied, and the other limb makes contact with a vessel containing saturated $\mathrm{KCl}$ solution. The standard half-cell also is connected to the $\mathrm{KCl}$ reservoir. It would appear that the use of sintered glass tips for agar bridges would be useful.

\section{Electrode Vessel}

The design of the vessel containing the oxidation-reduction system studied depends, of course, on the purpose and conditions of the experiment. If it is desired to maintain anaerobic conditions by bubbling purified nitrogen through the systems a vessel provided with a rubber bung, such as that described by Clark and Cohen

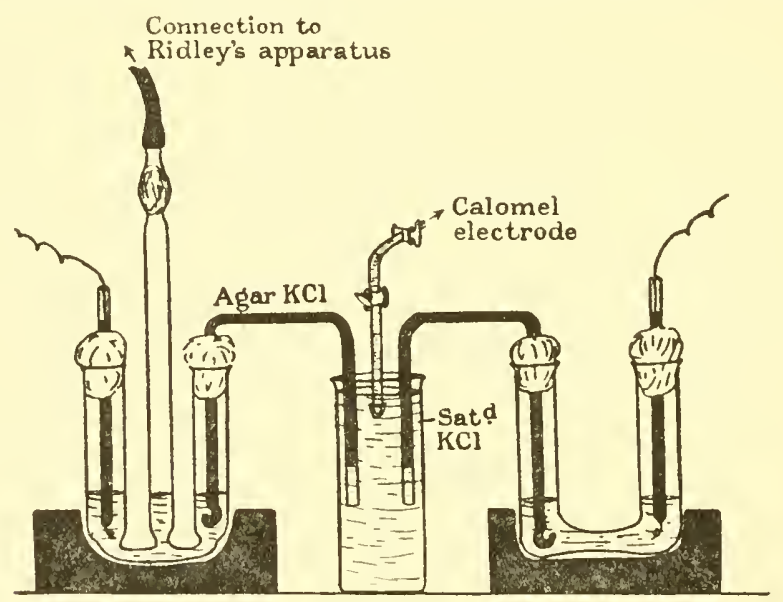

Fig. 7

$\mathrm{E}_{\mathrm{h}}$ of Bacterial Cultures

(Arrangement of apparatus in incubator)

(1923, 2), may be used. In the author's experiments aerobic bacterial culture, have been studied, and for this purpose glass double-limbed cells of $12 \mathrm{~mm}$. internal bore proved most satisfactory (see fig. 7). These are hot-air sterilised and, when the culture medium has been pipetted in and inoculated, the cotton-wool plugs are replaced by the sterilised electrode in one limb and the salt bridge in the other. Hollow wooden blocks, preferably provided with masts, support the cells. In some experiments the cultures are kept aerated and agitated by Ridley's apparatus (1928). 
In these cases a triple-limbed cell is used, the extra central limb being plugged with cotton wool and connected by rubber tubing to the aeration apparatus. Vacuum vessels have been described for special purposes (Lehmann, 1930; Baumberger, 1933).

When investigating unstable systems Ball and Chen (1933) used an electrode vessel through which reacting fluids were allowed to flow. By variation of the rate of flow, the electrode potential could be measured at different intervals after mixing.

\section{Standard Half-Cell}

Any convenient standard half-cell may be used to complete the cell. The potential of the calomel electrode, a common form of standard half-cell, depends on the concentration of $\mathrm{KCl}$ used in setting up, the half-cell being :-

Mercury : mercurous chloride, $\mathrm{KCl}$ solution : $\mathrm{KCl}$ solution

Various concentrations of $\mathrm{KCl}$ have been employed, including tenth-normal, normal, 3.5 normal and saturated $\mathrm{KCl}$ calomel electrodes. The author finds the $3.5 \mathrm{~N} . \mathrm{KCl}$ electrode very satisfactory, since it has the low temperature coefficient of the $\mathrm{N} / 10$ electrode, and alteration in concentration of $\mathrm{KCl}$ has only a slight effect, as with the saturated $\mathrm{KCl}$ electrode. The following may be taken as the values of the half-cells referred to the normal hydrogen electrodes :-

TABLE 6

\begin{tabular}{|c|c|c|c|}
\hline \multirow{2}{*}{ Temp. } & \multicolumn{3}{|c|}{ KCl Concentration } \\
\cline { 2 - 4 } & $0.1 \mathrm{~N}$ & Saturated & $3.5 \mathrm{~N}$. \\
\hline $20^{\circ} \mathrm{C}$. & 0.338 volt. & 0.250 volt. & 0.254 volt. \\
$38^{\circ} \mathrm{C}$. & 0.336, & $0.236,$, & $0.252,$, \\
\hline
\end{tabular}

These values are to be added to observed electrode potentials to obtain the value of $\mathrm{E}_{\mathrm{b}}$.

Another very simple half-cell which may be set up in a few minutes is the quinhydrone electrode. Any acidic buffer solution of known $\mathrm{pH}$ is taken, and a little quinhydrone is shaken into it. A platinum electrode is immersed in the solution and the cell is complete. It is essential that the $\mathrm{pH}$ of the buffer solution be known exactly. Convenient buffers are : (i) $0 \cdot 1 \mathrm{M}$. acetic- $0 \cdot 1 \mathrm{M}$. sodium acetate, which has $\mathrm{pH} 4 \cdot 60$, and (ii) $0.05 \mathrm{M}$. potassium hydrogen phthalate, which has $\mathrm{pH} 3 \cdot 974$, also $\mathrm{N} / 10 \mathrm{HCl}$ is frequently used.

The values of the quinhydrone electrode potential referred to the normal hydrogen electrode are given in table 7 .

TABLE 7

Potentuals of Quinhydrone Electrode

\begin{tabular}{|c|c|c|c|c|}
\hline Temp. & At pH 0. & N/10 HCl. & $\begin{array}{c}\text { KH Phthalate } \\
\mathrm{pH} \mathrm{3.97}\end{array}$ & $\begin{array}{c}\text { Acetate Buffer } \\
\mathrm{pH} \mathrm{4.60}\end{array}$ \\
\hline $20^{\circ}$ & 0.704 & 0.642 & 0.473 volt. & 0.437 \\
$38^{\circ}$ & 0.690 & 0.623 & $0.444,$, & 0.405 \\
\hline
\end{tabular}


Therefore, using the quinhydrone electrode with buffer solution, the appropriate values given in the table are to be added to the observed potential to obtain $\mathrm{E}_{\mathbf{n}}$. Quinhydrone electrodes should be re-assembled with fresh buffer solution daily.

A combined vacuum electrode and half-cell is described by Lehmann (1930).

The quinhydrone electrode is not a permanent standard and an electrode coming into very common use is the silver : silver chloride electrode which has a potential 45 millivolts more negative than the calomel electrode.

\section{Potentiometer}

The potentiometer to be used should be calibrated to \pm 1 volt, reading to the nearest millivolt. Greater accuracy than this is unnecessary in biological systems. The Cambridge Instrument Company supply a portable instrument which is calibrated as above and does not require the use of a standard cell.

\section{Galvanometer}

The choice of a suitable null-point instrument for detecting the point of potentiometric balance is of the greatest importance in this work. Biological systems are not well poised and measurements are most sensitive to errors due to polarisation. Even a minute current flowing through the cell will seriously disturb the results. Clark and Cohen $(1923,2)$ use a sensitive high resistance galvanometer for the purpose.

The author has found the Lindemann electrometer (1924) an excellent null point instrument with which polarisation effects were not observed. The needle can be kept charged whilst potentiometric balance is being obtained, which saves

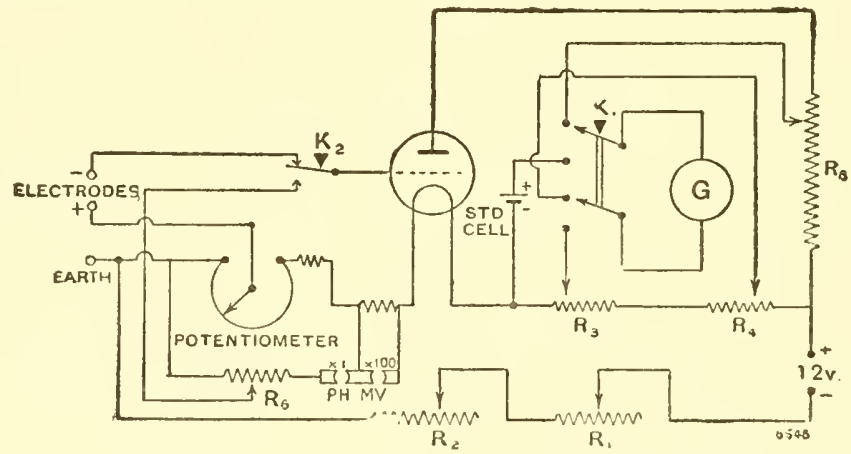

FIG. 8

Thermionic valve electrometer circuit

(Block icnt by Cambridge Instrument Company)

a great deal of time. Some trouble has to be expended in both the maintenance and use of this electrometer, but the results obtained with it have been of considerable value.

The rapid development of the thermionic valve during recent years has led to the increased use of valve circuits for electrometric purposes. Wurmser (1930) describes a suitable circuit for the measurement of potentials, and Kinight (1930) used a Harris (1928) circuit. Modern improved electrometer valves have become 
available, and as a result improved methods are now possible. Reference may be made to Harrison (1930), Morton (1931), Elema (1932) and others.

In fig. 8 is shown the circuit of a convenient instrument, incorporating an electrometer valve, which is constructed by the Cambridge Instrument Company. By simple adjustment the instrument may be used for the direct measurement of potentials or of $\mathrm{pH}$.

Further consideration is given to the choice of instruments in the next chapter.

\section{Arrangement of Apparatus}

In studying bacterial cultures the cells (1-8) containing the cultures (the author finds eight cultures a convenient number for simultaneous investigation), the $\mathrm{KCl}$ reservoir and the standard cell (S) are placed in the incubator (I) and leads from these run to a series of single-pole double-throw knife switches which enable each

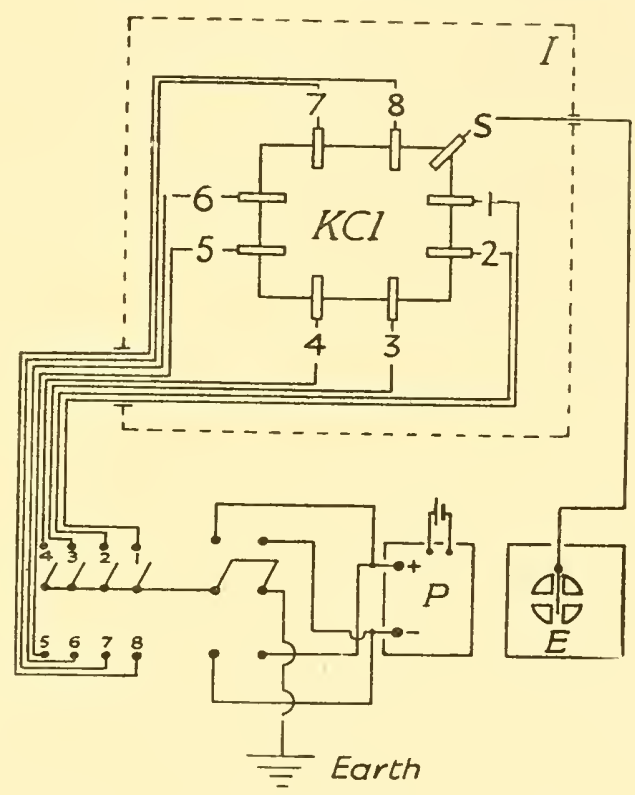

FIG. 9

$\mathrm{E}_{\mathrm{h}}$ of bacterial cultures

Diagram of circuit

culture-cell to be switched into circuit in turn. These single knife switches are outside the incubator and the centre terminals are joined to a double-pole doublethrow switch which enables the connections to the potentioneter $(\mathrm{P})$ to be reversed. The arrangement is represented in fig. 9. These simple switching devices serve to avoid the risk of earthing and polarising the electrodes involved in touching bare leads. The lead from the standard half-cell runs to the electrometer needle E. The completed arrangement therefore, beginning in the reverse order, is as follows:electrometer needle, standard half-cell, agar bridge, KCl reservoir, agar bridge, culture, platinum electrode, single-pole switch, double-pole switch, potentiometer, joined 
finally to earth. With this simple arrangement the potentials of eight cultures may be read in four minutes. With rapidly growing cultures during the logarithmic phase of proliferation, half-hourly readings of the potential should be taken, but in cultures which are continued for several days readings every few hours may be sufficient.

It is frequently desirable to obtain a record of the changes in electrode potential throughout the life history of a culture. Unfortunately the active life of a culture is rarely limited to the length of a normal working day so that an automatic recording apparatus would be of considerable advantage to the investigator. Bacterial cultures are, however, very susceptible to polarisation effects, so that such an automatic apparatus requires careful design. Automatic recording was described by Cannan, Cohen and Clark (1926), but might be improved by the use of modern apparatus.

\section{SumMary of Chap'TER II}

The general principles and methods of application of dyes to the study of electrode potentials are described together with the relevant data of a number of dyes suitable for use as oxidation-reduction indicators. The serious difficulties attending the use of dyes are mentioned, and the methods and apparatus for the direct potentiometric determination of electrode potentials are given with full experimental details. 


\section{CHAPTER II I}

\section{MEASUREMENT OF $\mathrm{pH}$}

A detailed account of the theory and practice of hydrogen ion determinations is outside the scope of this book, but in view of the analogies and relationships with oxidation-reduction potentials a brief discussion of $\mathrm{pH}$ determinations is desirable.

\section{HYDROGEN ELECTRODE}

The hydrogen electrode was once the main basis for $\mathrm{pH}$ determinations and is a special example of an oxidation-reduction electrode. Instead of measuring the oxidation-reduction condition of the system, this is held constant by maintaining an atmosphere of hydrogen in presence of a platinised platinum electrode and then the electrode potential depends upon the concentration of hydrogen ions. The reaction studied is :-

$$
\mathrm{H} \rightleftharpoons \mathrm{H}^{\oplus}+\mathrm{e}
$$

Applying the general electrode equation $(10)$ we obtain at $30^{\circ} \mathrm{C}$ :-

$$
\mathrm{E}_{\mathrm{h}}=\mathrm{E}_{\mathrm{o}}+0.06 \log \frac{\left[\mathrm{H}^{\oplus}\right]}{[\mathrm{H}]}
$$

Since $\mathrm{pH}=-\log \left[\mathrm{H}^{\oplus}\right]$ and $[\mathrm{H}]$ is held constant by bubbling hydrogeu at one atmospheric pressure, the expression can be simplified to :-

$$
\mathrm{E}_{\mathrm{b}}=\mathrm{k}_{1}-0.06 \mathrm{pH}
$$

so that there is a linear relationship between the potential and $\mathrm{pH}$, the higher the $\mathrm{pH}$ the lower the potential.

In practice $\mathrm{pH}$ measurements are not determined by absolute potential measurements but by measuring the difference between the potentials of a standard buffer solution and the unknown solution. As with oxidation-reduction potential measurements a standard reference half-cell is needed to complete the cell and the half-cells are joined by a suitable liquid junction.

The experimental arrangement having been set up the $\mathrm{pH}$ of the test solution is given by the expression :-

$p H$ of standard solution - difference of voltage of cells of test solution and standard buffer respectively $\div 0 \cdot 06$.

The factor 0.06 depends on temperature and values are given on page 40 .

The hydrogen electrode is not commonly used for biological $\mathrm{pH}$ measurements, firstly because more convenient methods not necessitating the use of hydrogen are available now, secondly because bubbling of hydrogen introduces difficulties due to frothing and to the removal of carbon dioxide which alters $\mathrm{pH}$ values, and thirdly because hydrogen may reduce components of the system 


\section{QUINHYDRONE ELECTRODE}

In solutions more acid than $\mathrm{pH} 7 \cdot 5-8$ the quinone: hydroquinone oxidationreduction system can be used for $\mathrm{pH}$ determinations. The oxidant and reductant form a compound or resonance complex which automatically maintains a 50 per cent. oxidised and reduced system. The $\mathrm{E}_{\mathrm{o}}: \mathrm{pH}$ curve has " 0.06 slope" ; that is to say that for every increase of $1 \mathrm{in} \mathrm{pH}$ value there is a decrease in potential of 0.06 volt and the electrode potential equation is :-

$$
\mathrm{E}_{\mathrm{h}}=0.695-0.06 \mathrm{pH}
$$

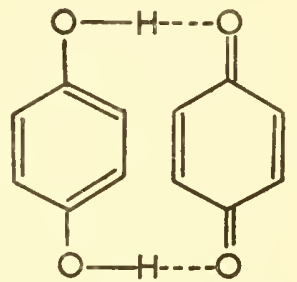

Quinhydrone Resonance Complex

The value 0.06 applies to $30^{\circ} \mathrm{C}$ and values for other temperatures are given in Table 8 .

The concentration of quinhydrone has little effect on the potential so that to measure the $\mathrm{pH}$ of a solution a little quinhydrone is shaken into it, a platinum (or gold) electrode is inserted and the half-cell is joined by an agar salt bridge to any standard reference half-cell such as calomel or silver chloride electrode. Again, in this case there is no need to attempt absolute potential measurements; it is sufficient to measure the difference in potential of cells containing a standard buffer and the unknown solution. The difference of potentials in the two cases divided by 0.06 (at $30^{\circ}$ ) gives the difference in $\mathrm{pH}$.

Other quinone systems have been used for $\mathrm{pH}$ measurements; for example chloranil (tetrachloroquinone) has the electrode potential equation :-

$$
\mathrm{E}_{\mathrm{h}}=0.664-0.06 \mathrm{pH}
$$

Although basically simple there are limitations in the use of the quinhydrone electrode for $\mathrm{pH}$ determinations. Quinhydrone is unstable at $\mathrm{pH}$ values above 7.5 to 8.0 so that the electrode cannot be used in alkaline solutions. Also, of course, other oxidising or reducing substances present will interfere with the quinonehydroquinone oxidation-reduction system and hence will alter the potential independently of $\mathrm{pH}$ changes.

\section{GLASS ELECTRODE}

The glass electrode has come to be used almost exclusively for electrometric $\mathrm{pH}$ measurements in biological work. Essentially this consists of a thin glass membrane which for all practical purposes is permeable only to hydrogen ions so that the difference of potential of electrodes immersed in the solutions on either side of the 
membrane is governed by the difference in $\mathrm{pH}$ of the solutions. In practice the glass electrode is generally a thin glass bulb blown on the end of a tube. Inside the bulb is placed a solution of constant $\mathrm{pH}$ and a silver or platinum wire dips into it. When the bulb is immersed in a solution the potential difference across the membrane will be $\left(\right.$ at $\left.30^{\circ} \mathrm{C}\right)$ :-

$$
\mathrm{E}_{\mathrm{h}}=\mathrm{k}_{1}-0.06\left(\mathrm{pH}_{1}-\mathrm{pH}_{\mathrm{x}}\right)
$$

The significance of the constant $k_{1}$ is that although theoretically there should be zero potential difference across the membrane when the internal and external $\mathrm{pH}$ is the same, yet in practice an asymmetry potential is frequently observed. So that experimentally the glass electrode is used as in the cases of other electrodes, by first immersing it in a buffer solution of known $\mathrm{pH}$ and then in the test solution when

$$
p H=p H \text { of buffer-Potential difference } \div 0.06
$$

A diagrammatic explanation of the glass electrode circuit is given in Fig. 10 .

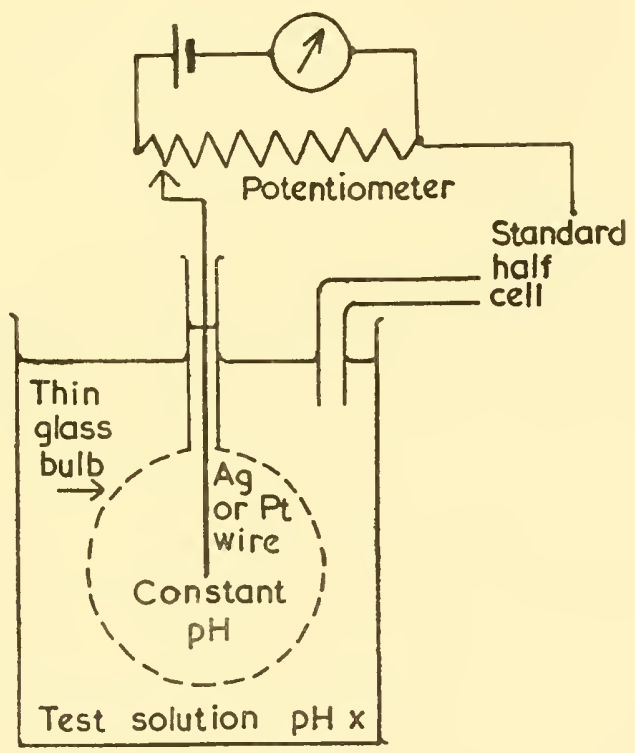

FIG. 10

Diagram of Glass Electrode Circuit

In very alkaline solutions the ordinary glass electrode cannot be used so that at $\mathrm{pH}$ values above 10 electrodes made of special glass must be used. Although many pH meters have scales reading from $\mathrm{pH} 0$ to 14 readings at the extremes should be examined most critically. The thin glass membranes do not last forever, and it is advisable to renew the electrode periodically if there is a suspicion of ageing. In addition the thin glass is likely to absorb denatured proteins so that careful cleansing is necessary when the electrodes are used for varying purposes. Although infrequently 
required in biological work glass electrodes are stated to be usable up to a temperature of $70^{\circ} \mathrm{C}$.

\section{Temperature Effect and Equation Constant}

In many of the electrode potential equations the term $2 \cdot 303 \mathrm{RT} \div \mathrm{F}$ occurs and at $30^{\circ} \mathrm{C}$ this approximates to 0.06 . The change of potential with $\mathrm{pH}$ varies, however, with temperature and for convenience in calculations the values of this term for other temperatures are given in Table 8.

TABLE 8

VAlues of $2 \cdot 303 \mathrm{RT} \div \mathrm{F}$ hor Various Temphraturhs

\begin{tabular}{|c|c|}
\hline Temp. ${ }^{\circ} \mathrm{C}$ & $2 \cdot 303 \mathrm{RT} \div \mathrm{F}$ \\
\hline 0 & $0 \cdot 0542$ \\
5 & $0 \cdot 0550$ \\
10 & $0 \cdot 0561$ \\
15 & $0 \cdot 0571$ \\
20 & 0.0581 \\
25 & 0.0591 \\
30 & $0 \cdot 0601$ \\
35 & 0.0611 \\
40 & $0 \cdot 0621$ \\
45 & 0.0631 \\
\hline
\end{tabular}

If the $\mathrm{pH}$ value is required to be accurate to the nearest $0.02 \mathrm{pH}$ the potentiometer must be accurate to the nearest millivolt, the galvanometer must be sensitive to a millivolt potential difference and the temperature must be controlled to the nearest $1^{\circ} \mathrm{C}$. In table 9 are summarised the maximum degrees of tolerance which should be allowed to attain various degrees of accuracy.

TABLE 9

Accuracy Toleranoes

\begin{tabular}{|c|c|c|}
\hline $\begin{array}{c}\text { Required accuracy of } \\
\text { pH measurement }\end{array}$ & $\begin{array}{c}\text { Potentiometer and } \\
\text { Galvanometer accuracy }\end{array}$ & $\begin{array}{c}\text { Temperature } \\
\text { control accuracy }\end{array}$ \\
\cline { 1 - 2 } $\mathrm{pH}$ & $\pm \mathrm{m} \mathbf{}$ & $\pm{ }^{\circ} \mathrm{C}$ \\
0.01 & $0 \cdot 5$ & $0 \cdot 5$ \\
$0 \cdot 02$ & $1 \cdot 0$ & $1 \cdot 0$ \\
$0 \cdot 05$ & $2 \cdot 5$ & $2 \cdot 5$ \\
0.10 & $5 \cdot 0$ & $5 \cdot 0$ \\
\hline
\end{tabular}

\section{pH METERS}

There are now many $\mathrm{pH}$ meters available and the prospective buyer is faced with an embarrassment of choice. There are, however, several factors which should govern the type to be chosen since the number of refinements must be reflected in the price and simplicity of standardisation and manipulation.

(1) Potential and $p H$ measurements.-If the meter is required for potential measurements in millivolts as well as $\mathrm{pH}$ determinations a suitable calibration must be incorporated. 
(2) Degree of accuracy required.-Only rarely in biological work is an accuracy greater than pH 0.02 required, and for many routine purposes such as media production the changes produced by heat sterilisation, loss of carbon dioxide, etc., are so great that an accuracy of $\mathrm{pH} 0.05$ is ample. For economy automatic temperature regulation may be omitted when accuracy greater than $\mathrm{pH} \pm 0.2$ is not required.

(3) Power supply.- - If the convenience of being able to plug in directly to electric power mains as sole power supply is required, it is necessary to have in the meter or externally a constant voltage transformer to eliminate the effect of variation in the mains voltage and also frequency stabilisers to avoid difficulties due to variations in the supply frequency, which occur when there are heavy demands on the electricity mains. The use of certain electrical apparatus in neighbouring laboratories has been reported as troublesome. As an alternative, chargeable accumulators may be used, high capacity car accumulators being satisfactory. Care in the maintenance and charging of the batteries is necessary and drifts in potential may occur if they are not kept in a state of constant charge. With the low-consumption thermionic valves available to-day it is possible to use dry batteries of the electric bell or deaf-aid type in many meters. These may last for months and meters can thus be made selfcontained and light in weight for portability. It is advisable to keep a replacement battery in stock and to replace the meter battery when potential drift is noted.

(4) pH readings.- In some instruments a null-point balance method is employed, a dial is rotated to bring the galvanometer needle back to zero and the $\mathrm{pH}$ value is read from the calibrated dial. A " magic eye" cathode tube can be used instead of a galvanometer for obtaining null-point balance. In other instruments the throw on the galvanometer needle is proportional' to $\mathrm{pH}$ differences and the galvanometer dial is calibrated in $\mathrm{pH}$ units. In some instruments the whole $\mathrm{pH}$ range can be covered on one dial, but in instruments reading to greater accuracy it may be necessary to have a range-change switch to cover the whole $\mathrm{pH}$ scale. This is particularly aunoying when the scale-change is in the neighbourhood of $\mathrm{pH} 7 \cdot 0$, which is about half way along the $\mathrm{pH}$ range, but is also in the middle of the biologically important range, and constant switching in the middle of readings may be necessary.

(5) Glass electrode and cell.-The glass electrode is generally in the form of a thin bulb blown in the end of a glass tube. The electrical resistance of the glass membrane is high (5-500 megohms), requiring specially designed electrometers, precautions against short circuits, and shielded leads. In the early days of the glass electrode both the capillary electrometer and Lindemann electrometer were used as null-point instruments, but the development of thermionic electrometer valves has made possible the use of relatively simple galvanometer milliammeters. Sometimes a long capillary tube of glass is used instead of the thin bulb membrane. To complete the cell any half-cell may be employed; this used to be a calomel electrode, but now the silver: silver chloride electrode is gaining popularity. Usually the half-cell is filled with saturated potassium chloride solution which also serves to minimise liquid : liquid junction potentials.

(6) Special biological problems.--The conventional glass electrodes may be found unsuitable for some purposes and special modifications may be necessary. The usual apparatus is difficult to sterilise after use with cultures of pathogenic bacteria and the 
use of saturated potassium chloride as a liquid junction may be undesirable. To avoid these difficulties the author has used a special arrangement, shown diagrammatically in Fig. 11.

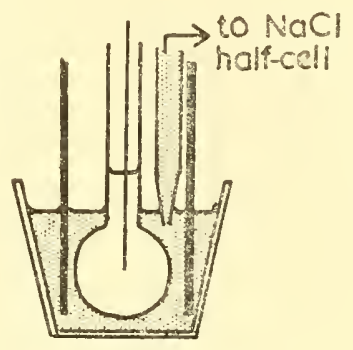

Fia. 11

Unconventional Micro-biological Eleotrode

The usual small-bulbed glass electrode is protected by being sheathed with a piece of glass tubing of slightly larger diameter than the bulb. The sheath tube is chipped away one side or perforated higher up to give access to fluid. The connection with the standard half-cell is by means of a capillary pipette opening just above the bulb and also encased in the sheath tube. The standard half-cell may be the usual simple calomel or silver-chloride type, but the fluid is physiological saline instead of saturated potassium chloride, so that the saline can be used to flush and clean the glass electrode. The theoretical objection to this is that liquid : liquid junction potentials are not as low as with saturated potassium chloride solution, but in practice, by using for the initial calibration of the meter a solution similar to that of the test solution, difficulties have not been encountered. The advantages of this theoretically indefensible electrode are :-

(1) A very small amount of test solution is required.

(2) The sheathing tube eliminates bulb breakage.

(3) By using saline in the half-cell much time is saved in flushing and cleaning the electrode and $\mathrm{KCl}$ does not contamiuate the sample.

(4) The apparatus is readily sterilised after use with cultures.

(5) The set-up is simple, cheap and robust.

\section{COLORIMETRIC $\mathrm{pH}$ METHODS}

The technique of colorimetric $\mathrm{pH}$ measurements is so general that little needs to be said. The greatly extended availability of photoelectric colorimeters and spectrophotometers may lead to their use in $\mathrm{pH}$ determinations especially by those who are colour-blind and have difficulty in colour matching. Fig. 12 gives the absorption curves of phenol red in acid and alkaline solution measured with $5 \mathrm{cc}$. of solution in a diffraction grating spectrometer (Unicam) and, for comparison, in a photoelectric colorimeter with Ilford colour filters. 
The curve with colour filters (Ilford 601-608 series) is closely similar to the grating spectrum.

It will be seen that if a suitable wave band is selected to suit the indicator ( $550 \mathrm{~m} \mu$ in the case of phenol red) it is as simple and rapid, and less liable to personal errors, to
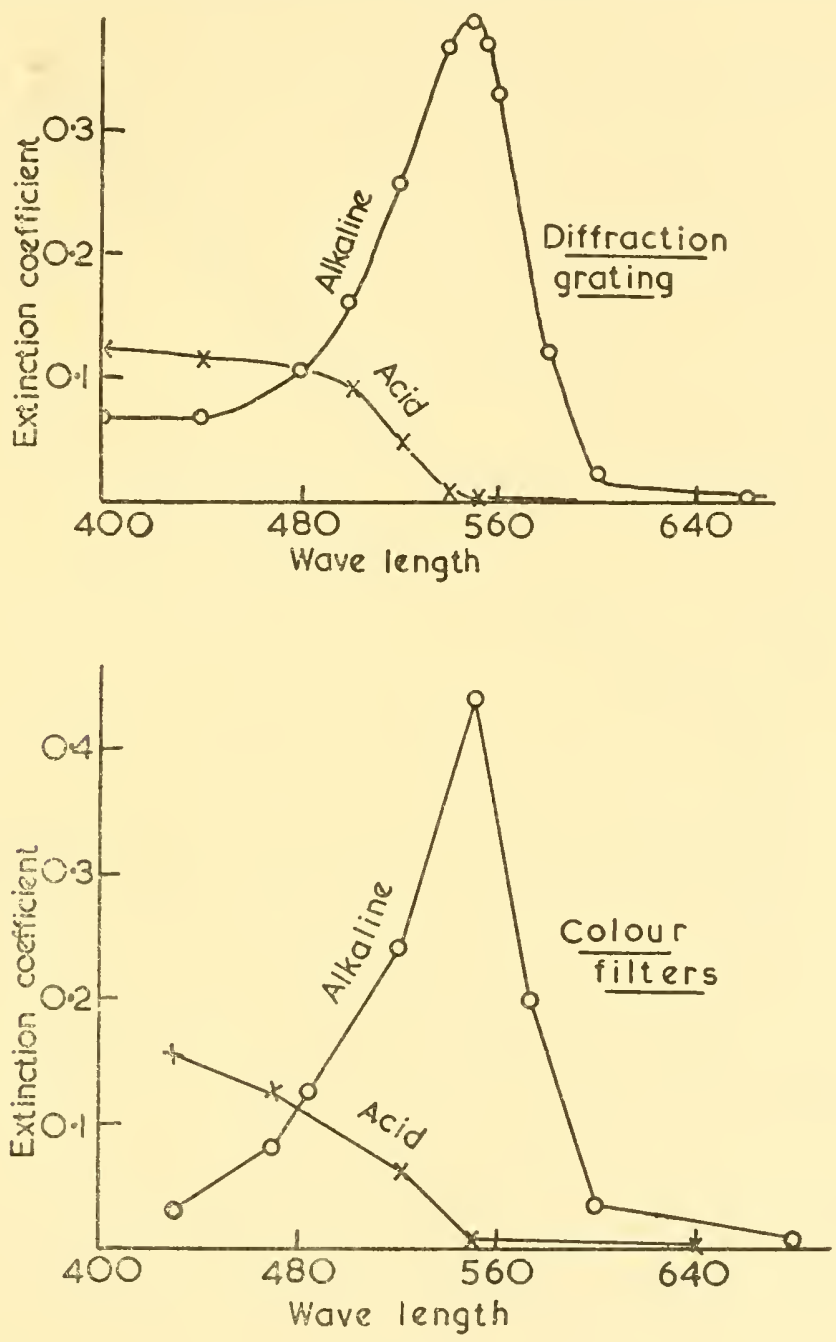

Fig. 12

Absorption spectra of Phenol Red

measure the $\mathrm{pH}$ by instrument as by eye, but it is first necessary to plot the extinction coefficient of the dye at different $\mathrm{pH}$ values. Once done there is no longer danger of matching against faded buffer standards. The instrument is first adjusted to 100 per cent. transmission at the selected wave band with the solution without indicator. The indicator is added and the reading again taken, and from the calibration curve the $\mathrm{pH}$ can be obtained directly. 
In Fig. 13 are plotted the extinction coefficients for $\lambda=550 \mathrm{~m} \mu$ of a series of buffers of different $\mathrm{pH}$ containing phenol red.

It is extremely simple to measure $\mathrm{pH}$ spectrophotometrically even at the extreme end of the range where matching by eye is often difficult.

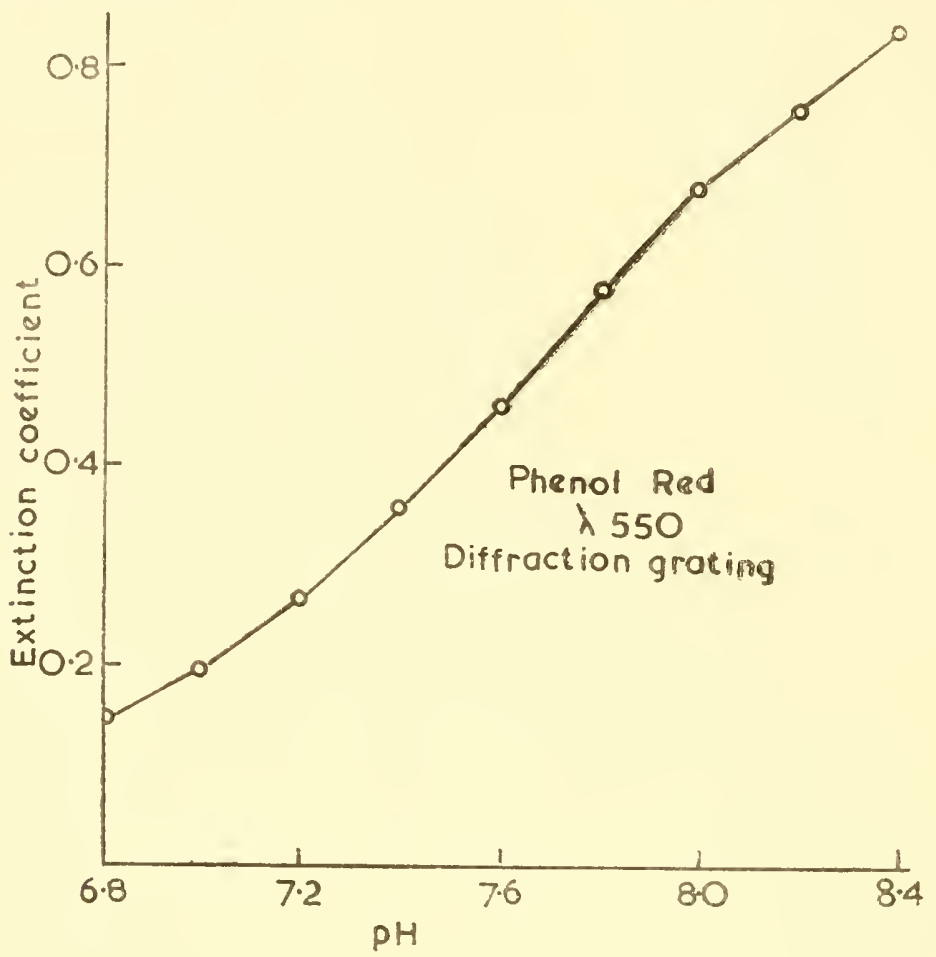

Fig. 13

Extinction coefficients ( $\lambda 550 \mathrm{~m} \mu$ ) of phenol red buffer tubes

For measuring $\mathrm{pH}$ values of drops of Aluid, e.g., cultures, the use of stronger indicator solutions than usual enables colour matching by eye to be carried out in capillary tubes.

Indicator papers (other than the familiar litmus paper) are coming into increased use, but, of course, great accuracy is difficult to attain especially with mixed indicators owing to "chromatographic absorption" effects and the development of bands of colour.

The "protein error" of indicators is well known and a word of caution should be given regarding the interpretation of colorimetric $\mathrm{pH}$ determinations, especially in very acid solution. On the acid side of the isoelectric point protein-dye compounds are formed (Hewitt, 1927) which do not change colour at the same pH as the dyes alone.

\section{Summary of Chapter III}

The applications of various oxidation-reduction potential systems to $\mathrm{pH}$ determinations are commented upon and some practical aspects of the selection of glass electrode apparatus and colorimetric $\mathrm{pH}$ methods are discussed briefly. 


\section{CHAPTER IV}

\section{SYSTEMS OF SPECIAL BIOLOGICAL INTEREST}

The wide variety of biological processes which are either oxidation-reduction systems or are affected by oxidation-reduction conditions makes a complete discussion of all of them impossible but the main purpose of this chapter is to discuss a number of systems of biological interest and a selection of the components of various metabolic processes. In later chapters the integration and interrelationships of some of these oxidation-reduction reactions will be dealt with as parts of more complete cycles. Despite their complexity a parallelism and similarity frequently become apparent among materials from widely divergent biological sources.

\section{SULPHYDRYL SYSTEMS}

Compounds containing a sulphydryl (SH) group are widely distributed in biological systems and are intimately concerned in many vital processes. Sulphydryl compounds give a characteristic colouration with nitroprusside. On oxidation they yield disulphides which, in turn, are reducible to $\mathrm{SH}$ compounds :

$$
2 \text { R.SH } \rightleftharpoons \text { R.S.S.R }+\mathrm{H}_{2}
$$

A familiar sulphydryl system is that of cysteine, which is oxidised to cystine :

$2 \mathrm{CH}_{2} \mathrm{SH} \cdot \mathrm{CHNH} \mathrm{CHOH}_{2} \cdot \mathrm{COOCOH} \cdot \mathrm{CHNH}_{2} \cdot \mathrm{CH}_{2} \cdot \mathrm{S} \cdot \mathrm{S}_{\mathrm{CH}} \cdot \mathrm{CH}_{2} \cdot \mathrm{CHNH}_{2} \cdot \mathrm{COOH}+\mathrm{H}_{2}$

$$
2 \text { cysteine } \rightarrow \quad \text { cystine }
$$

Hopkins $(1921,1929)$ isolated a tripeptide containing cysteine from yeast and many tissues. This tripeptide, glutathione, differs from cystine in that the oxidised form as well as the reduced sulphydryl compound is soluble in water and hence can continue to take part in oxidation-reduction processes when oxidised.

Apart from the important part sulphydryl compounds play in enzyme activation, which will be dealt with in a later paragraph, they possess direct oxygen carrying activities themselves. Thus the "thermostable residue" of muscle and the oxidised form of glutathione are separately each incapable of reducing dyes such as methylene blue. When mixed, however, oxidised glutathione is reduced by muscle "thermostable residue" :-

$$
\text { G.S.S.G. }+\mathrm{TH}_{2} \rightleftharpoons 2 \text { G.SH }+\mathrm{T}
$$

oxidised glutathione + thermostable residue $=$ reduced glutathione

The reduced glutathione reduces methylene blue to the colourless form, and in the same way a mixture of glutathione and " thermostable residue" will absorb oxygen by the following mechanism which continues until all the hydrogen donating power of the "residue" is exhausted :-

$$
\begin{aligned}
& 4 \text { G.SH }+\mathrm{O}_{2}=2 \text { G.S.S.G }+2 \mathrm{H}_{2} \mathrm{O} \\
& 2 \text { G.S.S.G }+2 \mathrm{TH}_{2}=4 \mathrm{G} . \mathrm{SH}+2 \mathrm{~T} \\
& 4 \text { G.SH }+\mathrm{O}_{2}=2 \text { G.S.S.G }+2 \mathrm{H}_{2} \mathrm{O}
\end{aligned}
$$

and so on. It is unknown to what extent these reactions take place in vivo.

In acid solution fats may be oxidised in the presence of oxygen, the fat taking the place of "thermostable residue" in the above scheme. 
The oxidation of carbohydrates appears not to be affected by the presence of glutathione, but the oxidation of proteins apparently occurs in neutral or alkaline solution by a slightly different mechanism, the protein and glutathione being oxidised simultaneously according to Hopkins and his collaborators.

\section{Protein Denaturation}

In many cases, proteins give tests for the presence of SH groups only when denatured although they contain cysteine in the protein molecule. The reason for this is still under discussion (Hewitt, 1943 ; Anderson, 1945), and arguments have been advanced to contradict the various explanations put forward. The SH group of cysteine present in proteins may be chemically combined and denaturation may liberate the free SH groups. The SH groups may not be chemically combined, but may be rendered inaccessible by the folding of the polypeptide chains in the protein, and the chains are unfolded during denaturation rendering the $\mathrm{SH}$ groups accessible. Finally, the SH groups may be inactive in native proteins owing to the binding together of the peptide chains by the hydrogen bonds and the rupture of these bonds on denaturation may increase the reactivity of neighbouring $\mathrm{SH}$ groups. Some proteins do not give tests for $\mathrm{SH}$ groups even when denatured since the cystine is present in the oxidised form.

\section{Enzyme Activation}

The enzyme glyoxalase is necessary for the conversion of methyl glyoxal to lactic acid :

$$
\mathrm{CH}_{3} \cdot \mathrm{CO} \cdot \mathrm{CHO}+\mathrm{H}_{2} \mathrm{O} \stackrel{+ \text { glyoxalase }}{\longrightarrow} \mathrm{CH}_{3} \cdot \mathrm{CHOH} . \mathrm{COOH}
$$

It has been shown that SH groups are necessary for the activation of the enzyme and that iodoacetic acid inhibits lactic acid production by inactivation of SH groups (Lundsgaard, 1930 ; Lohmann, 1932; Bersin, 1932). Reduced thiol compounds have been shown to be necessary for the functioning of urease and papain (Hellerman, Perkins and Clark, 1933) and for bacterial hæmolysins (Schwachman, Hellerman and Cohen, 1934). Iodoacetic acid, iodoacetamide and p-chloromercuribenzoate inactivate enzymes by attacking SH groups, but the inactivation of bacterial hæmolysins by dilute cholesterol suspensions is probably due to a different mechanism (Hewitt and Todd, 1930). On the other hand, reduced SH compounds inactivate the hæmolytic activity of diphtheria cultures which require conditions of aeration. (Hewitt, 1947).

A proteinase of hæmolytic streptococci has been shown to require $\mathrm{SH}$ activation (S. D. Elliott, 1945.)

K. A. C. Elliott (1946) gives the following list of enzymes requiring sulphydryl activation :-

Systems responsible for pyruvate oxidation, dismutation, decarboxylation and acetoacetate and acetylmethyl carbinol formation; hexosemonophosphate, phosphoglyceraldehyde, glycerol, a-ketoglutaric, succinic, malic, and alcohol (yeast) dehydrogenases; synthesis of $u$-ketoglutarate; adenosinetriphosphatase ; phosphoglucomutase; phosphorylase; hexokinase; pancreatic amylase; $\beta$-amylase of barley; stearate, oleate (bacteria) and acetate oxidases ; $\beta$-hydroxybutyric dehydrogenase; pancreatic lipase and esterase; cerebrosidase; $d$-amino 
acid oxidase; mono-amine oxidase; l-glutamic dehydrogenase; transaminase; urease ; cathepsins ; papain ; bromelin ; hæmolysins ; lysozyme ; choline oxidase ; cholinesterase; and choline acetylase.

The activity of the following enzymes is thought not to depend upon free. sylphydryl groups :-

Cytochrome oxidase; catalase; heart flavoprotein; alcohol (liver), lactic and isocitric dehydrogenases; uricase; diamine oxidase; polyphenol oxidase; oleic oxidase (peanuts); carbonic anhydrase; acid phosphatase; arginase; pepsin; and trypsin.

p-Chloromercuribenzoate has a strong affinity for $\mathrm{SH}$ groups and combines with them in low concentrations even when they are masked by oxidising agents. The combination is specific for $\mathrm{SH}$ groups and no other group present in proteins and it is reversed by addition of excess of simple mercaptans. This is not the case with certain vesicants which will be dealt with in more detail in the chapter on chemotherapy. When enzyme systems are inactivated by arsenic compounds the inhibition is, however, reversed by dithiols which form a stable five-membered ring with the arsenic as shown below.

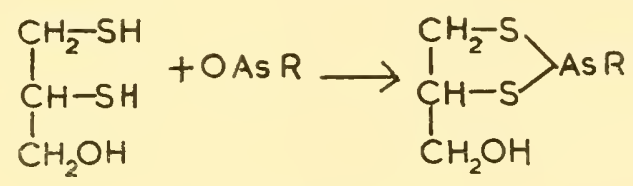

\section{Electrode Potentials}

The electrode potentials established in sulphydryl systems do not yield to the conventional theoretical treatment accorded to perfectly reversible systems. In the case of the equilibrium of the truly reversible system :-

$$
2 \text { R.SH } \rightarrow \text { R.SS.R }+\mathrm{H}_{2}
$$

the fundamental electrode equation defines the potential obtained in such a system, at constant $\mathrm{pH}$, as :-

$$
\mathrm{E}_{\mathrm{h}}=\mathrm{E}_{0}-\frac{\mathrm{RT}}{2 \mathrm{~F}} \ln \frac{[\mathrm{RSH}]^{2}}{[\mathrm{RSSR}]}
$$

but in practice it is found that the potential observed is dependent only on the concentration of the reduced form [RSH] and is independent of the concentration of the oxidised form [RSSR]. Several explanations of this phenomenon have been advanced. It was originally suggested that the real reversible equilibrium is not between RSSR and RSH but between a hypothetical, intermediate oxidation product say RS, and RSH.

Thus :

$$
\mathrm{RSH} \rightleftharpoons \mathrm{RS}+\mathrm{H}
$$

RS, directly it is formed, is transformed irreversibly into RSSR, so that significant quantities of RS are never present (Dixon and Quastel, 1923). There are many objections to this explanation. One is that RS concentration, although small, must be proportional to RSSR concentration, so that the concentration of RSSR ought to appear in the equation. 
In view of the high bond strength of the S.S covalent bond Waters (1948) considers the existence of a stable RS radical is unlikely. Pauling attributes to the $\mathrm{SH}$ bond the energy of 87,000 calories.

Michaelis and Flexner (1928) sought for an explanation of the anomalies of the thiol electrode in the catalytic effect of iron and other metals on oxidation of thiol compounds. It is possibie therefore that the discrepancies in results might be due to the electrodes being not "unattackable" but participating in the system. For a discussion on thiol-metal complexes Michaelis (1933) should be consulted.

On kinetic evidence Preisler (1930) concludes that the reduction of cysteine resembles a reaction of the second order and is not truly reversible. Other papers on the electrode potential of the sulphydryl system are :-Kendall and Ort (1926), Kendall and Nord (1926), Nord (1927), Dixon and Tunnicliffe (1927), Kendall and Loewen (1928, 1, 2), Harrison and Quastel (1928), Williams and Drissen (1930), Ghosh, Raychandhuri, and Ganguli (1932), Ghosh and Ganguli (1933, 1935), Green (1933), Larsson (1933).

It seems therefore that the sulphydryl systems do not fall readily into line with classical examples of reversible oxidation-reduction reactions.

On the basis of thermal data Borsook, Ellis and Hoffman (1937), deduce a rather lower potential than other workers. $(-0.39 \mathrm{v}$. at $\mathrm{pH} 7 \cdot 0$.)

The oxidation-reduction potentials of cysteine and related compounds have been studied by Ryklan and Schmidt (1944). For molar aqueous solutions they arrive at the following values for the normal oxidation-reduction potentials:

and in 70 per cent. ethanol :

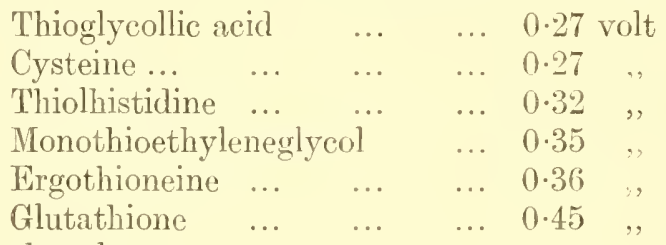

$\begin{array}{llllll}\text { Thiophenol } & \ldots & \ldots & \ldots & 0 \cdot 11 & , \\ \text { o-Thiocresol } & \ldots & \ldots & \ldots & 0.30 & ,\end{array}$

The catalytic waves observed with the polarograph in the case of cysteine and proteins containing cysteine are described in the chapter on Polarograpliy.

\section{HAEMOGLOBIN SYSTEMS}

The hæmoglobin-oxyhæmoglobin system is not a true oxidation-reduction process, but merely an addition of molecular oxygen to hæmoglobin. The system, therefore, cannot be studied potentiometrically (Conant, 1923). The hæmoglobinmethæmoglobin system has beer studied electrometrically (Conant and Fieser, 1925). Difficulties are encountered in that higl concentrations of the components have to be employed and the potentials are obtained only sluggishly. Between $\mathrm{pH} 6 \cdot 8$ and $8 \cdot 5$, the system is independent of alterations in hydrogen ion concentration and the electrode potentials obtained may be defined approximately by the equation

$$
\mathrm{E}_{\mathrm{h}}=+0 \cdot 1+\frac{\mathrm{RT}}{\mathrm{F}} \ln \frac{[\text { MetHb] }}{[\mathrm{Hb}]}
$$


More recently, however, Conant and Pappenheimer (1932) find that the electrode potential of the 50 per cent. oxidised system is $+0.152 \mathrm{v}$. at $\mathrm{pH} 7$, and that the number of electrons concerned in the reaction varies between 1 and $2 \cdot 5$. Unless auxiliary assumptions are made this is not in agreement with the requirements of the simple reaction :-

$$
\mathrm{Hb}_{4}-4 \text { electrons } \rightarrow \mathrm{MHb}_{4}
$$

Havemann and Wolff (1937) found the potentials were reached rather slowly, but that they could be accounted for by the equation :-

$$
\mathrm{E}=+0.526-\frac{\mathrm{RT}}{\mathrm{F}} \times \mathrm{pH}+\frac{\mathrm{RT}}{\mathrm{F}} \ln \frac{[\text { MetHb] }}{[\mathrm{Hb}]}
$$

In this equaticn again a single electron appears to participate in the HæmoglobinMethæmoglobin reaction.

Conant and Tongberg (1930) have studied the system parahæmatin-hæmochromogen and conclude that at $\mathrm{pH} 7 \cdot 5$ the electrode potential of the 50 per cent. oxidised system (i.e., $\mathrm{E}_{0}$ ) is - $0 \cdot 1$ volt.

Hæmochromogen systems have been studied also by Barron (1937). Cyanhæmochromogen was found to give rapid potentiometric equilibrium, the results being independent of $\mathrm{pH}$ and referable to a univalent system. With pyridinehæmochromogen the potentials varied with $\mathrm{pH}$ from those of a univalent to a divalent system, and alkaline hæmin was found to be dimeric.

Taylor and Hastings (1939) have reported on the oxidation-reduction potential of the hæmoglobin-methæmoglobin system and Taylor and Morgan (1942) on the myoglobin-methæmoglobin system.

Barron (1940) has studied Spirographis hæmin (1:3:5:8-tetramethyl-2formyl-4-vinylporphine-6:7-dipropionic acid iron chloride) and finds the $\mathrm{E}_{0}{ }^{1}$ values at $30^{\circ}$ to be $-0.089 \mathrm{v}$. at $\mathrm{pH} 7.22$ and $-0.230 \mathrm{v}$. at $9 \cdot 63$. The potentials of the hæmochromogens are: cyanide -0.113 v. at $\mathrm{pH} 9.95$; pilocarpine $-0.067 \mathrm{v}$; a-picoline $-0.01 \mathrm{v}$. at $\mathrm{pH} 9 \cdot 63$.

Lepper and Martin $(1929,1930)$ have examined the meat medium used for cultivation of anærobes and find an electrode potential of about $\mathrm{E}_{\mathrm{h}}-0.2$ volt. They conclude that the potential is established by the following mechanism: lipins absorb oxygen from the culture medium by virtue of the unsaturated acids they contain, the presence of hæmatin being necessary to catalyse the autoxidation. In addition to this reduction process there is diffusion of the parahæmatin-bæmochromogen system from the cooked meat. They point out that a potential of $-0 \cdot 18$ volt would indicate 95 per cent. reduction and -0.22 volt, 99 per cent. reduction of the parahæmatin system. The potentials they obtained agreed with the extent of reduction inferred from the bright pink colour observed in the bottom of meat media tubes where the medium is furthest removed from contact with air.

In considering the chain of reactions by which foodstuffs in the body are oxidised, hæmoglobin comes at the very end of the chain (or the beginning according to the point of view). It provides the transport by which air is carried by the lungs to the cells and tissues which require it. One of the penultimate links is provided by cytochrome which is dealt with in the next section. Both hæmoglobin and the cyto- 
chromes are protein compounds of an iron porphyrin. The general skeleton of iron porphyrin is shown below. By varying the substituents in the four pyrole rings the different porphyrins are derived.

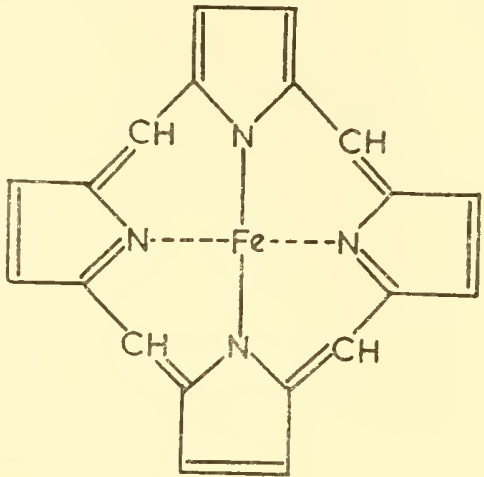

Chlorophyll is a magnesium porphyrin and catalase and peroxidase are ironporphyrin compounds. In hæmoglobin the iron is divalent and the protein component, globin is, therefore, combined with hæm ; the trivalent iron porphyrin is bæmatin, which is present in peroxidase. In the cytochromes, on the other hand, the enzymic properties are attributable to the alternate oxidation and reduction of the iron. The pigment turacin in feathers of the touraco is a copper-porphyrin compound, presumably without respiratory significance.

\section{CYTOCHROME}

MacMunn's observation in 1886 of a pigment probably of respiratory significance in tissues had to remain for nearly forty years before its fruitful development by Keilin (1925). The presence of the cytochromes can be detected by virtue of the characteristic absorption spectra possessed by the reduced pigments. The cytochrome absorption bands in a yeast suspension, for example, disappear when oxygen is bubbled throngh and they reappear during reduction on standing. There are systems in cells which can oxidise cytochromes aerobically and reduce them when air is excluded. The oxidised and reduced forms are now generally known as ferriand ferro-cytochrome respectively.

The reaction

$$
\mathrm{Fe}^{\oplus \oplus} \rightleftharpoons \mathrm{Fe}^{\oplus \oplus \oplus}+\text { electron }
$$

in the case of cytochrome does not occur spontaneously and appropriate enzyme systems have to be present for the reactions to proceed. Dehydrogenases effect reduction and cytochrome oxidase (or indophenol oxidase) effects oxidation.

succinate

$$
\begin{aligned}
& \text { Succinate }+ \text { Ferricytochrome } \underset{\text { dehydrogenase }}{\longrightarrow} \text { Fumarate }+ \text { Ferrocytochrome } \\
& \text { Cytochrome }
\end{aligned}
$$

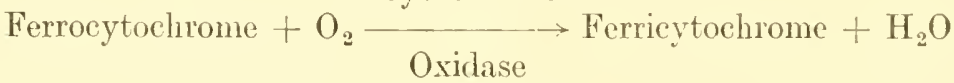

Study of this system, the details of which are still the subject of controversy, has been aided by the use of chemical compounds which act as differential inhibitors of 
one or other of the various reactions making up the whole system. The re-oxidation of cytochrome is inhibited by cyanide, carbon monoxide, azide, etc., all of which combine with the cytochrome iron. It is noteworthy that the inhibition by carbon monoxide is reversed by exposure to light. The dehydrogenase system is inhibited by narcotics.

It should be noted that oxidation of some substrates in the presence of cytochrome requires not only dehydrogenase but also coenzyme I or II.

The identity of cytochrome oxidase is the subject of some discussion. It has been found to be identical with the indophenol oxidase present in many cells, which catalyses the oxidative coupling of a-naphthol and p-phenylene diamine (the " Nadi" reagent) yielding indophenol blue. Warburg's iron-containing respiratory pigment or Atmungsferment has a similar distribution and absorption spectrum and it is now commonly thought to be identical with one of the cytochrome components $\left(a_{3}\right)$.

Largely on the basis of differences in absorption spectra cytochrome has been differentiated into a number of components $\left(a_{1}, a_{3}, b\right.$, c, etc.).
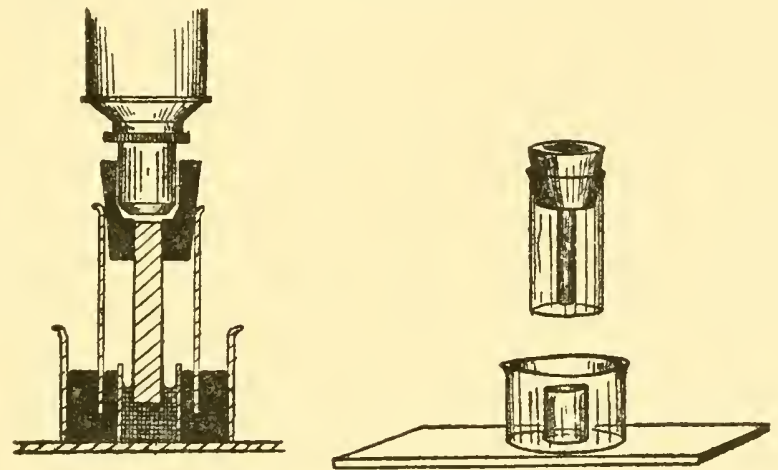

Fra. 14

A new observation cell for the micro-spectroscopic examination of bacteria, etc.

It may be mentioned incidentally that in order to overcome the difficulties associated with the spectroscopic examination of pathogenic bacteria, the simple apparatus shown in fig. 14 was devised by the author and has proved very effective. The apparatus is used with the ordinary microspectroscope (which is mounted, in place of the eye-piece, on a microscope). The device is made in two parts, the observation cell and an attachment to the microscope objective. The observation cell is mounted on a miscroscope slide and consists of an inner chamber to contain the suspension of organisms and an outer annular space to hold mercury and provide an air-tight seal, with the double advantage of preventing both evaporation and accidental scattering of organisms during the manipulation. The cell is construsted of two short lengths of glass tubing of internal diameter $8 \mathrm{~mm}$. and $18 \mathrm{~mm}$. respectively. One end of each of the tubes is ground flat and sealed to the slide with Canada balsam. This easily renewable method of sealing is of great advantage since the apparatus can be sterilised in boiling water after use, and then can be re-assembled readily, rapidly and cheaply. The other part of the apparatus is attached to the microscope objective by means of a rubber bung, the upper half of which is bored to fit over the objective. The lower half of the bung is bored to take a glass rod $5.5 \mathrm{~mm}$. 
in diameter. Both ends of this short glass rod are ground and polished, one end is held in close proximity to the objective lens and the other dips into the cell suspension. The bung is fitted into a piece of glass tubing $15 \mathrm{~mm}$. in bore. When the glass rod is lowered into the cell suspension this outer tube dips into the annulus of mercury and forms an air-tight seal. If a slide $1 \frac{1}{2}$ in. wide, instead of the usual 1 in., be used, more ample clearance between the overlapping glass tubes can be allowed, and by means of side-tubes any desired gas may be circulated through the inner chamber.

The inexpensive apparatus described has the following advantages :-

(1) The glass tube dipping into the suspension avoids the serious loss of illumination inevitable at an air-suspension interface, and brings the objective optically close to the suspension whilst actually separating it.

(2) The ordinary focussing arrangement of the microscope, by raising or lowering the glass rod attached to the objective, provides an effective method of varying the depth of suspension through which the light passes.

(3) The mercury seal prevents drying up of the suspension during observations and effectively prevents accidental scattering of organisms, a desirable precaution in the case of pathogenic bacteria.

(4) The objective of the microscope is protected and all parts of the apparatus coming in contact with bacteria may be sterilised in boiling water, the simple Canada balsam seals, being readily renewed after use.

Cytochrome occurs in aerobic bacteria but not in strict anærobes, and to its presence has been attributed the heat-stable peroxidase of bacteria, but successful isolation of cytochromes makes possible the direct testing of this point. (Yaoi and Tamiya, 1928). Facultative anærobes may be deficient in one or more of the cytochrome constituents. It is not, however, possible to obtain a close relation between the type of metabolism of a bacterium and its cytochrome composition since a number of alternative respiratory enzymes may be present.

As with some other biologically interesting systems the determination of the oxidation-reduction potentials of the cytochromes has presented some difficulties. Wurmser and Filitti-Wurmser (1938) found that the potential of cytochrome-C reached an equilibrium only after several hours but the value obtained ( $\mathrm{E}^{1}+0.253 \mathrm{v}$.) was confirmed by studying the equilibrium between cytochrome and reductinic acid. The oxidation-reduction potential was constant between $\mathrm{pH} 5$ and 8 . The usual potential equation was found to be obeyed :-

$$
\mathrm{E}_{\mathrm{h}}=\mathrm{E}_{\mathrm{o}}{ }^{2}-\frac{\mathrm{RT}}{\mathrm{F}} \ln \frac{\text { [Reduced cytochrome] }}{\text { [Oxidised cytochrome] }}
$$

By studying spectrophotometrically the equilibria between cytochrome and oxidation-reduction dyes Stotz, Sidwell and Hogness (1938), obtained the value $\mathrm{E}_{0}{ }^{1}+0.262 \mathrm{v}$. Using quinhydrone and cytochrome-C in washed muscle Laki (1938) found $\mathrm{E}_{0}{ }^{1}+0.28 \mathrm{v}$. at $\mathrm{pH} 7 \cdot 4$, and Ball (1938) gives the value +0.27 at $\mathrm{pH}$ 7.4. Green (1934) previously reported $\mathrm{E}_{0}{ }^{1}+0 \cdot 127 \mathrm{v}$. with yeast cytochrome -C. Working with heart muscle Ball (1938) has given figures for the $\mathrm{E}_{0}{ }^{1}$ values of three cytochrome components :-

Cytochrome-a, $+0.29 \mathrm{v} . ; \mathrm{b},-0.04 \mathrm{v} ., ; \mathrm{c},+0.27 \mathrm{v}$.

The oxidation-reduction potential behaviour of cytochrome-C has been studied by Paul (1947) and Rodkey and Ball (1947) who find an $\mathrm{E}_{0}$ value of about $+0 \cdot 26 \mathrm{v}$. 
Between $\mathrm{pH} 4$ and 7 the value remains constant, but there is a break at $\mathrm{pH} 6 \cdot 86$ and the potential falls by $0 \cdot 06 \mathrm{v}$. per $1 \mathrm{pH}$ unit.

In the chapter on Polarography mention is made of the work of Carruthers on the catalytic waves of cytochrome-C and other enzymes.

\section{PEROXIDASE AND CATALASE}

Before leaving the subject of iron-porphyrin compounds the two enzymes peroxidase and catalase should be mentioned.

Peroxidase from horse-radish has been crystallised and separated into ferriprotoporphyrin (hrmatin) and protein. In the presence of hydrogen peroxide peroxidase effects oxidation by the following mechanisin :-

$$
\text { Peroxidase }+\mathrm{H}_{2} \mathrm{O}_{2} \rightleftharpoons \text { Peroxidase } \mathrm{H}_{2} \mathrm{O}_{2}
$$

Peroxidase $\mathrm{H}_{2} \mathrm{O}_{2}+\mathrm{A} \rightleftharpoons$ Peroxidase $+\mathrm{AO}+\mathrm{H}_{2} \mathrm{O}$

In these reactions the iron in the peroxidase remains in the ferric state but dihydroxymaleic acid may be oxidised by peroxidase functioning as an aerobic peroxidase ; in this case carbon monoxide inhibits the reaction.

The characteristic oxidation-reduction potential of the reactants seems not to be the crucial factor since in the case of hydroquinone and pyrogallol, despite a similar $\mathrm{E}_{\mathrm{o}}$ value, the reaction rate differs tenfold. By special methods of observation of rapid colour changes, three colours of peroxidase- $\mathrm{H}_{2} \mathrm{O}_{2}$ compounds, green, pale red and deep red, are described by Chance (1949) and Roughton.

Catalase from liver, erythrocytes and bacteria has been crystallised; it is a protohæmatin-protein compound. It remains a puzzle why organisms such as Micrococcus lysodeititicus should produce such large amounts of catalase, far in excess of the need to break down peroxide (Herbert). The mechanism by which catalase decomposes hydrogen peroxide to oxygen and water is still disputed, the reactions suggested by Keilin and Hartree (1938) being :

$$
\begin{aligned}
& 4 \mathrm{Fe}^{\oplus \oplus \oplus}+2 \mathrm{H}_{2} \mathrm{O}_{2} \rightleftharpoons 4 \mathrm{Fe}^{\oplus \oplus}+4 \mathrm{H}^{\oplus}+2 \mathrm{O}_{2} \\
& 4 \mathrm{Fe}^{\oplus \oplus}+\mathrm{O}_{2}+4 \mathrm{H}^{\oplus} \rightleftharpoons 4 \mathrm{Fe}^{\oplus \oplus \oplus}+2 \mathrm{H}_{2} \mathrm{O}
\end{aligned}
$$

It is suggested that catalase can function as a secondary oxidation catalyst (Theorell, 1947).

A catalytic peroxidation which proceeds in vitro but has not been detected in vivo proceeds as follows (Albert and Falk, 1949). Cytochrome-C and methæmoglobin catalyse the oxidation by hydrogen peroxide of amino-and hydroxy-acridines and quinolines. Quinonimines and quinones are formed and these act as hydrogen carriers which oxidise ascorbic acid and cysteine antocatalytically.

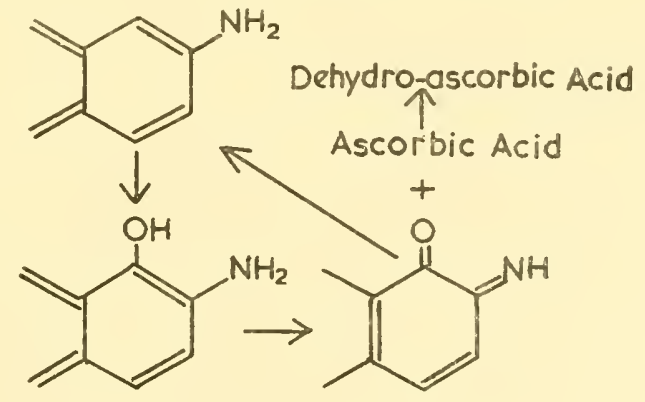


The need of Homophilus influenza for protoporphyrin for growth (the $\mathrm{X}$ factor, of Lwoff and Lwoff) depends upon the inability of the organisms to synthesise the necessary cytochrome etc., enzymes without the porphyrin into which iron may be incorporated; other porphyrins could not replace protoporphyrin (Granick and Gilder, 1946.)

\section{COPPER PROTEIN OXIDASES}

Several plant proteins containing copper have been found to function as oxidases : they include tyrosinase, laccase and ascorbic acid oxidase. In general the proteins are blue and catalyse the direct oxidation of their substrates by molecular oxygen but not by methylene blue and other dyes under anaerobic conditions and no hydrogen peroxide formation has been detected as has been done in the case of other dehydrogenases. Cyanide inhibits their action. (For a review see Dawson and Mallette, 1945.)

Laccase, obtained from the latex of lacquer trees, oxidases polyhydric phenols e.g., hydroquinone and guaiacum (Keilin and Mann, 1940; Kubowitz, 1937, 1938.) Tyrosinase occurs in mushrooms, potatoes, tea and tobacco as well as in insects and invertebrates. Under aerobic conditions it oxidises monophenols and O-dihydric phenols, among the substrates oxidised being phenol, p-cresol, catechol, tyrosine and adrenaline (Kubowitz, 1937 ; Raper, 1928; Keilin and Mann, 1938; Nelson and Dawson, 1944), and the darkening of injured tissues has been ascribed to tyrosinase activity. The meal-worm is a useful source of the pro-enzyme. Figge (1940) finds that melanin production by tyrosinase is subject to an oxidation-reduction potential optimum range for maximum activity.

Ascorbic acid oxidase oxidises ascorbic acid and is found in cabbages and many other plants. (Szent-Györgi ; Zilva ; Barron, de Meio and Klemperer, 1936 ; Stotz ; Meikeljohn and Stewart, 1941.)

Hæmocyanin is a complex copper protein occuring in the blood of invertebrates such as crabs and snails; it is blue when oxygenated and nearly colourless when de-oxygenated and it plays a rôle in respiration similar to that of hæmoglobin. Hæmocuprein is a blue copper protein found in mammalian blood, containing $0 \cdot 34 \%$ of copper with a molecular weight of 35,000 having two atoms of copper in the protein molecule.

The dropping mercury electrode has been used (Ames and Dawson, 1945) for the determination of copper in copper proteins.

\section{COBALT COMPLEXES-ANTI-PERNICIOUS ANAEMIA FACTOR}

The anti-pernicious anæmia factor of liver which is required, in addition to folic acid, for prevention of spinal degeneration has been isolated and found to be a deep red cobalt complex (Rickes et al, 1948, Smith and Parker, 1948) which is active in minute doses.

The power of cobalt complexes to unite reversibly with oxygen las been studied by Calvin and Barkelew (1946). The observation of Burk, Hearon, Caroline and Schade (1946) that cobalt inhibits the growth and respiration of micro-organisms, tissues and tumours led to the investigation of the chelate cobalt complexes of histidine. Purple complexes of trivalent cobalt were observed by Laland and Closs (1945) in the case of all amino acids except tryptophane, and with protein hydrolysates. The casein cobalt complex was not attacked by papain but was partly digested by 
trypsin liberating the complex into solution. Some reticulocyte response was elicited by these cobalt complexes suggesting the possibility of synthesising an anti-pernicious anæmia factor. The catalytic waves of cysteine in the presence of cobalt are mentioned in the Polarography chapter. Coloured cobalt: histidine complexes have been investigated by Michaelis (1947).

\section{FLAVOPROTEINS, VITAMIN $B_{\mathbf{z}}$}

The yellow oxidation enzyme, flavoprotein, obtained from yeast by Warburg and Christian (1932), was the fore-runner of a number of flavoproteins, with the properties of oxidation enzymes, that have since been described. By suitable methods these flavoproteins may be split into a prosthetic group, flavin or flavin phosphoric ester, and a protein carrier. The nature of this protein carrier may confer different properties on the flavoprotein. The prosthetic group is dimethyl alloxazine combined with ribose phosphoric ester and the properties of Vitamin $\mathrm{B}_{2}$ have been traced to riboflavin.

Flavoprotein effects oxidation not directly but through the intermediary of coenzymes I and II as suggested in the following scheme : substrate.

Coenzyme + dehydrogenase + substrate $\rightarrow$ Reduced coenzyme + oxidised

Reduced coenzyme + flavoprotein $\rightarrow$ Coenzyme + reduced flavoprotein.

Reduced flavoprotein $+\mathrm{O}_{2} \rightarrow$ Flavoprotein.

The oxidation-reduction reaction of flavin and the intermediate form may be represented as follows (Waters) :-

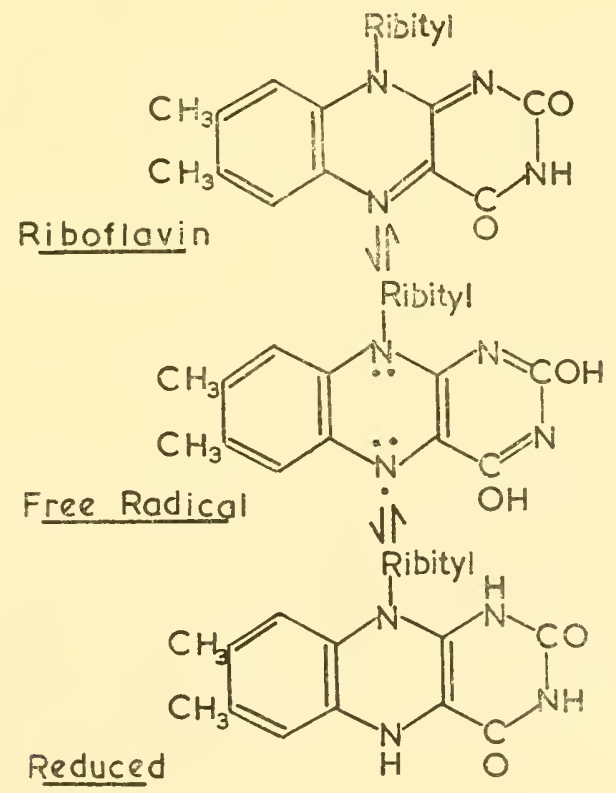

It has been calculated that one molecule of flavin catalyses the oxidation of 8,500 molecules of reduced coenzyme per minute at body temperature. 
As would be expected from its participation in oxidation-reduction reactions, riboflavin, the prosthetic group of the yellow enzymes, is subject to reversible oxidation-reduction reactions. The potential of the half reduced pigment at $\mathrm{pH} 7 \cdot 0$ having been given as $-0.22 \mathrm{v}$. Reduction of the pigment, however, occurs in two stages, and in acid solution an intermediate red form, a semi-quinone can be observed, whilst in neutral solution the intermediate form is green (Michaelis, Schubert and Smythe, Kuhn and Wagner-Jauregg, 1934; Klemperer, Bessey and Hastings, 1937). Haas has found that when the flavin is combined with its carrier protein the intermediate red form is seen even in neutral solution.

The electrode potential of the flarin is not affected by phosphorylation but combination with the carrier protein does affect the potential (Kuhn and Boulanger, 1936); $\mathrm{E}_{0}$ of the flavinphosphates is $0.187 \mathrm{v}$. and of the flavoprotein $0.373 \mathrm{v}$.

Among the many flavoproteins described is diaphorase from heart muscle, a flavin adenine dinucleotide. (Straub, 1939; Euler and Hasse, 1938; Dewan and Green, 1938).

\section{AMINO-ACID OXIDASE}

d-Amino-acid oxidase has been isolated from animal liver, kidney, etc., and is a flavoprotein containing adenine-flavine dinucleotide as prothetic group. It oxidises only d-amino acids and since natural amino acids are of l-configuration its significance is doubtful, but a relatively feeble l-amino-acid oxidase has been found. d-Aminoacid oxidase oxidises most $d$-amino acids with the notable exception of glutamic acid, but l-amino-acid oxidase attacks only mono-amino-monocarboxylic acids and not glycine or l-amino-acids containing the hydroxyl group. The oxidation proceeds as follows :-

\section{R.CH $(\mathrm{COOH}) \cdot \mathrm{NH}_{2} \rightarrow \mathrm{R} . \mathrm{C}(\mathrm{COOH}): \mathrm{NH}+2 \mathrm{H}$}

and the imino-acid is hydrolysed spontaneously to the keto acid and ammonia.

$$
\text { R.C }(\mathrm{COOH}): \mathrm{NH}+\mathrm{H}_{2} \mathrm{O} \rightarrow \mathrm{R} . \mathrm{CO} \cdot \mathrm{COOH}+\mathrm{NH}_{3}
$$

\section{XANTHINE OXIDASE}

Xanthine oxidase preparations contain adenine flavine dinncleotide so that it is probably a flavo-protein but other prosthetic groups may be present. The oxidase occurs in milk and catalyses the oxidation of hypoxanthine to xanthine, and of xantline to uric acid.

$$
-\mathrm{CH}=\mathrm{N}-+\mathrm{H}_{2} \mathrm{O} \rightarrow-\mathrm{CHOH} \cdot \mathrm{NH} \rightarrow-\mathrm{CO} \cdot \mathrm{NH}-+\mathrm{H}_{2} \mathrm{O}_{2}
$$

In both cases a hydrate is an intermediate and hydrogen peroxide is formed. The system itself does not give rise to an electrode potential although the peroxide formed does so in the nresence of oxygen. If methylene blue is added it is reduced and the characteristic potential of the dye is observed. With alloxan the potential characteristic of the alloxan : dialuric system is established.

\section{ALDEHYDE DEHYDROGENASE}

In animal tissues the dismutation

$$
\text { Acetaldehyde } \rightarrow \text { Ethyl alcohol }+ \text { acetic acid }
$$

occurs independently of the xanthine oxidase system. This was originally thought to be caused by a " mutase " enzyme activating a Cannizaro reaction, but it is now shown 
to be two reactions catalysed by separate enzymes, alcohol dehydrogenase and aldehyde dehydrogenase

$$
\begin{aligned}
& \mathrm{CH}_{3} \mathrm{CHO} \stackrel{\text { alcohol dehydrogenase }}{\longrightarrow} \mathrm{CH}_{3} \mathrm{CH}_{2} \mathrm{OH} \\
& \mathrm{CH}_{3} \mathrm{CHO} \stackrel{\text { aldehyde dehydrogenase }}{\longrightarrow} \mathrm{CH}_{3} \mathrm{COOH}
\end{aligned}
$$

The alkehyde dehydrogenase is a diphosphopyridine-nucleotide-linked enzyme (Racker, 1949). The apparent absence of alcohol dehydrogenase previously reported was due to the accidental removal of the coenzyme diaphorase during the purification.

\section{COENZYMES}

Yeast juice when dialysed no longer ferments glucose and from the dialysate coenzyme 1 can be isolated. This is a compound of nicotinamide, ribose, pyrophosphoric acid and adenine. Coenzyme II, isolated from erythrocytes has a similar structure to Coenzyme I, but it contains two phosphate residues. The Coenzymes I and II owe their biological function to reversible oxidation-reduction of the pyridine ring. A transient intermediate form in the reduction has been deduced and might be represented as follows (Waters, 1948) :-

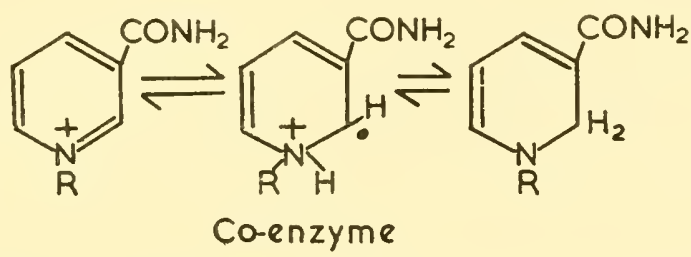

Not only is Coenzyme I essential for yeast fermentation as mentioned above, but it is also necessary for the glycolysis of sugars in muscle, etc. The coenzyme is reduced when diphosphoglyceraldehyde is oxidised to diphosphoglyceric acid in the presence of triosephosphate dehydrogenase and reoxidised when pyruvic acid is reduced to lactic acid later on in the glycolytic cycle, or when acetaliehyde is reduced to ethyl alcohol during alcoholic fermentation (as described in the next chapter).

In the following table (from Ochoa, 1946) are summarised the oxidation-reduction potentials of a number of dehydrogenase systems in which coenzymes I and II

\begin{tabular}{|c|c|c|c|}
\hline System & $\begin{array}{c}\mathrm{Eo}^{1} \mathrm{pH} 7 \cdot 0 \\
\text { volts }\end{array}$ & Coenzyme & $\begin{array}{l}\text { Occurrence of } \\
\text { dehydrogenase }\end{array}$ \\
\hline 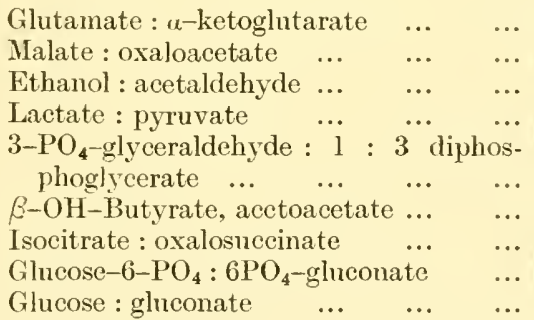 & $\begin{array}{r}-0 \cdot 03 \\
-0 \cdot 10 \\
-0 \cdot 16 \\
-0 \cdot 18 \\
-0 \cdot 28 \\
-0 \cdot 29 \\
-0 \cdot 30 \\
-0 \cdot 43 \\
-0.45\end{array}$ & $\begin{array}{c}\text { I or II } \\
\text { I } \\
\text { I } \\
\text { I } \\
\\
\text { I } \\
\text { I } \\
\text { II } \\
\text { II } \\
\text { I }\end{array}$ & $\begin{array}{l}\text { Yeast, bacteria, tissues. } \\
\text { Plants, bacteria, tissues. } \\
\text { Ycast, bacteria. } \\
\text { Bacteria, tissues. } \\
\text { Ycast, tissues. } \\
\text { Tissues. } \\
\text { Yeast, plants, tissues. } \\
\text { Yeast, erythrocytes. } \\
\text { Tissues. }\end{array}$ \\
\hline
\end{tabular}
co-operate.

TABLE 10

Pyridine Nucleotide Dehydrogenases 
The oxidation of reduced coenzyme by cytochrome is stated to be catalysed always by flavoprotein but Dickens and McIlwain have shown that phenazine dyes react directly with coenzymes in the hexose monophosphate system and are active oxygen catalysts in the absence of flavoproteins. It is perhaps significant that phenazines and quinones share with flavoprotein the property of forming semiquinones. In a later section, a fuller description of semiquinone pigments is given.

By indirect comparison with the $\beta$-hydroxybutyric acid system the normal potential of cozymase I has been estimated to be $-0.28 \mathrm{v}$. at $\mathrm{pH} 7$ (Borsook, 1940 ; Dewan and Green, 1937); direct potentiometric determination of the potential was not found to be possible. Comparison with the lactate-pyruvate system gives a value of $-0 \cdot 325$ v. at $\mathrm{pH} 7 \cdot 4$ (Clark, 1938).

Hamophilus influenza cannot synthesise the Coenzyme I necessary for giowth processes and the coenzyme must be supplied ( $\mathrm{V}$ factor of Lwoff and Lwoff). On the other hand some micro-organisms can synthesise it so that symbiotic growth of $H$. influenzce with some other organisms can occur in culture medium not containing any of the coenzyme.

\section{ANEURINE, THIAMINE, VITAMIN $B_{1}$, COCARBOXYLASE}

Cocarboxylase is the pyrophosphoric ester of Vitamin $\mathrm{B}_{1}$ (Aneurin or Thiamin). It functions as coenzyme for carboxylase which catalyses the conversion of pyruvic acid to acetaldehyde in the final stages of alcoholic fermentation (see next chapter) :-

$$
\mathrm{CH}_{3} \mathrm{CO} . \mathrm{COOH} \rightarrow \mathrm{CH}_{3} \mathrm{CHO}+\mathrm{CO}_{2}
$$

When dried yeast is washed with phosphate it loses its power of decarboxylation owing to the removal of cocarboxylase, which has been isolated also from blood, liver, kidney, etc. Aneurin contains a thiazole ring, but appears to behave as a thiol compound capable of reversible oxidation-reduction to the disulphide.

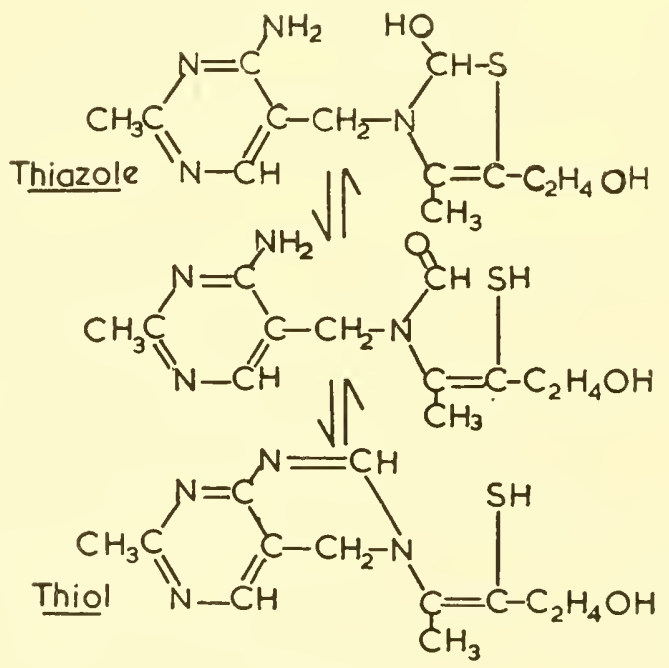

Thiamin 
Normally aneurin exists chiefly in the recluced (thiol) form unlike coenzymes I and II. Its polarographic behaviour is described in Chapter VIII.

The enzyme carboxylase is probably a compound of aneurin pyrophosphate, magnesium and protein (Green, Herbert and Subrahmanyan, 1940). In bacterial cultures pyruvic acid breakdown appears to follow a different course, but propionic acid bacteria, etc., have been found to synthesise aneurin in deficient media.

In normal brain tissue carbohydrate is completely oxidised, but Peters has found that in thiamine-deficient pigeons carbohydrate breakdown proceeds only as far as pyruvic acid. These pigeons show convulsive symptoms which are relieved rapidly by administration of thiamine. By tissue phosphorylation thiamine is converted to cocarboxylase and the pyruvic acid accumulation diminishes. Aerobically the pyruvic acid is completely oxidised, but anaerobically it is decarboxylated oxidatively to acetic acid whilst a second molecule is reduced to lactic acid, coenzyme I carrying out the necessary hydrogen carrying :-

Pyruvic acid $+\mathrm{H}_{2} \mathrm{O}+\mathrm{CoI} \rightarrow$ Acetic acid $+\mathrm{CO}_{2}+\mathrm{CoI} .2 \mathrm{H}$

Pyruvic acid + CoI.2H $\rightarrow$ Lactic Acid + CoI.

The use of the pyruvate oxidase system in the investigation of vesicants is described in Chapter VII.

The mechanism of oxidative decarboxylation by $B$. delbruckii has been studied by Lipmann, who traced the intermediate formation of acetyl phosphate. A fuller discussion of energy-rich phosphate bonds is reserved for the next Chapter, but it is sufficient to mention here that in acetyl phosphate, adenosine diphosphate (ADP) and adenosine triphosphate (ATP) the pyrophosphate groups are in a peculiarly reactive state indicated by the sign $\sim_{p h}$. The reaction proceeds :-

$$
\begin{aligned}
\text { Pyruvic acid }+ \text { phosphate } & \rightarrow \text { Acetylphosphate }+\mathrm{CO}_{2} \\
\mathrm{CH} \mathrm{COO} \sim \mathrm{ph}+\mathrm{ADP} & \rightarrow \mathrm{CH}_{3} \mathrm{COOH}+\mathrm{ATP}
\end{aligned}
$$

The whole process is evidently complicated and cocarboxylase, coenzyme I, adenosinediphosphate in addition to inorganic phosphate and magnesium ions are all participants in oxidative decarboxylation of pyruvic acid.

\section{VITAMIN $B_{6}$, PYRIDOXAL PHOSPHATE}

Vitamin $\mathrm{B}_{6}$, an antidermatitis vitamin, is pyridoxine and the related compounds pyridoxal and pyridoxal phosphate play most important roles in amino acid decarboxylation and in transamination.

The structure of pyridoxal phosphate is probably:-

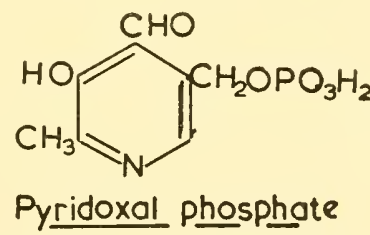

Related compounds function as coenzymes in the decarboxylation of $\alpha$-aminoacids as the prosthetic group of transaminases, occasionally pyridoxamine phosphate- 
being the active compound; and in the synthesis and breakdown of tryptophan. In some cases these coenzymes apparently function as carriers of amino groups and in others as hydrogen acceptors.

\section{ASCORBIC ACID (VITAMIN C)}

It is established that vitamin $\mathrm{C}$ is ascorbic acid (3-keto-1-gulofuranolactone), a substance with reducing properties. The vitamin-C content of foodstuffs may be determined by titration with oxidation-reduction potential indicators, such as 2 : 6-dichlorophenol-indophenol (Georgescu, 1932; Tillmans, Hirsch and Hirsch, 1932 ; Tillmans, Hirsch and Dick, 1932) or prune (Melville and Richardson, 1934). The reducing properties of the vitamin suggested that potentiometric study could be made of the reversible oxidation-reduction system concerned. Unfortunately, the oxidant is instable and is irreversibly oxidised so that at an electrode the potential difference set up is due only to the reduced form - a result superficially similar to that observed in the case of sulphydryl compounds. The instability of the oxidised form in any but very acid solutions makes it difficult to understand how the vitamin remains undestroyed in tissues which have an oxidising level of potential higher than that of ascorbic acid. It is possible that some stabilising substance is present. Laki (1933) found difficulties with electrode potential determinations as did Green (1933), who derives the following equation for ascorbic acid (in volts) :-

$$
\mathrm{E}_{\mathrm{h}}=+0.375-0.06 \mathrm{pH}
$$

Borsook and Keighley (1933) found difficulties in solutions less acid than $\mathrm{pH} 5 \cdot 75$, whilst Wurmser and de Loureiro (1933) suggest that two reducing groups in ascorbic acid behave normally whilst a third alcohol grouping is responsible for the irregular potential behaviour. Other papers dealing with this subject include Szent-Grörgi (1928), Birch, Harris and Ray (1933), Herbert, et alios (1933) and Zilva (1934).

Borsook and his co-workers (1937) find that dehydroscorbic acid is rapidly reduced by sulphydryl compounds and observe the oxidation-reduction potentials of three separate steps in the oxidation of ascorbic acid. These conclusions are disputed by Ball (1937) who finds that in the presence of "mediators" (generally oxidation-reduction indicator dyes) the electrode potentials of the ascorbic acid system could be measured and has obtained the following figures for $\mathrm{E}_{\mathbf{0}}{ }^{1}$ values at lifferent $\mathrm{pH}$ levels $\left(30^{\circ} \mathrm{C}\right.$.).

\begin{tabular}{llllr}
$p H$ & & & \multicolumn{2}{c}{$E_{0}$} \\
1.05 & $\ldots$ & $\ldots$ & $\ldots$ & +0.326 \\
$2 \cdot 16$ & $\ldots$ & $\ldots$ & $\ldots$ & 0.260 \\
3.04 & $\ldots$ & $\ldots$ & $\ldots$ & 0.209 \\
4.00 & $\ldots$ & $\ldots$ & $\ldots$ & 0.154 \\
$5 \cdot 19$ & $\ldots$ & $\ldots$ & $\ldots$ & 0.115 \\
6.32 & $\ldots$ & $\ldots$ & $\ldots$ & 0.078 \\
7.24 & $\ldots$ & $\ldots$ & $\ldots$ & +0.051 \\
8.57 & $\ldots$ & $\ldots$ & $\ldots$ & -0.012
\end{tabular}


The normal potential $\left(\mathrm{E}_{0}\right)$ was found to be $+0.3895 \mathrm{v}$., and the slope of the $\mathrm{E}_{0}{ }^{1} / \mathrm{pH}$ curve was found to change from 0.06 to 0.03 at $\mathrm{pH} 4$ and to remain at " 0.03 . slope " as far as pH 8.6. It was concluded that dehydroscorbic acid does not exist in tissues.

Ascorbic acid has been determined potentiometrically by Becker and Digleria (1937), Gillam (1945), and by Kirk and Tressler (1939).

Ascorbic acid is widely distributed through the plant kingdom increasing during germination and apart from being useful to animals who eat the plant products it probably has biological significance to the plant. Like other compounds themselves subject to oxidation-reduction reactions such as catechol, ascorbic acid acts as an anti-oxidant and protects susceptible compounds from oxidation. Some recent work by Virtanen and Hausen (1919), throws light on the possible importance of ascorbic acid to plants. The cotyledons of pea seedlings are rich in vitamin $\mathrm{C}$ and removal of the cotyledons stunts growth. Addition of ascorbic acid to the cotyledon-less seedlings improves growth and it has been found to lower the oxidation-reduction potential of the plant. Other reducing substances such as reductone, cysteine and glutathione had the same beneficial effect. Administration of vitamin $\mathrm{C}$ to plants already having a normal supply can restrict growth due to the development of too low an oxidation-reduction potential. It is concluded that the function of ascorbic acid in the plant is to regulate the oxidation-reduction potential at an optimum level.

Improper cooking of vegetables results in destruction of vitamin $\mathrm{C}$, traces of copper markedly accelerating the oxidation to dehydro-ascorbic acid :--

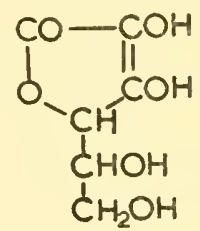

Ascorbic

acid

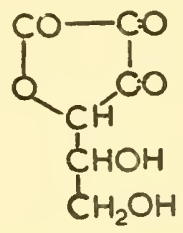

Detydro-ascorbic

acid

A number of enzyme systems oxidise ascorbic acid; these include catecnol oxidase, cytochrome, peroxidase and a specific ascorbic acid oxidase, which is a copper protein complex (see page 54) inhibited by copper precipitants.

\section{FOLIC ACID; PTEROYLGLUTAMIC ACID}

Administration of folic acid improves blood regeneration in pernicious anæmia (the cobalt complex already mentioned being necessary for prevention of spinal cord degeneration). It has been found that the factor necessary for the growth of Lactobacillus casei, for the growth of chicks and Vitamin MI from liver and yeast used to alleviate pregnancy anæmia in India are all identical with folic acid, which is pteroyl-glutamic acid with the following structure:- 


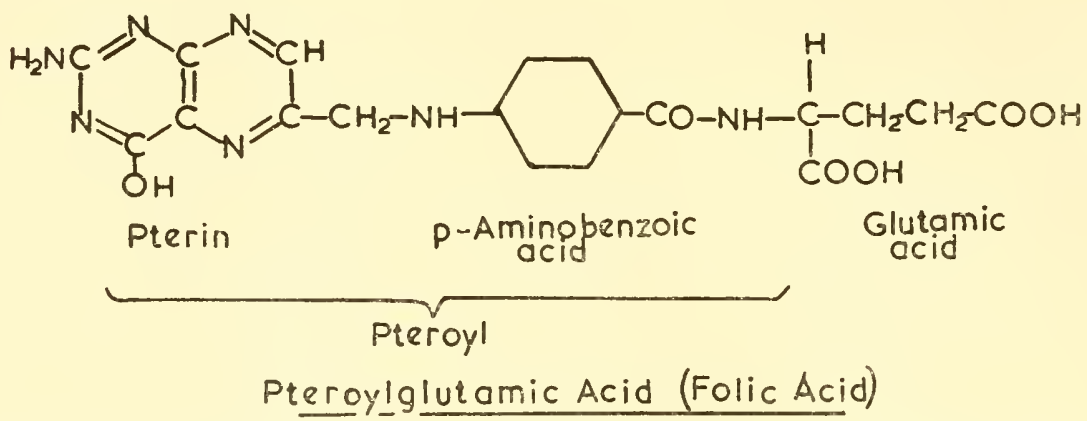

The combination of pterin, p-amino benzoic acid and glutamic acid suggests some of the functions of the vitamin. The similarity of the pterin portion of the molecule to riboflavin is evident. p-Amino benzoic acid appears to be a growth factor for some micro-organisms and the chemotherapeutic effect of sulphanilamides may be due to antagonism to this portion of the molecule. The great importance of glutamic acid in the nutrition of micro-organisms is being increasingly realised. It is interesting to note that xanthopterin occurring as a yellow pigment in the wings of butterflies is apparently without metabolic significance and the distribution of the pigment when ingested by guinea-pigs is of interest. The inhibition of mammary tumours by pteroyl-triglutamic acid may prove of importance.

\section{TOCOPHEROL, VITAMIN E}

Vitamin E or tocopherol, the antisterility factor for female rodents, is also an anti-oxidant and the question arises whether the physiological activity is associated with oxidation-reduction changes. Unlike anti-oxidants such as hydroquinone, tocopherol (I) contains only one unsubstituted phenol group and the first oxidant isolated (II) has the ring structure ruptured so that the oxidation is not reversible. The possibility still remains, however, that reversible oxidation-reduction with an intermediate radical might occur, the semiquinone differing from tocopherol by one electron.

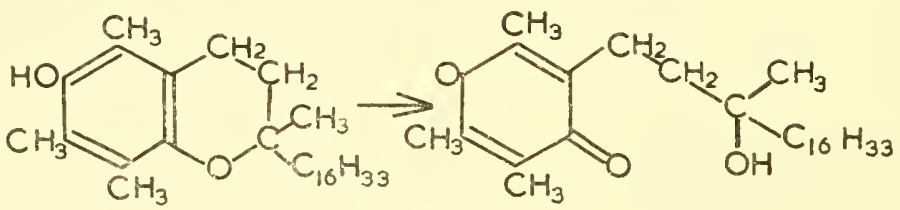

Tocopherol

Evidence for such a radical has been lacking, but Michaelis and Wollman (1949) dissolved tocopherol in organic solvents, froze the solution in liquid air, forming a glassy film and this was irradiated with ultra-violet light. The radiation supplied energy locally to remove an electron and an orange-coloured free radical accumulated. The low temperature prevented thermodynamic equilibrium being established homogenously through the film and local accumulation of the radical was possible. Immediately the temperature was raised, homogenous equilibrium occurred and the 
colour faded. It is suggested that in the body the activity of tocopherol may be associated with the formation of the free radical under physiological conditions.

\section{HERMIDINE AND ECHINOCHROME}

Cannan $(1926,1927)$ has successfully applied the study of electrode potentials to the biological pigments-hermidine and echinochrome. Crude extracts of gr en shoots of Mercurialis perennis were used in the work on hermidine. These are colourless but when exposed to air become first blue and then yellow. The reactions may be represented as (Haas and Hill, 1925):-

$$
\begin{aligned}
& \text { Hermidine } \rightleftharpoons \text { cyanohermidine }+2 \mathrm{H} \rightleftharpoons \text { oxidant } \rightarrow \text { chrysohermidine } \\
& \text { colourless blue yellow }
\end{aligned}
$$

The first two stages are completely reversible but the last is not. The electrode potential equation of the first stage was found to be, at $\mathrm{pH} 7 \cdot 61$, approximately

$$
\mathrm{E}_{\mathrm{h}}=-0.05+0.03 \log \frac{[\text { cyanohermidine] }}{\text { [hermidine] }}
$$

and the second, at $\mathrm{pH} 7 \cdot 61$,

$$
\mathrm{E}_{\mathrm{h}}=+0.01+0.03 \log \frac{\text { [oxidant] }}{\text { [cyanohermidine] }}
$$

It is possible that such pigments, subject to reversible oxidation-reduction processes, may play an important rôle in cellular respiration. In the plant, hermidine occurs in a condition of at least 95 per cent. reauction, i.e., the $\mathrm{rH}$ is 10 or less, and the $\mathrm{E}_{\mathrm{h}}$ less than $-0.09 \mathrm{v}$. at $\mathrm{pH} 7 \cdot 6$.

Echinochrome, obtained from a number of echinoderms, is also subject to reversible oxidation-reduction processes and the potentials observed agree with the electrode equation, at $\mathrm{pH} 7 \cdot 69$

$$
\mathrm{E}_{\mathrm{h}}=-0 \cdot 263+0 \cdot 03 \log \frac{[\mathrm{Ox} .]}{[\text { Red. }]}
$$

Wallenfels and Möhlle (1943) consider this potential to apply to an impure specimen from the shell.

It is probable that the pigment is mainly in the oxidised condition in the cell and its respiratory function is doubtful.

\section{PIGMENT OF CHROMODORIS ZEBRA}

The blue-purple pigment occurring in the blood and tissues of the nudibranch Chromodoris zebra has been studied chemically by Crozier (1916) and potentiometrically by Preisler (1930). It is capable of reversible oxidation-reduction, the reduced 
form being yellow, and one electron only is concerned in the reaction. The potential of the 50 per cent. oxidised system $\left(\mathrm{E}_{0}\right)$ at $\mathrm{pH} 7 \cdot 0$ is $-0.102 \mathrm{v}$.

It is unusual in an organic oxidation-reduction system for one electron only to be concerned. In the organism the pigment appears always to be in the oxidised form and it is considered likely that its oxygen carrying function is of significance in respiration.

\section{PYOCYANINE AND OTHER PIGMENTS}

Pyocyanine is the blue pigment of $B$. pyocyaneus and has been studied potentiometrically by Friedheim and Michaelis (1931), whose results were confirmed independently by Elema (1931). Pyocyanine is oxymethyl phenazine (Wrede and Strack, 1929). At $\mathrm{pH}$ values greater than 6 the pigment undergoes reversible reduction to a colourless leuco-compound, two electrons being concerned as with ordinary quinonoid dyes. The potential of the half-oxidised pigment at $\mathrm{pH} \quad 7 \cdot 4$ is about $-0.06 \mathrm{v}$. At $\mathrm{pH}$ values below 6 (i.e., in acid solutions) the pigment behaves in a different way. In these acid solutions, the pigment is ren, and its reduction is effected in two consecutive stages, each one involving one electronduring the first stage of reduction a green compound is formed and in the second stage a colourless leuco-compound. The midway reduction product appears to be a free radical rather than a meriquinone.

The alternative possibilities for the course of a reduction involving two electrons are as follows :- -

(1) Complete reduction in one stage,

$$
\text { Oxidant }+2 \text { electrons } \rightarrow \text { Reductant. }
$$

This applies to the reduction of blue pyocyanine to colourless leuco-compound at $\mathrm{pH}$ values over 6 .

(2) Half reduction and formation of mixed or meriquinone :-

$$
\begin{gathered}
\text { Oxidant }+1 \text { electron } \rightarrow \frac{1}{2} \text { (Oxidant Reductant) } \\
\frac{1}{2} \text { (Oxidant Reductant) }+1 \text { electron } \rightarrow \text { Reductant. }
\end{gathered}
$$

As an example, one might eonsider the half oxidation of hydroquinone to quinone when quinhydrone crystallises ont.

(3) Reduction in two stages:--

$$
\begin{array}{r}
\text { Oxidant }+1 \text { electron } \rightarrow \text { Semireductant } \\
\text { Semireductant }+1 \text { electron } \rightarrow \text { Reductant. }
\end{array}
$$

This last case is observed with pyocyanine in solutions of pH less than 6 . The oxidant is red, the semireductant green and the reductant is the colourless form. Michaelis and Elema independently have developed mathematical treatments of two-step reactions of the last-mentioned type. 


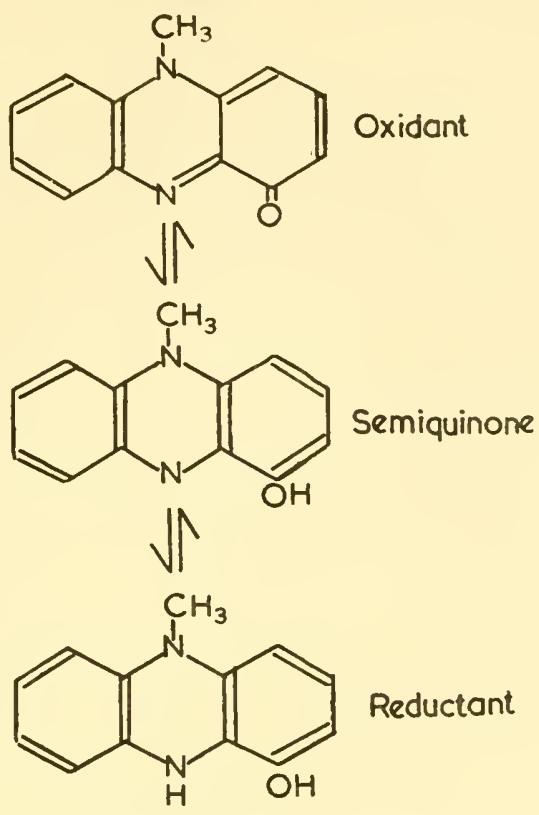

Pyocyanine

The list of reversible two-step oxidation-reduction systems is now formidable and, in addition to those already mentioned, includes $\beta$-hydroxyphenazine, $\mathrm{N}$ methyl- $\beta$-oxyphenazine, diphenyl benzidine sulphuric acid, phenanthraquinone- 3 sulphonate, lactoflavin, homogentisic acid, thiamin, lapachol, lomatiol, benzoin and various coenzymes.

It would appear that the intermediate radical in two-stage oxidations occurs in so many biological oxidation-reduction reactions that this type of compound is an essential factor in many dehydrogenase and oxidase systems.

Evidence for the existence of semiquinone radicals is found not only in potentiometric and polarographic measurements but also in measurements of magnetic susceptibility, since the radicals should contain an odd number of electrons and be paramagnetic. In the case of phenanthraquinone-3-sulphonate reduction in alkaline solution yielded a transient paramagnetic form but not in acid solution, in agreement with potentiometric results.

Pyocyanine is probably of respiratory significance, and increased oxygen consumption was noted by Friedheim when the pigment was added to suspensions of red blood corpuscles or washed suspensions of living bacteria (B. pyocyaneus, Staphylococcus aureus and pneumococcus, type III). Reed and Boyd (1932) also comment on the respiratory significance of pyocyanine in B. pyocyaneus cultures, and its effect on sea urchin eggs is described by Runnström (1935).

Young (1937) describes the initial acceleration followed by inhibition produced by pyocyanine on the metabolism of cerebral cortex. 
Friedheim (1933) has described a similar pigment (hallochrome) obtained from Halla parthenopea.

TABLE 11

SEMIQUINONE PIGMENTS

(After Stern, 1934)

\begin{tabular}{|c|c|c|c|c|c|}
\hline Pigment & Source & Authority & Holoquinone & $\begin{array}{l}\text { Semi- } \\
\text { quinone }\end{array}$ & $\begin{array}{c}\mathrm{E}_{\circ}^{\prime} \quad(\mathrm{pH} \\
7 \cdot 0)\end{array}$ \\
\hline Hallochrome & Halla parthenopea & Friedheim (1933) & $\begin{array}{l}<8.53 \text { red } \\
>8.53 \text { green }\end{array}$ & Brown? & +0.02 \\
\hline Hydroxyphenazine & Synthetic & $\begin{array}{l}\text { Michaelis and } \\
\text { others (1932). }\end{array}$ & Orange & Green & $-0 \cdot 07$ \\
\hline $\begin{array}{l}\text { Pyocyanine } \\
\text { (a-OH-N-Me- } \\
\text { phenazine). }\end{array}$ & B. pyocyaneus. & $\begin{array}{l}\text { Friedheim and } \\
\text { Michaelis (1931), } \\
\text { Elema (1931). }\end{array}$ & $\begin{array}{l}<4.9 \text { red } \\
>4.9 \text { blue }\end{array}$ & Green & $-0 \cdot 03$ \\
\hline $\begin{array}{l}\text { Chloraphine (phena- } \\
\text { zine-- } a \text {-carbona- } \\
\text { mide). }\end{array}$ & B. chloraphis & Elema (1933) & Yellow & Green & $-0 \cdot 12$ \\
\hline Photoflavin & All cells & Stern (1934) & Yellow & Red & $-0 \cdot 23$ \\
\hline Rosinduline $2 \mathrm{G}$ & Synthetic & Michaelis (1931) & Red & Violet & $-0 \cdot 28$ \\
\hline $\begin{array}{l}\text { Viologens ( } \gamma \gamma \text {-dipy- } \\
\text { ridylium chlorides) }\end{array}$ & Synthetic & $\begin{array}{l}\text { Michaelis and Hill } \\
\text { (1933). }\end{array}$ & None & $\begin{array}{l}\text { Blue- } \\
\text { Violet }\end{array}$ & $-0 \cdot 4$ \\
\hline
\end{tabular}

The green pigment of B. chloraphis, Guignard and Sauvageau, is a semiquinone stable only in very acid solution. On oxidation it gives chloraphine, a yellow holoquinone with the constitution phenazine- $\alpha$-carbonamide, and is therefore related to pyocyanine ( $a$-hydroxy-N-methyl-phenazine). The electrode potential of the half-reduced pigment at $\mathrm{pH} 7 \cdot 0\left(\mathrm{E}_{\mathbf{0}}{ }^{1}\right)$ is $-0.115 \mathrm{v}$ (Elema, 1933).

Friedheim (1933) has extracted from Arion rufus (red slugs), a pigment with $\mathrm{E}_{\mathrm{o}}^{1}$ at $\mathrm{pH} 7 \cdot 0$ of $-0 \cdot 027 \mathrm{v}$.

The pigment obtained from Urechis eggs is subject to an oxidation-reduction reaction, involving one electron and has an $\mathrm{E}_{0}{ }^{1}$ value of $+0 \cdot 186 \mathrm{v}$. at $\mathrm{pH} 7 \cdot 0$. It is suggested that the pigment is related to the hæmins since reduction in alkaline pyridine gives rise to the spectrum of a pyridine hæmochromogen (Horowitz and Baumberger, 1941).

Triphenyltetrazolium chloride has been used as a test for viable tissues which are stained red by reduction to a red dye by some enzyme system (Mattson. Jensen and Dutcher, 1937). The apparent oxidation-reduction potential of the dye is -0.08 volts.

\section{NAPHTHAQUINONES, MOULD PRODUCTS, PIGMENTS}

Very many natural products from bacteria, moulds and plants have been identified as 1:4-naphthaquinones. A few other natural products of quinonoic structure will also be dealt with in this section. Some of the products have pronounced 
bacteriostatic effects and consideration to these is given in the chapter on Chemotherapy and Antibiotics. The polarographic method of study has been applied to a number of these compounds and these are dealt with in the chapter on Polarography.

Citrinin is a yellow quinone isolated from Penicillium citrinium and has antibacterial properties (Raistrick and Smith, 1941). Fumigatin, obtained from Aspergillus fumigatin is purple in colour, being 3-hydroxy-4-methoxy-2:5-toluquinone (Anslow and Raistrick, 1938) and spinulosin, also purple, is 3: 6-dihydroxy-4methoxy-2: 5 -ditoluquinone and is obtained from Penicillium spinulosum. The halfwave potentials of these are given in the polarographic section.

The structure and interrelations of a number of mould pigments have been studied largely by Raistrick and his colleagues. These are substituted methyl anthraquinones and the most recently described is $1: 4: 5$-trihydroxy-2-methyl anthraquinone, a dark red pigment from Penicillium islandicum, which on oxidation yields cynodontin, the 8-hydroxy derivative previously obtained from three helminthosporia. On reduction and oxidation of the anthranol, chrysophanic acid is formed. Related mould pigments are Helminthosporin, Catenarin, Erythroglaucin, Frangula emodin and Ravenelin (Howard and Raistrick, 1949).

Lugg, Macbeth and Winzor (1936) determined the normal electrode potentials of a number of naphthaquinones by adding graded amounts of an oxidant to the reduced quinones in the presence of a platinum catalyst and measuring the e.m.f. The results are given in Table 12. The primary interest of these workers was the colouring matters present in a sundew, Drosera Whittakeri.

TABLE 12

Normal Electrode Potentials of Naphthaquinones, etc.

\begin{tabular}{|c|c|c|c|c|}
\hline \multirow{3}{*}{\multicolumn{2}{|c|}{$\begin{array}{l}\text { l : } 4 \text { Naphthaquinone } \\
\text { Iethylnaphthaquinone }\end{array}$}} & \multirow{3}{*}{$\begin{array}{l}\cdots \\
\cdots\end{array}$} & \multirow{2}{*}{\multicolumn{2}{|c|}{$\begin{array}{c}E_{o} \\
(\text { volts }) \\
0.485\end{array}$}} \\
\hline & & & & \\
\hline & & & $\ldots$ & 0.422 \\
\hline Lawsone $\quad .$. & $\ldots$ & & $\ldots$ & $0 \cdot 358$ \\
\hline Juglone & $\ldots$ & $\ldots$ & $\ldots$ & $0 \cdot 448$ \\
\hline Phthiocol $\quad \ldots$ & $\ldots$ & $\ldots$ & $\ldots$ & $0 \cdot 299$ \\
\hline isoNaphthazarin & $\ldots$ & $\ldots$ & $\ldots$ & $0 \cdot 288$ \\
\hline Methylnaphthazar & & $\ldots$ & $\ldots$ & $0 \cdot 322$ \\
\hline Naphthazarin & $\ldots$ & $\ldots$ & $\ldots$ & 0.372 \\
\hline Hydroxyjuglone & $\ldots$ & $\ldots$ & $\ldots$ & 0.315 \\
\hline Naphthapurpurin & $\ldots$ & $\ldots$ & $\ldots$ & $0 \cdot 249$ \\
\hline Hydroxydroserone & (natr & al) & $\ldots$ & $0 \cdot 200$ \\
\hline Hydroxydroserone & (synt & etic) & ... & $0 \cdot 200$ \\
\hline Lomatiol $\quad \ldots$ & $\ldots$ & $\ldots$ & $\cdots$ & $0 \cdot 293$ \\
\hline p-Benzoquinone & $\begin{array}{l}\cdots \\
\ldots\end{array}$ & $\begin{array}{l}\cdots \\
\cdots\end{array}$ & $\begin{array}{l}\cdots \\
\cdots\end{array}$ & 0.715 \\
\hline Tetrabromo-o-ben & oquir & & $\ldots$ & $0.86 \mathrm{~S}$ \\
\hline
\end{tabular}

Phthiocol, a pigment obtained from the tubercle bacillus is 2-methyl-3-hydroxy$1: 4$-naphthaquinone and is accordingly amenable to potentiometric study. The undissociated form is pale yellow, the ionised form is deep red and the reduced forms are colourless. At $\mathrm{pH} 7 \cdot 0$ the electrode potential when half reduced $\left(\mathrm{E}_{0}{ }^{1}\right)$ is $-0 \cdot 18 \mathrm{v}$, 
and the pigment may be of value as an oxidation-reduction potential indicator (Ball, 1934).

Friedheim (1934) has investigated the pigments obtained from walnut husks and henna leaves; they are juglon and lawson and the $\mathrm{E}_{0}{ }^{1}$ values at $\mathrm{pH} 7 \cdot 0$ are $+0.033 \mathrm{v}$. and $-0.139 \mathrm{v}$. respectively.

Phoenicin, a pigment isolated from Penicillium phoeniceum by Friedheim (1933) has an $\mathrm{E}_{0}{ }^{1}$ value at $\mathrm{pH} 7$ of $+0.047 \mathrm{v}$. An intermediate product in melanin formation, $5: 6$-diketohydroindole-2-carboxylic acid, has also been studied by Friedheim (1935). This compound, red in the oxidised form, gains two electrons on reduction and at $17^{\circ} \mathrm{C}$. the $\mathrm{E}_{0}{ }^{1}$ value at $\mathrm{pH} 4.62$ is $+0.171 \mathrm{v}$.

Posternak (1938) identifies phoenecin as $2: 2$-dihydroxy-4:4'-ditoluquinone.

Other 2-alkyl-3 hydroxynaphthaquinones have also been studied by Ball (1936). Lapachol is a yellow pigment present in the wood of many trees, and lomatiol is obtained from the seeds of Lomatio ilicifolia. In alkaline solution the yellow pigments become red and when reduced they are colourless. The normal potentials at $30^{\circ}$ are closely similar as shown in the table.

TABLE 13

Normal Potentials of 2 -aLkYL-3 hydroxy-1 : 4-Naphthaquinones

\begin{tabular}{|llc|}
\hline Pigment & Alkyl Group & $E_{\circ}$ \\
Lapachol & $\cdot \mathrm{CH}_{2} \cdot \mathrm{CH}: \mathrm{C}\left(\mathrm{CH}_{3}\right)_{2}$ & $0 \cdot 300$ \\
Lomatiol & $. \mathrm{CH}_{2} \cdot \mathrm{CH}: \mathrm{C}\left(\mathrm{CH}_{3}\right) \mathrm{CH}_{2} \mathrm{OH}$ & $0 \cdot 300$ \\
Hydroxyhydrolapachol &. $\mathrm{CH}_{2} \cdot \mathrm{CH}_{2} \cdot \mathrm{C}\left(\mathrm{CH}_{3}\right)_{2} \mathrm{OH}$ & $0 \cdot 300$ \\
Hydrolomatiol & $\cdot \mathrm{CH}_{2} \cdot \mathrm{CH}_{2} \cdot \mathrm{CH}\left(\mathrm{CH}_{3}\right) \mathrm{CHOH}$ & $0 \cdot 296$ \\
Hydroisolomatiol &. $\mathrm{CH}_{2} \cdot \mathrm{CHOH} \cdot \mathrm{CH}\left(\mathrm{CH}_{3}\right)_{2}$ & $0 \cdot 306$ \\
Dihydroxyhydrolapachol & $\cdot \mathrm{CH}_{2} \cdot \mathrm{CHOH} \cdot \mathrm{C}\left(\mathrm{CH}_{3}\right)_{2} \mathrm{OH}$ & $0 \cdot 308$ \\
Phthiocol &. $\mathrm{CH}_{3}$ & $0 \cdot 299$ \\
\hline
\end{tabular}

Ashley and Raistrick (1938) have isolated from the mycelium of a mould a quinone or semiquinone, Luteoleersin, and the corresponding phenol, Alboleersin, which are readily interconvertible by oxidation and reduction. It is suggested that these substances may form an oxidation-reduction system of biological significance in the life processes of Helminthosporium leersii (Atkinson).

\section{VITAMIN $\mathrm{K}$}

Vitamin $\mathrm{K}$ is necessary for the formation of prothrombin in the body and in Vitamin K deficiency the clotting time of the blood is prolonged. Normally there is sufficient Vitamin K in the diet, and intestinal bacteria can effect its synthesis, but deficiency occurs if intestinal absorption is disorganised in discases such as jaunclice. There is a deficiency of the vitamin in the new-born child and many neo-natal deaths have been ascribed to this deficiency.

Vitamin $\mathrm{K}$ is 3-phytyl-2-methyl-1 : 4-Naphthoquinone and a number of related compounds have similar effects, the synthetic substitute being menadione which has the same structure without the phytyl group. In sweet clover disease animals fed on spoiled clover were found to suffer from hæmorrhages and the blook did not clot after minor injuries. This was traced to the presence in the spoiled clover of dicoumarol. Inspection of the formulæ of Vitamin $\mathrm{K}$ (I) and dicoumarol (II) shows 
their similarity. There is here apparently a competitive inhibition, the dicoumarol ousting the vitamin from its place in the prothrombin formation cycle and a Vitamin $\mathrm{K}$ deficiency is simulated.

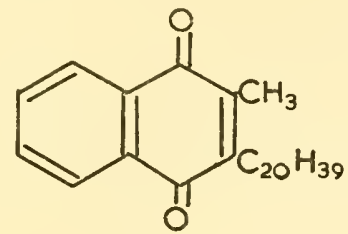

I.

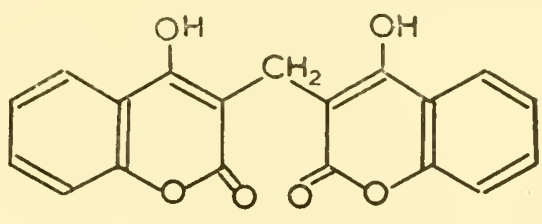

II.

The administration of large doses of aspirin or salicylates sometimes produces intestinal hæmorrhage, possibly due to a similar antagonism, and doses of Vitamin $\mathrm{K}$ are given to relieve the condition.

Vitamin E, tocopherol, has a structure somewhat similar to Vitamin $\mathrm{K}$ and it has been found that sterility caused by administration of the quinone of tocopherol can be prevented by Vitamin K.

Phthiocol from the tubercle bacillus possesses some Vitamin K activity; and both phthiocol and Vitamin $\mathrm{K}$ have a growth stimulating effect on Mycobacterium Johnei (Johne's bacillus). The final example in this complex of interrelationships and antagonisms is in relation to the purple pigment Iodinin (Clemo and McIlwain, 1938). This is obtained from Chromobacterium iodinum and is the di-N-oxide of dihydroxyphenazine, and it is therefore structurally related to pyocyanine. Its structure is, however, also similar spatially to Vitamin K. Iodinin inhibits the growth of a number of organisms especially hæmolytic streptococci and it is found that this inhibition is reversed by Vitamin K. McIlwain's view is that iodinin is inactivated by reduction by the bacteria in conjunction with the antagonising quinone; the problem is to explain why the quinones are more active in this respect than other oxidation-reduction systems.

2-Methyl-1 : 4-naphthaquinone may be determined quantitively by reduction to hydroquinone and titration with $2: 6$-dichlorophenol indophenol. In acid alcohol containing lithium the $\mathrm{E}_{0}$ value was found to be +0.363 using potentiometric methods, whilst with the polarograph the value of $+0.328 \mathrm{v}$. was obtained (Riegel, Smith and Schweitzer, 1940 ; McCawley and Gurchot, 1940 ; Trenner and Bacher, 1941).

\section{DIALURIC ACID - ALLOXAN SYSTEM}

The system dialuric acid-alloxan is a reversible oxidation-reduction system (Biilmann and Bentson, 1928) :

$$
\mathrm{O}+\mathrm{C}_{3} \mathrm{H}_{2} \mathrm{O}_{3} \mathrm{~N}_{2} \cdot \mathrm{CHOH} \rightleftharpoons \mathrm{C}_{3} \mathrm{H}_{2} \mathrm{O}_{3} \mathrm{~N}_{2} \text {. CO. } \mathrm{H}_{2} \mathrm{O}
$$

The reductant (dialuric acid) and oxidant (alloxan) also combine together to form alloxanthine, which is analogous to a meriquinone (described in the section on 
pyocyanine). The system has been studied by Biilmann and Lund (1923), Richardson and Cannan (1929), and Biilmann and Berg (1930). At $30^{\circ} \mathrm{C}$. and $\mathrm{pH} 7 \cdot 0$ the electrode potentials of the system are expressed (in volts) by the formula :-

$$
\mathrm{E}_{\mathrm{h}}=0.06+0 \cdot 03 \frac{[\text { Alloxan }]}{[\text { Dialuric acid }]}
$$

Hence two electrons are concerned in the reaction in accordance with theoretical requirements. Richardson (1932) rejects the view that the system is of biological significance. Hill and Michaelis (1933) find that iron is of importance in the establishment of the potential.

\section{CARBOHYDRATES}

An inert electrode immersed in a sugar solution slowly assumes a negative potential difference with respect to the solution. This potential difference is regarded as being due to an unknown reversible oxidation-reduction system present in the solution. The potential is said to be independent of the nature of the sugar and reaches a value of $-0.21 \mathrm{v}$. at $\mathrm{pH} 7.0$ and at $40^{\circ} \mathrm{C}$. (Goard and Rideal, 1924 ; Aubel Génevois and Wurmser, 1927 ; Preisler, 1927 ; Wurmser and Geloso, 1928, 1929, 1931 ; Nayer, 1929.)

\section{SUCCINATE-FUMARATE}

The system succinate-fumarate appears to be reversible in the presence of the appropriate enzyme (occurring in muscle and B. coli.).

$$
\mathrm{COOH} . \mathrm{CH}: \mathrm{CH} . \mathrm{COOH}+\mathrm{H}_{2} \rightleftharpoons \mathrm{COOH} \cdot \mathrm{CH}_{2} \cdot \mathrm{CH}_{2} \cdot \mathrm{COOH} \text {. }
$$

The system may be readily studied by the methylene blue technique in Thunberg (1921) vacuum tubes. The possible importance of the system depends on the fact that fumarate may act as hydrogen acceptor in bacterial systems and this accounts for some bacterial respiration processes. The constant for the system is stated to be, $\mathrm{E}_{0}=+0.005 \mathrm{~V}$. (Thunberg, 1925). Lehmann (1930) could obtain a readily reproducible electrode potential in the succinate-fumarate-succinic dehydrogenase system only in the presence of oxidation-reduction indicators, the potential observed being the same as that obtained by Thunberg. Wurmser and de Boe (1932) investigated the lactic acid-pyruvic acid system (in the presence of a bacterial autolysate) and observed a normal potential of $-0 \cdot 2 \mathrm{v}$. (See also Barron and Hastings, 1934; Baumberger, Jürgensen and Bardwell, 1932).

Laki (1937) finds the oxidation-reduction potential of the malic-oxaloacetic acid system to be $-0.169 \mathrm{v}$. at $\mathrm{pH} 7$ which approximates to that of the lactic-pyruvic acid systen and much lower than the succinate-fumarate level. Nevertheless, in muscle oxaloacetic acid is reduced more rapidly than fumaric acid.

The $\beta$-hydroxybutyric: acetoacetic acid system has been found to be a reversible oxidation-reduction system in the presence of tissue preparations and the normal potential at $\mathrm{pH} 7$ is given as $0.282 \mathrm{v}$. by Green, Dewan and Leloir (1937) and $-0.293 \mathrm{v}$. by Hoff-Jorgensen (1938). 
Tissues also catalyse the $a$-hydroxyglutaric: $a$-ketoglutaric acid reaction giving a reversible system with a normal potential of $-0.07 \mathrm{v}$. at $\mathrm{pH} 7$.

The alanine: ammonium pyruvate system in the presence of kidney $d$-amino oxidase and Nile blue (as a carrier) has $\mathrm{E}_{0}{ }^{1}-0.066$ v. at $\mathrm{pH} 7 \cdot 3$ (W urmser and FilittiWurmser, 1938).

\section{ADRENALINE}

Ball and Clark (1931) have investigated the adrenaline system; they plotted potential-time curves of mixtures of oxidant and reductant and by extrapolation obtained a value for the potential at zero time. The potentials characteristic of the system are closely similar to those of the closely related pyrocatechol system, but the stability is lessened by the presence of the side chain. It is suggested that the reduction potential of tissues is such as to protect the adrenaline from oxidation and rapid destruction.

Ball and Chen (1933) emphasise the instability of the oxidant of adrenaline and related compounds and give as the potential of the half-oxidised system $\left(\mathrm{E}_{0}{ }^{1}\right)$ at $\mathrm{pH} 7 \cdot 0$ a value of $+0 \cdot 38 \mathrm{v}$.

These workers measured the instability of a number of substances by observing the alteration of the electrode potential with time. Table 14 shows the alteration in potential (given in millivolts per second) of catechol and adrenaline in solutions of different $\mathrm{pH}$. The more unstable the system, of course, the greater is the change,

$-\frac{d E_{h}}{d t}$

TABLE 14

$\mathrm{E}_{\mathrm{o}}^{\prime}$ Values and Instability Factors of Catechol and Adrenaline at different $\mathrm{pH}\left(30^{\circ} \mathrm{C}\right.$.

\begin{tabular}{|c|c|c|c|c|}
\hline \multirow[b]{2}{*}{$\mathrm{pH}$} & \multicolumn{2}{|c|}{ Catechol } & \multicolumn{2}{|c|}{ Adrenaline } \\
\hline & $\begin{array}{l}E_{o}^{\prime} \\
\text { v. }\end{array}$ & $\begin{array}{l}-\frac{\mathrm{d} \mathrm{E}_{\mathrm{h}}}{\mathrm{dt}} \\
\mathrm{mv} / \mathrm{sec} .\end{array}$ & $\begin{array}{l}E_{o}^{\prime} \\
v .\end{array}$ & $\begin{array}{l}-\frac{\mathrm{d} \mathrm{E}_{\mathrm{b}}}{\mathrm{dt}} \\
\mathrm{mv} \cdot / \mathrm{sec} .\end{array}$ \\
\hline $0 \cdot 29$ & $0 \cdot 772$ & $0 \cdot 033$ & $0 \cdot 791$ & $0 \cdot 006$ \\
\hline $1 \cdot 28$ & 0.714 & 0.011 & $0 \cdot 733$ & $0 \cdot 03$ \\
\hline $4 \cdot 07$ & 0.547 & $0 \cdot 011$ & $0 \cdot 556$ & $15 \cdot 0$ \\
\hline $6 \cdot 08$ & $0 \cdot 427$ & $0 \cdot 040$ & $0 \cdot 430$ & $30 \cdot 0$ \\
\hline $7 \cdot 66$ & $0 \cdot 333$ & $1 \cdot 0$ & $0 \cdot 345$ & $150 \cdot 0$ \\
\hline $9 \cdot 28$ & $0 \cdot 253$ & $9 \cdot 0$ & - & - \\
\hline $10 \cdot 49$ & $0 \cdot 199$ & $29 \cdot 8$ & - & - \\
\hline $12 \cdot 07$ & $0 \cdot 111$ & $38 \cdot 2$ & - & 一 \\
\hline
\end{tabular}

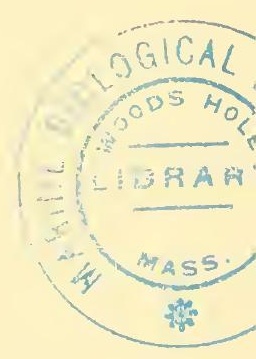

It will be noted that there is a general increase in instability as the systems become more alkaline. In table 15 are given the instability factors (alterations of potentials with time) of a number of related compounds studied by Ball and Chen. 
TABLE 15

E。 Values and Instability Factors of Various Compounds ( $\mathrm{pH} 1 \cdot 3 ; 30^{\circ} \mathrm{C}$.)

\begin{tabular}{|c|c|c|c|c|c|c|}
\hline \multicolumn{5}{|c|}{ Reductant } & \multirow{2}{*}{$\begin{array}{l}\mathrm{E}_{\circ}(\mathrm{v} .) \\
0.792\end{array}$} & \multirow{2}{*}{$\frac{-\frac{d E_{h}}{d t}(\mathrm{mv} \cdot / \mathrm{sec} .)}{0.011}$} \\
\hline Catechol .. & $\cdots$ & $\cdots$ & $\cdots$ & $\ldots$ & & \\
\hline Adrenaline & & $\ldots$ & $\ldots$ & $\ldots$ & $0 \cdot 809$ & $0 \cdot 03$ \\
\hline Dihydroxypheny & lala & & $\ldots$ & $\ldots$ & $0 \cdot 800$ & $0 \cdot 28$ \\
\hline Epinine $\quad \ldots$ & $\ldots$ & $\ldots$ & $\ldots$ & $\ldots$ & $0 \cdot 788$ & $0 \cdot 007$ \\
\hline Norhomoepineph & arine & $\ldots$ & ... & ... & 0.822 & $0 \cdot 004$ \\
\hline Adrenalone & $\ldots$ & $\ldots$ & ... & $\ldots$ & $0 \cdot 909$ & $2 \cdot 8$ \\
\hline Protocatechuic A & Acid & $\ldots$ & ... & $\ldots$ & $0 \cdot 883$ & 0.07 \\
\hline & & hyl est & & $\ldots$ & $0 \cdot 884$ & $0 \cdot 03$ \\
\hline Pyrogallol & $\ldots$ & $\ldots$ & ... & $\ldots$ & 0.713 & $37 \cdot 0$ \\
\hline Gallic Acid & $\ldots$ & $\ldots$ & ... & ... & $0 \cdot 799$ & $37 \cdot 0$ \\
\hline Gentisinic Acid & $\ldots$ & $\ldots$ & $\ldots$ & ... & $0 \cdot 793$ & $8 \cdot 3$ \\
\hline ,, , , & eth. & ester & ... & ... & $0 \cdot 793$ & $0 \cdot 15$ \\
\hline Benzohydroquine & one & $\ldots$ & ... & $\ldots$ & $0 \cdot 696$ & - \\
\hline
\end{tabular}

It is suggested by Heard and Welch (1935) that adrenaline is stabilised in the body by ascorbic acid.

Noradrenaline has been shown to be the sympathetic nerve impulse transmitter (von Euler, Blaschko, Holton).

\section{OXYTOCIC HORMONE OF PITUITARY GLAND}

Gulland and Randall (1935) find that the oxytocic principle of the posterior lobe of the pituitary gland is a reversible oxidation-reduction system.

Oxidation-reduction indicator dyes were reduced in an atmosphere of nitrogen and added to the hormone. Those dyes which reduced the potential to about $\mathrm{E}_{\mathrm{h}}$ $-0.11 \mathrm{v}$. had the maximum inactivating effect, bringing the oxytocic activity down to 50 per cent. of its original value. Reduced dyes which reduced the potential to leveis either above or below $-0 \cdot 11 \mathrm{v}$. had less effect on the activity, and both the least highly reducing dyes and the most highly reducing dyes had no effect at all upon the potency. The curves relating the fall in activity to the electrode potential of the system had the usual S-shape seen in percentage reduction:elcctrode potential curves.

Catalytic reduction with hydrogen destroys the activity irreversibly, possibly owing to its intense effect, buc electrolytic reduction results in a slow loss of activity some of which is slowly regained on oxygenation. Hydrogen sulphide reduces the activity to some 45-55 per cent. of its original value and oxygenation effects partial reactivation. Sulphur dioxide and hydrogen sulphide, both at $\mathrm{pH} 3 \cdot 5$, lower the activity, and this change is followed by reactivation, and finally by inactivation as the action of the gas is prolonged. Sodium cyanide and sodium sulphite destroy the activity irreversibly. This effect recalls the reaction of disulphide groups with sodium cyanide :-

\section{$\mathrm{RSSR}+\mathrm{NaCN} \rightarrow \mathrm{RSNa}+\mathrm{RSCN}$}

The RSCN compound cannot be reoxidised to RSSR, and, therefore, its formation results in disappearance of disulphide groups. 
In order to explain these facts, Gulland and Randall put forward a very interesting suggestion which is not claimed to be fully proved but which is nevertheless supported by much of the experimental evidence. It is suggested that the oxytocic hormone contains two reversible oxidation-reduction groups, at least one of which may be a disulphide group. On this view the hormone is fully active when both groups are oxidised; when one group is reduced the activity is decreaserl in one half ; and, most surprising of all, when both groups are reduced full activity is restored. It is to be hoped that further evidence will accumulate to test this interesting hypothesis. (See also Sealock and du Vigneaud, 1935.)

\section{CHORIONIC GONADOTROPIC HORMONE}

The activity of the hormone is lowered by oxidation and restored by reduction. One electron is concerned in the oxidation-reduction reaction, which has the $\mathrm{E}^{\mathrm{l}}$ value at pH 5.9 of $+0 \cdot 354 \mathrm{v}$. (Bowman, 1941).

\section{STARCH IODINE POTENTIALS}

Starch can be separated into two fractions by treatment of hot solutions with alcohols (Schoch, 1945). Amylose, which crystallises from the solution, is the longchained fraction which gives a blue colour with iodine, whilst amylopectin, which remains dissolved, has a branched chain structure and with iodine yields a reddish purple colouration. It is possible to determine the amount of amylose in starch by a

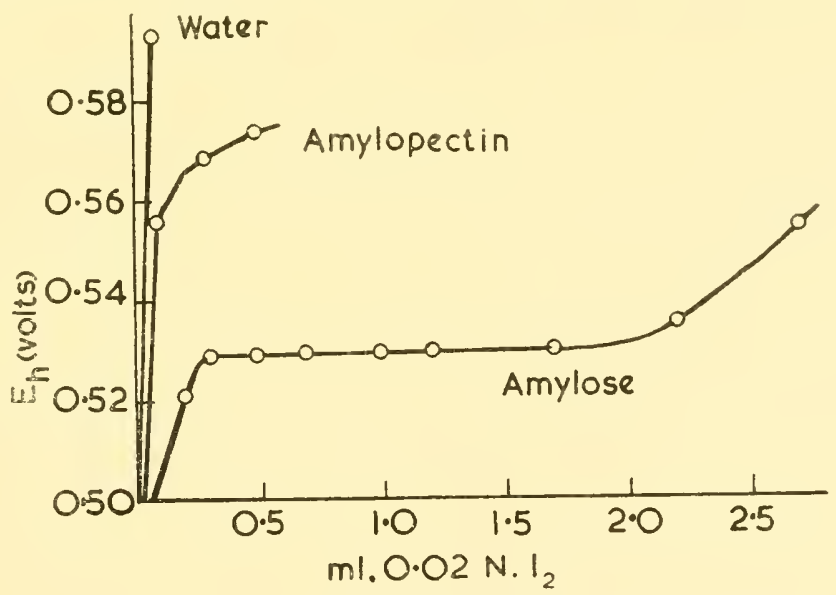

FIG. 15

Starch Iodine Potentials

potentiometric method. (Bates, French and Runale, 1943.) This depends upon the effect of starches on the electrode potential of the iodine : iodide cell. 'Two effects are shown by the results; an absorption of iodine by amylopectin fractions and some more firmer form of linking with amylose. When iodine solution is added stepwise to a dilute iodide solution containing amylopectin there is a gradual rise in potential, the curve differing little from that observed in the absence of starch; but with amylose 
the first additions of iodine have little effect on the potential, but there is a point of inflection when further iodine produces an abrupt rise, the curve afterwards smoothing out asymptotically with the amylopectin curve. The difference in behaviour of the two fractions is great enough to enable the potentiometric titration to be used for the determination of the amount of the fractions in starch samples. Measurement of the colours produced with iodine by the two fractions by photometric methods is less sensitive.

\section{BIO-LUMINESCENCE}

In the presence of the enzyme, luciferase, luciferin is slowly oxidised with developmient of luminescence, but since the reaction appears not to be thermodynamically reversible electrode potential measurements cannot be applied to its investigation in a direct manner (Harvey, 1926). Korr (1936) concludes that the reaction is reversible but that oxyluciferin is unstable, and that the potential reached in the system is close to that of quinhydrone.

Anderson (1936) has studied the reversible reaction of luciferin with oxidising agents, and Harvey (1940) the oxidation-reduction reactions of luciferin in the presence of dehydrogenases and luciferase. Cyanide was found to inhibit the luminescence of symbiotic bacteria but not the self luminosity of animals.

McElroy and Ballentine (1944) find that purified luciferin contains acid-labile phosphate which is converted to inorganic phosphate during luminescence. Bioluminescence is suggested to be almost a reversed photosynthesis whereby the group $\mathrm{R} \cdot \mathrm{CO} \cdot \mathrm{CH}_{2} \mathrm{OH}$ is oxidised in four steps to $\mathrm{R} \cdot \mathrm{COOH}$. The luminescence of Photobacterium phosphoreum is inhibited by blue light (Kluyver, van der Kirk and van der Burg, 1942) probably due to photochemical inactivation of dehydroluciferin. It is suggested that this may be a vitamin $K$ derivative and not of the coenzymeflavin type as suggested by McElroy and Ballentine (1944) and Johnson and Eyring, (1944). Quinine inhibits bacterial luminescence. (Johnson and Schneyer, 1944.) For reviews on bioluminescence, see Harvey (1941) and Johnson and others (1945).

\section{POTENTIALS OF CELLULAR CONTENTS}

A number of attempts have been made to determine the oxidation-reduction condition in the interior of cells by micro-injection of dyes and by diffusion of dyes into the interior of the cell. These experiments, naturally, are subject to the errors involved in the use of oxidation-reduction indicators, amongst which the following seem pertinent:-

(i) Damage to the cell by the dye or by injection. Although the cell may survive, the injury may have altered the electrode potential. Either the oxidised or reduced form of the dye, or both, inay be toxic.

(ii) The dye may catalyse biological oxidations (or act as oxygen carrier) and hence alter equilibrium.

(iii) The caparity of the dye system may be so large, compared with the system, that equilibrium may be disturbed, and the time involved for the reattainment of equilibrium may be very long.

(iv) 'The properties of the dye may be altered by combination with cellular contents, ete. 
Attempts to override some of these difficulties have been made by using a series of different dyes, both in the oxidised and reduced form, and by observation of the cells for considerable periods. Nevertheless considerable discrepancies still remain to be explained.

There is a considerable body of opinion that the electrode potential of the cell interior has little significance. It is certainly difficult to consider the conditions of the cell interior without taking account of the medium surrounding the cell.

Many of the results obtained with cells have been quoted in terms of rH, which, as shown in a previous chapter, involves unjustifiable assumptions concerning the effect of $\mathrm{pH}$ on the electrode potential.

The Needhams (1925, 1926) and Rapkine and Wurmser $(1926,1927)$ working witl various cells, including eggs of Parencentrotus lividus, Asterias glacialis, Ascidia mentala, and Sabellaria alveolata; and Amceba proteus, Nyctotherus cordiformis, and salivary gland cells of larvæ, observed, under aerobic conditions, $\mathrm{rH}$ of $19-22$ at $\mathrm{pH}$ $6 \cdot 6$ to $7 \cdot 6$. Cohen, Chambers and Reznikoff (1928), Chambers, Pollack and Cohen (1929) and Chambers, Cohen and Pollack (1931) observed in cells under aerobic conditions an $\mathrm{rH}$ as low as $12(-0.06$ v.). The Needhams state that aerobic Amobae have well poised potentials not lowered under anaerobic conditions. This is disputed by Chambers, Pollack and Cohen who find that the $\mathrm{rH}$ is lowered under anaerobic conditions. Rapkine and Wurmser (1926) claim that the nucleus has the same rH as protoplasm, but Chambers, Pollack and Cohen (1929), using the immature starfish egg, comment on the difficulties of this work. They found that many dyes stained the nucleus and all proved toxic, and they could draw no conclusions from the results. Chambers, Cohen and Pollack (1931) note the toxicity of dyes to echinoderm ova.

Dixon (1926) emphasises the difficulties in the use of dyes and points out that non-sulplronated dyes may be reduced by cells but not the sulphonic dyestufis so that the chemical constitution of the indicator dye affects the results. He further underlines the time factor in the use of dyes so that unless the time of observation is very long, equilibrium will not have been reached by the end of the experiment, since the dye will still remain partially in its original oxidised condition.

Turning to green cells, Brooks (1926) with the marine Alga valonia found the cell juice to have $\mathrm{rH} 16$ to 18 , whilst that of the protoplasm was rather undefined. Rapkine and Wurmser (1926) found that spirogyra cells were of $\mathrm{rH} 14$ to 16 at pH 6 .

Cohen and Chen (1933) injected oxidised and reduced dyes into Amoba dubia, kept under anaerobic conditions, with the following results :-

TABLE 16

\begin{tabular}{|c|c|c|c|}
\hline Indicator & $\begin{array}{c}\mathrm{E}_{\text {。 at }} \mathrm{pH} 7 \cdot 0 \\
\text { volt }\end{array}$ & Oxidant in cell & $\begin{array}{l}\text { Reductant } \\
\text { in cell }\end{array}$ \\
\hline 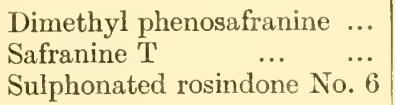 & $\begin{array}{l}-0.260 \\
-0.289 \\
-0.380\end{array}$ & $\begin{array}{l}\text { Partly reduced } \\
\text { Not ", }\end{array}$ & $\begin{array}{c}\text { Reoxidised } \\
, " \\
,\end{array}$ \\
\hline
\end{tabular}

The $\mathrm{E}_{\mathrm{h}}$ of the cell interior under anaerobic conditions would thus appear to be about -0.25 to $-0.3 \mathrm{v}$. It has been found by Beck (1933) that acids and bases 
which penetrate into the cell interior of starfish eggs $\left(\mathrm{CO}_{2}\right.$ and $\left.\mathrm{NH}_{2}\right)$ affect the $\mathrm{pH}$ and hence the $\mathrm{E}_{h}$ of the cell whilst $\mathrm{HCl}$ and $\mathrm{NaOH}$ which are non-penetrating do not. Machlis and Green (1933) using starfish sperm concluded that many of the more highly reducing dyes were reduced by enzyme action and that the anaerohic potentials investigated may be anenable to thermodynamic treatment but that aerobic potentials as measured in dye experiments did not correspond to an intrinsic property of the cell.

It is evident that the results obtained by different workers by introducing artificial dyes into cells are somewhat confused and contradictory. Evidence as to the oxidation-reduction conditions of the cell interior may be obtained by observation of the behaviour of naturally cccurring pigments which are normal constituents of the cell. Some of the disadvantages inherent in the use of dyes are not encountered when considering natural pigments in their native cells, but other difficulties, due to the abnormal behaviour of pigments in the presence of other cellular constituents may arise.

Hermidine occurs in green shoots, etc., of Mercurialis perennis and is at least 95 per cent. reduced, so that at $\mathrm{pH} 7.6$ the $\mathrm{E}_{\mathrm{h}}$ of the cells must he -0.09 volt, or more negative than this (Cannan, 1926).

Echinochrome, on the other hand, which occurs in many echinoderms is mainly in the oxidised condition. So that, assuming the $\mathrm{pH}$ to be $7 \cdot 7$, the $\mathrm{E}_{\mathrm{b}}$ of cells containing echinochrome must be less negative than $-0.2 \mathrm{v}$. if the pigment is at least 99 per cent. oxidised (Cannan, 1927).

In the nudibranch Chromodoris zebra, the pigment is mainly in the oxidised form so that the potential must be less negative than $-0 \cdot 1 \mathrm{v}$. (Preisler, 1930).

\section{TABLE 17}

\section{Approximate Electrode Potentials of Biological Systems}

(In the case of pigments, etc., the potential of the half reduced system, $\mathrm{E}_{\circ}^{\prime}$ at $\mathrm{pH} 7 \cdot 0$ is given. All the results are quoted in volts.)

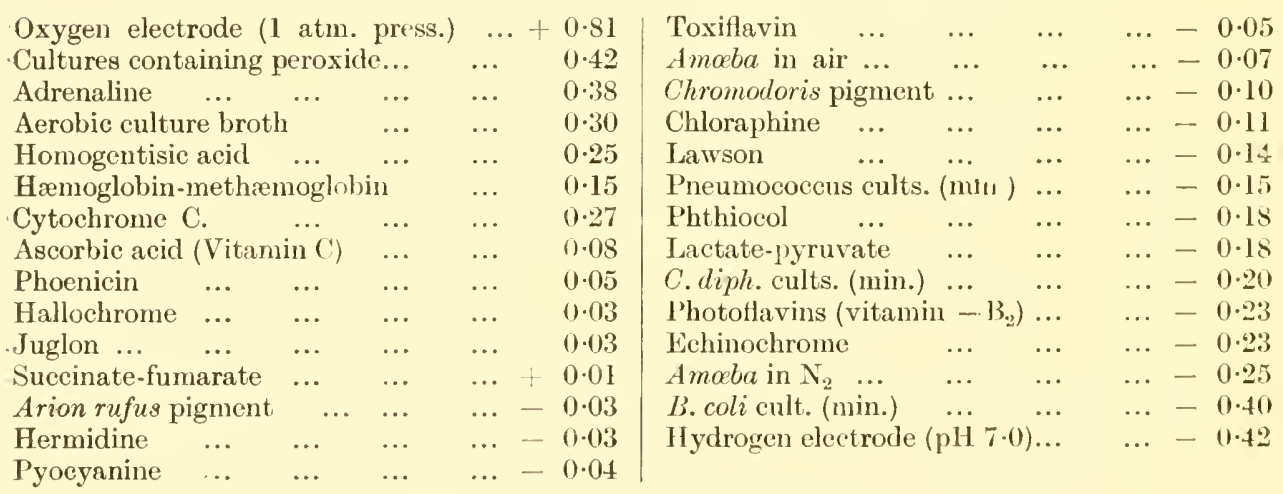

\section{TISSUE AND CELL SUSPENSIONS}

Ehrlich (1885) injected dyes into an animal and examined the condition of the dye in various organs of the animal immediately after death and so obtained some idea of the oxidation-reduction conditions of different tissues, but the significance 
of these vital-staining methods is somewhat ambiguous. Investigations of the oxidation-reduction conditions of tissues have been reported by Aubel, Aubertin. Deloyer, Mauriac, Pincussen, Redslob, Reiss, Roche, Seitz, Vellinger, Vlès, Wurmser. and others.

Suspensions of tissues reduce many oxidation-reduction dyes but Harlen and Norris $(1914,1915)$ found that yeast cells and muscle tissue no longer reduced methylene blue when they had been thoroughly washed; the reducing ability was restored by adding various organic compounds. Harden and Zilva (1915) extended the observation to $B$. coli. 'Thunberg's (1921) vacuum-tube technique depends on these observations. Washed tissues or cells are incubated in an evacuated tube with methylene blue. If the washing has been effective there is no reduction of the methylene blue, but when a suitable "metabolite" is added, the methylene blue becomes colourless showing reduction. The methylene blue, in the presence of appropriate enzyme systems of the cells and tissues, effects oxidation or dehydrogenation of the metabolite by acting as hydrogen acceptor. Thus succinic acid may be oxidised to fumaric acid by methylene blue in the presence of washed tissues. or cells :-

Succinic acid + methylene blue + enzyme $\rightarrow$ Fumaric acid + leuco-methylene blue.

A considerable volume of work on these lines has been published by Quastel, Stephenson, Whetham, Wooldridge and others using suspensions of washed B. coli. These washed bacteria were originally described as "resting bacteria " but the variable damage caused by the washing process led Kendall, Friedemann and Ishikawa (1930) to the conclusion:- "Finally it must be admitted that the procedure for obtaining 'resting' bacteria is not quantitative. Attempts to correlate chemical activity with density of suspension were not successful." This and the tendency of the organism to proliferate (Sandiford and Wooldridge, 1931) has led to caution in use of the term "resting" bacteria. The toxic effect of basic dyes on enzymes. (Quastel and Wheatley, 1931) also affects the conclusions reached.

In many of the experiments quoted above the extraneous and unknown effect of methylene blue or other dye is included and Clark and his collaborators (1926) have performed similar experiments in the absence of dyes and observed the oxidation-reduction potentials established. In this way the capacity-effect of the dye and other possible effects are obviated.

When pieces of fresh tissue, such as minced liver, or cell suspensions, e.g., yeast cells, were transferred to buffer solutions kept under anaerobic conditions the oxidation-reduction potential fell to a level of about $\mathrm{E}_{\mathrm{h}}-0.2$ volt, which indicates an intense reducing condition. In the presence of a dye, such as methylene blue, the fall in potential was slower as the oxidised form of the dye had first to be reduced to the leuco-form before the potential could fall below the potential corresponding to the oxidised form of the dye.

When the tissue or cells had been repeatedly washed before suspension in buffer solutions the electrode potential became ill-defined, and the more complete the washing the more indefinite was the potential, but when " metabolites" such as sodium succinate were added the characteristic drift of potential towards a negative (reducing) level was observed. In this case again the addition of dyes, such as methylene blue, in the oxidised condition, retarded the establishment of reducing 
conditions, as would be expected. Results pointing in the same direction are obtained by both potential measurements and dye methods but effects are complicated in the latter case by the poising action and capacity factor of the dyes.

Methylene blue is a thiazine dye of the following formula :-

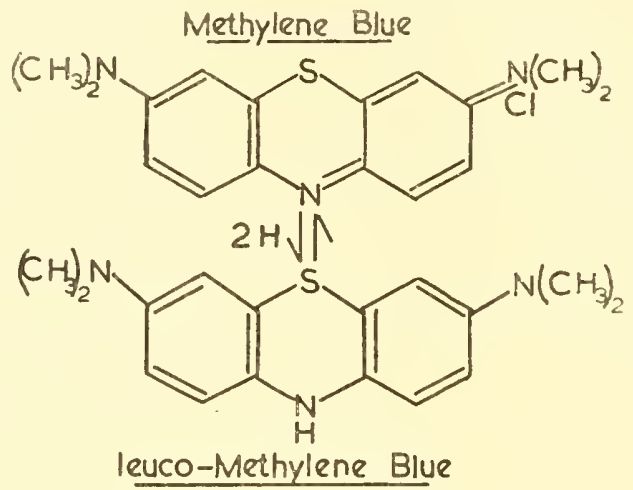

Tetrathionate has been added to culture media to assist in the isolation of Salmonella. A number of coliform organisms possess an enzyme tetrathionase catalysing the interconversion of thiosulphate and tetrathionate in the presence of hydrogen donators or acceptors.

$$
\mathrm{H}_{2} \mathrm{~S}_{4} \mathrm{O}_{6}+2 \mathrm{H} \rightleftharpoons 2 \mathrm{H}_{2} \mathrm{~S}_{2} \mathrm{O}_{3}
$$

Jebb (1949) has found that when a coliform organism with tetrathionase activity was added to reduced nile blue in a Thunberg tube the nile blue regained its colour due to transference of hydrogen to the tetrathionate. Nile blue is one of the oxazine dyes which are similar in constitution to thiazine dyes like methylene blue, but in which the sulphur atom in the ring is replaced by oxygen. Nile blue is reduced at a lower oxidation-reduction potential than methylene blue.

A variation of the dye decolourisation technique has been used by Kun and Abood (1949). Triphenyltetrazonium chloride is reducible to a red insoluble dye, so that when it is added to a dehydrogenase system the red precipitate can be separated, dissolved in an organic solvent and determined colorimetrically and photometric determinations directly on the reduced system, in the Thunberg tube as in the methylene blue technique, are unnecessary for quantitative results.

Some experiments on passing nitrogen through suspensions of washed bacteria have been described by Yudkin (1935). He found, as would be expected, slow drifts of potential and the greater the damage to the cells by storage the more definite were the potentials observed. Moribund bacteria in the absence of an appropriate culture medium cannot establish an electrode potential, but a certain amount of lysis of dead bacteria occurs during storage. The autolysed cells liberate sufficient nutrient material for the cells to develop, and ma nifest some of their normal metabolic activities. The mechanism of establishment of reducing conditions in growing bacterial cultures is discussed in the next chapter.

Reiss and Vellinger report experiments on the effect of the electrode potential of the medium on the development of fertilised eggs of the sea-urchin (Paracentrotus 
lividus) and of Sabellaria alveolate. The eggs did not develop when the potential was below about $+0.15 \mathrm{v}$. or above +0.65 to $0.7 \mathrm{v}$. Ordinary sea-water had a potential of $+0 \cdot 25 \mathrm{v}$. Below $\mathrm{E}_{\mathrm{h}}+0 \cdot 15 \mathrm{v}$. the development of the eggs was reversibly arrested but above $+0 \cdot 65 \mathrm{v}$. the cells were irreversibly damaged.

Reiss (1931) has observed the slowing down of the cardiac rhythm of a marine ascidian (Clavelina lepadiformis Muill.) when the $\mathrm{rH}$ of the medium was reduced below 20 .

Activation of eggs without sperm fertilisation leading to the initial stages of artificial parthenogenesis has been reported by Brooks (1947) who finds that various oxidation-reduction potential indicator dyes activated eggs of Urechis cando and Strongylocentrotus purpuratus in sea-water and suggests that there is a relationship between the activating effect and oxidation-reduction potential of the dye.

\section{TUMOURS AND TISSUE CULTURES}

In an investigation of tissue cultures it was found that the growth of embryonic chick heart tissue was, in general, the poorer the lower the electrode potential of the culture medium. Mitosis and migration of cells had almost entirely ceased at $\mathrm{E}_{\mathrm{h}}-0.03 \mathrm{v}$. (Havard and Kendal, 1934). A regression of transplantable tumours in rats and mice has been observed when methylene blue was injected into the tumour, but not with certain other oxidation-reduction potential indicator dyes (Brooks, 1934.) Some observations have been made upon the effect of certain oxidationreduction potential indicators on the respiration and glycolysis of tumour and normal tissues (Elliott and Baker, 1935). In low concentrations (1 in 100,000) the dyes generally are able to stimulate respiration by virtue of their catalytic oxygen-carrying effect. In higher concentrations ( 1 in 1,000) there is a distinction between the behaviour of normal and tumour tissues. These stronger solutions of dyes inhibit the oxygen uptake of slices of brain, testis, kidney and retina both in the presence and absence of glucose. In the case of tumour tissue the dyes inhibit oxygen uptake in the absence of glucose, but in the presence of glucose the oxygen uptake is accelerated. With liver slices the oxygen uptake is accelerated in either the presence or absence of glucose. Certain of the dyes investigated increase the aerobic glycolysis of tumour slices and to a less extent of tissue slices. The electrode potential and the chemical constitution of the dye are of importance in this respect.

Among papers on the oxidation-reduction potential relationships of tissues are the effect of dyes on tumour respiration, (Dickens) the potential in muscle, (Uchimura, 1937) the effect on neural growth (Waddington, Needham and Brachet, 1936) and on skin (Kelley and Williams).

\section{YEAST PREPARATIONS}

It has already been stated in the previous section that yeast cells which have been washed free from "metabolites" are no longer able to reduce dyes (Harden and Norris, 1914) or effect the usual fall in electrode potential (Cannan, Cohen and Clark, 1926). Addition of a suitable metabolite restores these activities of yeast cells. Boyland (1930) found that addition of dyes, e.g., methylene blue, which have an $\mathrm{E}_{0}{ }^{1}$ value at $\mathrm{pH} 6.0$ of $-0.05 \mathrm{v}$. to $+0.10 \mathrm{v}$. may accelerate yeast fermentation by acting as oxygen carriers. Lipmann (1934) found that in the presence of 
dyes the potential during rapid fermentation fell to $+0.03 \mathrm{v}$. or $+0.04 \mathrm{v}$. at $\mathrm{pH} 6.4$, various phosphorus compounds accelerating the fall in potential. Phospho-glyceric acid was found to be most effective. When the phosphorus compound was used up the potential rose, but in the case of arsenates, which also accelerated the potential fall, there was no rise in potential as long as any glucose remained unfermented.

Some interesting observations on the electrode potentials in cultures of different yeasts have been made by Kluyver and Hoogerheide (1934). They inserted an electrode in a Warburg manometer and investigated the potentials reached under aerobic and anaerobic conditions. In the case of nearly all yeasts the potentials established under anaerobic conditions were from $+0 \cdot 08 \mathrm{v}$. to $+0 \cdot 10 \mathrm{v}$. at $\mathrm{pH} 5 \cdot 4$. irrespective of conditions in the culture. In aerobic cultures the potential did not fall to as low a level and differences in conditions of fermentation and in different species of yeast were reflected in the potentials reached, as shown in table 17.

Fromageot and Desnuelle (1935) made some observations by means of indicators on the potential reached in top yeast fermentations carried out anaerobically, and found at $\mathrm{pH} 6.4$ potentials ranging from $-0.145 \mathrm{v}$. to $-0.185 \mathrm{v}$. Certain reduction reactions which are thermodynamically possible at this $\mathrm{E}_{\mathrm{h}}$ level were found to occur.

The keeping qualities of beer have been stated to be dependent upon the electrode potential (Clerck, 1934; Hartong, 1934; Mendlik, 1934; Pozen, 1935).

TABLE 18

Lowest Potentials reached ix Aerobic Cultures of Different Yeasts. etc.

\begin{tabular}{|c|c|c|c|c|c|c|c|}
\hline & Yeas & & & Substate & Conditions & $\mathrm{Q}_{02}: \mathrm{Q}_{\mathrm{C} 02}^{02}$ & $\mathrm{E}_{\mathrm{h}}$ \\
\hline $\begin{array}{l}\text { S. cerevisiae } \\
\text { Cryptococcus derm } \\
\text { Torula candida } \\
\text { S. marxianus } \\
\text { S. cerevisiae } \\
\text { S. cerevisiae }\end{array}$ & $\begin{array}{l}\cdots \\
\cdots \\
\cdots \\
\cdots \\
\cdots\end{array}$ & $\begin{array}{l}\cdots \\
\cdots \\
\cdots \\
\cdots \\
\cdots \\
\cdots\end{array}$ & \begin{tabular}{l|}
$\ldots$ \\
$\ldots$ \\
$\cdots$ \\
$\cdots$ \\
$\cdots$ \\
$\cdots$
\end{tabular} & $\begin{array}{l}\text { Lactate } \\
\text { Glucose } \\
\text { Glucose } \\
\text { Glucose } \\
\text { Glucose } \\
\text { Glucose }\end{array}$ & $\begin{array}{l}\text { Aerobic } \\
\text { Aerobic } \\
\text { Aerobic } \\
\text { Acrobic } \\
\text { Acrobic } \\
\text { Anaerobic }\end{array}$ & $\begin{array}{c}\propto \\
11 \cdot 5 \\
7 \cdot 5 \\
5 \cdot 0 \\
0 \cdot 18 \\
0\end{array}$ & $\begin{array}{l}+0 \cdot 31 \mathrm{v} . \\
0 \cdot 28 \\
0 \cdot 27 \\
0 \cdot 26 \\
0 \cdot 16 \\
0 \cdot 09\end{array}$ \\
\hline
\end{tabular}

The oxidation-reduction potential reached in yeast suspensions was found by Fromageot and Bost (1937) to be dependent upon the dye added, but Kakukawa (1938) found the potential reached in living yeast suspensions to be independent of the presence of indicator dyes. Dehydrogenations produced by wood-destroying moulds (Merulius and Fomes) have been studied by Vitucei, Pallares and Nord (1946). Resazurin proved a convenient oxidation-reduction potential indicator and electrode potentials were measured in growing cultures.

\section{WARBURG MANOMETRIC TECHNIQUE}

There is a considerable number of methods of measuring the respiratory activities of tissues, cells, enzyme systems, ete.. dependent upon alterations in pressure when oxygen gas is absorbed and carbon dioxide is liberated. 'The variations in experimental technique to suit individual needs are very numerous, but the general principles are similar. Many workers have made contributions to the technique and papers by Barcroft, Dickens. Elliott, Fenn, Keilin. Krebs. Roughton, Summerson. Thunberg 
and Warburg give a basis for further study. Two monographs on the subject are by Dixon and Umbreit, Burris and Stauffer. In the constant volume apparatus of the Warburg type a flask containing the cell and substrate is attached to a manometer. one end of which is open to the air, whereas in the Barcroft differential manometer each limb of the U-tube manometer is attached to a flask and the difference in pressure developed in the two flasks is measured. In the latter case differences in temperature and atmospheric pressure are automatically compensated, but since there are variations in both the pressure and volume of the flasks the theoretical treatment of the significance of the manometer readings is more complicated. In either case the apparatus is calibrated before the experiment begins.

The amount of oxygen absorbed by the respiring system may be determined directly by absorbing the carbon dioxide produced in alkali so that the pressure changes are due entirely to the oxygen absorption. By carrying out the same experiment in another flask without absorbing the $\mathrm{CO}_{2}$ some measure may be obtained of the $\mathrm{CO}_{2}$ output since the difference between the two flasks should give the volume of $\mathrm{CO}_{2}$ liberated. In order to avoid complications due to $\mathrm{CO}_{2}$ absorption by the contents of the flask, acid may be added from a side tube at the end of the experiment and all the $\mathrm{CO}_{2}$ liberated.

The production of lactic acid by glycolysis may be measured manometrically by carrying out the experiment in a bicarbonate medium when any lactic acid produced will liberate an equivalent amount of carbon dioxide. By using an atmosphere of either oxygen or nitrogen the aerobic and anaerobic glycolysis can be determined.

A micro-manometric method based on the Cartesian diver has been worked out by Linderström-Lang, Boell and Needham. In this method a small bulb is used to contain the respiratory system and the capillary tube leading from the bulb is sealed with a drop of oil. The bulb is loaded so that it just floats in a suitable solution. Gas absorption in the bulb will cause the diver to sink whilst gas evolution will lower the density and cause flotation. The whole apparatus is enclosed in a larger vessel fitted with a manometer and the pressure is adjusted throughout to maintain the diver floating at the same level. The readings on the external manometer reflect changes of pressure in the diver and the respiration of minute amounts of tissue can be followed.

In consideration of respiratory changes the symbol Qo represents the volume of oxygen (in cubic millimetres at $0^{\circ} \mathrm{C}$ and $760 \mathrm{~mm}$. pressure) absorbed in an hour by one milligram of tissue or cells. $\mathrm{Qco}_{2}$ represents the volume of carbon dioxide evolved in the same units. The respiratory quotient is the ratio of carbon dioxide evolved to. oxvgen absorbed :-

$$
\mathrm{RQ}=\frac{\mathrm{QCO}_{2}}{\mathrm{QO}_{2}}
$$

When carbohydrates are oxidised completely:

$$
\mathrm{C}_{6} \mathrm{H}_{12} \mathrm{O}_{6}+6 \mathrm{O}_{2} \rightarrow 6 \mathrm{C}_{2}+6 \mathrm{H}_{2} \mathrm{O}
$$

the $R Q$ is 1 . In the case of fat oxidation the $R Q$ is 0.7 and it is 0.8 when proteins are oxidised.

The symbols $\mathrm{Q}_{\mathrm{A}}{ }^{\circ}$ and $\mathrm{Q}_{\mathrm{A}}{ }^{\mathrm{N}_{2}}$ represent aerobic and anaerobic glycolysis respectively, being the amounts of $\mathrm{CO}_{2}$ liberated from bicarbonate by the lactic acid produced during glycolysis in atmospheres of oxygen and of nitrogen. (Tolumes are in cmm. per $1 \mathrm{mg}$. of cells per $1 \mathrm{hr}$.) 
The manometric technique is capable of an almost infinity of variation. Changes can be made in enzyme systems, substrates, conditions of $\mathrm{pH}$, gaseous environment and temperature, inhibitors (such as cyanide, fluoride, iodoacetate) can be added, and at the end of the experiment microanalyses can be carried out on the reaction products. Discretion in the interpretation of results is necessary and confirmatory studies by other methods are desirable, but the insight gained into many biological processes by the mere recording of the movement of the meniscus in a capillary tube is almost incredible.

\section{Summary of Chapter IV}

Many substances of biological importance including enzymes, vitamins, hormones and pigments behave as oxidation-reduction systems and in a number of cases the biological activity has been correlated with electrode potential behaviour. Oxidation-reduction conditions in cells and tissues, in cell suspensions and in tissue cultures have been investigated. 


\section{CHAPTER V}

\section{METABOLIC CYCLES AND CHAIN REACTIONS}

Such metabolic effects as the conversion of glucose to lactic acid or carbon dioxide are not simple one-stage reactions, but are made up of a complicated series of processes which are interrelated and which require at the appropriate stages the co-operation of many different enzymes, coenzymes and substrates. When the complete enzyme system for each reaction has been assembled at the proper stage in the cycle the necessary energy relationships required fron thermodynamic considerations must be observed, so that one reaction may be coupled with another to provide and absorb the essential free energy changes. In addition the coupling together of reactions is necessary to provide for the gathering together of the substrates and the removal of the reaction products to prevent stagnation by the accumulation of products of the forward reaction.

To summarise therefore: for each of the reactions in the chain to proceed smoothly it is essential to provide :-

(1) Suitable $\mathrm{pH}$, temperature, ionic concentrations.

(2) Synthesis of specific enzyme and coenzyme at the right time.

(3) Production of reactants by previous reaction in chain.

(4) Removal of products by succeeding reactions.

(5) Provision or removal of free energy by coupled reactions.

(6) The bringing together in intimate contact in space of reactants, enzymes, coenzymes, coupled reaction products and free energy simultaneously.

(7) The absence of reaction inhibitors and poisons.

Some of the necessary factors have been considered piecemeal in the preceding chapter and typical metabolic cycles that have been studied in some detail will indicate how some of the isolated facts can be synthesised into a larger scheme even though knowledge is still fragmentary and liable to revision.

Before discussing metabolic eycles it is necessary to consider the important position active phosphate groups play in energy changes and storage in metabolism.

\section{ENERGY RICH PHOSPHATE BONDS}

Lipmann (1941) has been responsible for developing the concept of the importance of energy-rich phosphate bonds in carbohydrate metabolism.

In the first chapter the free energy of chemical reactions was dealt with. It was pointed out that the change in free energy in a reaction is the important factor and not the total heat change. It is possible to have two compounds with the same total energy content, but the reactivity of the two may be entirely different owing to the different distribution of the energy among the various interatomic linkings. If in the breaking of a linkage a large amount of free energy is liberated the group linked will tend to be highly reactive.

The free energy content of the phosphate linking in phosphate esters is comparatively low, of the order of 3,000 calories, and these are designated energy-poor phos- 
phate groups (-ph). On the other hand in adenosine di- or triphosphate energy-rich phosphate bonds $(\sim$ ph) occur with an energy content of some 12,000 calories. In adenosine triphosphate the first phosphate is joined by an energy-poor bond, whilst the second two are joined by energy-rich bonds.

$$
\text { Adenosine }-\mathrm{PO}_{2} \mathrm{H} . \mathrm{O} \sim \mathrm{PO}_{2} \mathrm{H} . \mathrm{O} \sim \mathrm{PO}_{2} \mathrm{H} . \mathrm{OH}
$$

Creatine phosphate and arginine phosphate contain similar $\sim$ ph linkings. Acetyl phosphate and phospho-enol pyruvic acid contain $\sim$ ph groups joined to carboxyl or acidic enol groups.

The importance of these $\sim$ ph groups lies in the fact that cells utilise the free energy of metabolic reactions to build up the linkings, and the free energy can be thus stored to be available when required. The energy required to generate such bonds usually arises from the electron transfers in oxidation-reduction reactions, a change of potential of 0.25 volts giving rise to some 12,000 calories, which is the free energy change involved in the formation or rupture of one $\sim$ ph.

Adenosine triphosphate (ATP) constitutes a principal agent in phosphate transfers; when one $\sim_{\mathrm{ph}}$ is transferred to another compound the diphosphate (ADP) remains and this can be reconverter to ATP by reaction with creatine phosphate. ADP still contains one $\sim$ ph.

The free energy available in $\sim$ ph groups can be utilised for muscular work and for essential metabolic reactions and these $\sim$ ph linkings constitute one of the chief methods of storage of free energy.

The phosphate energy cycle may be diagrammatically represented as follows :-

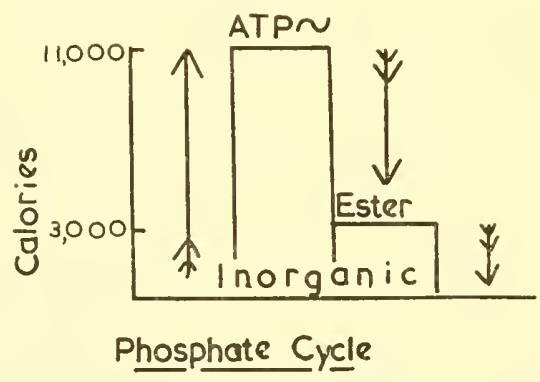

Fig. 16

Phosphate energy cycle

Some of the details of mechanism will be discussed in succeeding pages.

\section{ANAEROBIC MUSCLE GLYCOLYSIS}

The route by which glycogen is converted to lactic acid in muscle by anaerobic glycolysis is shown in Table 19. The reactions shown are as follows:-

(1) Glycogen in the presence of inorganic phosphate is converted by the enzyme phosphorylase to the Cori ester, glucose-1-phosphate. 
TABLE 19

Reaction Chais in Muscle Glycoi,ysis

\begin{tabular}{|c|c|c|c|}
\hline Product & Enzýme & & Cocnzyme \\
\hline $\begin{array}{l}\text { (1) Glycogen } \\
\text { (2) Glucose-1-phosphate } \\
\text { (3) Ghucose-6-phosphate } \\
\text { (4) Fructose-6-phosphate } \\
\text { (5) Fructosediphosphate } \\
\text { (6) Phosphodihydroxyacetone } \\
\text { (7) 3-Phosphoglyceraldehyde } \\
\text { (8) } 1: 3 \text { Diphosphoglyceraldehyde } \\
\text { (9) } 1: 3 \text { Diphosphoglycerate } \\
\text { (10) } 3 \text {-Phosphoglycerate } \\
\text { (11) 2-Phosphoglycerate } \\
\text { (12) Phosphoenolpyruvate } \\
\text { (13) Pyruvic acid } \\
\text { (14) Lactic acid }\end{array}$ & 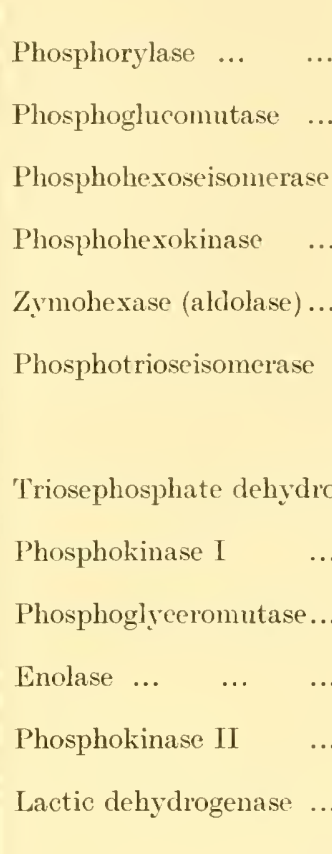 & $\begin{array}{c}\ldots \\
\ldots \\
\ldots\end{array}$ & $\begin{array}{c}\mathrm{SH}, \mathrm{PO}_{1} \\
\mathrm{Mg}, \mathrm{Mn} \\
\mathrm{ATP} \\
\mathrm{Zn,} \mathrm{Cu,} \mathrm{Cd,} \mathrm{Fe} \\
- \\
\mathrm{PO}_{1} \\
\mathrm{CO.I} \\
\mathrm{ADP} \\
\text { Fe, etc. } \\
\mathrm{Mg} \\
\text { ADP } \\
\text { CO.I }\end{array}$ \\
\hline
\end{tabular}

(2) Phosphoglucomutase (activated by Mg or Mn) transforms the Cori ester into the Robison ester, Glucose-6-phosphate.

(3) Phosphohexoseisomerase transforms the Robison ester to the Neuberg ester, Fructose-6-phosphate.

(4) Adenosinetriphosphate is now necessary as coenzyme to convert the Neuberg ester to Fructose diphosphate (Harden and Young ester) in the presence of phosphohexokinase. In this reaction one $\sim$ ph is utilised.

(5) Aldolase (or zymohexase) now splits the molecule giving a mixture of phosphodihydroxyacetone and 3-phosphoglyceraldehyde.

(6) Phosphotrioseisomerase can interconvert the two preceding compounds and as the 3-phosphoglyceraldehyde is consumed in the next reaction more is formed from phosphodihydroxyacetone.

(7) Phosphorylation of 3-phosphoglyceraldehyde occurs in the presence of inorganic phosphate and 1: 3 diphosphoglyceraldehyde is formed, no enzyme having been found to effect this reaction.

(8) An oxidation-reduction reaction now occurs and 1:3 diphosphoglyceric acid, containing one $\sim$ ph is formed. In this reaction triosephosphate dehydrogenase is necessary and also Coenzyme I. The coenzyme is reduced. 
$\mathrm{CH}_{2} \mathrm{O}-\mathrm{ph} . \mathrm{CHOH} . \mathrm{CH}(\mathrm{OH}) \mathrm{O}-\mathrm{ph}+\mathrm{CO} . \mathrm{I} \rightarrow \mathrm{CH}_{2} \mathrm{O}-\mathrm{ph} . \mathrm{CHOH} . \mathrm{COO} \sim \mathrm{ph}+\mathrm{CO} . \mathrm{I} .2 \mathrm{H}$

The accumulation of reduced coenzyme is prevented because this reaction is coupled with a later reaction (No. 13) in the chain, for when pyruvic acid is reduced to lactic acid the reduced coenzyme is reconverted to the oxidised form.

(9) A phospholinase now transfers the $\sim$ ph group to adenosine diphosphate and 3-phosphoglycerate is formed.

(10) Phosphoglyceromutase now transfers the ester phosphate group forming 2-phosphoglycerate.

(11) Enolase (which is activated by Mg and inhibited by fluoride) converts 2-phosphoglycerate to phosphoenolpyruvate which contains one $\sim$ ph.

$\mathrm{CH}_{2} \mathrm{OH} . \mathrm{CHO}-\mathrm{ph} . \mathrm{COOH} \rightarrow \mathrm{CH}_{2}=\mathrm{CO} \sim \mathrm{ph} . \mathrm{COOH}+\mathrm{H}_{2} \mathrm{O}$

(12) A phosphokinase enzyme transfers one $\sim$ ph group to arlenosine diphosphate and by a keto-enol transformation pyruvic acid is formed. $\mathrm{CH}_{2}=\mathrm{CO} \sim \mathrm{ph} . \mathrm{COOH}+\mathrm{ADP} \rightarrow \mathrm{CH}_{2}=\mathrm{COH} . \mathrm{COOH}+\mathrm{ATP} \rightarrow \mathrm{CH}_{3} \mathrm{CO} . \mathrm{COOH}$

(13) The second oxidation-reduction reaction of the chain now occurs. The reduced coenzyme I formed in reaction 8 together with lactic dehydrogenase reduces pyruvic acid to lactic acid.

$$
\mathrm{CH}_{3} \mathrm{CO} . \mathrm{COOH}+\mathrm{CO} . \mathrm{I} .2 \mathrm{H} \rightarrow \mathrm{CH}_{3} \mathrm{CHOH} . \mathrm{COOH}+\mathrm{CO} . \mathrm{I}
$$

(See Baldwin, 1948 for a discussion.)

\section{FREE ENERGY CHANGES OF GLYCOLYSIS}

The net result of the anaerobic glycolysis chain is that in the conversion of one molecule of glucose (from glycogen) to two molecules of lactic acid, one $\sim$ ph bond is absorbed in phosphorylation and four $\sim$ ph bonds are made available. Thus the free energy of three $\sim$ ph bonds or nearly 36,000 calories are accounted for. By calculation of the difference in the free energy contents of glucose and lactic acid there should be 58,000 calories. It is not clear where the missing free energy is to be traced. In the two oxidation-reduction reactions the coenzyme is both reduced and oxidised so that no free energy is involved, and since the oxidation of diphosphoglyceraldehyde and reduction of pyruvic acid occur at similar Eo' levels there should be no free energy change here.

\section{GLYCOGEN AND STARCH SYNTHESIS}

In animals carbohydrate is stored as glycogen and in plants as starch : in each case sugar can be brought into the reaction cycle immediately it is required by the agency of phosphorylase :-

$$
\text { Glycogen }+\mathrm{H}_{3} \mathrm{PO}_{4} \stackrel{\text { Phosphorylase }}{\longrightarrow} \longrightarrow \mathrm{d}-\propto \text {-glucopyranose-1-phosphate }
$$

The reaction is reversible and equilibrium is established between divalent phosphate ions of the inorganic phosphate and ghucose-1-phosphate. In the case of starch the long chained (amylose fraction) is formed and probably some other enzyme is requirect for the formation of the branched amylopectin structure. 
Presumably in vivo for glycogen synthesis the precursor of hexose-1-phosphate is hexose-6-phosphate, formed from glucose by the action of hexokinase in the presence of adenosine triphosphate as phosphate donator. In this case there is a disappearance of free energy since the $\tau$ ph group of ATP is transformed into the energy-poor ester phosphate linkage.

It should be noted that an explanation of the function of insulin is that it inhibits the effect of the anterior lobe of the pituitary gland which antagonises hexolinase, hence stopping glucose phosphorylation and sugar utilisation in the usual glycolytic chain (Cori, Colowick, Himsworth, Young).

\section{MUSCULAR CONTRACTION}

Szent-Györgyi has prepared separate proteins from fresh muscle, actin and myosin, which together form actomyosin. This reacts with ATP liberating inorganic phosphate and setting free the energy of the $\sim$ ph bond and providing the energy for muscular contraction. Thus the whole of the glycogen breakdown chain has been utilised to build up energy-rich phosphate bonds which are available immediately for the energy of muscular contraction. For the regeneration of phosphate linkings the whole glycolytic chain would be too slow for immediate action, but $\sim$ ph bonds are stored in phosphagen which can immediately regenerate ATP from ADP. Meanwhile glycolysis is set in motion for the regeneration of more $\sim$ ph bonds and the glycogen is converted to lactic acid, which is carried back to the liver for resynthesis to glycogen by a reversal of the glycolytic chain of reactions.

\section{YEAST ALCOHOLIC FERMENTATION}

The process of alcohol production from glucose by yeast follows a course closely similar to that of glycolysis, starting from glucose or maltose instead of glycogen; the initial phosphorylation requires hexokinase and ATP. Hexose-6-phosphate is thus formed directly instead of throngh the intermediary of hexose-1-phosphate.

The other difference from muscle glycolysis is at the end of the chain in the breakdown of pyruvic acid which, instead of being reduced to lactic acid, is first decarboxylated to acetaldehyde (and $\mathrm{CO}_{2}$ ) which is then reduced to alcohol. This reduction is effected by alcohol dehydrogenase and is coupled with the oxidation of diphosphoglyceraldehyde to diphosphoglyceric acid, whereby the coenzyme I reduced in the latter reaction is reoxidised in the acetaldehyde reduction. The final reactions, therefore, are :-

$$
\begin{gathered}
\text { Pyruvic acid } \rightarrow \text { Acetaldehyde }+\mathrm{CO}_{2} \\
\text { Acetaldehyde }+ \text { CO.I.2H } \rightarrow \text { Ethyl alcohol }+ \text { CO.I }
\end{gathered}
$$

The energy changes are similar to those discussed in the case of muscle glycolysis.

The flavour, bouquet and some of the physiological effects of alcoholic drinks are due in part to side reactions and to reactions involving nitrogenous materials from the raw materials and yeast cells. 


\section{BACTERIAL GLUCOSE FERMENTATION}

In 1901, Harden found that the fermentation of glucose by Bacillus coli could be represented by the equation:-

2 Glucose $\rightarrow 2$ lactic acid + acetic acid + ethyl alcohol $+2 \mathrm{CO}_{2}+2 \mathrm{H}_{2}$ Variations are observed under different experimental conditions and it would seem that pyruvic acid is formed as in the glycolytic and alcoholic fermentation chains discussed previously, and that the subsequent breakdown of pyruvic acid depends upon the experimental conditions, a $\mathrm{pH}$ below 7 favouring lactic acid formation when phosphate is present in appreciable amount.

With hæmolytic streptococci and pneumococci it was found (Hewitt, 1932) that about 70 per cent. of the glucose was transformed into lactic acid under a variety of experimental conditions, but in the absence of inorganic phosphate glucose breakdown did not oceur.

It is evident that the very different enzyme systems possessed by different micro-organisms will be reflected in different products of carbohydrate metabolisn.

\section{NEUBERG'S FERMENTATION SYSTEMS}

Other products besides quantitative yields of ethyl alcohol and carbon dioxide are found as the result of fermentation by yeast, small amounts of glycerol, acetic acid, etc., being formed. Neuberg's first form of fermentation was a series of reactions formulated to explain alcoholic fermentation as already described. The "Second Form " of fermentation occurs when sodium bisulphite is added to the fermentation system. The acetaldehyde formed instead of being reduced to alcohol (with the intervention of reduced (oenzyme I) is combined with the bisulphite as an end product of the fermentation. The reduced coenzyme which normally reduces acetaldehyde is now available for another purpose and, in fact, phosphoglyceraldehyde acts as hydrogen acceptor, being reduced to phosphoglycerol, which in the presence of yeast phosphatase is broken down to glycerol. So in this case acetaldehyde and glycerol are the fermentation products.

Neuberg's "Third Form" of fermentation occurs when the fermentation liquors are kept alkaline. In these circumstances the acetaldehyde is not quantitatively reduced to alcohol by reduced Coenzyme I, but again the coenzyme produces glycerol. The acetaldehyde is regarded as undergoing "dismutation," one molecule being reduced to alcohol and another being oxidised to acetic acid :-

$$
2 \mathrm{CH}_{3} \cdot \mathrm{CHO} \rightarrow \mathrm{CH}_{3} \mathrm{CH}_{2} \mathrm{OH}+\mathrm{CH}_{3} \cdot \mathrm{COOH}
$$

It will be recalled that this type of Camnizzaro reaction in animal tissues has been found to be due to two enzyme reactions catalysed by alcohol and aldehyde dehydrogenase respectively, with diaphorase and diphosphopyridine nucleotide as coenzymes.

\section{AEROBIC OXIDATION AND CITRIC ACID CYCLE}

When, in place of anaerobie glycolysis, ghlucose is broken down aerobically the initial stages are not very different from those of anaerobic glycolysis. Glucose is not oxidised directly to carbon dioxide, but the chain proceeds as in anaerobiosis until 
pyruvic acid is formed. The subsequent stages have been studied largely in pigeon breast muscle by Szent-Györgyi and much of the modern development is due to Krebs.

The cycle suggested is somewhat as follows:-

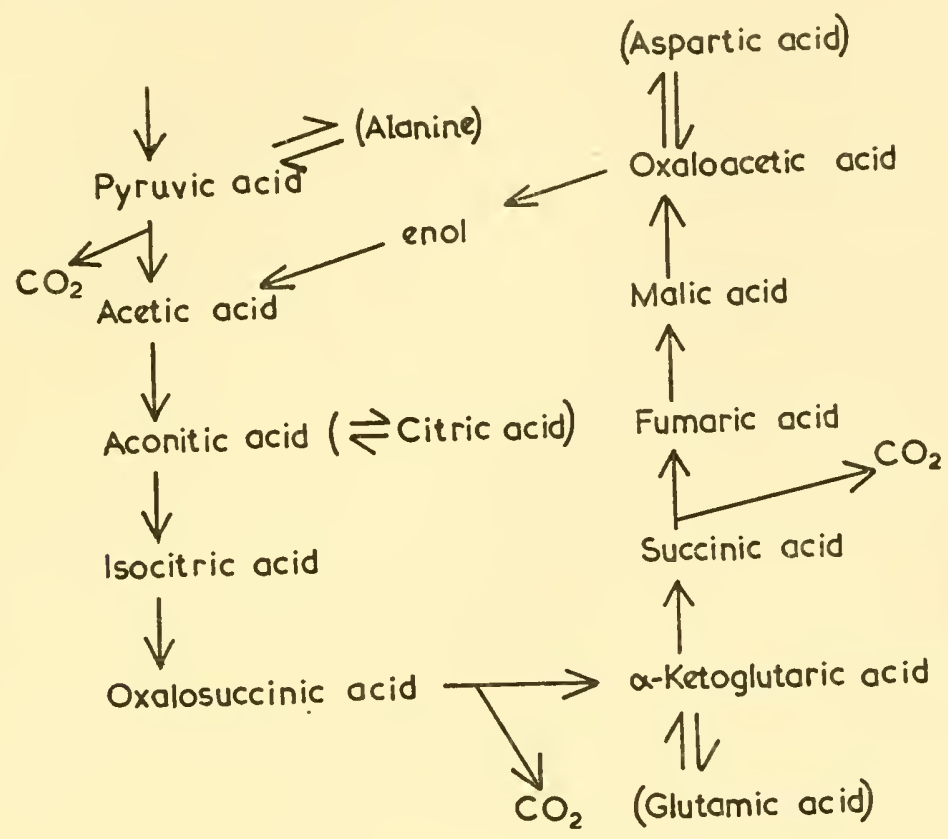

Fig. 17

Citric acid cycle

It will be seen that a complete cycle of reactions is visualised : at each turn of the cycle a molecule of pyruvic acid (from glycolysis, etc.), enters the cycle and three molecules of carbon dioxide are ejected. So the net result is :-

$$
\mathrm{CH}_{3} \mathrm{CO} . \mathrm{COOH}+5 \mathrm{O} \rightarrow 3 \mathrm{CO}_{2}+2 \mathrm{H}_{2} \mathrm{O}
$$

Oxaloacetic acid (enol) starts in the cycle reacting with acetic acid from the pyruvic acid introduced and a molecule of oxaloacetic acid is left at the end of the cycle.

Coenzymes I and II are concerned in reactions in the cycle, but this is not the place for a discussion of the evidence for the various reactions and the effect of inhibitors.

There are important interrelations between the tricarboxylic acid cycle and other metabolic processes. For example by transaminase mechanisms, glutamic acid can give rise to or be formed from $\alpha$-ketoglutaric acid, aspartic acid from oxaloacetic acid and alanine from pyruvic acid.

$$
\mathrm{R}_{1} \mathrm{CO} \cdot \mathrm{COOH}+\mathrm{R}_{2} \cdot \mathrm{CHNH}_{2} \cdot \mathrm{COOH} \rightarrow \mathrm{R}_{1} \cdot \mathrm{CHNH}_{2} \cdot \mathrm{COOH}+\mathrm{R}_{2} \cdot \mathrm{CO} \cdot \mathrm{COOH}
$$

The free energy changes involved in aerobic breakdown of carbohydrate are of some interest and are dealt with in the next section. 


\section{PASTEUR EFFECT}

Pasteur (1861) observed that the amount of sugar fermented by yeast was diminished in the presence of oxygen. In parenthesis, Barron (1943) light-heartedly comments that if Pasteur could have foreseen the misuses and misinterpretations of his observation he would never have mentioned the subject.

The utilisation of sugar in anaerobic fermentation is a relatively inefficient process and for the production of the same weight of yeast cells some ten times as much sugar is consumed anaerobically as in the presence of an abundant oxygen supply. A crude analogy here might be that of a motor car being driven with the air choke in action. For starting on a cold morning the use of the choke in cutting down the air supply and giving a " rich mixture " may accelerate starting ; but if the air supply is cut down for normal running the petrol consumption will be grossly excessive for the power developed.

The relative inefficiency of anaerobic fermentation follows from free energy considerations. In the complete oxidation of glucose to carbon dioxide 686,000 calories of free energy are liberated, but as indicated previously the theoretical maximum of free energy liberated during anaerobic glycolysis of glucose to lactic acid can only be 58,000 calories. Aerobic oxidation of sugar, therefore, yields nearly 12 times as much free energy for the performance of useful work compared with anaerobic glycolysis. As mentioned previously this free energy is stored by organisms in the form of energy-rich phosphate bonds $\left(\sim_{\mathrm{ph}}\right)$. Since some 3 or $4 \sim_{\mathrm{ph}}$ are made available in glycolysis it would appear that 36 to $48 \sim$ ph appear after aerobic oxidation of each molecule of glucose. Each $\sim$ ph bond accounts for nearly 12,000 calories of free energy. The mechanism by which these appear during the aerobic tricarboxylic acid cycle has not yet been detailed.

The mechanism by which aerobiosis inhibits fermentation has been the subject of much work and even more discussion.

The Meyerhof quotient:-

anaerobic fermentation - aerobic fermentation $\div$ respiration

gives the number of molecules of glucose which are inlibited from being fermented by every molecule of oxygen absorbed. Some values (after Lipmann) are given in Table 20.

TABLE 20

Meyerhof Quotients of Mrcroorganisus

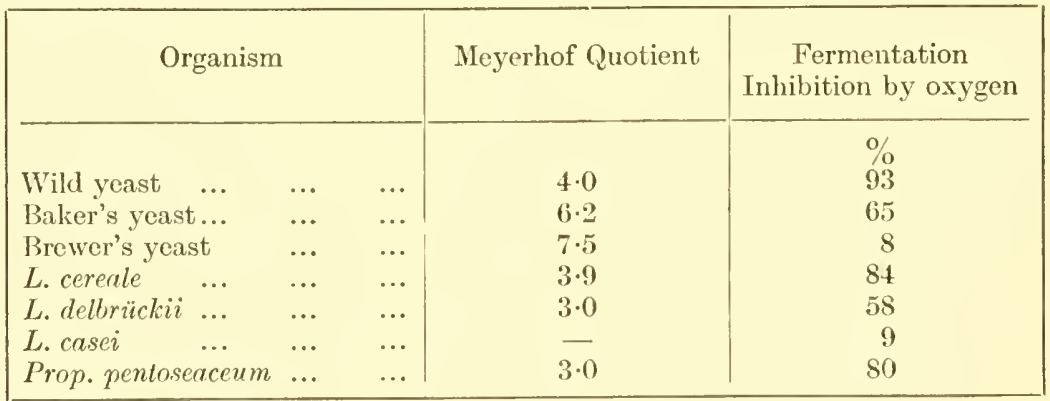


The effect of oxygen is probably not a simple one, but an effect on a number of enzyme systems in the fermentation chain of reactions. For example oxygen may oxidise SH groups, and these are necessary for the activation of a number of enzyme systems so that in the presence of air such enzyme reactions will be automatically inhibited. Michaelis and Smythe (1936) found that some oxidation-reduction potential dyes, by virtue of their oxidising effects, inhibit the conversion of the Neuberg ester to hexose diphosphate and thus bring the fermentation reaction chain to a standstill. On the other hand Dickens (1936) found that some dyes such as phenosafranine inhibited the Pasteur effect in brain and the inhibition was not due to the low oxidation-reduction potential of the dye. The reason for this appears to be found in the observation by McIlwain (1949) that the same dyes and nicotinamide which inhibit the Pasteur effect also inhibit the breakdown of Cozymase in brain tissue. The enzyme in brain also breaks down Coenzyme II, but the reduced Coenzymes I and II are not destroyed appreciably. Thus the oxidation-reduction potential of mixtures of coenzymes and reduced coenzymes treated with the brain enzyme is lowered and this affects the many enzymes sensitive to changes in potential. It is evident that if the coenzymes are destroyed many of the glycolytic reactions linked with them will come to a standstill and this accounts at least in part for the Pasteur effect, since under aerobic conditions the coenzymes will be mainly in the oxidised condition and hence susceptible to attack by the enzyme.

Some of the complicated effects of aerobiosis on fermentation reactions are indicated in a chart by Barron (1943) which indicates oxidation-reduction potential levels at which aerobic interference with fermentation appears likely.

\section{PHOTOSYNTHESIS BY PLANTS AND BACTERIA}

The ability to use the energy of light falling on the organisms to effect synthesis is a characteristic of plants containing chlorophyll, certain bacteria containing bacteriochlorophyll, green algae, etc.

\section{CARBON DIOXIDE FIXATION}

Synthesis of carbohydrate occurs through fixation of carbon dioxide :-

$$
6\left(\mathrm{CO}_{2}+\mathrm{H}_{2} \mathrm{O}\right) \rightarrow \mathrm{C}_{6} \mathrm{H}_{12} \mathrm{O}_{6}+12 \mathrm{O}
$$

but this general equation gives no information about the mechanism of the process, which is not yet completely understood although much work has been done. The mechanism appears to be different in the cases of green plants and bacteria, and also between different classes of bacteria. The purple and green sulphur bacteria need hydrogen sulphide or sulphur, which are oxidised in the process whilst the nonsulphur purple bacteria (Athiorhodaceae) oxidise organic acids, hydrogen, etc., during the reduction of carbon dioxide. The efficiency of utilisation of light energy by purple bacteria is over 10 per cent., some 0.12 molecules of carbon dioxide being fixed for each quantum of light absorbed. The first process in photosynthesis may be the reversible conversion of $\mathrm{CO}_{2}$ to carboxylic acids which are then reduced by the hydrogen liberated by the photolysis of water (see next section).

Another aspect of the utilisation of light for syntheses is the storage of the energy in the form of energy-rich phosphate bonds and work is already proceeding on this problem. 


\section{OXYGEN EVOLUTION BY CHLOROPLASTS}

Isolated chloroplasts in the presence of light and an appropriate hydrogen acceptor evolve oxygen (Hill, Warburg, French and others). The energy of light is utilised to produce oxygen and at the same time to effect reductions. Experiments with water enriched with the $\mathrm{O}^{18}$ isotope indicate that the oxygen arises from the photochemical decomposition of water.

$$
2 \mathrm{H}_{2} \mathrm{O} \rightarrow 4 \mathrm{H}+\mathrm{O}_{2}
$$

As hydrogen acceptors, ferricyanide, chromate, quinones and a number of oxidation-reduction potential dyes have found to be effective. Aronoff found a relationship between the normal oxidation-reduction potential of quinoid substances and the rate of oxygen evolution in their presence. The following table is given by Holt and French (1948).

TABLE 21

Decolourisation of Dyes by Illuminated Chloroplasts at pH $6 \cdot 6$

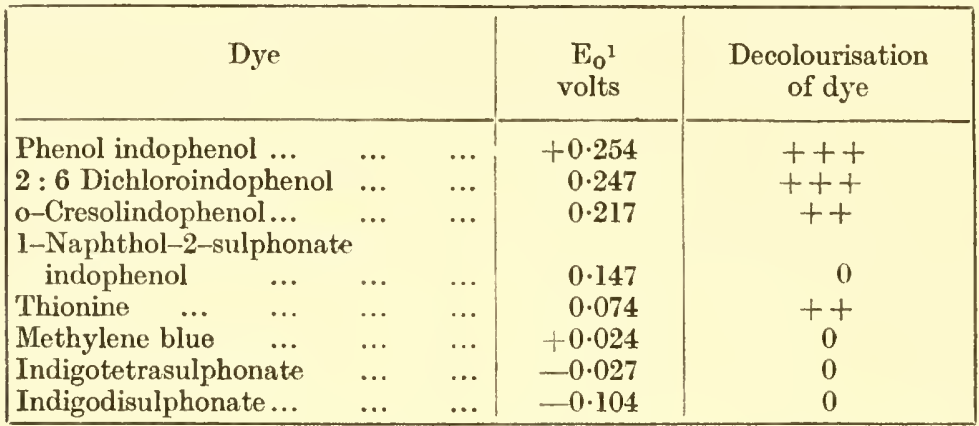

Thionine showed rather exceptional behaviour in its rate and extent of decolourisation and some other effect may have interfered. It is necessary to use dilute solutions of dyes since highly coloured solutions absorb so much light that the photochemical reaction cannot occur. By using dilute dyes it may be possible to investigate isolated constituents of the system. It appears possible that a combination of chlorophyll and protein behaves as an enzyme system, but the mechanism of the reactions require further study.

\section{PLANT RESPIRATION}

It is of interest to consider in what respects the metabolic cycles of plan ts resemble those of higher animals and bacteria. A fundamental difference, the utilisation by plants of the energy of light in effecting photosynthesis has already been mentioned briefly in a previous section.

The phosphorylation of starch as an initial process in glycolysis is closely similar to glycogen phosphorylation. Plants, however, make considerable use of sucrose, whereas animals have to invert the sucrose before it is broken down further, and many bacteria are unable to utilise sucrose. It appears likely that hexose diphosphates and monophosphates, triosephosphates, phosphoglycerate, pyruvate, acetaldehyde 
and ethyl alcohol are all part of the glycolytic cycle in plants as well as other organisms. Zymohexase, carboxylase and a number of dehydrogenases in plants have been characterised.

\section{OXIDATION CHAIN}

As the breakdown of carbohydrate proceeds through the various stages detailed in previous pages the systems pass from the highly reduced reactants related to glucose to the completely oxidised carbon dioxide and water. This is reflected in the oxidation-reduction potentials as indicated in the following table:-

TABLE 22

Approximate $\mathrm{E}_{0}{ }^{1}$ Values

\begin{tabular}{|c|c|c|c|}
\hline System & & & Volt \\
\hline Glucose : gluconic acid & & $\ldots$ & -0.45 \\
\hline Glucose-6-phosphate : phosphoglu & conic acid & $\ldots$ & $-0 \cdot 43$ \\
\hline $\begin{array}{llll}\text { Coenzymes } & \ldots & \ldots & \ldots\end{array}$ & $\ldots \quad \ldots$ & $\ldots$ & -0.33 \\
\hline Isocitrate : oxalosuccinate $\ldots$ & $\ldots$ & $\ldots$ & -0.30 \\
\hline$\beta-\mathrm{OH}$ butyrate : acetoacetate & $\ldots$ & $\ldots$ & -0.29 \\
\hline $3-\mathrm{PO}_{4}$-glyceraldehyde : glycerate & $\ldots$ & $\ldots$ & -0.28 \\
\hline $\begin{array}{llll}\text { Flavines } & \ldots & \ldots & \ldots\end{array}$ & $\ldots$ & $\ldots$ & -0.23 \\
\hline Lactate : pyruvate $\ldots$ & $\ldots$ & $\ldots$ & -0.18 \\
\hline Ethanol : acetaldehyde & $\ldots$ & $\ldots$ & $-0 \cdot 16$ \\
\hline Malate : oxaloacetate... & $\ldots$ & $\ldots$ & $-0 \cdot 10$ \\
\hline Alanine : pyruvate $\quad . . \quad \ldots$ & $\ldots$ & $\ldots$ & -0.07 \\
\hline Glutamate : $\alpha$-ketoglutarate & $\ldots$ & $\ldots$ & -0.03 \\
\hline Succinate : fumarate ... $\ldots$ & $\ldots$ & $\ldots$ & 0 \\
\hline Cytochrome-C... $\quad \ldots$ & ... & $\ldots$ & +0.27 \\
\hline Oxygen electrode & $\ldots$ & $\ldots$ & +0.81 \\
\hline
\end{tabular}

It will be recalled that the change in free energy associated with the formation or breaking of an energy-rich phosphate bond is about 12,000 calories corresponding to a change in potential of 0.25 volt. Allowing for a $60-70$ per cent. yield of energy the complete brcakdown cycle would allow of 3 phosphate bonds being formed in passing from the reduced substrates to the completely oxidised products.

In considering steps in the breakdown of nutrients that are concerned with oxidation-reduction changes it will be seen that in the initial stages hydrogen transfers are of importance and we have in the previous chapter dealt with a number of hydrogen-carriers.

Wieland (1913) attributes to the enzyme concerned in biological oxidations a hydrogen-activating effect, whereby the hydrogen may be transferred from the oxidisable substance $\left(\mathrm{AH}_{2}\right)$ to the oxidising agent or hydrogen acceptor $(\mathrm{B})$. In the presence of the appropriate specific enzyme the hydrogen linkings are weakened and may be transferred to any available hydrogen acceptor, thus :-

$$
\text { A. } \mathrm{H}_{2}+\mathrm{B} \rightarrow \mathrm{A}+\mathrm{BH}_{2}
$$

When oxygen itself acts as the hydrogen acceptor or oxidising agent, hydrogen peroxide may be formed:-

$$
\text { A. } \mathrm{H}_{2}+\mathrm{O}_{2} \rightarrow \mathrm{A}+\mathrm{H}_{2} \mathrm{O}_{2}
$$

This reaction is of importance in bacteriology and will be discussed later. In the presence of catalase the hydrogen peroxide is broken down to water and oxygen :-

$$
2 \mathrm{H}_{2} \mathrm{O}_{2} \rightarrow 2 \mathrm{H}_{2} \mathrm{O}+\mathrm{O}_{2}
$$


But the hydrogen peroxide may itself effect oxidations. In the presence of a peroxidase the following type of reaction occurs :-

$$
\mathrm{H}_{2} \mathrm{O}_{2}+\mathrm{B} \stackrel{+ \text { peroxidase }}{\longrightarrow} \mathrm{H}_{2} \mathrm{O}+\mathrm{BO} \text {. }
$$

Many bacteria possess peroxidase functions and these have been found to be associated with the presence of complex iron compounds such as cytochrome.

Warburg's (1923) theory is that oxygen activation is the crucial factor in biological oxidations and he attributes to iron compounds the function of catalysing oxidations by virtue of the change of valency from the ferrous to the ferric state.

This view derives its main support from analogies with iron systems, regarded as " models," and their inhibition by means of HCN and CO. The chief line of argument against the universal applicability of the oxygen-activation hypothesis is the difficulty of explaining on such a basis the high degree of specificity met with in biological oxidation-reduction reactions. Fusion of the two mutually helpful views would appear to promise the most reasonable hopes for progress.

Clark (1926) prefers to regard biological oxidation-reduction reactions in terms of electron transfer. Since oxidations and reductions may best be defined in terms of electrons it would seem logical to consider such reactions as electronic rearrangements, and to view the migration of atoms such as hydrogen as merely incidental to the maintenance of electrical neutrality. In the oxidation-reduction of methylene blue, for example, the reaction occurs, in accordance with electrode data, as follows :-

$$
\mathrm{Ox} . \oplus+\mathrm{H}^{\oplus}+2 \mathrm{e} \rightleftharpoons \mathrm{HR} \text {. }
$$

Methylene blue (cation) + hydrion +2 electrons $\rightleftharpoons$ methylene white.

Methylene blue in this reaction is just as much an "electron acceptor" as a "hydrogen acceptor" and if the same consideration is applied to the "hydrogen donator " in the experiment it will become apparent that the reaction may well be regarded as an electron transfer accompanied secondarily by an exchange of hydrogen ions. This point of view unifies and simplifies theories of oxidation-reduction processes and leaves open the question of how electron transfers are effected in the presence of the appropriate enzymic activity.

Wieland's (1931) views on biological oxidations may pertinently be quoted here :-

"It follows, therefore, that in the metabolism of the cell reduction products will be formed by the intervention of various hydrogen acceptors in the process of dehydrogenation. Conversely we may conclude that, whenever vital reduction takes place, it will be possible to demonstrate the process of aerobic dehydrogenation. The pre-eminence of oxygen is based not only on its high hydrogenation potential, but also on the chemical and physical inertness of its hydrogenation product-water."

\section{Summary of Chapter $\mathrm{V}$}

Some of the chains and cycles of elosely linked and delicately integrated enzyme reactions essential to the metabolic systems of living organisms are diseussed and consideration is given to the significance of oxidation-reductions, frce encrgy changes, phosphate bond energies and energy storage mechanisms. 


\section{CHAPTER VI}

\section{BACTERIOLOGICAL APPLICATIONS}

Why do bacterial cultures often develop strongly reducing conditions during growth? The answer is not perhaps obvious at once, but, as will be seen later, reduction follows as a necessary result of the metabolism of the organisms. In order to understand the origin of the electrode potentials developed it is necessary to consider briefly the nature of the metabolic processes occurring in bacterial cultures and also how these differ from the metabolic systems of highly organised multicellular organisms.

\section{LAG PHASE}

When bacteria are subcultured into fresh media there is usually a lag phase before the number of bacteria present begins to multiply appreciably. It is imuriguing to speculate why normal multiplication does not start immediately. It is evident that the spores of spore-bearing bacteria will require time to "germinate" before normal multiplication gets into its stride, but it is not so obvious that non-sporulating organisms should, when freshly subcultured and presented with abundant fresh food, undergo a phase lasting sometimes several hours before they begin to multiply at an appreciable rate. It is found that in this initial non-multiplying phase bacteria are generally increasing in size. Thus Wilson (1926) found the average size of Salmonella typhimurium cells to be $2.35 \times 0.79$ after 4 hours incubation and $1.13 \times 0.49$ after 26 hours. The volume of the lag phase cells is therefore more than five times that of their successors. The metabolic activities of the bacteria are intense during the lag phase (Winslow and Walker, 1939) and the oxidation-reduction potential of the culture is falling, as is seen in curves given later in this chapter.

At this stage it is necessary to draw attention to a concept that will be returned to more than once and that is the great difference between the life-problems of unicellular bacteria immersed in a foreign medium and the cells of multicellular higher organisms with their carefully adjusted environment with " everything laid on." The difference suggests that between an explorer setting up his bivouac and a town dweller returning to his service flat. Modern work of the last two decades has brought out with remarkable success the similarities and identities of bacteriological and "physiological " processes, but it appears necessary to emphasise that enthusiasm for recognising the analogies should not blind us to the differences.

The cell of a higher animal generally is highly specialised and is presented with nutriment exactly adjusted to his needs; the unicellular bacterium is faced with great difficulties and many things seem badly adjusted for him when he is freshly subcultured. Glucose may be available in quantity and also oxygen, but many stages must be gone through before

$$
\mathrm{C}_{6} \mathrm{H}_{12} \mathrm{O}_{6}+6 \mathrm{O}_{2} \rightarrow 6 \mathrm{CO}_{2}+6 \mathrm{H}_{2} \mathrm{O}
$$

The delicately adjusted aerobic and anaerobic glycolysis systems require many enzymes and coenzymes to function in tune under carefully controlled conditions. Glucose and oxygen are at the opposite ends of the metabolic chain. The initial stages of glycolysis tend to be anaerobic and oxygen is required in the later stages. 
As would be expected the lag in multiplication of bacteria newly subcultured is longer if the inoculum consists of an old culture in which the cells have spent a long time since multiplying, are therefore themselves "senile," and the enzymes, themselves proteins, are likely to be partly denatured with labile prosthetic groups decomposed. In this connection it should also be mentioned that many bacteria possess a variety of proteolytic enzymes and under some conditions are subject to complete autolysis. It requires little imagination to visualise self-destruction of enzymes with age.

Hinshelwood (1948) in a stimulating discussion emphasises the possibility of intermediate metabolites diffusing from the cells so that enzymic systems will not have the necessary substrates preformed for their activities.

Another point that will be developed later is the conditions in which the newly subcultured bacterial cells find themselves. Their breakdown of carbohydrates follows a plan roughly similar to that of the metabolic chains of glycolysis and fermentation developed in the previous chapter. In these the glycolytic system starts with the "reduced type" of reaction and ends up with the "oxidised type," and finally oxygen gas itself enters the system through the intermediation of hæmoglobin, cytochrome, etc. The bacterial cell on the other hand is faced with the problem of starting the metabolic chain involving reduced reactants with conditions that are oxidising. The Pasteur effect is relevant here; the presence of oxidising conditions inhibits fermentation activities. The bacterial cell, unlike the animal tissue cell has to alter its environment before it can get into normal action.

Finally the question of bacterial enzyme adaptation occurs; the old cells presumably have their enzyme systems adapted to dealing with conditions as they are in an old partially exhausted culture medium and the sequential development of enzymes now has to be begun for the utilisation of the substrates as they occur in a fresh culture medium. This again differentiates bacteria from tissue cells-not only do the bacteria have to adapt their own environment (they have no organised central authority to work in concert with them for the delivery of supplies at the right time, and concentration and no maintenance department for the enginecring services), but they have to adapt themselves to changing environment so that bacteria in cultures of different ages have to have differently adjusted enzyme systems. This will be discussed in greater detail later.

There is also the possibility of stale cells producing poisons and inhibitors against their own enzyme systems, but there is no evidence that diphtheria toxin, for instance, will poison the cells that produced it.

The lag in initiation of growth shown by aged cells of $B$. coli in a medium containing ammonia as sole nitrogen source has been traced to the need for the production from glucose of four-carbon compounds which can be aminated to yield essential amino-acids. The lag almost vanishes when glutamic acid or a-ketoglutaric acid is added (Morrison and Hinshelwood, 1949).

\section{LOGARITHMIC GROWTH PHASE}

Having surmounted its initial difficulties of adaptation to the fresh environment the bacterial cell now enters the active multiplication stage. The reproduction rate is now very high, the reproduction time may be as short as 20 minutes. That is to say 
in 20 minutes the cell has to re-synthesise itself entirely-all the cell structure and all the enzymes. In view of the complex of proteins, polysaccharides, nucleic acids and lipins this seems an incredible feat. At the end of the first twenty minutes 1 cell becomes 2 , another twenty minutes and the 2 become 4 . So that after $n$ periods of 20 minutes the original lone bacterial cell will be $2 n$; in 6 hours one bacterium becomes $1,000,000$. (If all the bacteria in the world started multiplying at this rate the earth's crust would be covered by layers of bacteria a mile deep in 24 hours.) If the number of bacteria is plotted against time a sharply rising curve soon runs off the graph paper ; but if the logarithm of the number of organisms is plotted against time a straight line is obtained, hence the term " logarithmic phase " of multiplication.

The logarithmic growth phase is characterised by intense enzymic and synthetic activities and, presumably, this phase could be extended indefinitely if the constituents of the medium could be suitably adjusted. In practice, however, this phase of intense activity is comparatively short-lived, lasting generally for only a few hours and hence covering a period of only 10 to 20 generation periods.

\section{STATIONARY AND DECLINING PERIODS}

Following the intense activities of the logarithmic growth phase things begin to slow down, multiplication occurs less frequently, cells begin to die: soon the death rate equals the multiplication rate and the population is stationary, then the death rate overtakes the generation rate and the count of viable organisms decreases. It is simple to measure what is happening in the culture as a whole, but this is a mere statistical figure; it gives no information as to what is happening to each individual cell. Assuming the logarithmic growth phase of a culture has ceased after 10 hours incubation what is the history of the individual cells still present after 24 hours incubation? What are the ages of cells in an old culture, i.e., how long is it since the individual cells have undergone sub-division? Can a cell survive long after it has ceased to sub-divide and are the surviving cells in an old culture still undergoing the process of sub-division, albeit very slowly. It is possible that bacteria cannot survive long after the processes associated with multiplication have ceased. Unlike the tissues of higher organisms it is possible that bacterial proteins are denatured and enzymes decay unless they are constantly renewed and take their place in new cells. It is known, however, that some bacteria which have been rapidly dehydrated, e.g., by freeze-drying, survive for many years in the dry (lyophilised) state when cell multiphication is impossible, but, on the other hand, protein denaturation is also slowed down to an almost zero value. Recent observations by Fry and others suggest that there is an "optimal dryness" for the preservation of live bacteria. It would seem that if they are not dry enough protein denaturation might occur, whilst if they are too dry the bacteria are killed by the desiccation. It is necessary, of course, to emphasise at this stage the danger of generalising too much about "bacteria" as a class-the individual variations are as great as the differences of diet of lions and giraffes.

It may be a mistake to class the post-logarithmic growth phase of bacteria with the decline of the Roman Empire as a mere slow decay of former glories. Many functions of interest to us happen to occur in this phase-for example, the occurrence of toxin in cultures of $C$. diphtherice and the production of penicillin in stationary cultures of Penicillia. The chemical composition of the filtrate changes greatly in this period, 
and presumably cellular enzymes are still capable of activity even though the synthesis of new cells has slowed down. It is possible that the distribution of enzyme systems in bacterial cells varies with age. In the logarithmic growth phase the syntheses of brand new enzyme systems for the multiplying cells must follow one another so rapidly that it is difficult to conceive or observe a sequence of enzyme distributions, but when the tempo of multiplication has become less hectic it is possible to visualise a succession of enzyme distributions, one type of reaction predominating for a time to be followed by another, perhaps by the unmasking of reaction catalysts previously unimportant on account of their slowness, but assuming priority when the faster reaction catalysts have decayed. In many biologically important systems the slow ripening processes in the autumnal harvesting may be as important as the vernal growth.

\section{REDUCING CONDITIONS IN BACTERIAL CULTURES}

It is a commonplace that bacterial cultures develop reducing conditions. Dyes such as methylene blue added to cultures are reduced; samples of milk contaminated with many bacteria rapidly reduce methylene blue (or resazurin) when incubatedthis constitutes an official test for contaminated milk. As will be seen in many later curves in this chapter the oxidation-reduction potentials in bacterial cultures begin to fall soon after the fresh sub-culture is made, the lowest potential being reached when the metabolic activities of the bacteria are most intense in the logarithmic growth phase. In electrode potentials we have a quantitative measure of the reducing intensities of systems as indicated in Chapter I.

What is the reason for the development of reducing conditions in bacterial cultures?

Coulter and Isaacs (1929) discuss the mechanism of establishment of reducing oxidations in bacterial cultures (B. typhosus). They suggest that during the phases of active proliferation the organisms exhaust all the free oxygen in the medium "thus permitting the characteristic potential of the culture medium to become manifest." When the phase of active multiplication of the organisms is over and the " rate of dying of the bacteria approaches and exceeds the rate of multiplication, it is suggested that dissolution of bacteria liberates reductive substances," and more. negative potentials are observed.

However not only are bacteria able to remove free oxygen from the medium but they are able to effect other reductive processes outside the cell in accord with their nutritive requirements. Coulter and Isaacs state that " the role of the bacteria is the establishment of the anaerobic state" and that " this point of view is opposed to that which regards the potentials of bacterial cultures as a manifestation of reductive substances liberated by the bacteria." It seems reasonable, however, to assume that neither of these hypotheses provides the underlying reason for the reducing conditions in bacterial cultures, but that the bacteria effect reduction as a natural result of metabolic activities. To obtain the energy necessary for proliferation, food materials in the broth must be oxidised, and for this purpose free oxygen, combined oxygen, hydrogen acceptors (or electron acceptors) or any suitable type of oxidising agent will be utilised by the cell. The actual agents used by the cell for the oxidations will depend on the enzymes and eatalysts available, and one after another of the oxidising systems will be reduced as the cell calls its 
various enzymic activities into play. To assume that the cell can affect the medium only (i) by removing free oxygen dissolved in the medium, and (ii) by liberation of reducing substances from autolysed cells is to ignore a number of facts accumulated from studies of bacterial metabolism. This point of view is one which is steadily gaining ground amongst students of the subject.

It is a common fallacy in the consideration of the reducing phenomena of bacterial cultures to confuse symptoms with functions. The utilisation of oxygen in the culture medium by bacteria is frequently regarded as a function, whereas it is nothing but a symptom of the dehydrogenation of nutrient materials by the organisms in their search for sources of energy. A further fallacy is to confuse bacteria with multicellular organisms. Since higher animals eat or absorb food and excrete waste products, a similar mechanism is frequently ascribed to bacteria. It is more helpful, however, to regard the micro-organism as an active centre where chemical reactions, catalysed by the cell enzymes, proceed near the cell surface. The conception that glucose is absorbed by a bacterium, digested as in the higher animals and then excreted as lactic acid requires amplification.

It has been calculated that a single bacterium may break down some millions of molecules of glucose in a minute. The transport problem involved in this process must be considerable even when the glucose molecules have merely to be led up to the cell surface and the metabolic products to be led away, but if the glucose has to diffuse into the cell interior and the metabolic products have to diffuse out the movements of materials must be even more intricate. Surface catalysis presents many analogies to cellular enzyme effects and the difficulties involved in the assumption of a multiplicity of specific enzymes may be lessened by acceptance of the theory that reactive molecules cannot react unless their configuration is such that they are absorbed at the surface, and the specificity of surface orientations helps to account for the selectivity of many cellular activities. The chemical material required for the building of new cellular material must, presumably, penetrate the bacterial envelope and the energy liberated in metabolic prosesses must also be available to the cell, but it would appear that many aspects of the physiology of cells become clearer if the postulate be accepted that many bacterial metabolic processes take place not in the cell interior but at its surface or near the surface.

The emphasis laid here on the distinction between micro-organisms and higher multicellular organisms has been criticised on the grounds that this ignores the vast amount of work carried out in the last decade or so showing similarities between the ultimate reactions of metabolism in bacteria and animals. This, however, is not intended and study of the previous two chapters will reveal the recurrence in vastly different organisms of the same patterns and building stones of metabolic processes. In point of fact the author claims some share of prophetic insight for the following, written in 1930 for the first edition of this book :

"Such advances in bacteriology are preliminary to advances in other realms of biology where the investigator has to deal, not with many cells of the same type, but with cells of countless different kinds. A fuller understanding of unicellular behaviour and its variations must precede the solution of the more complex problems."

The object then in distinguishing between the metabolic activities of bacteria and animals is not to discount the similarities of the fundamental reactions but to underline the differences in organisation. The tissue cell stays in situ, has brought to 
it the reactants it requires and has removed from it the waste products of metabolism. The bacterial cell on the other hand has to make its own conditions suitable for carrying out metabolic reactions, it is faced with the problem of collecting up the reactants from the medium in suitable quantity and it has no specialised colleagues to carry out syntheses or reactions for which it is not suited.

The accumulation of such compounds as glutamic acid has been shown by Gale to occur in bacteria ; but what ean we visualise in the case of large molecules. It is hardly conceivable that molecules as large as starch and some proteins can permeate through the cell membrane. Surely they must undergo breakdown at the bacterial surface. Again the lysis of erythrocytes by bacteria from which no soluble hæmolysin can be isolated must take place by the agency of the surface of the bacterium. One advantage of considering the surface activity theory is that specific absorptive effects at the cell surface can explain some of the specificities of bacterial actions and cut down to some extent the already enormous numbers of different enzymes that must be postulated to explain the many specific reactions observed.

How is one to visualise bacterial glycolysis for example? Let us assume that something very like the muscle glycolytic sequence occurs in bacterial cultures and there is much evidence that some of the steps are similar. In the rapid breakdown by one bacterium of millions of molecules of glucose each minute it is not easy to think of the glucose diffusing into a cell, being converted to hexose-6-phosphate and then diffusing out again. Then the bacterium would have to wait for molecules of hexose-6-phosphate to diffuse in again and having effected the transformation to the Neuberg ester again lose the reactant by diffusion. The only explanation would seem to be a mass production system in which the relevant enzymes are suitably situated in the cell and the metabolites pass along the row of enzymes on a conveyor belt principle so that each enzyme system in turn will produce its transformation and pass the product on to the next enzyme. Presumably there must be some preferential affinity by an enzyme for its specific substrate. It seems highly probable that much must occur at the bacterial surface, taken in its widest sense and representing layers of combined and inter-adsorbed proteins, nucleic acids and lipins.

It is difficult to think about the problems of the bacterial cell without a diagrammatic picture which is an aid to the visualisation of the mechanisms that have to be explained. For this purpose the diagram below has been constructed, but it is reproduced only with great trepidation. It does not represent the author's definitive views on the subject, but it does indicate the way in which a chemical engineer might tackle the problem if he were presented with the sort of data we now have available.

Let us try to trace the path of a molecule of glucose in the culture medium that is due for breaking down. First it has to come into contact with the phosphorylating system, and for this it has to find its way through the sticky capsule of the bacterium (if it is a capsulated organism), presumably by diffusion. Then the cell wall, generally a relatively sturdy structure in most views, has to be traversed. There is controversy here about the mechanism of transport through the cell wall. Is this a simple osmotic effect? Is the cell wall a semi-permeable membrane with interstices large enough to let through molecules of glucose (and even soluble enzyme proteins)? Even if it is diffusion through the pores of a membrane, free energy must be supplied in some cases since there may be ten times the concentration of glutamic acid, for example, inside 
the cell, as outside (Gale, Taylor). (An alternative explanation here is that inside the cell the constituents may be adsorbed on surfaces and not freely diffusible under normal circumstances; on the other hand such diffusion against a concentration gradient occurs only when the cell is actively metabolising and providing free energy.)

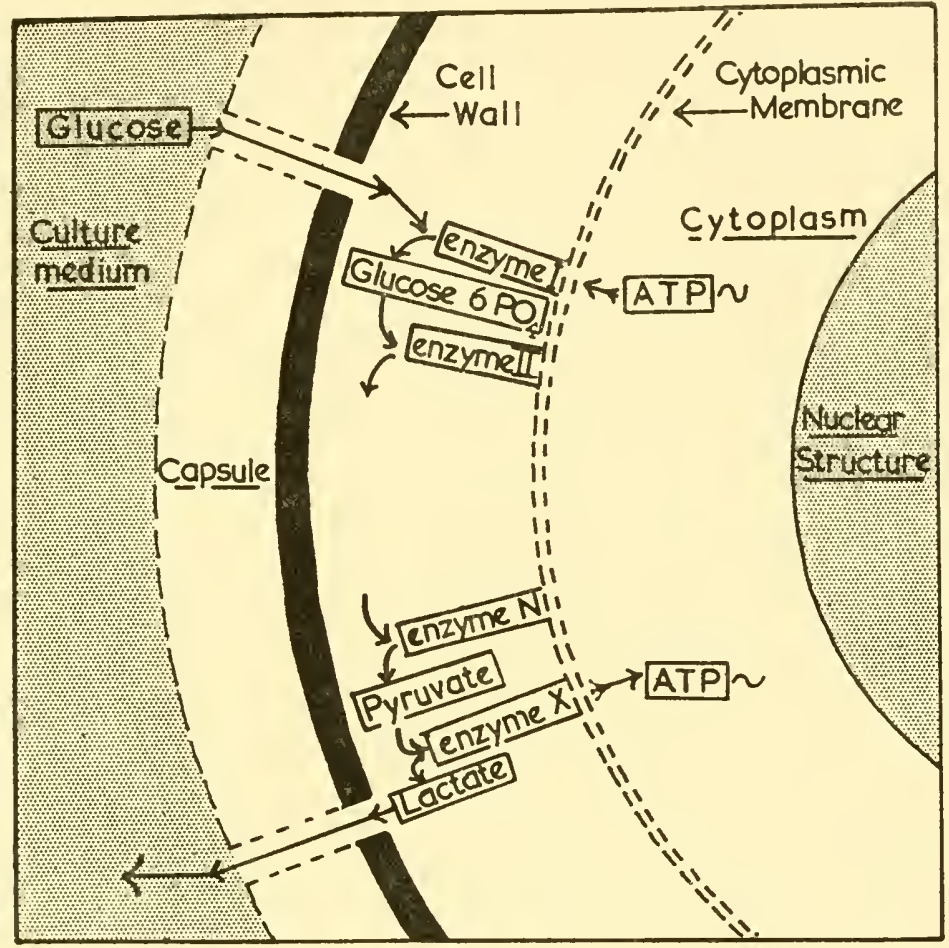

FIG. 18

Diagrammatic visualisation of Section of part of Bacterial surface

The cell wall, on the other hand, may be some kind of lipoprotein which adsorbs an entering molecule, produces necessary chemical changes in it (e.g., converts glutamic acid to glutamine) and then injects it into the cell interior after the inner side of the cell wall has reconverted it back into the original form (Glutamic acid). If this is so our diagram should be complicated by indicating the cell wall as bristling with enzyme systems.

Having negotiated the cell wall, by an agreed mechanism, our glucose molecule is now broken down. The enzymes in the diagram are represented as tethered to the comparatively fragile cytoplasmic membrane. (Stacey visualises some such arrangement for the magnesium-ribonucleate-protein Gram complex.) The advantage from our chemical engineer's point of view is that the bringing together of the substrate, enzyme, coenzyme and free energy is much simpler if the chemical plant and energy supplies are fixed in appropriate positions for the flow of raw materials, and are not all 
moving at high speed in different directions in his factory and even flying out of the door and windows.

Continuing to follow the glucose molecule: it will be anchored temporarily to the phosphorylating enzyme and perhaps the phosphate group and free energy of a molecule of adenosine triphosphate from the cytoplasmic interior will be utılised; then the glucose-6-phosphate is released by the enzyme and is attached by a neighbouring phosphohexose isomerase enzyme system. Thus the metabolite will pass along the series of enzyme systems until there is no appropriate enzyme system active enough to anchor it and transform its molecule further. Then the lactate or other product will be ejected from the cell, having again to traverse the cell wall and capsule. The whole of this process has to be repeated a million times a minute by each bacterial cell.

Although the hypothetical breakdown of a glucose molecule has been traced, the same considerations apply to nitrogen metabolism. During the logarithmic growth phase when the cells are re-synthesising themselves as frequently as every twenty minutes the complicated processes of specific protein synthesis have to be effected, and also that of the nucleic acids which are perhaps the directors and organisers of specific synthesis.

Again oxidation-reduction reactions effected by the cell are dependent upon oxidants being brought into contact with the necessary dehydrogenases, oxidases, etc., and their coenzymes, and dependent also upon the reduced substances being present to maintain electrode balance.

The importance of maintaining the reactants in a complex enzyme substrate system in close contact is emphasised by experiments of Keilin and Hartree (1949) who found that the presence of denatured proteins and of gelatinous precipitates formed on addition of various metallic salts activated the succinic dehydrogenasecytochrome system. It is suggested therefore that various additions such as proteins and metal salts may affect an enzyme system quite non-specifically causing activations and inhibitions which might, quite erroneously, be ascribed to effects on essential links in the catalytic chain. Caution in the interpretation of results is therefore necessary and it would be well to re-examine a number of phenomena in the light of this suggestion. It is natural to ascribe all effects to specific catalytic reactions, whereas the "colloidal state" of the system will effect the contiguity of the components and hence their ability to react. Especially is this true of bacterial systems where diffusion of reactants from the immediate vicinity of the cell to relatively enormous distances away in the culture medium will remove them from effective co-operation in the cell's economy.

The nature of the antigenic complex occurring at the surface of the Shiga dysentery bacillus is indicated by the possibility of dissociating the polysaccharidelipide-protein complex and then recombining the components to form a complete antigen (Morgan and Partridge, 1941).

\section{BACTERIAL REDUCTIONS}

At the risk of repetition it is necessary to emphasise the necessity to avoid confusing symptoms and functions. The development of reducing conditions in bacterial cultures is a symptom of the dynamic equilibrium, which is always in a state of change. In a bacterial culture, unlike a tissue cell's environment, there is not 
only lack of constancy, but also conditions do not oscillate about a mean value. Iu muscle although in periods of rest and activity there are changes, conditions are always reverting to a comparatively steady state. The initial problem of a bacterium inoculated into fresh medium is to make conditions suitable for its metabolism. In a highly oxidised medium such radicals as SH groups may be unable to remain reduced so that enzymes activated by $\mathrm{SH}$ cannot function. Yet some of the initial reacions in the glycolytic chain are just the ones which require reducing conditions. The enzyme systems such as those of cytochrome which tnrive under oxygenated conditions are those which come near the end of metabolic breakdown channs. The volume of culture medium compared with that of the inoculum of bacteria is enormous. Yet the electrode potential soon begins to fall; the oxygen dissolved in the medium is utilised by the organisms, any oxidation-reduction systems present in the medium are reduced as the potential falls to the level at which their equilıbrium potential lies. How are these constituents of the medium reduced? The less likely view is that bacteria eject a stream of reducing agent like squids squirting out sepla. The aspect in harmony with the metabolic eycles described in previous pages is that bacteria require energy for their rapid growth and metabolic processes and the most efficient methods of getting energy are by oxidising food materials. Oxidation or dehydrogenation, however, comes to a standstill unless there are hydrogen acceptors present, and there is no blood stream to bring fresh supplies of oxygenated hæ.noglobin. Once growth is established in a bacterial culture, therefore, oxygen donators and hydrogen acceptors must be seized upon avidly by the cells for their metabolism and the culture medium which started by having a high electrode potential will soon develop a low reducing potential as more and more hydrogren acceptors will have accepted all the hydrogen they can accept. The level to which the potential fall depends, of course, upon the enzyme systems possessed by the bacterium studied. The electrode potential reached will be governed by what hydrogen acceptors are reduced and this in turn depends upon the enzymes that are present and able to function.

So the electrode potential indicates the state of the dynamic equilibrium of the culture, between the activity of the cellular enzymes and the constituents of the medium. As would be expected Yudkin (1935) found that protecting the electrode from contact with the bacteria made no great difference to the electrode potential. It is the effects produced by the bacteria and not contact with the cells themselves that affects the potential.

The question is sometimes asked: why are intense reducing conditions developed in many bacterial cultures, and why not intense oxidising conditions or a high oxidation-reduction potential ? The answer lies in the great difference between conditions of bacterial growth and those of cells in multicellular animals - it lies in the constantly changing conditions of bacterial growth. At the outset, when freshly sub-cultured, the bacterium is in a medium which tends to be too oxidising for active growth to start (i.e., for enzymes in the initial stages of metabolism to be activated) and hence one of the reasons for the bacterial lag phase of growth. In the later stages of growth, when oxidising conditions would help metabolic processes, there is an oxygen deficit, and for the purpose of finding hydrogen acceptors every constituent possible in the culture medium is reduced. Then as bacterial enzymic activity wanes after the logarithmic phase of growth air slowly diffuses into the culture and the electrode potential drifts upwards again. 
This oxygen deficit at the time of active growth accounts for the success, for example, of aerated submerged cultures in the production of penicillin, diphtheria toxin and streptomycin. Formerly, all these products of micro-organisms were obtained on a large scale by incubating shallow layer's with its growth of organisms at the surface with maximal access of air. Frequently incubation had to continue for 7-14 days for the completion of the process, but in modern submerged culture plants, rapid production in 1 or 2 days is secured in cultures receiving an abundant air supply by a forced pressure feed of air. The oxygen demand of sewage is another example of the same phenomenon.

There should, however, be a word of warning here and that is the danger of generalisation. Bacteria vary enormously in the enzyme systems they possess and hence in their reaction to oxygen supplies and in the oxidation-reduction potentials developed in their cultures under different conditions. As will be seen, an abundant oxygen supply at the wrong time may stop the growth of anaerobes; and lead to sterilisation of cultures through peroxide formation in organisms deficient in catalase.

Again, it must be emphasised that reducing conditions per se are not the essentials of a medium suitable for bacterial growth, although, of course, growth may be impossible when oxidation-reduction conditions are unsuitable. To consider an analogous case, growth of bacteria is impossible in too acid a medium, but mere adjustment of any fluid to a neutral reaction does not constitute a satisfactory culture medium. There has been a tendency rather to over-emphasise the importance of reducing conditions in the initiation of bacterial growth and to attribute reducing properties to growth adjuvants on rather slender evidence. In the case of the aerobic organism $M$. lysodeikticus better growth and actually more highly reducing conditions were observed when the oxygen supply was increased by aerating the cultures (Hewitt, 1931).

In the presence of an abundant oxygen supply, the free oxygen available may be sufficient for preliminary oxidation processes, but when more anaerobic conditions are established other means of oxidation must be available; hydrogen acceptors must be present, which in the presence of cell enzymes oxidise nutrient materials by removing hydrogen from them. Anaerobic growth, therefore, requires a more carefully constituted medium than aerobic cultures. Hence it is frequently difficult to obtain luxuriant growth of certain organisms anaerobically in a culture medium which is quite suitable for aerobic growth. It is often observed that anacrobic cultures are more successful in the presence of glucose. This has been ascribed to the reducing properties of glucose, but a more probable explanation is that glucose may be fermented anaerobically, and the energy liberated in this reaction is available to the organisms, although it is only a fraction of the energy made available in aerobic oxidation.

Relatively little was known of the oxidation-reduction equilibria in bacterial cultures, and the study of the electrode potentials developed in cultures under different conditions has provided a most promising method of studying bacteria, and the results obtained are proving of value in the case of tissue and other cells.

Reducing conditions are established in bacterial cultures during growth owing to the metabolism of the organisms as mentioned above. 'The organisms use oxygen, oxygen donators and hydrogen acceptors to effect the oxidation of nutrient materials 
and hence obtain the energy necessary for life and proliferation. Definite electrode potentials are established in cultures, but we are not fully aware what substances are responsible for these potentials in many cases, nor what reversible oxidationreduction systems are actually being measured. Nevertheless, valuable conclusions may be drawn from such results. The effect of some of these systems, present in minute quantities, may be merely to indicate the potential of the system-the quantity present may be too small to affect the oxidation-reduction conditions of

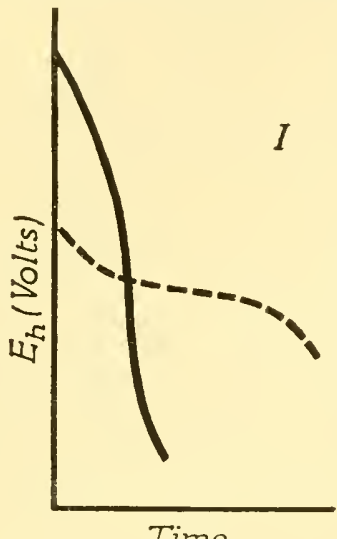

Time

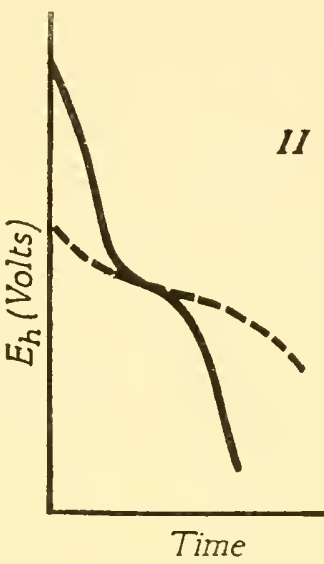

FIG. 19

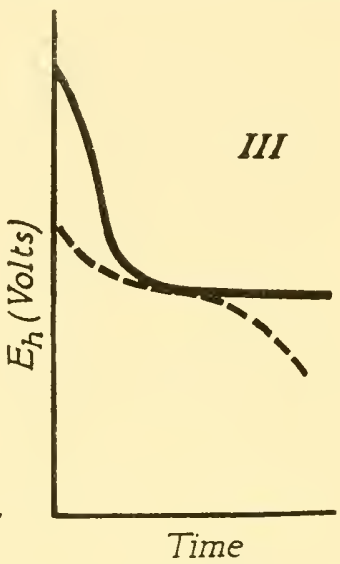

Time

$\mathbf{F}_{\mathrm{h}}$ : time curres of hypothetical cultures (continuous lines). (Broken line represents $\mathrm{E}_{\mathbf{h}}$ : percentage oxidation curve of poising system present.)

the culture. Other systems will have a poising effect and tend to obstruct oxidation or reduction processes since they themselves have to be oxidised or reduced before the level of electrode potential can be altered appreciably. It will be seen, therefore, that the quantity present of such systems, as well as their oxidation-reduction level of intensity will affect the drift in potential. Thus, in the curves above (fig. 19), the continuous lines represent the fall in electrode potential of hypothetical bacterial cultures during growth and the dotted lines represent the ordinary curve of an oxidation-reduction system, showing the potentials corresponding to different percentages of reduction. In $\mathrm{I}$, the amount of the oxidation-reduction system is so small that it does not affect the potential-time curve of the culture; in II, the amount is greater, but the culture is easily able to reduce it, so a small kink on the curve is seen; in III, the capacity of the system is so large that the culture is unable fully to reduce it, so that the potential is poised and prevented from falling to the usual low level. The same effect might be obtained by keeping the oxidationreduction system constant and using organisms of different reducing powers, I being the most intense reducer and III the least.

If the broken line in the figure is taken to represent an oxidation-reduction indicator dye, then in system I it would be rapidly and completely reduced, in II slowly reduced and in III it would remain in the oxidised form.

On the views presented bacterial cultures are to be regarded as dynamic, constantly altering systems and not static, fixed systems of unchanging properties. 
Bacterial cultures develop reducing conditions not so much because of the liberation of reducing substances as on account of the exertion of reducing activities, although, of course, the potential cannot fall unless a reducing substance is present.

At present our knowledge of the systems present in bacterial cultures is incomplete, but the data accumulating from electrometric studies are giving us some insight into the differences between different culture media and different organisms. The conditions governing the potentials established in bacterial cultures must be complicated and amongst the important factors are the following :-

(i) Kind of organism-Class, strain, etc.

(ii) Condition of organism-Previous history, colony form, etc.

(iii) Growth phase of the culture.

(iv) Nature of constituents and their quantities in culture medium.

(v) Conditions of cultivation.

It is not proposed to attempt a full description of the many publications dealing with the reduction of dyes in bacteriological cultures. That many dyes are reduced in bacterial cultures is well known, and the ease and rapidity of reduction varies with the potential range over which the dyes are reduced. The lower the electrodepotentials at which the dyes are reduced, the slower, in general, is the reduction of the dyes by cultures. Differences in ease of reduction of methylene blue have been used for the differentiation of organisms (Avery, 1922). Applications of dye reduction phenomena are found in testing milk (Schardinger, Thornton and Hastings, Wilson). and the putrescibility of sewage (Spitta and Weldert, Wooldridge and Standfast), detecting traces of oxygen in anaerobic apparatus (Hall, 1921), etc., and the study of enzymes in Thunberg tubes.

Before dyes can be used for the study of most of the wider problems of bacteriology it is essential that the fundamental facts be established and the initial difficulties removed by direct potentiometrie studies of reducing conditions in bacterial cultures. At the present stage the disadvantages attaching to the use of dyes are almost insuperable, and the discrepancies between the results obtained by colorimetric methods and those by electrometric measurement are considerable.

Although the measurements and interpretations of electrode potentials in bacterial cultures are still somewhat empirical, the importance and interest of the subject warrant, in the anthor's opinion, the space devoted to their eonsideration.

\section{ELECTRODE POTENTIALS OBSERVED IN BACTERIAL CULTURES}

Potter (1911) first noted that the electrode potential of inoculated culture medium was lower (i.e., more reducing) than the sterile culture medium. The development of reducing conditions was observed by following the fall in potential first by Gillespie (1920). This has been confirmed by Cannan, Cohen and Clark (1926) and many others. A systematic and comprehensive study of electrode potentials of bacterial cultures should assist considerably in the understanding of many bacteriological problems.

Perhaps the greatest difficulty in dealing with biological systems generally and with bacterial cultures in particular is that we have not rigidly defined static systems 
of fixed characteristics but constantly changing systems for ever in a state of flux. This proves a source of great difficulty to many students of the problems presented. In a bacterial culture, not only is the oxidation-reduction potential changing (as we shall show) but also the hydrogen-ion concentration, the chemical composition, the number and condition of the organisms and so on. To escape from these difficulties, investigators have tried to fix the hydrogen-ion concentration by means of buffer salts, to determine the chemical composition by use of synthetic culture media, and to stabilise the numbers of organisms by the use of thick suspensions of washed bacteria. These attempts are, however, doomed at the outset. From its very nature a bacterial culture is a constantly changing system, and if any factor is held artificially at a fixed level the culture is no longer the natural system with which the bacteriologist normally has to deal. Attempts to make artificial corrections for various changes, e.g., to make a correction, arbitrarily fixed for $\mathrm{pH}$ changes, are also useless. Knight (1930) has shown that, in the batch of culture broth used by him, the curve connecting electrode potential with $\mathrm{pH}$ varied between limiting "slopes" of 0.03 and 0.12 (a 300 per cent. variation) in the "physiological " range.

In synthetic media cultures of bacteria Ward (1938) finds the oxidation-reduction potentials more difficult to measure than in broth cultures, probably owing to the presence of poising and indicator systems in ordinary broth media and their absence from synthetic mixtures.

Another method of "standardising" conditions, namely, the attempt to fix the $\mathrm{pH}$ of culture media by buffering the broth, is full of pitfalls. A common method is to use phosphates for the purpose. Apart from the relative inefficiency of phosphates for buffering in the usual bacteriological range of $\mathrm{pH}$, there is the fact that phosphates have other effects on culture media. When autoclaved with phosphates, broth darkens and valuable constituents are destroyed, and, on the other hand, phosphates have an accelerating effect on carbohydrate metabolism (Hewitt, 1932). Thus the attempt to simplify the problem by $\mathrm{pH}$ fixation results in the introduction. of further complications.

Various attempts have been made to imitate the effects produced in bacterial cultures by bubbling nitrogen through culture media. Boyd and Reed (1931) have shown, however, that the potentials registered by inert electrodes immersed in culture media through which various gases are bubbled are the same as the potentials obtained under similar conditions with electrodes immerser in salt solutions. This observation, taken together with the obvious fact that the function of proliferating bacteria is so manifestly different from that of an inert gas, would suggest that little of significance can be expected from continued studies of the effects of bubbling nitrogen through culture media.

The bacteriologist frequently has to deal with pathogenic organisms requiring a rich and complex medium for typical proliferation to occur. The investigator cannot afford to ignore such systems if he wishes to gain an insight into some of the major problems of bacteriology and infection.

In the author's experiments and in an increasing number of those of others the conditions met with in ordinary bacteriological technique have been retained, as far as possible, in the study of electrode potentials. 
Typical curves relating the electrode potentials of aerobic cultures of hæmolytic streptococci and $C$. diphtherice (Hewitt, 1930, 2) at various stages of development are given in fig. 20. A small inoculum of hæmolytic streptococci was made into sterile peptone-infusion broth and even after 30 minutes the $\mathrm{E}_{\mathrm{h}}$ had commenced to fall, a minimum value $(-0 \cdot 16$ volt) being reached in 12 hours: this is approximately the duration of the logarithmic phase of growth and is characterised, as can be seen, by intense reducing activities. After this period the death rate of the

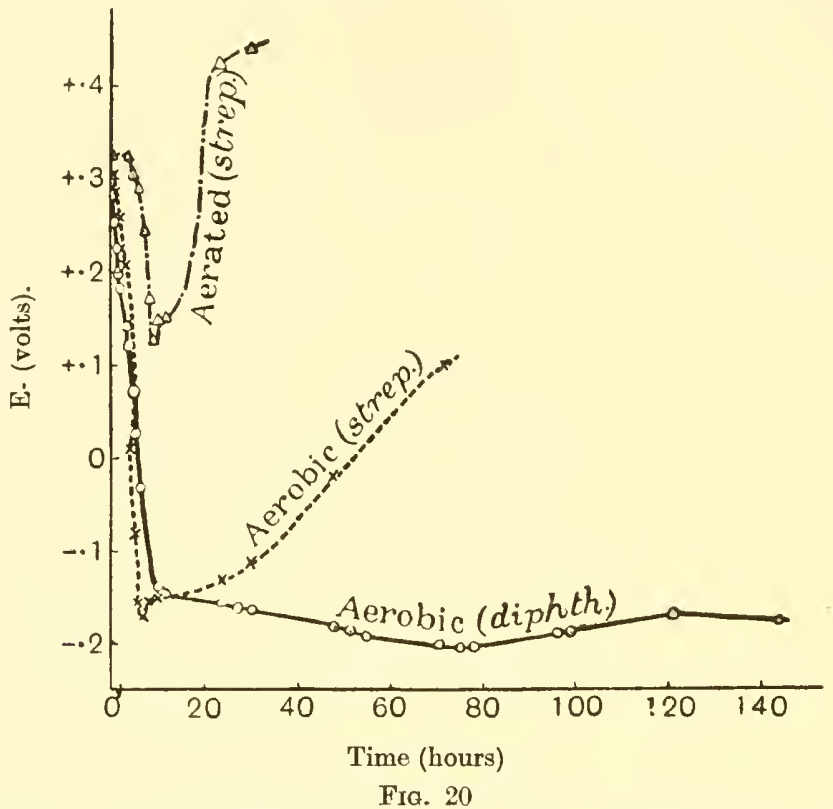

Electrode potential : time curves of infusion broth cultures of hæmolytic streptococci and $C$. diphtherice organisms becomes appreciable and the potential rises. Reducing conditions are not maintained under aerobic conditions when the organisms have ceased actively to proliferate. This increase in potential after the cessation of active multiplication is not, however, a general phenomenon exhibited by all organisms. In the case of C. diphtherice, for example, of which the corresponding curve is given in the same figure the potential falls to -0.2 volt, rather more slowly than with hæmolytic streptococci, but this level is maintained for some days.

When cultures are aerated, it is found, as would be anticipated, that the generous supply of oxygen prevents to some extent the establishment of intense reducing conditions. Thus in the case of hæmolytic streptococci (top curves in fig. 20) the potential in ordinary aerobic cultures falls to $-0 \cdot 16$ volt, whilst in specially aerated cultures it does not fall below $+0 \cdot 1$ volt, and a marked effect is seen after the phase of active proliferation. In the aerated culture, the potential rises rapidly and reaches +0.45 volt, a highly oxidising level, and peroxide may be detected in the culture.

In the case of $C$. diphtherice the aeration has some effect (fig. 21) in preventing the attainment of reducing conditions, but the effect is negligible compared with that observed in the case of hæmolytic streptococci. The electrocke potential rises 
somewhat after the logarithmic phase of growth but does not reach the high levels reached with streptococci and which correspond to peroxide formation.

If, now, two further organisms are studied, namely, pneumococcus and staphylococcus, it is found that the pneumococcus (fig. 13) behaves like hæmolytic streptococcus, whilst the staphylococcus (Hewitt, 1930, 3) resembles $C$. diphtheriar. It is significant that streptococci and pneumococci can form peroxide in cultures whilst $C$. diphtheria and staphylococci do not.

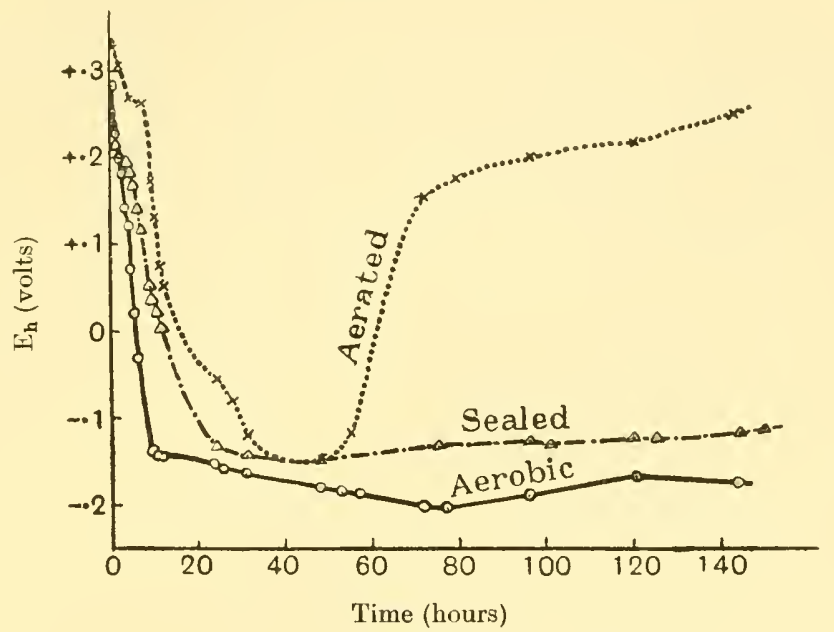

Fig. 21

Peptone infusion broth cultures of $C$. diphtherice

This brings us to an important phase in bacterial respiration and one which may be particularly amenable to study by electrode potential measurements.

\section{BACTERIAL PEROXIDE AND CLASSIFICATION OF ORGANISMS}

Hydrogen peroxide is of much more frequent occurrence than has perhaps been generally realised. The occurrence of hydrogen peroxide is supposed necessarily to accompany the formation of activated hydrogen in the presence of molecular oxygen. Much evidence has accumulated to prove the existence of dehydrogenating enzymes in bacteria. These activate the hydrogen in a hydrogen donator so that it is transferred to a hydrogen acceptor. Thus, in the presence of $B$. coli two atoms of hydrogen may be transferred from lactic acid to fumaric acid, whereby the lactic acid is oxidised to pyruvic acid and the fumaric acid is reduced to succinic acid ; thus :$\mathrm{CH}_{3} \mathrm{CHOH} . \mathrm{COOH}+\mathrm{COOH} . \mathrm{CH}: \mathrm{CH} \cdot \mathrm{COOH} \rightarrow \mathrm{CH}_{3} \cdot \mathrm{CO} \cdot \mathrm{COOH}+\left(\mathrm{COOH} . \mathrm{CH}_{2}\right)_{2}$ lactic acid fumaric acid pyruvic acid succinic acid

Oxygen itself may play the role of hydrogen acceptor and hydrogen peroxide is formed. Thus, in the presence of xanthine oxidase, xanthine is oxidised in the air to uric acid with concomitant formation of hydrogen peroxide :-

$$
\text { Xanthine }+\mathrm{O}_{2} \rightarrow \text { uric acid }+\mathrm{H}_{2} \mathrm{O}_{2} \text {. }
$$

The evidence for peroxide formation (Thurlow, 1925) frequently depends on such reactions as the oxidation of nitrate by the reaction mixture when peroxidase is added. 
Evidence has also been adduced for the formation of hydrogen peroxide when sulphydryl compounds, such as glutathione, are oxidised in the air :-

$$
2 \mathrm{GSH}+\mathrm{O}_{2} \rightarrow \mathrm{GSSG}+\mathrm{H}_{2} \mathrm{O}_{2} \text {. }
$$

Wieland and his co-workers have succeeded in obtaining quantitative yields of hydrogen peroxide in experiments with milk dehydrogenases, and Bertho and Glück (1931) have obtained high yields of peroxide in bacterial cultures.

Hydrogen peroxide is frequently produced as the result of the co-existence of "activated hydrogen " and molecular oxygen. McLeod and Gordon (1922, 1923) found that pneumococcal cultures produced hydrogen peroxide which inhibited bacterial growth. Avery with Morgan and Neill (1924) extended the study of peroxide formation and Neill and Avery (1925) found that sterile extracts of pneumococci produced peroxide when exposed to oxygen in the presence of appropriate "hydrogen donators." That the presence of actively proliferating cells is not essential for the formation of peroxide is in agreement with the author's

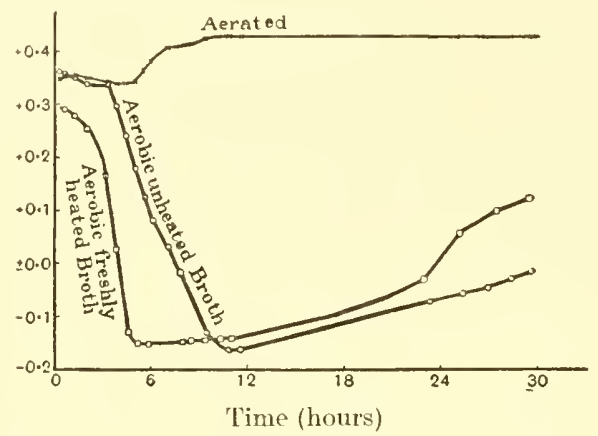

FIG. 22

Infusion broth cultures of pneumococeus, type II

experiments $(1930,1)$. It was found that in aerated cultures of hæmolytic streptococci reducing conditions were first established in the cultures but that after the logarithmic phase of growth, when the organisms had ceased to proliferate actively, oxidising condlitions were established and peroxide could be detected both by its reactions and by its effect on the electrode potential. Peroxide did not accumulate in cultures until after the active growth period when the number of living organisms was decreasing.

McLeod inclines strongly to the view that anaerobic organisms are unable to multiply because in the presence of air they would produce hydrogen peroxide, which would immediately inhibit growth. The greater the reducing power of the cell, in McLeod's opinion, the greater the tendency to form peroxide, hence the anaerobes would form peroxide readily. Many aerobic bacteria form catalase (Callow, 1923) in their cultures. In these cases, therefore, peroxide cannot accumulate as it is decomposed immediately it is formed. On the basis of the facts available McLeod classified organisms as follows :-

(i) Potential peroxicle producers. Devoid of catalase. Very sensitive to peroxide. The anaerobes. 
(ii) Peroxide producers. Devoid of catalase. Relatively insensitive to peroxide. Pneumococci and certain streptococci.

(iii) Non-peroxide producers. Devoid of catalase. Shiga's dysentery bacillus, certain streptococci.

(iv) Contain catalase. Majority of aerobes and facultative anaerobes.

It is obviously difficult, if not impossible, to establish the essential nature, or fortuitous arrangement of such a classification. Organisms of class IV might be sensitive or insensitive to peroxide if they did not contain catalase, and they might or might not form peroxide if they were without this enzyme. This group, therefore, may contain organisms of very different respiratory functions masked by their general property of producing catalase. although it must be conceded that the presence of catalase in many cells of aerobic habit must have the effect of protecting them from the destructive effects of peroxide. With regard to class (iii) it is possible that the absence of peroxide accumulation in cultures of organisms such as $B$. dysenterice

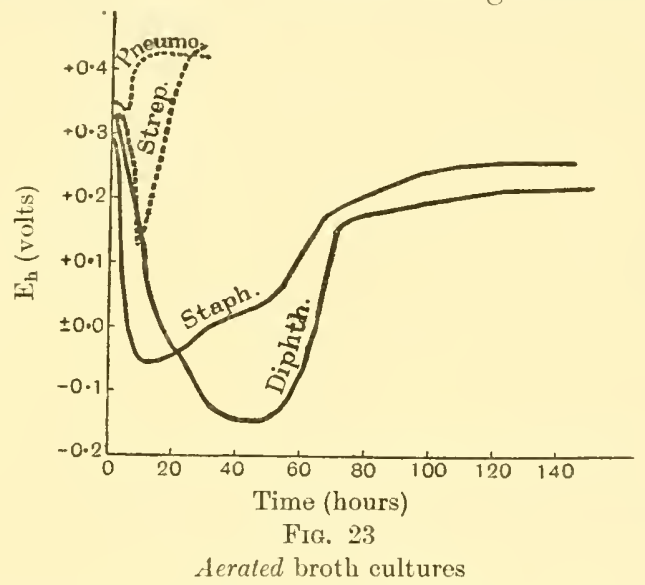

(Shiga), which do not contain catalase, may be due to the presence of peroxidase (Hewitt, 1931). It seems reasonable to suppose that when peroxidase is present any peroxide formed will rapidly disappear and not accumulate.

Two main problems emerge from this survey :-

(i) Does peroxide formation denote a different mechanism of respiration from that of non-peroxide forming organisms?

(ii) Are obligate anaerobes such because, if grown aerobically, they would form peroxide which would immediately stop growth?

The alternatives to these are that non-peroxide formation is an accidental phenomenon due to catalase production, etc., and that anaerobic organisms cannot grow in air for reasons other than peroxide production and its harmful effects.

To return to the experimental data given above, streptococci and pneumococci may be sharply differentiated in behaviour from staphylococci and $C$. diphtherioe. With the two former organisms the electrode potential commences to rise immediately after the cessation of active proliferation, whilst, with the latter organisms, the potentials remain at a low (i.e., reducing) level long after the logarithmic phase of growth. In aerated cultures (fig. 23) also the behaviour of the two different types of organisms may also be readily distinguished. With streptococci and pneumo- 
eocei the potential falls very much less than in stationary aerobie cultures. Under the conditions employed the fall in aerated cultures of these two organisms is only some 45 per cent. and 5 per cent. respectively of the fall in aerobic eultures, whilst, with staphylocoeci and $C$. diphtherice, the potential fall in aerated cultures is about 90 per cent. of the fall in aerobic cultures. After the phase of active proliferation the potential in streptococcal and pnemococcal cultures rises rapidly to the high oxidising level corresponding to peroxide formation, whilst in staphylococcal and diphtheria bacillus cultures the potential rises only slowly and never reaches a high level.

The high level of electrode potential reached by streptococei and pneumococci corresponds to the formation of hydrogen peroxide, which ean be detected in the cultures by reactions such as the benzidine-peroxidase test. [An acetic aeid solution of benzidine is added to the liquid or solid medium and a sliver of fresh potato is added. If peroxide is present, the surface of the potato assumes a blue tint of intensity proportional to the amount of peroxide present (Avery and Morgan, 1924).]

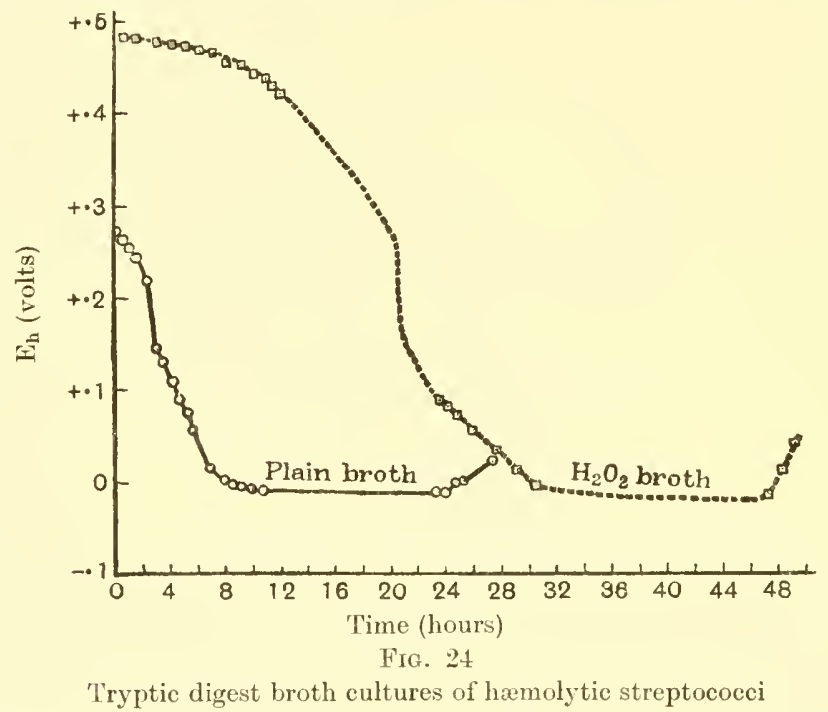

The potentials observed in eultures in which the presence of peroxide has been detected varies from $\mathrm{E}_{\mathrm{h}}+0.42$ to +0.51 volt according to the amount present. It is worthy of note that broth to which, approximately, 0.006 per cent. of hydrogen peroxide (A.R.) had been added had $\mathrm{E}_{\mathrm{h}}+0.48 \mathrm{v}$. and 0.02 per eent. hydrogen peroxide in saline had $\mathrm{E}_{\mathrm{h}}+0.52 \mathrm{v}$. Bacterial peroxide is identical therefore, at least in its electrode behaviour and chemical reactions, with hydrogen peroxide (Hewitt, 1930, 1), but reproducible and stable electrode potentials are not observed with peroxide and traces of peroxide disappear from eultures after reaction with constituents of the medium. A typieal wave is exerted by peroxides on the polarographie curve. (Chapter VIII.)

It is evident that the potential-time curves of peroxide-forming bacteria are quite different from those of the non-peroxide producers, but the question whether the differences can be explained solely by the catalase eontent of the latter organisms is not yet solved. Other enzymes eannot be without significance. 
An experiment was performed bearing on the sensitivity of organisms to peroxide. Hydrogen-peroxide disappears after a few hours when incubated in low concentration with some samples of tryptic digest broth. A 0.006 per cent. solution of hydrogen-peroxide in digest broth ( 8 c.c.) was inoculated with $0 \cdot 1$ c.c. of a 20 -hour broth culture of hæmolytic streptococci. When the culture was incubated, the potential (Fig. 24) fell gradually from its initial value of +0.48 volt and after 18 hours had reached the value of $\mathrm{E}_{\mathrm{n}}+0.3$ volt, which is the approximate level usually obtaining in laboratory stocks of broth. From this time the potential-time curve was similar to that of digest broth inoculated in the ordinary way with hæmolytic streptococci. The incubation with hydrogen-peroxide had had no appreciable effect on the behaviour of the organisms. Quastel and Stephenson (1926) found that incubation with hydrogen-peroxide did not interfere with the ability of the anaerobe $B$. sporogenes to proliferate when reducing conditions in the medium were established. This suggests that the toxic effect of peroxide is not responsible for the

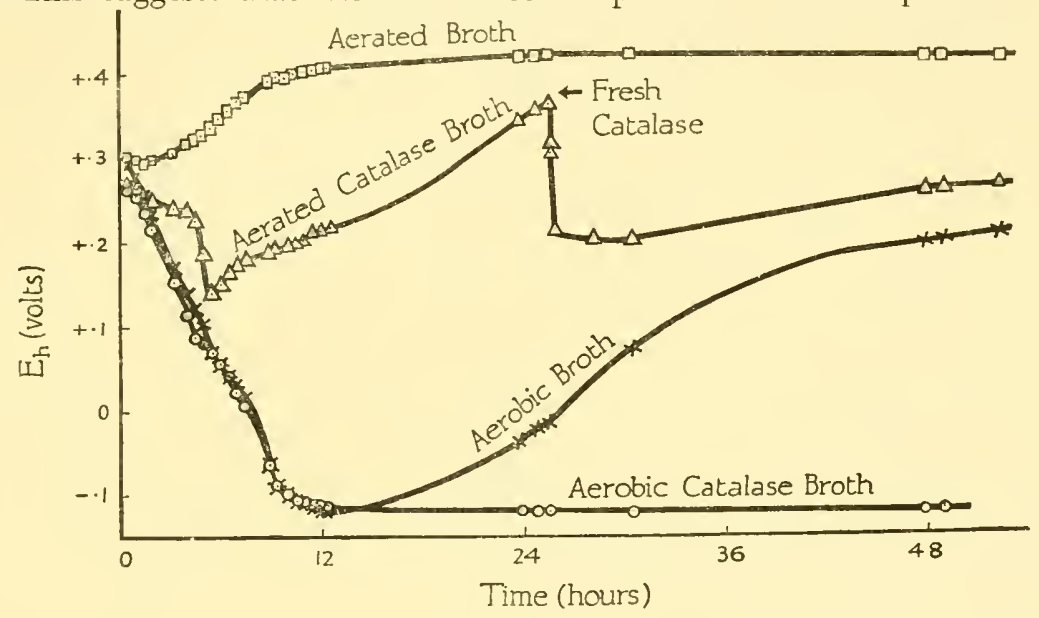

FIG. 25

Pneumococcus cultures

failure of anaerobes to grow aerobically, but McLeod (1930) criticises their experiments on a number of grounds. It would seem, therefore, that the question concerning the essential nature of peroxide formation in inhibiting the aerobic growth of anaerobic organisms must remain open (see also Johnstone, 1940; Kliger and Guggenheim, 1938 ; Molland, 1944 ; Reed and Orr, 1943).

Further observations (Hewitt, 1931) on peroxide formation by pneumococci indicate the important effect exerted by catalase on the electrode potential behaviour of bacterial cultures. When an active catalase preparation was added to an aerobic pneumococcus culture, the potential fell to the same level as in plain broth cultures, but after the logarithmic phase of growth a marked difference was seen. In plain broth cultures, the potential commences to rise after the cessation of active bacterial proliferation, but in cultures containing catalase the potential remained at a low level long after the cessation of active growth (see fig. 25). The rise in potential after growth is apparently associated with peroxide formation, although no peroxide 
can be detected chemically under these conditions. In specially aerated pneumococcus cultures, the potential fell to a much lower level when catalase was present. After a time, however, the potential in these aerated cultures commenced to rise, and this was due, in part at least, to destruction of catalase under the oxidising conditions established. This was shown by the fact that addition of a fresh catalase preparation resulted in an immediate fall in potential (see fig. 25).

The rapid fall in potential on adding catalase to cultures containing peroxide was noted on several occasions with cultures of pneumococci and of hæmolytic streptococci. This fall in potential is the more remarkable since, at the very time the potential is falling, the culture is being oxygenated by bubbles of oxygen liberated throughout the culture from the decomposed peroxide. Oxygen itself seems, in fact, to have a stimulating effect on the growth of both pneumococci and hæmolytic streptococei as long as the accumulation of peroxide is prevented. Thus an aerated fifty-hour culture of pneumococci was completely sterile. whereas in an otherwise similar culture to which catalase had been added growth was particularly good and the bacteria proliferated actively when sub-cultured. From the evidence presented it is clear that the harmful effects of peroxide on some bacteria at any rate are not due to the tendency to liberate molecular oxygen. The catalase preparation used in most of these experiments was prepared from liver, but similar results were obtained using red blood corpuscles and killed aerobic bacteria (M. lysodeikticus) as the source of catalase; allowance must be made, of course, for the differences in the gross properties of the enzyme preparations. Similar results were obtained with both pneumococci and hæmolytic streptococci.

The experiments present new evidence of the formation of hydrogen-peroxide in cultures of hæmolytic streptococci and pneumococci, and it is obvious that the presence or absence of catalase from bacteria has marked effects on their electrode potential behaviour. Some of the differences between $C$. diphtherioe and staphylococci on the one hand and hæmolytic streptococci and pneumococci on the other are evidently due to the presence of catalase in the former and its absence from the latter bacteria. It is probable, however, that there are other differences between the reducing activities of the two classes of bacteria.

Experiments bearing on the subject of bacterial peroxide formation by bacteria are described in a later section on bacterial variants.

\section{ANAEROBIOSIS}

Given the two postulates:-

(i) Anaerobes are very sensitive to peroxide which inhibits their growth;

(ii) They produce peroxide when exposed to air, since they do not contain eatalase ;

an explanation is provided of why anaerobes do not proliferate in the presence of air. It is difficult, however, to devise experimental proofs for or against this explanation which would be absolutely convincing and free from criticism.

In any case, the problem of anaerobiosis may be regarded from a different point of view. It has been mentioned that aerobic bacteria such as staphylococei, streptococci, pneumococei or C. diphtheria (Hewitt, 1930, 1, 2, 3, 4) reduce the medium in which they are cultivated, so that the original level of electrode potential of the medium $\left(\mathrm{E}_{\mathrm{h}}=+0.3 \mathrm{v}\right.$. circa) falls to about -0.15 to -0.20 volt. When 
obligate anaerobes are inoculated into broth kept under aerobic conditions, no reduction is effected and the potential remains unchanged at about $+0 \cdot 3 \mathrm{v}$. Lepper and Martin $(1929,1930)$ have investigated the meat tubes used for the cultivation of anaerobes. The pieces of cooked meat placed in these tubes are able to maintain reducing conditions in such tubes even when the surface of the medium is exposed to air. In fact, an $\mathrm{E}_{\mathrm{h}}$ of about -0.2 volt is established, the effect being ascribed to the autoxidation of lipins and to the reversible oxidation-reduction system :parahæmatin $\rightleftharpoons$ hæmochromogen. When staphylococci are inoculated into this medium no fall in potential occurs, in agreement with the results quoted above, namely that a minimum level of $-0 \cdot 2 \mathrm{v}$. is reached in cultures of staphylococci. But when anaerobic organisms such as $B$. tetani are introduced into the medium the potential falls to a level of $-0.4 \mathrm{v}$. or even lower. We find therefore that aerobic organisms are able to reduce ordinary aerobic media to the level $\mathrm{E}_{\mathrm{h}}-0.2$ volt, whilst anaerobes are unable to reduce ordinary aerobic culture media, but require the medium to be partially reduced before proliferation can commence. In addition some organisms, the facultative anaerobes, are capable of either aerobic or anaerobic growth.

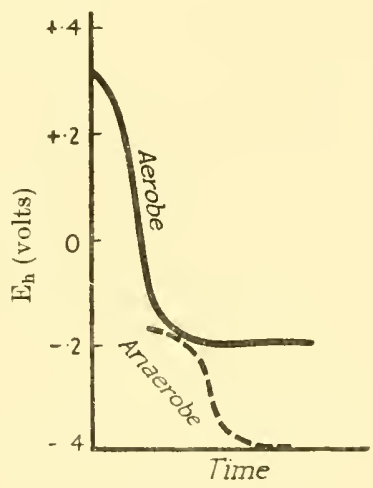

Fig. 26

Potential-time curve of hypothetical aerobe and anaerobe

The degree of reduction attained (or potential reached) is not necessarily different for aerobes and anaerobes. Some aerobes, e.g., B. coli, beginning with ordinary aerobic media, are capable of producing the most intense reducing conditions, even corresponding to the potential of the normal hydrogen electrode. On the other hand, some anaerobes are incapable of proliferating in ordinary aerobic media, and, even under anaerobic conditions, they are unable to give rise to intense reducing conditions or very low potentials. The distinguishing feature of aerobes and anaerobes, therefore, is not in the potential ultimately reached in the culture, but in the potential range at which they are able to initiate growth.

Figs. 26 and 27 are intended to illustrate this point of view. Fig. 26 represents the potential : time curve of a hypothetical aerobe and anaerobe. The aerobe is able easily to reduce the medium from the level of potential of ordinary aerobic culture media $\left(\mathrm{E}_{\mathrm{h}}\right.$ about $+0.3 \mathrm{v}$.) to about $-0.2 \mathrm{v}$. but no lower. The anaerobe, on the other hand, is unable to reduce ordinary aerobic media, but if the medium is subjected to a preliminary partial reduction the anaerobe can continue the reduction and reduce 
the medium to a level of potential of $-0.4 \mathrm{v}$. or even lower. The preliminary reduction of the medium may be effected by various methods, e.g., by :-

(1) Boiling off the air.

(2) Using $0 \cdot 2 \%$ agar gives a "sloppy" consistency preventing the diffusion of air back into the medium after expulsion of air.

(3) Sealing the medium with a vaseline seal to exclude air after de-aeration.

(4) Sealing with alkaline pyrogallol which absorbs oxygen.

(5) Ineluding a strip of iron which absorbs oxygen when it rusts.

(6) Adding a reducing agent such as $0 \cdot 1 \%$ thioglycollic acid. Brewer's medium consists of semi- "sloppy" agar ; it is boiled to expel air and thioglycollate is added. By using such media strict anaerobes ean multiply even under conditions of ordinary aerobic incubation.

(7) Growing an aerobic organism to lower the oxidation-reduction potential. This method provides the explanation of symbiotic aerobic growth of anaerobes in the presence of an aerobe.

(8) Removing air by burning hydrogen and incubating in a hydrogen atmosphere in a McIntosh and Fildes jar.

(9) Some anaerobes when inoculated heavily in aerobie media are able to multiply in ordinary culture media.

(10) Using meat media containing shreds of meat which de-oxygenate the medium by mechanisms discussed in Chapter III.

Limiting oxidation-reduction potentials for the growth of anaerobic bacteria are discussed by Aubel, Rosenberg and Grunberg (1946).

In fig. 27 are plotted the reducing activities at different $E_{\mathrm{h}}$ levels of a hypothetical aerobe and obligate anaerobe. The range of reducing activities of the aerobe is from about $+0.4 \mathrm{v}$. to $-0.2 \mathrm{v}$, whilst that of the anaerobe is about +0.05 to - $0.4 \mathrm{v}$. Probably no hard and fast line can be drawn between "aerobes" and "anaerobes," a continuous gradation of properties being observed. In media exposed to general contamination from the air, one organism after another proliferates freely as the $\mathrm{E}_{\mathrm{h}}$ level is depressed and reaches the optimum level for the reducing activities of the different bacteria. This description is intended to give a clear picture of the difference in behaviour of different organisms, without prejudice to the problem of peroxide formation, and the definition of the basis of these differences is the next important point. A reasonable explanation would seem to be that the redueing powers of bacteria depend on the enzymes they are able to produce. Aerobic organisms, such as staphyloeocei, are able to effect reversible oxidation-reduction processes at a high level (oxidising level) of $\mathrm{E}_{\mathrm{b}}$, but not at low levels ; whilst tetanus is able to effect reductions at low $\mathrm{E}_{\mathrm{h}}$ as its enzymes are able to catalyse reactions which oecur only under intense reducing conditions. A crude analogy might be made to vacuum pumps-an ordinary water pump is analogous to the aerobes and can reduce the pressure efficiently from $760 \mathrm{~mm}$. to $20 \mathrm{~mm}$. Mercury pumps are almost useless when the pressure is $760 \mathrm{~mm}$., but they are able to work efficiently where the water pump leaves off and reduce the pressure to $0.001 \mathrm{~mm}$.

Many biological processes for obtaining energy probably consist in large measure of reactions of the type

enzyme

$$
\mathrm{AH}_{2}+\mathrm{B} \rightleftharpoons \mathrm{A}+\mathrm{BH}_{2}
$$


At different levels of $\mathrm{E}_{\mathrm{b}}$ it can well be imagined that different hydrogen donators $\left(\mathrm{AH}_{2}\right)$ and different hydrogen acceptors $(\mathrm{B})$ come into use, and that these require different enzymes; so that the powers of bacteria to utilise such systems as sources of energy and hence to multiply at different levels of $\mathrm{E}_{\mathrm{h}}$ depend on the enzymic activities which they are able to call into play.

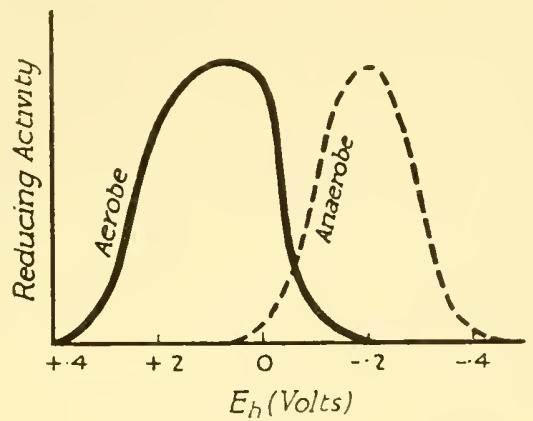

Fig. 27

Reducing activities at different levels of $\mathrm{E}_{\mathrm{h}}$ of hypothetical aerobe and anaerobe

The anaerobes present in an acute form the difference between bacteria and multicellular organisms. "Coarse" growing organisms, like Esch. coli, possess such a wealth of varied enzyme systems that they are able to adapt themselves to a wide variety of conditions, that is to say they are able to utilise many different substrates to obtain energy, and one or other of their enzyme systems are able to function under most cultural conditions. The anaerobes on the other hand probably have deficiencies in their armoury. They are deficient in cytochromes and oxygen utilising systems so they are unable to effect metabolic reactions and are unable to obtain the resulting supplies of free energy for synthetic reactions at high oxidation-reduction potential levels. This defect is cumulative; not only are they unable to start processes under oxidising conditions but they are unable as a result to start the synthetic and reductive processes which would assist in providing the energy and raw materials for anaerobic processes. When components of an enzyme reaction are kept permanently in an oxidised condition things may be brought to a standstill for lack of activated radicals which require to be partly reduced.

In addition, the type of reation which anaerobes are able to effect probably require $\mathrm{SH}$ activation and in the presence of air these may be all oxidised:

In the terms of the Pasteur effect mentioned in the previous chapter, anaerobic fermentations are inhibited by aerobic oxidation of various intermediates in the glycolytic chain, and since the anaerobe is deficient in the enzymes which can, in parallel reactions, effect reductions, the anaerobic fermentations are permanently stagnated.

To summarise, therefore, the Clostridia are incapable of aerobic growth at a high oxidation-reduction potential because they are deficient in enzymes capable of utilising oxygen; they are deficient in iron porphyrin enzyme systems such as catalase and cytochrome. Not only does this prevent them obtaining energy by the oxidation of nutrient material at the relating high oxidation-reduction potentials at which they function but also oxygen is not passed on to other enzyme systems not containing iron porphyrins, so that there may be a scarcity of acceptable hydrogen acceptors for 
metabolic reactions. An indirect effect of deficiency of "oxygen enzymes" may be even more important in that inhibitors of important aerobic fermentations may accumulate (e.g., peroxide cannot be rapidly removed in the absence of catalase) and activators, such as SH compounds, may not be formed in sufficient concentration.

It should perhaps again be emphasised that different classes of bacteria and even different strains vary so much that all anaerobes do not behave identically and many shades of difference can be detected from the very strictest anaerobes to the microaerophile, which can multiply slowly even in the presence of air. At the other extreme to the anaerobes are the obligate aerobes which flourish in an oxygen-rich environment and are well provided with iron-porphyrin and "oxygen" enzymes, but are singularly deficient in available fermentation enzymes and in the absence of abundant oxygen cannot multiply.

\section{EFFECT OF CULTURAL CONDITIONS ON POTENTIALS}

In the presence of serum, the electrode potentials of bacterial cultures frequently do not fall to as low a level as in plain broth (Hewitt, $1930 ; 1,2,3,4)$. A typical experiment is illustrated in fig. 28. In plain broth, the potential of the culture of hæmolytic streptococci fell to $\mathrm{E}_{\mathrm{h}}-0 \cdot 16$ volt, but in 50 per cent. serum-broth the potential did not fall below $+0 \cdot 10$ volt. This represents less than 50 per cent. of the fall in potential in plain broth. The same oxygen-carrying effect was found to be produced by the serum proteins prepared by salting out the proteins by sodium chloride and acetic acid. It has been tentatively suggested that sulphydryl groups in the protein molecule may have an oxygen-carrying effect.

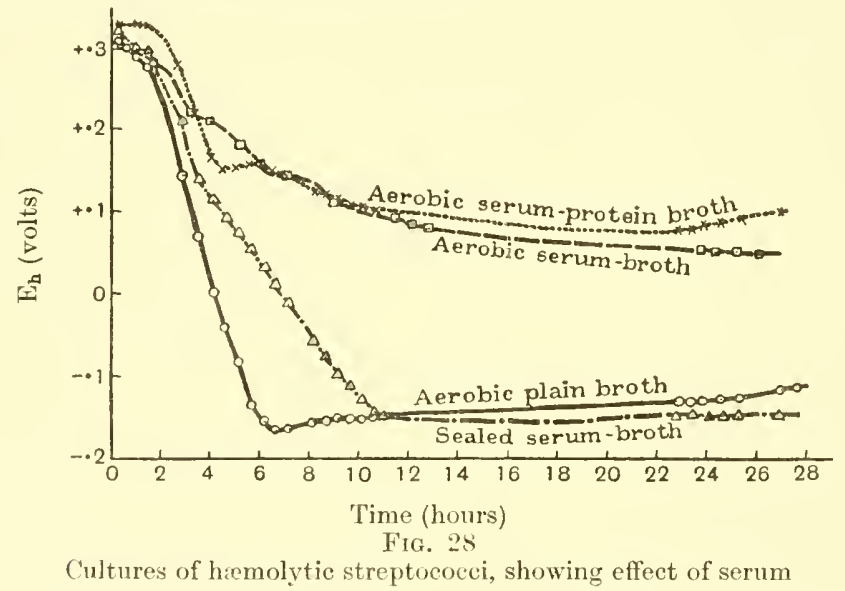

The presence of sulphydryl groups in proteins has been demonstrated by Hopkins. In certain cases, these groups can be detected chemically only after denaturation and reduction (1930), but it is possible that their effect on bacterial respiration may be manifested in the native proteins. In serum proteins, the sulphur compounds appeared to be in the oxidised condition, in agreement with observations of the poising effect mentioned above.

Lepper and Martin (1929) have shown that the unsaturated fatty acids in lipins and also hæmatin compounds are of importance in the reducing effects observed in culture media. These compounds may well occur in serum together with traces of hæmoglobin, thus making a very complex system. 
The amount of the oxygen-carrying effect varies somewhat for different samples of serum, but was observed with all the sera studied to some extent. This poising effect of serum on the electrode potentials developed in bacterial cultures is of considerable importance. It may account for the beneficial effect of serum on the cultivation of organisms such as hæmolytic streptocoeci and, above all, may account for the special biological behaviour of organisms freshly isolated from the blood stream. This subject is dealt with in the next section on bacterial variation. It is possible that the poising effect of proteins accounts for the non-germination of tetanus spores in the body. Fildes (1929) has shown that tetanus spores do not germinate unless the $\mathrm{E}_{\mathrm{h}}$ level is adjusted below that of the subcutaneous tissue. Fildes and Knight (1930) also investigated the levels of potential necessary for tetanus. spore germination.

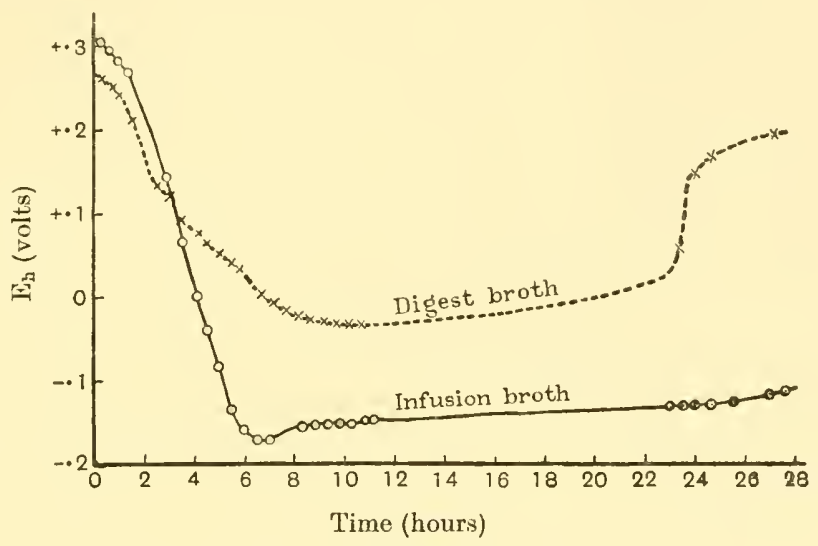

FIG. 29

Broth cultures of hæmolytic streptococci

Some samples of Douglas's tryptic digest medium have a quite considerable oxygen-carrying effect preventing the level of potential of bacterial cultures in this medium falling to the low level reached in infusion broth (fig. 29). It appears possible that tryptic digestion of flesh nay liberate oxygen-carrying substances similar to those present in serum proteins.

The presence of glucose produced characteristic effects on the electrode potentials reached in bacterial cultures (fig. 30 ). With each organism studied the potentials in 1 per cent. glucose broth fell rapidly at first, but after a few hours' growth the potential curve showed a short period of rapid increase followed by a slight fall and then a gradual rise. The sudden reversal in direction of the potential-time curve occurs at about the time when acid production becomes appreciable, but it is doubtful if the direct effect of $\mathrm{pH}$ upon the electrode potential accounts for the phenomenon, although it is true that the metabolic processes which give rise to the production of acid are also responsible for the changes in potential. In order to account for some of the rapid potential changes it would be necessary to have a $\mathrm{pH}$ change of the order of one unit within a few minutes. However, Gillespie and Rettger (1936) state, without giving details, that with one strain of a lactobacillus they are of opinion that the inversion of potential might be accounted for on the grounds of $\mathrm{pH}$ change. 
With hæmolytic streptococci the potential in aerated 1 per cent. glucose cultures falls very little despite the very luxuriant growth observed and no peroxide is detected. No obvious relation was noted between the amount of growth and the fall in potential of bacterial cultures.

With $C$. diphtherice and staphylococci the organisms are able to utilise intermediate fermentation products of glucose (e.g., lactic acid) in the presence of a generous oxygen supply, so that in some cases a vigoronsly aerated culture may be more reducing than in an otherwise similar ordinary aerobic culture.

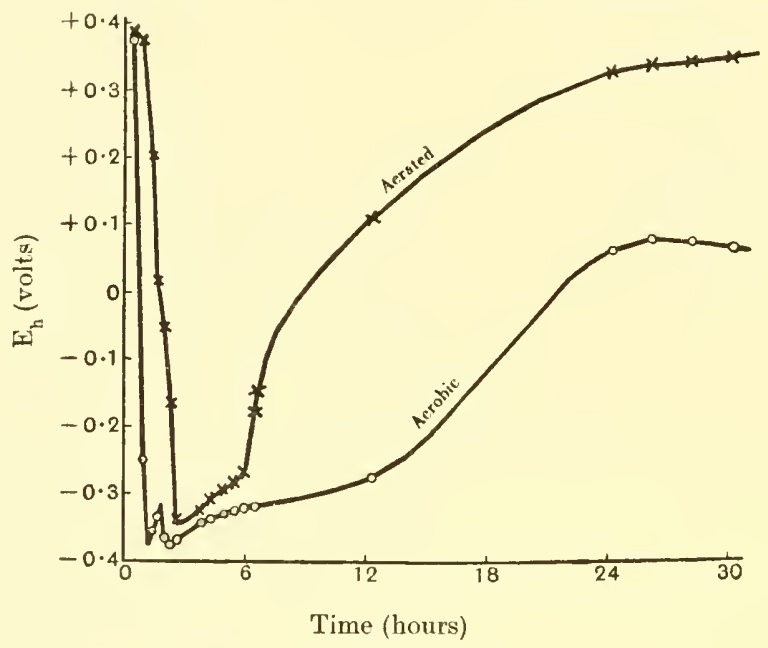

FIG, 30

Glucose broth cultures of $B$. coli

The measurement of electrode potentials of bacterial cultures reveals distinct differences between the effects of different media and cultural methods on the conditions to which the proliferating organisms are subject. The characteristic effects of the presence of serum and glncose on the oxidation-reduction conditions in sultures, the effect of aeration and the differences between peptone-infusion broth and trypticdigest media have already been mentioned. Fiven differences in the time since heating a culture medium are reffected in the potential time curve, since it is found that the potential falls more rapidly with some organisms when the medium has been freshly heated, and, particularly in the case of tryptic digest medium, the potential in streptococcal cultures rises more rapidly in the freshly boiled medium, with concomitant more rapid production of peroxide. These differences may be correlated with the observation of Dubos (1929) that smaller implants of organism are necessary for cultivation in freshly heated medium.

Different batches of the same type of broth vary considerably, as judged by the potential-time curves of cultures as well as by observations of the luxuriance of growth, amount of toxin production, etc. Particnlarly marked were the differences observed between different batches of tryptic-digest broth. which is not surprising when the difficulties in controlling the processes of digestion are eonsidered. Different samples of serum have varying effects on the potentials of cultures. These variations 
produced in different culture media, which are, perhaps, a commonplace to many bacteriologists, tend to obscure important generalisations and reveal the need for systematic scientific investigation of culture media by all available methods.

It might be anticipated that exclusion of air would always accelerate the establishment of reductive conditions in cultures. Actually, however, it is found with some arrobic bacteria studied that the potential falls more sluggishly when air is excluded. The rapid development of intense reducing conditions requires the presence of oxygen for the reducing antivities of the cells to reach their maximum intensity. Even when cultures are agitated and aerated vigorously, quite interse reducing conditions may be established, especially in the case of those organisms which do not form peroxide in cultures. These facts may be regarded in two ways. They indicate the comparatively slight effect of molecular oxygen on the potentials of cultures, and they indicate the avidity which aerobic bacteria evince for the oxygen they require for metabolic processes.

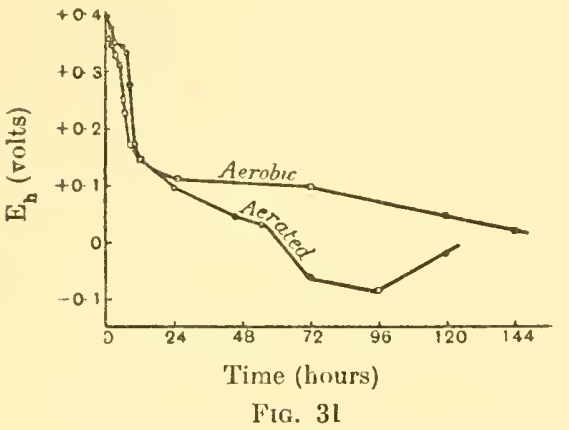

Broth cultures of M. lysodeikticus

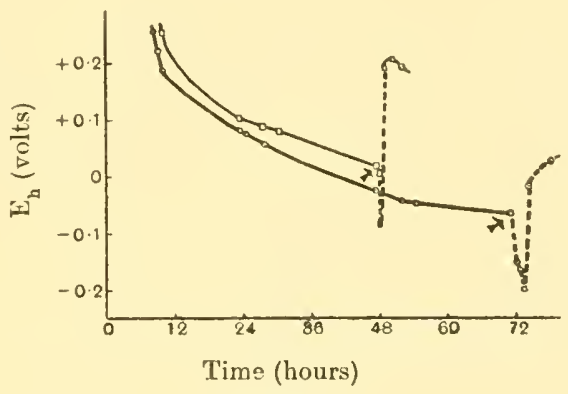

Fia. 32

Aerated cultures of M.lysodeikticus. Lysozyme (human tears) was added at the points marked by arrows

In the case of the aerobe, $M$. lysodeiticus, it was found that niore abundant growth and a more rapid fall in potential were observed when the oxygen supply was increased by aeration. (See fig. 31.)

\section{EFFECT OF LYSOZYME AND BACTERIOPHAGE}

A few experiments have been conducted on the effects of various lytic agents on the electrode potentials of bacterial cultures (Hewitt, 1931).

When Fleming's lysozyme (present in tears, egg-white, etc.) was added to aerated cultures of Micrococcus lysodeiliticus (see fig. 32) there was an immediate fall in potential; after this period reducing conditions are no longer maintained and the culture is completely lysed. The catalase activity of the organisms is enhanced when they are lysed, although the dehydrogenating activities are destroyed (Penrose and Quastel, 1930). It is probable that during the actual lysing process there is increased enzymic activity followed by destruction of some enzymes when lysis is complete. It is, of course, possible that lysis liberates intensely reducing substances from the interior of the bacteria and the author's disinclination to accept this hypothesis is, perhaps, personal rather than logical. 
When the appropriate bacteriophage was added to cultures of $B$. dysenterice (Shiga) no proliferation of the bacteria was observed and there was no fall in potential. Addition of bacteriophage to cultures after proliferation had occurred had little effect except to inhibit any appreciable further fall in potential. (See fig. 33.) In the case of $B$. coli communis, the addition of the bacteriophage delayed proliferation of the bacteria and also delayed the fall in potential but did not affect the ultimate growth

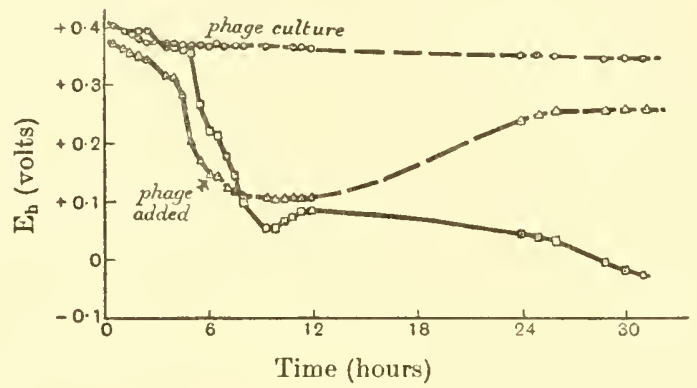

Fig. 33

Aerated broth cultures of $B$, dysenteria (Shiga)

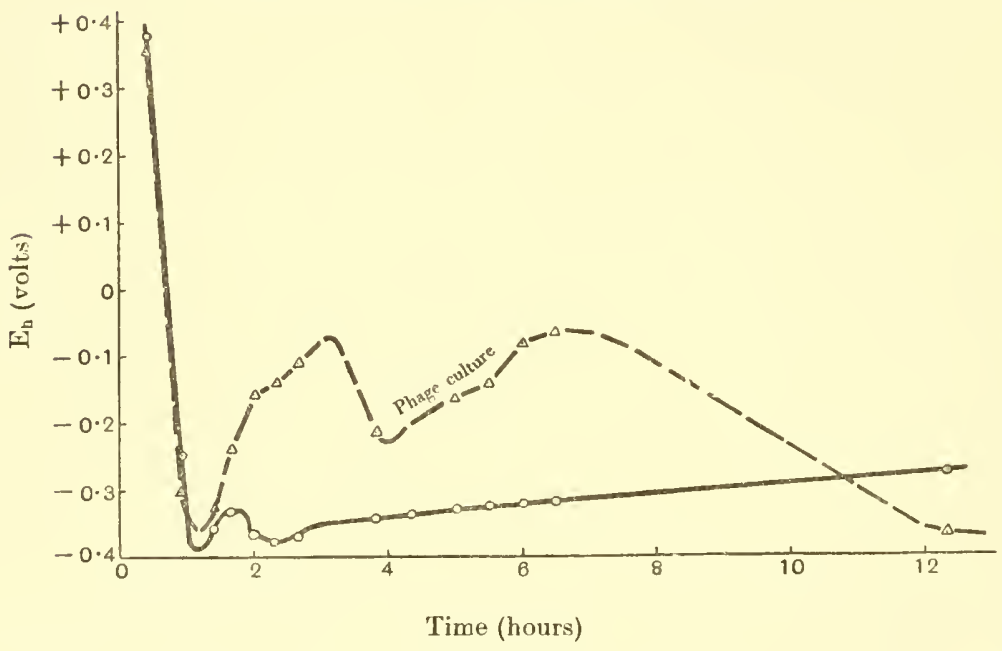

Fig. 34

Aerobic glucose broth cultures of $B$. coli communis

or potential of the culture. In the case of aerobic glucose cultures the potential fell initially even in the presence of bacteriophage despite the absence of visible growth in these early stages. After this early fall the potential rose and did not fall again until visible growth of the culture was noticeable. (Sce fig. 34.) The initial fall in potential was, perhaps, due to activation of the glucese by the non-proliferating bacteria inoculated into the medium. Rather similar phenomena were observed in the case of Siaphylococcus aureus. This last observation has been confirmed, in a personal communication, by Dr. Clifton of Stanford University, California. 


\section{POTENTIALS OF DIFFERENT BACTERIA}

Homolytic streptococci and pneumococci.-These organisms, as described in an earlier section, are deficient in catalase activity and hence peroxide is formed in aerated cultures. For this reason the electrode potential does not remain at a low level after the cessation of active proliferation, but begins to rise to the high positive potential characteristic of peroxide. These phenomena are not apparent when catalase preparations are added to the cultures (Hewitt, 1930, 1931). The bacteria are deficient in various oxidative mechanisms as well as catalase, and although they are fairly active in effective fermentations of sugars, they display little oxidising activity towards the fermentation products (Hewitt, 1932). Oxidation-reduction conditions affect the behaviour of the hæmolysin of those hæmolytic streptococci which are of importance in human infections and the maintenance of the virulence of these organisms also is apparently related to the electrode potentials of the cultures as described in a later section.

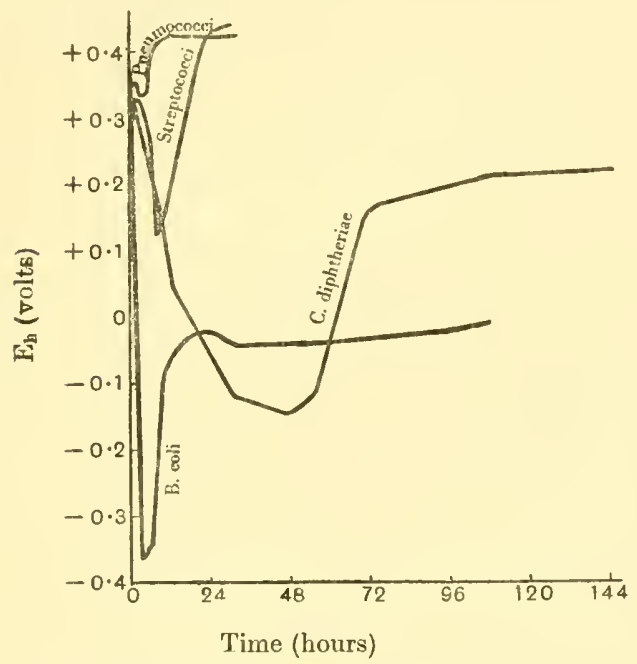

Fig. 35 Aerated broth cultures

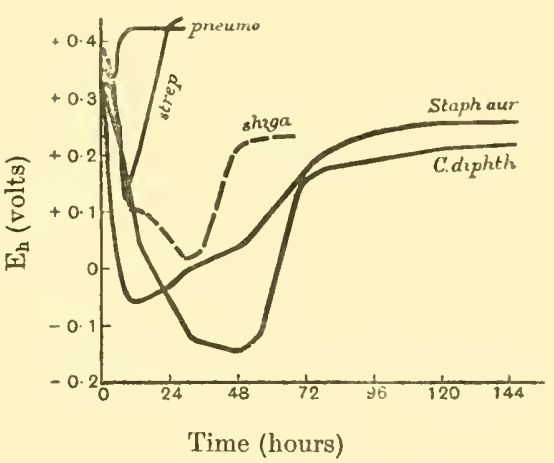

FIG. 36 Aerated broth cultures

C. diphtheria.-Diphtheria bacilli display very marked catalase activity, as may be demonstrated by letting fall a drop of hydrogen peroxide upon a culture on solid medium and observing the effervescence which is frequently vigorous enough to lift the colonies off the surface. It is evident, therefore, that peroxide cannot accumulate in such cultures, and it is found indeed that the electrode potential of diphtheria cultures remains at a low level long after the logarithmic phase of growth, and does not ever rise to the high level characteristic of peroxide formation (Hewitt, 1930). Diphtheria bacilli are able readily to oxidise substances such as fatty acids, etc., converting them to carbonates, hence aerobic cultures may become very alkaline (well over $\mathrm{pH} 8.0$ or even 8.5 ). For toxin production it is necessary to ensure a generous oxygen supply in the cultures as, for example, by using a shallow layer only of medium. No such conditions have been found necessary for the soluble toxins of hæmolytic streptococci. 
Staphylococcus aureus. - In general behaviour this organism resembles C. diphtheriae. The organisms display considerable catalase activity and do not form peroxide, and the electrode potentials of cultures remain at a low level after growth (Hewitt, 1930, 1931 ; Clifton, 1933).

B. dysenterice (Shiga).-Although deficient in catalase, these organisms behave in a manner resembling that of bacteria containing catalase, possibly on account of peroxidase activity (Hewitt, 1931.) The organisms possess rather feeble reducing powers, and even these are inhibited in the presence of bacteriophage.

Escherichia coli.-The electrode potentials in Escherichia coli cultures reach a very low level, as would be expected from the intense enzymic activity displayed (sce fig. 35.) Hydrogen is liberated from cultures, so that the low potentials of the hydrogen electrode are reached, or even surpassed, especially in cultures containing glucose (Gillespie, 1920 ; Cannan, Cohen and Clark, 1926; Aubel and Génevois, 1927 ; Hewitt, 1931; Boyd and Reed, 1931; Clifton, Cleary and Beard, 1934). Clifton, Cleary and Beard (1934) followed the ferricyanide reducing powers of $B$. coli cultures at different stages of growth, the results being as follows :-

TABLE 23

\begin{tabular}{|c|c|c|}
\hline $\begin{array}{c}\text { Age of culture. } \\
\text { (Days) }\end{array}$ & $\begin{array}{c}\text { Plate count } \\
\text { x 10" per 1 c.c. }\end{array}$ & $\begin{array}{c}\text { Ferricyanide reduced } \\
\text { (Mlillimols per cell per } \\
\text { minute) }\end{array}$ \\
\hline 1 & 80 & $7 \cdot 36 \times 10^{-14}$ \\
2 & 110 & $5 \cdot 15 \times 10^{-14}$ \\
3 & 83 & $4 \cdot 82 \times 10^{-14}$ \\
4 & 73 & $4 \cdot 41 \times 10^{-14}$ \\
6 & 51 & $3 \cdot 92 \times 10^{-14}$ \\
\hline
\end{tabular}

The intense reducing activity of the bacteria may be gauged from the fact that fifteen million molecules of oxidant may be reduced by one cell in a minute.

\section{Salmonella group.}

In $B$. typhosus cultures a potential of $-0 \cdot 145$ v. was reached (Coulter and lsaacs, 1929). Lepper and Martin (1930) examined meat broth cultures of $B$. paratyphosus $A$ and $B$, and found that the potential fell to a much lower level with $B$. paratyphosus $A$, possibly associated with the concomitant gas formation.

Burrows and Jordan (1935) have examined various members of the Salmonella group, and have concluded that each species produces in cultures an electrode potential characteristic of that species. In the next table (table 24) are summarised their results, the mean value of the potentials reached by a number of strains of each species after different incubation periods being given. 
TABLE 24

Electrode Potentials in Cultures of Members of Salmonella Grodp ( $\mathrm{E}_{\mathrm{h}}$ in volts)

\begin{tabular}{|c|c|c|c|c|c|c|}
\hline \multirow{2}{*}{\multicolumn{3}{|c|}{ Species }} & \multicolumn{4}{|c|}{$\mathbf{E}_{\mathbf{b}}$ after incubation for: } \\
\hline & & & 36 & 48 & 60 & $72 \mathrm{hrs}$. \\
\hline B. choleroe-suis. & $\ldots$ & $\ldots$ & +0.014 & +0.041 & +0.034 & +0.032 \\
\hline B. paratyphosus $A$. & $\cdots$ & $\cdots$ & -0.058 & $-0 \cdot 050$ & -0.057 & -0.048 \\
\hline B. typhosus ... & ... & ... & $-0 \cdot 090$ & $-0 \cdot 082$ & -0.076 & -0.075 \\
\hline B. paratyphosus $B$. & ... & ... & -0.091 & -0.091 & $-0 \cdot 090$ & -0.093 \\
\hline B. enteritidis ... & $\ldots$ & $\ldots$ & -0.171 & $-0 \cdot 175$ & $-0 \cdot 186$ & $-0 \cdot 189$ \\
\hline
\end{tabular}

Burrows and Jordan have attempted to fit an equation of the $y=a x+b$ type to these curves of potential drift, but, beyond stating that the different species behave differently, little more can be expected from a mathematical analysis of systems containing so many variable factors.

B. megatherium.-Knaysi and Dutky (1934) and Wood, Wood and Baldwin (1935) present different evidence upon the effect of electrode potentials on the initiation of growth of this organism.

Anaerobes.

The factors concerned in anaerobic growth have already been discussed in general terms.

Cl. welchii and Cl. tetani.-Lepper and Martin (1930) found that a low level of potential was attained by these organisms in media containing meat. In the latter case, at any rate, gas formation (hydrogen) did not account for the low potential reached. Plotz and Geloso (1930), Fildes (1929), and Knight and Fildes (1930) have investigated the upper limit of potential inhibiting the proliferation of $\mathrm{Cl}$. tetani and its spores.

$\mathrm{Cl}$. botulinum and Cl. sporogenes.-Plotz and Geloso (1930) described the low level of potential attained in cultures of these organisms. (See also Hanke and Bailey, 1945.)

Non-sporulating anaerobes. - In cultures of those anaerobic bacteria which do not form spores, a very wide range of potentials is reached. (Dack and Burrows, 1935.)

B. saccharobutylicus.-From observations on an anaerobic strain of the butyric acid bacillus it was concluded by Messing (1934) that the growth of this anaerobe is dependent upon the metabolic activities of the organism, and not solely upon the electrode potential of the culture medium.

M. lysodeikticus. - This aerobe was found to grow more readily and even attain more intense reducing potentials when the culture was vigorously aerated. Some fall of potential was okserved when the organisms were lysed by addition of lysozyme (Hewitt, 1931.)

B. subtilis and B. mycoides.-These were examined by Gillespie (1920) but were not found to attain the low levels of potential reached by soil organisms. The slow fall in potential of $B$. subtilis cultures was observed also by Cannan, Cohen and Clark (1926). 
B. fuorescens and Proteus vulgaris.-In cultures of B. fuorescens the potential reached a low level, but with Proteus vulgaris the potential fell slowly and did not attain a low value. (Cannan, Cohen and Clark, 1926.)

Denitrifying bacteria.-Elema (1932) found that the potentials of cultures of Pseudomonas pyocyanea fell rather slowly to a moderately low level. In a synthetic medium composed of potassium nitrate, potassium phosphate and ethyl alcohol the potentials of cultures of $B$. vulpinum fell to the level -0.116 v. in 7 hours. Similar results were obtained with $M$. denitrificans.

Elema, Kluyver and van Dalfsen (1934) have followed the electrode potentials reached in anaerobic cultures of $\boldsymbol{M}$. denitrificans. The culture medium contained phosphate, alcohol and nitrite, and as long as nitrite was present there was a poising effect on the potentials but as soon as all the nitrite had been converted to nitrogen the potential fell to a low level. Addition of nitrite now caused a rise in potential. HCN retarded the disappearance of the nitrite and the corresponding fall in potential. Zobell (1935) investigated the optimum $\mathrm{E}_{\mathrm{h}}$ for marine nitrifying organisms.

Brucella.-Tuttle and Huddleson (1934) find that in liver infusion broth the electrode potential of cultures of Brucella fell to a level of $E_{h}$ between +0.09 and $+0 \cdot 15 \mathrm{v}$. in 8 days; the $B r$. suis potential reached a slightly lower level than that of $B r$. abortus. or $\mathrm{Br}$. melitensis. In the presence of the oxidation-reduction indicator dye thionine $B r$. abortus failed to reduce the potential of the medium. The potential did not fall in $\mathrm{Br}$. suis cultures containing basic fuchsine. In the case of $\mathrm{Br}$. melitensis cultures neither thionine nor basic fuchsine interfered with the fall in potential. In describing their experiments the authors emphasise a point which is evident to practical bacteriologists but frequently overlooked in theoretical studies. "It is obvious that in making a comparative study of this nature on closely related aerobic bacteria, the growth conditions that are maintained should closely approximate those normally used in growing the organism."

Lactobacillus Casei.-Oxidation-reduction potentials in growing cultures of Lactobacillus Casei have been followed by Williams and Fieger (1947) with results strikingly similar to those obtained with hæmolytic streptococci, (Hewitt, 1930) The original fall in potential was followed by a rise in older cultures, presumably due to peroxide formation. The stimulation of growth and metaholic activity by certain non-ionic synthetic detergents containing oleates, and by biotin was reflected in the electrode potential-time curves.

\section{SULPHATE-REDUCING BACTERIA}

It is not possible to survey the history of the investigation of sulphate-reducing bacteria during the past fifty years, but their ubiquitous distribution, their importance in the terrestrial and marine sulphur cycle, their nuisance value and the theoretical problems raised by their metabolic problems are of too great importance to be ignored.

They reduce sulphates to hydrogen sulphide which contributes to the odours of putrefaction and has resulted in contamination of our coal and oil supplies. The sulphate reducers are responsible for the anaerobic corrosion of iron pipes in the ground. Plant needs for sulphur are comparatively small, but are very important.

The autotrophic mechanism of the sulphate reducing strains is not yet clarified. Hydrogen is oxidised presumably by an hydrogenase system and energy is thus made 
available for the reduction of sulphates and for the fixation of carbon dioxide, of which the mechanism is not yet explained. Elementary sulphur is reduced to sulphides and it is necessary to explain how the sulphur is brought into contact with the cellular enzymes; solution of the sulphur in unsaturated fats has been suggested.

Reference should be made to Kluyver (1931), Bunker (1936), Zobell (1937), Butlin, Adams and Thomas (1949).

\section{MILK TESTING AND GRADING}

The importance of being able to assess rapidly the cleanliness and keeping qualities of milk needs no emphasis. For a comprehensive review Wilson's (1935) monograph should be studied. One method of grading milk, the plate count, by attempting to count the number of bacteria present, is time-consuming, and difficult, leading to fallacious results. The nature of the infecting organisms is of equal importance to their numbers when considering the keeping quality of the milk. It follows that an oxidation-reduction indicator method by giving a measure of the metabolic activities of organisms present is likely to give a fair indication of their effect in milk-spoilage. Hobbs (1939) has studied the part played by bacteria in the reduction of methylene blue by milk samples. In good samples of milk coliform organisms and Staphylococcus aureus were the most common contaminants with other staphylococci, micrococci and streptococci present in smaller numbers. The most rapidly reducing organisms were the coliform group followed by Streptococcus lactis, fæcal streptococci, Staphylococcus aureius, Staphylococcus albus, Staphylococcus citreus, micrococci, group $\mathrm{C}$ hæmolytic streptococci, Streptococcus agalactiae and aerobic spore bearers.

The oxidation-reduction potentials of raw milk incubated anaerobically fell fairly slowly but the potential fell much more rapidly when the milk contained coliform organisms or Streptococcus lactis even with aerobic incubation. The potential fell to a much lower level with coliform organisms than in sterile milk incubated anaerobically.

The question arises whether the reductions effected in milk are due to natural systems in the milk or to the contaminating bacteria. There are at least four natural reducing systems in milk. The observation by Schardinger that unboiled milk will reduce methylene blue in the presence of formaldehyde may be due to xanthine oxidase; fat may augment its action both by absorbing the enzyme and substrate and by dissolving the colourless leuco-methylene blue, hence enabling the reduction of the methylene blue to go nearer to completion by the usual mass-action law. The enzyme responsible was found to be associated with the cream but was removed by churning. Lactose, glutathione and ascorbic acid may also contribute to the reducing powers of raw milks. When autoclaved milk develops reducing powers possibly due in part to aldehydes formed from lactose and protein hydrolysis products. In addition there has been discovered photochemical reduction by both raw and heated milk activated by exposure to sunlight.

Raw and pasteurised milks do not themselves, however, reduce methylene blue at any rapid rate under aerobic conditions unless they are contaminated with bacteria. The reducing activity of contaminated milk is due to the metabolic processes of the contaminating bacteria and may be followed potentiometrically or, a matter of greater practical importance, by the reduction of dyes. Methylene blue has been commonly used and with suitable precautions as to standardisation of reagents and 
conditions, shaking to suspend the cream, etc., has led to reliable official methods of grading. Recently, however, an official test utilising Resazurin has becr adopted by the Ministry of Agriculture. Resazurin is blue (in the oxidised form) at pH 6.5 and red at $\mathrm{pH} 5 \cdot 3$. Its first reduction product, Resorufin, is pink at $\mathrm{pH} 6.5$ and yellow at $\mathrm{pH} 4 \cdot 8$, whilst Dihydroresorufin is colourless. Fundamentally Resazurin is similar to methvlene blue both in constitution and behaviour but whereas Methylene blue is reduced at an $\mathrm{E}_{\mathrm{h}}$ range of +0.12 to $+0 \cdot 03 \mathrm{v}$., Resazurin is reduced before the potential has fallen so far, i.e., at a range of +0.18 to $+0.09 \mathrm{v}$.

Fresh milk containing discolved oxygen has an $\mathrm{E}_{\mathrm{b}}$ of $+0.2 \mathrm{v}$. so that any reducing system in the milk, either natural or from an infecting organism will redure Resazurin more quickly than metnylene blıe. So that, whilst methylene blue reduction can be ascriber to bacterial contamination Resazurin reduction may occur due to pus and tissue cells present in mastitis. Although the methylene blue test may be a more accurate indicator of the extent of bacterial contamination the Resazurin test will be a more delicate criterion of udder disease, a common cause of faults in cheese-making. (Davis, 1939.)

Twigg (1945) has studied the oxidation-reduction potential behaviour of Resazurin, and Vitucci and others (1946) have reported the effect of the dye on moulds.

\section{CHEDDAR CHEESE}

Some interesting observations on the significance of oxidation-reduction potentials in checse making have been described by Davies, Davis, Dearden and Mattick $(1931,1932,1934)$. The bacteria most active in the metabiotic stimulation of the pigment of "rusty spot" are those producing a low electrode potential, whilst the fault known as "oiliness" in dairy products may be prevented by the growth of suitable bacteria which so lower the potential that fat oxidation is prevented. These oxidative taints do not appear when the $\mathrm{E}_{\mathrm{b}}$ is less than $+0 \cdot 3 \mathrm{v}$. at $\mathrm{pH} 6 \cdot 5$, whilst " anaerobic " faults, such as rusty spot, do not appear when the $\mathrm{E}_{\mathrm{h}}$ is above $-0.1 \mathrm{v}$. at $\mathrm{pH} 5 \cdot 0$. Gassy fermentations are prevented by adding oxidants such as nitrates. The electrode potentials in the interior of a ripening cheddar cheese follow a well-defined course and it is concluded that there is first the establishment of an almost pure culture of Streptococcus lactis. followed by a lactobacillus in the later stages of ripening.

\section{HEMOLYSIN}

Neil and Mallory (1926) have found that the hæmolysin produced in certain cultures of hæmolytic streptococci is inactivated by oxygenation but is re-activated by treatment with reducing agents such as sodium hydrosulphite. Todd (1932, 1933, 1934) has extended this study and finds that there are several kinds of streptolysin. Those of greatest interest from the point of view of human disease are the streptolysins of group A hæmolytic streptococci (Lancefield's classification). These group A strains produce two kinds of streptolysin. One of these is not inactivated by oxygenation and does not appear to function as an antigen. The oxygen-labile hæmolysin is readily inactivated and re-activated by changes in the oxidationreduction conditions of the system; and it gives rise to an antibody when injected into animals. This antibody neutralises the hamolytic properties of the streptolysin and its presence in the scrum of patients is of great value in the diagnosis of infections with hæmolytic streptococci. 
Some old samples of serum were found to have an exalted power of neutralising the oxygen-labile hæmolysin of Group A hæmolytic streptococci. This was traced to the activity of a contaminating bacterium which had liberater from the sorum a lysin-neutralising substance, which was found to be cholesterol. Cholesterol suspensions diluted one in a million were found to leutralise the lysin. (Hewitt and Todd, 1939.) An interesting problem, so far unexplained, is why normal serum cholesterol does not neutralise the lysin since a considerable proportion in normal blood serum is "free" cholesterol. Evidently normal serum-cholesterol is not free enough to neutralise the lysin but requires the chemical activities of a contaminating bacterium to render it capable of combining with the lysin.

Schwachman, Hellerman and Cohen (1934) in an examination of pneumococcal hæmolysin, which is also subject to reversible inactivation by oxidising agents (Avery and Neill, 1924), find close analogies to the behaviour of papain and urease. They conclude that substances containing a thiol group are essential to the hæmolytic activity. Not only oxidising agents but also heavy metals which combine with thiol groups inactivate the hæmolysin. The question is left open whether the hæmolysin itself contains the essential sulphydryl group or whether another substance, similar to a coenzyme, must be present with a reduced - SH group before hæmolytic activity can occur.

In the case of hæmolysis by C. diphtherice (Hewitt, 1947) reduced thiol compounds inhibit hæmolysis and oxidising conditions favour hæmolytic activity.

\section{STREPTOCOCCAL VIRULENCE}

Hæmolytic streptococci grown on solid media can exist in two distinct colony forms - " matt" and "glossy." Glossy colonies contain avirulent organisms and the matt colonies may be either virulent or avirulent. It should be mentioned that with these organisms the virulence of the different variants may show over a millionfold variation. The matt form can be distinguished from the glossy by the possession of a specific substance which can be detected by precipitin methods (Todd and Lancefield, 1928 ; Lancefield and Todd, 1928).

Todd (1930) has shown that by cultivation under appropriate conditions, the matt form may become glossy, the matt attenuated may become virulent, and the matt virulent be attenuated, thus :-

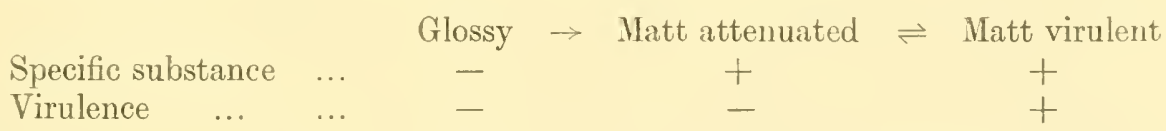

When grown on the surface of solid media fully exposed to air, the matt form may become glossy, and Todd $(1931,1)$, has found that this effect may be attributed to peroxide formation. The matt variants produce more peroxide than the glossy variants and the peroxide produced has a bactericidal effect. Autosterilisation of the matt forms may, therefore, be effected on solid media, since the matt colonies produce more peroxide which remains in their immediate vicinity, not diffusing uniformly throughout the medium as in liquid media. Repeated subculture on solid media results in gradual elimination of matt colonies, until the culture may consist entirely of the glossy variant. With some strains of hæmolytic streptococci there is another relatively rare form of slow, natural selection of glossy forms which 
occurs in liquid media. In these cases peroxide inhibits the proliferation of matt variants more than glossy variants, so that with repeated subcultures there will be a gradual predominance of the glossy variants. This method of selection is, however, very slow, since peroxide does not accumulate in cultures until after the logarithmic phase of growth, when proliferation is minimal. This process may, however, be accelerated by addition of hydrogen peroxide to the cultures, in order that the peroxide may exert its selective action during the phase of active proliferation.

These constitute striking examples of the effect of high oxidation-reduction potentials on the behaviour of bacteria, and Todd has made the following additional observations.

It is well known that organisms isolated from the blood stream of infected animals are frequently of high virulence, but when subcultured in artificial media the virulence falls. The virulence of hæmolytic streptococci may be maintained by subculturing in broth containing 50 per cent. of blood serum. Todd has found that this maintenance of virulence can be secured also by providing plain broth cultures with an ample supply of oxygen by aeration, especially in the presence of catalase which inhibits peroxide formation. The maintenance of virulence occurs only when the cultures have free access to air. That the maintenance of virulence is due to the same factors in 50 per cent. serum-broth and in aerated broth cultures is suggested also by the similarity of the potential-time curves of the cultures (fig. 28), which are entirely different from the potential curves of ordinary aerobic plain broth cultures (Hewitt, 1930, 1).

Elliott (1945), more recently, has carried the matter further and traced the course of the fall in virulence of sub-cultured strains. He has isolated a proteolytic enzyme from hæmolytic streptococci and this proteinase attacks the " $M$ " specific substance of Matt strains rendering them glossy. Hence a virulent strain under the action of the proteinase will lose its matt-specific substance and hence its virulence. The proteinase appears to require sulphydryl groups for its activation. This, therefore, would appear to explain why matt virulent strains retain their virulence, under highly aerobic incubation conditions, since the oxidation-reduction potentials are then maintained at a high level, sulphydryl groups will be oxidised, activation of the enzyme will thus be impossible and the matt specific substance will remain unattacked.

\section{BACTERIAL VARIATION, MUTATION, ADAPTIVE ENZYMES, DRUG RESISTANCE}

Bacterial variation, mutation, adaptation, etc., may roughly be classified into temporary effects that are readily reversed on sub-culture, and more permanent mutations. By their nature and cultural conditions bacteria are peculiarly liable to mutations and variations. As mentioned already bacteria are forced to adapt themselves to varying conditions and in the course of a single culture experience a wide variety of conditions from an ample air supply to almost complete anaerobiosis, from alkalinity to acidity, from abundance of carbohydrates to starvation. Cells grown in the presence of one carbohydrate may readily ferment that carbohydrate, but not another until gradually adapted by growing in the presence of the second carbohydrate. In other cases it has not been found possible to adapt some bacteria to some carbohydrates, although closely related strains ferment it quite readily. Again, some types of bacteria are much more readily adaptable than others. 
Apart from adaptive variation, a large subject which cannot be adequately discussed here, there is the subject of random mutation. The reproductive rate of bacteria is so rapid-it can be over 100,000 times faster than man-that random mutations are inevitably more commonly met than in the higher animals. Aside from the question of the number of generations, however, bacteria are more susceptible to detectable variations since variation of one cell in a multicellular organism might be missed and have negligible effects, neutralised by other cells in contact with it. In a unicellular organism there is no matrix of orthodox cells to regularise the unruly. Presumably all bacteria in the world had a common progenitor and the variety to-day is mostly the result of random mutation followed by natural selection of the fittest to survive in the relevant conditions.

The form of bacterial variation leading to drug-fastness and resistance to antibiotics is dealt with in the next chapter on Chemotherapy.

The change of type of pneumococci associated with enzymic changes of nucleic acids is discussed in the next section.

Another type of bacterial mutation is produced by exposure of the cells to various damaging agents including $\mathrm{X}$-rays, ultra-violet light and colchicine. The enzyme systems of bacteria may be altered by these agents so that bacteria deficient in one or more enzyme systems may be obtained. This becomes of great use in modern microbiological assay methods (page 133). These changes are probably caused by a damaging effect on the nucleic acids of the cell.

In the case of nitratase and tetrathionase adaptation Pollock and Wainwright (1948), have shown that the adaptation occurs in the lag phase before growth occurs. Anaerobic growth using nitrate and tetrathionate as hydrogen acceptors cannot occur until the necessary enzymes have been synthesised. It is clear, however, that not all types of bacterial enzymic adaptation can occur in the absence of multiplication. Some enzymic adaptations may require mutation and the selection of mutants, in which case multiplication of the cells is essential. It seems probable that the increase in nucleic acids during the lag phase (Caspersson) is a symptom of protein and enzyme synthesis, but it is not known how the presence of the substrate leads to modification of the nucleo-proteins responsible for the synthesis of the appropriate enzyme system.

\section{NUCLEIC ACIDS, GRAM STAINING, TYPE TRANSFORMATION}

It is becoming increasingly evident that in the nucleic acids reside many of the secrets of life. Stanley's work in isolating a virus in the form of a crystalline chemical compound, a nucleoprotein, was a milestone in biological research. In these nucleoproteins we have chemical compounds able to reproduce themselves, to effect their own autosynthesis, when in contact with the tissues of their host. Of course, a bacterium does the same when it infects another organism or is sub-cultured in broth, but in the case of bacteria or higher organisms a host of enzymes is known to be present and to many persons, a half-suspected "vital force" was necessary to give the spark of life. But when a crystalline chemical small enough to be certainly free of hypothetical enzymes, yet large enough to be seen in the electron microscope, can synthesise more of itself, a great stimulus is provided for research workers to continue their prying into nature without the fear that just around the corner they may meet the élan vital which may render negative all their efforts. 
It seems probable that nucleic acids may be the guide or skeleton on which protein and enzyme syntheses occur; always when reproduction occurs nucleic acids are found, as their name implies, at the nucleus.

The Gram-positive bacteria are fairly sharply differentiated from the Gramnegative. The differentiation is effected by a staining reaction. The organisms are first stained with crystal violet, then treated with a solution of iodine and finally washed with alcohol. In the case of Gram-negative organisms the alcohol washes out the dye, but in Gram-positive organisms the dye is retained. It is found that there are marked differences in the behaviour of the two classes of bacteria in their sensitivity to inhibiting agents, etc.

The cause of this difference in Gram-staining has now been traced to the presence of ribonucleic acid in Gram-positive organisms. Henry and Stacey have shown that when treated with bile salts in the presence of oxygen the magnesium salt of ribose nucleic acid is removed from the cells which then no longer retain the Gram-stain. The enzyme ribonuclease also removed the Gram-staining complex. Furthermore, if the cells were kept reduced by formaldehyde they could then be re-plated by magnesium ribonucleate from the same or some other source and thus became Grampositive again. Gram-negative organisms are found to contain a much smaller proportion of ribonucleic acid and they cannot be plated with magnesium ribonucleate to become Gram-positive. Presumably the proteins near the surface of Grampositive organisms have groups orientated to combine with the ribonucleic acid.

Another interesting function of nucleic acids in bacteria, this time in the case of pneumococci, has now been tracked down. It was shown by Griffith over 20 years ago that when $\mathrm{R}$ type II pneumococci which had lost their capsules and type-specific substance were inoculated into a mouse with some heat-killed capsulated Type I pneumococci, the organisms recovered after the infection were smooth Type I capsulated pneumococci. This change-over of type-specific substance was later carried out in vitro. Avery, MacLeod and McCarty (1944), have now succeeded in effecting this type transformation by adding purified desoxyribosenucleic acid from Type III pneumococci to non-capsulated Type II cells, which then became Type III cells and remained so on sub-culture. Again a nucleic acid has shown itself to be an organiser of synthesis. Once the cells were presented with the pattern of nucleic acid subsequent generations of cells continued to synthesise it and in turn the nucleic acid being present controlled the synthesis of the capsular polysaccharide.

\section{SOILS, SEWAGE AND SEA-WATER}

A considerable amount of work has been reported on oxidation-reduction potential studies on soils especially with regard to orchards and tea-gardens and the decomposition of vegetable matter. (Buchler, Martin and Parlis, 1939 ; Burrows and Cordon, 1936; Cummings and Reed, 1940; Darnell and Fisenmenger, 1936: Dirks, 1940; Heintze, 1935; Keaton, 1938; Pearsall. 1938; Peech and Batjer. 1935; Volk. 1939; Stcphenson, Schuster and Spulnik, 1938 ; Sturgis, 1936.)

Oxidation-reduction potential changes in sewage and sludges are reported by Dickinson, (1940), Moore (1942).

Hood (1948) has examined the oxidation-reduction potentials at the various stages of sewage purification and points out the differing potentials reached in sedimentation tanks under varying conditions (Fig. 37). 
He summarises the importance of oxidation-reduction potential measurements in sewage plant control as follows :-

(1) Detection of deposits and growths in sewer and pumping systems leading to septic conditions and sulphide production.

(2) Detection of industrial wastes and toxic conditions.

(3) Establishment of proper sludge pumping schedules.

(4) Detection of stagnation in primary tanks.

(5) Determination of internal conditions in filters and activated sludge aeration tanks.

(6) Detection of excessive sludge blanket in settling tanks.

(7) Determination of conditions in sludge digestion tanks.

(8) Examination of influents and effluents.

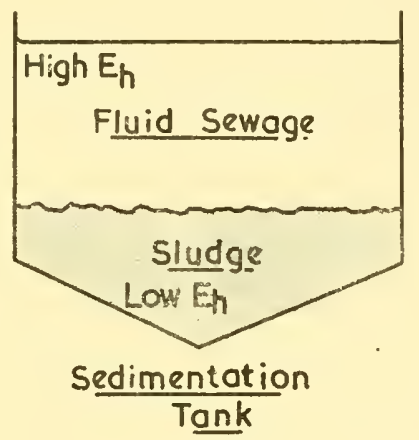

FIG. 37

Oxidation-reduction potentials in sewage sedimentation tank

The oxidation-reduction potentials developed in sewage and activated sludge passing through septic tanks have been followed. When subjected to slight aeration the $\mathrm{E}_{\mathrm{b}}$ of sewage dropped slightly at first and then rose. When not aerated the potential dropped from +0.28 to -0.1 volts in 10 hours. When aerated the $\mathrm{E}_{\mathrm{b}}$ again rose, but only to $+0 \cdot 24 \mathrm{v}$.; after each further anaerobic period in the septic tank aeration raised the potential less. Activated sludge in a septic tank developed a potential of 0 volt and after agitation with nitrogen this fell to $-0.3 \mathrm{v}$. (Moore and Ruchoft, 1943).

The potentials in sea-water and their relation to the decomposition of organic matter particularly in different depths of water have been studied by Zobell and by Cooper. (1937.)

\section{MICROBIOLOGICAL ASSAY}

It will have become evident from earlier sections that the metabolic requirements of bacteria are frequently similar to those of higher organisms. Hence in the assay of vitamins it is less common to use large, expensive and difficultly controlled animals for many vitamin determinations. Instead of having to rear animals under standard conditions and plan supplies for months ahead it is now possible in many cases to carry out vitamin assays on bacterial cultures. Results are obtained much more rapidly and uniformly, and so are the statistical requirements of adequate numbers in 
experimental groups. It is easier to prepare a standard bacterial culture than a standard disease-free colony of rats. It is merely necessary to select a bacterium that requires the given vitamin for growth and cultivate it in a medium adequate in all other respects, but deficient in the vitamin; and then add to different cultures graded amounts of a standard vitamin preparation and the test sample.

A similar method is used for amino-acid determination using an organism such as Lactobacillus casei which is exacting in its amino-acid requirements. A series of culture media is prepared, each deficient in one or other amino-acid; addition of graded amounts of the test sample to each of these media before inoculation again gives a measure of the content of the various amino-acids. Results obtained are comparable with those obtained chemically.

Purines and many other compounds may be assayed by similar methods. The use of the mould Neurospora crassa has proved a valuable tool and mutants obtained from it by $\mathrm{X}$-radiation deficient in power to synthesise a variety of compounds have been used extensively, not only for assays but for tracking down pathways of synthesis to investigate what intermediates or combinations of intermediates can act as substitutes for the deficient component.

\section{BACTERIAL TOXINS}

The significance of soluble bacterial toxins to both the bacteria that produce them and the animals they damage has received some elucidation within recent years. The extreme potency of some toxins is quite remarkable: Pappenheimer calculates that $1 \mathrm{mg}$. of tetanus or botulinus toxin is sufficient to kill more than 1,000 tons of guinea pig and that one molecule of toxin per cell is active.

The $a$-toxin of $\mathrm{Cl}$. welchii has been shown to be a lecithinase and its effect in hæmolysing erythrocytes is explicable on these grounds (R. G. McFarlane). Oakley and his colleagues have found evidence for a number of different proteinases in the pathogenic Clostridia with toxic effects.

An interesting suggestion has been made by Pappenheimer concerning the significance of diphtheria toxin in the respiratory system of $C$. diphtheria, although he does not claim that the hypothesis is definitely established. He suggests that diphtheria toxin, when inside the bacterial cell, forms the protein moiety of the cellular cytochrome. Diphtheria toxin, on this theory, only occurs in the culture filtrate as a soluble toxin when there is insufficient iron in the culture medium to form the iron porphyrin or protohaematin complex portion of the cytochrome molecules.

One of the chief lines of argument in favour of this view is the inverse linear relation between the iron content of the culture medium and the amount of toxin present in the culture filtrate. Although not intended as a contradiction to the theory some experiments of the author may be quoted as showing the limitations of the evidence.

In the curve is plotted the toxin found in the filtrates of a series of cultures of C. diphtheria of the Park-Williams 8-strain (the same as that used by Pappenheimer). It will be seen that as the iron content of the medium increases the toxin content falls, and over the portion of the curve studied by Pappenheimer a reasonably straight line is obtained for the relation between toxin production and iron content. If, however, 


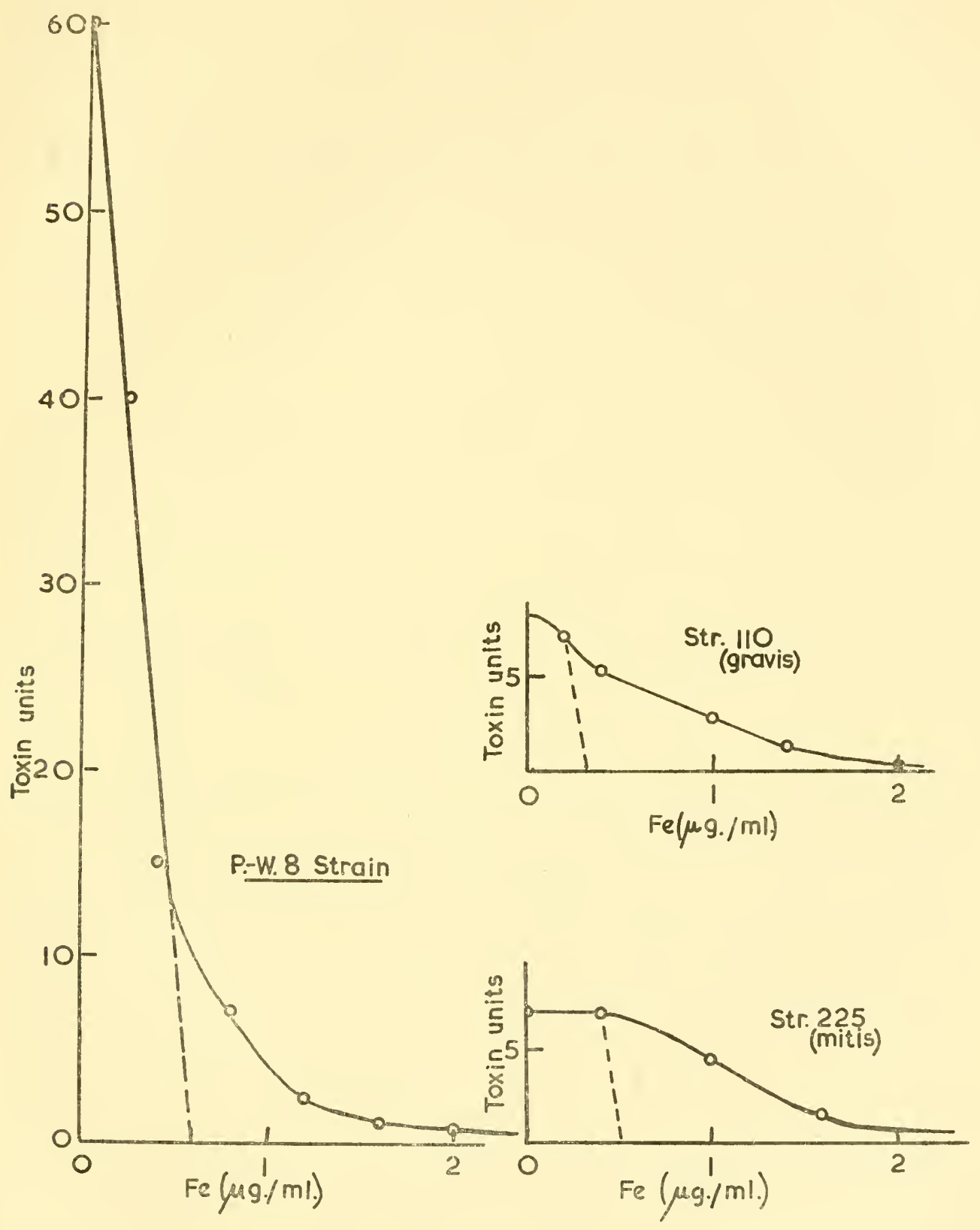

Fig. 38

Effect of Iron on Diphtheria Toxin Production

(Broken line indicates hypothetical linear relationship between iron content and toxin produotion) 
the study is extended beyond the range in which the flocculation method of toxin estimation, used by Pappenheimer, is possible and the intradermal method of toxin testing is used, then there is immediate departure from the linear relationship. Furthermore, although several hundred different strains have been studied no other has been found in which there is a linear relationship between toxin production and iron content. None of these other strains showed the abnormally high toxin production of the Park-Williams 8-strain which has long been habituated to laboratory sub-culture. Recently isolated strains do not behave in the same way.

A further interesting point arises from the effect of iron salts on diphtheria toxin production. Although the lethal effect of $C$. diphtheria has been traced to the effect of the soluble toxin (Hewitt, 1947, 1948), and full protection of animals against live cultures is given by administration of the specific antitoxin, yet the clinical severity of the disease has not been correlated with the amount of toxin produced by the strain when isolated in laboratory culture medium. Some of the strains (like ParkWilliams 8) are most innocuous clinically, yet produce most toxin in laboratory culture media. It has been suggested that this might be because laboratory culture media for diphtheria toxin production are carefully adjusted to have a low iron content, which favours toxin production, whilst the iron content of the tissues is fairly high and toxin production by different strains may be differently ordered. Although Mitis strains (clinically mild) produce more toxin generally than Gravis strains (generally considered clinically serious) in iron-deficient medium the reverse might be the case in iron-rich media like tissues. This point has been tested by the author in the case of several hundred recently isolated strains of $C$. diphtheria, but no correlation was found between the effect of iron and the Mitis-Gravis classification. Excess iron diminished the toxin production of all strains, but Mitis and Gravis strains were not distinguishable.

\section{Summary of Chapter VI}

The study of the oxidation-reduction conditions established in bacterial cultures has already led to a number of interesting observations. The behaviour of the peroxide-forming bacteria is entirely different from that of the catalase-containing organisms. Some of the former type are, however, deficient in other enzymes than catalase. The relation of peroxide to the obligatory-anaerobic bacteria is discussed and problems of anaerobiosis are reviewed. The different levels of oxidation-reduction potential at which different organisms multiply and the different effects they produce are a reflection of their metabolic effects and the enzyme systems they possess. Some differences in the behaviour of different bacteria, the effects of differences in culture media and cultural conditions and some effects of lytic agents are described. The inter-dependence of oxidation-reduction conditions and bacterial variation in virulence and morphology, is discussed. The reducing conditions observed in bacterial cultures are regarded as a necessary result of the metabolic activities of the bacteria, rather than being due to the explosive liberation of reducing substances from the cells. Bacterial cultures are to be regarded as dynamic constantly altering systems and not is static stagnant pools. 


\section{CHAPTER VII}

\section{CHEMOTHERAPY AND ANTIBIOTICS}

On the whole we have been concerned until now with the processes by which organisms obtain the energy and Bausteine for growth and multiplication, and the changes occurring during the life cycle. The subject of this chapter is a brief description of the agencies by which the higher animals, especially man, can be rid of microorganisms which have found their way into parts of the body where they wreak damage and destruction. Symbiosis, in which different organisms can live together in harmony for the inutual benefit, has been briefly mentioned, but disease hardly at all. The pathology of disease, the means by which micro-organisms damage and kill their host does not concern us here, but only the methods by which the invaders may be destroyed.

The process of disinfection or killing bacteria outside the body differs in many respects from chemotherapy in vivo. Not only are many potent in vitro disinfectants useless in the body owing to their toxicity to the host, but when introduced into the animal body chemical or even physical changes may be produced in them biologically which may make them ineffective anti-bacterial agents, or in some cases more effective.

\section{ANTIBODIES AND IMMUNITY}

In addition to this the body has its own armoury of defences which may be able to deal with an infective agent when the chemotherapeutic agent holds the infection in check. These defences may take the form of non-specific agencies such as the white cells which can often engulf checked invaders, or specific antibodies which can deal with only one closely defined type of foreign body. This plunges us into the subject of immunity which cannot be dealt with, but, nevertheless, should never be neglected in considerations of chemotherapy. However much we improve our chemotherapeutic agents and antibiotics we can never surpass some natural antibodies in their absolnte specificity of reacting only with the one toxic agent against which they have been elicited, and being completely harmless to the cells of the body. If a chemotherapeutic agent does no more it may save life if it holds invasive organisms in check whilst the natural defences of the body are mobilised. Before leaving this subject it should be emphasised once more that in considering the effects of chemotherapeutic agents in the body there are the following internal allies to take into account :-

(1) Non-specific rapidly mobilised leucocytes, etc.

(2) Specific slowly formed antibodies:-

(a) Antibacterial, acting on the bacteria themselves;

(b) Antitoxic, without action on the bacteria but neutralising poisonous products of the bacteria and thus protecting the host from injury.

Even if a therapeutic agent is not bactericidal but only temporarily bacteriostatic it may enable the body defences to eliminate the infection.

Perhaps the ideal chemotherapentic agent would have the properties of a synthetic prosthetic group of an antibody; it should be completely, rapidly and 
specifically lethal to the invasive agent; absolutely non-toxic to the host cells or beneficial symbiotic organisms; it should rapidly proceed to the focus of infection and should remain there. As this is not in sight it is necessary to discuss what agents we have, how they appear to function and hence to attempt to plan improvements since, despite all theorising most of our advances to date have arisen empirically, by trial and error and ex improviso.

\section{ORGANIC ARSENICALS}

Outside the body chlorine is one of the commonest disinfectants in use and the problem of our water supplies would be difficult to solve without chlorine. In the body, however, the oxidising properties of chlorine cannot be utilised for the destruction of micro-organisms, since the cells of the host are damaged first. The phenolic anti-septics also are restricted to use in vitro. In the case of arsenic compounds, on the other hand, not only does arsenite poison the enzymic activities of micro-organisms in the test-tube but organie compounds of arsenic are used in the body to eliminate trypanosomes in sleeping sickness and spirochaetes in syphilis.

Ehrlich and subsequent workers have concluded that when organic arsenicals are used for the treatment of protozoal infections the active agents are tervalent arseneoxides. If quinquevalent arsonic acids (I) are injected they are reduced in vivo to the oxide (II) and if III or IV are injected they are oxidised in the body to the oxide :-

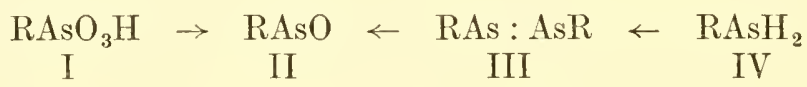

To be active therapeutically, therefore, organic arsenicals should be capable of reduction or oxidation to the tervalent oxide but the arsene oxide is also the toxic agent to the host. The possibility arises that the toxicity of arsonic acids is dependent upon the ease with which they are reduced to the arsene oxide. This is not an easy matter to determine since the arsonic acid : arsene oxide system appears not to be a reversible oxidation-reduction reaction which could be measured by the use of indicator dyes, since the arsonic acids do not oxidise the reduced dyes. In order to obtain a measure of the ease of reduction of the arsonic acids Cohen, King and Strangeways (1932) adopted an ingenions method. They first concluded that the ease of reduction of the arsonic acids would be inversely proportional to the ease of oxidation of the arsene oxide, and this was measured by adding coptically active cystine. The cystine oxidised the arsene oxide and was itself reduced to cysteine which has a much lower optical rotation so that, by following the fall in rotation, the rate of reduction of the cystine and hence the rate of oxidation of the arsene oxide was measured. It was not possible to obtain, however, any correlation between the rate of oxidation of the arsene oxide and the toxicity of the corresponding arsonic acid to the host, nor was there any relation to the curative effect of the arsonic acids in injections. The curative action is naturally dependent upon other factors such as the rate of excretion. (Sce also Crawford and Levvy, 1947.)

The toxicity and chemotherapeutic action of organic arsenicals have been investigated in a different way. The toxic effect has been traced to combination with sulphydryl groups whereby enzyme systems such as the pyruvic oxidase of 
brain are inhibited. Simple monothiols combine with aromatic arsene oxides and might be expected to protect enzyme sulphydryl groups but the combination is readily dissociated (Cohen, King and Strangeways, 1931).

Further advances have followed as the result of war-time researches. (Peters and Wakelin, 1946; Stocken and Thompson, 1946; Barron, Miller and Bartlett, 1947 : Danielli et al., 1947.) Arsenic compounds are not only chemotherapeutic agents but are also potential war gases and vesicants. It has been found that the toxic effect of arsenic can be neutralised by dithiols such as 2 : 3-dimercaptopropanol (BAL or British Anti-Lewisite) or its glucoside which form much more stable cyclic compounds than the monothiols with arsenic. The dithiols can compete successfully with protein SH Compounds for the arsenic and hence can protect them or even regenerate SH groups which have combined with arsenic. Enzyme systems can thus escape inhibition in the presence of arsenical compounds.

A result of these observations is that the possibility arises of reducing the toxicity to patients of therapeutic arsenicals (e.g., mapharside) without impairing the therapeutic efficency since the arsenic compound may be dissociated locally to produce its chemotherapeutic effect. (Peters and Stocken, 1947.) On the other hand it has been shown (Webb and van Heyningen, 1947 ; Barron, Miller and Meyer, 1947) that dithiol compounds themselves inhibit some enzyme systems by combining with heavy metals forming the prosthetic group, by reducing the rate of oxidation of cytochrome-C. and by inhibiting certain SH enzymes. Thus the dithiol compounds might not only reduce the toxicity of the therapeutic arsenicals to the host but might themselves have a chemotherapeutic effect by inhibiting enzyme systems of the infecting organisms. On the other hand the disadvantages of administering dithiols at the same time as arsenical chemotherapeutic agents would be that they might both reduce the inhibiting effect on the infecting parasites and yet damage the host by interfering with tissue enzyme systems.

TABLE 25

Half Wave Potentials of Phenylarsonic Acids (volts vs. saturated calomel electrode)

\begin{tabular}{|c|c|c|c|}
\hline Substance & & in $0.1 \mathrm{~N} . \mathrm{LiCl}$ & $\mathrm{E}$ at $\mathrm{pH} 2.97$ \\
\hline Phenylarsonic acid & $\ldots$ & $-1 \cdot 27$ & $-1 \cdot 25$ \\
\hline $4-\mathrm{CH}_{3}-\ldots \quad \ldots$ & $\ldots$ & $-1 \cdot 29$ & $-1 \cdot 27$ \\
\hline $4-\mathrm{CH}_{3} \mathrm{CONH}-\ldots$ & $\ldots$ & $-1 \cdot 30$ & $-1 \cdot 28$ \\
\hline $4-\mathrm{CH}_{3} \mathrm{O} \quad \ldots$ & $\ldots$ & $-1 \cdot 35$ & $-1 \cdot 34$ \\
\hline $4-\mathrm{Cl}-\quad \ldots \quad \ldots$ & $\ldots$ & $-1 \cdot 32$ & - \\
\hline 2 : 4-Dichloro- & $\ldots$ & $-1 \cdot 36$ & $-1 \cdot 34$ \\
\hline $4-\mathrm{OH}-\quad \ldots \quad \ldots$ & $\ldots$ & $-1 \cdot 37$ & - \\
\hline $4-\mathrm{NH}_{2}-\ldots \quad \ldots$ & $\ldots$ & $-1 \cdot 46$ & - \\
\hline $4-\mathrm{OH}-3 \mathrm{NH}_{2}-\ldots$ & $\cdots$ & $-1 \cdot 45$ & - \\
\hline $3: 4$-Diamino-... & ... & $-1 \cdot 47$ & - \\
\hline $4-\mathrm{CH}_{3} \mathrm{COO}-\quad \ldots$ & ... & - & $-1 \cdot 33$ \\
\hline
\end{tabular}

Breyer (1939) measured the half-wave potentials of a series of phenyl arsonicacids polarographically, and found that the introduction of substitutents increased the ease of reduction, but was unable to find a correlation between the oxidationreduction potential and toxicity. 


\section{BACTERICIDAL DYES}

That dilute solutions of some dyes stain bacteria suggested that they might be effective disinfectants and this was found to be so over fifty years ago. Some dyes inhibit bacterial growth in dilutions of one in a million. Not only have dyes been used as chemotherapeutic agents, with results generally only moderately successful, but study of the constitution of the most active dyes has led to the developinent of more successful non-coloured compounds.

Methylene blue and other effective dyes are in many cases reversible oxidationreduction potential indicators. Dubos developed the hypothesis that such dyes may be bacteriostatic because they poise the potential at a level at which organisms cannot proliferate. The diffusion of dyes into the bacterial cell followed by oxidation of an essential metabolite was suggested by Fildes. Such oxidation might well bring to an end the proper functioning of an enzyme-catalysed metabolic cycle and thus stop growth. Attempts have been made to correlate the potentials at which the dyes are reduced with their inhibitory effect on bacteria. In addition some dyes interfere with the chemotherapeutic activities of arsenicals and organic antimony compounds (Janesó and Jancsó, 1936).

In table 26 are given the oxidation-reduction potentials at which a number of dyes are 50 per cent. in the reduced state, together with their bacteriostatic effect against Staphylococcus aureus and their interference with the chemotherapeutic activity of 3-amino-4-hydroxy-phenyl-arsenoxide and stibophen (Page and Robinson, 1943).

TABLE 26

Oxidation-Reduction Potentials and Bacteriostasis by Dyes

\begin{tabular}{|c|c|c|c|c|c|c|}
\hline \multicolumn{4}{|c|}{ Dye } & $\begin{array}{c}\mathrm{E}_{0}{ }^{1} \text { at } \mathrm{pH} \\
\text { (volts) }\end{array}$ & $\begin{array}{c}\text { Bacteriostatic } \\
\text { dilution }\end{array}$ & $\begin{array}{l}\text { Chemo- } \\
\text { therapeutic } \\
\text { interference }\end{array}$ \\
\hline \multirow{3}{*}{\multicolumn{3}{|c|}{$\begin{array}{l}\text { Phenolindo-2: 6-diBr phenol } \\
\text { O-Cresolindophenol } \ldots \\
\text { l-Naphthol-2-sulphonate } \\
\text { indo-2:6-diCl phenol ... }\end{array}$}} & $\ldots$ & +0.218 & $<5,000$ & 0 \\
\hline & & & $\ldots$ & $0 \cdot 191$ & $<5,000$ & 0 \\
\hline & & & $\ldots$ & $0 \cdot 118$ & 10,000 & 0 \\
\hline Toluylene blue & $\ldots$ & $\ldots$ & $\ldots$ & $0 \cdot 115$ & 5,000 & ++ \\
\hline Thionine $\quad \ldots$ & $\ldots$ & $\ldots$ & $\ldots$ & $0 \cdot 063$ & 10,000 & ++ \\
\hline Brilliant eresyl blue & & $\ldots$ & $\ldots$ & 0.047 & 100,000 & $+t+$ \\
\hline Gallocyanine & $\ldots$ & $\ldots$ & $\ldots$ & 0.021 & $<5,000$ & $t+$ \\
\hline Methylene blue & $\ldots$ & $\ldots$ & $\ldots$ & 0.011 & 50,000 & $+t$ \\
\hline Toluidine blue & $\ldots$ & $\ldots$ & $\ldots$ & $0 \cdot 011$ & 100,000 & ++ \\
\hline Azur I $\quad \ldots$ & $\ldots$ & $\ldots$ & $\ldots$ & +0.011 & 50,000 & ++++ \\
\hline Janus green (a) & $\ldots$ & $\ldots$ & ... & $-0 \cdot 011$ & 50,000 & ++++ \\
\hline Indigo tetrasulphor & nate & .. & .. & $-0 \cdot 046$ & $<5,000$ & ++ \\
\hline Indigo trisulphona & & $\ldots$ & $\cdots$ & -0.081 & $<5,000$ & 0 \\
\hline Nile blue $\quad \ldots$ & $\ldots$ & $\ldots$ & ... & $-0 \cdot 122$ & 100,000 & 0 \\
\hline Indigo disulphonat & & $\ldots$ & $\ldots$ & -0.125 & $<5,000$ & 0 \\
\hline Cresyl fast violet & $\ldots$ & $\cdots$ & $\cdots$ & $-0 \cdot 167$ & 100,000 & 0 \\
\hline Phenosafranine & $\cdots$ & $\cdots$ & $\cdots$ & -0.252 & 50,000 & 0 \\
\hline Janus green (b) & $\ldots$ & $\cdots$ & $\cdots$ & $-0 \cdot 255$ & 500,000 & - \\
\hline Neutral red ... & $\ldots$ & $\ldots$ & $\ldots$ & $-0 \cdot 325$ & $<5,000$ & 0 \\
\hline
\end{tabular}

It will be seen at once that bacteriostatic activity cannot be correlated with oxidation-reduction potential at which the dye is reduced. In view of the very different chemical constitutions of the dyes it is hardly surprising that the potential should 
be the only factor in bacteriostasis. There is, however, some evidence that interference with the chemotherapeutic activity of organic arsenicals and antimonials is effected only by dyes within a certain range of reduction potential $(-0.05 \mathrm{v}$. to $+0 \cdot 11$ v.).

There is a marked difference in sensitivity to dyes between the Gram-positive and the Gram-negative bacteria. Particularly in the case of basic dyes (triphenylmethanes, such as brilliant-green and crystal violet, thiazines such as methylene blue and acridines such as acriflavine) the Gram-positive bacteria are generally much more susceptible, possibly due in part to the presence of ribosenucleic acid near the cell surface which may combine readily with the dye.

\section{FURACIN}

Cramer (1947) has made a potentiometric study of the mode of action of the antibacterial agent furacin, which is 2-(5-nitro)-furaldehyde semicarbozone. In Staphylococcus aureus cultures the usual fall in oxidation-reduction potentials was delayed by the smaller bacteriostatic doses of the antibiotic, and inhibited altogether by the larger bactericidal concentrations. The polarographic method was used to determine the amount of furacin remaining in the culture after different periods of incubation and the concentration of drug was correlated with the bacteriostatic effect as follows :-

$\begin{array}{ccc}\text { Hours after inoculation } & \% \text { Drug remaining } & \text { Growth } \\ 0 & 100 & 0 \\ 4 & 100 & 0 \\ 8 & 79 & 0 \\ 12 & 65 & \text { trace } \\ 18 & 21 & ++++ \\ 24 & 14 & ++++\end{array}$

\section{QUINONES}

It has been pointed out in a previous chapter that a number of substances found in nature are 1:4-naphthaquinones (the anti-hæmorrhagic vitamin $\mathrm{K}$, phthiocol, many pigments and mould products) or anthraquinones (mould pigments). In addition to their other biological importance and effects many of them also inhibit bacterial growth. This has been attributed to an inhibition of enzyme reactions by combination with SH groups, but it would seem that the inhibition is reversed by addition of thiol compounds only in the case of Gram-negative organisms, so some other explanation of the bacteriostatic effects is sought (Colwell and McCall, 1945 ; Cavallito and Bailey, 1944 ; Geiger and Conn, 1943). In view of their oxidationreduction equilibria and the possibility of semi-quinone formation Page and Robinson, (1943) attempted to find a correlation between the oxidation-reduction potentials at which they were reduced and the bacteriostatic effects of a number of quinone derivations. The results are summarised in table 27.

It will be seen that no correlation can be detected with the potentials in the case of the bacteriostasis of the Gram-negative Esch.coli, but in the case of the Grampositive Staphylococcus aureus all the actively bacteriostatic quinones have $\mathrm{E}_{0}{ }^{1}$ values 
at $\mathrm{pH} 7$ between $-0 \cdot 10$ volt and $+0 \cdot 15$ volt. These limits of potential are similar, as mentioned in the previous section, to those found by von Jancsó as being necessary for the interference of various oxidation-reduction potential dyes with the bactericidal effects of organic arsenic and antimony compounds. It is possible that poising of the oxidation-reduction potential between these limits has some significant effect on bacterial inhibitions.

\section{TABLE 27}

Bacteriostatic Activity and Oxidation-Reduction Potentials of Quinones

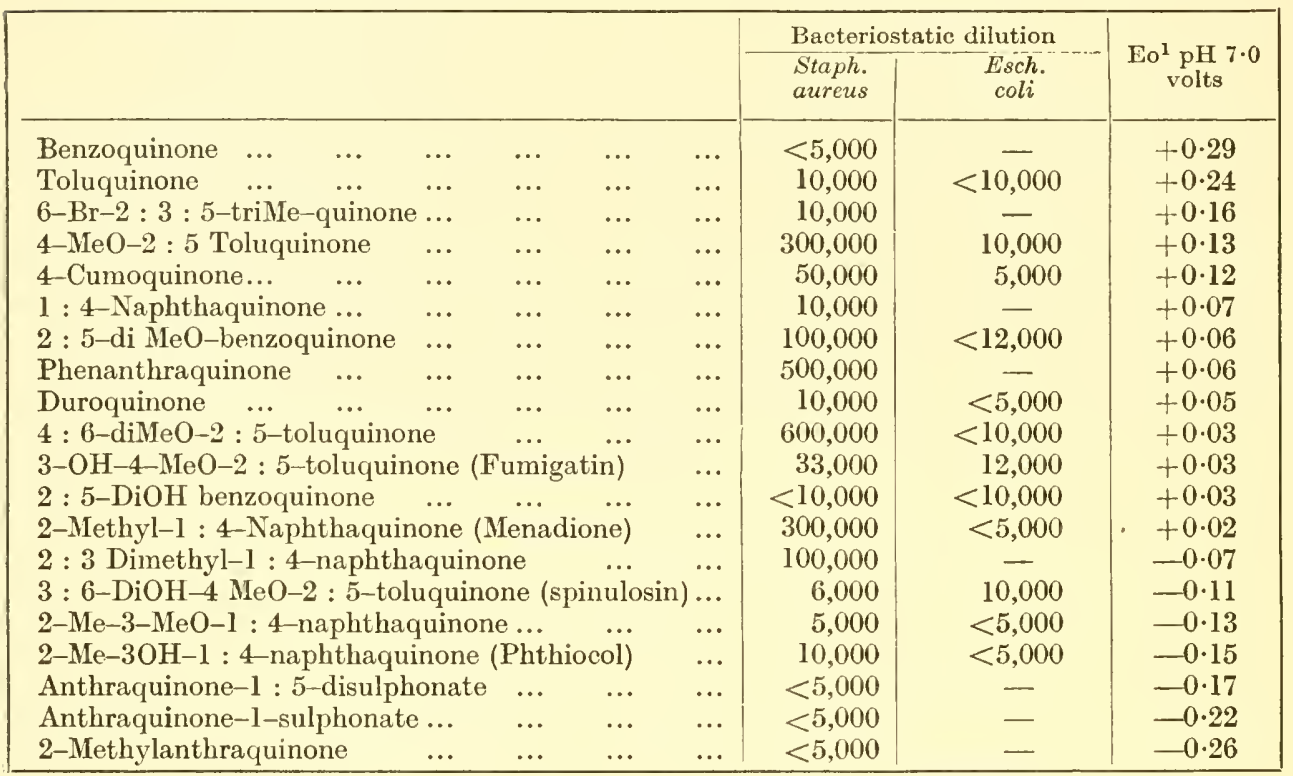

\section{ANTIMALARIALS, PALUDRINE, ANTRYCIDE}

One of the earliest successful chemotherapeutic agents, quinine has been succeeded in turn by a quinoline compound, plasmoquine, an acridine, mepacrine and then paludrine, for malarial treatment and suppression.

Paludrine (Curd and Rose, 1946) is a guanidine derivative,

$$
\mathrm{ClC}_{6} \mathrm{H}_{4} \cdot \mathrm{NH} . \mathrm{C}\left(\text { : NH) NH.C ( : NH) NH.CH }\left(\mathrm{CH}_{3}\right)_{2}\right. \text {. }
$$

Originally search was being made for active pyrimidine ring derivatives, but the open chain biguanide proved to be the most successful compound. For the ridding of the body of the last malarial parasites in benign tertiary malaria another drug, pentaquine, a derivative of methoxy quinoline is promising well. As in most chemotherapeutic problems the search is for an agent with the maximal therapeutic effect and the minimum toxicity to the host. Much interest attaches to the trials proceeding at present of antrycide, which is a pyrimidyl quinaldine :- 


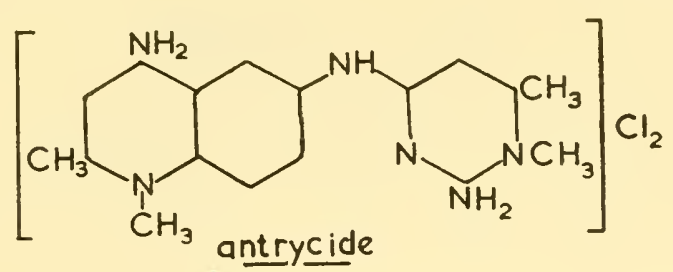

Single doses of $1 \mathrm{mg}$. per kg. were effective in curing infections with Trypanosoma congolense, etc., and the drug is also prophylactic. If cattle can be reared in tsetse-fly belt areas of Central Africa the effect on the world's meat supply may be remarkable. (Curd and Davey, 1949.)

\section{SULPHONAMIDES, ACTION OF DRUGS}

In view of the trypanocidal action of certain organic arsenical compounds containing the peptide linkage CO.NH, it was decided to synthesise and test the sulphur analogues containing the sulphonamide group, - $\mathrm{SO}_{2} . \mathrm{NH}$ (Hewitt and King, 1926; Hewitt, King and Murch, 1926). Two of the compounds investigated were $3^{1}$-amino-benzoyl-4-amino-2 hydroxyphenyl arsonic acid and the sulphur analogue $3^{1}$-amino benzene sulphoryl-4-amino-2-hydroxy-phenylarsonic acid :-

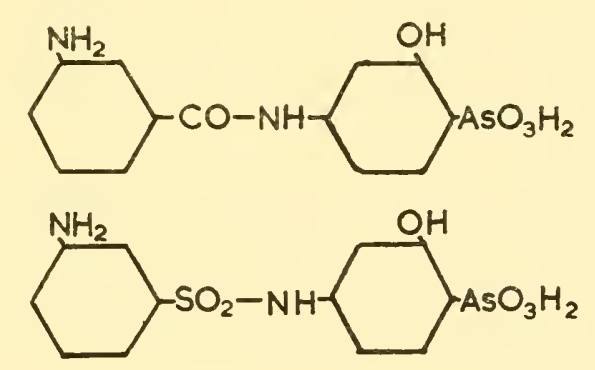

Therapeutic results against Trypanosoma equiperdum were disappointing, the sulphur analogue being four times as toxic as the peptide, and the investigation of sulphur analogues was abandoned. In Germany, however, work on these was evidently continuing since we had an intimation from workers there that patent rights were involved and in 1932, Prontosil was patented. Domagk in 1935, showed that this red dye was effective against streptococcal infections in animals, and Colebrook and Kenny established its value in puerperal septicaemia. Patients frequently developed a rosy pink colour when treated with Prontosil Rubrum. As a result of the work of Trefouël, Buttle, Colebrook, Fuller, Hare and their colleagues it was established that Prontosil was broken down in the body and the active compound was p-aminobenzenesulphonamide. 


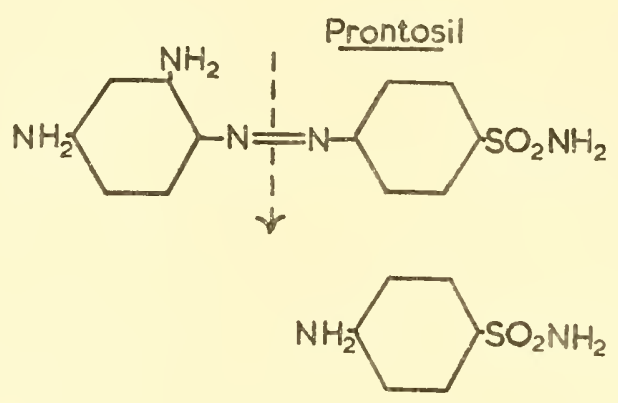

\section{Sulphanilamide}

In 1938, Whitby showed that sulphapyridine prepared by May and Baker was effective against pneumococcal infections and numerous other sulpha-drugs have been prepared since. Not only have many lives been saved by these drugs but an active stimulus was provided for chemotherapeutic research generally and probably assisted in the rapid development of antibiotics. The successful use of sulphonamide encouraged workers to investigate its mode of action and here again the stimulus has been effective outside the realm of the sulpha-drugs and practical therapeutics stretching into fundamental fields.

It was soon found that the presence of peptones and various cell extracts antagonised and inhibited the bactericidal effect of sulphonamide in vitro (Stamp, Green), and this effect was traced to the presence of $\mathrm{p}$-aminobenzoic acid (Woods). It will be recalled that p-aminobenzoic acid is a constitutent of folic acid (pteroyl-glutamic acid) the growth factor for Lactobacillus casei which stimulates blood regeneration in certain types of anæmia.

\section{STRUCTURAL ANALOGUE INHIBITION}

It is established that at least part of the bactericidal effect of sulphonamide is to interfere in some way with the need of certain bacteria for $p$-aminobenzoic acid. The structural relation of sulphonamide (ii) with p-aminobenzoic acid (i) and folic acid (iii) is indicated below :-<smiles>NC1CCC(C(=O)O)CC1</smiles>

(i)<smiles>NC1CCC(S(N)(=O)=O)CC1</smiles>

(ii)

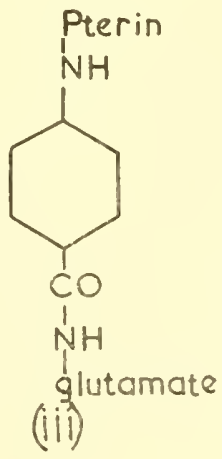


It cannot be that sulphonamide exerts its effect by preventing the synthesis of p-aminobenzoic acid since the antagonism is a competitive one and occurs when the $\mathrm{p}$-aminobenzoate is already present. Hence the interference is with the utilisation of the metabolite, and at least part of the effect is probably due to interference with the synthesis of folic acid. It will readily be appreciated that the enzyme system responsible for folic acid synthesis will have an affinity for the structural groups of p-aminobenzoic acid and for the closely similar sulphonamide molecule. There is little doubt that in many enzyme reactions combination between the enzyme and substrate must occur before activation of the substrate occurs.

Like so many biological phenomena the relation of p-aminobenzoic acid to the bactericidal effect of sulphonamide is not a simple one. It appears that other metabolites like the amino acid methionine, and the purines apparently unrelated to p-aminobenzoate, also function as sulphonamide antagonists; but this may be due to the fact that p-aminobenzoate (or folic acid) is a coenzyme in the synthesis of methionine, etc., and when these metabolites are supplied ready-made the coenzyme and synthetic mechanism are not required anyway, so that sulphonamide inhibition of the system is ineffective as far as bacterial growth is concerned. Other evidence also suggests that p-aminobenzoate may have other functions in metabolism besides being an intermediate in the synthesis of folic acid.

It is interesting to note that sulphanilamide affects plant growth by stopping nuclei coming into pro-phase so that cell division is reduced, and by an effect on the spindle mechanism, anaphase movement is inhibited. As with bacteria, so with plants, the effect of sulphanilamide is reversed by p-aminobenzoic acid (Hindmarsh, 1949).

A number of other cases of bacterial inhibition by sulphur analogues of growth substances and intermediate metabolic products have been studied. Pyridine-3sulphonic acid inhibits the bacterial growth promoting activity of pyridine-3-carboxylic acid (nicotinic acid). The sulphonic acid analogue pantoyltaurine $\left(\mathrm{C}_{8} \mathrm{H}_{16} \mathrm{O}_{3} \mathrm{~N}_{\text {. }} \mathrm{SO}_{3} \mathrm{H}\right)$ inhibits bacterial growth, and the inhibition is antagonised by the carboxylic acid analogue pantothenic acid $\left(\mathrm{C}_{8} \mathrm{H}_{16} \mathrm{O}_{3} \mathrm{~N} \cdot \mathrm{COOH}\right)$.

It is not only sulphur analogues that inhibit the growth of bacteria (and other cells) by selective combination with enzyme in place of the natural substances. Dichloroflavin $\left(\mathrm{R} . \mathrm{Cl}_{2}\right)$ inhibits the growth of organisms requiring riboflavin $\left(\mathrm{R}\right.$. $\left.\left(\mathrm{CH}_{3}\right)_{2}\right)$, and interference with the utilisation of riboflavin was also produced by dihydroriboflavin, lumichrome.

Harington (1948) has effected the synthesis of the sulphur analogue of thyroxine.
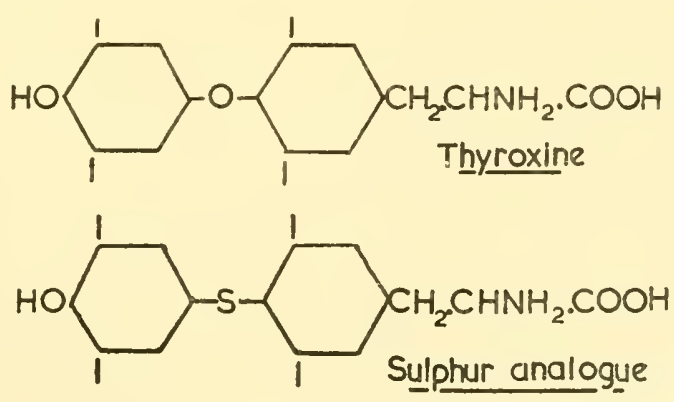
It will be of interest to determine whether this analogue will inhibit the thyrotrophic hormone from the anterior pituitary gland (Hewitt, 1929) or the direct action of thyroxine. The value of such a preparation in controlling hyperthyroidism clinieally is evident.

Thiourea and thiouracil derivatives have been used with considerable success for the treatment of hyperthyroidism, despite some toxic effects. The mechanism of the effect is still obscure; iodine excretion rapidly follows administration of the drug, but it is not certain that the effeet is directly on the thyroxine-producing cells. It has been suggested that one or other of the following enzyme systems may be inhibited by administration of the drug and the enzyme may be concerned in thyroxine synthesis: peroxidase, eytochrome oxidase, phosphatase, tyrosinase. It is diffieult, however, to know why such enzymes in the thyroid tissue should be inhibited without killing the patient. It has also been suggested by De Robertis that the oxidation-reduction potential of the follicular cells of normal thyroids is higher than that of colloid tissue and that activation of the gland inereases the potential of the colloid tissue. Thiourea is said to reduce the potential of both the eytoplasm and colloid of activated glands.

Some examples of inhibitory structural analogues are given in the table.

TABLE 28

Some Tnhibitory Structural Analogues

\section{Inhibitor}

Sulphonamides ...

Pyridine-3-sulphonate

3 -A cetylpyridine

Pantoyltaurine ... ...

Taurine ... ... ..

$\beta-\mathrm{NH}_{2}$ butyrate ... ...

isoSerine ... ... ...

Dichloroflavin $\quad \ldots \quad \ldots$

Lumichrome $\quad . .$.

Lumiflavin $\quad \ldots \quad \ldots$

Isoriboflavin

$2: 4-\mathrm{DiNH}_{2}-6: 7$-diMe

9-Ribityl-9 : 10-diH phenazine

Pyrithiamin

Oxythiamin $\cdots, \cdots$

Glucoscorbic acid $\quad \ldots \quad \ldots$

Dicoumarol $\quad \ldots \quad \ldots . \quad \ldots$

$\begin{array}{llll}\text { Iodinin } \quad \ldots & \ldots & \ldots & \ldots\end{array}$

$\propto-$ Tocophenol quinone ...

2 : 3-DiCl naphthoquinone

Cysteic acid

.

Malonate ... ...

Pyribenzamine ..

Anthisan ... .

Benadryl ... ...

Penicillin ... ...

Thiouracil$$
\text { (1) }
$$$$
\begin{array}{llll}
\cdots & \cdots & \cdots & \\
\cdots & \cdots &
\end{array}
$$$$
\begin{array}{lll}
\cdots & \cdots \\
\cdots & \cdots & -\ldots \\
&
\end{array}
$$$$
\ldots+\cdots \quad \cdots
$$$$
\begin{array}{lllll}
\cdots & \cdots & \ldots & \ldots
\end{array}
$$$$
\begin{array}{llll}
\cdots & \cdots & \ldots & \ldots
\end{array}
$$

\section{Biological Product}

p-Aminobenzoate, folic acid

.. Nicotinic acid

.. , , ,

.. Pantothenic acid

... B-alanine

... , ,

...

... Riboflavin

$\ldots$,

..

$\cdots, \quad$,

.. Thiamin

..

... Ascorbic acid

... Vitamin $\mathrm{K}$

... , ,

.. $\quad$,

$\cdots$

$\ldots$

... Aspartic acid

.. Adenine

.. Succinate

.. Histamine

.. $\quad$,

..

... ? Glutathione

... ? Thyroxine

Not all antiseptics or chemotherapeutic agents necessarily owe their effeet to being structural analogues of metabolites or eoenzymes, but since they generally owe 
their activity to an effect on some enzyme system in the cell it could be argued that some of them can give rise to structural analogues in vivo. The inactivations of enzyme systems produced by heavy metals reacting with thiol groups, by carbon monoxide with hæmoglobin, or by phenol with proteins might be ruled out as analogue inhibitions, but it is possible that the effect of some agents may be due to vital synthesis of inhibitory structural analogues.

The development of resistance to drugs will be discussed in a later section on antibiotics.

\section{DIAMIDINES}

Following the observation that aliphatic diamidines were active trypanocidal agents (King, Lourie and Yorke, 1938), Ewins, Ashley, Newbery and their colleagues have evolved a series of aromatic amidines with promising effects, although their toxicity limits their use in treating $C$. diphtherice infections (Hewitt, 1948).

\section{VIRUSES AND BACTERIOPHAGE}

Substances inhibiting succinic dehydrogenase lave been found to inhibit the multiplication of bacterial viruses. One difficulty in this work is to separate the effect on bacterial multiplication from the effect on bacteriophage development. The inhibition of development of the $\mathrm{T}_{2}$ phage of Esherichia coli strain B has been studied by Czekalowski and Dolby (1949) who report the following inhibitions :-

\begin{tabular}{|c|c|c|c|c|}
\hline \multicolumn{3}{|l|}{ Inhibitor } & $\begin{array}{c}\text { Concentration } \\
\text { (mM.) }\end{array}$ & $\begin{array}{l}\text { Number of lytic } \\
\text { particles (percen- } \\
\text { tage of original } \\
\text { inoculum) }\end{array}$ \\
\hline Control ... $\ldots$ & $\ldots$ & $\ldots$ & 一 & $2,000-10,000$ \\
\hline Hydroquinone ... & $\ldots$ & $\ldots$ & 30 & 58 \\
\hline & & & 15 & 78 \\
\hline & & & $7 \cdot 5$ & 84 \\
\hline 4: 6-DiMeO-toluqu & none & $\cdots$ & $5 \cdot 5$ & 99 \\
\hline & & & 0.55 & 124 \\
\hline Tetra-Me-p- ... & ... & $\cdots$ & $3 \cdot 0$ & 83 \\
\hline Phenylene diamine & $\ldots$ & $\ldots$ & $0 \cdot 3$ & 85 \\
\hline Malonic acid $\quad .$. & ... & ... & 100 & $0 \cdot 27$ \\
\hline & & & 20 & $94 \cdot 8$ \\
\hline & & & 10 & $81 \cdot 7$ \\
\hline & & & 5 & 142 \\
\hline Iodoacetic acid & ... & $\ldots$ & 25 & $44 \cdot 6$ \\
\hline & & & 5 & 62 \\
\hline & & & 1 & $78 \cdot 6$ \\
\hline Auramine & $\cdots$ & $\cdots$ & $0 \cdot 66$ & 108 \\
\hline & & & $0 \cdot 066$ & $72 \cdot 3$ \\
\hline Sodium Cyanide & $\cdots$ & $\ldots$ & 50 & $11 \cdot 4$ \\
\hline & & & 10 & $60 \cdot 5$ \\
\hline & & & 5 & $84 \cdot 4$ \\
\hline Sodium fluoride & $\cdots$ & $\cdots$ & 24 & 114 \\
\hline Methane $\quad \ldots$ & $\ldots$ & $\ldots$ & 300 & $77 \cdot 4$ \\
\hline Colchicine & $\ldots$ & $\ldots$ & $0 \cdot 008$ & 115 \\
\hline
\end{tabular}

\section{ANTIBIOTICS}

The distinction between chemotherapeutic agents and antibiotics is wholly artificial and mainly historical. In general an antibiotic is a substance produced by one micro-organism which antagonises the growth of another micro-organism. Useful 
antibiotics are successful chemotherapeutic agents and one of the most recently described antibiotics, chloromycetin, has now been synthesised and re-named chloramphenicol. Apart from their great therapeutic importance antibiotic chemotherapeutic agents are interesting from the structural point of view. The living cell is able to effect syntheses that tax the resources of the best equipped laboratory and some of the structures produced appear quite novel to the chemist, some of the moulds effecting the most versatile syntheses. The soil presents one of the richest fields for discovering antibiotic-producing micro-organisms, as would be expected since there must be a remarkable struggle for existence among the myriads of organisms occupying the earth's crust. Those micro-organisms that have survived countless ages of race-warfare might be expected to have potent weapons against each other, although, perhaps unfortunately from this point of view, pathogenic bacteria are relatively delicate organisms, do not generally inhabit the soil, and if they did could quickly be over-grown by vigorous competitors, so that it is not often that a potent antagonist can be found that is specific for human or animal pathogens.

\section{PENICILLIN}

Although microbial inter-antagonisms have been known for over fifty years the development of penicillin has over-shadowed all previous work and opened a new epoch of chemotherapy. Fleming's (1929) observation of a Penicillium that produced a soluble substance bactericidal to many Gram-positive bacteria was followed some ten years later by the preparation of purified penicillin which is a remarkably efficient therapeutic agent in many diseases (Chain, Florey, Gardner, Heatley, Jennings, Orr-Ewing and Sanders, 1940). Unlike many drugs penicillin is non-toxic, and it has a number of properties that make it an ideal chemotherapeutic agent as outlined earlier. The search still goes on, however, for other therapeutic agents, for penicillin has the following imperfections :-

(1) It is not effective against all micro-organisms, conspicuous failures are Gram-negative bacteria, the tubercle bacilli and the viruses.

(2) It is rapidly excreted and hence requires frequent administration preferably by injection.

(3) Organisms develop resistance to its action, and it then becomes ineffective against such organisms. The mechanisms of this resistance will be mentioned later.

Several different penicillins exist and $\mathrm{R}$ in the following formula may represent several groups, benzyl, pentenyl, etc. In connection with the mode of action of penicillin the similarity of the formula to that of glutathione will be evident, but the mechanism of its bactericidal action is discussed in a later section :-

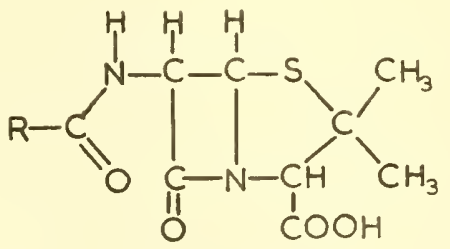

Penicillin

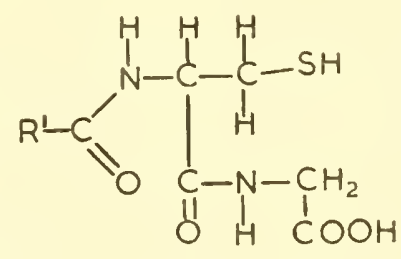

Glutathione 
Penicillin is now issued commercially in crystalline form, but methods for its synthesis have not been worked out, one of the greatest difficulties being the fourmembered ring which Penicillium notatum achieves so easily. The polarographic behaviour of penicillin derivatives is described in the chapter on Polarography, and the chemical work carried out is described in a compilation by Clarke, Johnson and Robinson (1949).

\section{STREPTOMYCIN}

The virtue of streptomycin, produced by an actinomycete Streptomyces griseus (Schatz, Bugie and Waksman, 1944) lies in its activity against the tubercle bacilli and against Gram-negative enterococci in urinary infections, etc. Tuberculosis has remained one of the worst scourges of man whilst one infectious disease after another has come under control by the use of drugs, immunisation, public health measures, etc. The exact value of streptomycin in the treatment of tuberculosis is still under investigation. In the case of tuberculous meningitis it has undoubtedly saved many lives. Although production has now reached adequate commercial proportions, both in the United States and the United Kingdom, clinical trials are still in progress, and treatment with a combination of both streptomycin and p-aminosalicylic acid is under trial as this is being written. In passing it may be remarked that $p$-aminosalicylic acid is a structural analogue of $\mathrm{p}$-aminobenzoate. Promizole ( $4: 2_{1}$-diaminophenyl$5_{1}$-thiazolylsulphone) has been used as an adjutant to streptomycin in the treatment of miliary tuberculosis and meningitis (Lincoln and Kirmse, 1949). There are at least two streptomycins; one has the following structure:-

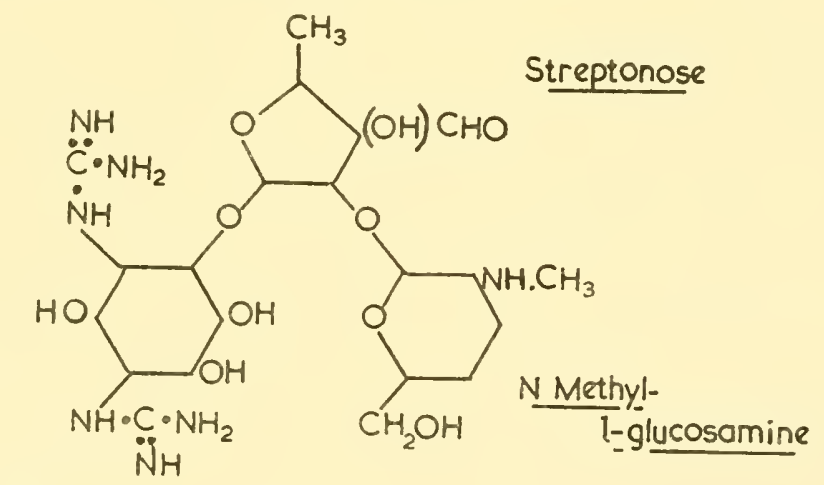

Streptidine

\section{Streptomycin}

Of these three main components of the structure, streptodine is a diguanido derivative of tetrahydroxycyclohexane and the presence of the two basic groups may be of some interest. The pentose, streptonose, contains a free aldehyde group, but streptomycin B, which is less active, contains maltose instead of streptonose. The remaining portion of the molecule is $\mathrm{N}$-methyl-l-glucosamine.

The rapidity of the bactericidal activity of streptomycin is reported by Garrod (1948). 
One disadvantage of streptomycin in treatment is the ease with which strains of bacteria become resistant to it. This is particularly disadvantageous in long-continued treatment of tuberculosis. Some observations in the case of $C$. diphtherice may be mentioned (Hewitt, 1948, a). Active prophylaxis is reducing the incidence of diphtheria, but carriers remain and hospital treatment is frequently unduly prolonged owing to the persistence of the organisms in the throat, so an effective bactericidal agent was sought. Although inferior to penicillin in its in vitro bacteriostatic activity against $C$. diphtheriae streptomycin proved very much superior in saving guinea-pigs infected with the organisms. Resistant strains were, however, developed rapidly in vitro in the case of some strains and these strains were also resistant to streptomycin in vivo, so that adequate initial dosage is necessary to minimise the risk of development of resistance. The development of streptonycin resistance did not affect toxin production or the pathogenicity of the organisms.

In view of the two basic guanido groups in streptomycin it was thought possible that the two basic groups in the diamidines might point to a similar mechanism of effect. Hence strains of $C$. diphtherio were made resistant to various diamidines, to streptomyein and to both (Hewitt, 1948, b).

TABLE 29

Bacterlal Resistance to Streptomycin and Diamidines

\begin{tabular}{|c|c|c|c|c|}
\hline \multirow{2}{*}{ Strain } & \multirow{2}{*}{\multicolumn{2}{|c|}{ Made Resistant to }} & \multicolumn{2}{|c|}{$\begin{array}{l}\text { Minimum Inhibitory } \\
\text { Concentration }(\mu \mathrm{g} / \mathrm{ml})\end{array}$} \\
\hline & & & Diamidine & Streptomycin \\
\hline 1 & Nil $\quad \ldots$ & & 1 & 1 \\
\hline $1 / \mathrm{D}$ & Diamidine $\quad \ldots$ & $\ldots$ & 10 & $1 \cdot 2$ \\
\hline $1 / \mathrm{S}$ & Streptomyein ... & $\ldots \quad \ldots$ & 1 & 1,000 \\
\hline $1 / \mathrm{DS}$ & Diamidine and St & tomycin & 10 & 1,000 \\
\hline
\end{tabular}

TABLE 30

Cross-resistance of C. Diphtheriae to Diamidines

\begin{tabular}{|c|c|c|c|c|c|c|}
\hline \multirow{2}{*}{$\begin{array}{l}\text { Original } \\
\text { Strain }\end{array}$} & \multirow{2}{*}{\multicolumn{2}{|c|}{ Subcultured in }} & \multicolumn{4}{|c|}{ Inhibitory Concentration of drug $(\mu \mathrm{g} / \mathrm{ml})$} \\
\hline & & & Propamidine & Hexamidine & $\begin{array}{l}\text { Dibromo- } \\
\text { propamidine }\end{array}$ & $\begin{array}{c}\text { Di-iodo } \\
\text { hexamidine }\end{array}$ \\
\hline l & Broth & $\ldots$ & 5 & 1 & 1 & $0 \cdot 3$ \\
\hline 1 & Propamidine & ... & 50 & 5 & 6 & 1 \\
\hline 1 & Hexamidine $\quad \ldots$ & ... & 50 & 5 & 5 & 1 \\
\hline 1 & Dibromopropamidine & ... & 60 & 7 & 10 & $1 \cdot 5$ \\
\hline 1 & Diiodohexamidine & ... & 5 & 1 & 1 & $0 \cdot 3$ \\
\hline $1 / \mathrm{S}$ & Broth $\quad \ldots \quad \ldots$ & ... & 10 & 1 & 1 & $0 \cdot 3$ \\
\hline $1 / \mathrm{S}$ & Propamidine & ... & 40 & 4 & 3 & 0.5 \\
\hline $1 / \mathrm{S}$ & Hexamidine $\quad \ldots$ & $\ldots$ & 60 & 7 & 10 & I \\
\hline $1 / \mathrm{S}$ & Dobromopropamidine & $\ldots$ & 60 & 7 & 7 & $1 \cdot 5$ \\
\hline $1 / \mathrm{S}$ & Diiodohexamidine & $\ldots$ & 60 & 7 & 10 & 2 \\
\hline
\end{tabular}

It will be seen that there is no cross-resistance developed between the streptomycin-resistant organisms and the diamidine-resistant strains, although organisms which developed resistance to one of the diamidines were resistant to the others. Hence it would appear that the mechanism of the effect of streptomycin is different from that of the diamidines despite their common basic groups. 
A disadvantage of streptomyein is its toxicity. Especially when administered over a prolonged period as is necessary in the case of many tubereular infections neurotoxic effects are observed. The reduced compound dihydrostreptomycin is, however, less toxic and this is now undergoing clinical trial.

\section{MECHANISM OF ESTABLISHMENT OF DRUG RESISTANCE}

Bacteria can acquire resistance to drugs in several ways, for example :-

(1) By becoming less permeable to the drug so that it cannot gain access to vulnerable systems in the organism.

(2) By the vulnerable part of the organism becoming less sensitive. For example, if the drug exerts its action by interfering with one enzymic reaction in a synthetic chain the organism may substitute another reaction which by-passes the vulnerable reaction.

(3) By developing a mechanism for inactivating the drug. For example, staphylococci develop an enzyme penicillinase which destroys penicillin when the staphylococci develop penicillin-resistance, as they do very readily.

There are two methods in which bacteria can develop resistance: they can develop resistance gradually, each organism in a culture developing by imperceptible stages greater resistance to the drug, or they can develop resistance by mutation. In the latter case, which appears to be considered the actual mechanism observed, an occasional organism, perhaps only one in a million, by a random mutation acquires resistance to the drug, and when the drug is present the resistant organism and its progeny will survive whilst non-resistant organisms perish. The resistance is inherited by the cells formed by sub-division of the resistant mutant so that a resistant strain is established. Of course, a mutant may arise in the resistant strain and the mutant may not be drug-resistant, but such a mutant would be difficult to detect and if subcultured in the presence of the drug would not survive. Hence reversion of drugresistant strains to drug-sensitive is not commonly observed.

Gale and Rodwell (1949) summarise the action of penicillin on Staphylococcus aureus as being due to interference with the assimilation of glutamic acid. Resistant strains do not actively assimilate glutamic acid, but synthesise the amino acid from glucose and ammonia. Hence the development of resistance to penicillin is associated with the development of the synthetic mechanism by which an essential amino acid can be produced in the cell, which thereby becomes independent of external supplies of glutamic acid and resistant to the assimilation-inhibitory effect of the antibiotic. It seems possible that penicillin may interfere with the cell membrane by inhibiting the enzymes responsible for the deamination-reamination process which, it has been suggested, is necessary for passage through the cell wall. Reverse mutation of resistant cells by which synthetic ability is decreased leads to increased penicillin resistance. Hence a consistent scheme of explanation of the phenomena has been provided. The additional method of developing resistance by production of a penicillin-destroying enzyme, penicillinase, is presumably entirely a separate phenomenon.

A rather remarkable feature of some bacteria which develop resistance to streptomycin is that they become streptomycin-dependent. That is to say they will only grow in the presence of streptomycin and streptomycin has become a necessary growth factor for such bacteria. Apparently some micro-organisms never exposed to. streptomycin also utilise it as a growth factor. 


\section{CHLOROMYCETIN, CHLORAMPHENICOL}

Chloromycetin has several special claims to interest. It is the first useful antibiotic to be synthesised so that we shall not be clependent upon very costly fermentation methods of production. Fermentation methods are not necessarily expensive, but the very small yields and delicate nature of many antibiotics have made their bulk production difficult. The distinction between chemotherapeutic agents and antibiotics is rapidly disappearing and "chloramphenicol," the name given to the synthetic product, has made the distinction between them even more narrow. Chloromycetin is remarkable in being a nitro-benzene derivative, hitherto not described in a natural product. It also contains dichloracetic acid in a side chain, an unusual but not unique occurrence. The structural formula of this relatively simple compound is $\cdot-$

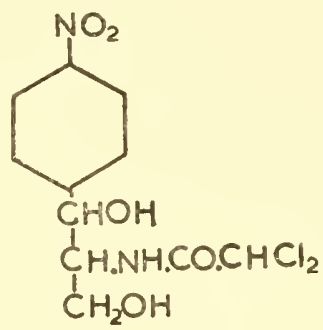

\section{Chloromycetin}

Its full name is (1)- $\psi-1-p-n i t r o p h e n y l-2-$ dichloroacetamidopropane-1 : 3-diol.

The chief value of chloromycetin at present is in the treatment of louse-borne typhus (due to infection with Rickettsia prowazeki) and scrub-typhus. A team of workers in Parke-Davis laboratories have been responsible for this interesting work (Ehrlich, Bartz, Smitl, Joslyn and Burkholder, 1947 ; Smadel and Jackson, 1949). The drug may also be of value in typhoid fever.

\section{OTHER ANTIBIOTICS}

In view of its interest and importance frequent further developments in this field may be anticipated, but a few of the many products described to date may be briefly mentioned.

\section{GRAMICIDIN AND TYROCIDINE}

Isolated from Bacillus brevis with the idea of finding an agent active against the Gram-positive complex (Dubos and Cattaneo. 1939), these polypeptides contain many d-(unnatural) amino acids (Hotchkiss, 1944). Their composition has been determined by differential hydrolysis and the order in which they occur determined with the aid of chromatographic analysis. The polypepticles are too toxic for parenteral use.

\section{LICHENIFORMIN}

Callow and Hart (1916) isolated this group of polypeptides from B. licheniformis. Licheniformin is very active against $C$. diphtherice and other bacteria in vitro, but is rather toxic to guinen-pigs (Hewitt, 1948). 


\section{KNAPIVEED}

It is of interest to note the variety of sources from which antibiotics are being obtained. The synthetic activities of moulds and mould-like bacteria are so diverse that they have constituted a prolific source of new compounds, but plants are also contributing to the store. Cavallito and Bailey (1949) have obtained from the leaves of the spotted knapweed an unsaturated lactone with antibacterial activity which is rapidly destroyed by cysteine and thioglycollic acid. It is concluded that lipophilic antibiotics are more active against Gram-positive organisms.

\section{POLYMYXIN}

This group of polypeptides investigated by Stansly, Shepherd and White (1947), and Ainsworth, Brown and Brownlee (1947) contains the amino acids l-threonine, l-ay-diaminobutyric acid, d-leucine, phenylalanine, $d$-serine and an unidentified fatty acid. Chromatographic absorption has facilitated characterisation of this group.

\section{STREPTOTHRICIN}

Streptothricin is a basic substance obtained from Streptomyces lavendulce (Waksman, 1943).

\section{AUREOMYCIN}

Described by Duggar (1948) this antibiotic with the trade name, Duomycin, is obtained from Streptomyces aureofaciens. Its chief advantages are that resistant strains are not readily developed and it has proved of value in urinary infections and some virus diseases (psittacosis-lymphogranuloma group and rickettsiæ).

\section{NEOMYCIN}

Waksman and Lechevalier (1949) obtained neomycin from a soil organism Actinomyces (or Streptomyces) fradii (or fradice). It inhibits the growth of streptomycin-resistant tubercle bacilli and salmonellæ, and hence its potential value. It is basic in nature and thermostable, and organisms appear not to develop neomycinresistance readily.

\section{Summary of Chapter VII}

The mode of action of chemotherapeutic agents and antibiotics, their relation to metabolic processes and enzyme systems, and problems of bacterial resistance and drug fastness, are discussed. 


\section{CHAPTER VIII}

\section{THE POLAROGRAPH}

Polarographic methods like oxidation-reduction potential measurements depend upon electrode potential relationships but they are applied in a different manner.

As already indicated in Chapter I, to measure an oxidation-reduction potential an inert electrode is immersed in the system and an equal and opposite external potential is applied so that no current flows in the system. With the Polarograph, however, various potentials are applied to an electrode in the system and the current flowing at each potential is measured. As the current flows hydrogen is liberated at the cathode effecting reduction whilst an equivalent amount of oxidation occurs at the anode if any oxidation-reduction systems are present. The magnitude of the current flowing is a measure of the rate of these oxidation-reduction reactions and hence, as will be shown later, of the concentration of oxidation-reduction systems present. With the Polarograph therefore, there is the possibility not only of recognising the qualitative nature of the oxidation-reduction systems present but

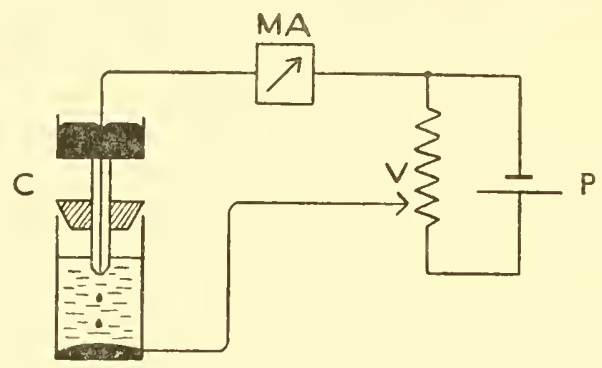

Fig. 39

Simplified diagram of polarographic apparatus, showing dropping mercury electrode, milliammeter (MA) to measure current and source of variable applied electromotive force (V). Amplifying circuits are omitted

also of their amount. When electrolytic current flows through such systems polarisation occurs and a small uniform electrode is required. Generally therefore the inert metal wire or foil electrode used in oxidation-rednction potential measurements is abandoned, and in its place drops of mereury continuously dropping from a fine capillary tube are used. In general the mercury drops form the cathode whilst the pool of mercury formed by the drops at the bottom of the vessel can be used as the anode. Since any oxygen present in the system may be reduced at the cathode and upset results the system is often deaerated by passing nitrogen or hydrogen before measurements begin.

Digrammatically the arrangement is represented in Fig. 39 ; by means of the potentiometer $\mathrm{P}$ different potentials can be applied to the Cathode $\mathrm{C}$ and the current flowing at each value of the potential can be measured by the galvanometer MA.

If a hypothetical oxidation-reduction potential system is considered the voltagecurrent curve obtained in the polarograph might be as given in Fig. 40.

As the negative voltage applied is increased from a zero value the current flowing increases very little until the point $\mathrm{A}$ is reached. The small current flowing 
until now is dependent upon the electrolytes present and is known as the Residual Current but when the voltage applied exceeds A (known as the Decomposition Potential) the current flowing increases considerably, until the voltage $\mathrm{C}$ is reached when the current settles down to a nearly constant value. The current represented by the vertical distance between the curves at $\mathrm{C}$ and $\mathrm{A}$ is known as the Limiting Current and gives a measure of the amount of the oxidation-reduction system present. At the voltage corresponding to point B (i.e., the Half Wave Potential) half the limiting current flows. This Half Wave Potential is characteristic of the oxidation-reduction system and is in fact the potential of the half oxidised system. This, as we have already seen, is the characteristic electrode potential or $\mathrm{E}^{1}{ }_{0}$ of the system. It will be scen at a glance that the Polarographic curve is of the same S-form as the curves on page 25 relating the electrode potential to the percentage oxidation or reduction of an oxidation-reduction system.

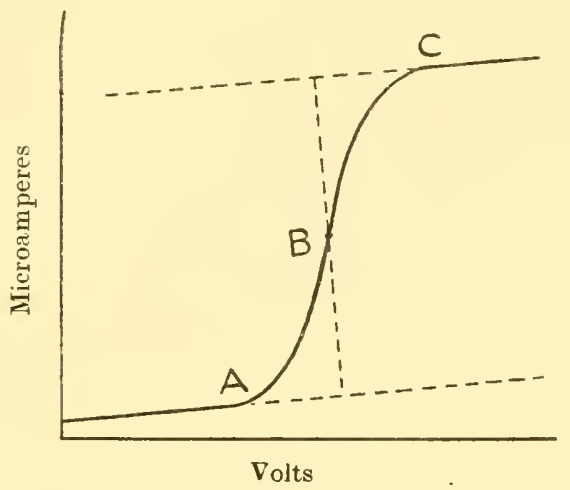

Fig. 40

Current-voltage curve obtained with oxidation-reduction system

A-decomposition potential

B-halfwave potential

C-limiting current

Some oxidation-reduction systems which are not truly reversible and do not give electrode potentials at inert electrodes nevertheless are found to be reducible at dropping mercury electrodes and a current flows and hence they can be studied polarographically. The Half-Wave Potentials or "Apparent Reduction Potentials" are not, however, always completely understood and in some cases are due to interaction of constituents of the system with the mercury of the electrodes.

Conant (1926) investigated some irreversible oxidation reduction systems by adding reversible oxidation-reduction systems of known potential and studying the rate of reaction-by this means Apparent Reduction Potentials were obtained (cf. also Müller and Baumberger, 1937). Both Michaelis (1933) and Kolthoff and Lingane (1941), agree that a thermodynamically satisfactory interpretation of Apparent Reduction Potentials is lacking and it therefore remains a convenient but empirical method of characterising some irreversible systems (cf. Shikata and Tachi 1932).

Before considering biological systems of interest it may be of value to consider the theoretical basis of the polarographic method. It is conditions in the immediate 
vicinity of the small drop of mereury issuing from the capillary tube of the cathode that determine the "voltammetric curve." Under the conditions of the polarographie method, with a minute eathode and a current flowing through the cireuit conditions throughout the system are not uniform as in the ordinary methods of measuring electrode potentials, described in previous ehapters. In the immediate vicinity of the drop of mercury the oxidation-reduction system may be almost completely reduced whilst in the main bulk of the solution the system is entirely in the oxidised condition, so it is important not to confuse conditions at the cathode with the general condition of the system.

When low potentials are applied to the system no eurrent flows until the decomposition potential is reached. But at potentials above this the system is reduced at the eathode, that is it loses its negative charge to the cathode and it current flows. It will be evident that at any given electrode potential a characteristic proportion of the system will be reduced in the immediate vicinity of the cathode. Eventually when the limiting current is reached the solution immediately surrounding the drop of mereury is completely depleted of oxidised form and the current flowing is dependent only on diffusion of the non-reduced form from the body of the solution to the layer of the mercury drop. Now the rate of this diffusion can be shown to be dependent only upon the concentration of the oxidationreduction system in the body of the fluid and to be independent of the applied potential, so the current-voltage curve becomes flat.

The Ilkovic equation giving the value of the diffusion current (Id in amperes) at any time is as follows :-

$$
I_{d}=0.732 \mathrm{n} \mathrm{FD}^{\frac{1}{2}} \mathrm{Cm}^{\frac{2}{3}} \mathrm{t}^{\frac{1}{3}}
$$

where $n$ is the number of electrons concerned in the oxidation-reduction reaction, $F$ is the Faraday (96,500 coulombs), $D$ is the diffusion coefficient of the electroactive material (in cms. per second), $C$ its concentration (in moles per ml.), $m$ the weight (in g.) of mercury flowing from the capillary per seeond, and $t$ the time (in seconds) of the period of life of the drop. The Ilkovic equation can be simplified and the following equation gives the mean current flowing :-

$$
\mathrm{I}_{\mathrm{d}}=605 \mathrm{n} \mathrm{D}^{\frac{1}{2}} \mathrm{Cm}^{\frac{2}{3}} \mathrm{t}^{\frac{1}{3}}
$$

where the current is in microamperes and the concentration is in millimoles per litre. It is interesting to note that the mean current flowing during the whole life of the drop is equal to six-sevenths of the maximum current flowing just before the drop falls. Although the current flowing fluctuates throughout the life of the drop it is possible, as mentioned above, to obtain a steady reading by using a galvanometer with a long period of vibration.

In the above equations all the factors for any system are constant except the concentration so that the current flowing is proportional to the eoncentration :-

$$
\mathrm{I}_{\mathrm{d}}=\mathrm{k} \mathrm{C} \text {. }
$$

Hence with any particular oxidation-reduetion system once the current for any known eoncentration has been determined the measure of the current flowing in other solutions will give the concentration of the system. 
It should be mentioned that the current flowing varies with the life of the drop of mercury falling from the cathode capillary tube ; as it becomes larger the current rises and when the mereury drop falls a new and smaller drop begins to form and the current decreases again (curve $\mathrm{T}$ in fig. 41 ), but by using a galvanometer of long period and incorporating a condenser in the circuit the variations in the current with the life of the drop are largely eliminated and a relatively smooth curve $(G)$ is obtained. The mean current ( $\mathrm{M}$ in fig. 41 ) is equal to six-sevenths of the maximum.

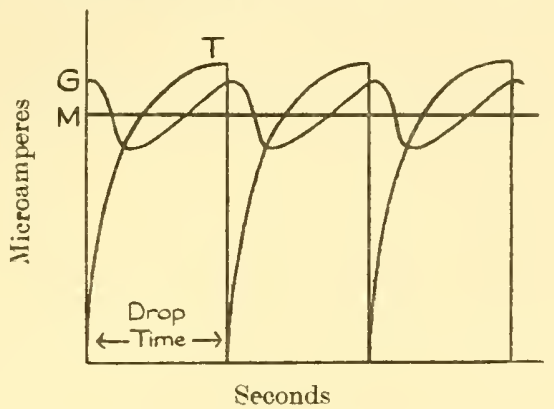

FIg. 41

Current-time curves during life-time of drops of mercury

T-true curve

G-galvanometer readings

II-mean current

Of course, when more than one oxidation-reduction system is present, there is a number of steps on the voltammetric curve each corresponding to one of the oxidation-reduction systems.

\section{EXPERIMENTAL METHODS}

The apparatus required for polarographic work consists first of the dropping mercury electrode which is merely a container of mercury to which is attached a capillary tube from which mercury drips continuously. The tip of the electrode dips under the surface of the solution investigated contained in the electrode vessel which has provisions for de-aeration, generally in the form of inlet and outlet tubes through which nitrogen or hydrogen can be passed. Occasionally a small stationary rotating or platinum electrode is used instead of the dropping electrode. The stationary electrode may be in the form of a pool of mercury at the bottom of the electrode with a wire making contact and projecting from the vessel or a salt bridge attached to an external half cell. By means of a convenient bridge circuit a variable, measured voltage is applied across the electrodes and the current passing at different voltages is measured by a sensitive galvanometer of long period to damp out the variations in current during the life of the drop of mercury at the capillary tip of the dropping electrode. The voltage applied is generally between -2 and +2 volts and the current should be measurable to 0.01 microamperes.

In the simplest manually operated form of the polarograph a slide wire potentiometer is used to apply the e.m.f. and a suitably shunted galvanometer is used to measure the current flowing through the cell at each value of the applied e.m.f. Generally, however, automatic recording devices are incorporated in the polarograph. The voltage applied is varied continuously by means of a small electric 
motor, the voltage is recorded and the current passing is also recorded. The record is in the form of a voltage current curve. Apart from the rapidity of measurement with an automatic polarograph, the results are obtained in the form of a permanent record and as a continuous curve on which small waves may be seen which would possibly be missed with a manually-operated apparatus. In most polarographs the recording is photographic (e.g., in the instrument of the Heyrovsky type made by the Cambridge Instrument Company of London, the Nedjedly Company of Prague and the E. H. Sargent Company of Chicago), but in the instruments made by Tinsley in this country and by Leeds and Northrup in the U.S.A., the recording is by a mechanical pen. The cathode ray oscillograph is being applied to polarographic measurements with interesting results in the case of slow electrode reactions.

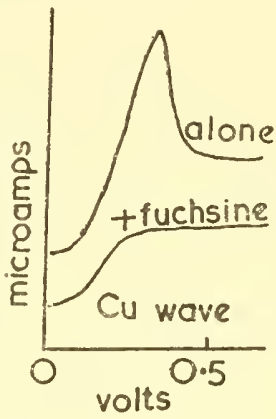

Fig. 42

Suppression of "maximum wave " by dye

When the metal after reduction is absorbed at the dropping mercury electrode there is a peak on the polarographic curve. If surface active substances such as dyes, protein, starch, etc., are added in small amounts the peak disappears. The phenomenon has been used for determining traces of surface active compounds. In the figure is shown the effect of fuchsine in abolishing the peak on the polarographic curve of copper.

It is essential in polarographic work to ensure that the solution is adequately buffered otherwise the hydrogen-ion concentration near the electrode will not be that of the bulk of the solution owing, probably, to diffusion of hydrogen or hydroxylions away from the immediate vicinity of the drop of mercury. Unstable potentials and variation of the half-wave potential may be due to inadequate buffering and much of the earlier work on the subject has been criticised for this fault. It is suggested that the buffer conce ntration should be one hundred times that of the reactant investigated.

It is important to note that in many papers on polarographic methods potentials are given not with reference to the normal hydrogen electrode as in oxidationreduction potential measurements, but are referred to the saturated calomel electrode (S.C.E.) which is $0.25 \mathrm{v}$. more positive at $20^{\circ}$.

\section{SYSTEMS OF BIOLOGICAL INTEREST}

Although much of the work with the polarograph has been applied to the detection of traces of metals there has been a considerable volume of work on other biologically interesting substances. 


\section{OXYGEN AND HYDROGEN PEROXIDE}

Dissolved oxygen in solution gives a typical polarogram and this may be of importance in determining traces of oxygen in biological systems such as bacterial cultures. There are two waves corresponding to the two stages of reduction of oxygen, first to hydrogen peroxide and then to water :-

$$
\begin{gathered}
\mathrm{O}_{2}+2 \mathrm{H}^{+}+2 \mathrm{e} \rightarrow \mathrm{H}_{2} \mathrm{O}_{2} \\
\mathrm{H}_{2} \mathrm{O}_{2}+2 \mathrm{H}^{+}+2 \mathrm{e} \rightarrow 2 \mathrm{H}_{2} \mathrm{O}
\end{gathered}
$$

The second wave, which is less sharp than the first is identical with that observed in an air-free solution of hydrogen peroxide.

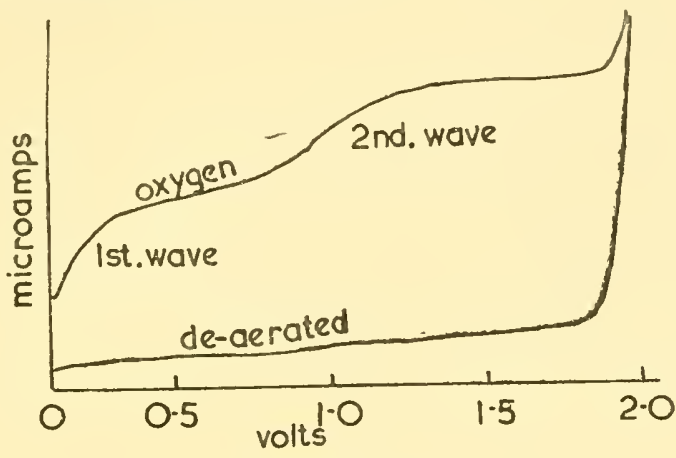

Fig. 43

Polarographic oxygen waves in presence of maximum suppressor

The reactions are irreversible at the electrode and are subject to over-voltage effects. The fact that dissolved oxygen gives waves on the polarographic curves accounts for the necessity of removing the oxygen by passing inert gases or by sulphite reduction when investigating other systems.

The polarographic method has been used for the study of respiration of green algae and in studying soils.

\section{POLAROGRAPHY OF THE CYSTINE-CYSTEINE SYSTEM}

In Chapter III it was pointed out that the electrode potentials of the cystinecysteine system could not be explained on the basis of the equation :-

$$
2 \mathrm{RSH} \rightleftharpoons \mathrm{RSSR}+2 \mathrm{H}^{+}+2 \mathrm{e}
$$

since the potential depended only upon the concentration of cysteine (RSH) and hydrogen ions and not upon the concentration of the oxidised form, cystine (RSSR). When the dropping mercury electrode is used the mercury reacts with cysteine and does not behave as an indifferent electrode.

Studying the anodic waves of cysteine Kolthoff and Barnum (1940) found that the results indicated not oxidation to cystine but to the reversible reaction :-

$$
\mathrm{RSH}+\mathrm{Hg} \rightleftharpoons \mathrm{Hg} \mathrm{RS}+\mathrm{H}^{+}+\mathrm{e}
$$

a compound of cysteine with mercury being formed. 
The experiments were conducted in the presence of perchloric acid in order to keep the mercury compound in solution.

When a platinum micro-electrode was used instead of the mercury dropping electrode, the curve obtained indicated irreversible oxidation of cysteine to cystine.

At the cathode reduction of cystine appeared to depend upon favourable orientation when adsorbed on the mercury droplets of the electrode, and to be affected by surface active substances such as thymol and camphor.

An interesting development of the behaviour of sulphydryl compounds at the polarographic electrode is found in the behaviour of proteins.

\section{SULPHYDRYL-CONTAINING PROTEINS}

In ammoniacal protein solutions containing a trace of a cobalt salt a characteristic catalytic cathode wave was observed by Heyrovsky, Brdicka and their colleagues. Sulphur containing proteins cause a double hump on the voltammetric curve obtained at the cathode and the magnitude of the deflection suggests a catalytic effect of the protein. The effect can be used for the quantitative determination of traces of protein and has even been suggested for the diagnosis of cancer.

The determination of $\mathrm{SH}$ groups in proteins by amperometric titration is described by Benesch and Benesch (1948). The protein, or denatured protein, solution is titrated with dilute silver nitrate. The galvanometer deflection obtained at a rotating platinum electrode (the cell being completed by a salt bridge and mercury: mercury iodide electrode) remains constant whilst silver mercaptide is precipitated, but increases immediately excess silver nitrate is present. When all or part of the SH groups are combined with p-chloromercuribenzoate the titratable $\mathrm{SH}$ groups show a corresponding decrease. The results in the case of egg albumin were in good agreement with previous amino acid analyses, but were lower in the case of serum albumin. It is in line with common experience that the $\mathrm{SH}$ groups in serum albumin are more "masked " and less " available" even after denaturation than in the case of egg albumin.

Cysteine and cystine give a single catalytic wave in ammoniacal solutions containing divalent cobalt or nickel. The magnitude of the wave is much greater than can be accounted for by the reduction of cystine to cysteine and appears to be catalytic in nature. It is suggested that cysteine forms a complex with divalent cobalt and the co-ordination bond with the sulphydryl group weakens the linkage with hydrogen which is deposited at the dropping electrode. Some dithiols behave similarly (Danielli et al, 1947).

These waves have been used to determine cystine in protein hydrolysates and as little as $0.001 \mathrm{~g}$. of human hair is sufficient for an analysis. Some other sulphur compounds have been found to behave similarly. It appears to be necessary to hydrolyse glutathione and mustard gas before they react in this way.

Applications of these phenomena have been the determination of protein in insulin and in cerebro-spinal fluid, and in the diagnosis of cancer but other inflammatory conditions are indistinguishable by the methods used.

\section{ENZYMES}

The catalytic waves of cytochrome $\mathrm{C}$ and other enzymes have been studied by Carruthers (1947). The cytochrome is dissolved in a solution of $\mathrm{pH} 9 \cdot 35$ containing 
ammonia, ammonium chloride and dilute $\left(10^{-3} \mathrm{M}\right)$ hexammino cobaltic chloride, and a small amount of gelatine is added to suppress the "maximum " wave. Small amounts of cytochrome (18 $\gamma$ per $\mathrm{ml}$.) produce a sharp wave with the peak at $-1.5 \mathrm{v}$. (versus saturated calomel electrode). By subtracting the current due to reduction of cobalt a quantitative measure of the cytochrome present can be obtained, and the progress of purification through a refining process can be followed. The wave is due to cystine, cysteine, etc., and no other amino acids give a catalytic wave. With cysteine and cystine the peak is at -1.75 volts and with glutathione at $-1 \cdot 1 \mathrm{v}$. The enzymes, ascorbic acid oxidase, tyrosinase, d-glyceraldehyde-3-phosphate dehydrogenase and aldolase also give catalytic waves with a peak at about - 1.45 volts. On the other hand prolactin, papain, pepsinogen, desoxyribonuclease and carboxypeptidase under the same conditions give two peaks at $-1 \cdot 1$ and -1.7 volts respectively.

\section{HAEMOGLOBIN AND HEEMATIN}

Hydrogen peroxide is reduced irreversibly at the dropping mercury electrode, and the reduction wave is flat but in the presence of hæmolysed erythrocytes, hæmoglobin or hæmatin, the peroxide wave approaches the first wave of oxygen. Curves are obtained in air-saturated solutions which make it possible to determine quantitatively hæmoglobin, hæmatin or coproporphyrin I, but cyanide inhibits the effect. Bilirubin gives reduction curves at the dropping electrode which have not yet been fully explained.

\section{SEMIQUINONES}

The formation of intermediate compounds in reductions involving two electrodes has been discussed in Chapter III :-

$$
\begin{gathered}
\mathrm{R}+\mathrm{e} \rightarrow \mathrm{R}^{-} \\
\mathrm{R}-+\mathrm{e} \rightarrow \mathrm{R}^{--}
\end{gathered}
$$

The semi-reductant $\mathrm{R}$ - may be recognised in the case of pigments by differences in colour. Müller (1942) has found two waves in the polarogram of $a--$ oxyphena-
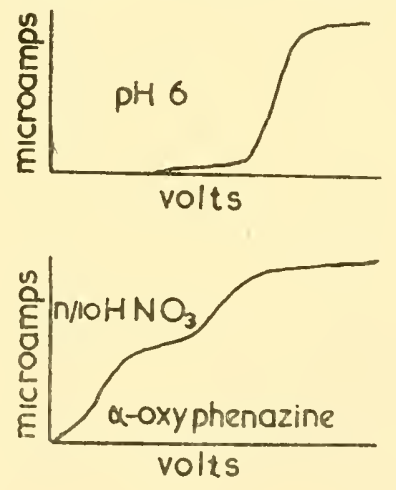

Fig. 44

Polarographic curves showing formation in acid solution of intermediate semiquinone in reduction of $\alpha$-oxyphenazine (after Müller)

zine in acid solution, the two points of inflection on the voltage-current curve corresponding to the two stages in the reduction. The half-wave potentials of the two 
stages of reduction are in agreement with results obtained by the measurement of the oxidation-reduction potentials of the systems. Anomalous waves often encountered in polarograms have been attributed to adsorption effects at the electrode which are sometimes removed by adding surface active substances to the system or varying the mercury-dropping time. In the case of pyruvic acid some of the effects seen have been attributed to keto-enol tautomerism and polymerisation.

\section{ANTIBIOTICS}

In an investigation of penicillin derivatives du Vigneaud and Melville (1949) studied acylated and non-acylated thiohydantoins polarographically. Acylation has no effect at the anode, both types of compounds giving a small wave between 0 and -0.2 volt. At the cathodically polarised dropping mercury electrode the nonacylated thiohydantoins have no effect, but the acylated 2-thiohydantoins have a pronounced double wave with half-wave potentials at -1.55 and -1.7 volts respectively, in an ammoniacal buffer at $\mathrm{pH} 9.2$; neither type of compound produces a catalytic cobalt wave like cysteine.

Penicillin has been assayed polarographically (Scudi and Woodruff, 1949). Cook, Hall, Heilbron and Roberts find that when penicillin is inactivated by alkali there is a marked SH wave in the polarograph proportional to the original biological activity. Hens, Page and Robinson use the catalytic wave in the presence of cobalt to assay penicillin after alkaline degradation.

\section{MOULD PRODUCTS AND QUINONES}

The half-wave potentials of a number of mould metabolites and related quinones have been measured by Page and Robinson (1943). The results are summarised in Table 30 . The measurements were made at $\mathrm{pH} 6 \cdot 24$, except in the case of citrinin and penicillic acid which were examined at $\mathrm{pH} 4 \cdot 63$.

TABLE 31

Half-wave Potentials of Quinones

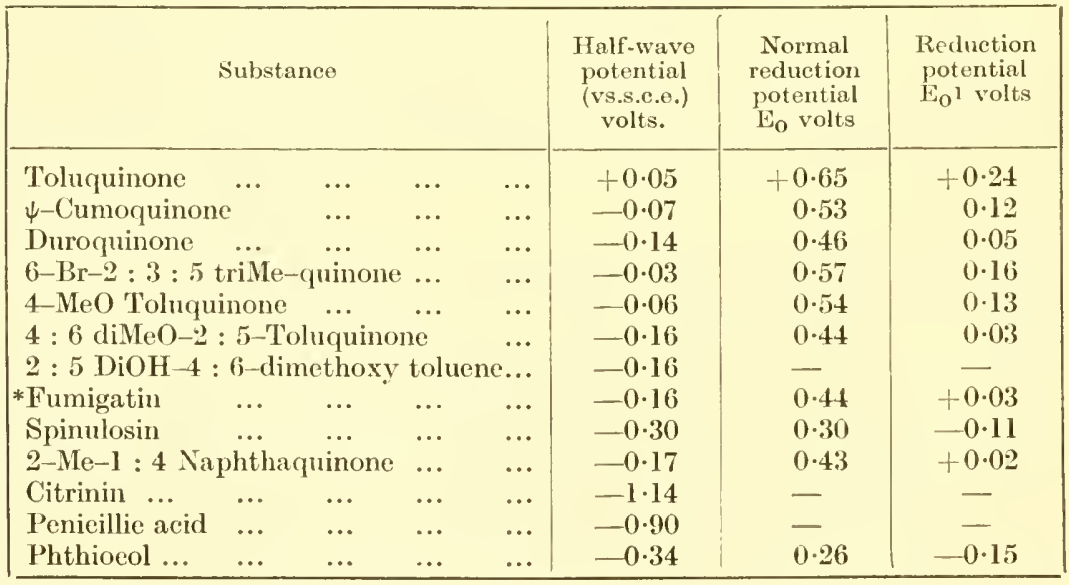

* 3-hydroxy-4-methoxy-2:5-toluquinone

$+3: 6$-dihydroxy-4-methoxy-2:5-toluquinone 


\section{VITAMINS}

Vitamin C yields an anodic wave and this has been used for determination of the vitamin but the oxidised form is not reducible at the dropping electrode.

Lingane and Davis have obtained some interesting results with the vitamin B group. Half-wave potentials (with the saturated calomel electrode as the reference value) in $0.1 \mathrm{~N} \mathrm{KC2}$ or $0.1 \mathrm{M}$ tetramethyl ammonium bromide were as follows :-

$\begin{array}{llll}\text { Riboflavin ... } & \ldots & \ldots & -0.35 \mathrm{v} \text {. } \\ \text { Thiamin } \ldots & \ldots & \ldots & -1.25 \\ \text { Nicotinic acid } & \ldots & \ldots & -1.7 \\ \text { Pyridoxin ... } & \ldots & \ldots & -1.8 \\ \text { Pantothenic acid } & \ldots & \ldots & -2.0\end{array}$

Anomalies in the case of riboflavin have been ascribed to the presence of surface inactive tautomers. Brdicka $(1941,1942)$, has studied the polarographic behaviour of riboflavin.

\section{SEX HORMONES}

Sex hormones containing a double bond conjugated with the ketone group (CH : $\mathrm{CH} . \mathrm{C}: \mathrm{O})$ give a wave at -1.7 volts, the height of the wave being proportional to the hormone concentration. These experiments were conducted in 90 per cent. ethyl alcohol containing lithium chloride. The half-wave potential of cholestenone in ammonium cliloride solution is $--1 \cdot 25$ volt (versus normal calomel electrode) (Adkins and Cox, 1938.)

It has been shown by Wolfe, Hershberg and Fieser (1940), that 17-ketosteroids treated with tetramethylammonium acethydrazide chloride (Girard $\mathrm{T}$ reagent) give hydrazides with a characteristic polarographic wave (half-wave potential at $-1 \cdot 4$ volts). This has been used for the determination of urinary ketosteroids (Barnett, Henly and Morris, 1946).

The polarograms of the steroid hydrazones are all similar to that given with the Girard $\mathrm{T}$ reagent (with a half-wave potential at about $-1 \cdot 3$ volt) except in the case of sulphur-containing analogues which have a lower potential (Barnett and Morris, 1946).

\section{FISCHER TITRATION METHOD FOR WATER DETERMINATION}

The Fischer (1935) reagent provides a convenient method for the determination of small amounts of water. In an anhydrous solvent iodine and sulphur dioxide do not react, but when water is added reaction occurs :-

$$
2 \mathrm{H}_{2} \mathrm{O}+\mathrm{SO}_{2}+\mathrm{I}_{2}=\mathrm{H}_{2} \mathrm{SO}_{4}+2 \mathrm{HI}
$$

pyridine is added to combine with the acids formed and the reagents are dissolved in anhydrous methyl alcohol. Excess of the Fischer reagent is generally added to the liquid which contains water and the excess of reagent is back titrated with a standard solution of water. The end point can be determined potentiometrically (Carter and Williamson, 1945). Two bright platinum electrodes are immersed in the liquid and a small potential difference is applied. The small current flowing between the electrodes remains constant during the titration whilst there is any moisture present, but rises suddenly directly there is excess of reagent. In the alternative method involving 
back titration of excess reagent with water a small current is passed between the electrodes. In a moist solution the electrodes are polarised and a potential difference characteristic of the system can be measured, but immediately there is a slight excess of reagent present the cathode is depolarised and the potential difference disappears. The sudden fall in potential can be observed with the aid of a galvanometer or by the "magic eye" of a cathode ray tube.

\section{TOXICOLOGY}

In view of the possibility of detecting traces of compounds the polarograph is valuable in toxicology. As an example it may be mentioned that aromatic nitrocompounds give characteristic polarograms and in nitro-poisoning investigations may be made directly on the serum of patients or on ether extracts.

The polarographic half-wave potentials of nitrobenzene derivatives have been studied by Dennis, Powell and Astle (1949). 'Toxic oxidation products of the chemotherapeutic drug arsphenamine have been detected with the polarograph.

\section{SUMMARY}

The general theory of polarographic methods is briefly described together with some experimental considerations. Applications of the polarograph to systems of biological interest such as dissolved oxygen, cysteine, proteins, enzymes, vitamins, hormones, chemotherapeutic agents and antibiotics, are discussed. 


\section{CHAPTER IX}

\section{GENERAL CONCLUSIONS}

Now that we have come to the end is it possible to arrive at any generalisations, or to detect any pattern in the complexity of data? It is evident that in addition to the wide variety of physiological processes that are primarily oxidation-reduction reactions there are a host of others which are governed or modified directly by oxidation-reduction conditions. The few reactions that do not fall into these two categorics are linked with other reactions in which oxidation-reduction potentials play a supreme role.

Perhaps one of the outstanding conclusions one can draw from the trend of modern work is the accumulating evidence of the inter-dependence of apparently independent processes. Reactions occur in chains and interference with one link ruptures the whole chain ; a reaction occuring early in a chain is closely linked with another near the end. The catalytic effects of enzymes are so nicely balanced and the partnership of coenzymes so close-knit that incredible feats of synthesis or breakdown occur almost isothermally at amazing speed.

Whereas a few years ago metabolic reactions were being studied in detail separately, it now begins to be possible to visualise broader plans of free energy changes, of cell synthesis, of phosphate cycles, of the oxidation-reduction balance. The harmonies are so finely adjusted that it is disconcerting to find an organism producing a substance that is not purely utilitarian and designed exclusively for the most efficient functioning of a metabolic process. The beauty of the pigments of wild flowers seems excessive for mere survival and the synthetic galaxies of the moulds appear to be exclusively for the humbling of organic chemists.

It is not surprising to find so many mould pigments and products to be related to the quinones, naphthaquinones and anthraquinones, all subject to study by oxidation-reduction potential methods and possibly of metabolic significance, but it is more surprising to find closely related compounds of significance in widely different organisms far distant in the genealogical tree. Frequently the metabolic process of the bacterium, the yeast cell and the mammalian muscle follows a similar course, despite the difference of medium and of organisation.

Nucleic acids play their predominating role of directing synthesis and differentiation in virus multiplication, in bacterial type differentiation and in animal chromosomes. The clue to the puzzle of self-multiplication is bound up in the nucleic acids and their role of providing patterns for the shaping of protein syntheses.

The same vitamins and growth substances are needed for man and microbe, and a vitamin assay is now more the task of a bacteriologist than a physiologist. But all these harmonies must not blind us to the differences. Possibly, just as the last two decades have shown us the similarities of widely different organisms, the next two may make plainer the differences - the control of cancerous growth, the defeat of the virus and the checking of infectious diseases depend upon our finding agents lethal to one type of cell, but harmless to another. Possibly hormonal control too may result from our finding antagonists to hormone production, as indeed is already suggested 
in recent work by Harington. Advances in our knowledge of diabetes have already shown us the possibilities of complex interhormonal control.

Antibiotics are rapidly becoming mere chemotherapeutic drugs now that chloromycetin has been synthesised, and chemotherapeutic drugs have already become metabolite analogues. Unless we are vigilant the gulf will widen between the general practitioner who prescribes the tablet and the laboratory worker who studies a dye that inhibits an enzyme that destroys a coenzyme that is necessary for the functioning of an enzyme system that is part of a chain of processes in the brain. The complexities of each speciality are multiplying so rapidly that it is not easy to ensure that members of research teams are working intelligently. It is not sufficient that senior members of the team should supply all the intellectual stimulus, leaving it to the junior members to be cogs on a wheel. For the maximum effect all should be mental as well as physical contributors. It is desirable that workers in the biological sciences should have as wide an understanding as possible of advances in other disciplines, and the problem of keeping up-to-date with scientific literature is becoming more formidable month by month. When the original literature became too bulky abstract journals solved the problem temporarily, and when these became too swollen Annual Reviews and Recent Advances proved a boon to research workers. These are now themselves so numerous and well filled that the rapid production of books summarising and co-ordinating recent advances is necessary and the debt owed to the compilers of stimulating scientific books is very considerable, since the labour and leisure devoted to their preparation cannot easily be spared. In previous chapters, therefore, full advantage has been taken of the ideas of many brains and although due acknowledgment of contributions to our understanding of biological phenomenon cannot be counted upon, the contributor of a valuable point of view has, at least, the satisfaction of feeling that he lias permanently affected the course of investigations. The close interweaving of experiment and interpretation with ideas from as broad fields as possible is the best guarantee of rapid progress and the saving of waste labour and time in pursuing fruitless quests.

Although widely divergent topics have been incorporated in the later chapters of this book, the unifying influence of the effect of oxidation-reduction conditions on biological functions impresses a pattern on the complex of data.

Biological electrode potentials have received an increasing amount of attention from investigators. Quantitative data are accumulating and interpretations of experimental results are becoming accepted as necessary accompaniments to progress. There was, a very few years ago, a great danger of stagnation and immobilisation, owing to the feeling on the one hand that experimental data could not be obtained until the theoretical side was in a more advanced stage of development, and, on the other hand, that no theories could be developed until more data had accumulated. The danger of stalemate was a very real one, but, fortunately, the subject has now opened out, and advantage can be taken of assistance forthcoming from very different directions.

Notwithstanding the initial difficulties, most encouraging progress has been made in the study of biological oxidation-reduction conditions, particularly in the realm of bacteriology, and it is remarkable how well deductions drawn from electrode potential measurements agree with the conclusions reached by workers proceeding along totally different avenues of approach. 
The more or less qualitative results on the reduction of dyes by tissues, yeast cells, bacteria, etc., have been generally corrected, extended and placed on a quantitative basis by the investigations of many workers on biological electrode potentials.

Many constituents of living organisms when isolated have been shown to be subject to reversible oxidation-reduction reactions. In a large number this reversible oxidation-reduction is essentially related to their vital function. Many biological pigments are known to constitute oxidation-reduction systems and their electrode potential relationships have been investigated. Respiratory functions have been attributed to some of these pigments.

A number of vitamins of the B-complex and ascorbic acid constitute oxidationreduction systems. It becomes increasingly difficult to distinguish between vitamins, enzymes, coenzymes, hormones and even toxins. All appear to function as biological catalysts and increasing numbers have been purified and crystallised. Their composition and mode of action have been made clearer and synthesis of some of them is within sight. Chemical methods of synthesis still appear crude, however, compared with the refined methods of the cell. Antibiotics such as penicillin and streptomycin are still produced commercially by the organisms themselves, but chloromycetin, one of the simpler antibiotics, is now a product of chemical synthesis.

As Michaelis has pointed out many of the enzymes and co-enzymes of significance in cellular respiration constitute two-stage oxidation-reduction systems, and it is possible that this type of reaction is essential for many biological enzymic oxidations.

The vitamins are by no means alone in their dependence upon oxidationreduction potentials, and some of the hormones, including adrenaline and the oxytocic hormone of the posterior pituitary gland, may also be oxidised and reduced.

In the latter case disulphide or sulphydryl groups appear to play an important part, and in this it resembles certain of the enzymes, namely, papain and urease, which function only in the presence of the reduced group-SH.

In their turn, these enzymes resemble two bacterial products, pneumococcus hæmolysin and one of the hæmolysins of hæmolytic streptococci, which are also inactivated by oxidation, etc. Study of the reduced streptolysin has led to interesting results in cases of streptococcal infection.

Whether the interior of a cell can be said to possess a characteristic electrode potential is a matter of some controversy. This, however, is an internal matter which primarily concerns the cell; a matter of more immediate interest is the study of the oxidation-reduction changes effected by the cell in its environmental medium and of the effect of different environmental conditions upon the behaviour of the cell. These investigations are in a very healthy state of development, and progress is being maintained, despite the difficulties inherent in the study of living organisms. For exact physico-chemical measurements the investigator would prefer to deal with a pure compound of known chemical constitution under fixed conditions, precluding the possibility of any cliange during the measurement. In practice the biochemist frequently can arrange for none of these ideals to be attained, and, to quote W. M. Clark (1934), the investigator by necessity " makes painfully exact measurements upon frightfully impure compounds." In a living organism and all its complexities we have the very antithesis of a pure chemical compound and it would be difficult for a chemist to prepare or even imagine a more heterogeneous and complicated mixture 
than is to be found in even the simplest unicellular organisms. In the matter also of keeping conditions constant during an experiment, faint hope can be entertained by the biochemist, for living implies constant changing; directly the dynamic state gives place to the static, we have not life but death, or, at least, a moribund state of suspended animation.

In studying the electrode potentials of biological systems, therefore, there are great difficulties, (1) in obtaining reproducible results, since no two organisms can be absolutely identical, and no organism can be quite the same on two different occasions; (2) in knowing what constituents of the system are responsible for the potential changes observed, and (3) in realising the effects of components of the system which do not directly affect the potential, but which do so indirectly by catalytic, poising or other activities. In the presence of appropriate cellular enzyme functions reversible oxidation-reduction processes occur which are unknown in their absence. Other oxidation-reduction systems which are irreversible or only semi-reversible affect the equilibria of reversible systems and complicate the results. In view of these difficulties, it is not surprising that many problems remain unsolved, but they need not be regarded as insuperable obstructions to progress. Even in the short listory of the subject numbers of successful circumnavigations round the obstacles are already reported.

Interesting facts emerge from a study of the changes in oxidation-reduction conditions produced by bacteria in the medium by which they are surrounded.

The metabolic activities of bacteria and their obtaining energy by oxidation of nutrient material result in a general development of reducing conditions in their cultures. Conclusions of considerable interest and of practical importance in the use of culture media are resulting from studies of the electrode potentials developed in bacterial cultures growing under conditions as nearly as possible identical with those used in bacteriological laboratories. It is evident that the conditions required for the manifestation of their characteristic properties must be the conditions chosen also for the study of electrode potentials if any correlation of the different bacterial activities is to be attempted.

The reducing conditions established in bacterial cultures during the logarithmic phase of growth vary from organism to organism. Different ranges of reducing effect may be seen; for example, the aerobes in general are able to reduce ordinary aerobic culture media until a moderately intense reducing level is reached, but many are unable to effect further reductions. The anaerobes, on the other hand, are unable to effect any reduction in ordinary aerobic cultures, but if the medium is partially reduced to begin with, e.g., by exclusion of the oxidising effect of air, they are able to establish and maintain quite intense reducing conditions.

Anaerobiosis like other properties of bacteria can be traced to the nnetabolic pattern of the organism and depends upon the enzyme systems that can be called into play. Being capable of adaptation and mutation with comparative ease the synthetic and catabolic functions of a strain of bacteria are susceptible to very wide variations, some of which are direct and fairly rapid adjustments to the environment and others only produced by considerable alteration to the "genes" or their nucleic acids. 
The importance of nucleic acids in biology is becoming increasingly evident. Nucleoproteins appear to be the self-reproducing units of living matter and an alteration to the nucleic acid results in a permanent alteration to the reproducing units. Just as an alteration to a dye or monld will affect all the subsequent productions cast in that mould so nucleic alteration affects the properties of the progeny of the cell or nucleoprotein molecule.

Apart from the range of reducing activities, other differences can be traced between different organisms. With some organisms, such as pneumococci, the level of reducing intensity reached is not maintained after the logarithmic phase of growth; but, on the other hand, highly oxidising conditions are gradually established. This is associated with the peroxide-forming function of these organisms and is a very characteristic property. The measurement of electrode potentials has proved of value in the study of peroxide formation by bacteria, and of the protective effect of the presence of catalase.

An apt quotation appears in a paper by Wieland: "The living cell is no furnace wherein all materials may be indiscriminately oxidised." Some substances may be utilised by one organism and not by another, hence differentiation of organisms may be accomplished by studying the development of reducing conditions in the presence of different possible nutrient inaterials, as in the Thunberg vacuum-tube method. The most probable explanation of the differences encountered between different organisms seems to lie in their possession of different enzymes. It seems likely that systematic classification of organisms will result from studies of oxidationreduction conditions in bacterial cultures.

The recognition of the effect of cultural conditions on the electrode potentials of bacterial cultures is leading to a wider problem, that of the relation between the oxidation-reduction conditions under which the cell is grown and its consequent biological behaviour. For example : hæmolytic streptococci are frequently extremely virulent when isolated from the blood stream of infected patients or animals, but when sub-cultured in broth in the ordinary way the organisms lose their virulence. The virulence may, however, be maintained by sub-culturing :-

(1) In broth to which blood-serum has been added;

(2) In aerated broth cultures.

The maintenance of virulence is effected by opposing the reducing effects of the organisms, by increasing their oxygen supply and this postulate is supported by the measurement of electrode potentials of cultures of hæmolytic streptococci. Both in serum-broth and aerated broth cultures the potential is prevented from falling to the low level reached in plain broth.

Furthermore, the matt form of hæmolytic streptococci may be transformed into the glossy variant at the high electrode potential produced by hydrogen-peroxide. This effect has been traced to two factors, the inhibition of proliferation of the matt form by the peroxide, and auto-sterilisation of the matt form, on solid media, by production of peroxide by the organisms themselves.

The mechanism of the effect is now apparent for the loss of virulence is due to the proteolytic effect of an enzyme produced by hæmolytic streptococci. This proteinase which digests the specific substance present in virulent organisms, requires reduced sulphydryl groups for its activation and under conditions of high oxidation-reduction 
potential no rednced SH groups are present. Wilson (1930) found that variations in virulence and colony form of $B$. aertrycke accompany alterations in the oxygen content of the gaseous environment of cultures.

The ripening of cheddar cheese without the occurrence of deleterious faults is apparently dependent upon the development on the correct series of electrode potentials at different stages Beer is said not to keep and tissue cultures not to proliferate at inappropriate electrode potentials. Milk is tested by the use of oxidation-reduction potential dyes. So that in the practical applications of biochemistry and bacteriology, as well as in the laboratory, electrode potentials have assumed prominence.

Potter (1911) observed the potential difference between a culture medium inoculated with bacteria and a sterile control, but Cohen (1931) has carried the matter to an extreme point. He has built up a bacterial battery by connecting in series a number of cells each composed of 10 e.c. of culture coupled to a sterile control. The culture medium contains a poising agent such as potassium ferricyanide or benzoquinone. Each unit "yields about $0.2 \mathrm{ma}$. at a pressure of 0.5 volt with very small polarisation for at least 5 minutes. By this means we have been able to build up a bacterial battery furnishing current of about 2 ma. at a pressure of 35 volts."

"The human body at rest uses about the same amount of energy as a 100-watt electric light bulb. Like the bulb, the body obtains this energy by a process which involves the flow of an electric current. In the living cell, electrons flow from the foodstuffs we ingest to oxygen, thus reducing the oxygen to form water. The 'filament' of the cell over which these electrons flow is not of uniform composition as is a light bulb. The electrons in the cell are passed along over a chain of compounds composed of iron-containing proteins, the cytochromes, and vitamincontaining units named coenzymes. The over-all process involves a potential change of about $1.17 \mathrm{v}$. and a total flow of eurrent in all the body cells which amounts to about 76 amps. The process occurs, however, in a stepwise fashion which involves five or six successive transfers of electrons between the various components comprising the cellular 'filament' or oxidative chain. Each pair of components may thus be looked upon as forming a battery, the pairs being connected in series. A drop in voltage occurs with the interaction of each pair in this series; its magnitude may be estimated from our knowledge of the oxidationreduction potentials of each of the systems involved. How the energy is utilised by the cell is not exactly known. A good portion of it, however, seems to be converted into high-energy phosphate bonds which, in turn, directly supply the driving force for many of the various physiological processes which constitute life." (Ball, 1947.)

The intense redncing activity of bacteria. associated necessarily with their metabolie funetions, is illustrated in a calculation by which it is shown that during the active logarithmie phase of growth a single cell of $B$. coli can reduce fifteen million molecules of oxidant each minute. The transport problem alone, of bringing millions. of molecules up to the cell surface and removing them after reduction, must be considerable.

Developments in chemotherapy and the rapid advances in the use of antibiotic: stimulated by the work of Fleming and Florey raise questions which impinge upon the 
subject of oxidation-reduction potentials. An abundant oxygen supply is necessary for penicillin production, which was originally carried out in surface cultures, but is now effected in aerated tanks. The similarities in the chemical formulæ of penicillin and biologically inportant compounds such as glutathione suggest possible mechanisms of action. The mode of action of sulphonamide drugs suggests that preliminary oxidation-reduction changes may be necessary, and the same holds with the organic arsenicals, the use of which has been simplified recently by the development of dithiols of the B.A.L. type.

A useful adjunct to electrode potentials for the study of biological oxidationreductions is found in polarography, which is of value in some systems with unstable potentials and which are not completely reversible. Once the current flowing in the system is measured it is possible with the Polarograph to obtain information concerning the amount of an oxidation-reduction system present as well as its. qualitative nature. Substances present in minute amount may sometimes be detected polarographically.

We begin to realise the important part that the study of electrode potentials may play in the explanation of bacterial problems and in the scientific development of bacteriology. The introduction of $\mathrm{pH}$ measurements has led to considerable improvement in bacterial technique, and it seems probable that electrode potential studies will play an important part in elucidating problems of bacterial behaviour. Such advances in bacteriology have preceded advances in other realms of biology where the investigator has to deal, not with many cells of the same type, but with cells of countless different kinds. A fuller understanding of unicellular behaviour and its variations must assist the solution of the more complex problems. A striking example of this has been the contribution of bacteriology to the study of the vitamins during the past fifteen years and the development of microbiological methods of assay.

It appeared to be the function of the nineteenth century to observe the simplicity and unity of natural phenomena; the twentieth seems rather to discover the complexity and intricacy of the pattern.

Closer understanding of the processes of metabolism and inheritance should now lead to a rational approach to their control and to the mitigation of suffering due to malnutrition, to infection, organic disease and perhaps old age. It may first be necessary, however, for man to differ from other organisms and avoid competitive inhibition.

The biologist has long studied living organisms as wholes and will continue to do so with ever-increasing interest. But these studies can tell us nothing of the nature of the "physical basis of life." which no form of philosophy can ignore. It is for chemistry and physics to replace the vague concept of "protoplasm"-a pure abstraction-by something more real and descriptive. I know of nothing which has shown that current efforts to this end do not deal with realities. It is only necessary for the biochemist to remember that his data gain their full significance only when he can relate them with the activities of the organism as a whole. He should be bold in experiment but cautions in his claims. His may not be the last word in the description of life. but without his hel, the last word will never be said.-Hopkins (1931). 


\section{B I B L I O G R A P H Y}

Abraham, E. P., Chain, E., Fletcher, C. M., Gardner, A. D., Heatley, N. G., Jennings, M. A. and Florex, H. W. (1941). Further observations on penicillin. Lancet, 2, 177.

Adkins, H., and Cox, F. W. (1928). J. Amer. Chem. Soc., 60, 1151.

Ainsworth, G. C., Brown, A. M., and Brownlee, G. (1947). Nature, 160, 263.

ALBERT, A., and FALK, J. E. (1949). The formation of hydrogen carriers by hæmatin-catalysed peroxidations. Biochem. J.. 44, 129.

Allyn, W. P., and Baldwin, I. L. (1932). Oxidation-reduction potentials in relation to growth of an aerobic form of bacteria. J. Bact., 23, 369.

AnEs, S. R. and Dawsox, C. R. (1945). Determination of copper in copper proteins using the dropping Mercury electrode. Ind. Eng. Chem. Anal. Ed. 17, 249-53.

—_and ElvehJer, C. A. (1945). Enzymic oxidation of glutathione. J. Biol. Chem., 549.

Anderson, A. B., and Hart, P. D. A. (1934). The viridans effect of the streptococci and the production of the green pigment from hæmoglobin by other reducing systems. J. Path. Bact., 39, 465.

Anderson, R.S. (1936). Chemical studies in bio-luminescence III. Reversible reaction of Cypridina luciferin with oxidising agents and its relation to the luminescent reastion. Jour. Cell. Comp. Physiol., 8, 261.

Andresen, P.H. (1946). Apparatus for anaerobic cultivation. Significance of reduction-oxidation potentials in bacteriology. Acta Path. Microbiol. Scand., 23, 153-63.

Anslow, W. K., and Raistrick, H. (1938). Fumigatin and spinulosiu. Biochem. J. 32,687.

ARAKI, T. (1939). The oxidation-reduction potentials of a bouillon nutrient medium with added vitamin C and the growth of tetanus bacilli. Oriental Jour. Diseases Infants., 26, 2.

Aronoff, S. (1946). Oxilation-reduction potentials and photo-reductions by chloroplast granules. Science, 104, 503.

Ashley, J. N., and RAistrick, H. (1938). The biochemistry of micro-organisms LVI. Luteoleersin and alboleersin ; metabolic products of Helminthosporium leersii Atkinson. A possible oxidation. reduction system. Biochem. J., 32, 449-54.

Atrinson, N., and Stanley, N. F. (1943). Antibacterial substances produced by moulds. IV. Detection and occurrence of suppressions of penicillin. V. Mechanism of the action of some penicillin suppressors. Australian J. Expt. Biol. Hed. Sci., 21, 249. 254.

Aubei, E., and Aubertin, E. (1927). Sur le potentiel d'oxydo-réduction des milieux où croissent les anaérobies stricts et les anaérobies facultatifs. Comp. rend. soc. biol., 97, I729.

- Aubertin, E., and Génevois, L. (1929). Sur le potentiel d'oxydo réduction de la levure, des anaérobies facultatifs, des anaérobies stricts, et des milieux où vivent ces organismes. Ann. physiol. et physicochem. biol., 5, 1 .

—, Aubertin, E., and Mauriac, P. (1928). Sur le potentiel d'oxydo-réduction des cellules de mammifères. Compt. rend. soc. biol., 98, 5 59.

and Génevors, L. (1927). Sur le potentiel d'oxydation-réduction de la levure, du bactérium coli et des milieux ou croissent ces micro-organismes. Compt.rend. Acad. Sci., 184, 1676.

_.-., - - and — Wuraser. R. (1927). Sur le potentiel apparent des solutions des sucres réductenrs. Compt.rcnd. Acad. Sci., 184, 407.

and Levy, R. (1929). Le potentiel d'oxydo-réduction dans les chenilles de Gallcria mellonella. Compt. rend. soc. biol., 101, 756.

and _ - (1930). Le potentiel limite d'oxydo-réduction dans les chenilles de Galleria mellonella. Compt. rend. soc. biol., 104, 86:.

—-, Mauriac, P., and Aubertin, E. (1929). Sur le potentiel d'nxydo-réduction et sur les vitesses des procès d'oxydo-réduction des cellules de mammifères. Ann. physiol. physicochem.biol., 5, 310.

- Rosenberg, A. (í, and Grünberg, M. (1946). Study of oxidation-reduction potential. Limit of growth of the anaerobic bacteria. Helv. Chim. Acti, 29, 1267-8.

Aubertin, F., see Aubel and Aubertin (19:7).

- -, AUbertin and (ienevots (19:9).

- - - and MaURiac (1928).

- Mauriac and Aubertin (1929).

Averv, O. T. (1922). Differentiation of hæmolytic streptococei from human and dairy sources, particularly with methylene blue. Abs. Bact., 6, 31.

- MacLeod, C. M., and McCARTY, H. (1944). Studies on the chemieal nature of the substance inducing transformation of pneumococcal types. J. Exp. Mcd., 79, 137.

and Motran, H. 1. (1924). The oceurrence of peroxide in eultures of pnenmococcus. J. Exp. Hed., 39, 275 .

and NeILl, J. M. (1924). Studies on oxidation and reduction by pneumococcus. I. II. III. IV. J. Kxp. Merl., 39, 347, 357, 543, 745.

see also Neill and Avery (1925).

Morgan and Avery (1933).

Thjötta and Avery (1921). 
Baker, B. B., and Michaelis, M. (1947). A correlation between oxidation-reduction potentials and synergisms in resting-bacteria. Nature, $159,197$.

BAKER, Z., see Elliott and Baker (1935).

Baldwin, E. (1948). Dynamic aspects of biochemistry. (Cambridge Univ. Press).

Baldwin, I. L., see Allyn and Baldwin (1932).

—, Brown and BALDWIN (1933).

- WOOD, WOOD and BALDWIN (1935).

BaLl, E. G. (1934). Studies on oxidation-reduction. XXI. Phthiocol, the pigment of the human tubercle bacillus. J. Biol. Chem., 106, 515.

(1936). Studies on oxidation-reduction. XXII. Lapachol lomatiol and related compounds. J. Biol. Chem., 114, 649-55.

(1937). Oxidation-reduction potentials of hydroxynaphthoquinones in alkaline solutions. $f . A m$. Chem. Soc., 59, 2071-2.

(1937). Studies on oxidation-reduction. XXIII. Ascorbic acid. J. Biol. Chem., 118, 219-39.

- (1938). Oxidation and reduction of the three cytochrome components. Biochem. Z., 295, 262-4.

- (1939). Xanthine oxidases: purification and properties. J. Biol. Chem., 128, 51.

(1939). The role of flavoproteins in biological oxidations. Cold Spring Harbor Symposia Quant. Biol., 7, 100.

(1947). Biochemical mechanism of cellular oxidation. Science, 106, 118.

and Chen, T. T. (1933). Studies on oxidation-reduction. XX. Epinephrine and related compounds. J. Biol. Chem., 102, 691.

and Clark, IV. M. (1931.) Potentiometric studies on epinephrine. Proc. Nat. Acad. Sci., Wash., 17,347 .

— and Ramsdell, P. A. (1940). Catalytic action of milk flavoprotein in oxidation of reduced diphosphopyridine nucleotide. (Cozymase.) J. Biol.Chem., 131, 767.

BARDWELl, K., see Baumberger, Jürgensen and Bardwell (1932).

Barnet', J., Henly, A. A., and Morris, C. J. V. R. (1946). The polarographic estimation of steroid hormones. I. Polarography of neutral 17-ketosteroids in urinary extracts. Biochem., J. 40, 445 .

- , and Morris, C. J. V. R. (1940). The polarographic estimation of steroid hormones. II. Polarography of related steroid hydrazones. Biochem.J., 40, 450.

Barrensciteex, H. K., and Beneschovsky, H. (1932). Die Rolle der Sulphydrylverbindungen im Kohlehydratabbau. Biochem., Ztschr., 255, 453.

Barrov. E. S. G. (1937). Biological oxidations. IX. The oxidation-reduction potentials of blood hæmin and its hæmochromogens. J. Biol. Chem., 121, 285-312.

(1939). The role of iron-porphyrin compounds in biological oxidations. Cold Spring Harbor Symposia Quant. Biol., 7, 154.

(1940). XIII. The oxidation-reduction potentials of Spirographis hæmin and its hæmochromogens. J. Biol. Chem., 133, 51-S.

(1943). Mechanisms of Carbohydrate Metabolism. Advances in Enzymology, 3, 182.

, De Meio, R. H., and Klemperer, F. (1936). V. Copper and hæmochromogens as catalysts for the oxidation of Ascorbic acid. Mlechanism of the oxidation. J. Biol. Chem., 112, 625.

and HAStivgs, A. B. (1934). Oxidation-reduction potential of the system lactate-enzyme-pyruvate. J. Biol. Chem., 107, 567.

J. Gen. Physiol., 13, 483.

sce also Flexner and Barron (1930).

Michaelis and Barron (1929).

, Miller, Z. B. and Bartlets, G. R. (1947). Reactivation by Dithiols of enzymes inhibited by Lewisite. Biochem., J., 41, 69.

- and MEYER, J. (1947). The effect of 2:3-Dimercaptopropanol on the activity of enzymes and the metabolism of tissues. Biochem. J., 41, 78 .

, Munch, R. and Sidwell, A. E., Jr. (1937). Influence of electrolytes on the oxygen dissociation of hæmoglobin. Science, 86, 39-40.

—, and Singer, T. P. (1945). Studies on biological oxidations. XIX. Sulfhydryl enzymes in carbohydrate metabolism. J. Biol. Chem., 157, 221-241.

Bates, F. L., French, D., and Rundle, R. E. (1943). Amylose and amylopectin content of starches determined by their iodine complex formation. Jour. Amer. Chem. Soc., 65, 142.

Badmberger, J. P. (1933). Apparatus for study of redox potential in biological systems. J. Gen. Physiol, 17, 1.

- (1939). The relation between the "oxidation-reduction potential" and the oxygen consumption rate of yeast-cell suspensions. Cold Spring Harbor Symposia Quant. Biol. 7, 195.

, Jürgensen, J. J., and BARDwell, K. (1932). The coupled redox potential of the lactate-enzymcpyruvate system. J.Gen. Physiol., 16, 961.

Beard, P. J., see Clifton, Cleary and Beard (1934). 
BECK, L. V. (1933). Intracellular oxidation-reduction studies VI. Effects of penetrating and nonpenetrating acids and bases on the oxidation-reduction phenomena in starfish eggs. J. Comp. Cell. Physiol., 3, 261.

Becker, E. and Di Gléria, J. (1937). Potentiometric determination of vitamin C. Z. Vitaminforsch. 6, 86-94.

BeLl, R. A., see Vickers, Sugden and Bell (1932).

Beltran, E., Adelbert, P. and Grasset, A. (1937). The oxidation-reduction potential of the elementary sap of the grapevine. Compt. Rend. Acad. Agr. France, 23, 533-8.

Benesch, R., and Benesch, R. E. (1948). Amperometric titration of sulphydryl groups in amino acids and proteins. Arch. Biochem., 19, 35 .

Beneschovsky, H., see Barrenscheen and Benescbovsky (1932).

Bentson, J., see Biilman and Bentson (1918).

BERa, N., see Biilman and Berg (1930).

BERGER, E., see Erlenmeyer, Berger and Leo (1933).

BerLINER, E. (1946). A relation between the oxidation-reduction potentials of quinones and the resonance energies of quinones and of hydroquinones. J. Am. Chem. Soc., 68, 49-51.

Bernieim, F., and Bernheim, M. L. C. (1939). The effect of various metals and metal complexes on the oxidation of sulfhydryl groups. Cold Spring IIarbor Symposia Quant. Biol., 7, 174.

Bersin, T. (1932). Uber die Beschleunigung der Autoxydation von Mercaptoverbindungen durch organische Katalysatoren. Ein Beitrag zue Erklärung der Wirkung von Jodessigsäure auf die Glykolyse im Muskel. Biochem. Ztschr., 248, 3.

and LOGEMANN, W. (1933). Influence of oxidising and reducing agents on the activity of papain. Z. physiol. Chem., 220, 209-16.

Bertho, A. and Gluck, H. (1931). Das Gebild von Wasserstoff superoxyd durch Milchsäurebakterien. Naturwiss., 19, 88.

Bierich, P.o, and Lavg, A. (1934). Das Potential des gelben Oxydoreduktionspigmentes. Ztschr. physiol. Chem., 223, 180.

-, (1936). Determination of the potentials of tumor tissues. Biochem. Z., 287, 411-17. 21, 496 .

Billman, E. (1927). L'electrode à quinhydrone et ses applications. Bull. soc. chim., 41, 213. and Bentson, J. (1918). Utber alloxoen und alloxanthin. Ber, deutsch. chem. ges, 51, 522. and Berg, N. (1930). Über den reduktions Potentiale der Alloxanthine und über die Darstellung der Alloxane und Alloxanthine. Ber. deutsch. chem. ges., 63, 2188.

and Lund, M. H. (1921). Sur l'electrode à quinhydrone. Ann. chem., 16, 321 .

and - (1923). Sur le potentiel d'hydrogènation des alloxanthines. Ann. chim., 19, 137.

Brrch, T. W., Harris, L. J. and RaY, S. N. (1933). A micro-chemical method for determining the hexuronic acid (vitamin C) content of foodstuffs, etc. Biochem. J., 27, 590.

Birkinshaw, J. H., Charles, J. H. and Clutterbuck, P. W. (1931.) Studies in the biochemistry of micro-organisms. 21. Quantitative examination by the carbon balance sheet method of the types of products formed from glucose by species of bacteria. Biochem. J., 25, 1522.

Blduenthal, D. (1936). An immunological study of the reduction of disulphide groups in proteins. J. Biol. Chem., 113, 473.

BoE, Z. DE., see Wurmser and de Boe (1932).

Borsook, H. (1940). The oxidation-reduction potential of eoenzyme. I. J. Biol. Chem., 133, 629-30.

-. Davenport, H. W.. Jeffreys, C. E. P. and WARner, R. C. (1937). Oxidation of ascorbic acid and it.s reduction. J. Binl. Chem., 117, 237.

Eluis, E. L. and HuffMan, H. M. (1937). Sulfhydryl oxidation-reduction potentials derived from thermal data. J. Biol. Chem., 117, 281-308.

-- and Keighley, G. (1933). Oxidation-reduetion potential of assorbic acid (vitamin ('). Proc. Nal. Acad. Sci., 19, 875.

see also Schott and Borsook (1933).

and Scirot, H. F. (1931). The role of the enzyme in the suceinate-enzyme-fumarate equilibrium. J. Biot. Chem., 92, 535-37.

Bowman, D. E. (1941). Oxidation-reduction properties of the chorionic gonadotropic hormone. J. Biol. Chem., 137, 293.

Boyn, E. M., and ReEd, G. B. (1931). Gas-metal electrorle potentials in sterile culture media for bacteria. Can.J. Res., 4, 54.

— and- (1931). Oxidation-reduction potentials in eultures of Es. coli. Can.J. Res., 4, 605.

Borland, E. (1930). Phosphoric esters in adcoholic fermentation. IV. Oxidation-reduction potentials of yeast preparations. Biochem.J., 24, 707.

BRACIET, J. and Rapkine, L. (1939). Oxidation and reduction of dorsal and ventral explants of the :mphibian gastrula. Compt. rend. Soc. Biol., 131, 759-91. 
BrDicka, R. (1937). Application of the polarographic effect of proteins in cancer cliagnosis. Nature, $139,330$.

(1937). Polarographic investigations in serological cancer diagnosis. Nature, 139, $1020-1$.

(1938). Serological studies by polarography and their application to carcor diagnosis. Acta inlern. Ver. Krebsbekäuslung, Louvain Bely., 3, 13-30.

(1941). Two-stage reversible elcetro-reduction with the formation of semiquinones and their Ii.ners at the dropping mereury elcetrode. Z. Elektrochem., 47, 314-26.

- (1912). The polarographic behavioul of riboflavin II. The absorption of the reduction products and their oscillographic investigation. Z. Elektrochem., 48, 686-93.

and KNoвцосн, E. (1941). Polarographic study of riboflavin. I. Determination of oxidationleituotion potentials. Z. Filektrochem.. 47, 721-8.

_- and Trapp, C. (1937). Polarographic sturlies on blood pigments and their dentratives. I. Activation of hydrogen peroxide by hæmoglobin and hæmatin. Biochem. Z., 289, 301-12.

:nd Wiesner, R. (1943). Polarographic determination of the velocity constant for the oxidation of ferrohæmoglobin and other ferrous complexes by hydrogen peroxide. Naturwissenschaften, $31,247$.

BREYER, B. (1938). Effect of substituents on the reduction potentials dissociation constants and surface activities of benzene arsonic acid?. Ber., 71B, 163-71.

(1939). Biochem. Z., 301, 68.

Buchanan, G. S., and Dutwell, H. (1944). Reduction potentials of acridines with reference to their antiseptic activity. J.Chem. Soc., 360-3.

Brooks, M. M. (1926). Penetration of certain oxidation-reduction indicators as influenced by $\mathrm{pH}$. Estimation of the $\mathrm{rH}$ of Valonia. Am. Journ. Physiol., 76, 360.

- (1934). The effects of methylene blue and other oxidation-reduction indicators on experimental tumours. Univ. Calif. Public, Zool., 39, 293.

- (1943). Methylene blue, potassinm eyanide and carbon monoxide as indicators for studying the oxidation-reduction potentials of developing marine eggs. Biol. Bull., 84, 164-77.

(1947). Activation of eggs by oxidation-reduction indicators. Science, 106, 320.

Brown, L. W., and BALDwn, I. L. (1933). 'The oxidation-reduction charaeter of agar media and the growth of aerobic bacteria. J. Bact., 25, 29.

Buehrer, T. F., Martin, W. P., and PARks, R. Q. (1939). The oxidation-reduction potential of alkaline calcareous soils in relation to pudlling and organic matter lecomposition. J. Am. Soc. Agron., 31, $903-14$.

BunkeR, H. J. (1936). A review of the physiology and biochemistry of the sulphur bacteria. Dep. Sci. Indust. Res. Chem. Res. Special Rep., No. 3.

Burk, D. (1939). A colloquial consideration of the Pasteur and neo-Pasteur effects. Cold Spring Harbor Symposia Quant. Biol., 7, 420.

, Hearon, J., Caroline, L. and Schade, A. L. (1946). J. Biol. Chem., 165, 723.

Burrows, W., and Jordan, E. O. (1935). Oxidation-reduction potentials in salmonella cultures, I. The development of potential levels characteristic of species. J. Inf. Dis., 56, 255. , sce also Dack and Burrows (1935).

(1941). Oxidation-reduction potentials in salmonella cultures. J. Infect. Diseases, 69, $141-7$. (1941). Oxidation-reduetion potentials in salmonella cultures. III. The relation between characteristic potential and antigenic structure. J. Infect. Diseases, 69, 141.

(1943). Oxidation-reduction potentials in salmonella cultures. IV. A note on the relation of observed potentials to $\mathrm{pH}$. J. Infect. Diseases, 71, 106-9.

and Condon, T. C. (1936). The influence of the decomposition of organic matter on the oxidationreduction potential of soils. Soil Sci., 42, 1-10.

- and JorDan, E. O. (1936). Oxidation-reduetion potentials in salmonella cultures. II. Characteristic potentials produced by members of the suipestifer and enteritidis groups. J. Infect. Diseases, 53, 259-62.

Butlin, K. R., Aonns, M. E., and Thomas, M. (1949). The isolation and eultivation of sulphatereducing bacteria. J. Gen. Microbiol., 3, 46.

CaLlow. A. B. (1923). On catalase in bacteria and its relation to anaerobiosis. Journ. Path. Bact., 26, 320 .

- (1926). Heat stable peroxidase of bacteria. Biochem. Journ., 20, 247.

Calıow, R. K., and Hart P. d'A., (1946). Antibiotic maicrial from Bacillus licheniformis. Nature, $157,334$.

Calvis. M., and Barkelew, C. H. (1946). Journ. Amer. Chem. Soc., 68, 2267.

and Bexson, A. A. (1949). The path of earbon in photosynthesis. Science $109,140$.

Caneron, A. E. (1938). Oxidation-rerluetion potentials of unstable organic systems. J. Phys. Chem., $42,1217-27$.

Canals, E., and Bayler, H. (1939). Reduction-oxidation potential of wines. J. Pharm. Chim., 29, 503-10. 
Cannan, R. K. (1926). Electrode potentials of hermidine, the chromogen of mercurialis perennis. Biochem. Journ., 20, 927.

(1927). Echinochrome. Biochem. Journ., 21, 184.

- Cohen, B., and Clark, W. M. (1926). Sudies on oxidation-reduction. X. Reduction potentials in cell suspensions. U.S. Pub. Health Rep., Suppl., 55.

and Richardson, G. M. (1929). The thiol-disulphide system. I. Complexes of thiol acids with iron. Biochem. J., 23, 1242.

, see also Gibbs, Cohen and Cannan (1925).

Richardson and Cannan (1929).

Carruthers, C. (1947). Polarographic determination of Cytochrome C. J. Biol. Chem., 171, 641.

Carter, R. J., and Williamson, L. (1945). Analyst, 70, 369.

Caspersson, T. (1946). The relations between nucleic acid and protein synthesis. Symp. Soc. Exp. Biol., 1, 127.

Cattaneo, C., and Neuberg, C. (1934). Umstellung der Coli-Gärung auf Milchsäure-Gärung. Biochem. Z. $272,441$.

Cattareo, C., and Sartori, G. (1942). A polarographic study of pyocyanine. Gazz. Chim. Ital., 72, 38-41.

CAvallito, C. J.. and Balley. J. H. (1944). Inactivation of antibiotics. Science, 100, 390.

- - and - (1949). An antibacterial principle from Centaurea maculosa. J. Bact., 57, 207.

Chain, E., Florey, H. W., Gardner, A. D., Heatuey, N. G., Jennings, M. A., Orr-Ewing. J., and Savpers, A. G. (1940). Penicillin as a chemo-therapeutic agent. Lancet, 1940, II, 226-8.

Chambers, R. (1933). Analysis of oxidation and reduction of indicators in living cells. Cold Spring Harb. Sympos. Quant. Biol., 1, 205.

- Cohen, B., and Pollack, H. (1931). Intracellular oxidation studies. III. Permeability. Echinoderm ova to indicators. Brit. J. Exp. Biol., 8, 1.

- Pollack, H., and Cohen, B. (1929). Intracellular oxidation-reduction studies. II. Reduction potentials of marine ova as shown by indicators. Brit. J. Exp. Biol., 6, 229.

—, see also Cohen, Chambers and Reznikoff (1928).

Chance, B. (1949). The properties of the enzyme-substrate compounds of horseradisls and lactoperoxidase. Science, 109.

Chang, S. L. (1946). Studies on Entamcba histolytica. IV. The relation of oxidation-reduction potentials to the growth, encystation, and excystation of Entamœba histolytica in culture. Parasitology, 37, 101-12.

Charles, J. H., see Birkinshaw, Charles and Clutterbuck (1931).

Chen, T. T., see Ball and Chen (1933).

Cohen and Chen (1933).

Christian, W., see Warburg and Christian (1932, 1933).

Clark, P. F., and Rueht, IV. H. (1919). Morphological changes during the growth of bacteria. J. Bact., 4, 615 .

Clark, W. M. (1923). Studies on oxidation-reduction. I. Introduction. U.S. Pub. Health Reports, 38, 443. (1928). Determination of hydrogen ions, 3rd Edition, London.

(1934). The potential energies of oxidation-reduction systems and their biochemical significance. Medicine, 13, 207.

(1938). Potential energies of biologically important oxidation-reduction systems. J. Applied Physics, 9, 97-108.

- (1939). Potentiometric and spectrophotometric studies of metalloporphyrins in co-ordination with nitrogenous bases. Cold Spring Harbor Symposia Quant. Biol., 7, 18.

and CoHen, B. (1923, 1). Studies on oxidation-reduction. II. An analysis of the theoretical relations between reduction potentials and $\mathrm{pH}$. U.S. Pub. Health Reports, 38, 666.

and - $(1923,2)$. Studies on oxidation-rerluction. III. Electrode potentials of mixtures of 1-naphthol-2-sulphonic acid indophenol and the reduction product. U.S. Pub. Health Reports, $38,933$.

- $\frac{38}{P}$ and GibBs, H. D. (19:5). Studies on oxidation-recluction. VIII. Methylene bluc. U.S. Pub. Health Reports, 40, 1131.

,$- \frac{\text { and }}{-}-(1926)$. Studies on oxidation-reduction. IX. A potentiometric and spectrophotometric study of meriquinones of p-phenylenediamine and benzidine series. U.S. Pub. Health Reports Suppl., 54.

,$- \frac{1}{-}$ and Suldivan, I. X. (1927). Stuclies on oxidation-reduction. XII. A note on the Schardinger reaction (in reply to Kodama). U.S. Pub. Health Reports Suppl.. 66.

- - see also Ball and Clark (193I).

Cannan, Cohen anıl Clark (1920).

Cohen, Gibbs and Clark (1924, 1, 2).

Gibbs, Cohen aud Clark (1925).

Hellerman, Perkins and Clark (1933).

Phillips, Clark and Colien (1927).

Stichler and Clark (1933).

Sullivan, Cohen and Clark (1923). 
Clarke, H. T., Johnson, J. R., and Robinson, R. (1949). The chemistry of penicillin (Princeton).

Claudatus, I. (1940). An apparatus for determining the oxidation-reduction potentials in vivo and the hydrogen-ion concentration by a single puncture. Biochem. Z., 304, 49-55.

Cleary, J. P., see Clifton and Cleary (1934).

Clifton, Cleary and Beard (1934).

Clemo, J. R., and MCIlwain, H. (1938). J. Chem. Soc., 479.

Clerck, J. DE (1934). Woch, Brau., 51, 213.

Cliftos, C. E. (1933). Oxidation-reduetion potentials in cultures of staphylococcus aureus. $J$. Bact., 25,495 .

(1937). A comparison of the metabolic activities of Aerobacter aerogenes, Eberthella typhi and Escherichic coli. J. Bact., 33, 145.

- and Cleary, J. P. (1934). Oxidation-reduction potentials and ferricyanide reducing activities. in glucose peptone cultures and suspensions of Esch. coli. J. Bact., 28, $56 \mathrm{I}$.

-,$\ldots$ and BEARD, P.J. (1934). Oxidation-reduction potentials and ferricyanide reducing activities in peptone cultures and suspensions of Esch. coli. J. Bact., 28, 541 .

Clutterbuck, P. W., see Birkinshaw, Charles and Clutterbuck (1931).

Cohen, A., King, H. and Strangeways, W. I. (1932). Trypanocidal power and chemical constitution 14. The relative velocity of oxidation of arylarsenoxides. J. Chem Soc., 2866.

-_- - - and- (1931). Trypanocidal action and chemical constitution. X. Arylthioarsinites. XI. Aromatic arsonic acids containing amide groups. J. Chem. Soc., 1931, 3236-57.

COHEN, B. (1931). The hacterial culture as an electrical half-cell. J. Bact., 21, 18.

(1933). Reactions of oxidation-reduction indicators in biological material and their interpretation. Cold Spring Harb. Sympos. Quant. Biol., 1, 214.

- Chambers, R., and Reznikorf, P. (1928). Intracellular oxidation studies. I. Reduction potentials of Amœba dubia by micro-injection of indicators. Journ. Gen. Physiol., 11, 585 .

- Gibbs, H. D., and Clark, W. M. $(1924,1)$. Studies on oxidation-reduction. V. Electrode potentials of simple indophenols each in equilibrium with its reduction product. U.S. Pub. Health Reports, 39, 381 .

,$- \frac{1}{-}$ and $-(1924,2)$. Studies on oxidation-reduction. VI. A preliminary study of indophenols : (A) Dibromo substitution products of phenol indophenol; (B) Substituted indophenols of the ortho type; (C) Miscellaneous. U.S. Pub. Health Reports, 39, 804.

—- and Chen, T. 'T. (1933). Reduction intensity in anaerobic Amoba dubia. Proc. Soc. Exp. Biol. Med., 31, 115.

and Phillips, 11. (1929). Studies on oxidation-reduction. 15. Potentiometric studies of the amino indophenols ; phenol blue, m-toluylene diamine indophenol, and of o-toltuidine indophenol. U.S. Pub. Health Rep. Suppl. No. 74.

—_ and Preisler, P. W. (1931). Studies on oxidation-reduction. 16. The oxazines: Nile blue. brilliant cresyl blue. methyl capri blue and ethyl eapri blue. U.S. Pub. Health Reports Suppl., No. 92.

and Schwachmas, H. (1935). Some oxidation and reduction reactions of pneumococcal hæmolysin. J. Bact., 29, 54.

--, see also Cannan, Cohen and Clark (1926).

Chambers, Cohen and Pollack (1931).

Chambers, Pollack and Colien (1929).

Clark and Cohen $(1923,1 \& 2)$.

Clark, Cohen and Gibbs (1925; 1926).

Clark, Cohen and Sullivan (1927).

Gibbs, Cohen and Cannan (1925).

Hall, Preisler and Cohen (1928).

Phillips, Clark and Cohen (1927).

Schwachman, Hellerman and Cohen (1934).

Sullivan, Cohen and Clark (1923).

Corle, H. D., see Werkman, Johnson and Coilc.

Colwill, C. A., and MCCALL, M. (1945). Antibacterial action of 2-methyl-1, 4-naphthoquinone. Science, 101, 592-4.

Conant, J. B. (1923). An electrochemical study of hæmoglobin. Journ. Biol. Chem., 57, 401.

- (1926). Chem. Rev., 3, 1.

and Fieser, L. F. (1925). Methæmoglobin. Journ. Biol. Chem., 62, 595.

and I.UTz, R. E. (1924). Irreversible reduction of organic compounds, I.

The relation between apparent reduction potential and hydrogen-ion concentration. J. Amer. Chem. Soc., 46, 1254.

- and PAPPENheimer, A. M. (1932). Oxidation potential of the hæmoglobin-methæmoglobin system. Journ. Biol. Chem., 98, 57.

- and Tongberg, C. O. (1930). Oxidation-reduction potentials of hæmin and related substances. Journ. Biol. Chem., 86, 733. 
Conspen, R., Gordon, A. H., Martix, A. J. P., and Sysge, R. L. M. (1946). "Gramicidin S.," the sequence of the amino-acid residues. Biochem.J., 40, Xitili.

Conway, E. J., and O'Malley, E. (1946). The nature of the Cation Exchanges during Yeast Fermentation with Formation of 0.02 N.H. ion. Biochem. J., 40, 59.

Cook, W. H. and Chadderton, A. E. (1940). pH, oxidation-reduction potential and miscellaneous measurements on bacon and pickle. Can.J. Rescarch, 18, D, 149-58.

Coolides, T. B. (1931). Oxidation-reduction potential of complex iron componnds in yeast. Nature, $128,223$.

(1932). Cytochrome and yeast iron. Journ. Biol. Chem., 98, 755.

Cooper, I. H. N. (1937). Oxidation-reduction potential in seawater. J. Marine Biol. Assoc., United Kingdom, 22, No. 1, 167-73.

Cori, C. F., Colowick, S. P., and Cori, G. T. (1938). The formation of glucose-1-phosphoric acid in eytracts of mammalian tissues and of yeast. J. Biol. Chem., 123, 375.

- and CorI, G. T. (1936). Mechanisin of formation of hexosemonophosphate in muscle and isolation of a new phosphate ester. Proc. Soc. Exp. Biol. Med., 34, 702.

Corran, H. S., Dewan, J. G., Gornon, A. H., and Green, D. E. (1939). Xanthine-oxidase and milk flavoprotein. Biochem J., 33, I694.

and Grees, D. E. (1938). The isolation of a flavoprotein for eow milk. Biochem. J., 32, 2231. - and Stratb, F. B. (1939). The catalytic function of heart flavoprotein. Biochem. J., 33, 793 .

CORY ELL, D. D. (1939). Existence of chemical interactions between the hæmes in ferrihæmoglobin (methæmeglobin) and the role of interactions in the interpretation of ferro-ferrihæmoglobin electrorle potential measurements. J. Physical Chem., 43, 841 .

Coryeld, C. D. (1940). Science, 92, 380.

Coulter, C. B. (1928). Oxidation-reduction equilibria in biological systems. I. Reduction potentials of sterile culture bouillon. Journ. Gen. Physiol., 12, 139.

and IsaAcs, M. L. (1929). Oxidation-reduction equilibria in biological systems. II. Potentials of aerohic cultures of B. typhosus. Journ. Exp. Med., 49, 711 .

CozIc, Mr. (I936). Contribution à la connaissance des potentials d'oxydo-reduction provoqués par le métalonlisme des bacteries acétiques. Rev. gen. de Botanique, 48, 141. Reprint.

('Raner, D. L. (1947). The mode of action of nitröfuran compounds. II. J. Bact., 54, 119.

Crawford, T. B. B. and Lerry, G. A. (1947). Biochem. J., 41, 333.

Cross, R. J., Taggart, J. V., Coro, G. A., and Green, D. E. (1949). Studies on the cyclophorase system. VI. The coupling of oxidation and phosphorylation. J. Biol. Chem., 1949, 177, 655 .

Crozier, IW. J. (1916). Cell penetration by acids. II. Further observations on the blue pigment of chromodoris zebra. Journ. Biol. Chem., 26, 217.

Cummises, P. W., and Reed, J. F. (1940). Some applications of the polarograph in soil investigations. Soil Sci. Soc. Proc., 5, 167-70.

Curd, F. H. S., and Davey, D. G. (1949). Antrycide; a new trypanocidal drug. Nature, 163, 89.

- - and Rose, F. L. (1946). Synthetic antimalarials : some aryl-diguanide derivatives. J. Chem. Soc., 729.

Czenaluowsk, J. W., and Dolby, D. E. (1949). Effect of enzyme inhilitors on the genesis of phage. Nature, 163, 719.

DACK, C. M., and Burrows, IV. (1935). Oxidation-reduction potentials of some non-sporulating obligate anaerobes. Proc. Soc. Exp. Biol. Mcd., 32, $144 \mathrm{I}$.

DAGLeY, S., DAWEs, E. A., and Morrisov, C. A. (1949). Application of bacterial kinetics to biochemical problems. Nature, 163, 532.

Dalfsen, J. W. van, see Elema, Kluyver and ran Dalfsen (1934).

Danielli, J. F., and M., Fraser, J. B., Mrtchell, P. Q., Owen, L. N., and Shaw, G. (1947). BalIntrav: a new non-toxic thiol for intravenous injection in arsenical poisoning. Biochem. J., 41, 325 .

Darnell, M. C.. Jr., and Eisenmenger, WV. S. (1936). Oxidation-reduction potentials of soil suspensions in relation to acidity and nitrification. J. Agr. Research, 53, 73-80.

DAURreSne, M. and V. R. (1938). Comparative potentiometric measurements on cultures of spirochaetes from the human mouth. Compt. rend. soc. biol., 128, 773-4.

Davies, W. L., Davis, J. G., Dearden, I). V., and Mattick, A. T. (1934). Studies in cheddar cheese. II. The effect of controlled oxirlation-leduction potential on ripeniug. J. Dairy Research, 5, 144.

Davis, J. G. (1932). Studies in cheddar cleese. I. The oxidation-reduction potentials of ripening cherl!ar cheese. J. Dairy Research, 3, 241. see also Davies, Davis, Dearden and Mattick (1934). Mattick, Davis and Dearden (1931).

(1938). Indueed oxidation-reduction potentials, rates of growth, and the volatile acid production of lactic acid bacteria in milk. J. Dairy Research, 9, 85-94.

Dawson, C. R., and Mallette, R. F. (1945). The copper proteins. Rec. adv. Protein Chcm., II., 208. 
Dearden, D. V., see Davies, Davis, Dearden and Mattick (1934). Mattick, Davis and Dearden (1931).

DeEdS, F., and EDdY, C. W. (1938). Phenothiazine. III. Conversion of phenothiazine to thionol. J. Am. Chem. Soc., 60, 1446-7.

- - (1938). Phenothiazine. IV. Potentiometric characterization of thionol. J. Am. Chem. Soc., 60, 2079-84.

Deloyers, L., see Vlès, Reiss and Deloyers (1931).

Dennis, S. F., Powell, A. S., and Astue, M. J. (1949). The reduetion of substituted nitrobenzenes at the dropping mereury cathode. J. Amer. Chem. Soc., 71, 1484.

Desnuelle, P., see Fromageot and Desnuclle (1935).

Dewan, G. J. and Grees, D. F. (1937). Coenzyme-linked reactions between dehydrogenase systems. Biochem. J., 31, 1074-85.

Dick, H., see Tillmans, Hirsch and Dick (1932).

Dickens, F. (1936). Mletabolism of normal and tumour tissues. XVI. Action of some oxidationreduction systems. Biochem. J., 30, 1064. and McIlwain, H. (1938). Phenazine compounds as carriers in the hexosemonophosphate system. Biochem. J., 32, 1615-25.

Dickinson, D. (1940). System activated sludge-oxygenated water. V. Changes in oxidationreduction potential with the sludge floc. J. Soc. Chem. Ind., 59, 257-8.

Dirks, B. (1940). The oxidation-reduction system of the soil as a new factor in growth of outstanding importance and to other growth factors of the soil. Bodenkunde u. Pflanzenernäkr, 21/22, 684-697.

Dixos, M. (1926). Studies on Xanthine oxidase. 7. The specificity of the system. Biochem. Journ., 20, 703 .

(1927). On the mechanism of oxidation-reduction potentials. Proc. Roy. Soc. B., 101, 57.

Dixon, M. (1943). Manometric methods. 2nd Edn. (Cambridge Univ. Press).

and Quastel, J. H. (1923). A new type of oxidation-reduction system. I. Cysteine and glutathione. Journ. Chem. Soc., 123, 2943.

and Tunnicliffe, H. E. (1927). On the reducing power of glutathione and cysteine. Biochem. Journ., 21, 844.

Donker, H. J. L., see Kluyver and Donker (1925).

Dorfmax, V. A. (1936). Redox polarity of the amphibian egg and its relationship to the bioelectric polarity of the egg. Protoplasma, 25, 427-34.

Dod DorofF, 11. (1943). Studies on the phosphorylation of sucrose. J. Biol. Chem., 151, 351.

Drtssen, E. M., see Williams and Drissen (1930).

DuBos, R. (1929). The initiation of growth of certain facultative anaerobes as related to oxidation. reduction processes in the medinm. Journ. Exp. Med., 49, 559.

Dubos, R. J. (1947). The Bacterial Cell.

Dedley, H. W. (1931). Inhibition of glyoxalase by iodacetate. Biochem. J., 25, 439.

DUoal, L. P. (1936). Determination of oxidation-reduction potentials (in biological media.). Naturaliste Canadien, 63, 113-33.

Duggar. B. M. (1948). Aun. N.Y., Acad. Sci., 51, 177.

Dutky, S. R., see Kne.ysi and Dutky (1934).

Dyer, see Voegtlin, Johnson and Dyer (1924).

Eaton, M. D. (1931). Bacteriophage and staphylococcus aureus. J. Bach., 21, 143.

Eogers, H. (1942). An electrode vessel for oxidation-reduction potential measurements. Biochem. $Z$., $310,231-2$.

and Dieckinass, H. (1941). Oxidation-reduction potential of phenazine series. Biochem. Z., 310,231 .

Eggleton, P., and Eggleton, G. P. (1927). Biochem. J., 21, 190.

Ehrismann, O., and Noethling, W. (1936). Absorption spectra of pyocyanin, prodigiosin and vio. lacein. Biochem. Z., 284, 376.

Ehrltch, J., Bartz, Q. R., Surth, R. M., Joslyn, D. A., Burkholder, P. R. (1947). Science, 106, 417.

EHrLich, P. (1885). Zur biologischen Verwertung des methylenblaus. Cent. Med. Wissensch., 23, 113.

- (1885). Das Sauerstoff-Bedürfnis des organismus. Eine farben-analytische Studie. Berlin.

Elema, B. (1931). Studies on the oxidation-reduction of pyocyanine. II. Redox potentials of pyocyanine. Rec. trav. chim. Pays-bas, 50, 807.

- (1932). De Bepaling van de Oxydatie-reductiepotentiaal in Bakteriencultures en haare Beteekenis voor de Stofwesseling. Proefshrift. Delft.

(1933). Theory of the reversible two-step oxidation. Journ. Biol. Chem., 100, 149.

(1933). Oxidation-reduction potentials of chloraphine. Rec. trav. chim. Pays-bas, 52, 569.

Kldyver, A. J. and van Dalfsex, J. W. (1934). Uber die Beziehungen zwischen den Stoff wechsel-vorgängen der Mlikroorganismen und dem Oxydoreduktionspotential im Medium. I. Biochem. Ztschr., 270, 317. 
Elimoff, W. W., Nekrassow, N. J. and Elimoff, A. (1928). Die Einwirkung des oxydations Potentials und der H-Fonen-konzentration auf die Vermehrung der Protozoen und Abwechslung ihrer Orten. Biochem. Ztschr., 197, 105.

ELLIO'TT, K. A., and BAKER, Z. (1935). The effects of oxidation-reduction potential indicator dyes on the metabolism of tumour and normal tissues. Biochem. J.. 29, 2396.

— and - 1935). The effect of oxidation-reduction potentiai indicator dyes on the metabolism of tumour and normal tissues. Binchem. J., 29, 2396-2404.

Elliot', K. A. C., (1946). Annual Review of Biochemistry, 15, 1.

Elliotт, S. D. (1945). A proteolytic enzyme produced by a group A streptococei. J. Exp. Med., $81,573$.

Enders, C. and Theis, K. (1937). Polarographic studies on beers and melanoidin solutions. Wochenschr. Brau, 54, 250-1.

EPSTEIN, S. S. (1936). Methylene blue reduction and oxidation-reduction potential studies on members of the eolon-aerogenes group of bacteria. Iowa State Coll. J. Sci., 10, 303-16.

Erlenmeyer, H., Berger, E., and Leo, N. (1933). Eine potentiometrische Methode zur Bestimmung eines Antikörper-Hapten-Gleichgewichts. Biochem. Ztschr., 266, 355.

Euler, H. V., and Hellstron, H. (1938). Oxidation-reduction equilibrium in the system desaminocozymase-alcohol apodehydrogenase-alcohol. Arkiv Keni. Mineral. Geol., 1213, No. 55, 7. and - (1938). Respiratory enzyme systems in muscle, Jensen sarcoma, lung and spleen. Z. physiol. Chem., 255, 159-68.

Evans, M. G. (1946). Bond fixation and the oxidation-reduction potentials of quinones. Trans. Faraday Soc., 42, 113.

Evans, R. MI. and Hansom, W. T., Jr. (1937). Reduction potential and photographic developers: effect of sulfite in developer solutions. J. Phys. Chem., 41, 509-34.

— and - (1935). Reduction potential and the composition of $11-\mathrm{Q}$ developer. J. Soc. Motion Picture Engrs., 30, 559-67.

Farrell, MI. A. (1935). The respiratory mechanism of the streptococi. J. Bact.. 29, 10.

Fieser, L. F. (1930). I. The potentials of some unstable oxidation-reduction systems. An inclirect method of studying the oxidation-reduction potentials of unstable systems, inclucling those of the phenols and amines. Journ. Amer. Chem. Soc., 52, 4915, 5204.

-

Frage, F. H. J. (1939). Melanin : a natural reversible oxidation-reduction system and indicator. Proc. Soc. Exp. Med. Biol., 41, 127.

Fildes, P. (1929). Tetanus. VIII. The positive limit of oxidation-reduction potential required for the germination of spores of $B$. tetani in vitro. IX. Oxidation-reduction potential of the subcutaneous tissue fluid of the guinea pig; its effect on infection. Brit. Journ. Exp. Path, $10,151,197$.

(1935). The tryptophan and sporogenes vitamin requirements of B. botulimus. Brit. J. Exp. Path., 16, 309.

_- Gladstone, G., and Knigut, B. C. (1933). The nitrogen and vitamin requirements of B.typhosus. Brit. J. Exp. Path., 14, 189.

_- , see also Knight and Fildes $(1930,1933)$.

Fink, H. (1932). Klassifizierung von Kulterhefen mit Hilfe des Cytochromspektrums. Zischr. Physiol. Chem., 210, 197.

Fischer, K. (1935). Angew. Chem., 48, 394.

Fleming, A. (1922). On a remarkable bacteriolytic element found in tissues and secretions. Proc. Roy. Soc., Lond., B, 93, 306.

- (1929). The antibacterial action of cultures of a Penicillium, with special reference to their use in the isolation of B. influenza. Bril. J. Exp. Path., 10, 226-36.

Flexner, L. B. (1939). Biochemieal changes associated with onset of sceretory activity in the metanephros of the fetal pig. The eytochrome system and oxidation-reduction potentials. J. Biol. Chem.. 131, 703-11.

FLexner, L. B., and Barron, E. S. G. (1930). Oxidation-reduction potentials at earbon and tungsten electrodes. Journ. Amer. Chem. Soc.. 52, 2773.

- - see also Michaelis and Flexner (1928)

FRED, E. B., see Ingraham and Fred (1933).

Fred, R. B., and KNIGHT, S. G. (1949). The reduction of 2, 3, 5-triphenyltetrazolium chloride by Penicillium chrysogenum. Science, 109, 168.

Frei, W., Riedmuller, L., and Almasy, F. (1934). Über Cytochrom und Das Atmungssystem der Bakterien. Biochem. Zlschr., 274, 253.

French, S. J., and Kahlenbers, L. (1928). The nature of gas-metal electrodes. Trans. Am. Electrochem. Soc., 54, 163. 
Friedneim, E. A. (1933). Das Pigment von Halla parthenopea, ein akzessorischer Atmungskatalysator. Biochem. Z., 259, 257.

(1933). Ein natürliches, die Zellatmung katalysicrendes Redox-System. Naturwiss, 21, 177.

(1933). Sur la function respiratoire du pigment rouge de Penicillium phoniceum. Compt. rend. soc. biol., 112, 1030.

(1933). Un système d'oxydo-réduction réversible biologique: Le pigment d'Arion rufus. Arch. sci. phys. nat., $V$, Suppl. 162.

(1934). Natural reversible oxidation-reduction systems as accessory catalysts in respiration: Juglon and Lawson. Biochem. J., 28, 180.

(1935). Atmungskatalyse durch ein natürliches Redox-system, Zwischenprodukt der melaninbildung. Schueiz. med. Wochschr., 16, 256.

— and Michaflis, L. (1931.) Potentiometric study of pyocyanine. J. Biol. Chem., 91, 355.

Friedrich, H. (1937). The relationship between storage temperatures of sound and diseased potato tubers and the oxidation-reduction potential of their tissue extracts. Phytopath. Z., 10, (6), $559-77$.

Fromageot, C. (1927). Contribution a l'étude physico-chimique du metabolisme. Jour. Chim. Phys., $24,513,623$.

— and Desnuelle, P. (1935). Über das Oxydoreduktionspotential von Hefesuspensionen und einige damit im Zusammenhang stehende Fragen. Biochem. Ztschr., 279, 34.

- - and Bost, G. (1937). The reducing power of living yeast in the course of alcoholic fermentation. Compl. rend Soc. Biol., 204, 1008-10.

Fujita, A. and Kodama, T. (1934). Respiration and fermentation of pathogenic bacteria. I. Determination of metabolic quotients of pathogenic bacteria. Biochem. Z., 269, 367-74.

,$--(1934)$. Studies on the respiration and fermentation of pathogenic bacteria. IJ. Respiration and fermentation of $C$. diphtherioe. Biochem. Z., 271, 185-98.

- - - (1935). Respiration and fermentation of pathogenic bacteria. IV. Oxygen consumption and hydrogen peroxide production of pneumococcus. Biochem. Z., 277, 17-31.

Fuller, A. T. (1937). Is p-amino benzenesulphonamide the active agent in prontosil therapy? Lancet, i. 194.

GALE, E. F. (1947). Chemical activities of bacteria.

- - and Rodwell, A. W. (1949). The assimilation of amino-acids by bacteria. VII. The nature of the resistance to penicillin in Staphylococcus aureus. J. Gen. Microbiol., 3, 127.

Galliet, J. (1947). Investigations on the oxidation-rednction potential of cholera vibrio. Ann. Inst. Pasteur, 73, 154.

Gavguli, S. C., see Ghosh, Raychandhuri and Ganguli (193:2).

Ghosh and Ganguli (1934, 1935).

Garrod, L. P. (1948). Brit. Med.J., i. 382.

GAUTHERET, R. (1939). The oxido-reduction potential of culture media with vital colouring substance in the presence of yeasts. Compt. rend., 208, 1840-2.

- (1939). Action of Saprolegnia dictira on the oxidation-reduction potential of culture media containing (reducible) dyes. Compt. rend. Soc. Biol., 131, 616-18.

Geake, A. and Lexon, J. T. (1938). Semiquinone formation by anthraquinone and some simple derivatives. Tran. Faraday Soc., 34, 1409-27.

Geiger, W. B. and Conn, J. E. (1945). Antibiotic action of clavaocin and penicillic acid. J. Am. Chem. Soc., 67, 112.

Geloso, J., see Wurmser and Geloso (19:8, 19:9, 1930, 1931).

GÉnevo1s, L., see Aubel, Aubertin and Génevois (1929).

Aubel, Génevois and W'urmser (1927).

Aubel and Génevois (1927).

Georgescu, I. D. (1932). Sur le potential d'ozydo-réduction des acides hexuroniques. J. Chim. phys., 29,217 .

Ghosh, J. C., Raychandhuri, S. N., and Gaxguli, S. C. (1932). Oxidation-reduction potential. 1. Cystine. 2. Thioglycollic and thiolactic acids. Journ. Indian Chem. Soc., 9, 43.

and Ganguli, S. C. (1934). A Note on the reduction potential of eysteine-cystine mixtures. Biochem J., 28, 381 .

and (1935). Das Redoxpotential des glutatbions. Biochem. Ztschr., 279, 296.

and Char, T. L. R. (1937). The oxidation-reduetion potential of ascorbic acid. (Vitamin C.) Z. physiol. Chem., 246, 115-23.

Gibbs, H. D., Cohen, B. and Canvan, R. K. (1925). Studies on oxidation-reduction. VII. A study of dichloro substitution products of phenol indophenol. U.S. Pul. Health Reports, 40, 649.

- , see also Clark, Cohen and Gibbs (1925; 1926).

Cohen, Gibbs and Clark (1924: 1, 11).

Gillam, W. S. (1945). Polarographic determination of vitamin $\mathrm{C}$ in fruits and vegetables. Ind. Eng. Chem. Anal. Ed., 17, 217-21. 
Gillespie, L. J. (1920). Reduction potentials of bacterial cultures and of water logged soils. Soil. Sci., 9, 199.

Gillespie, R. W., and Rettger, L. F. (1936). Oxidation-reduction potentials of certain anaerobic and facultative anaerobic bacteria. I, II. J. Bact., 31, 14.

- and - (1938). Bacterial oxidation-reduction studies. I. Differentiation of the species of the spore-forming anaerobes by potentiometric technique. J. Bact., 36, 605-20.

and $-(1938)$. II. Differentiation of lactobacilli of diverse origin. J. Bact., 36, 621-31.

and Porter, J. R. (1938). III. Characteristic potentials of the cultures of derobacillus species. J.B act., 36, 633-7.

GrRŠsvičus, J. O. (1933). Some properties of the enzyme glyoxalase. II. pH activity curve with phenyglyoxal and the effect of glutathione. Biochem. J., 27, 573-42.

Gladstone, G., see Fildes, Gladstone and Knight (1933).

Glasstone, S. (1940). Oxidation-reduction potentials and their applications. Trans. Electrochem. Soc., 77, 13 pp.

_ (1947). Thermodynamics for Chemists. (van Nostrand.)

GLück, H., see Bertho and Glück (1931).

GLYuph, E. M. (1941). The polarographic method in the investigation of several Acetobacter suboxydans fermentation products. Iowa State Coll. J. Sci., 16,52-4.

Goard, A. K., and Rideal, E. K. (1924). On the measurement of certain "inaccessible" potentials. with a controlled oxygen electrode. Trans. Far. Soc., 19, 740.

-... and - (1924). Catalytic and induced reactions. (i) In the presence of salts of cerium. (ii) In the presence of salts of iron. Proc. Roy. Soc., A., 105, 135, 148.

Gordox, J., see Mcleod and Gordon (1922, 1923).

Gотніє, S. (1941). Oxidation-reduction potential during fecundation in Asearis megalocephala. Compt. rend. Soc. Biol., 135, 643-4.

Granick, S., and Gilder, H. (1946). J. Qen. Physiol., 30, 1.

- Michaelis, L. and Schubert, M. P. (1940). Semiquinones of oxazines, thiazines and selenazines. J. Am. Chem. Soc., 62, 1802-10.

Green, D. E. (1933). The reduction potentials of cysteine, glutathione and glycyleysteine. Biochem. J.. 27, 678.

(1933). The potentials of ascorbic acid. Biochem. J., 27, 1044.

- - Stickland, L. H. and TaRr, H. L. A. (1934). Studies on reversible dehydrogenase systems. III. Carrier-linked reactions between isolated dehydrogenases. Biochem. J., 28, 1812.

_- see also Machlis and Green (1933).

- -, Dewan, J. G. and Lelorr, L. F. (1937). $\quad \beta$-Hydroxybutyric dehydrogenase of animal tissue. Biochem. J., 31, 934-49.

- and - (1938). Coenzyme factor of yeast. Biochem. J., 32, 1:00-3.

Green, D. E., Herbert, D.. and Subrahuanyan, V. (1940). J. Bio?. Chem., 135, 795.

GrennBANk, G. R. (1940). Variations in the oxidation-reduction potential as a cause for the oxidised flavour in milk. J. Duiry Sci., 23, 725-44.

Greville, G. D., and Stern, K. G. (1935). The reduction of nitrophenols by redox indicators and enzymes. Biochem.J., 29, 485.

-..--, see also Stern and Greville (1933).

Griffioen, K. (1935). Oxidation-reduction potential in lignifying cells. Nature, 141, 876-7.

Grifrith, E. (1928). J. Hyg., 27, 113.

Gullan1, J. N. and Pandall, S. S. (1935). The oxytocic hormone of the posterior lobe of the pituitary gland. V, VI. Biochem. .J., 29, 378, 391 .

- and - (1936). Oxytocic hormone of posterior lobe of pituitary gland. Chem. and Ind., 442.

Gurchot, C. and McCawley, E. L. (1940). Action of urea in the healing of wounds. Univ. Calif. Pwb. Pharmacol., 1, 325.

HaAs, E. (1937). The mode of action of the yellow pigment protein. Biochem. Z., 288, 123-5.

- (1938). Isolation of a new yellow enzyme. Biochem. Z., 298, 375-390.

HaAs, P., and Hirl, T. G. (1924). Mercurialis. I. II. Biochem. J., 19, 223, 236.

НакомоRI, S. (1931). Reaction of hydrogen peroxide with some metallic ions. I. l'otential of hydrogen peroxide. T'ech. Rep. Toholu, 9, 106.

HaL, J. C. (1921). Chemical eriteria of anaerobiosis, with special referenee to methylene blue. Journ Bust., 6, 1 .

Hald, W. h., Preislek, l'. W. and Cohen, B. (1928). Studies on oxidation-reduetion. 14. Equilibrium potentials of 2 , 6-dibromobenzenone indophenol-2-sodium sulphonate, ete. U.S. Pub. Health Reports suppl. No. 71.

Handoysky, H. and Hauss, L. (1939). Determination of $\mathrm{r} H$ in endocrine extracts of a protein nature. Bull. Sor. Chem. Biol., 21, 112-14.

HANEs, (C. S. (1940). The breakdown and synthesis of starch by an enzyme system from pea seeds. Proc. Roy. Stor. B.. 123, +21. 
HANKe, M. E. and BALfey, J. H. (1945). Oxidation-reduetion potential of Cl. Welchii and other Clostridia. Proc. Soc. Exptl. Biol. Hed., 59, 163-6.

HARDEN, A. (1901). The chemical aetion of $B$. coli communis and similar organisms on carbohydrates and allied eompounds. J. Chem. Soc., 79, 610.

(1932). Aleoholic fermentation. (Fourth edition) London.

and Norris, R. V. (1914). The enzymes of washed zymin and dried yeast (Lebedev). II. Redue. tase. Biochem J., 8, 100 .

and - (1915). The redueing enzymes of dried veast (Lebedev) and of rabbit musele. Biorlem. J., 9, 330 .

_-_ and ZiLva, S. S. (1915). The redueing enzyme of B. coli communis. Biochem. .J., 9, 379.

Harington, C. R. (1948). Synthesis of a sulphur-eontaining analogue of thyroxine. Biochem. J., 43,434 .

HARRIS, D. T. (1928). Journ. Sci. Inst., 5, 161.

Harris, L. J., see Birch, Harris and Ray (1933).

Harrison, D. C. and Quastel, J. H. (1928). Reduetion potential of cysteine. Biochem.J., 22,683.

Harrison, G. B. (1930). Application of a new type of triode valve to the determination of hydrogen-ion concentration with glass eleetrodes. Journ. Chem. Soc., 1528.

HART, P. D. A., see Anderson and Hart (1934).

Hartong, B. D. (1934). Woch. Brau., 51, 409.

Harver, E. N. (1926). The oxidation-reduction potential of the luciferin-oxylueiferin system. Journ Gen. Physiol., 10, 385.

(1929). Reducing intensity of luminous bacteria. Journ. Gen. Physiol., 13, 13.

(1941). Review of biolumineseenec. Ann. Rer. Biochem., 10, 531-52.

Hastings, A. B., see Barron and Hastings (1934).

Hastivas, E. G., see Thornton and Hastings (1929).

McCarter and Hastings (1935).

Haurowitz, F. (1937). Reaetion between hæmin and hydrogen peroxide. Enzymologia, 4, 139.44.

Havard, R. E., and Kendal, L. P. (1931). The effect of the oxidation-reduetion potential of the medium on the growth of tissue cultures. Biochem. J., 28, 1121.

Havemane, R., (1943). The oxidation-reduction potential of methrmoglobin and hremoglobin. Biochem. Z., 314, $118-34$.

and WoLfF, K. (1937). The reduction-oxidation system methmæoglobin-hæmoglobin. Biochem. Z., 293. 399-404.

HEARD, R. D. and WELCH, A. D. (1935). The perfusion of the adrenal gland with reference to the mechanism of adrenaline stabilisation. Biochem. J., 29, 999.

Нелтн, J. C. (1946). Polarographie behaviour of adenine. Nuture, 158, 23.

Heintze, S. G. (1935). Soil oxidation-reduetion potentials and pH values. Soil Research, 4, 35l-5.

Hellerman, L., Perkıns, M. F. and Clark, IV. M. (1933). Urease activity as influeneed by oxidation and reduetion, Proc. Nat. Acad. Sci., 19, 855.

_- see also Schwachman, Hellerman and Cohen (1934).

and -. - (1934). Activation of enzymes (II) papain aetivity as influeneed by oxidation-reduetion and by the action of metal eompounds. J. Biol. Chem., 107, 241-55.

Hellström, H. (1927). Meehanism of Hydrosulfite reduction of eozymase. Z. physiol. Chem., 246, I55-62.

(1936). The shift in reduetion-oxidation potential on iron-bearing methylene blue solution. Naturwissenschaften, 24, 217.

HENRY, H., and StACEY, M. (1943). Histoehemistry of the gram-staining reaction of miero-organisms. Nature, 151, 67 l.

Herbert, R. W. and others (1933). The constitution of aseorbic acid. J. Chem. Soc., I270.

Hewit , L. F. (1927). Combination of proteins with phthalein dyes. Biochem. J., 21, 1305. (1929). Hormones of the anterior pituitary gland. Biochem. J., 23, 718.

- $(1930,1)$. Oxidation-reduetion potentials of cultures of hæmolytie streptoeoeei. I. Biochem. J., 24, 512 .

$(1930,2)$. Oxidation-reduction potentials of cultures of $C$. diphtherice. I. Biochem. J., 24, 669.

(1930, 3). Oxidation-reduetion potentials of eultures of staphyloeoeci. I. Biochem.J., $24,676$. $(1930,4)$. Oxidation-reduetion potentials of cultures of pneumococci. I. Biochem. J., $24,1551$. (1931, 1). Oxidation-reduetion potentials of pneumoeoceus cultures. II. Effeet of eatalase. Biochem. J., 25, 169.

$(1931,2)$. Oxidation-reduction potentials of hamolytie streptoeoeei. II. Effeet of eatalase. Biochem. J., 25, 858 .

(1931, 3). Effeet of bacteriophage on oxidation-rednetion potentials of B. dysenterio (Shiga) cultures. Biochem. J., 25, 1447.

$(1931,4$.$) Effeet of lysozyme on the oxidation-reduction potentials of M$. lysodeilicus cultures Biochem. J., 25, 1452 . 
$(1931,5)$. Effect of bacteriophage on the oxidation-reduction potentials of $B$. coli communis cultures. Biochem. J., 25, $16+1$.

$(1931,6)$. Oxidation-reduction potentials of Staphylococcus cultures. II. Effect of bacteriophage. Biochem. J., 25, 2068.

$(1932,1)$. Bacterial metabolism. I. Lactic acid production by hæmolytic streptococci. Biochem. $J ., 26,208$.

$(1932,2)$. Bacterial metabolism. II. Glucose breakdown by pneumococcus variants and the effect of phosphate thereon. Biochem. J., 26, 464 .

(1938). The polysaccharade content and reducing power of proteins and of their digest products. Biochem. J., 32, 1554.

(1943). Proteins and amino-acids. Annual Review of Biochemistry, XII, sl.

(1947). Hemolytic activity of $C$. diphtheria.. J. Path. Bact., 59, 145.

$(1948,1)$. Protection by streptomyein, penicillin and licheniformin against $C$. diphtherice infections. Brit. J. Exp. Path., 29, 289.

$(1948,2)$. Effects of chemotherapeutic agents on $C$. diphtherice with special reference to the diamidines. Brit.J. Exp. Path., 29, 447.

and King, H. (1926). Trypanocidal action and ehemical constitution. IV. Arylamides of aminohydroxyphenylarsinic acids. Jour. Chem. Soc., 817.

- - - - and MURCH, W. O. (1926.) Trypanocidal activity and chemical constitution. V. Arylsulphonamides of some phenylarsinic acids. Jour. Chem. Soc., 1355.

- and TODD. E. W. (1939). The effect of cholesterol and of sera contaminated with bacteria on the hæmolysin produced by hæmolytic streptococci. J. Path. Bact., 49, 45. , see also Todd and Hewitt (1932).

Heymans, H. (1949). The two-step reduction-oxidation of thiaxanthone-5-dioxide and thiaxanthenol5-dioxide. .J. Amer. Chem. Soc., 71, 260 .

Heyrovsky, J. (1927). The reduction of oxygen at the dropping mercury cathode. Casopis Cesko. slovenskiho Lekámictva, 7, 24:-51.

(1932). Application of the polarographic method to micro-analytical work. Mikrochemie, 12, $25-64$.

(1943). Polarographie. Theoret Grundlagen prakt. Ausführung und Anrendungen der Elektrolyse mit der tropfenden Quecksilber-elektrode.

HeYrovskí, J. and Syóer, I. (1932). Polarographic studies with the dropping mercury cathode. 30. Electroreduction and estimation of fructose and sorlsose. Collection Czechoslovak Chem. Comm., 4, 5:1.

Hill, E. S. (1937). The two-step oxidation-reduction of phthiocol. Proc. Soc. Exptl. Biol. Mcd., 35, 363. (1938.) Two-step oxidation-reduction of lapachol, lomatiol and related compounds. $\mathrm{J}$. $\mathrm{Am}$. Chem. Soc., 60, 1990-4.

and Micha ELIS, L., (1933). Effect of iron on the establishment of the oxidation-reduction potential of alloxanthin. Science, $\mathbf{7 8}, 485$.

_- see also Michaelis and Hill (1933).

Michaelis, Hill and Sehubert (1932).

and Shaffer, P. A. (1936). Two-step oxidation of anthraquinone sulphonates. Proc. Soc. Exptl. Biol. Med., 8, 11.

Hicl, R. (1939). Oxygen produced by isolated chloroplasts. Proc. Roy. Soc., B.127, 192.

Humsworth, H. l'. (1949). Diabetes mellitus. Lancet, i, 435.

Hindiarsh, M. (1949). Effect of sulphanilamide and p-amino-benzoic acid on mitosis. Nature, 163,610 .

Hinsuelwood, C. N. (1946). The chemical kinetics of the bacterial cell. (Oxford.)

Hinser, P. W., ser Tillmans, Hirseh and Hirsch (1932).

$\longrightarrow$, - and Dick (1932).

Hirschy, II. W. and huoff, P. M. (1942). Polarographic determination of citrinin. J. Am. Chem. Soc., 64, 1490-1.

Hoar, T. 1'. (1933). Mechanism of the oxygen electrode. Proc. Roy. Soc., A. 142, 628.

Новвs, Р. С. (1939). The part played by bacteria in the reduction of methylene blue in milk. J. Dairy Res., 10, 35 .

Hoff-Jurgensex, E. (1938). lieduction-oxirlation potential determination in the system : $\beta$-hydroxybutyric acid-rlehydrogenase-acetoacetic acid. Skand. Arch. Physiol., 80, 176-92.

Hofenan, Z. A., sce Barron and Il offman (1930).

Hogness, T. R. (1939). Cytochrome Oxidase. Cold Spring IIarbor Symposia Quant. Biol., 7, 121.

Holmes, B. E. (19:26). Oxidative mechanisms of tumour tissuc. The anaerobic habit of tumour tissue. Biochem. J., 20, 812 .

HoLst, G. (1935). Oxidation-reduction pritential. Il. The study of a coupled reduction-oxidation equilibrium hy photoelectric light extinetion measurements. Z. physik. Chem., A175, 99-126.

Hott, A. S., and Frenser, C. S. (1948). Oxygen production by illuminaterl chloroplasts suspended in solutions of oxidants. Arch. Biochem., 19, 365. 
Hood, J. W. (1948). Measurement and control of sewage treatment process efficiency by oxidstionreduction potential. Sewage IVorks Journal, 20,640.

HoogerHeide, J. C., sce Kluyver and Hoogerheide (1934).

Hopkins, F. G. (192I). On an autoxidisable constituent of the cell. Biochem. Journ., 15, 286.

- (1929). On glutathione, a reinvestigation. Journ. Biol. Chem., 84, 269.

- (1930). Denaturation of proteins by urea and related substances. Nature, 126, 328, 383.

, see also Morgan, Stewart and Hopkins (1922).

and Morgav, E. J. (1938). The influence of thiol groups in the activity of dehydrogenases. Biochem. J., 32, 611-20. $556-7$.

(With an addendum on the location of dehydrogenases in muscle.) Biochem. J., 32, 1829-47.

Horowitz, N. H. and BAUMBERGER, J. P. (1941). Respiratory pigment of Urechis eggs. J. Biol. Chem., $141,407-15$.

Hosoya, S. and Kuroya, M. (1923). Water soluble vitamin and bacterial growth. Sc. Reps. Gov. Inst. Inf. Dis., Tokyo, 2, 233.

Howard, B. H., and Raistrick, H. (1949). Studies in the biochemistry of micro-organisms. 80. The colouring matters of Penicillium islandicum, Sopp. Part I. 1:4:5-trihydroxy-2-methylanthraquinone. Biochem. J., 44, 227.

Huddesson, I. F., see Tuttle and Huddleson (1934).

Hughes, T. P. (1932). Growth requirement of staphylococci. J. Bact., 23, 437.

HUNTER, F. E. (1949). Anaerobic phosphorylation due to a coupled oxidation-reduction between a-ketoglutaric acid and oxalacetic acid. Jour. Biol. Chem., 277, 361.

Hutchison, D., Swart, E. A., and Waksman, S. A. (1949). Arch. Biochem 22, 16.

Ilkovic, D. (1938). The value of diffusion currents observed in electrolysis by the dropping mercury electrode. Polarographic study. J.Chim. phys., 35, 129.

Isaols, R. S. (1942). Dissolved-oxygen recordings with the dropping mercury electrode. Ind. Eng. Chem. Anal. Ed., 14, 256-8.

INorAHAM, M. A., and FRED, E. B. (1933). The relation between the bacteriostatic action of gentian violet and the oxidation-reduction potential of the medium. Journ. Bact., 25, 23.

Ingram, M. (1941). Use of the polarograph for the analysis of meat-curing brines. J. Soc. Chem. Ind., $60,126-31$.

ISAACS, M. L., see Coulter and Isaacs (1929).

IsHIKAwA, A. (1935). The oxidation-reduction potential of leucocytes (measured with the micromanipulator). Z. Klin. Path. Hämatol (Japan) 4, 403. Nagoya J. Med. Sci., 10, 259.

IssakaWa-Keo, N. M., see Pavlov and Issakawa-Keo (1929).

Iтo, S. (1930). Studien über das Cytochrom. Trans.Jap. Path. Soc., 20, 360.

JACKson, C. J. (1936). Factors in the reduction of methylene blue in milk. J. Dairy Research, 7, 31-40.

JAHN, T. L. (1935). Oxidation-reduction potential of protozoan cultures. II. Reduction potential of cultures of Chilomonas paramecium. Arch. Protistenk, 86, 225-37.

Javcsó, N. v. and JANCSO, H. v. (1936). Chemotherapeutic action, oxidation catalysis and oxidationreduction potential. Z. Immunitäts, 88, 275-323.

JANICKI, J. (1937). Oxidation-reduction potential of aqueous extracts of fermenting barley. Enzymologia, 4, 107-10.

JANkE, A. (1937). Oxygen use and oxidation-reduction potential of acetic acid bacteria. Arch. Mikrobiol., 8, 348-52.

JARES, J. J. (1935). Effect of methylene blue on oxygen consumption and respiration quotient of normal and tumour tissue. Am.J. Cancer, 24, 80.

JnBB, W. H. H. (1949). The use of Nile Blue in the study of tetrathionase activity. J. Gen. Microbiol., 3, 112 .

Johnson, C. A., see Werkman, Johnson and Coile.

Johnson, F. H., and Schneyer, L. (1944). Quinine inhibition of bacterial luminescence. Am. J. Trop. Med., 24, 163.

— and Eyring, H. (1944). The luciferin-Iuciferase system. J. Am. Chem. Soc., 66, 848.

- - Steblay, R., Chaplin, H., Huber, C., and Gherardi, G. (1945). Nature and control of reactions in bioluminescence-reversible inhibitions by hydrogen and hydroxyl ions, temp., pressure, alc., urethan and sulfanilamide in bacteria. J. Gen. Physiol, 28, 463.

Jounson, J. M., see Voegtlin, Johnson and Dyer (1924).

Johnstone, K. I. (1940). The relationship of the oxidation-reduction potentials developed in bacterial cultures to the production of hydrogen peroxide. J. Path. Bact., 51, 59-74.

JoRDAN, E. O., see Burrows and Jordan (1935). 
JüHLing, L.. Tropp, C., and Wohlisch, E. (1939). Polarographic investigation of proteins. II. Polarographic investigation of the changes of state of fibrinogen. Z Z. physiol. Chem., 252, 199-209.

Jüraensen, J. J., see Baumberger, Jürgensen and Bardwell (1932).

KahLenberg, L., see French and Kahlenberg (1928).

Kakukawa, T. (1935). Uber das Redoxpotential der suspension lebender Hefezellen. Sci. Rep. Tôhokio Imp. Univ., 12, 551.

KANEL, E.S. (1941). Oxidation-reduction potential in bacterial cultures. Microbiology (U.S.S.R.), 10, 595-620. Chem. Z. (1942), I. 2412.

Karrer, P., and Benz, F. (1936). Reduction product of nicotinic amide methiodide. II. Helv. Chim. Acta, 19, 1028-9.

- Scwarzenbach, G. Berry, F., and Solmssen, U. (1936). Reduction products of nicotinic acid amide methyl iodide. Helv. Chim. Acla, 19, s11-28.

KAY, H. D. (1926). Note on the variation in the end products of bacterial fermentation from increased combined oxygen uptake in the substrate. Biochem. J., 20,321.

Keaton, C. M. (1938). Oxiclation-reduction potentials of arsenate-arsenite systems in sand and soil media. Research Studies Coll., Washington, 6, 99-101.

- Clark, M., and Kardos, L. T. (1940). Oxidation-reduction potentials of arsenate-arsenite systems in sand and soil media. Soit Sci., 50, 189-207.

KeEeEr, R. M. (1946). Polarographic determination of cupric glycinate and cupric alaninate complexes. J. Am. Chem. Soc., 63, 2329.

KeELEY, T. C., see Lindemann, Lindemann and Keeley (1924).

Keenan, J. A., Barrett, W. D., and Rutan, H. (1937). Resazurin test for milk, preliminary studies on its practicalities and possibilities. J. Mill Tech., 1, No. 1, 22-25.

Keighley, G., sce Borsook and Keighley (1933).

KeILIN, D. (1925). On cytochrome, a respiratory pigment common to animals, yeast and higher plants. Proc. Roy. Soc., B., 98, 312.

(1929). Cytochrome and respiratory enzymes. Proc. Roy. Soc. B., 104, 206.

(1934). Cytochrome and the supposed direct spectroscopic observation of oxidase. Nature, 133, 290.

and Harpley, C. H. (1941). Cytochrome system in Bacterium coli commune. Biochem. J., 35,688 .

and Hartree, E. F. (1938). Mechanism of the decomposition of hydrogen peroxide by catalase. Proc. Roy. Soc. B., 125, 171.

and - (1945). Properties of azide-catalase. Biochem. J., 39, 148, 293.

—_ and - (1949). Activity of the succinic dehydrogenase-cytochrome system in different tissue preparations. Biochem. $J$., 44, 205.

- and Mann, T. (1938). Polyphenol oxidase; purification nature, and properties. Proc. Roy. Soc. B., 125, 187-204.

— and - (1939). Laccase, a blne Cu protein oxidase from the latex of Rhus seccesanea. Nature, $143,23$.

Kelley, R. M., and Wrlliams, J. W. (1941). A technique for measuring the oxidation-reduction potential of skin and other surfaces. J. Investigative Dermatol., 4, 279-83.

KeMPNER, W. (1939). The role of oxygen tension in biological oxidations. Cold Spring Harbor Symposia Quant. Biol., 7, 269.

Kendal, L., see Havard and Kendal (1934).

Kendale, A. I., Friedemann, T. E., and Ishikawa, M. (1930). Studies in bacterial metabolism. 88-95 Journ. Inf. Dis., 47, 186 et seq.

Kennall, 1.. C., and Lonwen, D. F. (1928, 1). Reducing power of cysteine. Biochem. Journ., 22, 649. and - $(1928,2)$. Mechanism of oxidation-reduction potential. Biochem. Journ., 22, 669.

- and NorD, F. F. (1926). Reversible oxidation-reduction of cysteinc-cystine and reduced and oxidised glutathione. Journ. Biol. Chem., 69, 295.

— and ORT, J. M. (1926). Oxidation-reduction potentials of 2 : ketodihydroindole-3- $\beta$-propionic acid and its halogen derivatives. Journ. Biol. Chem., 68, 611.

Kirolcher, N. V. (1935). Oxidation-reduction potentials of pneumococcus cultures. J. Microbiol. Epidemiol. Immunobiol., 15, 52-5.

KInG, H., see Cohen, King and Strangeways (1932).

Kirk, M. M. and Tressler, D. K. (1939). Determination of ascorbic acid. Electronctric titration method. Ind. Eng. Chem. Anal. Ed., 11, 322-3.

Kissin, M., see Meio, Kissin and Barron (1934).

Klemperer, F.. Bessey, O. A., and Hastings, A. B. (1937). Oxidation-reduction potentials of certain synthetic flavins. 'roc. Soc. Exptl. Biol. Med., 37, 114-15. 
Kliger, I. J., and Guggenneim, K. (1938). The influence of vitamin C on the growth of anaerobes in the presence of air, with special reference to the relative significance of $\mathrm{E}_{\mathrm{h}}$ and $\mathrm{O}_{2}$ in the growth of anaerobes. J. Bact., 35, 141-56.

KLUYver, A. J. (1931). Chemical activitics of micro-organisms. London.

- and DoNkER, H.J. L. (1925). The unity in the chomistry of the fermentative sugar dissimilation processes of mierobes. Kon. Akad. Wetensch. Amsterdam Proc., 28, 297.

-.- and Hoogerheide, J. C. (1934). Uber die Beziehungen zwisehen den Stoffweichsel-vorgängen der Mikroorganismen und den Oxydoreduktions-potential im Medium. II. Versuche mit Hefearten. Biochem. Ztschr., 272, 197.

_- see also Elema, Kluyver and van Dalfsen.

- and Hoogerheide, J. C. (1936). Some romarks on the reduction intensity of living cells. Proc. Kon. Akad. Wet. Amsterdam., 39, 298.

— and - (1936). Beziehungen zwischen den Stoffwechscl Vorgängen von Hefen und Milchsaürebakterien und dem Redox-Potential im Medium. Enzymologia, 1, 21.

(1936). Reduetion intensity of living cells. Proc. Acad. Sci. Amsterdam, 39, 298-305.

van der Krrk, G. J. and van der BuRG, A. (1942). Luminescence of Photo-bacterium phosphorum. Proc. Med. Aliad. van Wetenschaffen, 45, 886-962.

Kraysi, G., (1946). Elements of bacterial eytology.

- and Dutkx, S. R. (1934). The growth of $B$. megatherium in relation to the oxidation-reduction potential and the oxygen content of the medium. J. Bact., 27, 109.

and - (1936). The growth of a butanol clostridium in relation to the oxidation-reduction potential and oxygen content in the medium. J. Bact., 31, 137-49.

Kлгян, B. (1930). Oxidation-reduction studies in relation to bacterial growth. I. The oxidationreduction potential of sterile meat broth. II. A method of poising the oxidation-reduction potential of bacteriological culture media. Biochem. Journ., 24, 1066.

— (1935). An essential growth factor for Staphyloccocus aureus. Brit. J. Exp. Path., 16, 315, and FILdes, P. (1930). Oxidation-reduction studies in relation to bacterial growth. III. The positive limit of oxidation-reduction potential required for the germination of $B$. tetani spores in vitro. Biochem. J., 24, 1496.

and - (1933). Vitamin necessary for growth of $B$. sporogenes: its relation to auxin and other growth factors. Brit. J. Exp. Path., 14, 112.

$\longrightarrow$, see also Fildes, Gladstone and Knight (1933).

KNorr, M. (1925). Die Entwicklung des Vitamingedankens in der Bakteriologie. Ergebn. Hyg. Bakt., 7,641 .

Kockelmeyer, J. and Hauss, L. (1939). The relation between the polarographic constants of the different forms of adrenaline and adrenolone hydrochloride and their pharmacodynamio properties. J. pharm. Belg., 21, 305-7.

Kodama, S. (1926). Studies on xanthine oxidase. The oxidation-reduction potential of the oxidase system. Biochem. J., 20, 1094.

Kолıмa, S. (1931). Peroxidase. I. Potentiometric studies. Journ. Biochem. Japan, $14,79$.

Kollath, W. and Erhardt, A. (1936). Life, span, reduction-oxidation position and fuandin action in Opisthorchis in vitro. Biochem. Z., 287, 287-8.

and Stadler, P. (1939). Peduetion-oxidation potentials and Metabolism. Ergeb. Physiol. biol. Chem. exptl. Pharmakol, 41, 806-81.

Kolthoff, I. M. and BARNuM, C. (1940). The anodic reaction and waves of cysteine at the droppingmereury electrode and at the platinium micro-wire electrode. J. Am. Chem. Soc., 62, 3061-5.

(1941). The reduction of eystine at the dropping mereury electrode. J.Am. Chem. Soc., 63, $520-6$.

and Lingane, J. J. (1941). Polarography. (New York.)

Korr, I. M. (1936). Luciferin-oxyluciferin system. J. Am. Chem. Soc., 58, 1060-1.

(1938). Oxidation-reduction potentials in heterogenous systems. J. Cellular Comp. Physiol., $11,233-45$.

Kотт, A. E. (1936). The significance of $\mathrm{pH}$ and $\mathrm{rH}$ in brewing. Brewer's J., 75, No. 10, 90-2.

Krassinskit, N. (1936). Oxidation-reduetion potential of cells of higher plants. Protoplasma, $25,41$.

Krebs, H. A., and Egglestox, L. V. (1940). Biochem. J., 34, 442, 1383.

Kubo, H., Yamaga, T., Ogihara, G., and Nakamura, M. (1938). The oxidation-reduction potential of the yellow enzyme. Compt. rend. soc. biol., 127, 1253-4.

Kubowitz, F. (1937). Chemical composition of the potato oxidase. Biochem. Z., $292,221$.

_ (1938) Resynthesis of phenoloxidase from protein and copper. Biochem. Z., 296, 443.

(1938). Cleavage and resynthesis of polyphenoloxidase and of hemocyanin. Biochem. Z., $299,32$.

and HAAS, E. (1932). Ausbau der photochemischen Methoden zür Untersuchung des sauerstoffbetragenden Fermentes. Biochem. Ztschr., 255, 247. 
Kunn, R. and Moruzz, G. (1934). Uber das Reduktions-oxydations-Potential des Laeto-flavins und seiner Derivate. Ber., 67, B., 1220.

and WAGNER-JAUREGG, T. (1934). Oxidation-reduction relations and a colour reaction for lactoflavin. Ber., 67B, 361-3.

and Bovlanger, P. (1936). Relationship of the oxidation-reduction potential and chemical constitution of flavin. Ber., 1936, 69B, 1557-66.

—, and Ströвele, R. (1937). Synthesis of flavin glucosides. Ber., 70B, 747-55.

,--1937 . Verdo-chloro- and rhodo-flavins. Ber., 70B, 753-60.

KUn, E., and ABooD, L. G. (1949). Colorimetric estimation of suceinie dehydrogenase by triphenyltetrazolium chloride. Science, 109, 144.

Kunoya, M., see Hosoya and Kuroya (1923).

KusNetzow, S. J. (193I). The dependence of the oxidizing fermentations on the oxidation-reduction potential of the external medium. Zentr. Bakt., II., 83, 37.

LAKI, K. (1933). Das Ox-Redoxpotential des Ascorbin säure. Ztschr. physiol. Chem., 217, 54.

(1937). The role of the second carboxyl group in the enzymic hydrogenation of oxalacetic acid Z. physiol. Chem., 249, 57-60.

(1938). Cytochrome of pigeon-breast muscle. Z. physiol. Chem., 254, 27.

Laland, P., and Closs, K. (1949). Formation of trivalent cobalt complexes in protein hydrolysates. Nature, 163, 564 .

Lancefield, R. C., and Tond, E. W. (1928). Antigenic differences between matt hemolytie streptoeocei and their glossy variants. Journ. Exp. Med., 48, 769.

see also Todd and Lancefield (1928).

Lang, A., see Bierich and Lang (1934).

——— and Rosenbohm (1933).

Larsen, P. B., Gould, I. A., and Trout, G. M. (1941). Oxidation-reduction potentials and the oxidised Havour in homogenized milk. J. Dairy Sci., 24, 789-93.

LaRsson, E. (1933). Tioglykolsyre-ditioglykolsyre-systemets reduktions-oxidationspotential. Svensk Kem. Tidskr., 45, 65.

Latimer, W. M. (1938). The oxidation states of the elements and their potentials.

LAUFER, S. (1936). The colorimetric determination of oxidation-reduction potential and its application to brewing practice. Am. Brewer, 69, No.1.15-22, 24-5.

Lemiann, J. (1930). Zur Kenntnis biologiseher oxydations-reduktions Potentiale. Messungen im System : Succinate-Fumarate Succino-dchydrogenase. Skand. Arch. Physiol., 59.

- (1934). Zur Kenntnis biologiseher oxydation-reduktionspotentiale. Vorläufige Potential. Messungen im System Alkohol-dehydrogenase-Acetaldehyd. Biochem. Ztsh., 274, 321.

- and HoFf-Jongensen, E. (1939). Reduction-oxidation potential measurements in the system malie acid-dehydrogenase-oxalic acid. skand. Arch. Physiol, 82, 113-24.

Leloir, L. F., Trucco, R. E., Cardini, C. E., Paladini, A., and Caputto, R. (1948). The coenzyme of phosphoglucomutase. Archives of Biochemistry, 19, 339.

Lennerstrand, A., and Runnströr, J. (1935). Oxidation, phosphorylation and fermentation by apozymase in presence of reversible oxido-reduction systems. Biochem. Ztschr., 283, 12.

Leo, M., see Erlenmeyer, Berger and Leo (1933).

Lepper, E., and MIARtin, C. J. (1929). The chemical mechanisms exploited in the use of meat media for the eultivation of anaerobes. Brit.Journ. Exp. Path., 10, 327.

— and - $-(1939,1)$. The oxidation-reduction potential of cooked meat media. Brit. Journ. Exp. Path. 11, 137.

— and - $(1930,2)$. The oxidation-reduction potential of cooked meat following the inoculation of baetcria. Brit.Journ. Exps. Path., 11, 140.

and - (1931). On the behaviour of "indifferent" clectrodes when used for the determination of oxidation-reduction in the presence of hydrogen. Biochem.Journ., 25, 45.

Lévy, R., see Aubel and Lévy (1929. 1930, 1931).

LEWIS, G. N., and RaNDaLL, M. (1923). Thermodynamies and the frec energy of ehemical substances. (MeGraw-Hill.)

Lincoln, E. M., and Kiruse, 'T. W'. (1949). Streptomyein and promizole in miliary tubereulosis and tuberculous meningitis in children. Lancet, 256, 766.

Lindemann, F'. A., Lindemanx, A. F', and Keeley, 'I'. C. (1924). A new form of electrometer. Phil. Mag., 47.

Linderstrom-Lang. K., and Dusiriva, l'. (1935). Keratin digestion in the larva of the clothes moth. Nature, 135, 1039-40.

Lipuann, F. (1934). Versuchr zur potentiometrischen Erfassung der Oxydoreduktions-vorgänge in gäronden Hefeextrakt. Biochem. Ztschr.. 274, 329, 412.

(1937). Pyruvie acid dehydrogenation, vitamin B, and eocarboxylase. Nature, 140, 849.

(1941). Mctabolie generation and utilisation of phosphate bond energy. Adv. Enzymology. 1, 99 . 
Lipton, M. A., and Elvehjem, C. A. (1939). Chemical reaction of thiamine and cocarboxylase in vivo. Cold Spring Harbor Symposia Quant. Biol., 7, 184.

Loewen, D. F., see Kendall and Loewen (1928, i, ii).

Lohman, K. (1932). Beitrag zur enzymatischen Umwandlung von synthetischem Methylglyoxal in Milchsäure. Biochem. Ztschr., 254, 332 .

Lominski, I. (1935). Inactivation du bactériophage par oxydation ; réactivation par l'acide ascorbique. Compt. rend. soc. biol., 119, 1345.

Lonosworth, L. G., and MacInnes, D. A. (1935). Bacterial growth with automatic pH control. (A) An apparatus. (B) Some tests on the acid production of Lactobacillus acidophilus. $J$. Bact., 29, 595-607.

- (1936). Bacterial growth at constant $\mathrm{pH}$. Apparent oxidation-reduction potential and population studies of Lactobacillus acidophilus under anaerobic conditions. J. Bact., 32, 567-85.

Loureiro, J. A., see Wurmser and de Loureiro (1933).

Lvag, J. W. H. (1935). Anomalous reduction-oxidation potentials of sulfhydryldisulfide systems. J. Indian Chem. Soc., 12, 706-11.

Killeen, M. A., and Winzor, F. L. (1936). Colouring matters of Drosera Whittakeri. IV. The reduction potentials of some naphthaquinones. J. Chem. Soc., 1936, 1457-62.

Lugo, L. F., Macbetr, A. K., and Winzer, E. L. (1936). J. Chem. Soc., 145.

Lund, M. H., see Biilmaun and Lund (1921, 1923).

LUNDSGAARD, E. (1930). Untersuchungen ïber Muskelkontraktionen ohne Milchsäurebildung. Biochem. Ztschr., 217, 162.

(1930). Die Monojodoessigeäurewirkung auf die enzymatische Kohlenhydratspaltung. Biochem. Ztschr. 220, 1, 8 .

Lutz, R. F., see Conant and Lutz (1924).

Lwoff, A., and Lworf, M. (1937). Studies on co-dehydrogenases. I. Nature of growth factor "v." Proc. Roy. Soc., B., 122, 352.

MaAS, J. (1937). The polarographic method with the dropping-mercury electrode for the use of pharmaceutical analysis. Acta Brevia Neerland. Physiol. Pharmacol. Microbiol., 7, 140-4.

McAlister, D. F. (1938). Effect of fungi on the oxidation-reduction potentials of liquid culture media. Am.J. Botany, 25, 286-95.

MACBETH, A. K. (1937). The chemistry of the hydroxynaphthaquinones and the colouring matters of Drosera Whittakeri. Australian Chem. Inst. J. and Proc., 4, 207-22.

McCarter, J., and Hastings, E. G. (1935). The relation between the oxidation-reduction potential of the medium and the dissociation of an acid-fast organism. J. Bact., 29, 15.

MAChLIS, S. and Green, D. E. (1933). Intracellular oxidation-reduction studies. VII. Mechanism of reduction potential in starfish sperm. J. Cell. Comp. Physiol., 4, 61.

McIlwarn, H. (1949). Sigmificance of the enzymic degradation of cozymase in living organisms. Nature, 163, 641.

Mackie, T. J., and McCartney, J. E. (1948). Handbook of Practical Bacteriology. (Eighth Edition: Livingstone.)

McLean, D. (1941). Studies on diffusing factors. Biochem J., 35, 159.

McLeod, J. W. (1930). A system of bacteriology. Vol. 1., chap. 7. Medical Research Council, London.

- and Gordon, J. (1922). The production of peroxide by bacteria. Biochem. Journ., 16, 499. and - (1923). Catalase production and sensitiveness to hydrogen-peroxide amongst bacteria with a scheme of classification based on these properties. Journ. Path. Bact., 26, 326.

Macliunn, C. A. (1886). Researclı on the myohæmatin and the histohæmatins. Trans. Roy. Soc., $177,267$.

- (1890). Contributions to animal chromatology. Quart. Journ. Microsc. Sci., 30, 51.

Macrae, F. F., see Wieland and Macrae (1930).

Magara, M. (1935). Sur le potential d'oxydo-réduction des tissus de l'ovaire; influence de l'urine sur ce potential. Compt. rend. soc. biol., 120, 1015.

(1935). Oxidation-reduction potential of orarian tissuc. Effect of wine on the potential. Compt. rend. soc. biol., 120, 1015-18.

Marwea, L., see Sevag and Maiweg (1934).

Malloch, J. G. and YounG, R. S. (1940). Oxidation-reduction potentials and carbon dioxide production. Can. J. Research, 18C, 142-50.

Mans, T., and KeIlin, D. (I93S). Hrmocuprein, a copper protein compound of red blood corpuscles. Nature, 142, 148.

Mapsox, L. W. (1945). Influence of halides on the oxidlation of ascorbic acid. II. Action of Cl. on the cupric-cuprous system. Biochem.J., 39, 228-236.

Marks, G. W. (1935). The inactivation of catalases from certain marine plants by oxygen. Biochem.J., 29, 509.

Martin, C. J., see Lepper and Martin (1929, 1930, 193I). 
Martius, C., and Knoop, F. (1936). The oxidation-reduction potential of ethyl $\alpha$-amino- $\beta$ Ketobutyrate and of reductone (enol tartronaldehyde.) Z. physiol. Chem., 240, 195-7.

Mattick, A. 'T., Davis, J. G., and Dearden, D. V. (1931). Rusty spot in cheddar and other cheese. III. J. Dairy Research, 2, 190.

_-, see also Davies, Davis, Dearden and Mattick (1934).

- Hiscox, E. R., and DAvis, J. G. (1937). Bacteriology and mycology applied to Dairying. J. Dairy Research, 8, 369.

Mattson, A. M., Jensen, C. U., and Dutcher, R. A. (1947). Triphenyltetrazolium chloride as a dye for vital tissues. Science, 105, 294.

Mauriac, P., see Aubel, Aubertin and Mlauriac (1928). Aubel, Mauriac and Aubertin (1929).

Mayer, N. (1929). Sur le potentiel des solutions de glucides. Compt. rend. Acad. Sci., 189, 319. (1937). Oxidation-reduction potential of reductic acid. J. chim. phys., 34, 109-16.

Meier, L. (1939). Determination of the reduction-oxidation potential of blood (in vitro) and the effect on the potential of the addition of so-called reduction-oxidation substances. Biochem. Z., $303,32-9$.

Meireljohn, G. T. and Stewart, C. P. (1941). Ascorbic acid oxidase from eucumber. Biochem. J., $35,755-60$.

Meto, R. H. de, Kissin, M., and Barrox, E. S. G. (1934. Biological oxidations, IV. Mechanism of the catalytic effect of reversible dyes on cellular respiration. J. Biol. Chem., 107, 579.

MeLdRUM, N. U., and TARR, H. I. A. (1935). Reduction of glutatbione by the Warburg-Christian system. Biochem. J., 29, 108.

Melville, J., and Richardison, G. M. (1934). Prune as an oxidation-reduction indicator. Its suitability for titration of ascorbic acid. Biochem. J., 28, 1565.

Mendeik, F. (1934). Woch. Brau., 51, 305.

Messina, W. A. (1934). 'The mechanism of bacterial anaerobiosis. III. The oxidation-reduction potential of the butyric bacillus in presence of sulphydryl compounds. Biochem. J., 28, 1894.

Messina, V., and Semich, A. (1935). The relation of the oxidation-reduction potential of Clostridium botulinum cultures to toxin formation. J. Microbiol. Epidermiol. Immunobiol., 15, 665-7. Biochem. Ztschr., 256, 105.

MeYeb, K. (1932). UỦer den Einfluss der Monojodessigsäure auf die bakterielle Milchsäurebildung.

Meyer, L. (1934). Sur les variations du rH apparent du sol pendant la eroissance des plantes. Compt. rend., 198, 2199.

_- see also Vles and Meyer (1932).

MEyerhoF, O. (1927). Recent investigations on the aerobic and anaerobic metabolism of carbohydrates. Journ. Gen. Physiol., 8, 531.

Mrchaelis, L. (1931). The formation of semiquinones as intermediary products from pyocyanine and some other dyestuffs. Journ. Biol. Chem., 96, 211.

(1932). Reversible two-step oxidation. Journ. Biol. Chem., 96, 703.

(1933). Oxydations-Reduktions Potentiale. Zweiter Anflage. Berlin.

- Reversible two-step oxidation. Cold Spring Harb. Sympos. Quant. Biol., 1, 224.

(1947). The magnetic properties of the cobalt-histidine complex before and after oxygenation. Arch. Biochem., 14, 17.

and Barrox, E. S. G. (1929). Oxidation-reduction systems of biological significance. II. Reducing effect of eysteine induced by free metals. Journ. Biol. Chem., 81, 29.

- Boeker, G. K., and Reber, R. K. (1938). Paramagnetism of the semiquinones of phenanthrenequinone-3-sulphonate. J.Am. Chem. Soc., 60, 202-4.

and Fletcher, E. S. (1937). Two-step oxidation of benzoin to benzil. J. Am. Chem. Soc., $59,1246-9$.

- and - (1937). Equilibrium of the semiquinones of phenanthrene-3-sulfonate with its dimeric compound. J. Am. Chem. Soc., 59, 2460-7.

and Fltixner, L. (1928). Oxidation-reduction systems of biological significance. I. The reduction potential of eysteine. Journ. Biol. Chem., 79, 689.

and Frieduen, li. (1931). Potentiometrie studies on complex iron eompounds. Journ. Biol. Chen. 91, 343.

- and Granick. S. (1911). Oxidation-reduction equilibrium over the whole $\mathrm{pH}$ range, $\alpha$-oxonine and some related dye stuffs. J. Am. Chem. Soc., 63, 1636-43.

- - and ScIuvert, M. P. (1937). Some problems in two-step oxidation treated for the case of phenanthrenequinonesulphonate. J. Biol. Chem., 119, 133.

, and Granick, S. (1939). Free radicles of the type of Wurster's salts. J. Am. Chem. Soc. 61, 198I-92.

Schubert, M. I., Reber, R. K., Kuck, J. A., and Granick, S. (1938). Potentiometric and magnetometric study of the duroquinone system. $J$. Am. Chem. Soc., 60, 1678-83.

-, Schumert, M. 'P., and Sryтrie, C. V. (1936). Potentiometric study of the flavins. J. Biol Chem., 116, 587-607. 
and Schwarzenbach, G. (1938). Intermediary form of oxidation-reduction of the flavins. J. Biol. Chem., 123, 527.

___ and Surthe, C. V. (1936). Influence of certain dyes on fermentation and respiration of yeast extract. J. Biol. Chem., 113, 717.

and - (1938). Biological oxidations and reductions. Am. Rer. Biochem., 7, I.

- and Wollinan, S. H. (1949). The semiquinone radical of tocopherol. Science, 109, 313.

Mrues, A. A., see Wilson and Miles.

Mrrsky, A. E., and Asson, M. (1936). Thiol groups and disulphide groups of proteins. II. Relation hetrveen number of SH and S-S groups and quantity of insoluble protein in denaturation and in reverse of denaturation. III. Sulfhydryl groups of native proteins of the crystalline lens. J. Gen. Physiol., 19, 427-50.

Mrrra, B. N. (1940). Oxidation-reduction potentials of Jibrio cholera and related organisms. Rept. Proc. 3rd Intern. Congr. Microbiol., 1939, 248.

Mонг, W. IV. J. (1936). Use of the polarographic method in the investigation of solutions containing milk proteins. Milchw. Forsch., 18, 123-30.

Molland, J. (1944). Oxidation-reduction potentials in cultures of anaerobic bacteria. Acta Path. Microbiol. Scand.. 21, 673-712.

Moore, W. A., and RuchoFT, C. C. (1943). Oxidation-reduction studies. II. Reduction potentials in sewage and sewage-activatel sludge mixtures. Sewage Works J., 15, 880.

- - - and WatTie, E. (1942). Oxidation-reduction potentials developed by pure cultures in sewage. Sewage Works J., 14, 980-90.

Morgan, E. J., Stewart, C. P., and Hopkins, F. G. (1922). On the anaerobic and aerobic oxidation of xanthine and hypoxanthine by tissues and milk. Proc. Roy. Soc., Lond. B. 94, 109.

Moroan, H. J., and Avery, O. T. (1923). Studies on bacterial nutrition. IV. Effect of plant tissue upon growth of streptococcus and pneumococcus. J. Exp. Med., 38, 207.

- _. , see also Avery and Mlorgan, (1924).

Morgan, W. T. J., and Partridge, S. M. (1941). Studies in immuno-chemistry. VI. The use of phenol and of alkali in the degradation of antigenic material isolated from Bact. dysenterice (Shiga). Biochem. J., 35, 1140.

Morrison, G. A., and Hrnshelwood, C. N. (1949). Nitrogen utilisation and growth of coliform bacteria. III. Journ. Chem. Soc., 380.

Morton, C. (1931). The determination of glass-electrode potentials by means of a null ballistic valve electrometer, and valve potentiometers. Journ. Chem. Soc., 2977, 2983.

- (1932). The automatic control and recording of hydrogen-ion concentration by means of the glass electrode. Journ. Chem. Soc., 2469.

Moruzzr, G., see Kuhn and Moruzzi (1934).

MÜLLER, O. H. (1940). Application of the dropping-mercury electrode for the detection of intermediate radicals. Ann. N.Y. Acad. Sci., 40, Art. 2, 91-109.

(1942). Oxidation-reduction potentials measured with the dropping-mercury electrode. IV. Polarographic study of $\alpha$-hydroxyphenazine. J. Biol. Chem., 145, 425-41.

and BAUMBERger, J. P. (1937). Oxidation-reduction potentials measured with the dropping Mercury electrode. I. II. Trans. Electrochem. Soc., 71, 169.

- (1937). II. Polarographic investigation. An introduction to a new method. Trans. Electrochem. Soc., 71, 14 pp.

__ and Davis, J. S. (1947). Polarographic studies of proteins and their degradation products. II. Normal values of the "Protein Index." Archiv. Biochem., 15, 39.

Needham, D. M., and Nempham, J. (1925). Hydrogen-ion concentration and oxidation-reduction potential of the cell interior: a micro-injection study. Proc. Roy. Soc. B., 98, 259.

Neoelein, E., see Warburg and Negelein (1931).

- and WULF, H. J. (1937). Crystallization of the protein of acetaldehyde reductase. Biochein. Z., 289, 436-7. $-\frac{289,436-7}{290,445-6 .}$. Dissociation constants and activity of acetaldehyde reductose. Biochem. Z.,

NeItL, J. M., and Avery, O. T. (1925). Studies on oxidation and reduction systems in sterile pneumococcus extracts. Journ. Exp. Med., 41, 285.

- and Mallory, T. B. (1926). Studies on the oxidation and reduction of immunological substances. IV. Streptolysin. Journ. Exp. Med., 44, 241 .

-

Nekrassow, N. (1932). Die Rolle der indifferenten Elektrode in wässeriger Lösungen, die keine spezi fischen oxydations-reduktions Stoffe enthalten. Ztschr. f. Electrochernie, 38, 186.

—., see also Elimoff, Nekrassow and Elimov (1928).

Nelson, J. M. (1939). Tyrosinase. Cold Spring Harbor Symposia Quant. Biol., 7, 148.

and Dawson, C. R. (1944). Tyrosinase. Advances in Enzymology, 4, 99-152.

Newbery, C., Lustic, H., and Cagan, R. N. (1943). Enzymatic Reduction of Furil and Furoin Phytochemical reduction. Archiv. Biochem., 1, 391. 
Nord, F. F. (1927). Influence of heat and hydrogen-ion concentration on biologioal transportation systems containing sulphur. Journ. Phys. Chem., 31, 867.

- , see also Kendall and Nord (1924).

NorRIS, R. V., see Harden and Norris (1914, 1915).

Northrop, J. H., Kunitz, M., and Herriot, R. M. (1948). Crystalline enzymes (second edition).

Nrman, P., and Reiners, F. (1941). Polarographic determination of Lobeline. Dansk Tids. Farm., 11, 292-8.

OAKLey, C. L., Warrack, G. H., and van Heyningen, W. E. (1946). The collagenase (K toxin) of Cl. Welchii type A. J. Path. Bact., 58, 229.

OCноA, S. (1946). Enzymic mechanisms of carbon dioxide assimilation. Currents in Biochemical Research, 12 .

Orr, J. M., see Kendall and Ort (1926).

PAGE, J. E., and Robinson, A. F. (1943). Polarographic studies: Mold metabolites and related quinones. J. Chem. Soc., 133-5.

- and - (1943). An examination of the relationship between the bacteriostatic activity and the normal reduction potentials of substituted quinones. Brit.J. Exp. Path., 24, 89.

Pappenheimer, A. M. (1935). Nature of the "sporogenes" vitamin, an essential growth factor for Cl. sporogenes and related organisms. Biochem. J., 29, 2057.

_. , see also Conant and Pappenheimer (1932).

Pardee, A. B., and Potrer, V.R. (1949). Malonate inhibitions of oxidations in the Krebs tricarboxylic acid cycle. J. Biol. Chem., 178, 241.

Pasternak, R., and Halban, V. H. (1946). Polarographic studies of organic compounds. Helv. Chim. Acta, 29, 190-9.

PASTEUR, L. (1861). Animalcules infusoires vivant sans gaz oxygène libre et determinant des fermentations. Compt. rend. Acad. Sci., 52, 344.

(1861). Experiences et vues nouvelles sur la nature des fermentations. Compt. rend. Acad. Sci., 52, 1260 .

—_ (1878). Remarques à l'occasion de la communication de M. Gunning sur l'anaérobiose. Comp. rend. Acad. Sci., 87, 33.

PAUL, K. G. (1947). Archiv. Biochem., 12, 441.

Pavlov, V. A., and Issakowa-Keo, N. AI. (1929). Studien über Redoxpotentiale in biologischen System. Redoxpotentiale im Hühnerei und während der Entwicklung. Biochem. Ztschr., 216, 19.

Pearsall, W. H. (1938). The soil complex in relation to plant communities. I. Oxidation-reduction potentials in soils. J. Ecology, 26, 180-93.

PeEch, M., and BatiJer, L. P. (1935). Methods for measuring oxidation-reduction potentials of soils with special reference to orchard soils. N.Y. (Cornell) Agr. Expt. Sta. Bull., 625, 23 pp.

Penrose, M., and Quastel, J. H. (1930). Cell structure and cell activity. Proc. Roy. Soc. B., 107, 168.

Perdrat, J. R., and Todd, C. (1933). The photodynamic action of methylene blue on bacteriophage. The photodynamic action of methylene blue on certain viruses. Proc. Roy. Soc., Lond. B., 112, $277,288$.

Perkins, M. E., see Hellerman, Perkins and Clark (1933).

PesketT, G. L. (1933). Growth factors of lower organisms. Biol. Rev., 8, 1.

PetTers, R. (1898). Über Oxydations und Reduktionketten und den Einfluss komplexer Ionen auf ihre elektromotorische Kraft. Ztschr. physik. Chem., 26, 193.

Peters, R. A., and WAKelin, R. W. (1946). Observations upon the relation between sulphydryl groups and pyruvate oxidation in brain tissue. Biochem. J., 40, 513.

- and (1949). The toxicity of vesicants and some other compounds to the pyruvate oxidase system (brain). Brit. J. Pharmacul., 4, 51 .

- and Stocken, L. A. (1947). Mapharside-BAL compound. Biochem. J., 41, 53.

Petrovano, G. (1935). Phenomène d'oxydo-réduction du bleu de methylene dans la lyse transmissible. Compt. rend. soc. biol., 119, 218.

Philltps, M., Clark, W. M., and Cohen, B. (1927). Studies on oxidation-reduction. II. Potentiometric and spectrometric studies of Bindschedlers green and toluylene blue. U.S. Pub. Health Reports. Suppl., 61.

-

Pнпlpot, F. J. (1937). Oxidation of tyramine in the liver. Biochern. $J ., 31,856$.

PierRe, L. (1938). Rapid methorl for the determination of the state of oxidatiou-reduction of worts and beers. Brasseur franc., 2, 536-8.

Pinoussen, L., and Seitz, O. (193I). Utber Redoxpotentiale I. Methodik und Befunde bei Messung von Organpotentialen. Biochem. Ztschr., 241,364.

Plotz H., and Geloso, J. (1930). Relations entre la croissance des micro-organismes anaérobies ot le potentiel du milieu de culture. Ann. Inst. Past., 45, 613.

PonL, J. (1888). Zur lehre von der Wirkung substituierter Fetteïuren. Arch. Exp. Path. Pharm.. 24, 142. 
Poltuck, H., see Chamber, Cohen and Pollack (1931).

- see Chambers, Pollack and Cohen (1929).

Pollock, M. R., and KNox, R. (1943). Bacterial reduction of tetrathionate. Biochem. J., 37, 476.

and Wainwrianr, S. D. (1948). The relationship between nitratase and tetrathionase adaption and cell growth. Brit. J. Exp. Path., 29, 223.

Polonovski, M., JAYLE, M. F., and Fraddet, G. (1941). Oxidation-reduetion potential of the system hæmoglobinethyl-hiydroperoxide. Compt. rend., 213, 887-9.

Pope, C. G. (1928). A simple electrometric comparator for the determination of hydrogen-ion concentrations. Brit. Journ. Exp. Path., 9, 225.

Porter, J. R. (1946). Bacterial ehemistry and physiology. (Wiley.)

- and Gillespie, R. W. H. (1937). Bacterial oxidation-reduction studies. III. Characteristic potentials of the Aerobacillus species. J. Bact., 33, 112.

Posternak, T. (1938). Biochemistry of the lower fungi. II. Constitution and synthesis of Phoenicine and some new derivatives of $4,4^{1}$-ditoluquinone. Helv. chim. Acta, 21, 1326-37.

Potel, P., and Chaminade, R. (1935). Oxidation-reduction potentials of flours. Compt. rend. soc. biol., 200, 2215-17.

Potter, M. C. (1911). Electrical effects accompanying the decomposition of organic compounds. Proc. Roy. Soc. B., 84, 260.

Pozen, M. A. Oxidation-reduction potential in brewing. Brewery Age, 3, 41, 45, 53.

Pratt, R., and Dufrenoy, J. Penicillin mechanism, and reduction of triphenoltetrazolium chlorine. J. Bact., 1949, 57, 9.

Preisler, P. W. (1927). Eiectrometric reduction potentials of sugars. Journ. Biol. Chem., 74, XIVIII.

- $(1930)$. Kinetics of reduction of eysteine and related dithio-acids by reversible oxidationreduction systems. Journ. Biol. Chem., 87, 767.

- (1930). Oxidation-reduction potentials and the possible respiratory significances of the pigment of the nudibranch Chromodoris zebra. Journ. Gen. Physiol., 13, 349.

- and BERGER, L. (1947). Oxidation-reduction potentials of thiol-dithio systems: thioureaformamidine disulficle. J. Am. Chem. Soc., 69, 322 .

- and Hempelman, L. H. (1936). Oxidation-reduction potentials of derivatives of Thioindigo. I. Thioindigo tetrasulfonate. J.Am. Chem. Soc., 59, 141 .

- and - (1937). Oxidation-reduction potentials of $\beta$-hydroxyphenazine and $\mathrm{N}$-metliylB-oxyphenazine. J .Am. Chem. Soc., 59, 141.

-

Hall, Preisler and Cohen (1928).

PRÉvot, A. R. (1938). Role of the oxidation-reduction potential in the mode of growth of bacteria deep agar. Compt. rend. soc. biol., 127, 489-90.

- (1938). Oxidation-reduction potential and toxin formation by the tetanus bacillus. Compt rend. soc. biol., 127, 685-7.

Proctor, B. E. (1941). Reduction-oxidation potential indicators in the quality control of foods. Rept. Proc. 3rd Intern. Congr. Microbiol., 1939, 706-7.

- and Greencie, D. G. (1939). Reduction-oxidation potential indicators in quality control of foods. I. Correlation of resazurin reduction rates and bacterial plate counts as indexes of the bacterial condition of fresh and frozen foods. Food Research, 4, 441-6.

PURr, A. (1935). Studies on the reversible inactivation of papain and cathepsin. Biochem. J., 29, $5,13$.

Quastel, J. H., and Stephenson, M. (1926). Experiments on strict anaerobes. I. The relationship of B. sporogenes to oxygen. Biochem. Journ., 20, 1125 .

- and Wheatley, A. H. M. (1931). The action of dyestuffs on enzymes. Biochem. Journ., 25, 629.

— and Wheтнам, M. D. (1925). Dehydrogenations produced by resting bacteria. I. II. Biochem. Journ., 19, 520, 645 .

and Wooldridge, W. R. (1929). Reduction potential, energy exchange and cell growth. Biochem. Journ., 23, 115.

-

Penrose and Quastel (1930).

RACKER, E. (1949). Aldehyde dehydrogenase, a diphosphopyridine nucleotide-linked enzyme. Journ. Biol. Chem., 278, 177.

RADAELI, G. (1938). The oxidation-reduction potential and the reducing processes in the living skin. Arch. Dermatol. Syphilis, 178, 253-9.

RaIstrick, H., and SMiri, G. (1941). Antibacterial substances from moulds; citrinin, a metabolic product of Penicillium citrinum Thom. Chem. and Ind., 60, 828.

RANDALL, S. S., see Gulland and Randall (1935).

Raper, H. S. (1928). The anaerobic oxidases. Physiol. Rev., 8, 244-82. 
Rapkine, L. (1927). Le potentiel de réduction et les oxydations. Compt. rend. Soc. Biol., 96, 1280. and Wurmser, R. (1926). Sur le potentiel de réduction du noyau et les oxydations cellulaires. Compt. rend. Soc. Biol., 94, 989.

- and - (1926). Le potentiel de réduction des cellules. Compt. rend. Soc. Biol., 95, 604. and - (1926). Le potentiel de réduction des cellules vertes. Compt. rend. Soc. Biol., 94, 1347.

— and - (1927). Intracellular oxidation-reduction potential. Proc. Roy. Soc., Lond. B., 102, 128.

RAY, S. M., see Birch, Harris and Ray (1933).

RAYCHANDHURI, S. N., see Ghosh, Raychandhuri and Ganguli (1932).

RAYNaUd, M., and Vistontivi. M. (1945). Oxidatron-reduction potential of anaerobic culture media. Ann. Inst. Pasteur, 71, 172-87.

Redslob, E.. and Reiss, P. (1930). Le potentiel d'oxydation-réduction du corps vitré. Arch. Phys. Biol., 7, 221.

REed, G. B., and BOyd, E. M. (193:). Pyocyanine and growth potential changes of Ps. pyocyaneus. Can. Journ. Research, 8, 173.

and ORr, J. H. (1943). Cultivation of anaerobes and oxidation-reduction potentials. J. Bact., 45, 309-20.

REiss, P. (1930). Les potentiels d'arret dans la division des eufs d'Oursin et de Sabellaria. Arch. Phys. Biol., 8, 39.

- (1931). Sur les modifications du rythme cardiaque de Clavelina lepadiformis Müll. dans des tampons d'oxydation-réduction. Compt. rend. Soc. Biol., 108, 1205.

(1935). Le potenticl de platine correspondent a l'inactivation du pouvoir protéolytique de la papaine par les oxydants. Compt. rend. Soc. Biol., 120, 908.

(1936). Condition d'oxydation-réduction dans laquelle les produits de digestion papaine, une condensation. Compt. rend. Soc. Biol., 122, 568-70.

(1938). L'action du potentiel d'oxydo-réduction du milien sur la protéolyse de la pulpe de rato. Compt. rend. Soc. Biol., 128, 1197.

(1939). Influence of the oxidation-reduction potential on the proteolytic activity of barley. Compt. rend. Soc. Biol., 131, 539-41.

- (1943). Influence of the oxidation-reduction potential on protein autolysis. Arch. Phys. Biol., 16, No. 5 Suppl., 4-6, 123.

- (1944). Measurement of oxidation-reduction in the blood. Bibliographical review. Arch. Phys. Biol., 17, Suppl., 69-72.

— and Roche, J. (1931). Recherches physico-chimiques sur le corps vitré de l'œil. Arch. Phys. Biol., 9, 77.

- and Vellinger, E. (1929). Le potentiel d'arrêt des divisions de l'œuf d'oursin. Arch. Phys. Biol., 7, 80 .

—

Vlés, Reiss and Delovers (193I).

and Achard, G. (1944). Influence of $\mathrm{pH}$ and oxidation-reduction potential of the medium on the activity in vitro of tissue proteinases of the silkworm. Arch. Phys. Biol., 17, Suppl. 88-90. and Lemaire, R. (194t). Changes in the oxidation-reduction potential of human blood in vitro. Arch. Phys. Biol., 17, 7:-4.

Remezov, I. and Sosi, J. (1936). The quasi-reduction-oxidation potential of cholesterol sols. Biochem. Z., 287, 358-64.

Remick, A. E. (1936). Reduction potentials of organic systems. I. Bimolecular reduction of thioindigodisulphonate. J.Am. Chem. Soc., 58, 733-6

Rettaer, L. F., see Gillespie and Rettger (1936).

Reznikoff, P., see Cohen, Chambers and Reznikoff (1928).

Richards, W. T. (1928). The oxygen clectrorle as a quasi-quantitative instrument. Journ. Phys. C'hem., 32, 990.

Richarbson, (4. M. (1932). 'The autoxiclation of dialuric acid. Biochem. Journ., 26, 1959.

- and Cannay, R. K. (1929). The dialuric acid-alloxan equilibrium. Biochem. Journ. 23, 68., sec also Cannan and Richardson (1929).

Fildes, Cladstone and Knight (1933).

Melville and Richardson (1934).

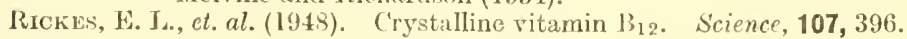

RIDEAL, E. K., see Goard and Rirleal (1924).

Ridley, F. (1928). An apparatus for mixing cultures and other fluicls. Brit.Journ. Lxp. P'ath., 9, 253.

RIEDMÜLlis, L., zee Frei. Riedmüller and Allmasy (1934).

Riegel, B., Smitr, P'. G., anel Schwertzer, C. E. (1940). Oxidation-reduction potential of vitamin k. J. Am. Chem. Soc., 62, 992.

Rinderknecut, H., Ward, J. L., Bergie, F., and Morrison, A. L. (1947). Biochem. J., 41, 463. 
RitTer, D. M. (1947). Oxidation potentials of some compounds related to vanillin. J. Am. Chem. Soc., 69, 46.

Roberts, E. R. (1941). Application of the polarograph to biochemistry. Sci. J. Roy. Coll. Sci., $11,10-18$.

Robertis, De, E., and Moura Goncalves, J. (1945). The oxidation-reduction potential of the thyroid follicle in normal and experimental conditions. Endocrinology, 36, 245-50.

Rосне, J., see ReIss and Roche (1931).

Rodkey, F. L., and BALL, E. G. (1947). Federation Proc., 6, 286.

Rонціс, G. A. (1944). Oxidation and reduction measurement in activated sludge and activated sludge-sewage mixtures. Sewage Works J., 16, 540-57.

Rona, P. and Nicolar (1926). Uber den Fermentsstoffwechsel der Bakterien. I. Atmung und Glykolyse bei Bakterium coli. Biochem. J., 172, 82 .

Rosenbohm, A., see Bierich, Lang and Rosenbohm (1933).

ROSENFELD, B., see Wieland and Rosenfeld (1929).

Rosenthal, H. G. (1937). Polarographic determination of the disulfide, and sulfhydryl groups in biological substances. Michrochemie, 22, 2333-41.

Rosenthal, S. M., and Vocatlin, C. (1933). Action of heavy metals on cysteine and on sulphydryl groups of proteins. U.S. Pub. Health Reports, 48, 347.

RunNer, M. E., and Kilpatrick, M. L. (1947). Polarographic study of the restriction of the tautomerism of amidines by hydrogen bonding. $J . A m$. Chem. Soc., 69, 1406.

RUNNSTR6m, J. (1935). Influence of pyocyanine on respiration of sea-urchin's eggs. Biol. Bull., $68,327$.

- , see also Lenverstrand and Runnström (1935).

RykLAN, L. R., and Schmid, C. I. A. (1944). Oxidation potentials of cystine-cysteine and related compounds. Univ. Calif. Pub. Physiol., 8, 257.

SAITO, K. (1935). Oxidation-reduction potentials in hæmoglobinmethæmoglobin system. J. Biochem. (Japan), 22, 409.

Sandiford, B. R., and Wooldridge, W. P. (1931). "Resting" bacteria. Biochem. Journ., 25, 2172.

Sartori, G., and Cattaneo, C. (1941). Polarographic investigations of some derivations of naphthoquinone. Gazz, chim. ital., 71, 713-22.

SARver, L. A., and Kolthoff, I. M. (1937). Electrochem. properties of diphenylbenzidine sulfonio acid. J.Am. Chem. Soc., 59, 23.

Schardinger, F. (1902). Über das Verhalten der Kuhmilche gegen Methylenblau und seine Verwendung zär Unterscheidung von ungekochter Milch. Ztschr. Nahr. Genussm., 5, 161.

Sohatz, A., Bugre, E., and IVAKsuan, S. A. (1944). Streptomycin. Proc. Soc. Exp. Biol. Med., 55, 66.

Sсносн, T. J. (1945). The fractionation of starch. Advances in Carbohydrate Chemistry, 1, 247.

Sснотт, H. F., and Borsоoк, H. (1933). Coupled reactions in biological systems. Science, 77, 589.

Schubert, M. P., see Michaelis, Hill and Schubert (1932).

Schüler, H. (1932). Ưber die Oxydation des Hämoglobineisens durch Ferricyankahium und das Gleichgewicht der Reaktion. Biochem. Ztschr., 258, 474.

Schwachman, H., Hellerman, L., and Cohen, B. (1934). On the reversible inactivation of pneumococcal hæmolysin. The effects of oxidation and reduction and of metal compounds. J. Biol. Chem., 107, 257.

_- see also Cohen and Schwachman (1935).

Schwarzenbach, G. and Michaelis, L. (1938). Semiquinone radicals in the indamine and indophenol groups. J. Am. Chem. Soc., 60, 1667-7S.

Scott, E. M., and Sandstrom, W. M. (1943). The Activation of Papain. Archiv. Biochem., 1, 103.

Scudi, J. V., and Woodruff, H. B. (1949). Assay of penicillin, see Clarke, Johnson and Robinson (1949).

Seal, S. C., and Mitra, B. N. (1939). Oxidation-reduction potentials of Vibrio choleræ and related organisms. Indian J. Med. Reseurch, 26, 625-30.

Sealock, R. R., and du Vigneaud, V. (1935). Reduction of pitressin and pitocin with cysteine. $J$. Pharm. Exp. Ther., 54, 433.

Seitz, O., see Pincussen and Seitz (1931).

Selzer, L., and Bauberoer, J. P. (1942). The Polarograph and respiration of living cells. J. Cell. Comp. Physiol., 19, 193.

Seroent, A. L. (1928). Les facteurs de croissance des microbes sur milieux artificiels. (Paris.)

Szvao., M. G. (1933). Uber den Atmungsmechanismus der Pneumokokken, I, II. Annal. Chem 507, 92. Biochem. Ztschr., 267, 211.

- and Maiweo, L. (1934). The respiration mechanism of pneumococcus, III. J. Exp. Med., 60,95 .

Sey Derheli, R., MUldi, K., and T'IYYSSen (1937). The determination of reduction-oxidation potentials in flowing blood. Münch. med. Workschr., 84, 620-3. 
ShafFer, P. A. (1936). Catalysis of ionie oxidation-reduction reactions by dyes and its probable mechanism. J. Physiol. Chem., 40, 1021.

- - and Williams, R. D. (1935). Sugar detection by the ferricyanide eleetrode. J. Biol. Chem., III, 707.

Shaner, V. C., and Sparks, M. R. (1945). Application of the polarograph to the analysis of photographic fixing baths. J. Soc. Motion Picture Engrs., 45, 20-32.

Shapiro, H. (1939). Some funetional correlatives of cellular metabolism. Cold Spring Harbor Symposia Quant. Biol., 7, 406.

Smbata, K., and Tamira, H. (1930). Untersuchungen über die Bedentung des Cytochroms in der Physiologie der Zellatmung. Acta. Phytochim., Tokyo, 5, 23.

ShibuYa, K., SAekr, H. and Ryv, K. (I936). The ehange of oxidation-reduetion potentials of waterlogged soils. II. Lateritie soils and sandstone-shale soils. J. Agr. Chem. Soc. Jap̊n, 12, $1141-51$.

Shukata and TaChi (1932). J. Chem. Soc., Japan, 53, 834.

Srmpson, G. K., and Traill, D. (1946). Polarographic Determination of Thyroxine and Diiodotyrosine. Biochem. J., $40,116$.

Sizer, I. W. (1942). The activity of yeast invertase as a function of oxidation-reduction potential. J. Gen. Physiol., 25, 399-409. and TyтеLL, A. A. (1941). The activity of crystalline urease as a funetion of oxidation-reduction potential. J. Biol. Chem.. 138, 63I-42.

Smadel, J. E., Jackson, E. B., Lex, H. L., and Lewthwaite, R. (1949). Proc. Soc. Exp. Biol. Med., 70, 191 .

Sмrтн, E. L. (1948). Purification of anti-pernieious anæmie faetors from liver. Nature, 161, 638.

Smith, L. I., Kolthoff, I. M., Wawzonek, S., and Ruoff, P. M. (1941). Chemistry of vitamin E. XXIX. Studies of the behaviour of eompounds related to vitamin $\mathrm{E}$ at the dropping mereury electrode. J. Am. Chem. Soc., 63, 1018-24.

- Splllane, L. J. and Kolthoff, I. M. (I942). The ehemistry of vitamin E. XXXV. The behaviour of tocopherols at the dropping mereury electrode. J. Am. Chem. Soc., 64, 447-5I.

$-\ldots,-\ldots$ (1942). Chemistry of vitamin E. XXXVI. Behaviour at the dropping mereury electrode of quinones related to vitamin E. J. Am. Chem. Soc., 64, 644-5.

SMOLER, I., see Heyrovsky and Smóler (1932).

SpITta, D., and Weldert (1906). Indikatoren für die Beurteilung biologisch gereinigter Abwasser. Mitt. Prufungsanst. Wasserversorg. Berlin, 6, 161.

Standfast, A., see Wooldridge and Standfast (1933).

Stannard, J. N. (1939). The mechanism involved in the transfer of oxygen in frog musele. Cold Spring Harbor Symposia Quant. Biol., 7, 394.

Stansly, P. G., and Brownlee, G. (1949). Nomenelature of polymyxin antibioties. Nature, 153, 611.

—, Shephern, R. G., and White, H. J. (1947). Bull. Johns Hopkins Hosp., 81, 43.

Stare, F. J. (1935). Potentiometrie study of hepatoflavin. J. Bio. Chem., 112, 223.

- and BaUmann, C. A. (1939). Fumarate in biologieal oxidations. Cold Spring Harbor symposia Quant. Biol., 7, 227.

Stepinenson, M. (1928). On laetic dehydrogenase; a cell free enzyme preparation obtained from bacteria. Biochem. Journ., 22, 605 .

- (1949) Baeterial metabolism. London.

and Stickland, L. H. (1931). Hydrogenase, a baeterial enzyme activating molceular hydrogen. I. II. Biochem. Journ., 25, 205, 215.

-

Stephenson, R. E., Schuster, C. E., and Spulnik, J. (1938). Oxidation-reduetion potentials in orchard soils. J. Am. Soc. Agron., 30, 91-6.

Stern, K.G. (1934). Potentiometrie study of photo-flavin. Biochem. J., 28, 949.

- (1935). Oxidation reduetion potentials of toxoflavin. Biochem. J., 29, 500.

- (1939). Respiratory catalysts in heart muscle. Cold Spring IIarbor Symposia Quant. Biol.. 7, 312 .

and Greville, G. D. (1933). Uber Urochrom und die Teilnahme ron Lyochromen an der Zellatmung. Naturwiss., 21, 720.

- - see also Greville and Stern (1935).

Stewart, C. P., see Morgan, Stewart and Hopkins (1922).

Stickland, L. H. (1934). Studies in the metabolism of the strict anaerobes (genus Clostridium). I. Biochem.J., 28, 1746.

— (1935). Studies in the metabolism of the striet anaerobes (genus Clostridium), II. The reduetion of proline by $\mathrm{Cl}$. sporogenes. Biochem. J.. 29, 288.

(1949). The activation of phosphoglueomutase ly metal ions. Biochem. J., 44, 190.

-_- see also Green, Stickland and Tarr (1934).

Stephenson and Stickland (1931). 
St'tehler, R. D., and ClakK, W. M. (1933). Studies on oxidation-reduction. XIX. Aposafranines. J. Amer. Chem. Soc., 55, 4097.

Sтоск, J. T. (1946). A microcell for polarography and amperometric titration. Analyst, 71, 583.

Stocken, L. A., and Thoupson, R. H. S. (1946). British Anti-Lewisite. I. Il. Biochem. J., 40, $529,535$.

StткеS, J. L. (1949). Fermentation of glucose by suspensions of Escherichia coli. J. Bact., 57, 147.

Stonehu., H. I. (1944). Oxidation-reduction potentials : their significance and applications. J. Soc. Dyers Colourists, 60, 176-83.

Sтотz, E. (1939). Cytochrome oxidase and cytochrome. Cold Spring Harbor Symposia Quant. Biol., $7,111$.

-., Sidwell, A. E., and Hogness, T. R. (1938). The spectro-photometric determination of the equilibrium in oxidation-reduetion systems; the potential of cytochrome. J. Biol. Chem., 124, 11-23.

STrack, E., see Wrede aud Strack (1929).

Strangeways, W. I., see Cohen, King and Strangeways (1932).

Straub, F. B., Corran, H. S., and Green, D. E. (1939). Mechanism of the oxidation of reduced coenzyme I. Nature, 143, 119.

StuART, L. S. and JAMES, L. H. (1938). The effect of sodium chloride on Eh of protogenous media. J. Bact., 35, 369-80.

- - - (1938). The effect of Eh and sodium chloride concentration on the physiology of halophilic bacteria. J. Bact., 35, 381-96.

Strrais, M. B. (1936). Changes in the oxidation-reduction equilibrium in soils as related to the physical properties of the soil and the growth of rice. La. Agr. Expt. Sta., Bull., 271, 37 pp.

SUGDEN, J. A., see Vickers, Sugden and Bell (1932).

Sullivan, M. X., Cohen, B., and Clark, W. M. (1923). Studies on oxidation-reduction. IV. Electrode potentials of indigo sulphonates. U.S. Pub. Health Reports, 38, 1669.

-

Sumner, J. B., and Somers, G. F. (1947). Chemistry and methods of enzymes (second edition).

Suranyi, J. (1926). Oxydations-reduktions-potentiale. Ihre Anwendung in der Physiologie-übersichts referat. Jahr, ges. Physiol., 7, 154.

Swanson, A. M., and Somuer, H. H. (1940). Oxidised flavour in milk. IT. The relation of oxidationreduction potentials to its development. J. Dairy Sci., 23, 596-614.

Szent-György, A. Von (1928). Observations on the function of peroxidase systems and the chemistry of the adrenal cortex. Description of a new carbohydrate derivative. Biochem. J., 22, 1387. (1933). The free energy of lactic acid oxidation. Reference scales of biological oxidation-reduction potentials. Z. Physiol. Chem., 217, 51-3.

'TAmiYA, H., see Shibata and Tamiya (1930).

Yaoi and Tamiya (1928).

TANG, P. S., and LIN, C. Y. (1937). Kinetics of cell respiration. (IV.) Oxidation-reduction potentials of Chlorella suspension in light and darkness. J. Cell. Comp. Physiol., 9, 149.

TArr, H. L. A., see Green, Stickland and Tarr (1934).

Meldrum and Tarr (1935).

TATI, I. (1940). Electrolytic-reduction potentials of organic compounds, XXVIII. Determination of sugars by the polarographic method. Determination of pentoses and pentosan. J. Agr. Chem. Soc. Japan, 16, 1057-63.

TAYLOR, J. F., and Hastings, A. B. (1939). Oxidation-reduction potentials of the methæmoglobinbaemuglobin system. J. Biol. Chem., 131, 619-62.

and MORGAN, V. (1942). Oxidation-reduction potentials of the metmyoglobin-myoglobin system. J. Biol. Chem., 144, 15-20.

Theorell, H. (1936). Physiological reoxidation of reduced yellow enzyme. Biochem. Z., 288, 317-28.

- (1947). Hæme-linked groups and mode of action of some hæmoproteins. Advances in Enzymology, 7, 265.

Гнü̈tтA, T., and Averx, O. T. (1921). Studies on bacterial nutrition. II. Growth accessory substances in the cultivation of hæmophilic bacteria, III. Plant tissue as a source of growth accessory substances in the cultivation of $B$. influenze. J. Exp. Med., 34, 97, 455.

Thomassen, J. (1939). Polarographic studies of the growth hormone, insulin and other hormones of protein structure. Acta Brevia Neerland. Physiol. Pharmacol. Microbiol., 9, 83-4.

'Thornton, H. R., and Hastivgs, E. G. (1929). Studies on oxidation-reduction in milk. I. Oxidationreduction potentials and the mechanism of reduction. Journ. Bact., 18, 293, 319.

Thunberg, T. (1921). Zur Kenntnis des intermediären Stoffwechsels und der dabei wirksamen Enzymen. Skand. Arch. Physiol., 40, 1.

- (1925). Das reduktions-oxydations Potential eines Gemisches von Succinat-fumarat. Skand. Arch. Physiol., 46, 339. 
Thurlow, S. (1928). Studies in Xanthine oxidase. IV. Relation of xanthine oxidase and similar oxidising systems to Bach's oxygenase. Biochem. Journ., 19, 175.

Tillmans, J., Hirsch, P., and Hirsch, W. (1932). Das Reduktionsvermögen pflanzlicher Lebens. mittel und seine Beziehung zum Vitamin C. I. Der reduzierende Stoff des Citronensaftes. Ztschr. Untersuch. Lebensmit., 63, 1.

— - - and Dick, H. (1932). Uber das Reversibilität der Oxydationen des reduzierenden Stoffes im Citronensaft. Ztschr. Untersuch. Lebensmit., 63, 267.

Tовгn, L. C. (1946). Convenient measurement of oxidation-reduction potentials in fermentation studies. Chemist Analyst, 35, 63.

Todd, A. R., Bergel, F., Fraenkel-Corrat, H. L., and Jacob, A. (1936). Aneurin. VI. A synthesis of thiochrome and related compounds. J. Chem. Soc., 1601.

Topd, C., see Perdrau and Todd (1933).

Todd, E. W. (1928). Further observations on the virulence of hæmolytic streptococei with special reference to the morphology of the Colonies. Brit. Journ. Exp. Path., 9, 1.

$(1930,1)$. Virulence of hæmolytic streptococei. I. The influence of oxygen on the production of glossy variants. Brit. Journ. Exp. Path., 11, 368.

$(1930,2)$. Virulence of hæmolytic streptococci. II. The influence of oxygen on the maintenance of virulence in broth cultures. Brit. Journ. Exp. Path., 11, 469.

$(1930,3)$. Virulence of hæmolytic streptococei. III. The influence of oxygen on the restoration of virulence to matt attenuated cultures. Brit. Journ. Exp. Path., 11, 4 S0.

(1932). Antigenic streptococeal hæmolysin. Journ. Exp. Med., 55, 267.

(1933). The hæmolysin produced by streptococci in serum media and its effect on antistreptolysin in vitro. Journ. Path. Bact., 36, 435.

(1934). A comparative serological study of streptolysins derived from human and from animal infections, with notes on pneumococeal hrmolysin, tetanolysin and staphylococcus. toxin. $J$. Path. Bact., 39, 299.

— and Hewitr, L. F. (1932). A new culture medium for the production of antigenic streptocoecal hæmolysin. Journ. Path. Bact., 35, 973.

- and Lancefield, R. C. (1928). Variants of hrmolytic streptococei; their relation to the type specifie substance, virulence and toxin. Journ. Exp. Med., 48, 751.

, see also Lancefield and Todd (1928).

Toeuf, G. DE (1937). Oxidation-reduction potential of the cytochrome of baking yeast. J. Chim. Phys., $34,740-55$.

Tompkins, P. C., and Schuint, C. L. A. (1942). Polarographic characterization of nicotinic acid and related compounds. I. Pyridine and nicotinic aeid. J. Biol. Chem., 143, 643-53.

- and - (1943). A polarographic characterisation of nicotinic acid and related compounds II-V. Univ. Calif. Pub. Physiol., 8, 221-256.

Tongberg, C. O., see Conant and Tongberg (1930).

'Trapp, C., Jühl, Na, L., and Geiger, F. (1939). Polarographic investigation of proteins. III. Albumin, globulin, fibrinogen, plasma, and serum. Z. Physiol. Chem., 262, 225-42.

- and Geiger, F. (1942). Polarographic investigations of proteins. 1V. The influence of urea on protein solutions. Z. Physiol. Chem., 272, 121-33.

Trefouël, J., TrefouëL, Mme. J., Nitti, F., and Bovet, D. (1935). Action of p-a minophenysulfamide in experimental streptococcus infections of mice and rabbits. Compt. rend. Soc. Biol., 120, 756-8.

Trenner, N. R., and BaCher, F. A. (1941). A quantitive reduction-oxidation method for the estimation of vitamin $\mathrm{K}$ and assoeiated auinones and naphthoquinones. J. Biol. Chem., 137, 745.

Tropp, C. (1939). Polarographic investigations of proteins. I. Polarography as a method. Z. Physiol. Chem., 262, 199.

—-, Jü Huivg, L., and Geiger, F. (1939). Polarographic investigations of proteins. III. Albumin, globulin, fibrinogen, plasma and serum. Z. Physiol. Chem., 262, 225.

Tunnicliffe, H. E., see Dixon and Tunnicliffe (1927).

Tuttle, C. D., and Hudpleson, I. F. (1934). Oxidation.reduction studies of growth and differentiation of species of Brucella. J. Inf. Dis., 54, 259.

and - (1934). Determination of oxidation-reduction potentials of sterile culture media with graphite electrode. J. Inf. Dis., 54, 273.

Twigg, R. S. (1945). Oxidation-reduetion aspects of resazurin. Nature, 155, 401-2.

Ucmu⿰ка, T. (1937). Effeet of ultra-violet and Röntgen rayss on the reduction-oxidation potential of frog musele. J. Biochem. (Japan), 25, 207.

Unbreit, IV. W., Burris, R. II., and Stauffer, J. F. (1945). Manometrie techniques and related methods for the study of tissue metabolism. (Burgess, Minn.)

Urban, F. (1939). Reactions in which eytochrome and yellow enzymes take part. Cold spring Harbor Symposia Quant. Biol., 7, 130.

VÁCZI, L. (1944). Aetion of sulfonamides on the electropotential of Staphylococcus albus. Z. Immunitäts, 105, 178-88. 
VASARHely I, v. J. (1935). ber Udie oxyclierende und reduzierende Fermentwirkung der Typhusbazillen. Zentr.f. Bakt., 133, 369.

VEIDENBAKH, V.A. (1944). The effect of oxidation-potential and concentration of the oxydising agent on the process of bleaching of a photographic image. J. Applicd Chem. (U.S.S.R.), 17, 546-51.

Velidinghr, E. (1927). Recherches potentiométriques sur le pH intérieur et sur le potentiel d'oxydationréduction de l'œuf d'oursin. Arch. Phys. Biol., 6, 141 .

(1929). Notes sur le potentiel d'oxydation-réduction de matières colorantes usuelles et leur emploi comme tampons de rH. Arch. Phys. Biol., 7, 113.

- see also Reiss and Vellinger (1929).

VENNESLAND, B., and HANEE, M. (1940). The oxidation-reduction potential requirements of a non-sporeforming, obligate anaerobe. J. Bact., 39, 139-69.

Vickers, A. E. J., S'ucden, J. A., and BeLL, R. A. (1932). An apparatus for the continuous recording. of pH. Journ. Soc. Chem. Ind., 51, 545, 570.

Vigneaud, V.du, Fitch, A., Pekarek, E., and Lockwood, W. W. (1931). The inactivation of crystalline insulin by cysteine and glutathione. J. Biol. Chem., 94, 233-42. and Melville, D. B. (1949). See Clarke, Johnson and Robinson (1949).

Vinzent, R., and DAUfresse, M. (1938). Study of the potential of a medium suitable for the growth of the common spirochaetes found in man. Compt. rend. Soc. Biol., 128, 770-42.

Virtanen, A. I., and Hausen, S. S-V. (1949). Role of substances formed during germination in the growth of plants. Nature, 163, 482.

VLÈs, F. (1914). Oxidation-reduction potentials of nucleic acid-colchicine mixtures. Arch. Phys. Biol., 17, Suppl., 50-2.

and Meyer, L. (1932). Arch. Phys. Biol., 9, 284.

- Reiss, P., and Leloyers, L. (1931). Le potentiel de platine et le rH du sang circulant des mammifères. Compt. rend. Soc. Biol., 108, 37.

Voegtuin, C., Johnson, J. M., and Dyer, H. A. (1924). Quantitative estimation of the reducing power of normal and cancer tissue. Journ. Pharm. Exp. Ther., 24, 305.

-., see also Rosenthal and Voegtlin (1933).

Volk, N. J. (1939). The effect of oxidation-reduction potential on plant growth. J. Am. Soc. Agron., $31,665-70$.

(1939). The determination of reduction-oxidation potentials of soils. J. Am. Soc. Agron., 31, $344-51$.

VRIES, T. DE (1947). Handbook of chemistry and physics. (Chemical Rubber Company.)

Wadoington, C. H., Needham, J., and Brachet, J. (1936). Studies on the nature of the amphibian organization centre. III. The activation of the evocator. Proc. Roy. Soc. (London), B.120, $173-98$.

Waksman, S. A. (1943). Production and activity of streptothricin. J. Bact., 46, 299.

— (1947). Microbial antagonisms and antibiotic substances (second edition).

- and Lechevalier, H. A. (1949). Neomycin, a new antibiotic active against streptomycinresistant bacteria, including tuberculosis organisms. Science, 109, 305.

Waldschuidt-Leitz, E., and Mayer, K. (1939). Polarographic eancer diagnosis. Z. Physiol. Chem., 261, 1-19.

Walker, A. C., and Schmidt, C. L. A. (1914). Extension of the Thunberg technique for measurement of dehydrogenase activity. J. Biol. Chem., 155, 683.

WALlexfels, K., and GaUhe, A. (1943). Dehydrogenation of echinochrome and other 2,3-dihydroxynaphthoquinones by peroxidase and hydrogen peroxide. Ber. deut. Chem. Ges., 76, 325. and MoHLE, W. (1943). Reduction-oxidation potentials of the naphthoquinones. Ber. deut. Chem. Ges., 76, 924.

WarbuRG, O. (1923). Utber die Grundlagen der Wielandsche Atmungstheorie. Biochem. Ztschr., $142,518$.

and Christuan, W. (1932). Utber ein neues Oxydationsferment und sein Absorptionsspektrum. Biochem. Ztschr., 254, 438.

- and Christian, W. (1933). Utber das gelbe Ferment und seine Wirkungen. Biochem. Ztschr., $266,377$.

and Negelein, E. (1934). Cytochrom und säuerstoffübertragendes Ferment. Naturwiss, 22, 206.

- and Christian, W. (1935). The yellow enzyme. Biochem. Z., 298, 368. chem. Z., 301, 221-2.

WARD, W. E. (1938). Apparent oxidation-reduction potentials of bright platinum electrodes in synthetic media cultures of bacteria. J. Bact., 36, 337 .

WARING, W. S., and Werkman, C. H. (1943). Iron requirements of Heterotrophic Bacteria. Archives Biochem., 1943, 1, 425.

Warren, C. O. (1942). The Pasteur effect in bone marrow, with particular reference to results obtained bv different methods. J. Cell. Comp. Physiol., 19, 193-209. 
IVARRen, J., Street, J. A., and Stockinger, H. E. (1939). Influence of sulfanilamide and related compounds upon oxidation-reduction potentials of the hæmolytic streptococcus. Proc. Soc. Exptl. Biol. Med., 40, 208-12.

WARTENBERG, H. (1939). The reduction-oxidation potentials of tissue suspensions and of tissue press juice of different plant parts. Biochem. Z., 302, 262-76.

— and HEY, A. (1936). The reduction-oxidation potential of potato-tuber broth. The electrometric determination of the quality of potato tubers. III. Planta, 25, 258-81.

Waters, W. A. (1948). The chemistry of free radicals (second edition). (Oxford.)

WEBER, K. (1935). Role of oxidation-reduction potential and acidity in the quenching of fluorescence in solution. Z. Physik. Chem., B.30, 69-83.

WeBb, R. E., and HLLEMAN, J. L. (1937). The relation of the oxidation-reduction potential of milk to oxidised flavour. J. Dairy Sci., 20, 47-57.

WebB, G., and Van Heyningen, R. (1947). The action of BAL on enzyme systems. Biochem. J., 41.

WeIL-Malmerbe, H. (1937). The oxidation pf l (一) $\alpha$-hydroxy-glutaric acid in animal tissue. Biochem. J., 31, 2080-94.

WELCH, A. D., see Heard and Welch (1935).

WELDERT, see Spitta and Welder (1906).

Werkman, C. H., Johnson, C. A., and CoILe, H. D. Electron tube potentiometer for the determination of reduction-oxidation potentials. Iowa State Coll. J. Sci., 7, 163.

Westrall, B. B., Thompson, J. W., Burk, D., Bishop, R., Jarrels, G., and Moore, R. (1945) Polaro. graphic response of deproteinated serum of individual rabbits before and after implantation with the Brown-Pearce carcinoma. J. Natl. Cancer Inst., 5, 407-14.

Wheatley, A. H. M., see Quastel and Wheatley (1931).

WhetнaM, M. D., see Quastel and Whetham (1925).

White, A., and Stern, K. G. (1936). Constitution of insulin (I). Properties of reduced insulin preparations. J. Biol. Chem., 119, 215.

Whitehean, H. R. (1924). Search in tryptic broth for the substance enabling the growth of streptococcus. Biochem. J., 18, 829.

Wieland, H. (1913). Über den Mechanismus der Oxydations-Vorgänge. Ber. deutsch. chem. Ges., 46, 3327 .

(1931). Recent researches on biological oxidation. Journ. Chem. Soc., I055.

- and Macrae, T. F. (1930). Über den Mechanismus der Oxydations-Vorgänge, 26. Annalen, 483, 217.

and - (1931). Über die Oxydation der Harnsäure durch Hydroperoxyd unter physiologischen Bedingungen. Ztschr. physiol. Chem., 203, 83.

and Mitchell, W. (1932). Úber den Mechanismus der Oxydations-Vorgänge, 29. Annalen, $492,156$.

and Rosenfeld, B. (1929). Über den Mechanismus der Oxydations-Vorgänge, 21. Annalen, 477, 32.

Windiers (1901). Nouvelle substance indispensable au developpement de la levure. La Cellule, 18,314 .

Williams, J. W. (1940). Gradient of $\mathrm{E}_{\mathrm{h}}$ and its significance in bacteriological media and body tissues. J. Bact., 39, 19.

and DRISSEN, E. M. (1930). Oxidation-reduction potentials of certain sulphydril compounds. Journ. Biol. Chem., 87, 441 .

Williams, V. R., and Fiegre, E. A. (1947). Further studies on lipide stimulation of Lactobacillus casei. J. Biol. Chem., 170, 399.

WiLson, G. S. (1930). The relationship between morphology, colonial appearance, agglutinability and virulence to mice of certain variants of $B$. aertrycke. Journ. Hyg., 30, 40.

(1930). The effect on the virulence of $B$. aertrycke of cultivation in atmosphere containing varying proportions of oxygen. Journ. Hyg., 30, 433.

, 'Twigg, R. S., Wright, R. C., Hendry, C. B., Cowell, M. P., and Maier, J. (1935). Special Report, Medical Research Council. London. No. 206.

and Mrees, A. A. (1946). Principles of Bacteriology and Immunity. ('Topley and Wilson.) Third Edition.

Winslow, C. E. A., and WaLker, H. H. (1939). The earlier phases of the bacterial enlture cyele. Bact. Revs., 3, 147.

Wishart, G. MI. (1923). On the reduction of methylene blue by tissue extracts. Biochem. Journ., 17, 103.

Wolfe, J. K., Hersberc, E. M., and Fieser, L. F. (1940). J. Biol. Chem., 136, 653.

Wollenberger, A. (1915). A catalytic effect of thiamine at the dropping mercury electrode. Science, $101,386-8$.

Wood, W. B., Wood, M. L., and BaLdwin, I. L. (1935). Relation of oxidation-reduction to growth of an acrobic micro-organism. J. Bact., 30, 593. 
Woons, D. D. (1940). 'I'he relation of p-amino-benzoic acid to the mechauism of the action of sulphanilamide. Brit.J. Exp. Path., 21, 74.

Wooldridge, W. R. (1933). The "stability test" of sewage and its relation to enzyme activit y Biochem. Journ., 27, 193.

— and Standfast, A. F. B. (1933). The biochemical oxygen demand of sewage. Biochem. Journ., 27, 183.

see also Quastel and Wooldridge (1929).

Sandiford and Wooldridge (1931).

Knox, R., and Glass, V. (1936). Variability in the activity of bacterial enzymes. T. The effect of age of the culture. Biochem. J., 30, 926 .

Work, T. S., and Work, E. (1948). The basis of chemotherapy. (Oliver and Boyd.)

Wrede, F., and Strack, E. (1929). Uber das Pyocyanin, der blauen Farbstoff des Bacillus pyocyaneus. IV. Die Konstitution und Synthese des Pyocyanin. Z. physiol. Chem., 181, 58.

Wurmser, R. (1925). Sur le potentiel d'oxydo-réduction cellulaire et les phenomènes d'oxydo-réduction. Compt. rend. Soc. Biol., 93, 1478.

(1930). Oxydations et Réductions. Paris.

and BOE, Z. DE (1932). Sur le potentiel d'oxydo-réduction du système acide lactique-acide pyruvique. Compt. rend. Acad. Sci., 194, 2139.

and Geloso, J. (1928). Sur le potentiel des solutions des glucides. I. Journ. Chim. Phys., 25,641 .

and - (1929). Sur le potentiel d'oxydation des glucides. II. Journ. Chim. Phys., 26, 424. and - (1930). Sur les potentiels d'oxydo-réduction intra-cellulaires. Compt. rend. Soc. Biol., $104,135$.

and - (1931). Sur les potentiels d'oxydation des solutions des glucides. III. Journ. Chim. Phys., 28, 260.

_- and DE Lourerro, J. A. (1933). Le potentiel d'oxydo-réduction de l'acide ascorbique. Compt. rend. Soc. Biol., 113, 543.

—. see also Aubel, Gènevois and Wurmser (1927).

Rapkine and Wurmser (1926, 1928).

(1932). La signitication des potentiels d'oxyderéduction. Biol. Rev., 7, 350 .

(1937). Oxiation-reduction potentials of organic systems. Bull. Soc. Chim. (5), 4, 1942-62.

and Finetri-Wurmser, S. (1937). Proteoflavin in the electro-chemical equilibrium of cells. Enzymologia, 4, 137-8.

—_, - - (1937). Oxidation-reduction potentials of organic systems. Bull. Soc. Chim. (5), 4, 1942-62.

- - - - (1938). Reduction-oxidation potential of Cytochrome. J. Chim. Phys., 35, 81-8.

, - (1938). Oxidation-reduction potential of the system (unnatural) 1. alanine-ammonium pyruvate. Compt. rend. Soc. Biol., 128, 133-5.

-, - (1935). Oxidation-reduction potential of cytochrome c. Compt. rend. Soc. Biol., 127, 471-3.

and MAYER, N. (1935). Oxidation-reduction potential of reductone. Compt. rend., 201-8.

, - and Crépy, O. (1936). Oxidation-reduction potential of reductone. J. Chim. Phys., 33, 101-10.

WYND, F. L., and VARNEY, P. L. (1941). A vessel for the measurement of pH and oxidation-reduction potential of bacterial eultures. J. Lab. Clin. Hed. 26, 1513-16.

Yaо, H., and Tamry, H. (1928). On the respiratory pigment, cytochrome, in bacteria. Proc. Imp. Acad. Tokyo, 4, 436.

Young, I. (1937). The effect of pyoeyanine on the metabolism of cerebral cortex. I. Biol. Chem., $119,659$.

YUdkix, J. (1935). Peduction potential of bacterial suspension. Biochem. J., 29, 1130.

Zerfas, I. G., and Drxox, Ml. (1940). An improved cell for measurements of oxidation-reduction potential. Biochem. I., 34, 36.570

ZiLva, S. S. (1934). The reversible enzymic oxidation of vitamin C. Biochem. J., $28,663$.

- see Harden and Zilva (1915).

ZnNsser. H., and Scroenbach, E. B. (1937). Studies on the physiological conditions prevailing in tissue cultures. J. Exptl. Hed., 66, 207.

Zobelt, C. E. (1935). Oxidation-reduction potentials and the activity of marine nitrifiers. J. Bact.. $29,78$.

- (1937). Oxidation-reduction conditions in marine sediments, with particular reference to oxidation-reduction potentials, oxygen deficit and bacteria. Assoc. Ocean. Phys. Proc. Verb., 2, 159 .

- and Andersox, D. Q. (1936). Vertical distribution of bacteria in marine sediments. Bull. A $m$. Assoc. Petrolium Geol., 20, 358-69. 



\section{AUTHOR INDEX}

[Names of other authors are given in the bibliography]

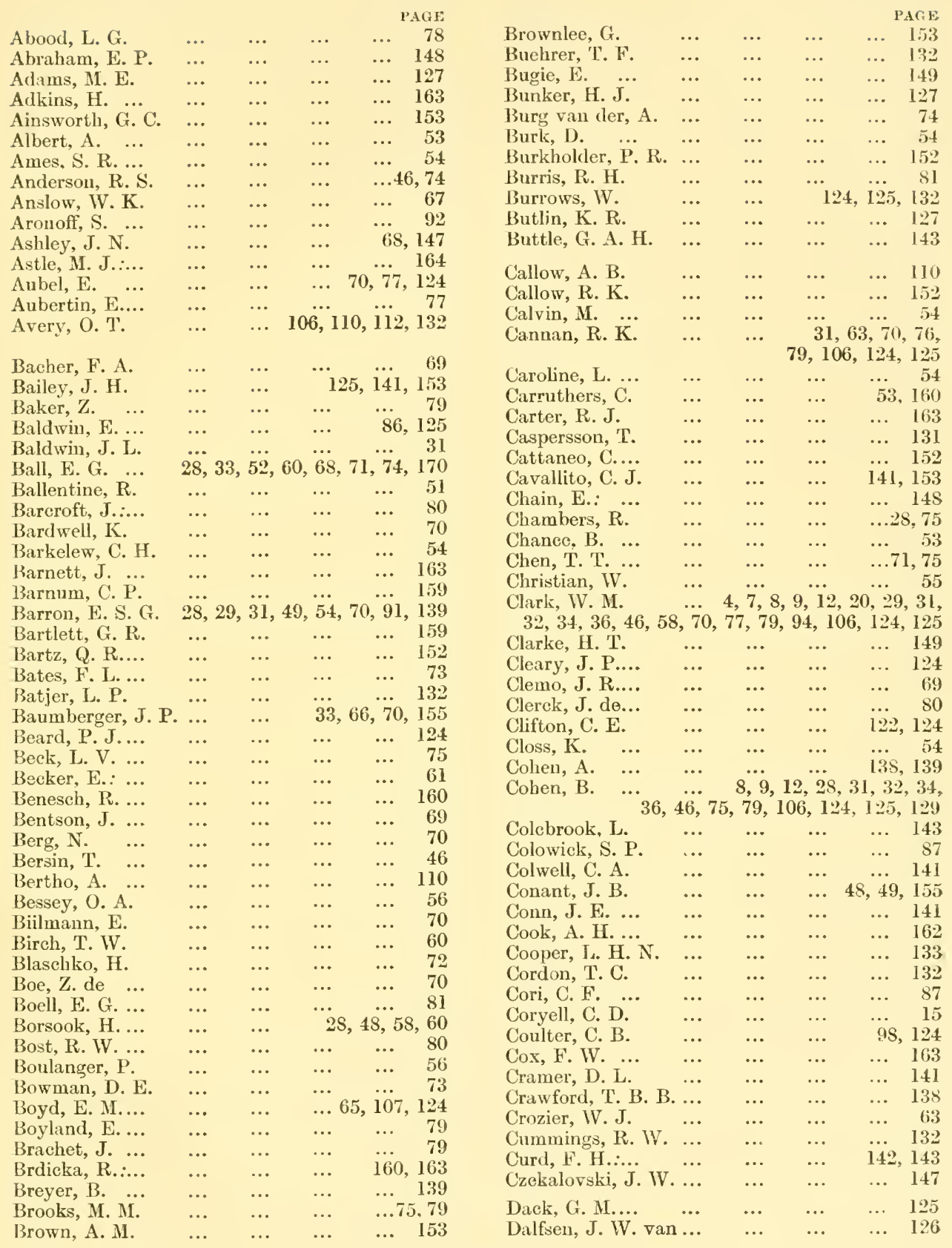


Danielli, J. F.

Darnell, M. C.

Davey, D. G.

Davies, W. L.

Davis, J. G....

Davis, O. L....

Dawson, C. R.

Dearden, D. V.

Deloyers, L....

Dennis, S. F.

Desnuelle, P.

Dewan, G. J.

Dick, $\mathrm{H}$.

Diekens. F. ...

Dickinson, D.

Digleria, E. ...

Dirks, B. ...

Dixon, H. .

Domagk, G....

Drissen, E. ML.

Dubos, R. ...

Duggar, B. M.

Dutcher, R. A.

Dutky, S. R.

Ehrlich, J.

Ehrlich, P. ...

Eisenmenger, IT. S.

Elema, B. ... ..

Elliott, K. A.

Elliott, S. D.

Ellis, E. L. ...

Euler, von, H.

Eyring, H. ...

Falk, J. E. ....

Fenn, IV.:O...

Fieger, E. A.

Fieser, L. F...

Figge, F. H. J.

Fildes, P.

Fischer, K. ...

Fleming, A. ...

Eletcher, C. MI

Flexner, L. B.

Florey, $\mathrm{H}$.

French, D. ... ...

French, C.S. …

Friedemann, T. E....

Friedheim, E. A. H.

Fromageot, C.

Fuller, A. T'...

\section{Gale, E. F.}

Ganguli, s. (.)

Gardner, A. D.

Garrod, L. P'.

Geiger, W. B.

Geloso, J.

Gènevois, L.

Grorgescu, I. D.

Ghosh, J. C....
PAGE

139, 160

... 132

... 143

... 128

... 128

... 163

... 54

... 128

... 77

... 164

... 80

... $56,58,70$

... $\quad \ldots \quad 60$

$58,79,80,91$

... $\quad \ldots \quad 132$

$\begin{array}{lll}\ldots & \ldots & 61\end{array}$

... $\quad \ldots \quad 132$

... $47,48.75$

... $\quad \ldots \quad 147$

$\begin{array}{lll}\ldots & \ldots & 143\end{array}$

... $\quad \ldots \quad 48$

$130,140,152$

... 153

... 66

... 125

.. 152

76,135

$\begin{array}{lll}\ldots & \ldots & \\ \ldots & \ldots & 132\end{array}$

... 14, 35, 64, 66, 126

... $46,79,80$

46,130

... 48

56,72

... 147

$\begin{array}{lll}\ldots & \ldots & 14 \\ \cdots & \ldots & 74\end{array}$

$\begin{array}{lll}\ldots & \ldots & 53\end{array}$

... $\quad \ldots$ so

... $\quad \ldots \quad 1: 6$

48,163

$\ldots \quad \ldots \quad 54$

$27,119,125,140$

... $\quad \ldots \quad 163$

$121,148,170$

... 148

...31, 4s

$14 \$, 170$

… 14,73

$\begin{array}{lll}\ldots & \ldots & 92\end{array}$

$\begin{array}{lll}\cdots & \ldots & 77\end{array}$

$64,65,66,6 \mathrm{~s}$

... so

... 143

101,151

... 48

... 145

... 149

... 1.41

70,125

70,124

60
48

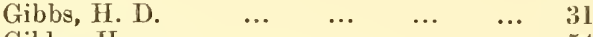

$\begin{array}{lllllll}\text { Gilder, } \mathrm{H} . & \ldots & \ldots & \ldots & \ldots & \ldots & 5 \pm\end{array}$

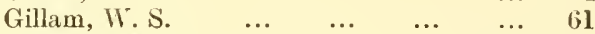

Gillespie, L. J. $\quad \ldots \quad \ldots \quad \ldots 106,124,125$

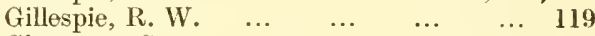

$\begin{array}{llllll}\text { Glasstone, S. } & \ldots & \ldots & \ldots & \ldots & 17\end{array}$

$\begin{array}{lllllll}\text { Gluek, } H . & \ldots & \ldots & \ldots & \ldots & \ldots & 110\end{array}$

Goard, A. K. $\quad \ldots \quad \ldots \quad \ldots . \quad \ldots 12,70$

$\begin{array}{lllllll}\text { Gordon, J. } & \ldots & \ldots & \ldots & \ldots & \ldots & 110\end{array}$

$\begin{array}{rrrrrr}\text { Granick, s. } \ldots & \ldots & \ldots & \ldots & \ldots & 54\end{array}$

Green, C. A... $\quad \ldots \quad \ldots \quad \ldots, \quad \ldots \quad 144$

Green, D. E. $\quad$... 28, 48, 52, 56, 58, 59, 60 ,

$70,7+5$

Greville, G. D.

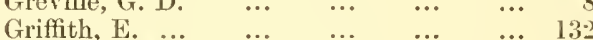

$\begin{array}{llllll}\text { Grünberg, M. } & \ldots & \ldots & \ldots & \ldots & 116\end{array}$

$\begin{array}{llllll}\text { Guggenheim, } \mathrm{K} . & \ldots & \ldots & \ldots & \ldots & 113\end{array}$

Gulland, J. M. $\quad \ldots \quad \quad \ldots \quad \ldots \quad \ldots 7:, 73$

$\begin{array}{llllll}\text { Gurehot, C. ... } & \ldots & \ldots & \ldots & \ldots & 69\end{array}$

$\begin{array}{lllllll}\text { Haas, E. } & \ldots & \ldots & \ldots & \ldots & \ldots & 56\end{array}$

$\begin{array}{lllllll}\text { Haas, } P . & \ldots & \ldots & \ldots & \ldots & \ldots & \ldots \\ \end{array}$

$\begin{array}{llllll}\text { Hakamori, } \mathrm{S} . & \ldots & \ldots & \ldots & \ldots & 31\end{array}$

$\begin{array}{lllllll}\text { Hall, J. C. } & \ldots & \ldots & \ldots & \ldots & \ldots & 106\end{array}$

$\begin{array}{llllll}\text { Hall, R. H. ... } & \ldots & \ldots & \ldots & \ldots & 162\end{array}$

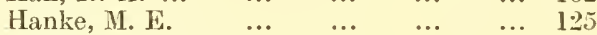

Harden, A. ... $\quad \ldots \quad \ldots \quad \ldots .77,79,88$

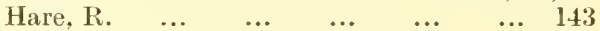

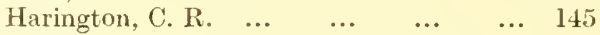

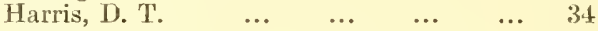

$\begin{array}{llllll}\text { Harris, L. J.... } & \ldots & \ldots & \ldots & \ldots & b 0\end{array}$

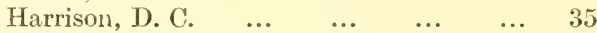

$\begin{array}{llllll}\text { Harrison, G. B. } & \ldots & \ldots & \ldots & \ldots & 48\end{array}$

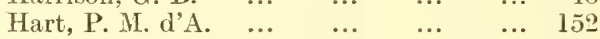

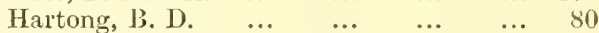

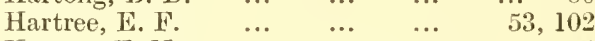

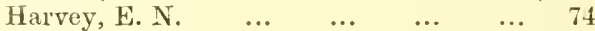

$\begin{array}{lllllll}\text { Hasse } & \ldots & \ldots & \ldots & \ldots & \ldots & \\ \text { Hat } & \ldots & \ldots & \ldots & 56\end{array}$

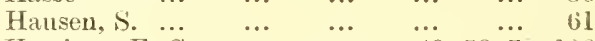

Hastings, E. G. $\quad \ldots \quad \ldots \quad 49,56,70,106$

$\begin{array}{llllll}\text { Havard, R. E. } & \ldots & \ldots & \ldots & \ldots & 79\end{array}$

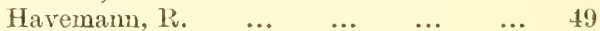

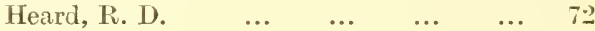

Hearon, J. $\quad \ldots \quad$... $\quad \ldots \quad$...

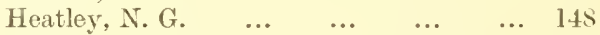

Heilbron, I. M. $\quad \ldots \quad$... $\quad \ldots \quad$.. 162

$\begin{array}{llllll}\text { Heintre, S. G. } & \ldots & \ldots & \ldots & \ldots & 13:\end{array}$

Hellerman, L. $\quad \ldots . \quad \ldots . \quad \ldots \quad 46,129$

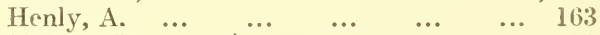

Henry, H. ... . ... ... ... ... 13.2

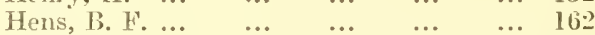

Herbert, 1. ... $\quad \ldots . \quad \ldots \quad \quad \ldots \quad \quad 53,59$

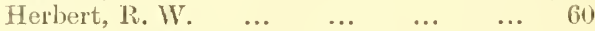

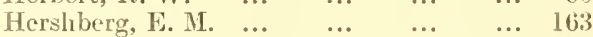

Hewitt, L. F. $\quad \ldots \quad 30,31,41,46,58,104$, $108,109,110,111,112,113,114,118,121$. $123,124,125,126,129,130,136,142$.

146. $1.47,150,152$

Heyrovsky, J.

158,1601

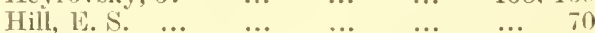

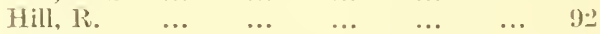

$\begin{array}{lllllll}\text { Hill, T. G. } & \ldots & \ldots & \ldots & \ldots & \ldots & 63\end{array}$

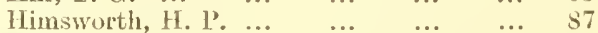

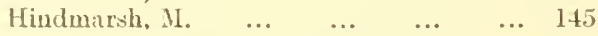




\begin{tabular}{rrrr} 
& & \multicolumn{2}{r}{ PAGE } \\
$\ldots$ & $\ldots$ & $\ldots$ & 96 \\
$\ldots$ & $\ldots$ & $\ldots$ & 60 \\
$\ldots$ & $\ldots$ & $\ldots$ & 12 \\
$\ldots$ & $\ldots$ & $\ldots$ & 127 \\
$\ldots$ & $\ldots$ & $\ldots$ & 70 \\
$\ldots$ & $\ldots$ & $\ldots$ & 28 \\
$\ldots$ & $\ldots$ & $\ldots$ & 48 \\
$\ldots$ & $\ldots$ & $\ldots$ & 52 \\
$\ldots$ & $\ldots$ & $\ldots$ & 92 \\
$\ldots$ & $\ldots$ & $\ldots$ & 72 \\
$\ldots$ & $\ldots$ & $\ldots$ & 132 \\
$\ldots$ & $\ldots$ & $\ldots$ & 80 \\
$\ldots$ & & 45,118, & 171 \\
$\ldots$ & $\ldots$ & $\ldots$ & 66 \\
$\ldots$ & $\ldots$ & $\ldots$ & 152 \\
$\ldots$ & $\ldots$ & $\ldots$ & 67 \\
$\ldots$ & $\ldots$ & 31, & 126
\end{tabular}

$\begin{array}{lrrrrr}\text { Hinshelwood, C. N... } & \ldots & \ldots & \ldots & 96 \\ \text { Hirsch, R. IV. } & \ldots & \ldots & \ldots & \ldots & 60\end{array}$

Hoar, T. P. ... … …

Hobbs, B. C. $\quad \ldots . \ldots 127$

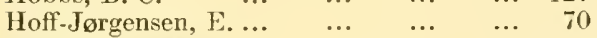

Hoffman, H. M. ...

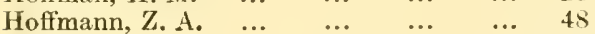

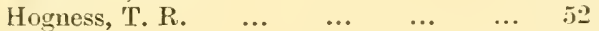

Holt, A. S. ... $\quad \ldots \quad$.. $\quad \ldots \quad \ldots, \quad \ldots, \quad 92$

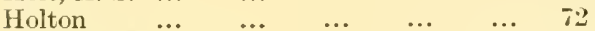

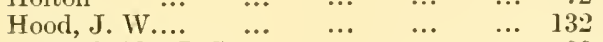

Hoogerheide, J. C.... $\quad . . \quad \ldots . \quad \ldots \quad 80$

Hopkins, F. G. $\quad \ldots \quad \quad \ldots \quad 45,118,171$

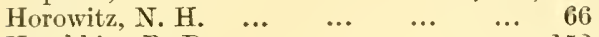

$\begin{array}{rllllr}\text { Hotchkiss, R. D. } & \ldots & \ldots & \ldots & \ldots & 152\end{array}$

$\begin{array}{lllllr}\text { Howard, B. H. } & \ldots & \ldots & \ldots & \ldots & \\ \text { Huddleson, J. F. } & \ldots & \ldots & \ldots & 31, & 126\end{array}$

Ilkovic, D. $\quad \ldots \quad \quad \ldots \quad \quad \ldots, \quad \ldots \quad \ldots \quad 156$

Isaacs, M. L. $\quad \ldots . \quad \ldots . \quad \ldots \quad 98,124$

Ishikawa, M. $\quad \ldots . \quad \ldots . \quad \ldots . \quad \ldots, \quad 77$

Jackson, E. B. $\quad \ldots . \quad \ldots . \quad \ldots, \quad \ldots \quad 152$

Janesó, N. V. $\quad \ldots . \quad \ldots . \quad \ldots \quad 140,142$

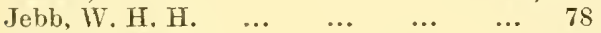

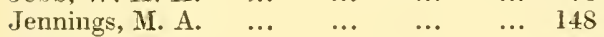

$\begin{array}{llllll}\text { Jensen, C. O. } & \ldots & \ldots & \ldots & \ldots & 66\end{array}$

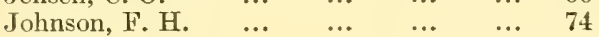

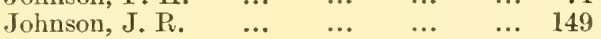

Johnstone, K. I. $\quad \ldots . \quad \ldots . \quad \ldots . \quad \ldots .113$

Jordan, E. O. $\quad \ldots . \quad \ldots . \quad \ldots . \quad 124,125$

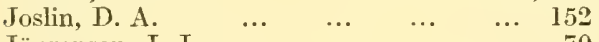

$\begin{array}{llllll}\text { Jürgensen, J. J. } \quad \ldots & \ldots & \ldots & \ldots & 70\end{array}$

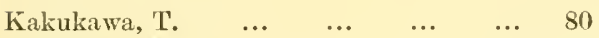

$\begin{array}{lllll}\text { Keaton, C. M. } & \ldots & \ldots & \ldots & \ldots \\ & \ldots & \ldots & \ldots & 60,132\end{array}$

Keighley, G.... $\quad \ldots \quad \quad \ldots \quad \quad \ldots \quad \ldots 60$

Keilin, J. $\ldots . \quad \ldots \quad \ldots 50,53,54,80,102$

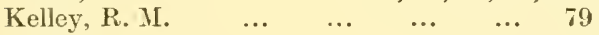

Kendal, L. P. $\quad \ldots . \quad \ldots . \quad \ldots . \quad \ldots \quad 79$

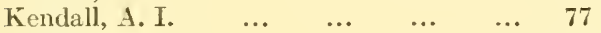

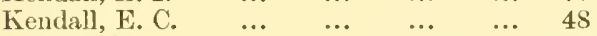

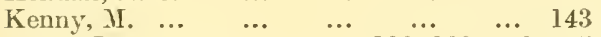

$\mathrm{King}, \mathrm{H} . \quad \ldots . \quad \ldots . \quad \ldots, 138,139,142,147$

Kirk. M. M. ... $\quad . . \quad \ldots . \quad \ldots \quad \ldots \quad \ldots 6 \quad 61$

Kirk, van de, G. J.... $\quad \ldots .614$

$\begin{array}{llllll}\text { Kirmse, T. W. } & \ldots & \ldots & \ldots & \ldots & 149\end{array}$

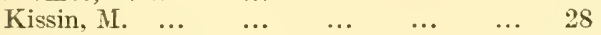

Klemperer, $\begin{array}{lllll}\text { F. } & \ldots & \ldots & \ldots & \ldots \\ & \ldots & \ldots & \ldots & \ldots 54,56\end{array}$

Kliger, I. J. ... $\quad \ldots \quad \quad \ldots \quad \ldots \quad \ldots \quad \ldots \quad 113$

Kluyver, A. J. $\quad \ldots . \quad \ldots \quad 74,80,126,127$

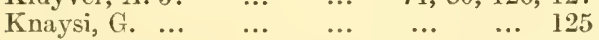

Knight, B. $\ldots . \quad \ldots . \quad \ldots \quad 34,107,119,125$

Kolthoff, I. M. $\quad$... $\quad \ldots \quad \quad \ldots \quad 155,159$

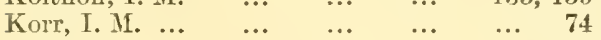

Krebs, H. $\quad \ldots . \quad \ldots . \quad \ldots . \quad \ldots \quad \ldots 80,89$

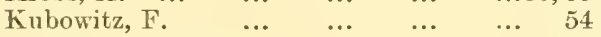

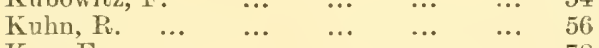

$\begin{array}{lllllll}\text { Kun, E. } & \ldots & \ldots & \ldots & \ldots & \ldots & 78\end{array}$

Laki, $\mathrm{K} . \quad \ldots . \quad \ldots \quad \quad \ldots \quad \ldots \quad \ldots 2,60,70$

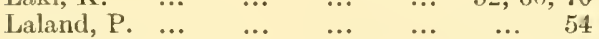

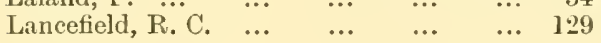

Larsson, F. ... $\quad \ldots \quad 48$

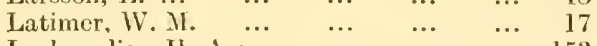

Lechavalier, H. A. ... $\quad \ldots \quad \ldots \quad \ldots \quad \ldots \quad 153$

Lehmann, J. $\quad \ldots . \quad \ldots . \quad \ldots \quad 33,34,70)$

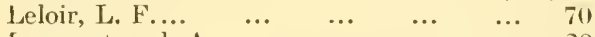

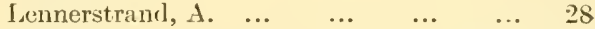

Lepper, E. ... $\quad \ldots 31,49,115,118,324,125$

Levvy, G. A. $\quad \ldots \quad$... $\quad \ldots . \quad \ldots \quad 138$

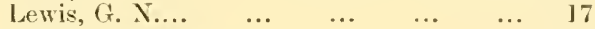

Lineoln, E. M. $\quad \ldots \quad$... $\quad \ldots . \quad \ldots, \quad 149$

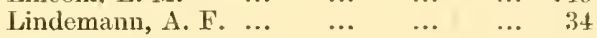

Linderström-Lang, $\mathbf{K} . \quad \ldots \quad \quad \ldots \quad \quad \ldots \quad 81$

Lingane, J. J. $\quad \ldots \quad \quad \ldots . \quad \ldots . \quad 155,163$

Lipmann, F... $\quad \ldots \quad \ldots \quad \ldots 59,79,83,90$

Loewen, D. F. $\quad \ldots . \quad \ldots \quad$... $\quad$...

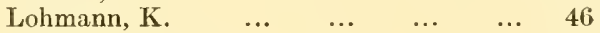

Longsworth, L. G. ... $\quad \ldots \quad$... $\quad \ldots \quad 31$

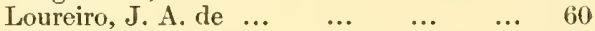

Lowrie, E. M. $\quad \ldots . \quad \ldots \quad \quad \ldots . \quad \ldots \quad 147$

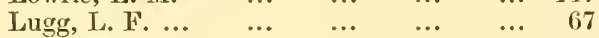

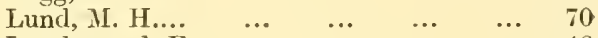

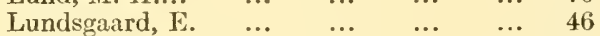

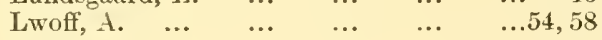

$\begin{array}{llllll}\text { Macbeth, A. K. } & \ldots & \ldots & \ldots & \ldots & 67\end{array}$

$\begin{array}{llllll}\text { McCarty, } \mathrm{MI} . . . & \ldots & \ldots & \ldots & \ldots & 132\end{array}$

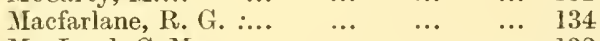

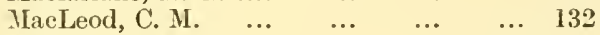

IIcCleod, J. W. $\quad \ldots . \quad \ldots . \quad \ldots \quad$ 피 113

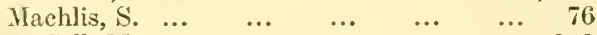

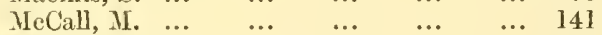

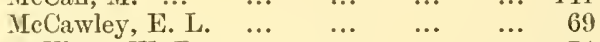

McElroy, W. D. $\quad \ldots \quad$... $\quad \ldots \quad$... 74

McIlwain, $\mathrm{H}, \quad \ldots . \quad \ldots . \quad \ldots .58,69,91$

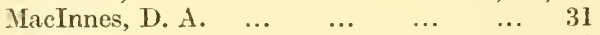

$\begin{array}{llllll}\text { MacIntosh, J. } & \ldots & \ldots & \ldots & \ldots & 116\end{array}$

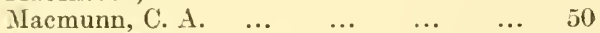

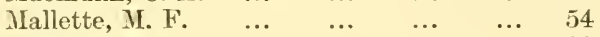

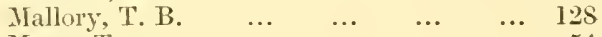

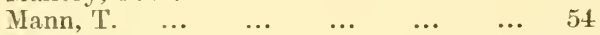

Martin, W. P. $\quad \ldots . \quad \ldots . \quad \ldots . \quad \ldots, 132$

Martin, C. J. $\quad \ldots 31,49,115,118,124,125$

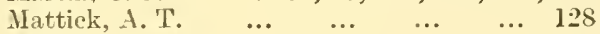

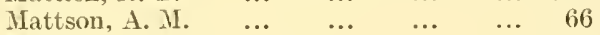

Mayer, $\mathrm{N} . \quad \ldots, \quad \ldots \quad \ldots 66,70$

Meikeljolın, G. T. ... $\quad \ldots . \quad \ldots . \quad \ldots, \quad 54$

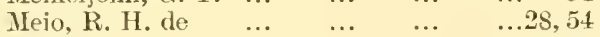

Melville,, T. $\ldots . \quad \ldots \quad \quad \ldots \quad \ldots 6,162$

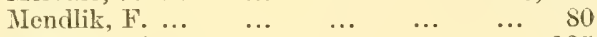

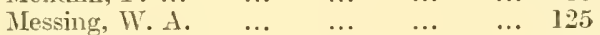

$\begin{array}{lllllll}\text { Meyer, } \text { N. } & \ldots & \ldots & \ldots & \ldots & \ldots & 139\end{array}$

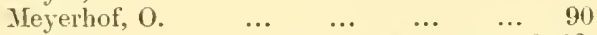

Michaelis, L. $\quad \ldots \quad 1, \dddot{12}, 14,48,55,56,62$,

$64,70,91,155$

Miller, Z. B.... $\quad \ldots \quad \quad \ldots, \quad \ldots . \quad \ldots \quad 139$

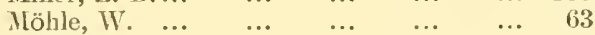

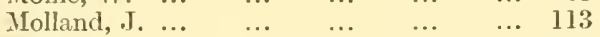

IIoore, IV. A. $\quad \ldots . \quad \ldots . \quad \ldots . \quad 132,133$

Mlorgan, E. J. $\quad \ldots . \quad \ldots . \quad \ldots . \quad \ldots \quad 49$

Mlorgan, H. I. $\quad \ldots . \quad \ldots . \quad \ldots . \quad 110,112$

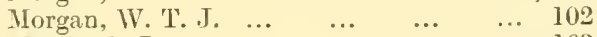

$\begin{array}{llllll}\text { Morris, C. J. } & \ldots & \ldots & \ldots & \ldots & 163\end{array}$

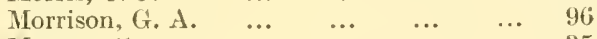

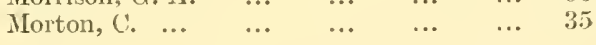


Müller, O. H. 155,161

Mureh, IW. O. $\quad \ldots . \quad \ldots \quad \ldots . \quad \ldots \quad 143$

Needham, D. M.

Needham, J.

Neill, J. M. .

Nelson, J. M.

Neuberg, C. ...

Nowbery, G...

Nord, F. F. .

Oakley, C. L.

Ochoa, S.

Orr-Ewing, $\ddot{J}$.

Orr, J. H.

Ort, J. M

Page, J. E. ...

Pállares, $\mathrm{C}$.

Pappenheimer, A. $\ddot{\mathrm{M}}$.

Parker

Parks, R. Q....

Pastenr, L. ...

Pearsall, W. H.

Peech, M.

Partrilge, S. M.

Paul, K. G. ..

Penrose, M. ...

Perdrau, J. R.

Perkins, M. E.

Peters, R.

Peters, R. A.

Pincussen, L.

Plotz, H.

Pollack, H. ...

Polloek, M. R.

Posternak, T.

Potter, M. C.

Powell, A. S.

Pozen, M. A.

Preisler, P. W.

Quastel, J. H.

Racker, E. ...

Raistrick, $\mathrm{H}$.

Randall, $\mathbf{M}$.

Randall, S. S.

Raper, H. S....

Rapkine, L....

Ray, S. N. ... ...

Raychandhuri, S. N.

Redslob, E. ..

Reed, G. B. .

Reed, J.

Reiss, $\mathbf{P}$.

Rettger, L. F.

Reznikoff, $P$.

Richards, WV. T.

Pichardson, G. M.

Riekes, K. I.

Rirleal, E. Kr.
$29,31,47,48,77,113,121$

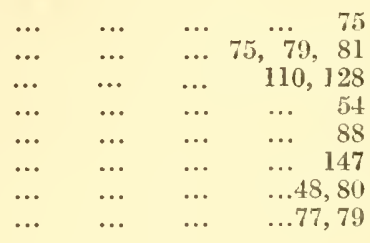

$$
\begin{array}{rrrrr}
\ldots & \ldots & \ldots & \ldots & 134 \\
\ldots & \ldots & \ldots & \ldots & 57 \\
\ldots & \ldots & \ldots & \ldots & 148 \\
\ldots & \ldots & \ldots & \ldots & 113 \\
\ldots & \ldots & \ldots & \ldots & 48
\end{array}
$$

$140,141,162$

$$
\begin{aligned}
& \begin{array}{llr}
\ldots & \ldots . & 80 \\
\ldots & 49, & 134
\end{array} \\
& \begin{array}{llr}
\text {.. } & \ldots & 54
\end{array} \\
& \begin{array}{lll}
\ldots & \ldots & 132
\end{array} \\
& \text {.. } \quad \ldots 1,90 \\
& \begin{array}{lll}
\ldots & \ldots & 132
\end{array} \\
& \begin{array}{lll}
\ldots & \ldots & 132 \\
\ldots & \ldots & 102
\end{array} \\
& \begin{array}{llr}
\cdots & \cdots & 102 \\
\cdots & \ldots & 52
\end{array} \\
& \begin{array}{rrr}
\ldots & \ldots & 121
\end{array} \\
& \begin{array}{lll}
\ldots & \ldots & 29 \\
\ldots & \ldots & 46
\end{array} \\
& \begin{array}{llr}
\ldots & \ldots & 6 \\
\ldots & \ldots & 6 \\
\ldots & 59, & 139
\end{array} \\
& \begin{array}{rr}
\ldots & 77 \\
\ldots & 125
\end{array} \\
& \text {..28, } 75 \\
& \text {... } 131 \\
& \text { ‥ } 68 \\
& \text {... } 164 \\
& \text {... } \quad \ldots .80
\end{aligned}
$$$$
48,63,70,76
$$

$$
\begin{array}{ccccr}
\ldots & \ldots & \ldots & \ldots & 57 \\
\ldots & \ldots & \ldots & \ldots 67,68 \\
\ldots & \ldots & \ldots & \ldots & 17 \\
\ldots & \ldots & \ldots & \ldots 72,73 \\
\ldots & \ldots & \ldots & \ldots & 54 \\
\ldots & \ldots & \ldots & \ldots & 75 \\
\ldots & \ldots & \ldots & \ldots & 60 \\
N & \ldots & \ldots & \ldots & 48 \\
\ldots & \ldots & \ldots & \ldots & 77 \\
\ldots & \ldots & \ldots & 65,113 \\
\ldots & \ldots & \multicolumn{1}{r}{107,124,132} \\
\ldots & \ldots & \ldots & 77,78,79 \\
\ldots & \ldots & \ldots & \ldots & 119 \\
\ldots & \ldots & \ldots & \ldots & 75 \\
\ldots & \ldots & \ldots & \ldots & 12 \\
\ldots & \ldots & \ldots & \ldots 60,70 \\
\ldots & \ldots & \ldots & \ldots & 54 \\
\ldots & \ldots & \ldots & \ldots 12,70
\end{array}
$$

PAGE

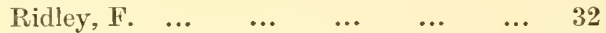

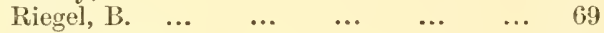

$\begin{array}{llllll}\text { Robertis de } \ldots & \ldots & \ldots & \ldots & \ldots & 146\end{array}$

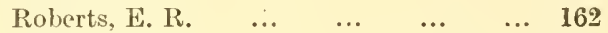

Robinson, F. A. $\quad \ldots \quad \ldots \quad \ldots 140,141,162$

Robinson, R. $\quad$ R. $\quad \ldots \quad$... $\quad \ldots \quad 149$

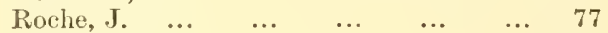

$\begin{array}{llllll}\text { Rodkey, F. L. } & \ldots & \ldots & \ldots & \ldots & 52\end{array}$

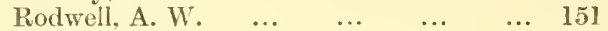

$\begin{array}{llllll}\text { Rose, F. L. ... } & \ldots & \ldots & \ldots & \ldots & 142\end{array}$

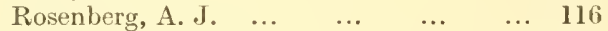

Roughton, F. J. IV. $\quad \ldots . \quad \ldots . \quad \ldots 53,80$

$\begin{array}{llllll}\text { Ruchoft, C. C. } \quad \ldots & \ldots & \ldots & \ldots & 133\end{array}$

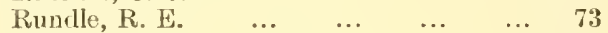

Runnström, J. $\quad \ldots . \quad \ldots \quad \quad \ldots . \quad \ldots 28,65$

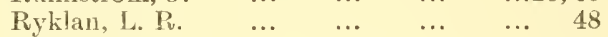

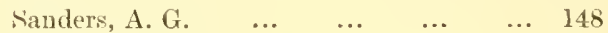

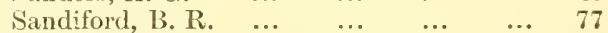

$\begin{array}{llllll}\text { Sichade, A. I. } & \ldots & \ldots & \ldots & \ldots & 54\end{array}$

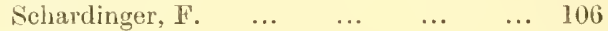

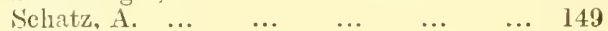

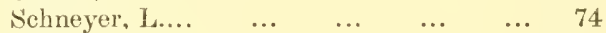

$\begin{array}{llllll}\text { Sehoch, T. J. } & \ldots & \ldots & \ldots & \ldots & 73\end{array}$

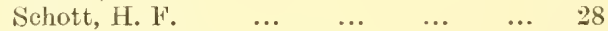

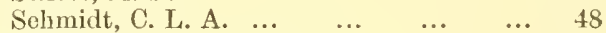

$\begin{array}{llllll}\text { Sehubert, M. P. } & \ldots & \ldots & \ldots & \ldots & 56\end{array}$

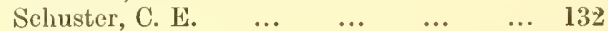

Scliwachman, H. $\quad \ldots . \quad \ldots . \quad \ldots . \quad 46,129$

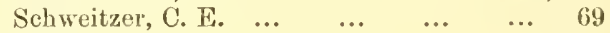

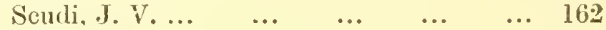

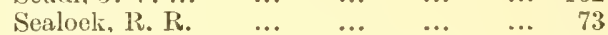

$\begin{array}{lllllll}\text { Seitz, } 0 . & \ldots & \ldots & \ldots & \ldots & \ldots & 77\end{array}$

Shepherd, R. G. $\quad \ldots . \quad \ldots \quad \quad \ldots . \quad \ldots \quad 153$

$\begin{array}{llllll}\text { Shikata, M. ... } & \ldots & \ldots & \ldots & \ldots & 155\end{array}$

$\begin{array}{llllll}\text { Sidwell, A. E. } & \ldots & \ldots & \ldots & \ldots & 52\end{array}$

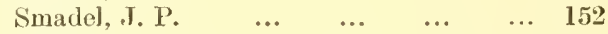

$\begin{array}{llllll}\text { Smith, E. L.... } \quad \ldots & \ldots & \ldots & \ldots & 54\end{array}$

$\begin{array}{lllllll}\text { Smitlı, G. } & \ldots & \ldots & \ldots & \ldots & \ldots & 67\end{array}$

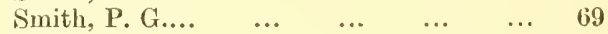

$\begin{array}{llllll}\text { Smith, R. M. } & \ldots & \ldots & \ldots & \ldots & 152\end{array}$

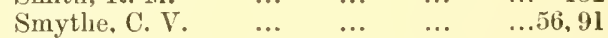

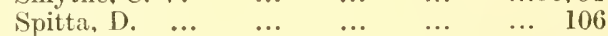

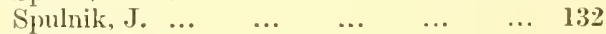

Stacey, M. $\quad \ldots \quad \quad \ldots . \quad \ldots . \quad \ldots . \quad 101,132$

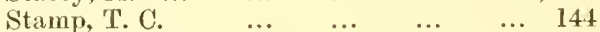

$\begin{array}{llllll}\text { Standfast. A. } & \ldots & \ldots & \ldots & \ldots & 106\end{array}$

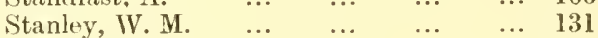

$\begin{array}{llllll}\text { Stansly, P. G. } & \ldots & \ldots & \ldots & \ldots & 153\end{array}$

$\begin{array}{llllll}\text { Stauffer, J. F. } & \ldots & \ldots & \ldots & \ldots & \text { sl }\end{array}$

Steplienson, M. $\quad \ldots . \quad \ldots . \quad \ldots . \quad 77,113$

Stephenson, R. E. ... $\quad \ldots . \quad \ldots . \quad \ldots \quad 132$

Stern, K. G. $\quad \ldots . \quad \ldots \quad \quad \ldots \quad \quad 28,66$

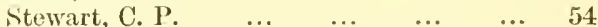

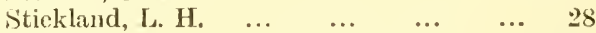

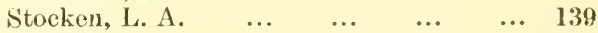

Stotz, lis. $\quad \ldots \quad \quad \ldots \quad \quad \ldots \quad \quad \ldots \quad \quad \ldots 52,54$

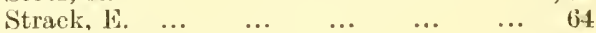

Strangeways, IV. I... $\quad \ldots \quad$... $\quad \ldots \quad$ 138, 139

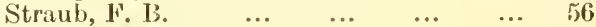

$\begin{array}{llllll}\text { Sturgis, M. B. } & \ldots & \ldots & \ldots & \ldots & 132\end{array}$

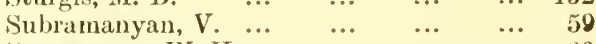

Summerson, W. H... $\quad \ldots \quad$... $\quad \ldots .80$

Szent-Györgi, A. von $\quad \ldots \quad \ldots .51,87,100$ 
$\begin{array}{rlllllr} & & & & & & \\ \text { Tamiya, } & \cdots & \ldots & \ldots & \ldots & \ldots & 15 .\end{array}$

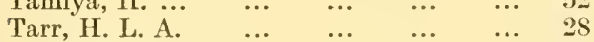

$\begin{array}{llllll}\text { Taylor, E. S. } & \ldots & \ldots & \ldots & \ldots & 101\end{array}$

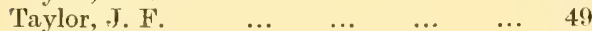

$\begin{array}{llllll}\text { Theorell, H... } & \ldots & \ldots & \ldots & \ldots & 53\end{array}$

$\begin{array}{llllll}\text { Thomas, } \text { M. ... } & \ldots & \ldots & \ldots & \ldots & 127\end{array}$

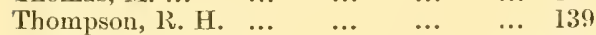

Thornton, H. R. $\quad \ldots . \quad \ldots . \quad \ldots . \quad \ldots \quad 106$

Thunberg. T. $\quad \ldots \quad \quad \ldots . \quad \ldots \quad 70,77,80$

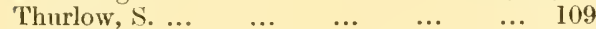

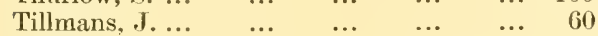

$\begin{array}{lllllll}\text { Todd, C. } & \ldots & \ldots & \ldots & \ldots & \ldots & 29\end{array}$

Todd, E. W.... $\quad \ldots . \quad \ldots . \quad \ldots 44,128,129$

Tongberg, C. O. $\quad \ldots . \quad \ldots . \quad \ldots, \quad \ldots, \quad 49$

$\begin{array}{llllll}\text { Tréfouël, J. ... } \quad \ldots & \ldots & \ldots & \ldots & 143\end{array}$

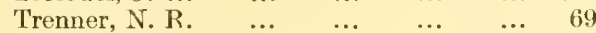

$\begin{array}{llllll}\text { Tressler, D. K. } & \ldots & \ldots & \ldots & \ldots & 61\end{array}$

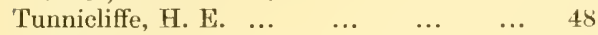

$\begin{array}{lllll}\text { Tuttle, C. D. } & \ldots & \ldots & \ldots & 31,126\end{array}$

$\begin{array}{llllll}\text { Twigg, R. S... } & \ldots & \ldots & \ldots & \ldots & \ldots\end{array}$

$\begin{array}{llllll}\text { Uchimura, T. } & \ldots & \ldots & \ldots & \ldots & 79\end{array}$

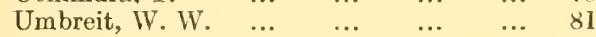

$\begin{array}{llllll}\text { Van Heyningell } & \ldots & \ldots & \ldots & \ldots & 139\end{array}$

$\begin{array}{lllll}\text { Vellinger, E.... } & \ldots & \ldots & \ldots & \ldots 7 \\ \text { Vign } & \ldots & \ldots & \ldots & \ldots 77,78\end{array}$

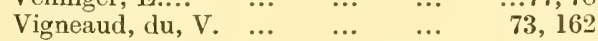

Virtanen, A. I. $\quad \ldots . \quad \ldots . \quad \ldots . \quad \ldots \quad 61$

$\begin{array}{lllll}\text { Vitucci, J. C. } & \ldots & \ldots & \ldots & \text {. } \\ \text { V0, } 128\end{array}$

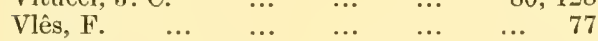

$\begin{array}{llllll}\text { Volk, N. J. ... } & \ldots & \ldots & \ldots & \ldots & 132\end{array}$

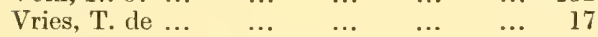

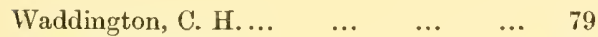

$\begin{array}{lllll}\text { Wagner-Jauregg, } \mathrm{T} . & \ldots & \ldots & \ldots & 56\end{array}$

$\begin{array}{llllr}\text { Wainwright, S. D. ... } & \ldots & \ldots & \ldots & 51\end{array}$

$\begin{array}{llllll}\text { Wakelin, J. ... } & \ldots & \ldots & \ldots & \ldots & 139\end{array}$

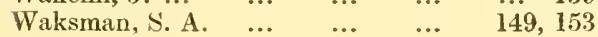

PAGF

$\begin{array}{llllll}\text { Walker, H. H. } & \text {.. } & \text {... } & \ldots & \ldots & 95\end{array}$

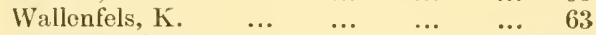

Warburg, $0 \ldots . \quad \ldots \quad \quad \ldots \quad \quad 55,81,92,94$

Ward, W. E. $\quad$.. $\quad \ldots . \quad \ldots . \quad \ldots, 107$

Waters, W. A. $\quad \ldots \quad \quad \ldots . \quad \ldots \quad 48,55,57$

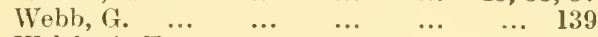

$\begin{array}{lllllr}\text { Welch, A. Т. } & \ldots & \ldots & \ldots & \ldots & 72\end{array}$

$\begin{array}{lllllll}\text { Weldert } & \ldots & \ldots & \ldots & \ldots & \ldots & 106\end{array}$

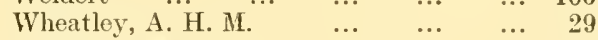

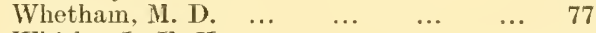

Whitby, L. E. H. ... $\quad$... $\quad \ldots . \quad \ldots .144$

$\begin{array}{llllll}\text { White, H. J. } & \ldots & \ldots & \ldots & \ldots & 153\end{array}$

Wieland, H... $\quad \ldots \quad \ldots . \quad \ldots .93,94,110$

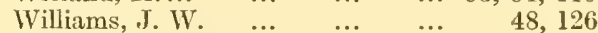

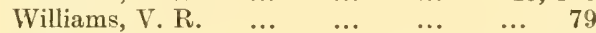

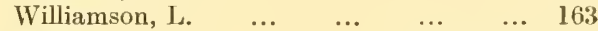

Wilson, G. S. $\quad \ldots . \quad \ldots \quad 95,106,127,170$

Winslow, C. E. A. ... $\quad \ldots \quad$... $\quad \ldots .95$

$\begin{array}{llllll}\text { Winzor, E. L. } \quad \ldots & \ldots & \ldots & \ldots & 67\end{array}$

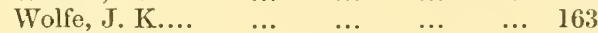

$\begin{array}{lllllll}\text { Wolff, K. } & \ldots & \ldots & \ldots & \ldots & \ldots & 168\end{array}$

$\begin{array}{llllll}\text { Wollman, S. H. } & \ldots & \ldots & \ldots & \ldots & 62\end{array}$

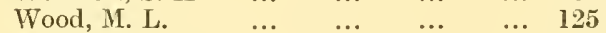

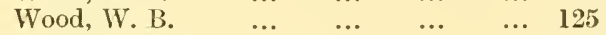

$\begin{array}{llllll}\text { Woodruff, H. B. } \quad \ldots & \ldots & \ldots & \ldots & 162\end{array}$

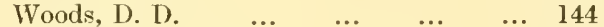

Wooldridge, W. R. ... $\quad \ldots . \quad \ldots . \quad 77,106$

Wrede, F. ... $\quad$.. $\quad \ldots . \quad \ldots \quad$... 44

Wurmser, R. $\quad \ldots \quad 34,52,60,64,70,71$,

75,77

$\begin{array}{lllllll}\text { Yaoi, } \mathrm{H}, & \ldots & \ldots & \ldots & \ldots & \ldots & 52\end{array}$

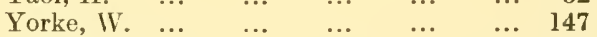

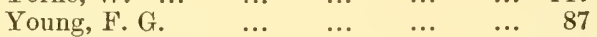

$\begin{array}{llllll}\text { Young, L. } & \ldots & \ldots & \ldots & \ldots & \ldots 28,65\end{array}$

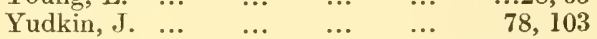

Zilva, S. S. $\quad \ldots \quad \quad \ldots \quad \quad \ldots \quad \quad \ldots \quad 54,60,77$

Zobell, C. E.... $\quad \ldots . \quad \ldots \quad \ldots \quad 126,127,133$ 



\section{SUBJECT INDEX}

[Names of organisms are listed as given by anthors of the papers quoted.]

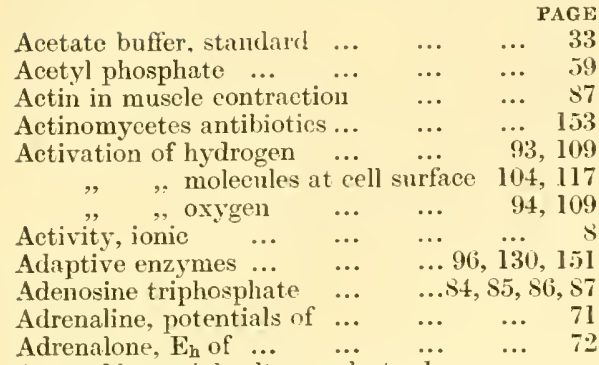

Aerated bacterial cultures, electrode potential of $\quad \ldots \quad \ldots \quad \ldots \quad 108$ et seq.

Aerated bacterial cultures; peroxide formation in $\quad . . \quad \quad \ldots \quad \quad \ldots \quad \ldots \quad$... 109 et seq. Aerated bacterial cultures; proliferation in 111 Aeration, apparatus for cultures ... $\quad \ldots \quad 32$

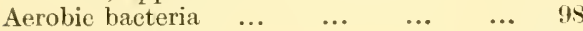
, $\begin{array}{cccccc}\text { cultures } & \ldots & \ldots & \ldots & \ldots & 102\end{array}$ " metabolism $\quad \ldots . \quad \ldots s 8,90,93,98$

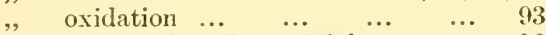
Affinity, ehemical, and potentials $\quad \ldots . \quad 12$ $\begin{array}{llllll}\text { Agar-salt bridges } & \ldots & \ldots & \ldots & \ldots & 32\end{array}$ Alanine-ammonium pyrurate system $\quad . . \quad$ il

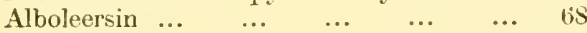
Alcohol dehydrogenase $\quad \ldots \quad \ldots \quad 56,57$, sS Alcoholie fermentation $\quad \ldots \quad \ldots . \quad \ldots \quad$ s7 Aldehyde dehydrogenase $\ldots . \quad \ldots \quad 56, \mathrm{~s} 7, \mathrm{ss}$ $\begin{array}{llllll}\text { Alga valonia... } & \ldots & \ldots & \ldots & \ldots & 75\end{array}$ Alloxan-dialuric acid, system $\quad \ldots . \quad \ldots \quad 69$ Amino acid oxidase $\quad \ldots \quad \ldots . \quad \ldots \quad 56$ p-Aminobenzoic acid $\quad \ldots \quad \ldots 62, \mathrm{I} 44,145$ p-Aminosalicylic aeid $\quad \ldots . \quad \ldots . \quad \ldots \quad 149$ $\begin{array}{llllll}\text { Amoba dubia } & \ldots & \ldots & \ldots & \ldots & 75\end{array}$ $\begin{array}{llllll}\text { Amoba proteus } & \ldots & \ldots & \ldots & \ldots & 7.5\end{array}$ Amobae, electrode potentials of ... $\quad \ldots \quad$... $\begin{array}{llllll}\text { Amylepectin } & \ldots & \ldots & \ldots & \ldots & 73\end{array}$

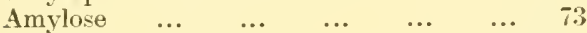
Anaemia, pernicious, factor $\quad \ldots \quad \ldots 54,61$ Anaerobic bacteria and eatalase ... 110 et seq. , ", elassification ... I09 et seq. " $\quad$ ", reducing powers $\quad$... 114 ,$\quad$, sensitivity to peroxide 114 , glycolysis $\quad$... $\quad$... $\quad 84$ et seq. " metabolism $\quad \ldots . \quad \ldots . \quad \$ 4,109$ Analognes, stuctural $\quad \ldots . \quad \ldots . \quad \ldots \quad 14 t$

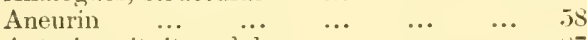
$\begin{array}{llllll}\text { Anterior pituitary lobe } & \ldots & \ldots & \ldots & s 7\end{array}$

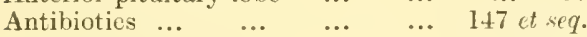
$\begin{array}{lllllll}\text { Antibodies } & \ldots & \ldots & \ldots & \ldots & 14 & \\ \text { Antiber } & \ldots & \ldots & \ldots & \ldots & 137\end{array}$

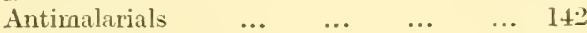

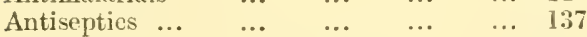

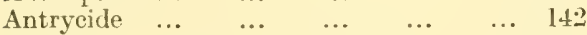
Apparent reduction potentials $\quad \ldots \quad$... 1.55

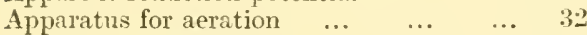

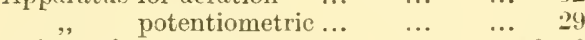
Arion rufus pigment $\quad \ldots \quad \ldots 6, \quad \ldots 60,76$ Arsenicals in chemotherapy $\quad \ldots \quad$... 13s
Arsenic and dithiols $\quad \ldots \quad \ldots \quad \quad \ldots \quad 47,139$

Ascorbic acicl, potentials $\quad \ldots \quad \ldots \quad \quad \ldots \quad 60,163$ ". $\quad .$, oxidlase $\quad \ldots \quad \ldots . \quad \ldots 4,61$

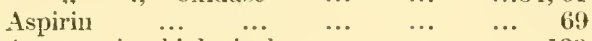
Assay, microbiological $\quad \ldots \quad$... $\begin{array}{lllllll}\text { A.T.P. } & \ldots & \ldots & \ldots & \ldots & \ldots & \text { S4 }\end{array}$

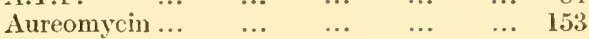
Avidity for oxygen, bacterial $\quad \ldots \quad 104,121$

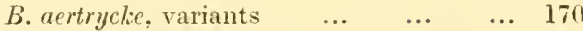

B. cholerae suis, $\mathrm{E}_{\mathrm{h}} \quad \ldots \quad \quad \ldots \quad \quad \ldots \quad 125$

B. coli communis, potentials of cultures 122,124

B. denitrificans $\quad, \quad, \quad 126$

B. dysenterice (Shiga) ,, $\quad, 111,122,124$

B. enteritidis ",, 125

B. fluorescens $\quad$, $\quad, \quad, \quad 126$

B. megatherium ,, ,

B. mycoides $\quad$., $\quad$ ", 125

B. paratyphosus A and $\mathrm{B} \quad$,, $\quad 125$

B. pyocyuneus and pyocyanine $\quad \ldots \quad$... 65

$\begin{array}{lllll}\text { B. Saccharobutylicus } & \ldots & \ldots & \ldots & 125\end{array}$

$B$. sporogenes, sensitivity to peroxide ... 113

B. subtilis, potentials of cultures ... $\quad \ldots \quad 125$

$\begin{array}{llllll}B \text {. } \text { etani } \quad, & , & \ldots & \ldots & 125\end{array}$

$\begin{array}{lllll}, & \text { spores, germination of } & \ldots & \ldots & 115\end{array}$

$B$. typhosus, potentials of eultures $95, \mathbf{1 2 5}$

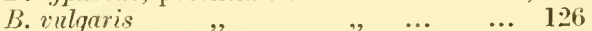

B. vulpinum $\quad,, \quad, \quad, \quad \ldots, \quad \ldots, 126$

$\begin{array}{lllll}\text { B. welchii } \quad, & , & \ldots & \ldots & 125\end{array}$

Bacteria, anaerobic... ... ... 109-11s classification of ... $\quad \ldots . \quad \ldots \quad \mathbf{1 0 9}$ , differentiation by $\mathrm{E}_{\mathrm{h}}$ methods

108 et seq. drung resistance ... ... 130, 151 electrocle potentials of cultures

106 et seq. growth of and $\mathrm{E}_{\mathrm{h}} \quad \ldots \quad \ldots \quad \ldots \quad 10^{\circ}$ metabolism of $\quad . . \quad \ldots . \quad \ldots s 5,98$

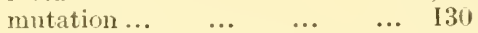
peroxicle formation by ... $\quad$... 109 reduction by $\quad \ldots \quad \quad \ldots \quad 98$ et seq. $\begin{array}{llllll}\text { resting } & \ldots & \ldots & \ldots & \ldots & 77\end{array}$ sulphate reducing $\quad \ldots . \quad \ldots, \quad 126$ variants of $\quad$... $129,130,151$ virulence of $\quad \ldots \quad \quad \ldots \quad \quad \ldots, \quad 129$

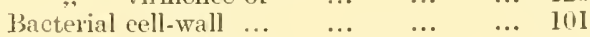
fermentation $\quad \ldots \quad$... $\quad \ldots$ ss

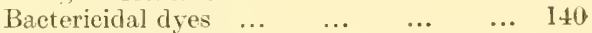

Bacteriophage, effect on potentiais $\quad \ldots \quad 121$

Bacteriophage and enzyne inhibitors $\quad \ldots .6147$

B.A.L. $\quad \ldots \quad \quad \ldots \quad \quad \ldots \quad \quad \ldots \quad 4 \quad 47,139$

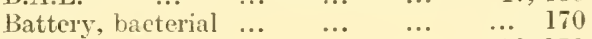

$\begin{array}{llllll}\text { Beer } . . . & \ldots & \ldots & \ldots & \ldots & 80,170\end{array}$

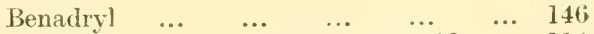

Benzidine-peroxidase test for peroxide ... 11:

Benzohydroquinone, Eh of $\quad \ldots \quad \ldots \quad$ i:

Biologieal oxidation-reductions ... 45 et seq.

Blood stream, vimlent organisms from ... 130

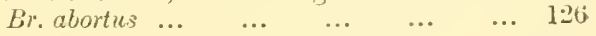




\begin{tabular}{|c|c|c|c|c|}
\hline & PAGE \\
\hline Br. melitensis & ... & ... & $\ldots$ & $\ldots \quad 126$ \\
\hline Br. suis $\quad \ldots$ & ... & ... & ... & 126 \\
\hline Bridges, salt... & $\ldots$ & $\ldots$ & $\ldots$ & $\ldots \quad 32$ \\
\hline Brilliant alizarino & olue & $\cdots$ & $\cdots$ & $\ldots 2426$ \\
\hline British Anti-Lewis & te & $\ldots$ & $\ldots$ & 47,139 \\
\hline $\mathrm{m}$-Bromophenol $\mathrm{i}$ & ndophe & nol, & $1_{0}$ data & $\ldots 21,23$ \\
\hline o-Bromophenol ir & dophen & ol, & data & $\ldots 21,23$ \\
\hline Broth, differences & & ... & ... & ... 118 \\
\hline , electrode pe & tential & of & $\ldots$ & $\ldots \quad 107$ \\
\hline glueose & $\ldots$ & $\ldots$ & $\ldots$ & 101,119 \\
\hline peptone inf & 1sion & ... & ... & ... $10 \mathrm{~s}$ \\
\hline serum & $\ldots$ & ... & ... & 118 \\
\hline ,, tryptie dige & & ... & $\ldots$ & 119 \\
\hline Buffer, acetate & $\ldots$ & $\ldots$ & $\ldots$ & $\ldots$ \\
\hline ., effeet & $\ldots$ & ... & $\ldots$ & $\ldots$ \\
\hline phthalate & $\ldots$ & ... & $\ldots$ & ... \\
\hline solutions & $\ldots$ & ... & $\ldots$ & $\ldots$ \\
\hline
\end{tabular}

C. diphtherice, $\mathrm{E}_{\mathrm{h}}$ of cultures of ... 108 et seq. Calomel electrode $\quad \ldots \quad$... $\quad \ldots . \quad \ldots \quad 33$ $\begin{array}{llllll}\text { Capacity effect } & \ldots & \ldots & \ldots & \ldots & 7\end{array}$

", $\quad$, of dyes $\quad \ldots \quad$.. $\quad \ldots 27,75$

Carbohydrates, effeet on eultures... $\quad$... 119 $\begin{array}{lllll}, & \text { oxidation of } & \ldots & \ldots & 93\end{array}$ , potentials of $\quad \ldots, \quad \ldots, \quad 70$

$\begin{array}{lllll}\text { Carboxylase ... } & \ldots & \ldots & \ldots & \ldots 58,87\end{array}$

Carrier linked reactions $\quad \ldots \quad \ldots . \quad \ldots \quad$...

$\begin{array}{llllll}\text { Cartesian diver } & \ldots & \ldots & \ldots & \ldots & 81\end{array}$

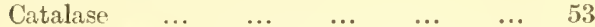

and elassification of bacteria $110 \mathrm{et}$ seq.

effect on potentials of cultures ... 113

Catalyst funetion $\quad . . \quad \quad \ldots \quad \quad \ldots \quad \quad \ldots \quad 15$

Catalytic effeet of dyes $\quad \ldots \quad \ldots . \quad \ldots 27,75$

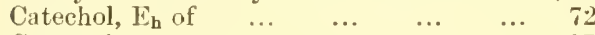

$\begin{array}{lllllll}\text { Catenarin } & \ldots & \ldots & \ldots & \ldots & \ldots & 67\end{array}$

$\begin{array}{lllllll}\text { Cathepsin } & \ldots & \ldots & \ldots & \ldots & \ldots & 67\end{array}$

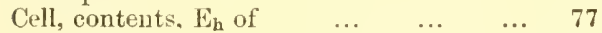

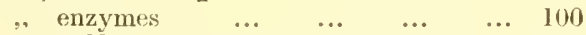

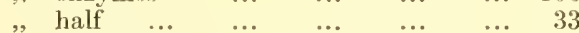

, oxidation-reduction in $\quad \ldots . \quad \ldots .6103$

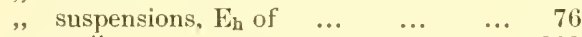

$\begin{array}{lllllll}\text {, wall } & \ldots & \ldots & \ldots & \ldots & \ldots & \end{array}$

$\begin{array}{lllllll}\text { Cheese } & \ldots & \ldots & \ldots & \ldots & \ldots & 101 \\ \text { Chemica } & \ldots & \ldots & \ldots & \ldots & \ldots & 128\end{array}$

Chemical affinity and electrode potential 12

$\begin{array}{lllll}\text { Chemotherapy } & \ldots & \ldots & \ldots & 136 \mathrm{et} \text { seg. }\end{array}$

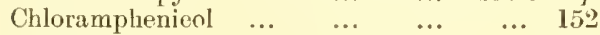

$\begin{array}{llllll}\text { Chloraphine ... } & \ldots & \ldots & \ldots & \ldots & 152\end{array}$

$\begin{array}{llllll}\text { Chloroplasts } & \ldots & \ldots & \ldots & \ldots & 92\end{array}$

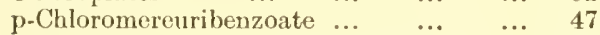

$\begin{array}{llllll}\text { Chloromycetin } & \ldots & \ldots & \ldots & \ldots & 152\end{array}$

o-Chlorophenol indophenol, $\mathrm{E}^{1}{ }_{0}$ curve ... 25 data $\quad . .2$ i, 23

$\mathrm{m}$-Chlorophenol indo-2 : 6--dichlorophenol,

$\mathrm{E}_{0}^{1}$ dlata $\ldots \quad \ldots \quad \ldots \quad \ldots \quad \ldots 21,23$

$\begin{array}{llllll}\text { Chlorophyll } \ldots & \ldots & \ldots & \ldots & \ldots & 91\end{array}$

Chorionie gonadotrophic hormono $\quad \ldots \quad 73$

$\begin{array}{llll}\text { Chromatographic adsorption } & \ldots & \ldots & \mathbf{1} 53\end{array}$

Chromodoris zebra, pigment $\quad$... $\quad . .63,76$

Ciba scarlet sulphonato $\quad . . \quad \ldots . \quad \ldots 24,26$

Circuits, eleetrical, practical $\quad \ldots \quad$... 35

,, ", theoretical $\ldots . \quad \ldots .30$

$\begin{array}{llllll}\text { Citric acid eyele } & \ldots & \ldots & \ldots & \ldots & 88\end{array}$

$\begin{array}{lllllll}\text { Citrinin } & \ldots & \ldots & \ldots & \ldots & \ldots & 67\end{array}$

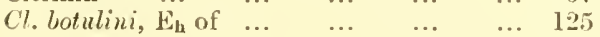

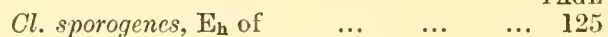

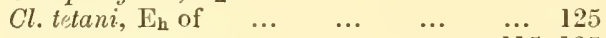

",, spores $\quad \ldots \quad$... $\quad \ldots \quad$ I15, 125

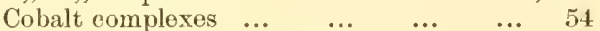

$\begin{array}{llllll}\text { Coenzymes } \ldots & \ldots & \ldots & \ldots & \ldots & 57\end{array}$

Colony form, variation with $\mathrm{E}_{\mathrm{h}} \quad \ldots \quad \ldots \quad \ldots \quad 129$

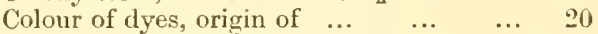

$\begin{array}{llllll},, \quad, \quad \text {, usefulness of } & \ldots & \ldots & 27\end{array}$

Contamination, general bacterial ... $\quad \ldots \quad 116$

Copper protein oxidases, current voltage

$\begin{array}{lllllll}\text { eurves } & \ldots & \ldots & \ldots & \ldots & \ldots & 5 t\end{array}$

$\begin{array}{lllllll}\text { Cori ester } & \ldots & \ldots & \ldots & \ldots & \ldots & 85\end{array}$

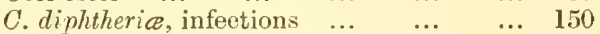

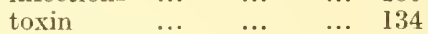

Cotyledons and ascorbic acid $\quad \ldots \quad \ldots 6 r$

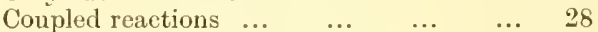

$\mathrm{m}$-Cresolindophenol, $\mathrm{E}^{1}{ }_{0}$ data $\quad \ldots \quad \ldots 21,23$

o-Cresolindophenol, $\mathrm{E}_{0}^{1}{ }_{0}$ data $\ldots . \quad \ldots 21,23$

Cresyl blue ... $\quad \ldots \quad \ldots . \quad \ldots \quad \ldots 23,26$

Cryptococcus derm., $\mathrm{E}_{\mathrm{h}}$ of $\ldots . \quad \ldots . \quad \ldots \quad 80$

Culture media, electrode potential of $\quad \ldots \quad 107$

, $\quad$, reduction of $\quad \ldots \quad 102$ et seq.

" , $\quad$ selection of suitable $\quad$... 118

,, $\quad$, variations in $\quad \ldots \quad \ldots \quad \ldots 107$

$\begin{array}{llllll}\text { Cynodontin } & \ldots & \ldots & \ldots & \ldots & 67\end{array}$

Cysteine-oystine system, electrodo potentials of $\quad \ldots \quad \ldots . \quad \ldots \quad \ldots . \quad \ldots \quad 47$

Cysteine-cystine system, electrode poten-

tials of, mechanism of establishment ... 47

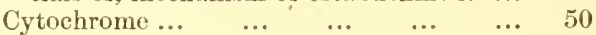

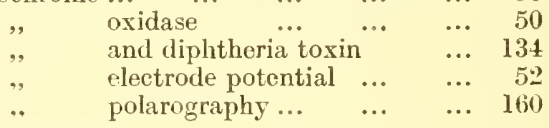

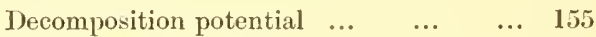

$\begin{array}{llllll}\text { Dehydroaseorbic acid } & \ldots & \ldots & \ldots & 61\end{array}$

$\begin{array}{lllllll}\text { Diabetes } & \ldots & \ldots & \ldots & \ldots & \ldots & 97\end{array}$

Dialuric aeid-Alloxan, equilibrium poten-

$\begin{array}{lllllll}\text { tials } & \ldots & \ldots & \ldots & \ldots & \ldots & 69\end{array}$

Diamidines $\ldots \quad \ldots \quad \ldots \quad \ldots \quad \ldots \quad 147,150$

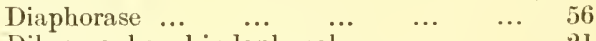

Dibromophenol indophenot $\quad \ldots . \quad \ldots \quad$ 2I

Dichlorophenol indophenol $\quad \ldots \quad \ldots \quad \ldots 1$

2: 6-Dichlorophenolindo-o-eresol, $\mathrm{E}^{1}{ }_{0}$ $\begin{array}{llllll}\text { data } & \ldots & \ldots & \ldots & \ldots & \ldots 21,23\end{array}$

2 : 6 -Dichlorophenolindophenol, $\mathrm{E}_{0}^{\mathbf{1}}$ data 21,23

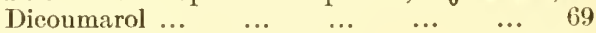

Differentiation of baeteria... $\quad \ldots \quad 106 \mathrm{et} \mathrm{seq}$.

$\begin{array}{llllll}\text { Digest broth... } \quad \ldots & \ldots & \ldots & \ldots & 108\end{array}$

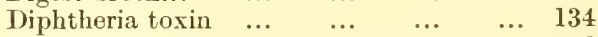

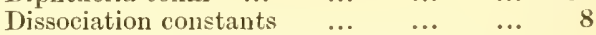

Dihydroxyphenylalanine, $\mathbb{E}_{\mathrm{h}}$ of $\ldots \quad \ldots \quad 72$

$5: 6$ Diketohydroindolecarboxylic acid, $\mathrm{E}_{\mathrm{h}}$

$\begin{array}{lllllll}\text { of } \ldots & \ldots & \ldots & \ldots & \ldots & \ldots & 68\end{array}$

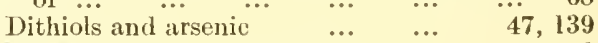

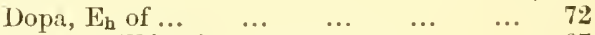

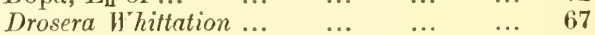

Drug resistance $\quad \ldots . \quad \ldots . \quad \ldots \quad 130,15 \mathrm{I}$

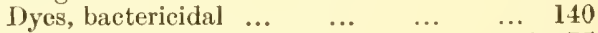

, eapacity effect of $\quad \ldots \quad \ldots . .27,75$

, catalytic effect of $\quad \ldots \quad \ldots . \quad \ldots, \quad \ldots 27,75$

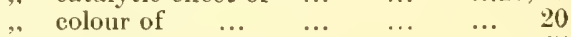

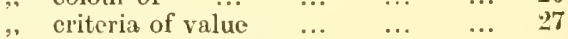


PACE

Dyes, data on clectrode potentials of $21 \mathrm{et}$ seq.

. limitations in use of... ... ..27, 75

, microinjection of $\quad \ldots \quad$... $\quad \ldots . \quad 75$

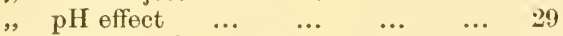

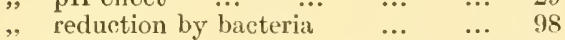

, toxicity of $\quad . . \quad \quad \ldots \quad \ldots . \quad \ldots 29,75$

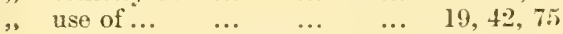

" see also under names of dyes.

$\begin{array}{cccccr} & \mathrm{E}_{0} \text { relationships } & \ldots & \ldots & 63 \\ \mathrm{E}_{\mathrm{h}} \text {, definition } & \ldots & \ldots & \ldots & \ldots & 2\end{array}$

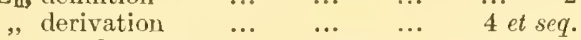

," see also Electrode potential.

Electrical apparatus

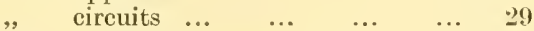

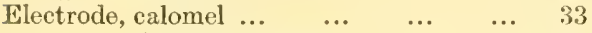

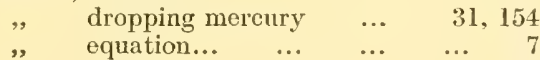

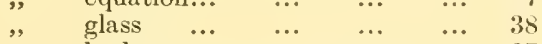

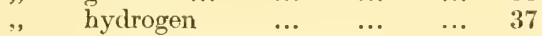

$\begin{array}{llll}\text {, normal hydrogen } & \ldots & \ldots & 6\end{array}$

," potential, bacterial cultures ... 106

, $\quad$, biological systems ... 45

, $\quad$, cell contents $\quad \ldots .77$

, $\quad$., $\quad$ cell suspensions $\quad \ldots \quad 76$

", limmoglobin systems 48

, , $\quad$ measurement of, by dyes $\quad$... $\quad$... 19

measurement of, electrically $\quad \ldots \quad \quad \ldots \quad \mathbf{2 9}$

mechanism of establishment of ...2, 106

relation to percentage oxidation... ...7. 105

sulphydryl systems $\quad 47$

tissue suspensions ... 76

and variation of bac-

teria $\quad \ldots \quad 129,151$

quinhydrone $\quad \ldots \quad \ldots \quad \ldots 33,38$

silver chloride $\ldots . \quad \ldots \quad \ldots \quad 41$

unattackable, definition $\quad \ldots \quad t$

, , matcrials for ... 30

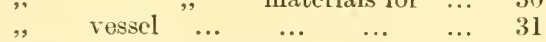

Electrometer, Lindemann ... $\quad \ldots . \quad \ldots \quad 34$

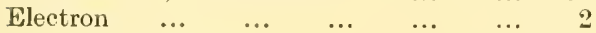

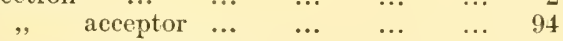

, concentration $\quad \ldots \quad$... $\quad \ldots \quad$;)

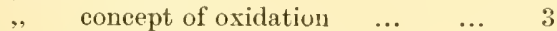

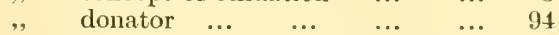

, escaping tendency $\quad \ldots \quad$...

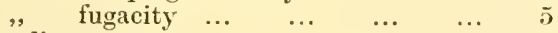

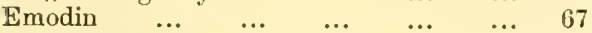

Energy requirements, of organisms 1,98 et seq.

Energy-rich phospliate bonds $\quad . . \quad$... 83

$\begin{array}{lllll}\text { Endergonic reactions } & \ldots & \ldots & \ldots & 14\end{array}$

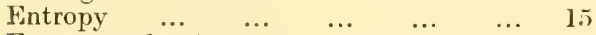

Enzymes adaptive ... $\quad \ldots \quad 96,130,151$

Enzymes, bacterial, and anærobiosis $\ldots 110$

, $\quad$, reduction by ... 102 et seq.

, cell, and surface effects $\quad \ldots \quad 101$

, multiplicity of ... $\quad \ldots \quad \ldots \quad \ldots \quad 104$

," oxidations in presence of $\quad 38,10 \%$

, specificity of $\quad \ldots \quad$... $\quad \ldots \quad 100$
$\mathrm{E}_{0}$ and $\mathrm{E}^{1}$, data of dyes

definition $\quad 21$ et seq. of biological systems... $\quad 40$ et seq.

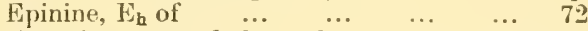

Equation, general electrode $\quad \ldots . \quad \ldots, \quad 7$

Eseherischia coli, $\mathrm{E}_{\mathbf{h}}$ of $\quad \ldots \quad \ldots . \quad 122,124$

$\begin{array}{llllll}\text { Erythroglaucin } & \ldots & \ldots & \ldots & \ldots & 67\end{array}$

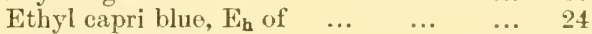

$\begin{array}{lllll}\text { Exergonic reactions } & \ldots & \ldots & \ldots & 14\end{array}$

$\begin{array}{lllllll}\mathbf{F} \text { (faraday) } & \ldots & \ldots & \ldots & \ldots & \ldots & 7\end{array}$

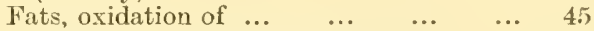

Fermentation, Neuber's's schemes _.. 88

Ferrous-ferric ion system $\ldots \quad \ldots \quad \ldots \quad \ldots \quad$ 12

Fischer, Karl, titration $\quad \ldots \quad \ldots \quad \ldots \quad \ldots \quad 163$

$\begin{array}{llllll}\text { Flavoproteins } & \ldots & \ldots & \ldots & \ldots & 55\end{array}$

$\begin{array}{llllll}\text { Folic acid } & \ldots & \ldots & \ldots & \ldots & 61,144\end{array}$

Free energy and oxidation potentials ... 14 of glycolysis $\quad \ldots \quad \quad \ldots \quad \quad \ldots \quad 86$

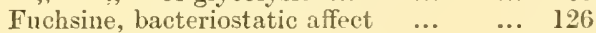

$\begin{array}{lllll}\text { Fumaric acid } \quad \ldots & \ldots & \ldots & \ldots 70,77\end{array}$

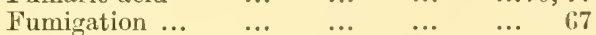

$\begin{array}{lllllll}\text { Furacin } & \ldots & \ldots & \ldots & \ldots & \ldots & 141\end{array}$

Gallic acid, $\mathrm{E}_{\mathrm{h}}$ of $\quad \ldots \quad \quad \ldots \quad \ldots \quad \ldots \quad \ldots \quad 72$

Gallocyanine $\quad \ldots \quad \ldots . \quad \ldots . \quad \ldots 24,26$

Gallophenine $\quad \ldots \quad \ldots . \quad \ldots \quad \ldots 24,26$

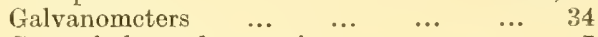

General electrode equation $\quad \ldots \quad \ldots .7$

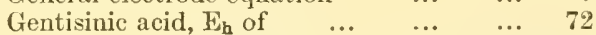

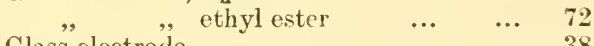

$\begin{array}{llllll}\text { Glass electrode } & \ldots & \ldots & \ldots & \ldots & 38\end{array}$

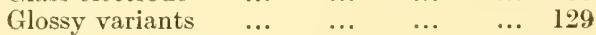

Glucose, broth cultures $\quad \ldots \quad \ldots \quad \ldots \quad 101,119$ , $\quad$ oxidation of $\quad \ldots, \quad \ldots . \quad \ldots, 70$

$\begin{array}{lllll}\text { Glutamic acid } & \ldots & \ldots & \ldots & \ddot{10} 1,151\end{array}$

Glutathione, biological significance $\quad . .445$ clectrode potentials of $\quad \ldots \quad 47$

Glycerol fermentation $\quad \ldots \quad \ldots . \quad \ldots .68$

$\begin{array}{lllllll}\text { Glycogen } & \ldots & \ldots & \ldots & \ldots & \ldots & 86\end{array}$

$\begin{array}{lllllll}\text { Glycolysis } & \ldots & \ldots & \ldots & \ldots & \ldots & 84\end{array}$

Glyoxalase, and $\mathrm{SH}$ compounds $\ldots . \quad \ldots \quad 46$

$\begin{array}{llllll}\text { Gold electrodes } & \ldots & \ldots & \ldots & \ldots & 30\end{array}$

$\begin{array}{lllllll}\text { Gramicidin } & \ldots & \ldots & \ldots & \ldots & \ldots & 152\end{array}$

$\begin{array}{llllll}\text { Gram staining } & \ldots & \ldots & \ldots & \ldots & 152\end{array}$

$\begin{array}{lllll}\text { Graphite electrodes... } & \ldots & \ldots & \ldots & 31\end{array}$

Growth, bacterial, onergy for $\quad$... 103 et seq. $\begin{array}{lll}, & , & \text { accessory substances for } 69 \\ , & , & \text { relation to } \mathrm{E}_{\mathrm{h}} \ldots \quad 106 \text { et seq. }\end{array}$

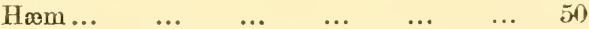

Hæmatin-hæmochromogen, electrode potentials of... 48 in meat media ... 115 , 118,125

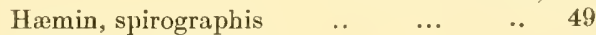

$\begin{array}{llllll}\text { Hæmochromogen } & \ldots & \ldots & \ldots & \ldots & 49\end{array}$

$\begin{array}{llllll}\text { Hæmocuprein } & \ldots & \ldots & \ldots & \ldots & 54\end{array}$

$\begin{array}{llllll}\text { Hæraocyanine } & \ldots & \ldots & \ldots & \ldots & 54\end{array}$

Hæmoglobin-metlıglobin, electrode poten.

tial $\ldots$... $\quad \ldots \quad \ldots$ is

$\begin{array}{lll}\text { oxyhæmoglobin system } \quad \ldots & \ldots & 48\end{array}$ $\begin{array}{llll}\text { polarography } & \ldots & \ldots & 161\end{array}$

Hæmolysin, oxidation-reduction $\ldots \quad \ldots \quad \ldots \quad 128$ 
PAGE

Hamolytic streptococci, electrode potentials of cultures 108 et seq. peroxide formation by $\quad$... 108 variants of $\quad \ldots \quad 129$

Hom"ophilus influenze $\quad \ldots \quad \ldots . \quad \ldots \quad \ldots 5 t, 58$

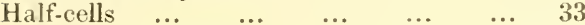
$\begin{array}{lllll}. & \text { standard } \ldots & \ldots & \ldots & \ldots .32 \\ & & \ldots & \ldots & \ldots 32,33\end{array}$ $\begin{array}{lllll}\text { Half wave potential } \quad \ldots & \ldots & \ldots & 155\end{array}$

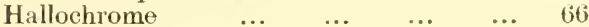
$\begin{array}{llllll}\text { Helminthosporin } & \ldots & \ldots & \ldots & \ldots & 67\end{array}$

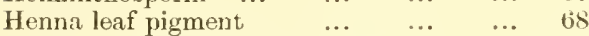
Hermidine, electrode potentials of $\quad$... $\quad 63$

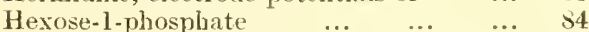

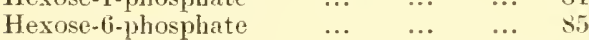
$\begin{array}{lllllll}\text { Histamine } & \ldots & \ldots & \ldots & \ldots & \ldots & 146\end{array}$

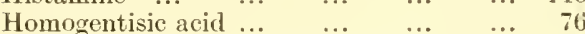
B.Hydroxybutyric-acetoacetic system $\quad \ldots \quad 70$ a-Hydroxyglutaric acid system ... ... 71 Hydrogen, acceptor's and donators $\quad$... 77 , $\begin{array}{lllll}\text { activation } & \ldots & \ldots & \ldots & \ldots\end{array}$

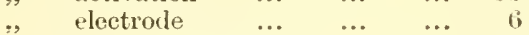

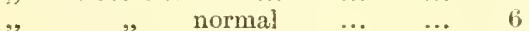

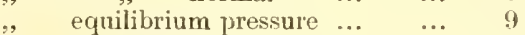
, partial pressure $\quad \ldots . \quad \ldots .99$ ,. peroxide, see Peroxicle.

Hydroquinone: quinone system ... ...20.35

Hydroxyphenazine ... $\quad \ldots \quad \ldots \quad \ldots \quad$..

$\begin{array}{lllllll}\text { Immunity } & \ldots & \ldots & \ldots & \ldots & \ldots & 137\end{array}$

Indicators, oxidation-reduction, sce Dyes.

Indigodisulpbonate, $\mathrm{E}^{3}{ }_{0}$ enrve $\quad \ldots \quad \ldots \quad \ldots \quad 25$

, data ... ... 2)

Indigomonosulphonate, $\mathrm{E}_{0}^{1}$ curve $\quad \ldots \quad 25$

Indigotetrasulphonate, $\mathrm{E}_{0}{ }_{0}$ curve... $\quad . . \quad 25$

.

Indigotrisulphonate, $\mathrm{E}^{1}{ }_{0}$ curve $\quad \ldots \quad \ldots . \quad 25$

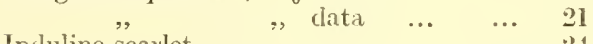

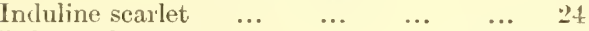

Infusion broth $\quad \ldots \quad \quad \ldots \quad \quad \ldots \quad$ los $f t$ seq.

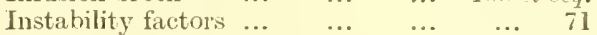

$\begin{array}{lllllll}\text { Insulin } & \ldots & \ldots & \ldots & \ldots & \ldots & 81\end{array}$

$\begin{array}{lllllll}\text { Iodinin } & \ldots & \ldots & \ldots & \ldots & \ldots & 69\end{array}$

Intensity level, oxidation-1eduction $\quad \ldots \quad 7$

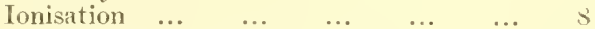

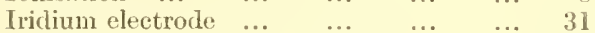

Iron, effect on Alloxan potential ... $\quad . . . \quad$ 70

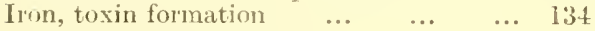

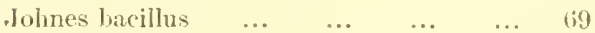

Juglon, $\mathrm{E}_{0}$ of $\quad \ldots \quad \ldots . \quad \ldots \quad \ldots 67,68$

Kar Fischer titration $\quad \ldots \quad \ldots \quad \ldots \quad \ldots \quad$ I183

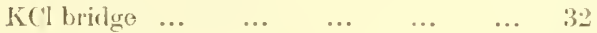

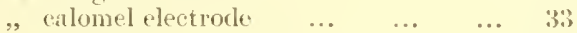

$\begin{array}{llllll},, \text { reservoir } & \ldots & \ldots & \ldots & \ldots & 3: 2\end{array}$

$\begin{array}{lllllll}\text { Knapweed } & \ldots & \ldots & \ldots & \ldots & \ldots & 153\end{array}$

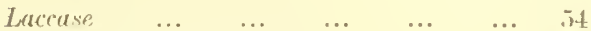

I actic acid, from glucose $\ldots \quad \ldots \quad \ldots \quad$ st $\begin{array}{lllll}., & \text {., lehyrlogenase } \quad . . & . . & \text { sis }\end{array}$

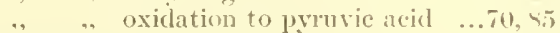

Lactate-pyruvate system... $\quad \ldots \quad \ldots 70$, s.j

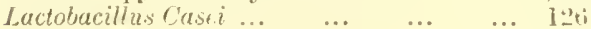

PAGE

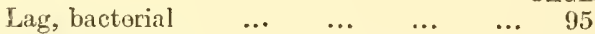

$\begin{array}{lllllll}\text { Lapuchol } & \ldots & \ldots & \ldots & \ldots & \ldots & 68\end{array}$

Lawson, $\mathbf{E}_{0}$ of $\quad \ldots \quad \ldots 67,68$

$\begin{array}{llllll}\text { Licheniformin } & \ldots & \ldots & \ldots & \ldots & \ldots\end{array}$

Limitations in use of dyes... $\quad \ldots . \quad \ldots 27,75$

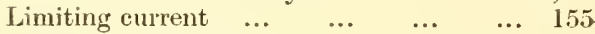

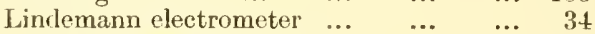

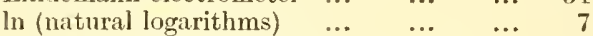

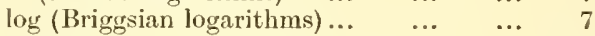

Logarithmic growth phase... $\quad \ldots . \quad \ldots \quad .96$

$\begin{array}{lllllll}\text { Lomatiol } & \ldots & \ldots & \ldots & \ldots & \ldots & 68\end{array}$

$\begin{array}{lllllll}\text { Luciferin } & \ldots & \ldots & \ldots & \ldots & \ldots & 74\end{array}$

$\begin{array}{llllll}\text { Luminescence } & \ldots & \ldots & \ldots & \ldots & 74\end{array}$

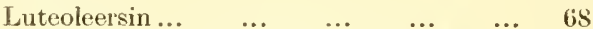

Lysis, effect on potentials of cultures $\quad \ldots \quad 121$

Lysozyme, effect on cultures $\quad . . \quad \ldots \quad 121$

$\begin{array}{llll}\text { Malic-oxaloacetic acid system } & \ldots & \ldots & 70\end{array}$

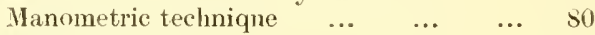

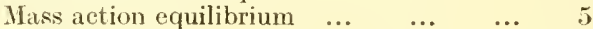

$\begin{array}{llllll}\text { Matt variants } & \ldots & \ldots & \ldots & \ldots & 129\end{array}$

Maximum suppressors $\quad \ldots . \quad \ldots . \quad \ldots \quad$ I5s

Heat media $. . . \quad \ldots \quad \ldots \quad \ldots 49,115,125$

Ilechanism of electrode potential establish-

$$
\begin{gathered}
\text { ment } \ldots \\
\text {, bacterial redinctions } \\
102 \text { et seq. }
\end{gathered}
$$

Media, culture $\quad \ldots \quad \ldots . \quad \ldots \quad \ldots \quad \ldots \quad 106$

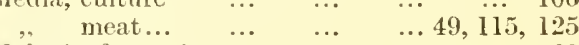

Melanin formation ... $\quad \ldots \quad \ldots . \quad \ldots \quad 68$

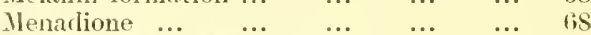

Wercuralis perennis pigment $\quad \ldots \quad \ldots 63,76$

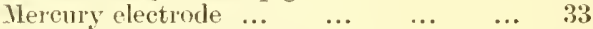

Meriquinones, potentials of $\quad \ldots . \quad \ldots .64$

$\begin{array}{llllll}\text { Metabolic eycles } & \ldots & \ldots & \ldots & \ldots & 83\end{array}$

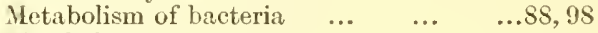

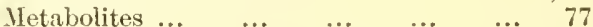

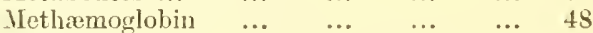

$\begin{array}{llllll}\text { Nethods } \quad \ldots & \ldots & \ldots & \ldots & \ldots 19,37\end{array}$

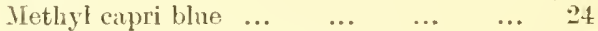

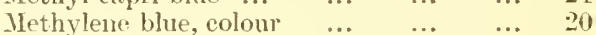

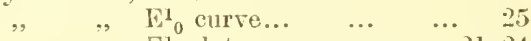$$
, \quad, \quad \mathrm{E}_{0}^{1} \text { data } \ldots . \quad \ldots \quad \ldots 21,24
$$

", reduction ... $\quad \ldots \quad$...

$\begin{array}{lllll}\text { Mlicrobiological assay } & \ldots & \ldots & \ldots & 133\end{array}$

Microspectroscopic cell for bacteric $\quad \ldots \quad 51$

$\begin{array}{llllll}\text { Milk, testing } & \ldots & \ldots & \ldots & \ldots & 127\end{array}$

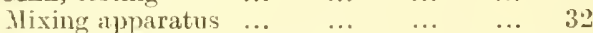

H. lysodeikticus, potentials of cultures $1: 21,1: 5$

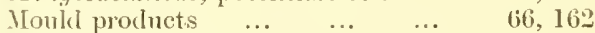

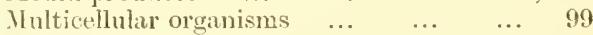

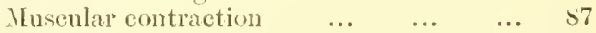

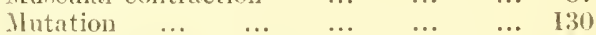

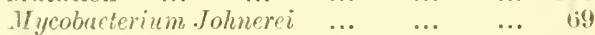

$\begin{array}{lllllll}\text { Myosin } & \ldots & \ldots & \ldots & \ldots & \ldots & 57\end{array}$

$\begin{array}{llllllll}n & \ldots & \ldots & \ldots & \ldots & \ldots & \ldots & 7\end{array}$

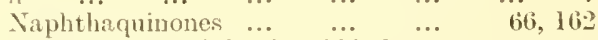
1 Naphthol-2-sulpluonic acid inclo-3: : 5

diclilorowhenol, $\mathrm{E}_{0}$ lata $\quad \ldots 21,2,0$

indophenol. $\mathrm{Fi}_{0}{ }_{0}$ curve $\quad \ldots \quad 25$

$\begin{array}{lllllll}\text { Veomycin } & \ldots & \ldots & \ldots & \ldots & \ldots & \mathbf{1 5 3}\end{array}$ 
PAQE

$\begin{array}{lllllll}\text { Neurospora crassa } & \ldots & \ldots & \ldots & \ldots & \text { I34 }\end{array}$

$\begin{array}{lllllr}\text { Neutral red ... } & \ldots & \ldots & \ldots & \ldots & \text {.. }\end{array}$

$\begin{array}{llllll}\text { Nicotinic acid } & \ldots & \ldots & \ldots & \ldots & 163\end{array}$

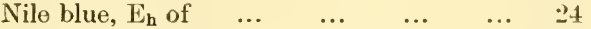

Nile blue in Thunberg technique ... $\quad \ldots .67$

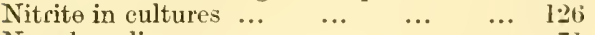

$\begin{array}{llllll}\text { Noradrenaline } & \ldots & \ldots & \ldots & \ldots & 71\end{array}$

Norhomœpinephrine, $\mathrm{E}_{\mathrm{h}}$ of $\quad \ldots . \quad \ldots \quad 72$

Normal hydrogen electrode $\quad \ldots . \quad \ldots \quad 6$

$\begin{array}{llllll}\text { Nucleic acids } & \ldots & \ldots & \ldots & \ldots & 131\end{array}$

Nutrient material, bacterial oxidation $10 \geq$ et seq.

$\begin{array}{llllll}\text { Obligate anaerobes... } & \ldots & \ldots & \ldots & 114\end{array}$

Oxidase, Warburg's $\quad \ldots . \quad \ldots \quad$... 55

Oxidation, and life ... $\quad \ldots \quad \ldots . \quad \ldots \quad$ I

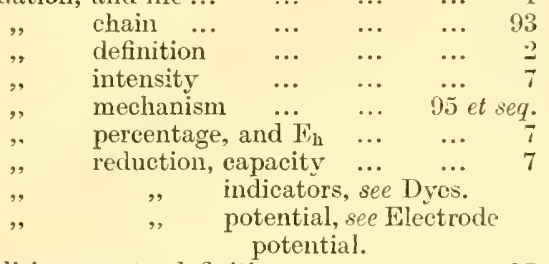

Oxidising agents, definition $\quad \ldots \quad \ldots \quad$ IT

$, \quad,$, grading of $\quad \ldots \quad \ldots \quad \ldots \quad 17$

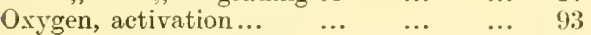

, carrying effect of cytochrome $\ldots . .50$

, ", ,, , enzymes ... 93

, $\quad$ ", , , ", proteins $\quad \ldots .93$

", , , , $\quad \begin{gathered}\text { sulphydryl } \\ \text { compounds }\end{gathered} 45$

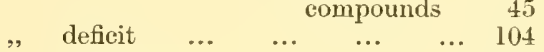

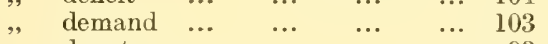

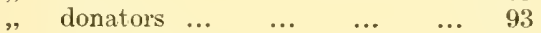

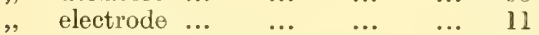

" importance of $\quad \ldots \quad \ldots . \quad \ldots, \quad \ldots 1,102$

,, polarography $\quad \ldots \quad$... $\quad \ldots . \quad 159$

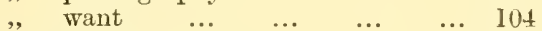

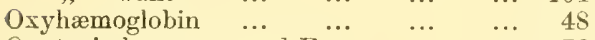

Oxytocic hormone, and $\mathrm{E}_{\mathrm{h}} \quad \ldots \quad \ldots 7^{\circ}$

Oxyphenazine $\quad \ldots \quad \quad \ldots \quad \ldots .66,161$

Palladium electrode $\quad \ldots \quad$...

$\begin{array}{lllllll}\text { Paludrine } & \ldots & \ldots & \ldots & \ldots & \ldots & \text { I4: }\end{array}$

Pantothenic acid $\quad \ldots \quad \quad \ldots \quad \quad \ldots \quad \quad 146,163$

Papain and thiol group $\quad \ldots \quad \ldots . \quad \ldots \quad \ldots$

Parahæmatin-hæmochromogen system, $\mathrm{E}_{0}$

,

,

meat media 49

$\begin{array}{llllll}\text { Parthenogenesis } & \ldots & \ldots & \ldots & \ldots & 79\end{array}$

$\begin{array}{llllll}\text { Pastenr effect } & \ldots & \ldots & \ldots & \ldots & 90\end{array}$

$\begin{array}{lllllll}\text { Penicillin } & . . & \ldots & \ldots & \ldots & \ldots & 148\end{array}$

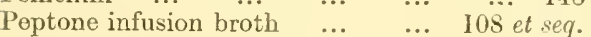

Pernicious anæmia factor ... $\quad \ldots . \quad \ldots 54,61$

Peroxidase ... $\quad . . \quad \ldots . \quad \ldots \quad \ldots 5$

$$
\begin{array}{llll}
\text { bacterial } & \ldots & \ldots & \ldots \\
\text { and } 111
\end{array}
$$

Peroxide, and anærobic growth $\quad \ldots \quad$ I09 et scq.

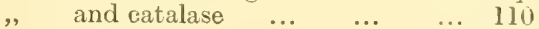

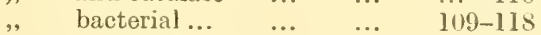

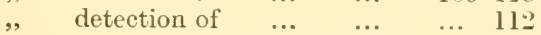

", effect on bacterial variation $\quad . . \quad 129$

, , , , electrode potential ... 112

, formation in cultures ... 109 et seq.
Peroxide, prochicect

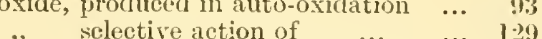

," sensitivity of bacteria to $\quad \ldots .611$

, similarity to hydrogen peroxide 112

, toxic effect of $\quad . . \quad \ldots . \quad \ldots \quad 111$

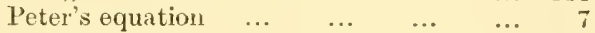

$\mathrm{pH}$ colorimetric measurement $\quad \ldots \quad \ldots \quad$ 4.

$\begin{array}{lllll}\text {, electrometric } \quad, & & \ldots & & \end{array}$

,, effect on electrocle potential ... $\quad$ s' et seo.

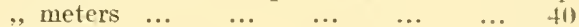

$\begin{array}{lllll}\text { Phenazine pigments } & \ldots & \ldots & \ldots & 46\end{array}$

$\begin{array}{lllll}\text { Phenol red spectrum } & \ldots & \ldots & \ldots & 43\end{array}$

Phenolindo-2 : 6-rlibromophenol, $\mathrm{E}_{0}^{1}$ data 21,23

Phenolindophenol, $\mathrm{E}_{0}^{1}$ data $\quad \ldots \quad \ldots 21,23$

Phenol- $m$-sulphonate-indo-2 : fi-dibromo-

phenol, data $\quad \ldots \quad \quad \ldots . \quad \ldots . \quad \ldots 2 l, 23$

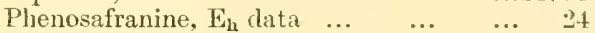

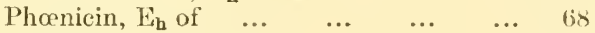

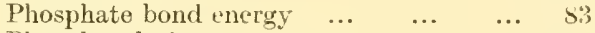

$\begin{array}{llllll}\text { Phosphorylation } & \ldots & \ldots & \ldots & \ldots & \text { s. }\end{array}$

Photodynamic effect of dyes $\quad \ldots \quad$... 29

$\begin{array}{llllll}\text { Photoflavins... } & \ldots & \ldots & \ldots & \ldots & 5.7\end{array}$

$\begin{array}{llllll}\text { Photosynthesis } & \ldots & \ldots & \ldots & \ldots & 91\end{array}$

$\begin{array}{llllll}\text { Phthalate buffer } & \ldots & \ldots & \ldots & \ldots & 33\end{array}$

$\begin{array}{lllllll}\text { Phthiocol } & \ldots & \ldots & \ldots & \ldots & \ldots & 69\end{array}$

$\begin{array}{lllll}\text { Pituitary hormone } . . . & \ldots & \ldots & \ldots & 67\end{array}$

Plant growth, ascorbic acid $\quad \ldots \quad \ldots$ (il

$\begin{array}{llllll}\text { Plant respiration } & \ldots & \ldots & \ldots & \ldots & 92\end{array}$

Platinum electrode, preparation $\ldots . \quad \ldots . \quad 31$

$\begin{array}{llllll}, & , & \text { value of } \quad \ldots & \ldots & 30\end{array}$

Pneumococcus cultures, electrode potential

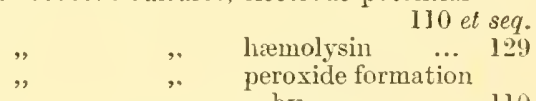

$\begin{array}{rrrr}\text { by } & \ldots & \ldots & 110\end{array}$

Poising effect $\quad \ldots \quad \quad \ldots \quad \quad \ldots \quad 7,27,105$

Polarisation of electrodes $\ldots \quad \ldots \quad \ldots . \quad \ldots \quad 35$

$\begin{array}{llllll}\text { Polarograph ... } & \ldots & \ldots & \ldots & \ldots & 154\end{array}$

,, apparent reduction potential 155

, experimental methods ... $15 \%$

, hrmoglobin and hrematin ... I6l

$\begin{array}{llll}\text {.. } & \text { half-wave potential ... } & \ldots & 155\end{array}$

,. hydrogen peroxide $\quad . . \quad$... $\quad$ I5!)

, $\quad$ limiting current $\quad \ldots \quad$... 15.5

$\begin{array}{lllll}, & \text { mould products } & \ldots & \ldots & 15\end{array}$

$\begin{array}{lllll} & \text { proteins } \quad \ldots & \ldots & \ldots & \text { I60 }\end{array}$

,, semiquinones... $\quad \ldots . \quad \ldots$ I6I

," $\quad$ sulphydryl compounds $\quad \ldots .6159$

$\begin{array}{llllll}\text {, } & \text { vitamins } & \ldots & \ldots & \ldots & 163\end{array}$

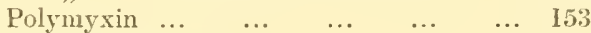

$\begin{array}{llllll}\text { Potential, sign of } & \ldots & \ldots & \ldots & \ldots & 17\end{array}$

standard... $\quad \ldots \quad \ldots \quad \ldots \quad 14$

Potentiometer, ehoice of $\quad \ldots \quad$...

Potentiometric, apparatus... $\quad \ldots . \quad \ldots 29,40$

$\begin{array}{lllll}. . & \text { circuit } \quad \ldots & \ldots & \ldots 30,35\end{array}$

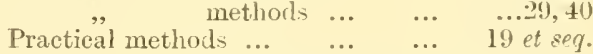

$\begin{array}{lllll}\text { Proteins, denatured } & \ldots & \ldots & \ldots & 46\end{array}$

," effect on bacterial vimlence $\quad \ldots \quad 130$

," $, \quad, \mathrm{F}_{\mathrm{h}}$ of cultures... $\quad \ldots$ lls

, oxidation of $\quad \ldots \quad$... $\quad \ldots \quad$...

,. oxygen carrying effect of $\quad \ldots \quad$ IIs

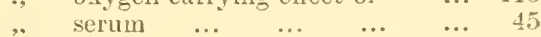


Proteins, SH groups in $\ldots$...

Protocatechuic aeid, $\mathrm{E}_{\mathrm{h}}$ of... $\quad \ldots \quad \quad \ldots \quad 72$

Pteroylglutamic acid $\begin{array}{cccr}\text { ethyl ester... } & \ldots & 72 \\ & \ldots & \ldots & 62,144\end{array}$

Pyocyanine, electrocle potentials of $\quad \ldots \quad 64$

$\begin{array}{lllll}\text { Pyıridine nucleotides } \quad \ldots & \ldots & \ldots & 57\end{array}$

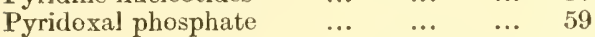

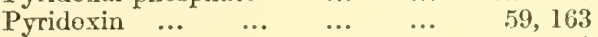

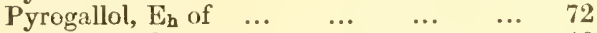

$\begin{array}{llllll}\text { Pyruvic acid } & \ldots & \ldots & \ldots & \ldots & \\ & & \ldots & \ldots & \ldots & 46\end{array}$

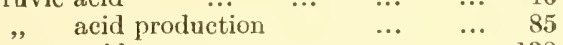

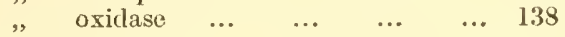

Quinhydrone electrode $\quad \ldots \quad \ldots \quad \ldots \quad \ldots 33,38$

,, reasonance complex $\quad \ldots 20,38$

Quinine $\quad \ldots \quad \ldots . \quad \ldots \quad \ldots . \quad \ldots \quad 142$

Quinone-hydroquinone system $\quad \ldots \quad$... 2, 20

Quinones bactericida! $\quad \ldots \quad$... $\quad \ldots \quad 141$ $\begin{array}{lllll}, \text { polarography } & \ldots & \ldots & \ldots & 162\end{array}$

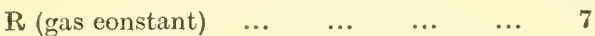

$\begin{array}{lllllll}\text { Ravenelin } & \ldots & \ldots & \ldots & \ldots & \ldots & 67\end{array}$

Redox potential, see Eleetrode potential.

Reducing agents, definition of $\ldots . \quad \ldots 7,17$

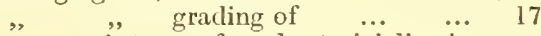
$" \quad$ substanees from bacterial dissolıtion

Rectuction, accompanies oxidation biologieal …74,88, $10^{\circ}$ definition $\quad \ldots \quad \quad \ldots \quad 3,7,17$ in baeterial cultures ... $\quad \ldots \quad 102$ intensity of baeteria ... 98 et seq. $\begin{array}{lllll}\text { of broth } & \ldots & \ldots & \ldots & 102\end{array}$ $\begin{array}{lllll}\text { of dyes ... } \quad \ldots & \ldots & \ldots & 74\end{array}$ percentage, relation to $\mathrm{E}_{\mathrm{h}} \quad 22,105$ potential, see Electrode potential 2

$\begin{array}{lllllll}\text { Resazarin } & \ldots & \ldots & \ldots & \ldots & \ldots & 128\end{array}$

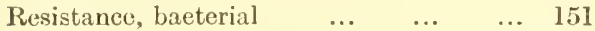

Respiration, bacterial $\quad . . . \quad \ldots \quad 102$ et seq.

Respiratory enzyme, Warburg's ... $\quad . . \quad 55$

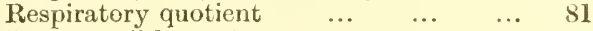

"Resting "bacteria $\quad \ldots \quad$... $\quad \ldots .77$

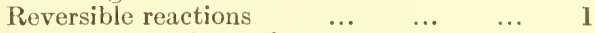

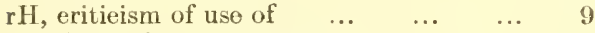

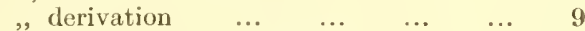

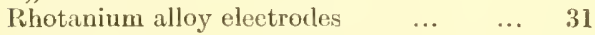

$\begin{array}{lllllll}\text { Riboflavin } & \ldots & \ldots & \ldots & \ldots & \ldots & 55\end{array}$

$\begin{array}{llllll}\text { Ribonuclease } & \ldots & \ldots & \ldots & \ldots & 132\end{array}$

Rickettsial infections $\quad \ldots . \quad \ldots . \quad \ldots \quad 152$

$\begin{array}{llllll}\text { Robison ester } & \ldots & \ldots & \ldots & \ldots & 85\end{array}$

$\begin{array}{llllll}\text { Rosindone sulphonate } & \ldots & \ldots & \ldots & 24\end{array}$

Saccharomyces cerevisio, $\mathrm{E}_{\mathbf{h}}$ of $\quad \ldots \quad \quad \ldots \quad 80$

", marxianus, $\mathrm{E}_{\mathrm{h}}$ of $\ldots . \quad \ldots \quad 80$

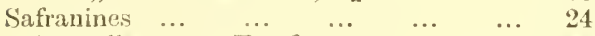

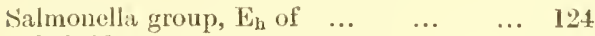

$\begin{array}{llllll}\text { Salt bridges } \ldots & \ldots & \ldots & \ldots & \ldots & 32\end{array}$

Selection of bacterial variants $\quad \ldots \quad 129,151$

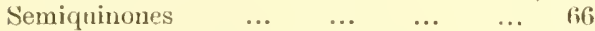

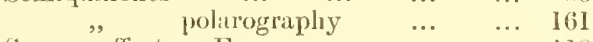

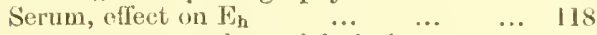

, , , , hacterial virulence $\quad \ldots \quad 129$

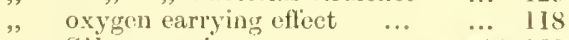

, Sli groups in $\quad \ldots \quad \ldots . \quad \ldots \quad 46,160$

Sewage sedimentation tanks $\quad \ldots \quad \ldots l 33$

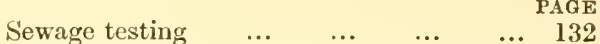

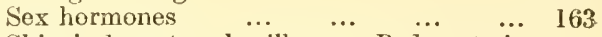

Shiga's dysentery bacillus, see $B$. dysenteria.

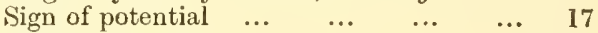

$\begin{array}{llllll}\text { Slndge sewage } & \ldots & \ldots & \ldots & \ldots & 132\end{array}$

Slugs, orange pigment of $\ldots . \quad \ldots \quad \ldots 66,76$

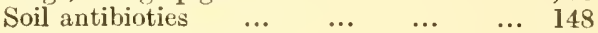

$\begin{array}{llllll}\text { ", } \text { eorrosion } & \ldots & \ldots & \ldots & \ldots & 126\end{array}$

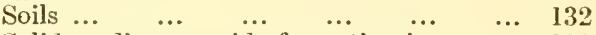

Solid media, peroxide formation in $\quad \ldots .130$

Speeific substance of bacteria $\quad \ldots \quad 129,132$

Specificity of enzymes $\quad \ldots \quad \ldots \quad \ldots \quad \ldots \quad 102$

Speetroseope, miero-eell for $\quad \ldots . \quad \ldots . \quad 51$

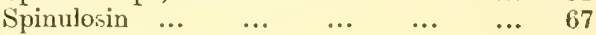

$\begin{array}{llllll}\text { Spores, see Tetanus. } & & & & \\ \text { Standard half-cells ... } & \ldots & \ldots & \ldots & 32\end{array}$

Standard potentials $\quad \ldots .616$

Staphylocoeeal eultures, electrode poten. tials of $\quad \ldots \quad \ldots \quad \ldots \quad \ldots \quad 111 \mathrm{et} \mathrm{seq.}$

Starch, fractionation $\quad \ldots . \quad \ldots . \quad \ldots \quad 73$ , iodine potentials ... $\quad \ldots . \quad \ldots . \quad 73$

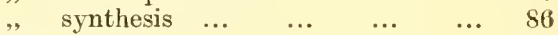

$\begin{array}{llllll}\text { Starfish eggs... } & \ldots & \ldots & \ldots & \ldots & 75\end{array}$

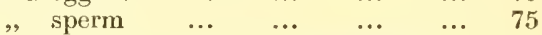

Streptocoeci, see Hæmolytic streptococei.

Streptococcus lactis in cheese $\quad \ldots \quad \ldots \quad \ldots \quad 128$

$\begin{array}{llllll}\text { Streptomycin } & \ldots & \ldots & \ldots & \ldots & 149\end{array}$

$\begin{array}{llllll}\text { Streptothricin } \quad \ldots & \ldots & \ldots & \ldots & 153\end{array}$

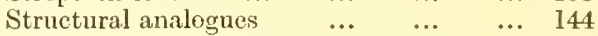

Subcutaneous tissue, $\mathrm{E}_{\mathrm{h}}$ of $\quad \ldots . \quad \ldots \quad 119$

Succinate-fumarate system $\quad \ldots \quad$... 70

Succinie dehydrogenase $\quad \ldots \quad$... $\quad \ldots . \quad 70$

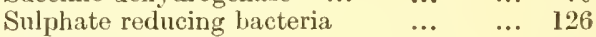

$\begin{array}{llllll}\text { Sulphonamide drugs } \quad \ldots & \ldots & \ldots & 143\end{array}$

$\begin{array}{llllll}\text { Sulphydryl systems } & \ldots & \ldots & \ldots & 45\end{array}$ and enzymes $\ldots . \quad \ldots \quad \quad \ldots \quad 46$ and hremolysins $\quad \ldots \quad \ldots \quad 129$ and oxytoeie aetivity... $\quad \ldots \quad 72$ $\begin{array}{lllll}\text { polarography } & \ldots & \ldots & \ldots & 159\end{array}$

Sunmaries of ehapter's $17,36,44,82,94,136$,

Suppressors, maximum ... ... $\quad \ldots .158$

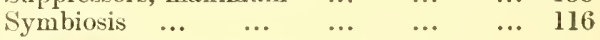

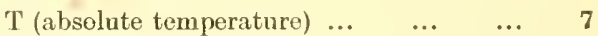

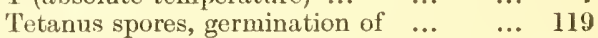

$\begin{array}{llllll}\text { Tetrathionase } & \ldots & \ldots & \ldots & \ldots & 78\end{array}$

Tetramethylsafranine, $\mathrm{E}_{\mathrm{h}}$ of $\quad \ldots . \quad \ldots . \quad 24$

$\begin{array}{lllll}\text { Thermostable residue } & \ldots & \ldots & \ldots & 45\end{array}$

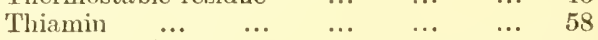

Thionine, $\mathbf{E}_{0}^{1}$ eurve $\quad \ldots . \quad \ldots . \quad \ldots .25$

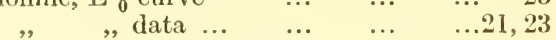

," $\quad$, and bacteriostasis $\ldots . \quad \ldots \quad 126$

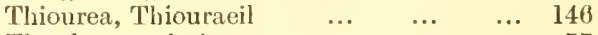

$\begin{array}{lllll}\text { Thunberg teehnique } & \ldots & \ldots & \ldots & 77\end{array}$

$\begin{array}{lllllll}\text { Thyroxine } & . . & \ldots & \ldots & \ldots & \ldots & 145\end{array}$

Time factor in dyo equilibria $\quad \ldots \quad \ldots \quad \ldots \quad 27$

$\begin{array}{llllll}\text { Tissue cultures } & \ldots & \ldots & \ldots & \ldots & 79\end{array}$

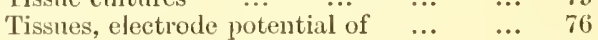

Tocopherol $\ldots \quad \ldots \quad \ldots \quad \ldots \quad \ldots . \quad \ldots 62,69$

Toluylene blue, $\mathbf{E}_{0}^{1}$ data $\ldots . \quad \ldots . \quad \ldots 21,23$

Torula candide, $\mathrm{F}_{\mathrm{h}}$ of $\quad \ldots . \quad \ldots . \quad \ldots \quad 80$

Toxicity of dyes $\quad \ldots \quad \quad \ldots \quad \quad \ldots \quad \quad \ldots 28,75$

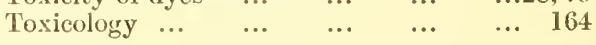


PAGE

$\begin{array}{lllllll}\text { Toxins } & \ldots & \ldots & \ldots & \ldots & \ldots & 135\end{array}$

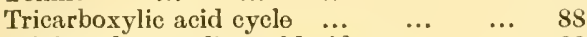

Triphenyltetrazolium chloride $\quad \ldots . \quad \ldots \quad 66$

$\begin{array}{llllll}\text { Tryptic digest broth } & \ldots & \ldots & \ldots & 108\end{array}$

$\begin{array}{llllll}\text { Trypanocidal agents } \quad \ldots & \ldots & \ldots & 143\end{array}$

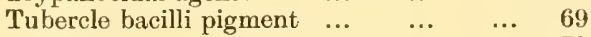

$\begin{array}{llllllll}\text { Tumours } & \ldots & \ldots & \ldots & \ldots & \ldots & 79\end{array}$

$\begin{array}{lllll}\text { Tungsten electrodes } & \ldots & \ldots & \ldots & 31\end{array}$

$\begin{array}{lllllll}\text { Turacin } & \ldots & \ldots & \ldots & \ldots & \ldots & 31 \\ & & \ldots & \ldots & \ldots & 50\end{array}$

Two-stage oxidations $\quad \ldots \quad \ldots . \quad \ldots 14,66$

Type transformation, bacterial $\quad \ldots \quad \ldots \quad \ldots \quad 132$

$\begin{array}{lllllll}\text { Typhus } \quad \ldots & \ldots & \ldots & \ldots & \ldots & 152\end{array}$

$\begin{array}{lllllll}\text { Tyrocidin } & \ldots & \ldots & \ldots & \ldots & \ldots & 152 \\ & \ldots & \ldots & \ldots & \ldots & \ldots & 152\end{array}$

$\begin{array}{lllllll}\text { Tyrosinase } & \ldots & \ldots & \ldots & \ldots & \ldots & 54\end{array}$

Unattackable electrodes, definition $\quad$... 4

" $" \quad$ materials of $\ldots 30,31$

Unicellular organisms $\quad \ldots \quad$... $\quad \ldots \quad 87$

Units of measurement $\quad \ldots \quad$... $\quad \ldots .67$

$\begin{array}{llllll}\text { Unstable systems } & \ldots & \ldots & \ldots & \ldots & 72\end{array}$

$\begin{array}{lllll}\text { Urease and thiol groups } & \ldots & \ldots & \ldots & 46\end{array}$

$\begin{array}{lllll}\text { Urechis eggs pigment } & \ldots & \ldots & \ldots & 66\end{array}$

Valency bonds and electrons $\quad \ldots \quad \ldots \quad 20$

Valves, thermionic, for potentiometric measurements $\quad \ldots \quad \ldots \quad \ldots \quad \ldots$
PAGE

Variants, bacterial ... $\quad \ldots \quad \ldots \quad 129,151$

Variation, bacterial, dependence on $\mathrm{E}_{\mathrm{h}} 129,151$

$\begin{array}{llllll}\text { Vessel, electrode } & \ldots & \ldots & \ldots & \ldots & 32\end{array}$

$\begin{array}{lllllll}\text { Viologen dyes } & \ldots & \ldots & \ldots & \ldots & 26\end{array}$

Virulence of bacteria depends on $\mathrm{E}_{\mathrm{h}} \quad \ldots \quad 129$

Viruses and enzymes inhibitions ... $\quad \ldots \quad 147$

$\begin{array}{lllllll}\text { Vitamin } B_{1} & \ldots & \ldots & \ldots & \ldots & \ldots & 58\end{array}$

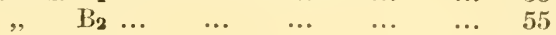

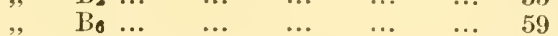

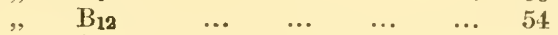

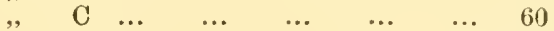

$\begin{array}{lllllll}, & \mathrm{C} & \cdots & \ldots & \ldots & \ldots & \ldots \\ , & \mathrm{E} & \cdots & \ldots & \ldots & \ldots & \ldots 62,69\end{array}$

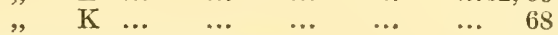

Vitamins, bacterial growth $\quad \ldots . \quad \ldots 54,69$

$\begin{array}{lllll}\text { Vitamin polarography } & \ldots & \ldots & \ldots & 163\end{array}$

Voltammetric titrations $\quad \ldots \quad \ldots \quad 157,163$

Walnut husk pigment $\quad \ldots \quad \ldots \quad \ldots 67,68$

$\begin{array}{lllll}\text { Warburg manometer } & \ldots & \ldots & \ldots & 80\end{array}$

$\begin{array}{lllll}\text { Water determination } & \ldots & \ldots & \ldots & 163\end{array}$

$\begin{array}{lllll}\text { Xanthine oxidase } & \ldots & \ldots & \ldots & 56,109\end{array}$

$\begin{array}{lllll}\text { Yeast fermentation... } & \ldots & \ldots & \ldots & 87\end{array}$

$\begin{array}{lllll} & \text {, potentials in cultures } & \ldots & \ldots & 80\end{array}$

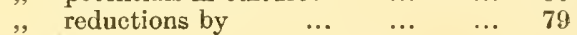







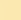




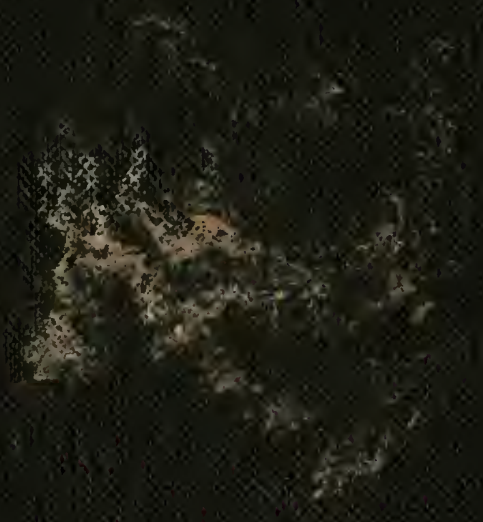

\&

${ }^{2}$ 